LÚCIO FLÁVIO VISMARI

\title{
VIGILÂNCIA DEPENDENTE AUTOMÁTICA NO CONTROLE DE TRÁFEGO AÉREO: AVALIAÇÃO DE RISCO BASEADA EM MODELAGEM EM REDES DE PETRI FLUIDAS E ESTOCÁSTICAS.
}

Dissertação apresentada à Escola Politécnica da Universidade de São Paulo para obtenção do Título de Mestre em Engenharia 


\title{
LÚCIO FLÁVIO VISMARI
}

ENGENHEIRO ELETRICISTA PELA ESCOLA POLITÉCNICA DA UNIVERSIDADE DE SÃO PAULO, 2001.

\section{VIGILÂNCIA DEPENDENTE AUTOMÁTICA NO CONTROLE DE TRÁFEGO AÉREO: AVALIAÇÃO DE RISCO BASEADA EM MODELAGEM EM REDES DE PETRI FLUIDAS E ESTOCÁSTICAS.}

\author{
Dissertação apresentada à Escola \\ Politécnica da Universidade de São Paulo \\ para obtenção do Título de Mestre em \\ Engenharia \\ Área de Concentração: Sistemas Digitais \\ Orientador: Professor Livre-Docente \\ João Batista Camargo Junior
}


Este exemplar foi revisado e alterado em relação à versão original, sob responsabilidade única do autor e com a anuência de seu orientador.

São Paulo, de outubro de 2007.

Assinatura do autor

Assinatura do orientador

FICHA CATALOGRÁFICA

Vismari, Lucio Flavio

Vigilância dependente automática no controle de tráfego aéreo: avaliação de risco baseada em modelagem em redes de Petri fluidas estocásticas / L.F. Vismari. -- ed.rev. -- São Paulo, 2007.

272 p.

Dissertação (Mestrado) - Escola Politécnica da Universidade de São Paulo. Departamento de Engenharia de Computação e Sistemas Digitais.

1.Tráfego aéreo (Segurança) 2.Redes de Petri 3.Análise de risco 4.Simulação de sistemas I.Universidade de São Paulo. Escola Politécnica. Departamento de Engenharia de Computação e Sistemas Digitais II.t. 


\section{AGRADECIMENTOS}

Tanto a agradecer e tão pouco espaço para escrever!

Primeiramente aos meus pais, Dorival e Liderce, muito obrigado por todo o amor, dedicação e bom exemplo com o qual vocês criaram a mim e a minha irmã, Luciana (que aproveito para agradecer, também), e que, sem os quais, não teríamos chegado até aqui! Amo todos vocês.

À minha esposa, Simone, primeiramente peço desculpas por, além de privá-la da minha presença ao longo deste trabalho, tê-la feito carregar meu fardo em alguns momentos difíceis. Agradeço imensamente pela compreensão, apoio e companheirismo com os quais lidou com toda esta situação. Muito obrigado por estar em minha vida! Amo você.

Meu muito obrigado ao professor Dr. João Batista Camargo Junior, meu orientador, pela acolhida, orientação, amizade e, sobretudo, por toda a confiança depositada em mim. Saiba que nos momentos difíceis, onde minha crença pessoal estava abalada, seu otimismo e entusiasmo me deram forças para prosseguir.

Meus mais sinceros agradecimentos às pessoas que fazem do GAS - Grupo de Análise de Segurança da Escola Politécnica da USP - um local excepcional para se trabalhar e conviver. Ao prof. Dr. Paulo Cugnasca, responsável pelo meu primeiro contato com o grupo (lá nos idos de 1999), e ao prof. Dr. Jorge Rady, responsável pela orientação de minha Iniciação Científica, meu muito obrigado por tudo. Aos amigos "GASosos" de maior convivência: Andréia Rossi, Danilo Shibata, Ítalo Romani, Gilberto Menezes, Jamil Kalil, Ricardo Gimenes e Sérgio Paz, meus agradecimentos pelo sempre prazeroso e frutífero convívio ao longo destes anos. Ao Alan Borim, obrigado por toda a ajuda com a manipulação de figuras e ilustrações, além do suporte com aquele "indivíduo" chamado Linux. A todos os demais integrantes do GAS, do passado e do presente, não nomeados aqui (não propositadamente), meu muito obrigado!

Meu muito obrigado aos ex-estagiários do GAS Marcos Skystimas Filho, Fernando Cesário e Guilherme Matiussi, cujos trabalhos de iniciação científica contribuíram, em muito, para que este trabalho chegasse até aqui. 
Meu apreço e gratidão aos especialistas Bemildo Ferreira e Carlos Poli (em memória), da TWR Guarulhos, ao Major Renny, do atual ICEA, e ao Major Eno Siewerdt (salve, Eno!), por toda a paciência, disponibilidade e dedicação em nos transmitir valiosos ensinamentos sobre este fantástico mundo chamado "Gerenciamento de Tráfego Aéreo". Sem vocês, grande parte deste trabalho não faria sentido!

Agradeço ao Prof. Kishor Trivedi e a sua equipe na Universidade de Duke por ceder-nos a Stochastic Petri Nets Package (SPNP) e por ter-nos dado o suporte necessário à resolução dos problemas encontrados.

Meu muito obrigado à Dra. Lídia Cristine. Saiba que sem toda sua ajuda e profissionalismo eu não teria superado todos os recentes momentos difíceis.

Ao LCCA - Laboratório de Computação Científica Avançada da USP, meus agradecimentos por toda a infra-estrutura computacional e por todo suporte prestado.

À Fundação para o Desenvolvimento Tecnológico da Engenharia (FDTE), na qual trabalho como engenheiro em projetos de análise de sistemas críticos em segurança desde 2003, meu muito obrigado.

E por último, agradeço a você, leitor. A consulta a esta obra possibilita sua disseminação, motivando outros a continuar esta jornada. Há muito para ser feito ... 


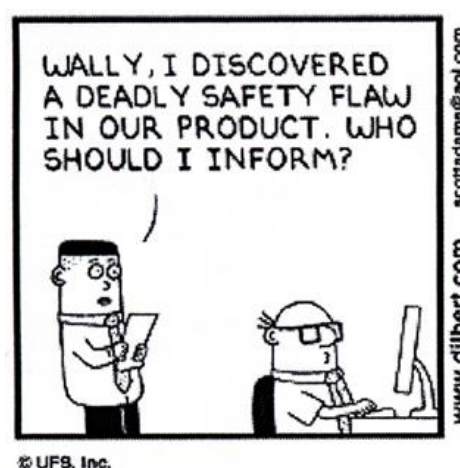

vurs. inc.
NO ONE. THE STOCK WOULD PLUNGE AND

WE'D HAVE MASSIVE

LAYOFFS. YOUR

CAREER WOULD BE

RUINED.

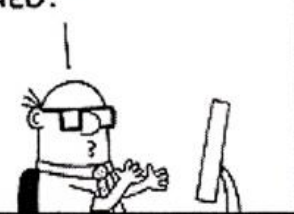

BUT MY NEGLIGENCE COULD CAUSE THE DEATHS OF A DOZEN CUSTOMERS.

THE FIRST

DOZEN IS

ALWAYS THE HARDEST.

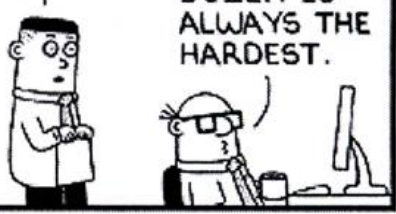

(Scott Adams)

Que nossos esforços permitam às futuras gerações observar este tipo de "conflito" apenas na forma do humor. 


\section{RESUMO}

Ao longo das últimas décadas, o paradigma de sistemas críticos em segurança vem sofrendo transformações como forma de se adequar às novas necessidades demandadas, tais como redução de custos e aumento da produtividade. No Sistema de Gerenciamento de Tráfego Aéreo, esta transformação é preconizada pelo paradigma CNS/ATM (Communication, Navigation, Surveillance / Air Traffic Management), baseado no uso de novas tecnologias digitais, sobretudo satélites, aplicadas à comunicação, à vigilância, à navegação e ao gerenciamento do tráfego aéreo. O CNS/ATM visa reduzir as restrições do atual paradigma de tráfego aéreo como forma de atender sua crescente demanda, mantendo (ou melhorando) os atuais níveis de segurança. Porém, esta mudança de paradigma traz consigo novos desafios e necessidades, sobretudo, quanto à forma de se avaliar os sistemas resultantes. Em face destes novos desafios e problemas enfrentados, este trabalho propôs um método de avaliação de risco, constituído pela união dos métodos "absoluto" e "relativo" preconizados pela Organização da Aviação Civil Internacional (OACI), pelo emprego do formalismo das redes de Petri Fluidas e Estocásticas (RPFE) na modelagem dos sistemas, e pela comparação entre os valores de métricas de segurança estimados para o sistema avaliado e para um sistema legado. Este método foi aplicado para avaliar a segurança na mudança do atual paradigma de vigilância aérea, baseado em equipamentos Radar, para o paradigma de Vigilância Dependente Automática por Radiodifusão (ADS-B). Como conclusões, o método proposto mostrou-se promissor para avaliar a segurança de sistemas baseados nos atuais paradigmas de sistema críticos em segurança, especialmente o CNS/ATM, onde o formalismo das RPFE proporcionou modelar suas principais características, e a simulação por eventos discretos permitiu estimar as métricas desejadas. Além disso, a ADS-B mostrou-se uma aplicação viável para a vigilância no Sistema de Controle de Tráfego Aéreo, sendo capaz de reduzir o nível de exposição das aeronaves a eventos de perda de separação e, assim, melhorar os níveis de segurança do tráfego aéreo.

Palavras-Chave: Tráfego Aéreo (Segurança), Redes de Petri, Análise de Risco, Simulação de Sistemas. 


\begin{abstract}
In last decades, the safety critical systems paradigm has changing to adapt itself to new necessities, such as costs reduction and productivity demand growth. In the Air Traffic System, those changes are ruled by CNS/ATM paradigm (Communication, Navigation, Surveillance / Air Traffic Management), based on new digital Technologies, mainly Satellites, applied to Communication, Surveillance, Navigation and Air Traffic Management. CNS/ATM intends to reduce the restrictions of current air traffic paradigm, enabling the growth of air traffic capacity without affecting current safety levels. However, this new paradigm brings together new challenges and needs, mainly related to safety assessment. In face of these new challenges, this work proposed a method of risk assessment constituted by the union of the "absolute" and "relative" assessment methods adopted by the International Civil Aviation Organization (ICAO), by modeling systems using Fluid Stochastic Petri Nets (FSPN) formalism, and by comparison between safety metrics obtained from proposed and legacy system simulations. This method was applied to assess a new concept of air traffic surveillance, named "Automatic Dependent Surveillance - Broadcasting" (ADS-B). As main conclusions, the proposed method was promising to assess system safety properties based on current safety critical system paradigm, especially the CNS/ATM, where FSPN formalism provided important modeling capabilities and discrete event simulation allowed estimating the desired safety metric. Besides, ADS-B has meaningfully reduced the separation losses risks and, therefore, it could be used to air traffic control surveillance system to improve capacity and/or safety levels of air traffic system.
\end{abstract}

Keywords: Air Traffic (Safety), Petri nets, Risk Analysis, Systems Simulation. 


\section{LISTA DE ILUSTRAÇÕES}

Figura 1 - O Sistema de Controle do Tráfego Aéreo ............................................................. 9

Figura 2 - Representação de uma Rota ATS em uma Carta Aeronáutica................................11

Figura 3 - Simbologia utilizada para os Radioauxílios à Navegação ..................................... 11

Figura 4 - Arquitetura do Controle de Tráfego Aéreo ........................................................... 13

Figura 5 - Camadas da Região de Proteção e incertezas no ATC (Reynolds; Hansman, 2000)

Figura 6 - Garantia da Separação e RxP (adaptada de Shakariam; Haraldsdottir (2001)) ...... 17

Figura 7 - Os fatores do RTSP e a região de proteção (adaptada de Camus (2002)) ............... 18

Figura 8 - Esquema Funcional de um Radar Primário (PSR) ................................................2 24

Figura 9 - Esquema Funcional de um Radar Secundário (SSR) ..........................................26

Figura 10 - Evolução Tecnológica dos elementos CNS .................................................... 35

Figura 11 - Melhorias no CNS e impacto sobre o ATM (adaptada de Galotti (1997)) ............36

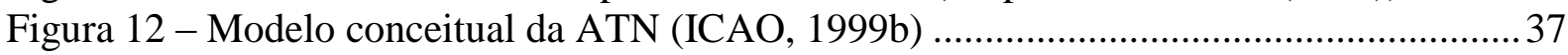

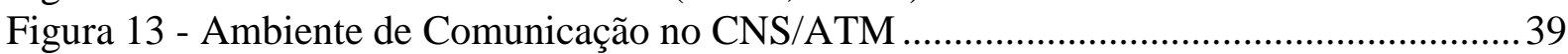

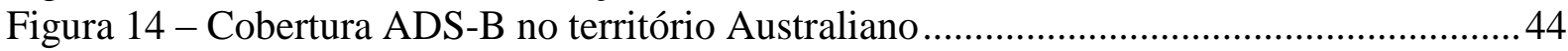

Figura 15 - Relação Funcional entre ADS-B e a aplicação de Vigilância................................45

Figura 16 - Processo de Vigilância - mensagens ADS-B.......................................................47

Figura 17 - Esquema Funcional de um Sistema ADS-B para ATC ...................................... 48

Figura 18 - Relação entre conceitos capacidade, tecnologias e segurança no ATC ................50

Figura 19 - Manifestação dos defeitos e relação com os estados do sistema. ..........................53

Figura 20 - Relação entre Separação, Capacidade e Risco de Colisão. ...................................57

Figura 21 - Estatísticas de acidentes relacionados com perda de separação entre aeronaves e

entre aeronaves e veículos terrestres (BLOM, 2004)........................................................59

Figura 22 - Aumento conceitual nas margens de segurança do serviço de controle radar

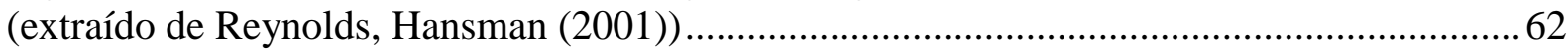

Figura 23 - Processo de determinação dos valores de separação mínima (ICAO, 1998) ........64

Figura 24 - Método de Avaliação do Risco em relação a um valor de Limiar (ICAO, 1998). 65

Figura 25 - Método ICAO (1998) de Avaliação do Risco por Comparação com uma Sistema

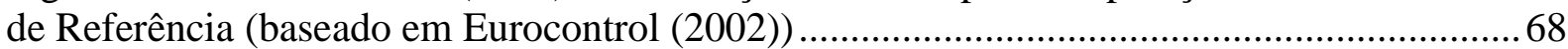

Figura 26 - Método proposto para avaliação de risco ........................................................... 72

Figura 27 - Relação entre Sistema e Aplicação Crítica em Segurança no ATC.......................74

Figura 28 - Variáveis de Recompensa Instantânea, Acumulada e Média .............................. 75

Figura 29 - Processo de obtenção de medidas de interesse no método de avaliação proposto.

Figura 30 - Sistemas ATC de "Referência" e "Proposto" ..................................................... 77

Figura 31 - Arquitetura do Sistema de Tráfego Aéreo Controlado (Glover, Lygeros (2004)) 80

Figura 32 - Variáveis de Estado de uma Aeronave e o vetor Vento (W) ...............................81

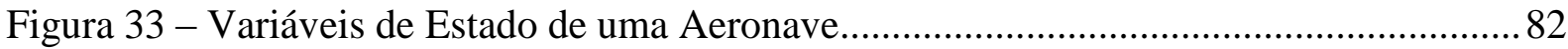

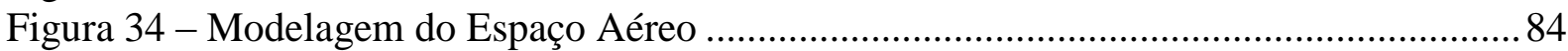

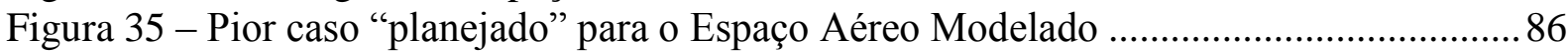

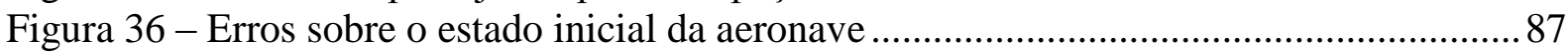

Figura 37 - Modelo para o Sistema de Navegação .............................................................. 90

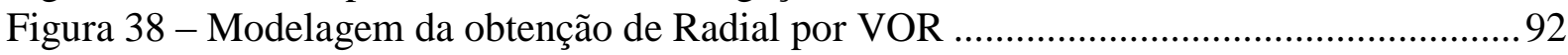

Figura 39 - Diagrama de Bloco da Navegação por VOR .......................................................92

Figura 40 - Modelagem da obtenção de desvio lateral de Rota utilizando GPS......................99

Figura 41 - Diagrama de Bloco da Navegação por GPS ....................................................95

Figura 42 -Relação entre os parâmetros de Vigilância (exemplo em 1 dimensão) ..................96 
Figura 43 - Esquema de Funcionamento da Vigilância Radar .............................................97

Figura 44 - Esquema de Funcionamento da Vigilância ADS-B .............................................98

Figura 45 - Exemplo de Trajetórias para Resolução de Conflito .............................................99

Figura 46 - Seqüência de Eventos para resolução de conflito .............................................. 100

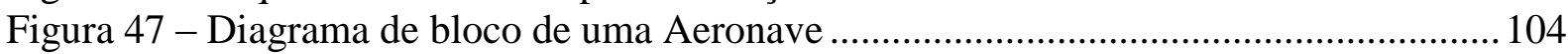

Figura 48 - Modelo de Estado da Aeronave “i”" em RPFE .................................................. 105

Figura 49 - Modelo de Estado da Navegação em RPFE ...................................................... 110

Figura 50 - Modelo-base para o Sistema de Vigilância ..................................................... 114

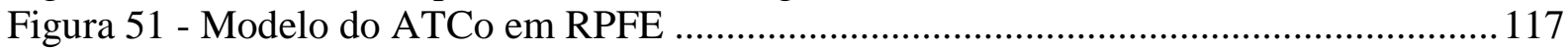

Figura 52 - Relação entre as métricas e os eventos no ATCo ............................................1122

Figura 53 - Relação entre processo tático do ATM e os elementos do ATC .........................127

Figura 54 - Exposição à Perda de Separação (TLmin_i) para Condições Normais de

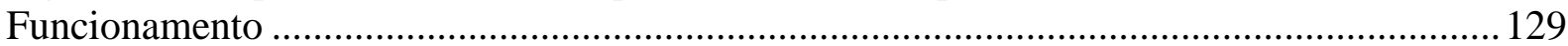

Figura 55 - Exposição à Perda de Separação (TLmin_i) para Degradação da Acurácia GNSS

Figura 56 - TLmin_i para Degradação da Taxa de Atualização com Acurácia GNSS Normal

Figura 57 - TLmin_i para Degradação da Taxa de Atualização com Acurácia GNSS

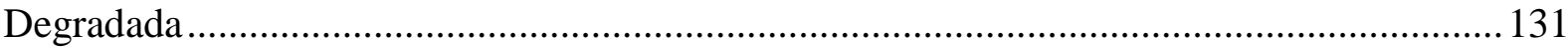

Figura 58 - TPS_INT para Condições Normais de Funcionamento.....................................132

Figura 59 - TPS_INT para Degradação da Acurácia GNSS ................................................ 133

Figura 60 - TPS_INT para Degradação da Taxa de Atualização com Acurácia GNSS Normal

Figura 61 - TPS_int para Degradação da Taxa de Atualização com Acurácia GNSS

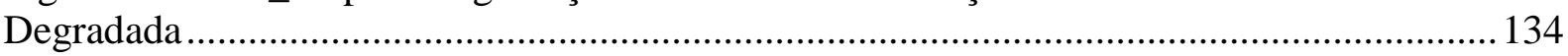

Figura 62 - RPS_interv para Condições Normais de Funcionamento................................... 135

Figura 63 - NPSM_Detec para Condições Normais de Funcionamento .................................. 136

Figura 64 - TPSR_NDetec para Condições Normais de Funcionamento ................................ 136

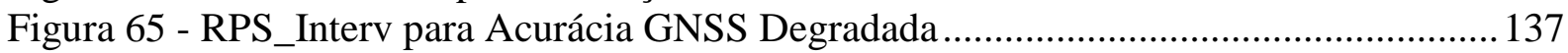

Figura 66 - NPSM_Detec para Acurácia GNSS Degradada ............................................. 137

Figura 67 - TPSR_NDetecv para Acurácia GNSS Degradada........................................... 138

Figura 68 - RPS_interv para Degradação da Taxa de Atualização com Acurácia GNSS

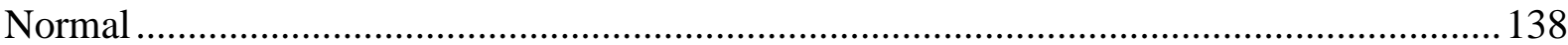

Figura 69 - NPSM_Detec para Degradação da Taxa de Atualização / Acurácia GNSS Normal

Figura 70 - TPSR_NDetec para Degradação da Taxa de Atualização / Acurácia GNSS Normal

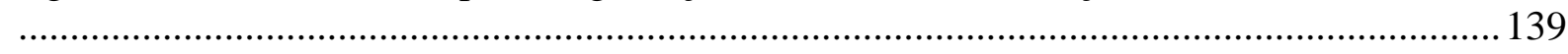

Figura 71 - RPS_interv para Degradação da Taxa de Atualização / Acurácia GNSS Degradada

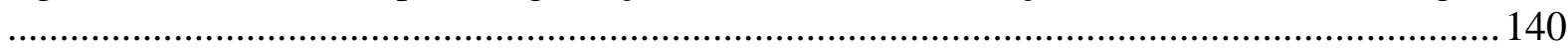

Figura 72 - NPSM_Detec para Degradação da Taxa de Atualização / Acurácia GNSS

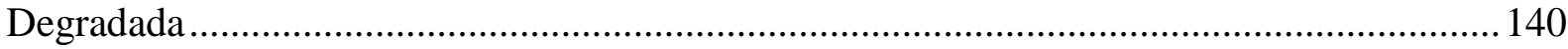

Figura 73 - TPSR_NDetec para Degradação da Taxa de Atualização / Acurácia GNSS

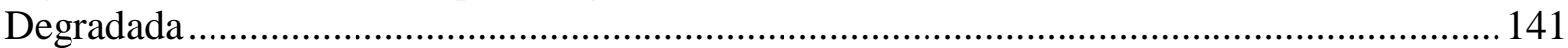

Figura 74 - TPSR_Nvig para Condições Normais de Funcionamento....................................141

Figura 75 - TPSR_NVig para Acurácia GNSS Degradada ................................................ 142

Figura 76 - TPSR_Nvig para Degradação da Taxa de Atualização / Acurácia GNSS Normal

Figura 77 - TPSR_Nvig para Degradação da Taxa de Atualização / Acurácia GNSS

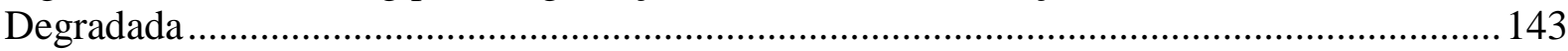

Figura 78 - O Sistema de Gerenciamento do Tráfego Aéreo ................................................. 172 
Figura 79 - Estrutura Funcional do Sistema de ATM (adaptado de Haraldsdottir, 1997) ..... 174

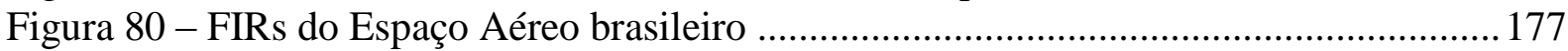

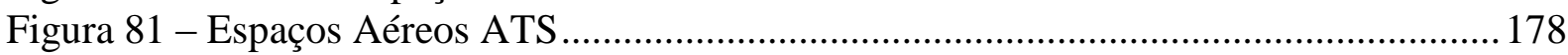

Figura 82 - Fases de um vôo (adaptado de Haraldsdottir (1997) e Cavcar (2004)) .............. 181

Figura 83 - Abrangência dos CINDACTAS (adaptado de DECEA (2005)) ......................... 182

Figura 84 - Exemplo da navegação inercial em uma dimensão.......................................... 186

Figura 85 - Método gráfico para estimar posição de um fixo através de NDBs.....................188

Figura 86 - Princípio de operação do DME ……................................................................... 190

Figura 87 - Componentes do ILS: Localizer (a), Glide Slope (b) e Markers (c)................... 192

Figura 88 - Elementos do Sistema GPS ........................................................................... 193

Figura 89 - Constelação GPS (a) e determinação de posição baseado na constelação GPS (b)

Figura 90 - Piloto, Aeronave e Navegação no Tráfego Aéreo Controlado.............................2202

Figura 91 - Relação entre "Aplicação" e "Sistema” crítico em segurança (safety) ................208

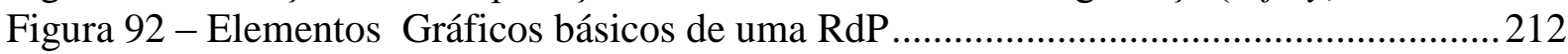

Figura 93 - Exemplos de redes elementares e suas representações matemáticas ..................218

Figura 94 - Exemplo de aplicação das políticas de reamostragem .....................................222

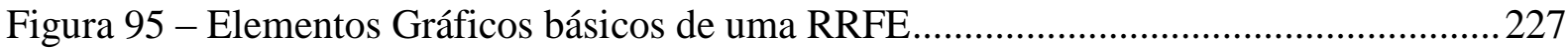

Figura 96 - Exemplo de SPN (Modelo de Funcionamento / Falha sem reparo)....................232

Figura 97 - Exemplo de SPN (Modelo de Funcionamento / Falha com reparo). ..................233

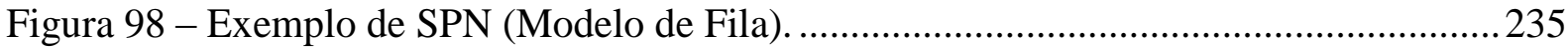

Figura 99 - Estrutura de um processo de simulação ...........................................................241

Figura 100 - RPFE com comportamento instável (Ciardo, Nicol, Trivedi (1999)) ................243

Figura 101 - Taxonomia das SRN e métodos de análise disponíveis no SPNP ....................253

Figura 102 - Exemplo de arquivo de saída do SPNP ('modelo'.out) ....................................261

Figura 103 - Processo de modelagem do Erro Espacial para o Sistema Radar .....................268

Figura 104 - Estrutura de análise desenvolvida para a ferramenta SPNP...........................2272 
LISTA DE TABELAS

Tabela I - Classificação do Espaço Aéreo ATS .............................................................. 178

Tabela II - Equivalência entre modelo para DES e SPN .................................................238 


\section{LISTA DE ABREVIATURAS E SIGLAS}

ADS-B - Automatic Dependent Surveillance - Broadcast

AP - AutoPilot

ATC - Air Traffic Control

ATCo - Air Traffic Control Operator ou Air Traffic Controller

ATM - Air Traffic Management

ATS - Air Traffic Services

CINDACTA - Centro Integrados de Defesa Aérea e Controle de Tráfego Aéreo

COTS - Commercial off-the-shelf

CRM - Colision Risk Modeling

CSPL - C-based Stochastic Petri nets Language

CNS/ATM - Communication, Navigation, Surveillance/Air Traffic Management

DECEA - Departamento de Controle do Espaço Aéreo

DME - Distance Measure Equipment

ERC - En Route Chart (Carta de Rota)

FAA - Federal Aviation Administration

FANS - Future Air Navigation System

FIR - Flight Information Region

FIS - Flight Information Service

FMC - Fligth Management Computer

FOM - Figure of Merite

GNSS - Global Navigation Satellite System

GPS - Global Position System

HFOM - Horizontal Figure of Merite

HPL - Horizontal Protection Limit

IEEE - Institute of Electrical and Eletronic Engineering

ICAO - International Civil Aviation Organization

IFR - Instrument Flight Rules

LCCA - Laboratório de Computação Científica Avançada.

NACp - Navigation Accuracy Category for position

NDB - Non Directional Beacon

NIC - Navigation Integrity Category 
NUC - Navigation Uncertainty Category

OACI - Organização da Aviação Civil Internacional (tradução de ICAO).

PANS-RAC - Procedures for Air Navigation Services: Rules of the Air Traffic Services PSR - Primary Surveillance Radar

RADAR - Radio Detection and Range

RAIM - Receiver Autonomous Integrity Monitoring

RNP - Required Navigation Performance

RPFE - Redes de Petri Fluidas e Estocásticas

RSP - Required Surveillance Performance

RTSP - Required Total System Performance

SIL - Surveillance Integrity Level

SISCEAB - Sistema de Controle do Espaço Aéreo Brasileiro

SPNP - Stochastic Petri Nets Package

SSR - Secondary Surveillance Radar

TLS - Target Level of Safety

VFR - Visual Flight Rules

VOR - VHF Ominidirecional Range 


\section{SUMÁRIO}

1. INTRODUÇÃO ....................................................................................................................... 1

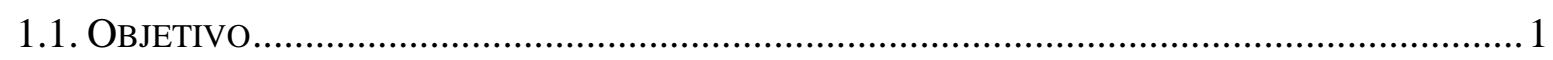

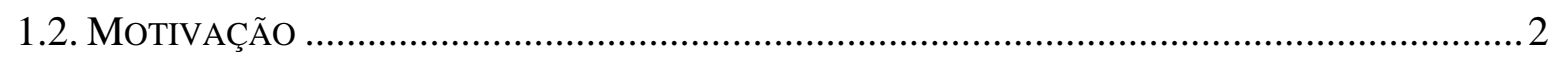

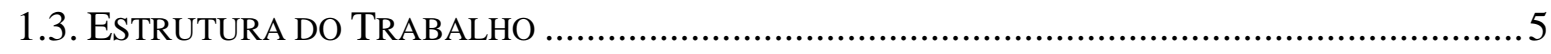

2. O SISTEMA DE TRÁFEGO AÉREO ...........................................................................

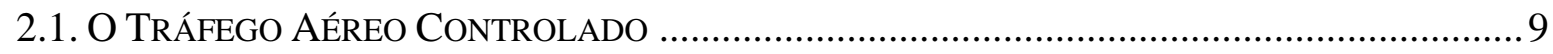

2.1.1. Os Elementos do ATC e a Capacidade do Tráfego Aéreo ...................................... 13

2.1.2. As Tecnologias dos elementos CNS do Controle de Tráfego Aéreo Atual.............. 19

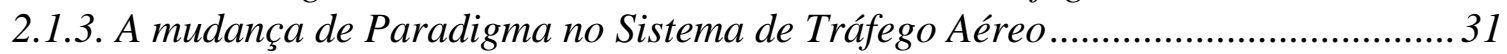

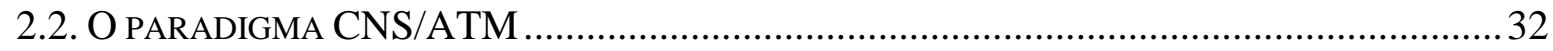

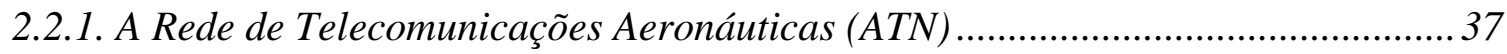

2.2.2. A Vigilância Dependente Automática por Radiodifusão $(A D S-B)$........................... 40

2.2.3. A Segurança do Tráfego Aéreo e o paradigma CNS/ATM...................................... 49

3. A SEGURANÇA NO CONTEXTO DO TRÁFEGO AÉREO ....................................51

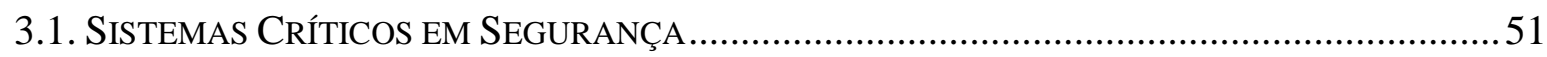

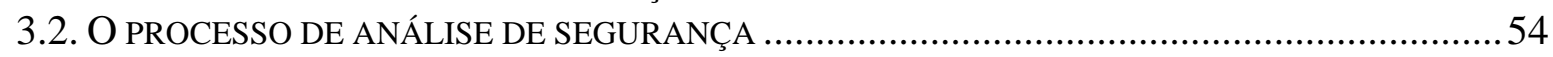

3.3. CAPACIDAdE E SEGURANÇA NO SiSTEMA DE TRÁFEGO AÉREO ......................................56

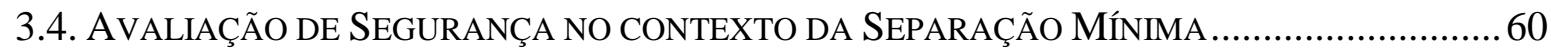

3.4.1. Método de Avaliação de Segurança da OACI.......................................................... 63

3.4.2. Avaliação do Risco em relação a um valor de Limiar ...............................................64 64

3.4.3. Avaliação do Risco por meio de Comparação com um Sistema de Referência ..... 67 3.5. PRoposta de Avaliação de Risco BASEAda EM ModElaGEM EM REDES DE PETRI Fluidas E EsTOCÁSTICAS (RPFE), SiMUlaÇÃo E COMPARAÇÃO COM SiSTEMAS LEGAdOS 70

\section{AVALIAÇÃO DE SEGURANÇA DO SISTEMA DE CONTROLE DE TRÁFEGO} AÉREO BASEADO EM ADS-B ............................................................................................. 77

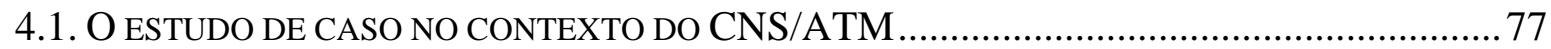

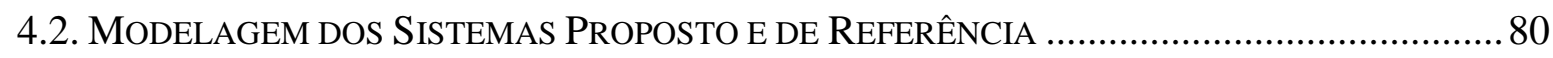

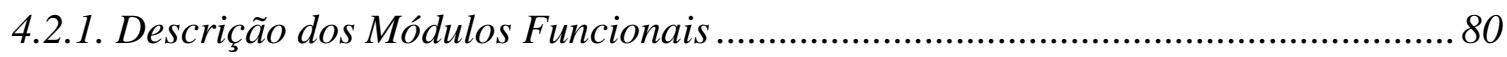

4.2.2. Modelagem dos Módulos Funcionais em RPFE e utilizando a SPNP .................. 102

4.3. MÉTRICAS E PARÂMETROS CONSIDERADOS NA AVALIAÇÃO .......................................118

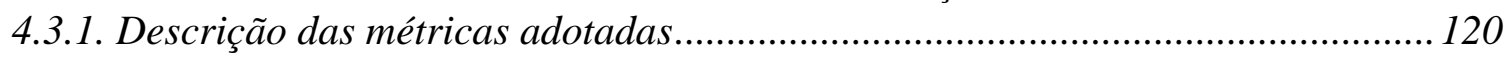

4.3.2. Parâmetros considerados na análise ................................................................... 123

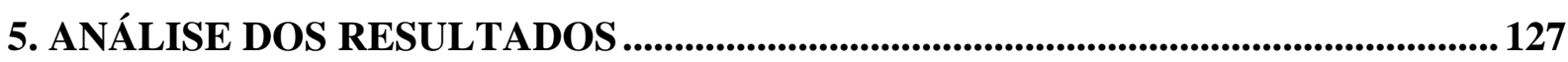

5.1. EXPOSIÇÃO A PERDA DE SEPARAÇÃO MENORES QUE 3,5NM ....................................... 128

5.2. EXPOSIÇÃO À PERDA DE SEPARAÇÃO MÍNIMA NOS CASOS DE INTERVENÇÃO ................131

5.3. EXPOSIÇÃO À PERDA DA SEPARAÇÃO ANTES DA DETECÇÃO PELO ATCO ........................134

5.4. EXPOSIÇÃO À PERDA DE SEPARAÇÃO SEM APRESENTAÇÃO AO ATCO ............................ 141

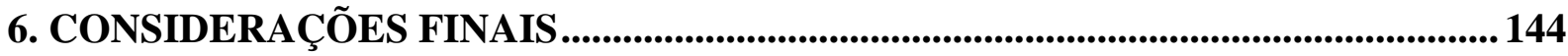

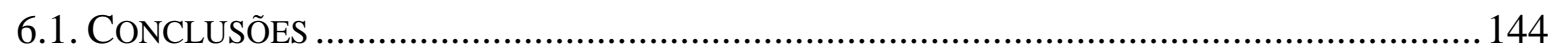

6.1.1. Conclusões com relação à proposta de Método de Avaliação Risco.................... 144

6.1.2. Conclusões com relação à modelagem em RPFE.............................................. 145 
6.1.3. Conclusões com relação à Ferramenta SPNP...................................................... 147

6.1.4. Conclusões Finais sobre a segurança do ATC baseado em ADS-B .................... 148

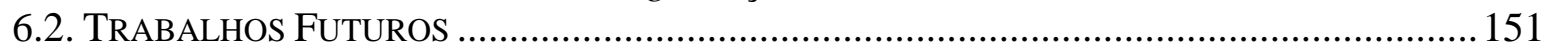

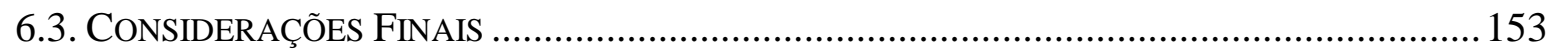

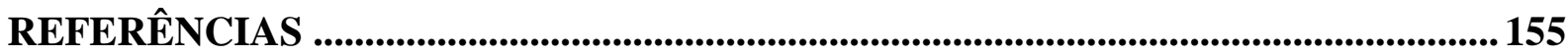

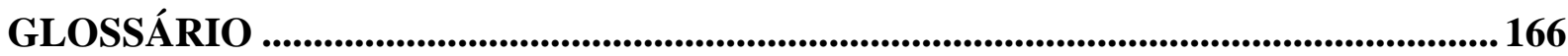

APÊNDICE A - O SISTEMA DE GERENCIAMENTO DO TRÁFEGO AÉREO ...... 168

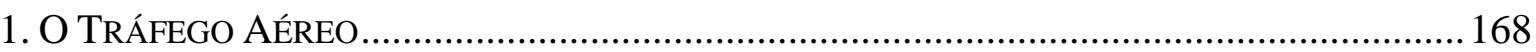

2. O SiSTEMA DE GERENCIAMENTO DE TRÁFEGO AÉREO ................................................ 171

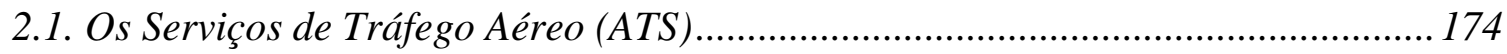

APÊNDICE B - AS TECNOLOGIAS ATUAIS EMPREGADAS NA NAVEGAÇÃO

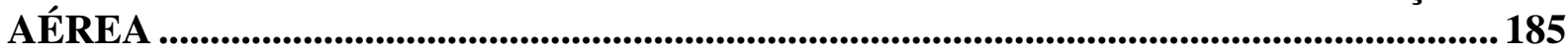

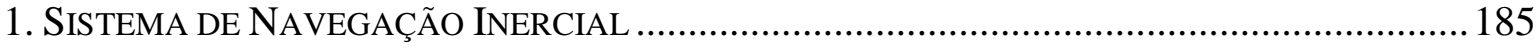

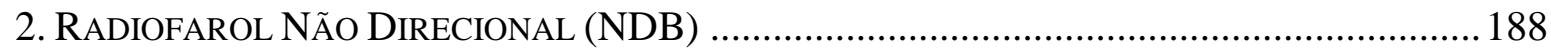

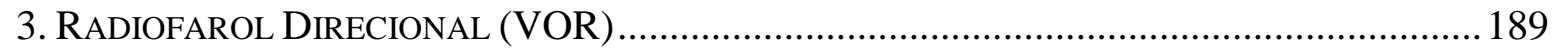

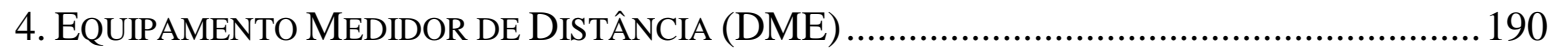

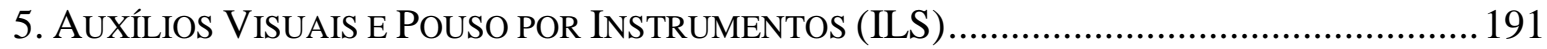

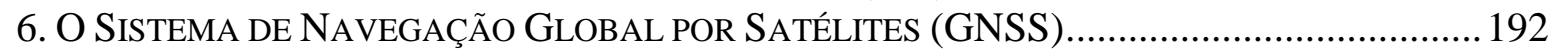

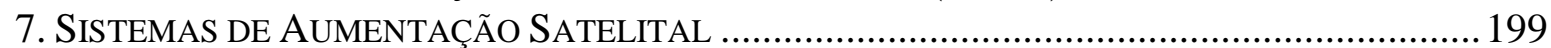

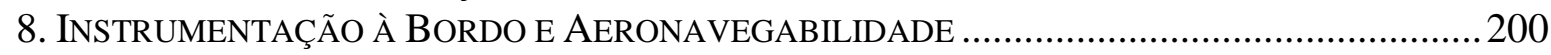

APÊNDICE C - O PARADIGMA ATUAL DOS SISTEMAS CRÍTICOS EM

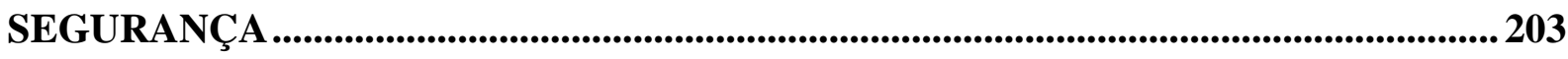

1. SISTEMAS DE CONTROLE BASEADOS EM TECNOLOGIA DA INFORMAÇÃO UTILIZADOS EM

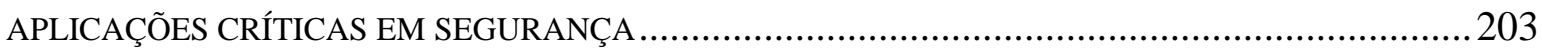

2. PROBLEMAS E DESAFIOS ENCONTRADOS NO PARADIGMA ATUAL .......................................205

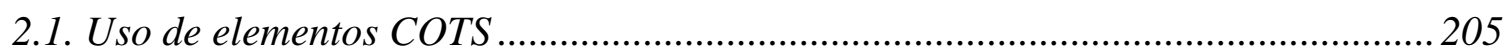

2.2. Uso de redes de comunicação não dedicadas e de padrão aberto ...........................206

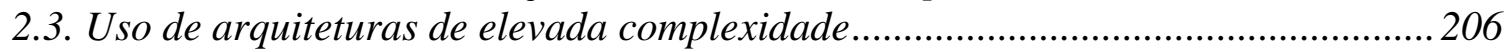

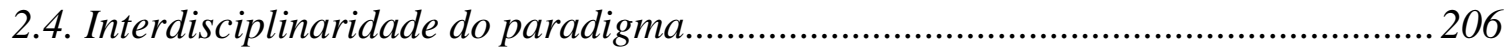

2.5. Ausência de modelos e metodologias bem estabelecidas.......................................207

3. CARACTERÍSTICAS DOS SISTEMAS CRÍTICOS EM SEGURANÇA ATUAIS ..............................207

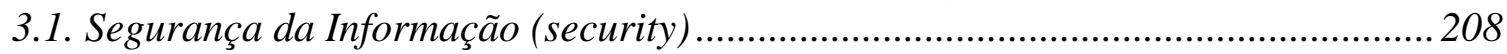

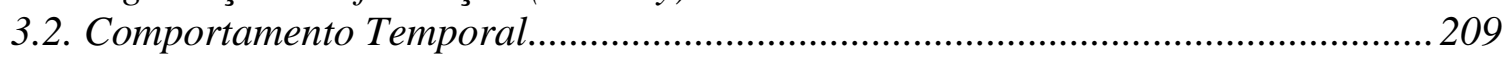

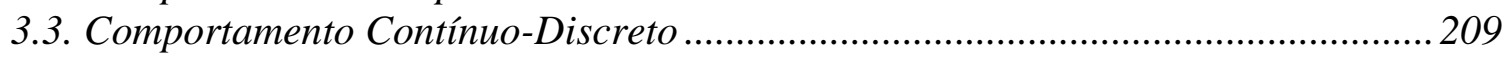

APÊNDICE D - MODELAGEM E AVALIAÇÃO DE SISTEMAS CRÍTICOS EM SEGURANÇA UTILIZANDO REDES DE PETRI FLUIDAS E ESTOCÁSTICAS.... 210

1. As REDES DE PETRI Fluidas E EstOCÁSTICAS (RPFE) ................................................2.

1.1. Considerações iniciais a respeito das redes de Petri..............................................211

1.2. Redes de Petri Temporizadas e Estocásticas ...........................................................220

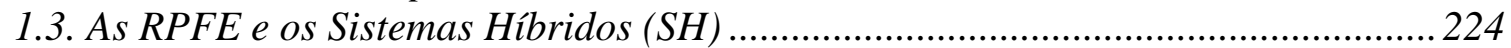

1.4. Análise Quantitativa e as redes de Petri de Recompensa (SRN) ............................229

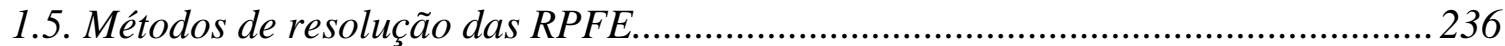

1.6. Estimação de Medidas de Avaliação por meio de Simulação....................................246

APÊNDICE E - CARACTERÍSTICAS, LIMITAÇÕES E CONTRIBUIÇÕES NO USO DA FERRAMENTA SPNP.................................................................................................251 


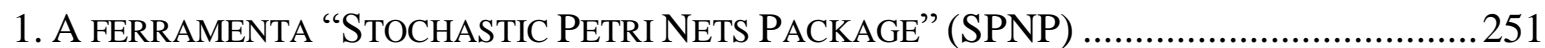

1.1. Avaliação das ferramentas computacionais disponíveis.......................................251

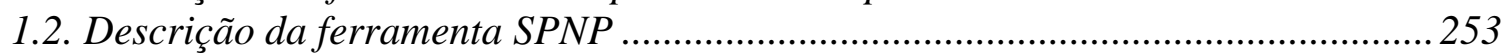

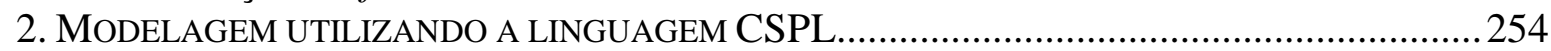

3. CARACTERÍSTICAS APLICADAS À SIMULAÇÃO DE RPFE...............................................2262

3.2. Dinâmica de execução de uma rede em CSPL .........................................................264

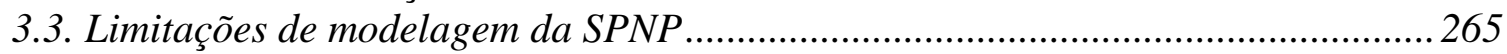

4. MELHORIAS DESENVOLVIDAS SOBRE A FERRAMENTA SPNP …....................................26

4.1. Modelagem de comportamento espacial não determinístico ..................................266

4.2. Análise de Sensibilidade para parâmetros modelados ..........................................2272 


\section{INTRODUÇÃO}

Este capítulo apresenta os temas abordados nesta Dissertação de Mestrado, definindo os objetivos deste trabalho de investigação científica e apresentando as motivações que levaram à escolha do tema.

\subsection{Objetivo}

Este trabalho de investigação científica tem como objetivo principal avaliar o impacto do uso da Vigilância Dependente Automática (Automatic Dependent Surveillance), mais especificamente sua forma por Radiodifusão (ADS-B), sobre os níveis de segurança do Sistema de Controle de Tráfego Aéreo.

Por meio de um método de avaliação de risco proposto, deseja-se verificar se a mudança do atual paradigma de vigilância aérea - baseado em equipamentos Radar e com fortes características de independência do ambiente vigiado, determinismo e sincronismo - para o paradigma de Vigilância Dependente Automática por Radiodifusão (ADS-B) - com fortes características de dependência, estocasticidade e assincronismo - é capaz de reduzir o nível de exposição das aeronaves a eventos de perda de separação.

O método proposto neste trabalho é constituído pela união dos métodos "absoluto" e "relativo" de avaliação de risco, preconizados em ICAO (1998) pela Organização de Aviação Civil Internacional (OACI), pelo emprego do formalismo das redes de Petri Fluidas e Estocásticas (RPFE) na modelagem dos sistemas, e pela comparação entre os valores de métricas de segurança estimados para o sistema avaliado e para um sistema legado. Defendese a tese de que o método proposto potencializa as qualidades individuais dos métodos "absoluto" e "relativo" da OACI.

A escolha do formalismo das RPFE tem o objetivo de possibilitar a modelagem de características atualmente observadas em sistemas complexos, tais como interdependência entre variáveis, espaço de estados contínuo-discreto e outras características dos sistemas críticos em segurança existentes a serem determinadas neste trabalho.

Portanto, no contexto do tráfego aéreo, este trabalho espera contribuir com um método de avaliação de risco que possa ser empregado no novo paradigma de sistema de tráfego aéreo denominado CNS/ATM (Communication, Navigation, Surveillance/Air Traffic Management), 
verificando se a melhoria na qualidade das informações providas ao sistema de tráfego aéreo - preconizado por este paradigma - possibilitará o aumento de sua capacidade sem que haja redução dos níveis atuais de segurança.

Além do contexto do tráfego aéreo, este trabalho pretende contribuir com um arcabouço conceitual - apresentando características de paradigmas, conceituando formalismos de modelagem e de simulação, especificando e ilustrando a utilização de ferramental computacional - que possa ser utilizado na avaliação de sistemas críticos em segurança empregados nas diversas áreas de aplicação, tais como transportes, energia, indústria, entre outros.

\subsection{Motivação}

Conforme citado pelo Departamento de Controle do Espaço Aéreo Brasileiro (DECEA, 2002) “... Nos últimos cinqüenta anos, o tráfego mundial de passageiros (doméstico e internacional) ... aumentou segundo uma taxa média anual de $8.9 \%$, enquanto que, em matéria de carga ... os fluxos aumentaram na taxa média anual de $11 \%$...". Estimativas da Organização da Aviação Civil Internacional (ICAO, 2004b) apontam para um crescimento médio, até o ano de 2015 , de 4,2\% ao ano do número de aeronaves-quilômetro e de 3,2\% a.a. do número médio de decolagens.

O crescimento do tráfego aéreo mundial é, atualmente, limitado pela saturação da capacidade do sistema de tráfego aéreo. Uma das causas diretas desta saturação vem das restrições em se reduzir os valores da separação aplicados entre aeronaves e, ao mesmo tempo, manter-se os níveis de segurança atuais. Os valores de separação aplicados são limitados pela habilidade com a qual os controladores de tráfego aéreo conseguem estabelecer e manter a separação das aeronaves. Esta habilidade de controle é influenciada diretamente pelas tecnologias e procedimentos utilizados no atual conceito de controle de tráfego aéreo e, consequentemente, pelo Sistema de Controle do Espaço Aéreo Brasileiro (SISCEAB).

Portanto, como pode ser notado, existe uma cadeia de restrições no conceito atual de sistema de tráfego aéreo, cujos elementos tecnológicos empregados refletem diretamente na capacidade do tráfego aéreo. Os elementos utilizados no atual conceito de controle de tráfego aéreo, tal como a comunicação entre piloto e controlador baseadas em canais de voz e a vigilância baseada em imagens de posição Radar, cuja tecnologia possui cobertura limitada e restrita à linha de visada, são os mesmos há aproximadamente 6 décadas. Mesmo tendo 
sofrido refinamentos ao longo dos anos, concluiu-se que a possibilidade de crescimento do tráfego aéreo, baseada em seu paradigma atual, exauriu-se (Siewerdt, 2000).

As limitações do atual sistema de tráfego aéreo foram reconhecidas pela Organização de Aviação Civil Internacional (OACI) no início da década de 1980, onde se estabeleceu um comitê denominado "Comitê sobre o Sistema de Navegação Aérea do Futuro" (FANS), com a finalidade de “... identificar, estudar e avaliar novos conceitos e tecnologias e fazer recomendações para o desenvolvimento coordenado e evolutivo da navegação aérea em um horizonte de 25 anos ..." (ICAO, 2000). Este comitê concluiu que haveria a necessidade de se desenvolver e implementar, em nível mundial, um novo sistema de tráfego aéreo baseado em novos conceitos de comunicação, navegação, vigilância e gerenciamento de tráfego aéreo. Este conceito, denominado CNS/ATM (Communication, Navigation, SurveillancelAir Traffic Management), foi aprovado pela $10^{a}$ Conferência de Navegação Aérea, realizada em 1991, e detalhado ao longo dos anos seguintes.

O conceito CNS/ATM, sucessor do atual conceito de sistema de tráfego aéreo, baseia-se em novas tecnologias digitais aplicadas à comunicação, à vigilância, à navegação e ao gerenciamento do tráfego aéreo. A implementação de comunicação de dados digitais e de navegação por satélite, entre outras tecnologias, permitiria obter maiores níveis de automação e de acurácia no controle do tráfego aéreo e, a princípio, minimizaria as restrições existentes no sistema de transporte aéreo atual. Por conseqüência, seria possível atender a crescente demanda por tráfego aéreo mantendo-se (ou, de preferência, elevando-se) os níveis de segurança atuais.

Um dos conceitos pertencentes ao CNS/ATM a serem empregados no Sistema de Tráfego Aéreo é a Vigilância Dependente Automática por Radiodifusão (ADS-B), definida pela OACI como um dos elementos da camada de aplicação da rede de telecomunicações aeronáuticas (ATN). Esta aplicação permite a distribuição ominidirecional (por radiodifusão) de informações de vigilância, de qualquer elemento devidamente equipado, por meio de um enlace de dados, para qualquer elemento no raio de cobertura do transmissor devidamente equipado. A ADS-B está sendo encarada pela OACI como “... an enabler of the global ATM operational concept bringing substantial safety and capacity benefits ...” (ICAO, 2006).

Portanto, o paradigma CNS/ATM introduz um novo conceito ao sistema de tráfego aéreo. Desta forma, é necessário avaliar qual o impacto das novas tecnologias e, consequentemente, 
do novo conceito, sobre a segurança do tráfego aéreo. Deve-se garantir - de preferência, por meio de métodos formais - que estas novas tecnologias possam promover o aumento da capacidade do sistema de tráfego sem comprometer seu nível de segurança atual. No programa de transição do SISCEAB para os sistemas CNS/ATM (DECEA, 2003), fica explicitamente relatado a necessidade de determinar-se o "... impacto dos novos conceitos nos diversos serviços (de tráfego aéreo) prestados...”. Estas necessidades podem ser listadas, entre outras, como a "...determinação dos parâmetros associados ao modelo utilizado para determinação do risco de colisão em espaços aéreos onde se aplica a redução da separação...", a “...determinação dos riscos de colisão associados às operações no espaço aéreo...” e a “...realização de comparações dos riscos obtidos com os limites de riscos aceitos...”.

Os métodos atualmente utilizados para avaliar níveis de segurança em função de alterações no sistema de tráfego aéreo não contemplam os graus de automação e as novas tecnologias inseridas pelo paradigma CNS/ATM. Alguns métodos aplicados na avaliação da segurança destes novos sistemas utilizam modelagem matemática para risco de colisão. Métodos baseados em modelagem e análise matemáticas são poderosos, pois permitem considerar apenas os parâmetros relevantes à análise em questão, além de fazerem uso de propriedades matemáticas intrínsecas ao próprio método formal utilizado. Porém, estes métodos, aplicados em novos conceitos, podem levar à obtenção de valores de risco irreais, pois os modelos utilizados não podem ser plenamente validados devido à inexistência de valores históricos reais de seus parâmetros, além de não haver plena compreensão dos processos de incertezas do sistema.

Como forma de reduzir a possibilidade de haver discrepâncias relevantes nos valores de risco obtidos para o novo sistema, pode-se utilizar métodos de análise baseados em comparação direta entre as características dos sistemas. Porém, tal como a Organização de Aviação Civil Internacional (OACI) preconiza em sua metodologia (ICAO, 1998), estas comparações são válidas apenas quando alguns critérios de similaridade entre sistemas a serem comparados são respeitados, o que não seria válido, considerando o método da OACI, ao se comparar o conceito atual de sistema de tráfego aéreo com o sistema CNS/ATM.

Concluindo, existe a necessidade latente de desenvolverem-se métodos de avaliação de risco que contemplem as características do novo paradigma de tráfego aéreo, tanto para aplicá-los sobre novos conceitos como forma de garantir que os níveis de segurança do sistema de tráfego aéreo serão respeitados quanto como ferramental para decisão dos melhores 
procedimentos a serem utilizados. As aplicações não ficam limitadas apenas ao Sistema de Controle de Tráfego Aéreo, mas também a todos os sistemas críticos em segurança cujos paradigmas estão se alterando como forma de suprir novas necessidades sociais.

\subsection{Estrutura do Trabalho}

Este texto está estruturado com base em 6 Capítulos e 5 Apêndices.

O Capítulo 2 aborda os conceitos relacionados ao Sistema de Tráfego Aéreo, tanto no paradigma atual quanto em sua evolução ao CNS/ATM. Este capítulo ilustra a relação entre os elementos do sistema e sua capacidade de tráfego, detalhando como as características de navegação, vigilância e comunicação podem restringir o cumprimento da demanda por tráfego aéreo.

O Capítulo 3 aborda o conceito de sistemas críticos em segurança e, em seguida, apresenta a relação entre segurança e capacidade do sistema de tráfego aéreo. São ilustradas as metodologias de avaliação de segurança atualmente utilizadas em aviação, principalmente a proposta pela ICAO. Por fim, propõe-se um método de avaliação de risco, cujo objetivo é minimizar as limitações encontradas nos demais métodos ilustrados.

No Capítulo 4, utiliza-se o método proposto no Capítulo 3 para avaliação da segurança do sistema de controle de tráfego baseado em vigilância dependente automática por radiodifusão (ADS-B). Este Capítulo apresenta o estudo de caso proposto, modela os sistemas em análise e define as métricas de segurança a serem utilizadas.

O Capítulo 5 analisa os resultados obtidos para as métricas de segurança adotadas com a aplicação do método de avaliação proposto sobre o estudo de caso apresentado.

O Capítulo 6 apresenta as conclusões obtidas em decorrência deste trabalho de investigação científica, além de propor algumas linhas de investigação futuras.

O APÊNDICE A apresenta a classificação e estruturação do espaço aéreo, complementando o Capítulo 2 deste trabalho.

O APÊNDICE B apresenta as tecnologias de navegação atualmente empregadas no sistema de tráfego aéreo, complementando o Capítulo 2 deste trabalho.

O APÊNDICE C apresenta as características do atual paradigma de sistemas críticos em 
segurança e os conseqüentes novos desafios impostos aos seus ciclos de vida. Este estudo serve para demonstrar que o conceito CNS/ATM possui as mesmas características e desafios do atual paradigma de sistemas críticos em segurança, baseando a escolha do formalismo de modelagem utilizado.

O APÊNDICE D apresenta conceitos relacionados ao formalismo das Redes de Petri Fluidas e Estocásticas (RPFE), adotada como o formalismo de modelagem dos sistemas avaliados segundo o método proposto neste trabalho, além de abordar os conceitos relativos à simulação por eventos discretos (DES) e de inferência estatística.

O APÊNDICE E aborda a ferramenta computacional Stochastic Petri Nets Package (SPNP), utilizada para modelagem e simulação computacional segundo o formalismo das Redes de Petri Fluidas e Estocásticas. 


\section{O SISTEMA DE TRÁFEGO AÉREO}

Dentre os modais de transporte existentes, o transporte aéreo é o que oferece a maior velocidade na condução de passageiros e de cargas entre pontos terminais, possibilitando uma alta produtividade (quantidade de operações por unidade de tempo). Mesmo que cada aeronave possua uma baixa capacidade individual, o alto valor agregado das cargas transportadas propicia um custo moderado de transporte por unidade de distância percorrida, desde que estas distâncias sejam suficientemente longas. Papacostas; Prevedouros (1993) descrevem que a escolha do modo de transporte para a realização de viagens de longa distância é influenciada por dois critérios: tempo de viagem e custo. Comparando alguns modos de transporte (rodoviário, ferroviário e aeroviário), estes autores concluem que o transporte aéreo é o que provê a maior rapidez para distâncias superiores a 500 milhas (aproximadamente $800 \mathrm{~km}$ ). Desta forma, a relação entre custo e tempo de serviço torna o transporte aéreo a melhor opção, sobretudo, para transporte de passageiros por longas distâncias, de cargas com alto valor específico, perecíveis, emergenciais ou outras que necessitem ser entregues em prazos curtos.

O transporte aéreo, comparado com outros modos de transporte, possui uma participação modesta no cenário mundial de transporte de cargas e de passageiros, principalmente se forem consideradas as métricas "passageiros transportados por quilômetro" (pax-km) e "toneladas de carga transportadas por quilômetro" (ton-km). Dados de 1995 demonstram que o sistema de transporte aéreo participou com aproximadamente 5\% dos pax-km transportados e com aproximadamente 1\% das ton-km transportados no mundo (Pereira Filho et al, 1998). Porém, como mencionado anteriormente, o mercado consumidor do transporte aéreo é direcionado às viagens de longa distância ou ao transporte de cargas que possuem alto valor específico e prazos curtos de entrega. Desta forma, considerando o valor transportado por quilômetro, a participação do transporte aéreo no cenário mundial é expressiva. Percebe-se a importância do transporte aéreo sobre a economia por meio de seus modelos de previsão de demanda, onde se verifica uma relação direta entre os indicadores macroeconômicos, tal como o Produto Interno Bruto (PIB), e a demanda por este tipo de serviço (Pereira Filho et al, 1998).

O sistema de transporte aéreo atende sua demanda fazendo com que, entre outras atividades, as aeronaves trafeguem no espaço aéreo de forma eficiente e segura. $\mathrm{O}$ sistema de tráfego aéreo é responsável por esta atividade do sistema de transporte aéreo. Devido às características do tráfego, onde as aeronaves podem navegar em três dimensões espaciais, 
com velocidades elevadas e, em parte do tempo, com baixa visibilidade por parte do operador da aeronave (piloto), o sistema de tráfego aéreo necessita de elementos e procedimentos que habilitem os pilotos a conhecerem suas localizações e, assim, poderem cumprir seus percursos.

Em espaços aéreos com baixas densidades de tráfego e com condições aceitáveis de visibilidade, os pilotos podem ser capazes de manter a segurança do tráfego seguindo regras de vôo visuais, sem a necessidade de existir gerenciamento externo do tráfego. Porém, em espaços aéreos complexos, com grande densidade de tráfego ou em condições de visibilidade degradadas, a manutenção da eficiência e da segurança do tráfego somente pode ser obtida através do gerenciamento do tráfego realizado externamente às aeronaves. Neste caso, o sistema de tráfego torna-se mais complexo, devendo possuir elementos funcionais e procedimentos que possibilitem aos gerenciadores do tráfego planejar os fluxos antes que eles ocorram e, durante suas ocorrências, conhecer as posições das aeronaves e intervir sobre as mesmas de forma a manter seus fluxos ordenados e as aeronaves separadas por distâncias seguras.

A capacidade de um sistema de transporte está relacionada à definição dos seus elementos funcionais e à arquitetura com a qual é implementado. Mesmo com o gerenciamento do tráfego, o sistema de tráfego possui uma demanda máxima que pode cumprir de forma eficiente e segura. Quando esta demanda excede sua capacidade, é necessário fazer alterações no sistema de transporte para que esta demanda possa ser atendida. Determinar onde estas alterações devem ser realizadas com a finalidade de aumentar a capacidade do sistema depende, sobretudo, do entendimento de seu funcionamento, da avaliação dos possíveis gargalos existentes, da determinação de quais alterações eliminam ou minimizam estes gargalos e, finalmente, da verificação se estas alterações atendem aos critérios de eficiência e de segurança desejados.

Este capítulo tem o objetivo de definir quais são os conceitos atuais e os gargalos relacionados ao sistema de controle de tráfego aéreo. Em seguida, apresenta-se o conceito CNS/ATM (Communication, Navigation, Surveillance / Air Traffic Management), que define quais alterações serão adotadas no sistema de tráfego aéreo como forma de minimizar os gargalos atuais ao crescimento da sua capacidade. $\mathrm{O}$ destaque será dado sobre o conceito da vigilância aeronáutica, tanto independente quanto dependente e/ou cooperativa, e quais seus impactos sobre a segurança do tráfego aéreo. 


\subsection{O Tráfego Aéreo Controlado}

As aeronaves que operam em regiões de vôo controlado são constantemente monitoradas pelos controladores de tráfego aéreo (ATCo). Os ATCos são os indivíduos que compartilham com os pilotos a responsabilidade pela condução das aeronaves, de modo a garantir a segurança e a fluidez dos vôos executados em regiões do espaço aéreo controlado. Os ATCos utilizam elementos funcionais e seguem procedimentos como forma de manter a vigilância sobre as aeronaves dentro do espaço aéreo sob suas jurisdições. Esta vigilância tem a função de fornecer aos controladores as posições, velocidades e direções atuais dos vôos das aeronaves sob suas responsabilidades, além de estimativas de suas posições futuras. Desta forma, os ATCos são capazes de monitorar os vôos controlados, verificando se os mesmos seguem os planos de vôo em vigor, e de intervir sobre as aeronaves caso detectem conflitos ou desvios dos planos adotados, comunicando aos pilotos quais ações devem ser executadas para que o conflito detectado seja resolvido.

De forma sintética, a Figura 1 ilustra o que pode ser denominado como "Sistema de Controle do Tráfego Aéreo", pois é um conjunto de elementos funcionais (Aeronaves no espaço aéreo controlado $\left(\mathrm{A}_{1}, \mathrm{~A}_{2}, \ldots\right)$, ATCos, elementos de Comunicação e de Vigilância) que interagem com o objetivo de cumprir a missão do serviço de controle de tráfego aéreo (ATC): prevenir colisões, acelerar e manter ordenado o fluxo do tráfego aéreo.

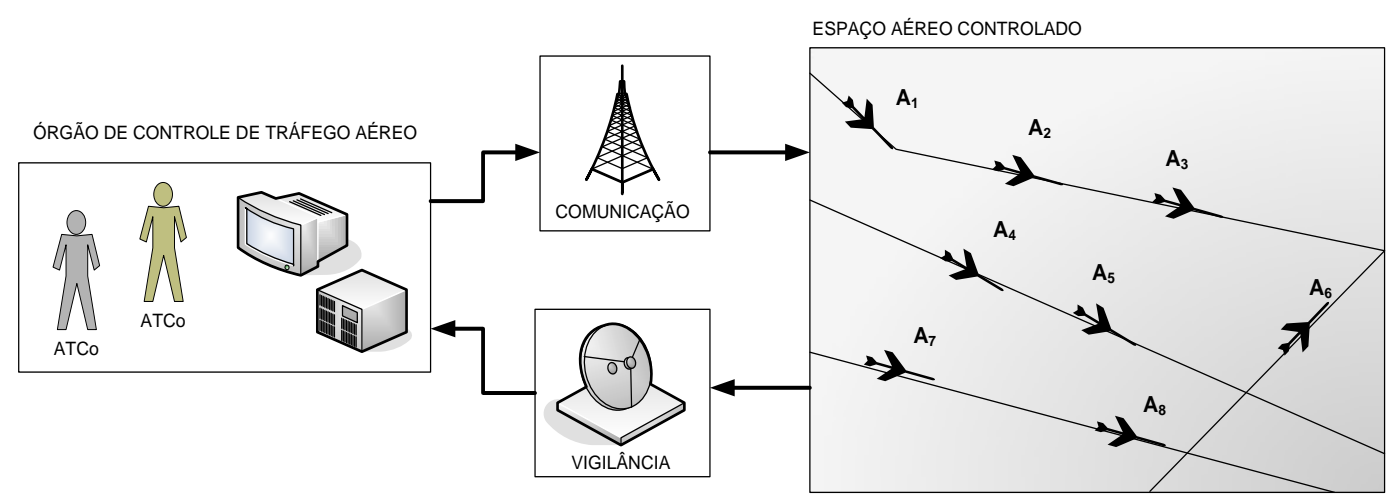

Figura 1 - O Sistema de Controle do Tráfego Aéreo

Um dos requisitos para a prestação do serviço de controle de tráfego aéreo (ATC) é a existência de radiocomunicação bilateral contínua entre o órgão ATC e as aeronaves que navegam sob sua jurisdição (Ministério da Aeronáutica, 1999 e 2000). Esta radiocomunicação 
é utilizada pelo piloto para notificar ao órgão ATC, em determinadas situações ${ }^{1}$, qual é sua posição e a hora desta ocorrência, seu nível de vôo ou altitude ${ }^{2}$, sua próxima posição e hora estimada para este sobrevôo (Ministério da Aeronáutica, 1999). Desta forma, os controladores de tráfego aéreo (ATCo) utilizam as informações contidas nestas notificações para elaborar um mapa situacional do espaço aéreo controlado e manter a vigilância sobre as aeronaves sob sua responsabilidade. Este método de vigilância, que depende das notificações de posição fornecidas pelos pilotos, é conhecido como "Vigilância Convencional" (ou, no inglês, Procedural Surveillance). Em contrapartida, é possível utilizar o método de vigilância conhecido como "Não Convencional" (ou "non Procedural") nas regiões do espaço aéreo onde o ATCo pode obter informações de posição das aeronaves independentemente das notificações emitidas pelos pilotos. Um exemplo de vigilância não convencional é a Vigilância Radar, que pode ser utilizada pelo órgão ATC em regiões do espaço aéreo onde exista cobertura de vigilância por equipamentos Radar. Em regiões onde não exista esta funcionalidade, a radiocomunicação é utilizada pelo sistema de controle de tráfego aéreo tanto para vigilância quanto para a comunicação, exercendo um papel essencial na segurança e na eficiência dos vôos.

Além da vigilância, que propicia ao ATCo monitorar os vôos sob sua responsabilidade, e da comunicação, que permite ao ATCo intervir sobre estes vôos através da emissão de instruções e de autorizações aos pilotos, a navegação é uma funcionalidade cujo bom desempenho é essencial à eficiência do sistema de controle de tráfego aéreo. A princípio, a navegação é uma funcionalidade diretamente relacionada ao nível da "condução e navegação da aeronave" no sistema de gerenciamento do tráfego aéreo. Os auxílios à navegação fornecem referências que permitem ao piloto, de forma individual, localizar-se no espaço aéreo e aderir à sua trajetória planejada. Porém, no caso de vôos controlados, uma aderência eficiente às trajetórias planejadas permite que o ATCo reduza o número de intervenções às aeronaves com o objetivo de corrigir possíveis desvios de seus percursos desejados. Neste sentido, definir trajetórias específicas por onde as aeronaves podem navegar, balizando-as por meio de auxílios à navegação, é uma forma de aumentar a previsibilidade para suas posições e a aderência aos

\footnotetext{
${ }^{1}$ A mensagem de posição é exigida nas seguintes situações: sobre, ou imediatamente após, a aeronave passar por um ponto de notificação compulsório (definido em cartas de rotas (ERC) e em cartas de área (ARC)); em intervalos de tempo pré-estabelecidos, caso as rotas navegadas não sejam definidas por pontos de notificação compulsórios; por solicitação dos órgãos ATS; no cruzamento de limites laterais de áreas de controle ou FIR; quando as condições meteorológicas assim exigirem. (Ministério da Aeronáutica, 1999).

${ }^{2}$ Altitude: "Distância vertical entre um nível, um ponto ou um objeto considerado como ponto e o nível médio do mar." (Ministério da Aeronáutica, 1999).
} 
planos de vôo. Assim, os vôos providos com os serviços de tráfego aéreo (FIS, ATC e/ou AS) devem navegar sobre Rotas $\mathrm{ATS}^{3}$, que são estipuladas pelos órgãos competentes e representadas em cartas aeronáuticas, conforme exemplificado na Figura 2 (Ministério da Aeronáutica, 2000).

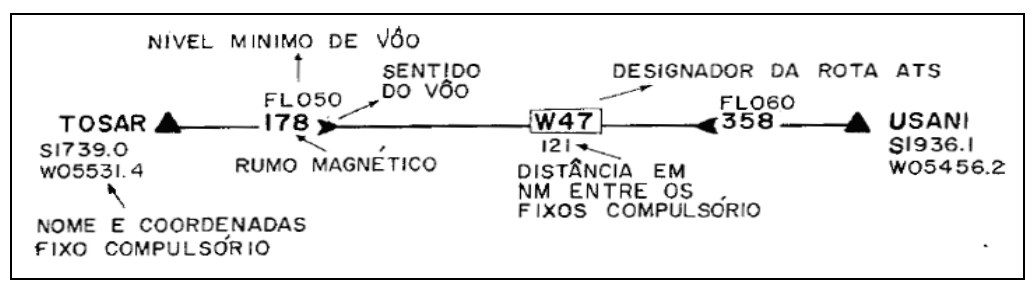

Figura 2 - Representação de uma Rota ATS em uma Carta Aeronáutica

Para navegar sobre uma rota ATS, os pilotos devem conhecer suas características (níveis, direções e sentidos da rota) e, principalmente, o posicionamento físico (coordenadas) dos auxílios à navegação que as balizam. Estes auxílios são representados em cartas aeronáuticas com a simbologia ilustrada na Figura 3 (Ministério da Aeronáutica, 2000). No caso das aerovias (Rotas ATS para vôos controlados), as mesmas são balizadas pelos rádioauxílios à navegação VOR (Radiofarol Direcional - Very High Frequency Ominidirecional Range) e NDB (Radiofarol Não Direcional - Non Directional Beacon) (Ministério da Aeronáutica, 2000). Ao navegar sobre uma rota ATS, os pilotos se orientam com as referências fornecidas pelos auxílios e, assim, aderem às trajetórias planejadas.

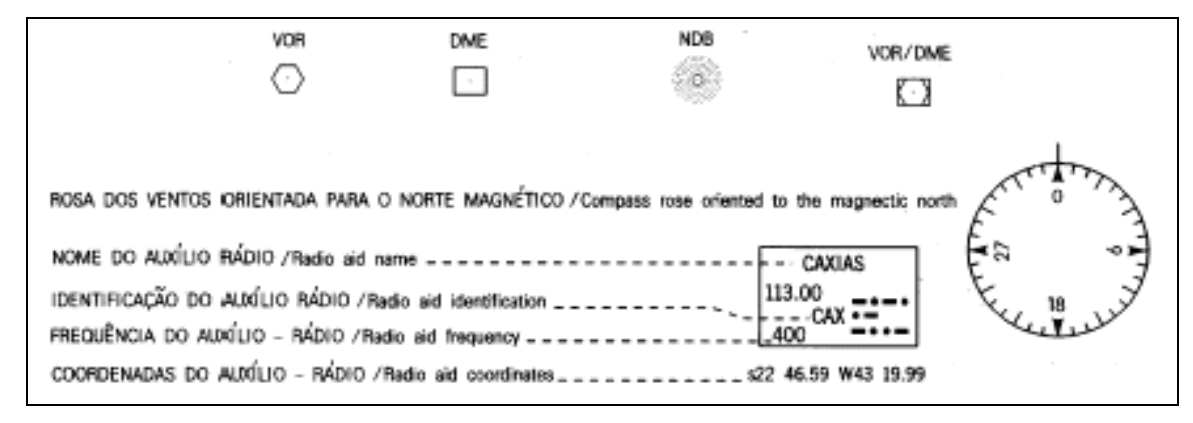

Figura 3 - Simbologia utilizada para os Radioauxílios à Navegação

Mesmo os vôos não controlados podem se utilizar dos auxílios à navegação. Por exemplo, para executar vôos do tipo IFR (seguindo regras de vôo por instrumentos), as aeronaves devem possuir, obrigatoriamente, instrumentos de radioauxílio à navegação com alcance

\footnotetext{
${ }^{3}$ Rotas ATS: "Rota especificada, de acordo com a necessidade, para proporcionar serviços de tráfego aéreo. Pode se aplicar, segundo o caso, a aerovias, rota de assessoramento, rotas com ou sem controle, rotas de chegada e saída, etc." (Ministério da Aeronáutica, 1999)
} 
mínimo de 27 milhas náuticas (Ministério da Aeronáutica, 1999), mesmo que o vôo não seja controlado (ocorra nas classes F e G do espaço aéreo). Diversos tipos de navegação (e equipamentos de auxílio) podem ser utilizados, conforme suas disponibilidades e regras de vôo. Em vôos seguindo regras por instrumentos (IFR), a navegação deve servir-se de radioauxílios (tais como o Rádio Farol Direcional (VOR), o Rádio Farol Não Direcional (NDB), o Medidor de Distância (DME), o Sistema de Aproximação de Precisão (ILS)). Tanto em vôos VFR quanto IFR, o piloto pode fazer uso da Navegação Inercial ou da Navegação por Satélite (Sistema de Posicionamento Global (GPS), Sistema de Navegação Global por Satélite (GNSS)). Individualmente, todos estes tipos de navegação são projetados para auxiliarem os pilotos a aderirem às suas trajetórias pré-estabelecidas (rotas ATS, no caso de vôos servidos pelos serviços de tráfego aéreo). Suas eficiências afetam a eficiência do controle de tráfego aéreo, pois podem reduzir o número de intervenções por parte do ATC - e sua conseqüente carga de trabalho (workload) - no caso dos pilotos conseguirem manter a aderência, com maior probabilidade, sobre as trajetórias planejadas. Além dos impactos sobre a carga de trabalho, a eficiência da navegação é crítica em situações onde o controle de tráfego aéreo utiliza vigilância convencional, pois afeta a qualidade dos dados de posicionamento utilizados pelos pilotos nas notificações de posição transmitidas aos ATCos.

Pode-se afirmar, portanto, que as características dos elementos de navegação, comunicação e vigilância são as bases que definem o sistema de controle de tráfego aéreo, pois fornecem os recursos utilizados por seus usuários diretos (controladores de tráfego e pilotos) no monitoramento, detecção, intervenção e resolução de conflitos entre aeronaves. Os controladores de tráfego aéreo (ATCo) utilizam os recursos de vigilância e comunicação para monitorar, detectar e intervir sobre as aeronaves, comunicando aos pilotos as instruções que devem ser seguidas. Por sua vez, os pilotos utilizam os recursos de comunicação e navegação para receber os procedimentos que devem seguir e, assim, atuar sobre as superfícies de controle da aeronave, fazendo-a aderir ao perfil de vôo comandado.

Desta forma, a Figura 4 representa a arquitetura simplificada deste sistema, ilustrando o fluxo de informação entre seus elementos. 


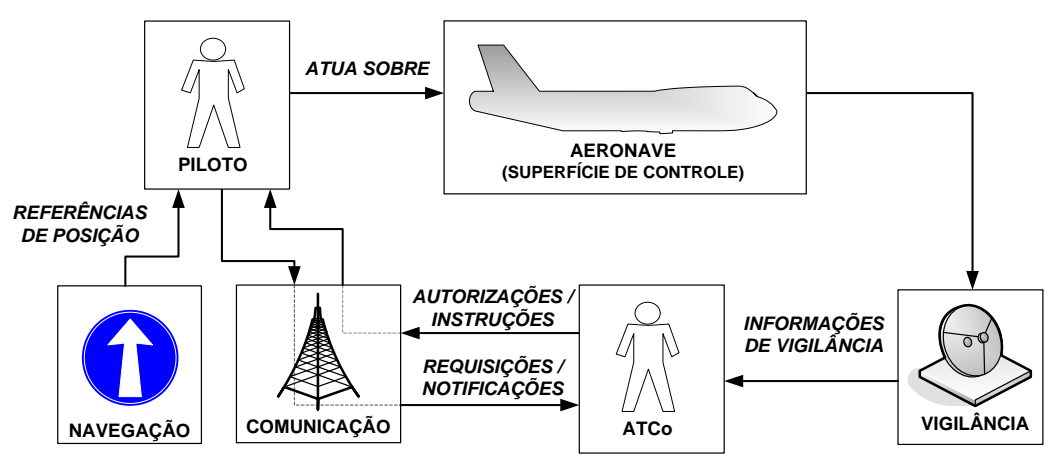

Figura 4 - Arquitetura do Controle de Tráfego Aéreo

\subsubsection{Os Elementos do ATC e a Capacidade do Tráfego Aéreo}

Segundo Banks (2002), a capacidade de um sistema de transporte é definida como o número máximo de veículos (ou passageiros, conforme a métrica adotada) que podem ser acomodados neste sistema por unidade de tempo, sob certas condições e com uma razoável probabilidade de ocorrência. Devido a capacidade ser uma variável não determinística, ela pode sofrer flutuações de valor dependendo das janelas de tempo consideradas em sua determinação. Por isso, a expressão "com razoável probabilidade de ocorrência" indica que a capacidade de um sistema de transporte ou recurso pode ser considerada, ainda segundo Banks (2002), como a média de fluxo máximo que pode ser mantida por um tempo indeterminado, tão longo quanto não houver alteração na demanda. Matematicamente, a capacidade (ou taxa de fluxo máxima) é inversamente proporcional ao tempo médio de separação entre veículos (conceito denominado como "headway"). Por princípio, quanto menor o headway entre veículos, maior será a capacidade (ou taxa de fluxo máxima) deste sistema de transporte.

Em espaços aéreos controlados, o serviço de controle de tráfego aéreo (ATC) tem a função de gerenciar as distâncias de separação entre aeronaves, pois atua no nível da garantia de separação para o tráfego aéreo em execução (nível tático). Desta forma, para se aumentar a capacidade (taxa média de fluxo máximo) do sistema de tráfego aéreo, deve-se reduzir os tempos médios de separação aplicados entre aeronaves. Como os vôos servidos pelo serviço de controle de tráfego aéreo devem aderir às rotas ATS (Ministério da Aeronáutica, 2000), esta redução na separação pode ser obtida tanto pelo aumento do número de rotas em uma determinada área quanto pela redução da separação entre aeronaves que trafegam sobre uma mesma rota. Este último caso pode ser exemplificado por meio do conceito de separação vertical mínima reduzida, conhecida como RVSM (Reduced Vertical Separation Minimum) (Costa (2005)). O RVSM reduz em 1000 pés (de 2000 pés para 1000 pés) a separação vertical 
mínima para vôos executados em rotas ATS entre o FL290 (nível de vôo 29.000 pés) e o FL410 (nível de vôo 41.000 pés).

Contudo, existem limitações à redução dos valores de separação aplicados a um sistema de tráfego aéreo. Os valores de separação praticados estão relacionados - considerando os níveis funcionais de "garantia da separação" e da "condução da aeronave e da navegação" do sistema de tráfego aéreo - à qualidade das informações disponíveis ao piloto e ao controlador de tráfego aéreo (desempenhos da comunicação e da vigilância), e à acurácia com a qual o piloto consegue aderir a sua trajetória (desempenho da navegação) (ICAO, 1998b). Com relação à comunicação e à vigilância, suas imprecisões e limitações introduzem incertezas sobre a real situação do ambiente monitorado (as posições das aeronaves, sobretudo), afetando a capacidade de detecção e de resolução de conflitos por parte dos operadores do tráfego. Com relação à navegação, suas imprecisões e limitações induzem ao aumento de potenciais conflitos, pois os pilotos tendem a ocupar, indevidamente, regiões maiores do espaço aéreo. Portanto, estas limitações técnicas são fatores que promovem restrições à redução dos tempos médios de separação entre aeronaves, pois, para que se garanta a segurança das operações, devem-se incorporar estas imprecisões, tanto temporais quanto espaciais, sobre os valores de separação providos, de forma a minimizar a ocorrência de conflitos.

A Figura 5, adaptada de Reynolds; Hansman (2000), ilustra uma forma de representar as incertezas produzidas pelos elementos do sistema de controle de tráfego aéreo sobre os valores de separação praticados. Como as imprecisões introduzidas por cada um dos elementos funcionais do sistema geram incertezas sobre a real posição das aeronaves (sob o ponto de vista dos operadores do sistema) representa-se uma região de proteção ao redor das aeronaves. Esta região de proteção corresponde ao local no espaço, em um determinado instante de tempo, onde existe grande probabilidade de que uma aeronave esteja presente e, por isso, deve ser mantida livre de outros elementos, sejam outras aeronaves ou elementos em solo. 


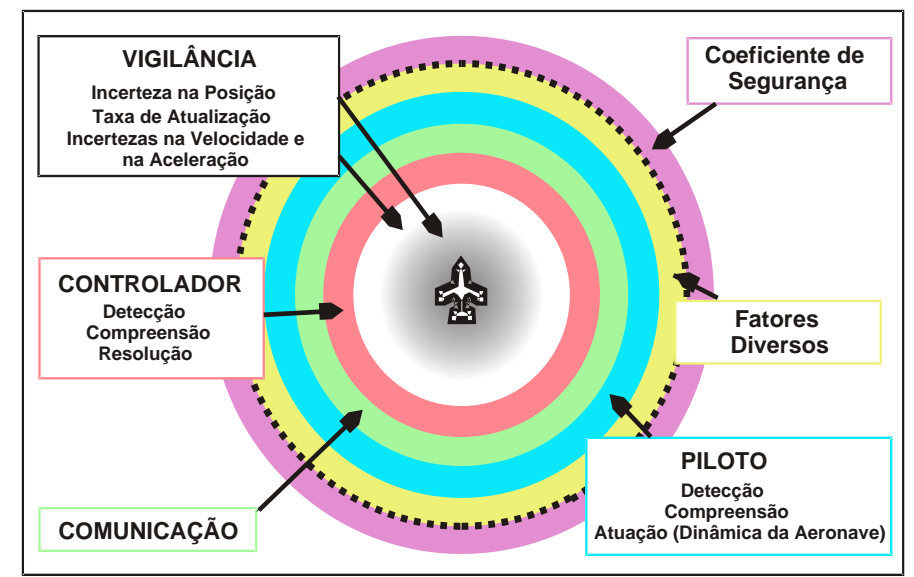

Figura 5 - Camadas da Região de Proteção e incertezas no ATC (Reynolds; Hansman, 2000)

Uma região de proteção pode ser dividida em diversas camadas, onde cada qual representa as incertezas de um ou mais elementos do sistema de tráfego aéreo controlado. Na Figura 5, a camada imediatamente ao redor da aeronave representa as incertezas, observadas pelo controlador, relativas aos elementos de vigilância utilizados. Estas incertezas estão relacionadas à obtenção dos valores de posição, velocidade e aceleração das aeronaves, influenciadas por características de acurácia dos sensores, taxa de atualização das informações de vigilância, atrasos, cobertura, conteúdo das mensagens de vigilância (para vigilância convencional), entre outros (ICAO, 1998b).

Das três camadas seguintes da região de proteção, duas estão relacionadas aos aspectos de desempenho humano dos operadores do sistema, tanto controladores de tráfego quanto pilotos. Com relação ao controlador de tráfego, a limitação no seu desempenho afeta suas ações de detecção, compreensão, tomada de decisão e comunicação de suas decisões para a resolução de conflitos. Este desempenho é afetado por características relativas à estruturação do espaço aéreo, tais como a setorização, cujos tamanhos influenciam a quantidade de aeronaves e o tempo médio de permanência de cada uma dentro do setor; a quantidade de rotas e de interseções entre as mesmas, que influencia a quantidade de comunicações entre aeronaves e controlador e, consequentemente, eleva a carga de trabalho do controlador; entre outras características (Ministério da Aeronáutica, 1990).

Além da estruturação do espaço aéreo, tem-se que os recursos de automação disponíveis e as regras e procedimentos que devem ser seguidos pelos controladores podem afetar, respectivamente, os tempos de detecção e decisão e a quantidade de trabalhos manuais do controlador (por exemplo, preenchimento de fichas de progressão de vôo (strips)), reduzindo 
sua disponibilidade em realizar a atividade-fim de controle.

Com relação ao piloto, a limitação no seu desempenho afeta suas ações de detecção, compreensão e execução das decisões comunicadas pelos controladores. Além do desempenho humano do piloto, considera-se também nesta última camada mencionada o desempenho dinâmico da aeronave em responder aos comandos do piloto e, consequentemente, aderir à trajetória comandada. Estes desempenhos são afetados por características relativas ao ambiente, tais como visibilidade, ventos, turbulência; por experiência de vôo do piloto, por características de manobrabilidade e de equipamentos disponíveis na aeronave, entre outros (Cohen, 1998).

Entre as camadas da região de proteção relacionadas aos elementos "controlador" e "piloto", existe uma camada relacionada ao elemento comunicação, cujas limitações funcionais restringem a disponibilidade dos canais, a capacidade e a velocidade com a qual pilotos e controladores trocam informação de controle do sistema. Estes desempenhos são afetados pelas características de linha de visada, de disponibilidade, integridade, direcionalidade, número de canais analógicos (para voz), disponibilidade e largura de banda da comunicação digital, entre outras.

As duas últimas camadas da região de proteção, ainda segundo Reynolds e Hansman (2000), incorporam as demais imprecisões que possam existir em função de outros fatores. A camada mais externa está relacionada à aversão pessoal que os operadores do sistema possuem quanto à possibilidade da ocorrência de um acidente, a qual pode ser traduzida como um "coeficiente de segurança" na execução do serviço de controle de tráfego aéreo. A camada mais interna está relacionada às incertezas introduzidas pelos procedimentos utilizados e por outros fatores não considerados nas demais camadas. Como exemplo, e mesmo não tendo sido mencionado por Reynolds e Hansman (2000), pode-se considerar nesta camada às limitações decorrentes dos elementos de navegação, pois, conforme visto anteriormente, eles afetam a capacidade do piloto em manter as trajetórias desejadas, além de influenciar na qualidade das informações de vigilância quando utilizado o método de vigilância convencional.

Baseado na exposição acima, pode-se demonstrar que as características dos elementos do sistema de controle de tráfego aéreo, representados na Figura 4, são fatores que contribuem com restrições para a redução da separação e, conseqüentemente, para o aumento da capacidade de tráfego. Esta relação entre o desempenho dos elementos funcionais do ATC e 
sua capacidade está mais bem fundamentada através do conceito de Desempenho Total Requerido para o Sistema (ou RTSP - Required Total System Performance). Este conceito, desenvolvido pela Boeing (Boeing ${ }^{4}$ apud Shakariam; Haraldsdottir (2001)), a pedido da Administração de Aviação Federal norte-americana (FAA) e apresentado à Organização de Aviação Civil Internacional (OACI) em seu painel de conceitos operacionais em gerenciamento de tráfego aéreo (Camus, 2002), define a adoção de métricas de desempenho que relacionam a capacidade técnica dos elementos do sistema com a separação aplicada e, consequentemente, com a capacidade do sistema de tráfego aéreo. O conceito de RTSP define requisitos de desempenho para os elementos de Navegação (ou Required Navigation Performance - RNP), Vigilância (Required Surveillance Performace - RSP) e Comunicação (Required Communication Performace - RCP), e os relacionam às etapas do processo de garantia de separação realizadas pelo serviço de controle de tráfego aéreo. A Figura 6, adaptada de Shakariam; Haraldsdottir (2001), detalha o processo de garantia da separação, o qual foi previamente ilustrado dentro do contexto de Gerenciamento de Tráfego Aéreo (Figura 79), e relaciona seus elementos aos conceitos de "RxP”: RNP, RSP e RCP.

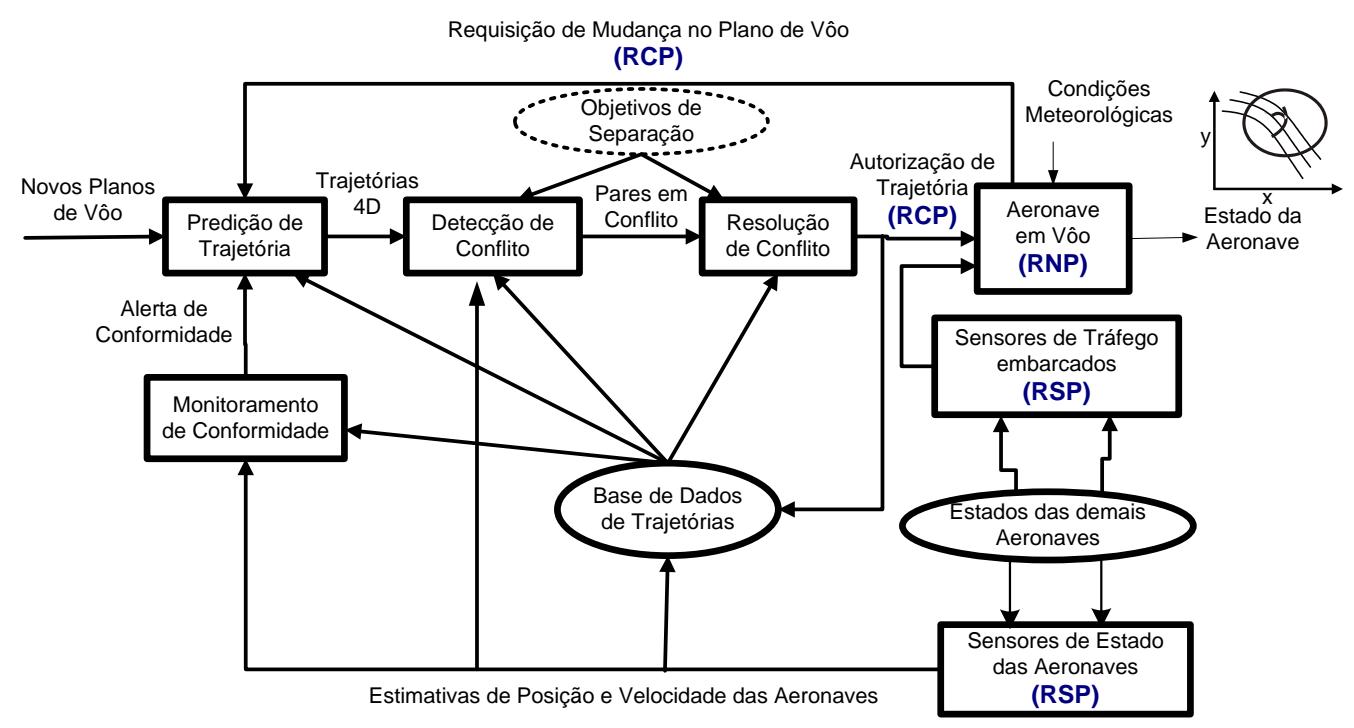

Figura 6 - Garantia da Separação e RxP (adaptada de Shakariam; Haraldsdottir (2001))

Observando-se a Figura 6, pode-se confirmar, tal como citado anteriormente, que o desempenho dos elementos do sistema afeta sua capacidade de reduzir as separações aplicadas entre aeronaves, pois limita a capacidade de Predição, Detecção e Resolução de conflitos por parte do controle de tráfego aéreo. Desta forma, da mesma maneira como havia

\footnotetext{
${ }^{4}$ http://www.boeing.com/commercial/caft/reference/documents/rtsp.pdf (último acesso: 12/05/2004).
} 
sido proposto por Reynolds e Hansman (2000), pode-se derivar do conceito de RTSP regiões de proteção ao redor da aeronave e relacioná-las com as características de seus elementos funcionais. A Figura 7, adaptada de Camus (2002), faz a correlação entre as funcionalidades do ATC (Figura 6), os fatores do RTSP (RNP, RSP e RCP) e suas respectivas regiões de proteção ao redor da aeronave.

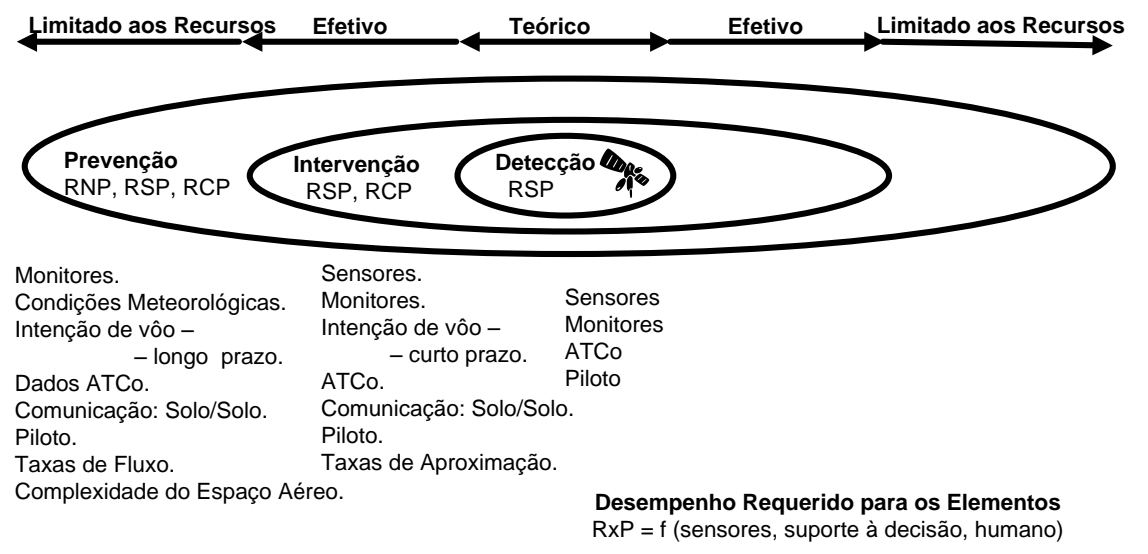

Figura 7 - Os fatores do RTSP e a região de proteção (adaptada de Camus (2002))

Tal como ilustrado na Figura 5 por Reynolds e Hasnman (2000), a camada mais interna da região de proteção está relacionada à limitação da Vigilância (RSP), pois o processo de detecção de conflitos é afetado pela capacidade de monitoramento do espaço controlado. A camada intermediária, a de Intervenção (resolução de conflitos), representa, além das limitações da Vigilância (RSP), as características da Comunicação (RCP), pois está relacionada com a capacidade de comunicação entre controlador e piloto. Por fim, a camada de Prevenção está relacionada com as características de todos os elementos funcionais, pois atua no nível estratégico dentro do processo de garantia da separação, prevendo trajetórias e planejando o tráfego de forma a prevenir sobrecarga dos controladores.

Comparando a Figura 5 e a Figura 7, verifica-se que são consideradas as respectivas parcelas de desempenho humano, bem como as ferramentas de suporte à decisão, na determinação dos requisitos de desempenho dos elementos do sistema (RSP, RCP e RNP). Considerar a atuação humana no laço de controle do sistema de tráfego aéreo, mesmo no conceito de RTSP, condiz com o que foi exposto anteriormente na definição das camadas da região de proteção propostas por Reynolds e Hasnman (2000).

Em resumo, o sistema de tráfego possui uma demanda máxima que pode cumprir de forma eficiente e segura e, quando esta demanda excede sua capacidade, é necessário fazer 
alterações conceituais no sistema para elevá-la. Para o sistema de tráfego aéreo, os valores de separação praticados e, consequentemente, a capacidade do sistema, estão relacionados à qualidade das informações disponíveis aos seus operadores (ICAO, 1998b). Portanto, deve-se avaliar os gargalos nos provedores de informação (Navegação, Vigilância e Comunicação), bem como nos elementos que as utilizam (controladores de tráfego aéreo e pilotos), para determinar quais alterações eliminariam ou minimizariam estes gargalos e que, ao mesmo tempo, atenderiam aos critérios de eficiência e de segurança desejados.

Para que seja possível avaliar qual o nível de afetação que os elementos do sistema causam sobre sua capacidade, segue um estudo detalhado sobre os subsistemas atualmente utilizados para vigilância, comunicação e navegação no tráfego aéreo.

\subsubsection{As Tecnologias dos elementos CNS do Controle de Tráfego Aéreo Atual}

Neste item, o sistema de tráfego aéreo será analisado sob o ponto de vista de seus elementos funcionais. Desta forma, tanto Navegação, Comunicação e Vigilância serão avaliados, pontualmente, como sistemas que, tratados em conjunto, formam o sistema de tráfego aéreo controlado.

\subsubsection{O Sistema de Navegação}

Segundo o Ministério da Aeronáutica (2000), a navegação aérea é "a arte de conduzir uma aeronave, com segurança e eficiência, de um ponto a outro, sobre a superfície da Terra, determinando sua posição a qualquer momento". No sistema de gerenciamento de tráfego aéreo, o sistema de navegação atua no nível da "condução da aeronave e da navegação", e tem como missão permitir que a aeronave seja conduzida de modo a aderir ao vôo previamente planejado e de forma eficiente e segura. Portanto, as funcionalidades da navegação são, entre outras: prover informações de posição; gerenciar o plano de vôo em execução, verificando se há aderência entre o vôo executado e o planejado; conduzir e controlar a aeronave, monitorando e controlando velocidades (vertical, horizontal), aceleração, altitude, proa ${ }^{5}$, atitude $^{6}$, ângulo de ataque ${ }^{7}$ e outras variáveis de estado da aeronave (Haraldsdottir, 1997).

\footnotetext{
${ }^{5}$ Proa: ângulo formado entre um meridiano (verdadeiro ou magnético) e o eixo longitudinal da aeronave. Denomina-se "Proa Verdadeira" no caso de se considerar um meridiano verdadeiro, e "Proa Magnética" no caso de se considerar um meridiano magnético. (Ministério da Aeronáutica, 2000)
} 
Em um ambiente de tráfego aéreo controlado, planeja-se conduzir uma aeronave através de uma seqüência de pontos de passagem (waypoints) definidos sobre rotas ATS. Estes pontos, denominados "fixos de posição", possuem coordenadas (latitude e longitude) préestabelecidas, representadas em cartas aeronáuticas (vide Figura 2). Portanto, ao conduzir uma aeronave, seu operador deve ser capaz de determinar sua posição atual, a direção do próximo fixo de posição que deve ser cumprido e a distância entre sua posição atual e este próximo waypoint. Além disso, deve ser capaz de conduzir a aeronave mantendo tanto sua proa em direção ao fixo desejado quanto o nível de vôo e a velocidade planejada e/ou comandada pelo controlador de tráfego aéreo.

Atualmente, o sistema de tráfego aéreo tem disponíveis as seguintes tecnologias aplicadas à funcionalidade da navegação aérea: o Sistema de Navegação Inercial (INS/IRS), o Radiofarol não Direcional (NDB), o Radiofarol Direcional (VOR), o Equipamento Medidor de Distância (DME), os Auxílios Visuais e de Pouso por Instrumentos (ILS), o Sistema de Navegação Global por Satélites (GNSS), os Sistemas de Aumentação Satelitais, além do conjunto de instrumentação a bordo da Aeronave. Devido à grande quantidade de tecnologias, os detalhes deste estudo estão alocados no APÊNDICE B deste trabalho.

\subsubsection{O Sistema de Vigilância}

Segundo DoD/DoT (2001), “... vigilância é a observação de uma área ou espaço com o objetivo de determinar a posição e a movimentação de veículos nesta área ou espaço. ...”. No sistema de Gerenciamento de Tráfego Aéreo, o Sistema de Vigilância participa do nível da "garantia da separação", provendo ao Controlador de Tráfego Aéreo (ATCo) informações de estado (posição e movimentação) das aeronaves contidas em um determinado volume de espaço aéreo. Com estas informações, o ATCo pode elaborar um mapa situacional do espaço aéreo controlado e atuar com antecedência sobre as aeronaves de forma a mantê-las separadas com distâncias seguras e aderindo às trajetórias planejadas.

Desta forma, a vigilância tem um papel central no Sistema de Controle de Tráfego Aéreo,

\footnotetext{
6 "Atitude" pode ser definida como a orientação da aeronave em relação ao horizonte, considerando tanto o ângulo formado entre seu eixo longitudinal e o plano de solo (pitch) quanto em relação à rotação realizada em torno deste mesmo eixo (roll).

7 “Ângulo de Ataque" é o ângulo formado entre o plano de movimento do centro de massa da aeronave e o plano formado pela asa. A taxa de subida de uma aeronave é diretamente proporcional ao seu ângulo de ataque, porém limitado a um valor máximo que corresponde à perda de sustentação aerodinâmica (stall).
} 
pois a qualidade das informações de posição obtidas tem influência direta nas normas de separação entre aeronaves e, consequentemente, afeta a eficiência com a qual o espaço aéreo pode ser utilizado (Dunstone; Osuwu, Hewitt, 2007). Devido a sua funcionalidade, um sistema de vigilância aérea é qualquer sistema com o qual se possa monitorar aeronaves. Os serviços de vigilância podem ser classificados em 3 categorias (DoD/DoT, 2001):

1. Vigilância Dependente, cujo monitoramento do estado das aeronaves depende de informações fornecidas pelos próprios elementos monitorados;

2. Vigilância Cooperativa, cujos alvos monitorados cooperam com o processo de vigilância, utilizando equipamentos a bordo para a aquisição ou derivação das informações de vigilância; e

3. Vigilância Independente, cujo monitoramento do estado das aeronaves independe de informações fornecidas pelos elementos monitorados.

Com relação ao sistema de controle de tráfego aéreo, um exemplo já abordado de serviço de vigilância dependente é a vigilância convencional, na qual os controladores de tráfego aéreo se baseiam em notificações emitidas exclusivamente pelos pilotos das aeronaves. Portanto, o mapa situacional do espaço aéreo é totalmente dependente de informações emitidas pelos próprios alvos que o compõe. Em contrapartida, citou-se a vigilância não-convencional, mais especificamente a vigilância Radar, como exemplo de vigilância independente, pois o ATCo pode obter informações de posição das aeronaves independentemente das notificações emitidas pelos pilotos.

Um sistema de vigilância é composto pelos seguintes elementos (Dunstone; Osuwu, Hewitt, 2007):

- $\quad$ Sensores de Posição e Altitude;

- Sistema para transmitir os dados entre os sensores e o centro de controle;

- $\quad$ Sistema de visualização dos dados de vigilância pelo ATCo;

- $\quad$ Controladores de Tráfego Aéreo (ATCo) suficientemente treinados; e

- Normas e Procedimentos bem estabelecidos que regrem o uso do sistema de vigilância. 
Ainda segundo estes autores, um sistema de vigilância pode ser caracterizado por meio dos seguintes parâmetros:

- Volume de Cobertura: volume do espaço aéreo no qual o serviço de vigilância está dentro de suas especificações;

- $\quad$ Acurácia: a diferença entre a posição obtida para o alvo e sua posição real;

- $\quad$ Integridade: indicação de que o alvo estimado está com acurácia mínima (mesma definição de integridade utilizada para o sistema GNSS);

- $\quad$ Taxa de Atualização (ou de Varredura): taxa com a qual as posições são atualizadas para o usuário final;

- $\quad$ Confiabilidade: a probabilidade de que o sistema opere dentro de suas especificações durante um período de tempo considerado.

- $\quad$ Disponibilidade: a porcentagem de tempo na qual o sistema está operando dentro de suas especificações.

O tipo de vigilância a ser aplicado pelo ATCo sobre o espaço aéreo está relacionado ao tipo de sistema de vigilância disponível (instalada e funcionando dentro das especificações). Considerando que as normas da Organização de Aviação Civil Internacional (OACI) definem duas formas pelas quais o ATCo mantém a separação entre aeronaves: por separação convencional e por separação radar (ICAO, 1998b), e observando que todos os espaços aéreos onde é provido serviço de separação têm, como requisito, a existência de comunicação bilateral contínua, conclui-se que a vigilância convencional é o tipo de serviço de vigilância disponível em todo espaço aéreo controlado. A aplicação de vigilância Radar fica restrita às áreas que sejam cobertas por este tipo de sistema.

Devido a sua importância para esta investigação científica, segue uma descrição detalhada do Sistema de Vigilância Radar.

\subsection{Sistema de Vigilância Radar}

O Radar, acrônimo para Radio Detection and Range, é uma tecnologia na qual se detecta a distância (range) e o azimute (azimuth) de um elemento no espaço (alvo) baseando-se na diferença de tempo entre a transmissão de uma onda eletromagnética em direção a este alvo e 
a recepção da energia refletida do mesmo (Dunstone; Osuwu, Hewitt, 2007).

Mesmo que o conceito e os primeiros experimentos com Radar tenham sido realizados pelo engenheiro alemão Christian Hülsmeyer no início da primeira década do século 20, seu desenvolvimento mais acentuado ocorreu a partir da década de 1930 para uso militar na II Guerra Mundial. Atualmente, existem diversas aplicações civis para radares, desde sua utilização na navegação (incluindo o sistema de controle de tráfego aéreo), passando por sensoriamento remoto do ambiente, em radio astronomia e em várias outras aplicações de sensoriamento, inclusive industriais.

Em relação à sua aplicação no Controle de Tráfego Aéreo (ATC), o Radar tem a capacidade de apresentar aos controladores de tráfego, em tempo real, as posições das aeronaves no espaço (latitude, longitude e altitude) e com um grau elevado de acurácia e confiança. Comparado à separação convencional, o uso da separação radar permite uma redução significativa nas separações aplicadas entre aeronaves, além de possibilitar a vetoração ${ }^{8}$ de vôos e evitar que aeronaves colidam com o solo (Dunstone; Osuwu, Hewitt, 2007).

Construtivamente, um sensor (Antena) Radar pode ser do tipo monoestático (a mesma antena emite e recebe o sinal) ou biestático (a emissão e a recepção dos sinais são realizadas por antenas independentes). Com relação à forma de onda utilizada, os Radares podem ser do tipo Pulso (normalmente utilizados em vigilância), Doppler (utilizado para medir velocidades) e Modulado em Freqüência (medidas de distância com requisitos de alta acurácia) (Räisänen, Lehto, 2003).

Os sistemas de vigilância Radar podem ser divididos em dois tipos: o Radar Primário de Vigilância (ou Primary Surveillance Radar - PSR) e o Radar Secundário de Vigilância (ou Secondary Surveillance Radar - SSR). A descrição de cada um destes tipos será apresentada a seguir.

\subsection{Radar Primário de Vigilância (PSR)}

O Radar Primário de Vigilância (PSR) funciona segundo o princípio básico no qual a antena (sensor) emite um sinal eletromagnético de alta potência e que, ao ser refletido por um alvo,

\footnotetext{
${ }^{8}$ Vetoração (Radar): provisão de orientação de navegação às aeronaves, em forma de rumos específicos, baseada na observação de uma apresentação Radar. No serviço de vetoração radar, o ATCo é responsável pela navegação da aeronave (MINISTÉRIO DA AERONÁUTICA, 1999).
} 
retorna para a antena Radar. A distância entre a Antena Radar e o alvo (range é obtida pela diferença de tempo entre o instante no qual o sinal foi emitido e o instante no qual o sinal refletido retornou à antena. A direção do alvo (azimuth - em relação à antena) é a direção na qual a face da antena (que corresponde ao seu lóbulo de irradiação) está posicionada. A Figura 8, adaptada de Dunstone, Owusu, Hewitt (2007), ilustra o funcionamento de um Radar Primário. Vale notar que, para vigilância e rastreamento utilizam-se, normalmente, Radares do tipo Pulso (Räisänen, Lehto, 2003).

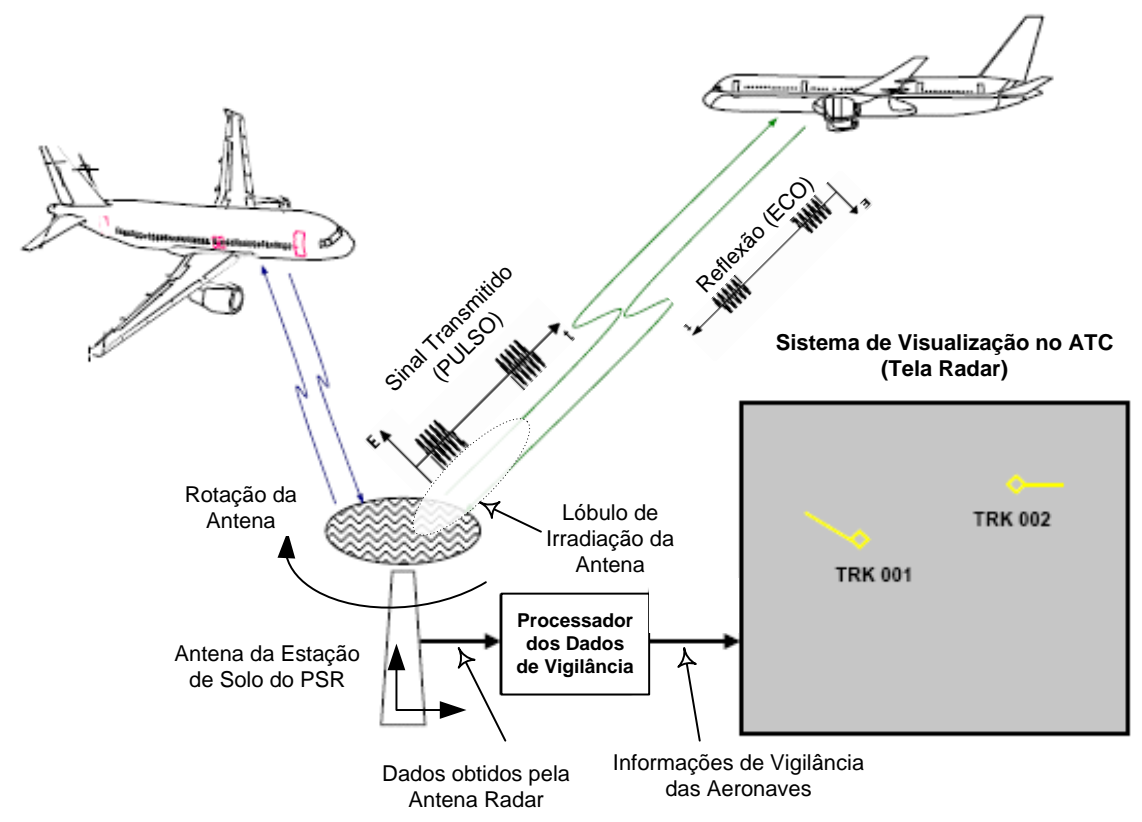

Figura 8 - Esquema Funcional de um Radar Primário (PSR)

Os sistemas de Vigilância com Radares Primários podem ser divididos em duas categorias (ICAO, 1998b), conforme a sua aplicação e o volume de cobertura radar: Radares de Vigilância Terminal, aplicados em áreas de controle terminal (TMA) e com coberturas (em distância) de até 60NM; Radares de Vigilância "Enroute", aplicados em Controle de Área (UTA e CTA) para vôos em rota e com coberturas (em distância) maiores que 100NM.

A vigilância provida por um Sistema de Radar Primário de Vigilância (PSR) é independente. Desta forma, o PSR tem a vantagem de poder ser utilizado em espaços aéreos onde se deseja monitorar o tráfego sem que haja consentimento das aeronaves (vigilância de fronteira, ambiente de conflito bélico, entre outros) ou nos casos onde haja impossibilidade técnica por parte das aeronaves (falha ou ausência de equipamentos a bordo). Porém, o PSR possui algumas desvantagens, tais como (ICAO, 1998b), (Dunstone; Osuwu, Hewitt, 2007): 
Dificuldade de se obter e manter a identificação das aeronaves monitoradas devido ao não provimento de identificação do alvo por parte do PSR;

Obtenção apenas de posições bidimensionais (2D - latitude e longitude), pois o PSR não fornece informação de altitude dos alvos;

Taxa de Atualização relativamente baixa (de $4 \mathrm{~s}$ a $12 \mathrm{~s}$ ) devido às características construtivas do radar, as quais exigem um mecanismo de rotação para a antena.

Vigilância limitada à linha de visada da antena do PSR, limitando os locais de instalação das antenas;

$\checkmark \quad$ Dificuldade de distinguir dois alvos próximos e na mesma distância (range), devido à baixa acurácia de azimute;

Probabilidade alta de reportar falsos alvos, tais como pássaros, nuvens, entre outros;

Desempenho de detecção baixo na presença de condições meteorológicas desfavoráveis;

Necessidade de utilizar potências de transmissão altas, o que pode afetar o ambiente eletromagnético no qual o PSR está inserido; e

Altos custos de instalação e manutenção, devido à necessidade de uma infra-estrutura cara e dedicada (energia, refrigeração, entre outros).

\subsection{Radar Secundário de Vigilância (SSR)}

Devido sua característica de independência, o Radar Primário de Vigilância (PSR) teve grande importância, principalmente, na II Guerra Mundial, por possibilitar a detecção de aeronaves com antecedência suficiente para que medidas defensivas fossem tomadas. Porém, a incapacidade do PSR em prover identificação dos alvos detectados fazia com que não se soubesse se os alvos representavam aeronaves Amigas (Friend) ou Inimigas (Foe). Um dos primeiros "sistemas" de identificação de "amigos" e "inimigos", também conhecido como IFF (Identification Friend and Foe), foi utilizado pelos alemães na própria II Guerra Mundial, e consistia em girar suas aeronaves sobre o próprio eixo longitudinal. Esta atitude de vôo produzia uma diferenciação no formato dos alvos na tela radar, permitindo a identificação da aeronave (Siewerdt, 2004). 
O IFF moderno funciona pelo seguinte princípio: um transponder (transmissor / receptor) em solo envia uma seqüência de pulsos, por meio de uma antena direcional e utilizando um canal de rádio com frequiência de portadora de $1.030 \mathrm{MHz}$, "Interrogando" o transponder a bordo de uma aeronave. Este transponder, por sua vez, envia uma mensagem ao solo, por meio de outro canal de rádio (com frequiência de portadora de 1090MHz), “Respondendo" à interrogação de solo com um código contendo sua identificação (Squawk Code), além de outras informações pertinentes, como sua altitude. Como resultado, o sistema de visualização do ATC apresenta a posição do alvo radar, tal como no PSR, além de informações de identificação da aeronave (código alfanumérico) e nível de vôo (FL) quando disponível (ICAO, 1998b). A Figura 9, adaptada de Dunstone, Owusu, Hewitt (2007), ilustra o funcionamento de Sistema IFF montado em conjunto com um PSR.

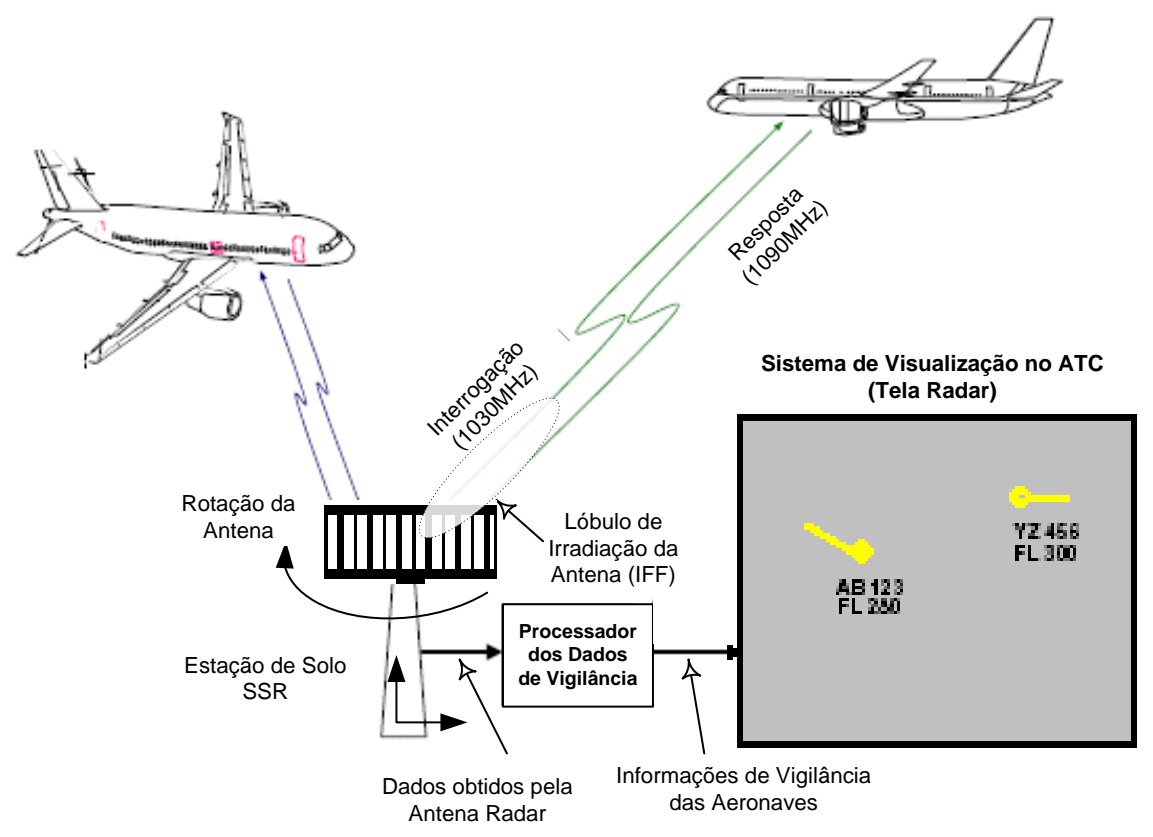

Figura 9 - Esquema Funcional de um Radar Secundário (SSR)

O sistema IFF possui 4 modos de funcionamento - modos 1, 2, 3/A e C - que se diferenciam na forma como os pulsos do transponder interrogador são codificados e, consequentemente, por sua aplicação. Os modos 1 e 2 possuem apenas aplicações militares. Já os modos 3/A e C possuem aplicação civil, e são utilizados no Sistema de Controle de Tráfego Aéreo. O Modo 3/A é a modalidade padrão de IFF para o sistema de tráfego aéreo, utilizado amplamente desde o final da II Guerra Mundial, sendo comumente conhecido como Radar Secundário (Siewerdt, 2004). O Modo C incorpora a funcionalidade do modo 3/A de obter-se a identificação da aeronave juntamente com informações automáticas de altitude (altitude 
barométrica).

Além de informações de distância e azimute, os modos 3/A e C fornecem identificações com 12 bits de resolução (4096 códigos possíveis), e a resolução da altitude, no Modo C, é de 100 pés. Porém, com o passar do tempo, estas características de quantidade de códigos disponíveis e de resolução na altitude tornaram-se limitações ao tráfego aéreo. Como solução, desenvolveu-se o Modo S (de Seletivo), incorporando as funcionalidades dos modos 3/A e C (denominados também como Modo A/C) com a capacidade de endereçamento seletivo e enlaces de dados bidirecionais entre aeronaves e solo (ICAO, 2004). A utilização de 24 bits de endereçamento permite prover mais de 16 milhões de códigos de identificação, e o enlace de dados bidirecional suporta, em teoria, taxas de comunicação de 4Mbits/s entre solo e aeronave e 1Mbits/s entre aeronaves e solo (ICAO, 1998b), (Dunstone; Osuwu, Hewitt, 2007) . Outra evolução no Modo S, em relação ao Modo $\mathrm{A} / \mathrm{C}$, é a melhoria na resolução da informação de altitude, de 100 pés (modo A/C) para 25 pés (Modo $S$ ).

Segundo Dunstone, Owusu, Hewitt (2007), existem duas classes de Radares Secundários (SSR) atualmente utilizados:

- $\quad$ SSR Convencional (ou Clássico): a detecção baseia-se na presença ou na ausência de resposta dentro do período onde há uma interrogação e na faixa coberta pelo lóbulo de irradiação da antena. Devido às características da antena, esta classe de SSR possui baixa acurácia para o azimute, além de significativas anomalias de multipercurso, e a acurácia para a distância depende dos atrasos nos transponder.

- SSR Monopulso: as características de sua antena permitem obter medidas de azimute com maior acurácia e significativa redução nos efeitos de multipercurso.

De acordo com ICAO (2004), a probabilidade de detecção do SSR é proporcional a 1/R ${ }^{2}$ (onde $\mathrm{R}$ é a distância entre alvo e a antena radar), contra à proporção de $1 / \mathrm{R}^{4}$ para o PSR, fazendo com que a probabilidade de detecção do SSR seja maior que 95\%. O volume de cobertura do SSR, independente das condições meteorológicas, está entre 1NM e 200NM em distância e entre $0,5^{\circ}$ e $40^{\circ}$ de elevação acima da linha paralela com o horizonte. A acurácia do SSR na detecção de alvos, para distância e azimute, respectivamente, é de $250 \mathrm{~m}$ e $0,15^{\circ}$ $(1 \sigma)$ no caso de SSR Convencional e $100 \mathrm{~m}$ e $0,06^{\circ}(1 \sigma)$ para SSR Monopulso e Modo S.

A vigilância provida por um Sistema de Radar Secundário de Vigilância (SSR) é cooperativa, 
pois depende dos equipamentos a bordo da aeronave. Em relação ao Radar Primário, que é um método de vigilância independente, o SSR possui melhor desempenho de detecção em caso de condições meteorológicas desfavoráveis, além de possibilitar a identificação de alvos e a obtenção de posições tridimensionais. Além disto, no caso do modo S, é possível manter uma comunicação de dados entre Aeronaves e Controle de Solo. Porém, por ser cooperativo, parte de sua detecção depende de equipamentos a bordo da aeronave, e os custos de instalação e manutenção, devido à necessidade de uma infra-estrutura cara e dedicada (energia, refrigeração, entre outros), continuam altas. Outra desvantagem mantida é a vigilância limitada à linha de visada da antena do SSR, a qual restringe os locais possíveis à instalação das antenas;

\subsection{Normas de Separação Radar}

A OACI define a possibilidade do uso da separação Radar no controle de tráfego aéreo e, desta forma, o PANS-RAC ("Procedures for Air Navigation Services: Rules of the Air Traffic Services") da OACI estabelece 5,0NM como o valor de separação horizontal mínimo a ser aplicado entre aeronaves fazendo uso de vigilância Radar. Este documento também possibilita a redução da separação para 3,0NM no caso das características do equipamento Radar assim permitirem, ou para 2,5NM no caso de aeronaves em aproximação final, limitado a algumas características indicadas naquele documento (ICAO, 1996). Uma característica importante que limita as distâncias de separação mínima é o efeito da esteira de turbulência produzida pelas aeronaves. Por isso, a separação longitudinal entre aeronaves depende da categoria das aeronaves, que podem ser "Pesada" (Heavy), "Média" (Medium) ou "Leve" (Light). Como exemplo, deve-se manter uma separação mínima de 6,0NM quando uma aeronave pesada é seguida por uma aeronave leve (pior caso).

Assim como o Doc.4444 da OACI estabelece os valores e as condições para aplicação da separação mínima Radar (ICAO, 1996), o Doc.9426 da OACI (ICAO, 1998b) estabelece os fatores que devem ser observados no processo de separação Radar, tais como a posição relativa e velocidade das aeronaves, as características do Radar e as limitações do ATCo.

\subsubsection{O Sistema de Comunicação}

Segundo a Instrução IMA-102-6, “Telecomunicações Aeronáuticas” (Ministério da Aeronáutica, 1999b), o Serviço de Telecomunicações Aeronáuticas é constituído de: 
- $\quad$ Serviço Fixo Aeronáutico (AFS): serviço de telecomunicações prestado entre pontos fixos, que se aplica primordialmente para a segurança da navegação aérea e para que seja regular, eficiente e econômica a operação dos serviços aeronáuticos;

- $\quad$ Serviço Móvel Aeronáutico (AMS): serviço móvel entre "estações aeronáuticas e estações de aeronave" ou entre "estações de aeronave", em que também podem participar as estações de embarcações ou dispositivo de salvamento; também podem considerar-se incluídas neste serviço as estações de radiofarol de localização de sinistros que operem nas freqüências de socorro e de urgência designadas;

- $\quad$ Servico de Radionavegacão Aeronáutica: serviço de radionavegação destinado às aeronaves e a sua utilização em condições de segurança, tais como VOR/DME, ILS, $\mathrm{ADF}$, entre outros elementos radiogoniométricos;

- $\quad$ Servico de Radiodifusão Aeronáutica: destinado à transmissão de informações relativas à navegação aérea, tais como informações meteorológicas (VOLMET) (Ministério da Aeronáutica, 2002).

Os serviços de Radionavegação, mesmo fazendo parte dos Serviços de Telecomunicações Aeronáuticas, possuem funcionalidade de navegação no contexto do controle de tráfego aéreo aqui tratado e, portanto, foram descritos anteriormente. O serviço de "comunicação" relacionado ao serviço de controle de tráfego aéreo ilustrado anteriormente na Figura 1, é o Serviços Móvel Aeronáutico (AMS), utilizado na comunicação entre o controle de tráfego aéreo (ATC) e as aeronaves. O Serviço Fixo Aeronáutico (AFS) está indiretamente relacionado ao contexto de separação entre aeronaves, pois é utilizado na comunicação entre órgão de controle com finalidades de planejamento e coordenação do tráfego aéreo, além de ser responsável pela distribuição de informações de vigilância (dados dos Radares, por exemplo).

O Serviço Móvel Aeronáutico, atualmente, possui infra-estrutura para comunicação tanto de mensagens de voz, devido a quase totalidade da comunicação entre controladores de tráfego (ATCo) e pilotos dar-se por meio de comunicação oral em rádio freqüência (ICAO, 2005), quanto de dados, tal como visto anteriormente no caso do Radar Secundário Modo S.

No caso das comunicações orais, a radiocomunicação na faixa de freqüência do VHF é comumente utilizada em espaços continentais povoados, pois ondas eletromagnéticas nesta 
faixa de freqüência são imunes a perturbações atmosféricas - o que torna a comunicação mais limpa quanto a ruídos -, além de se propagar em linha de visada - o que a torna a comunicação confinável a áreas restritas e, assim, tem-se uma melhor distribuição de canais no espaço. No caso das comunicações orais sobre oceanos e em regiões isoladas, faz-se uso de radiocomunicação na faixa do HF, cujo alcance é maior, mas de baixa qualidade.

Portanto, a capacidade de utilizar-se de radiocomunicação em VHF e HF é prerrogativa ao vôo controlado. Por exemplo, os equipamentos básicos de radiocomunicação a bordo de aeronaves que utilizam o espaço aéreo sob jurisdição do Brasil são (Comando da Aeronáutica, 2005):

- $\quad$ Transmissor e Receptor (Transceptor) de VHF, operando na faixa de $118,000 \mathrm{MHz}$ a $136,975 \mathrm{MHz}$, modulação AM e com espaçamento entre canais de $25 \mathrm{kHz}$;

- Transceptor de HF, operando na faixa de 2,0MHz a 18,0MHz, modulação SSB-USB, com 5 canais disponíveis.

A radiocomunicação por satélites pode ser uma opção no lugar da radiocomunicação HF. Porém, estes equipamentos, no caso brasileiro, são considerados como suplementares e, portanto, não podem ser considerados como únicos meios de comunicação (Comando da Aeronáutica, 2005).

Atualmente, não há especificação de equipamento básico para comunicação de dados (digitais) em vôo sobre o espaço aéreo brasileiro controlado. A instrução ICA 102-9 (Ministério da Aeronáutica, 2005) especifica, para uso suplementar a operação, o uso de enlace de dados digital em VHF (ou VHF digital link - VDL) nos modos 2, 3 e 4, sob a alegação de serem reconhecidos pela Organização da Aviação Civil Internacional (OACI) (Comando da Aeronáutica, 2005). Os modos 2 e 4 são utilizados apenas para comunicação de dados digitais. O VDL modo 3 pode ser utilizado tanto para comunicação digital de dados quanto de voz.

Estudos recentes demonstraram que uma significativa quantidade de acidentes e incidentes aéreos foi influenciada pelo uso da comunicação oral no controle de tráfego aéreo (Lozito et al, 2003). O uso de VHF e HF possuem limitações, tais como o uso do protocolo PPT (pushto-talk), onde apenas 1 elemento transmite e os demais elementos em sua área de cobertura recebem. Este fato promove, além de colisões entre elementos que tentem estabelecer uma 
transmissão ao mesmo tempo, congestionamentos, devido à limitação no número de canais disponíveis. Uma última desvantagem aqui citada sobre as comunicações orais é o problema de inteligibilidade, tanto devido a degradação do sinal quanto aos problemas de fonética e de manutenção de um único idioma entre os usuários do sistema.

\subsubsection{A mudança de Paradigma no Sistema de Tráfego Aéreo}

Após uma análise dos elementos atuais do sistema de tráfego aéreo, pode-se destacar algumas limitações que, de fato, restringem o aumento da capacidade deste sistema:

i. com relação aos elementos de navegação, existe um conflito entre a "densidade de auxílios (e custos)” x “desempenho”. Ou seja, para manter-se níveis aceitáveis de aderência às rotas estabelecidas necessita-se, a princípio, de uma quantidade razoável e homogeneamente distribuída de auxílios à navegação com bom desempenho, tais como os VOR/DME. Além do empecilho de custo de implementação e manutenção destes auxílios em áreas continentais, há a impossibilidade técnica de suas implementações em oceanos e áreas remotas. Nestas áreas, os elementos de navegação disponíveis, tais como a Navegação Inercial e o Loran-C (detalhados no APÊNDICE B), possuem baixo desempenho, impossibilitando a redução das separações aplicadas entre aeronaves;

ii. com relação aos elementos de vigilância, também ocorre conflito entre a "volume de vigilância" x "desempenho". Os equipamentos radar, tanto PSR quanto SSR, possuem bom desempenho. Porém, o alto custo para aquisição, instalação e manutenção inviabiliza a aplicação de cobertura de vigilância radar em grandes áreas. Além disto, oceanos e áreas remotas são inviáveis quanto a instalação deste tipo de instalação. Outra fragilidade do sistema radar é sua cobertura em linha de visada, o que pode ocasionar regiões de sombra de cobertura. A vigilância convencional, utilizada em áreas desprovidas de equipamentos radar, possui baixo desempenho, além de ser afetada pelas características de desempenho tanto da navegação quanto da comunicação utilizada;

iii. com relação aos elementos de comunicação, ficou claro, segundo exposição de Lozito et al (2003), que as limitações técnicas da radiocomunicação oral influenciam diretamente a ocorrência de acidentes e incidentes. 
Desta forma, pode-se concluir que existe uma cadeia de restrições no conceito atual de sistema de tráfego aéreo, cujos elementos empregados no sistema afetam diretamente a capacidade do espaço aéreo. Estes elementos de comunicação, navegação e vigilância, mesmo tendo sofrido refinamentos ao longo dos anos, são os mesmos há aproximadamente 6 décadas. Constata-se, portanto, que a capacidade de crescimento do tráfego aéreo, baseada no conceito atual e sem que haja mudanças significativas no paradigma, exauriu-se (Siewerdt, 2000).

As limitações do atual sistema de transporte aéreo foram reconhecidas pela Organização de Aviação Civil Internacional (OACI) no início da década de 1980, onde se estabeleceu um comitê denominado "Comitê sobre o Sistema de Navegação Aérea do Futuro" (FANS), com a finalidade de “... identificar, estudar e avaliar novos conceitos e tecnologias e fazer recomendações para o desenvolvimento coordenado e evolutivo da navegação aérea em um horizonte de 25 anos ..." (ICAO, 2000). Este comitê concluiu que haveria a necessidade de haver o desenvolvimento e a implementação, em nível mundial, de um novo sistema de tráfego aéreo baseado em novos conceitos de comunicação, navegação, vigilância e gerenciamento de tráfego aéreo. Este conceito, denominado como CNS/ATM (Communication, Navigation, Surveillance/Air Traffic Management), foi aprovado pela $10^{\mathrm{a}}$ Conferência de Navegação Aérea, realizada em 1991, e detalhado ao longo dos anos seguintes.

Portanto, segue a descrição do conceito CNS/ATM, ilustrando suas principais características e dando destaque ao conceito da Vigilância Dependente Automática por Radiodifusão - ADS-B (Automatic Dependent Surveillance - Broadcast), reconhecida pela Organização da Aviação Civil Internacional (OACI) na $11^{\text {a }}$ Conferência de Navegação Aérea como “... an enabler of the global ATM operational concept bringing substantial safety and capacity benefits ..." (ICAO, 2006).

\subsection{O paradigma CNS/ATM}

Conforme ICAO (2000), o CNS/ATM (Communication, Navigation, Surveillance / Air Traffic Management) é definido como:

“Communications, navigation, and surveillance systems, employing digital technologies, including satellite systems together with various levels of automation, applied in support of a seamless global air traffic management system." 
Ainda segundo a ICAO (2000), a missão do sistema CNS/ATM será o de desenvolver um sistema global e uniformizado de serviços de tráfego aéreo que supra o crescimento da demanda por este modal de transporte, acompanhado de melhorias nos níveis de segurança, regularidade e eficiência do tráfego aéreo, disponibilizando o uso das rotas desejadas pelos usuários e minimizando as diferenças quanto ao uso de equipamentos atualmente observadas em função das regiões do planeta.

Desta forma, o paradigma CNS/ATM vem como sucessor para o atual conceito de sistema de tráfego aéreo, utilizando-se de "novas" tecnologias digitais sobre os elementos de comunicação, navegação e vigilância, os quais darão suporte ao gerenciamento do tráfego aéreo. A implementação de comunicação de dados digitais e de navegação por meio de satélites, entre outras tecnologias, tem por objetivo obter-se maiores níveis de automação e, consequentemente, melhoria de desempenho no controle do tráfego aéreo, minimizando as restrições existentes no sistema de transporte aéreo atual. Em face deste novo contexto, seria possível suprir a crescente demanda por tráfego aéreo mantendo-se ou, de preferência, elevando os níveis de segurança (safety) atuais.

O CNS/ATM é composto por 4 elementos principais: Comunicação (Communication), Navegação (Navigation), Vigilância (Surveillance) e Gerenciamento de Tráfego Aéreo (ATM). A respeito de cada um destes elementos do CNS/ATM, a OACI faz as seguintes considerações (ICAO, 2000):

\section{$\rightarrow$ Comunicação $(\mathrm{C})$}

No CNS/ATM, as comunicações por canais orais em VHF continuarão a existir, mas serão utilizadas apenas em situações atípicas ou de emergência. Ao invés da atual forma analógica, os canais de comunicação serão baseados em enlaces digitais de dados, e a comunicação por meio de mensagens compreenderá a quase totalidade da comunicação entre elementos no sistema. A comunicação de dados e voz por meio de satélites, devido sua capacidade de cobertura global, será introduzida por meio de canais de comunicação em HF digital. Além disto, poderá ser utilizado o Modo S dos radares secundários (SSR) para realizar comunicação digital solo-ar em regiões providas destes elementos.

Em resumo, a existência de uma rede de telecomunicações aeronáuticas (Aeronautical Telecommunication Network - ATN) proporcionará a troca de dados digitais entre usuários finais localizados em sub-redes, mesmo não similares, tanto para comunicação terra-ar quanto 
terra-terra. Desta forma, o uso regular de comunicação digital de dados com o propósito do gerenciamento do tráfego aéreo introduzirá enlaces de comunicação entre controle e aeronaves de forma mais eficiente e direta, possibilitando o aumento dos níveis de automação do ATC.

\section{$\rightarrow$ Navegação $(\mathbf{N})$}

O uso da Navegação Global por Satélites (GNSS) proverá serviços de navegação com altos níveis de integridade, acurácia e em quaisquer condições meteorológicas. A plena implementação do GNSS possibilitará a navegação em qualquer tipo de espaço, em qualquer parte do planeta e utilizando equipamentos simples a bordo para receber e processar os sinais recebidos dos satélites. Este fato possibilitará a redução, ou mesmo a completa eliminação, da infra-estrutura de auxílios à navegação em solo.

\section{$\rightarrow$ Vigilância (S)}

Radares secundários (SSR) continuariam a ser utilizados, com a gradual introdução do Modo $\mathrm{S}$ em áreas terminais e áreas continentais com alta densidade de tráfego. Porém, a maior quebra de paradigma será a implementação da Vigilância Dependente Automática (ou Automátic Dependent Surveillance - ADS). O ADS permitirá que as aeronaves transmitam, automaticamente, informações de estado - tais como posição, velocidade, proa e quaisquer outras medidas de interesse contidas no sistema de gerenciamento de vôo (FMS) - por meio de qualquer tipo de enlace de comunicação digital existente, incluindo Satélites, que serão recebidas pelos usuários finais do sistema, incluindo controladores de tráfego, e utilizadas tal como as informações provenientes, atualmente, dos radares. O ADS representa a fusão entre as tecnologias de comunicação e navegação e, juntamente com sistemas automatizados em solo, permitirão grandes avanços para o ATM, tal como a detecção e resolução automática de conflitos.

\section{$\rightarrow$ Gerenciamento de Tráfego Aéreo (ATM)}

O avanço nas tecnologias CNS servirão de suporte ao ATM, tanto do contexto dos serviços de tráfego aéreo (controle de tráfego, por exemplo), quanto nas suas demais missões, tais como o Gerenciamento de Fluxo do Tráfego (ATFM), Gerenciamento do Espaço Aéreo (ASM) e todas as demais atividades do ATM descritas anteriormente. A integração global do ATM, por meio do uso comum de tecnologias CNS, permitirá aos usuários do sistema navegarem 
conforme suas preferências, de forma dinamicamente adaptada, permitindo melhorias na relação custo $x$ eficiência.

Com o objetivo de cumprir o cenário CNS/ATM desejado, a OACI possui o seguinte planejamento evolutivo para as tecnologias aplicadas aos elementos de Comunicação, Navegação e Vigilância do sistema de tráfego aéreo, do conceito atual para o CNS/ATM. A Figura 10 ilustra esta evolução.

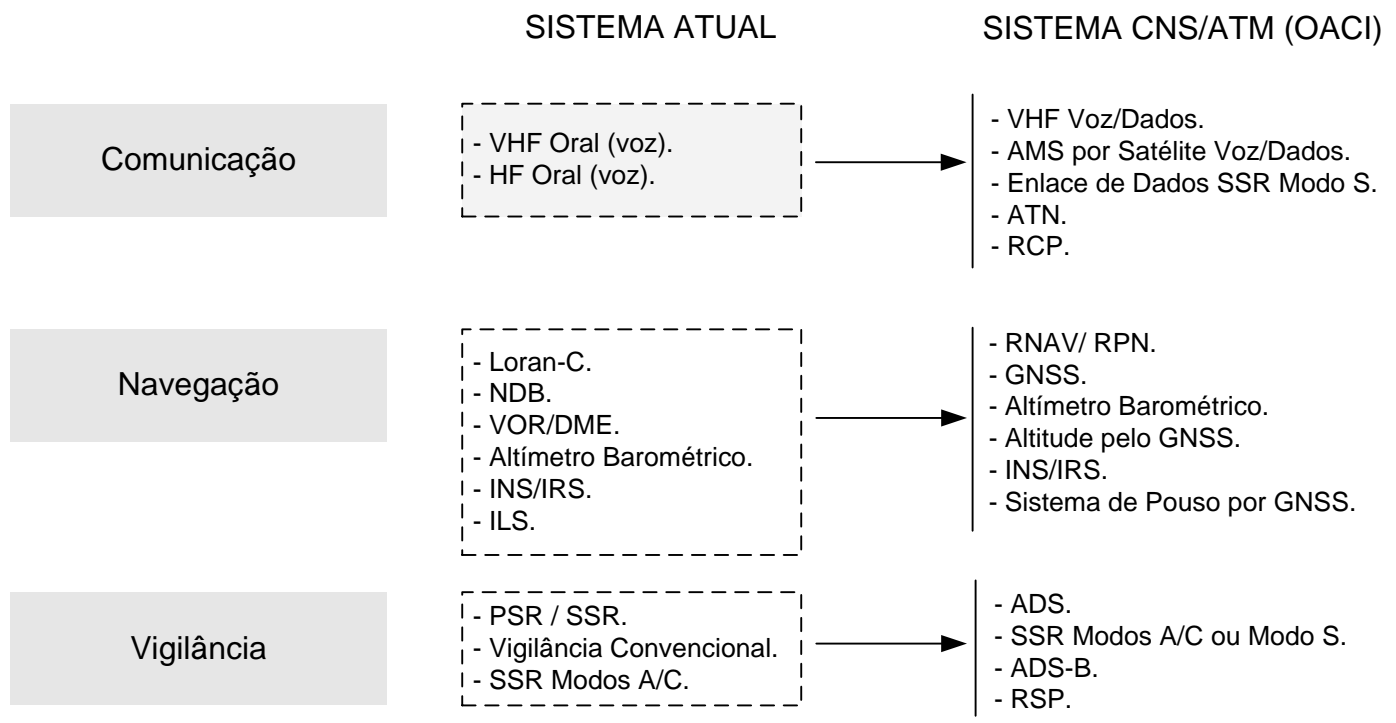

Figura 10 - Evolução Tecnológica dos elementos CNS

O cenário tecnológico do CNS/ATM, como pode ser observado na figura anterior, objetiva introduzir, comparado ao paradigma atual de sistema de tráfego aéreo, as seguintes melhorias (ICAO, 2000):

- Comunicação: incremento na cobertura, acessibilidade, capacidade, integridade, desempenho e segurança (security) dos sistemas de comunicação aeronáuticos, em acordo com os requisitos do ATM;

- Navegação: incremento na cobertura e na capacidade de operação em quaisquer condições meteorológicas e tipos de espaço aéreo, incluindo aproximações e pousos, enquanto mantém ou aumenta os níveis de integridade, acurácia e desempenho, em acordo com os requisitos do ATM;

- Vigilância: expansão na cobertura efetiva sobre oceanos e áreas remotas, e incremento dos níveis de consciência situacional dos pilotos, em acordo com os 
requisitos do ATM;

Portanto, a Figura 11 (adaptada de Galotti (1997)) resume as melhorias planejadas segundo o paradigma CNS/ATM, tanto sobre os elementos individuais (CNS) quanto seu impacto sobre o Gerenciamento do Tráfego Aéreo (ATM).

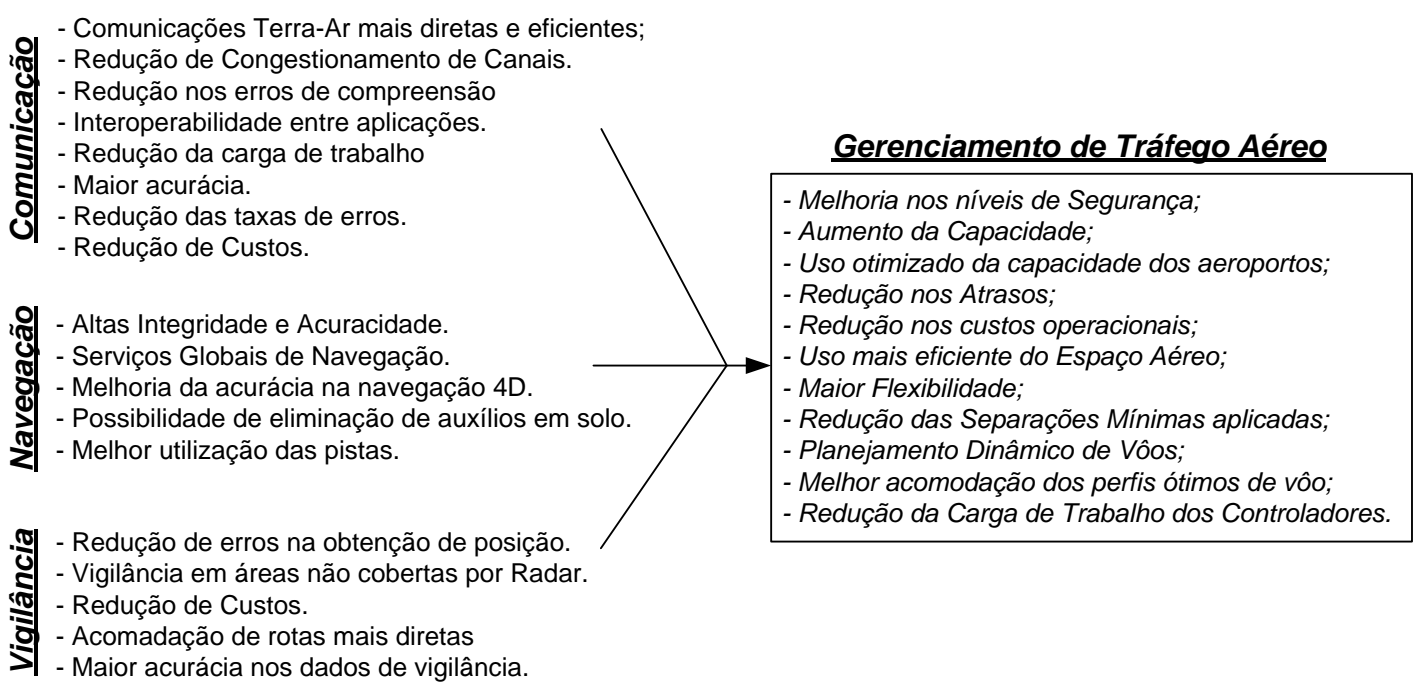

Figura 11 - Melhorias no CNS e impacto sobre o ATM (adaptada de Galotti (1997))

Como se pode perceber, o paradigma CNS/ATM é solução para minimizar as restrições ao crescimento da oferta, principalmente no que se refere ao aumento da acurácia dos dados de vigilância, o aumento de sua área de cobertura e a redução do congestionamento nos canais de comunicação, além da possibilidade de melhoria das técnicas de detecção e resolução de conflitos devido à elevação dos níveis de automação do sistema. Os elementos-chave deste paradigma estão baseados na existência de um sistema de global de navegação por satélites (GNSS), que proverá tanto a funcionalidade de navegação quanto informações de vigilância ao sistema de tráfego aéreo e, sobretudo, na existência de uma rede de telecomunicações aeronáuticas (Aeronautical Telecommunication Network - ATN) que seja capaz de trafegar, de forma segura e eficiente, toda a informação aeronáutica, em formato digital, entre os diversos usuários do sistema;

Como relatado anteriormente, a vigilância dependente automática (ADS), além de ser "...an enabler of the global ATM operational concept bringing substantial safety and capacity benefits ..." (ICAO, 2006), representa a fusão entre as tecnologias de comunicação (o ATN) e navegação (o GNSS). Desta forma, o estudo a seguir dará o enfoque na rede de telecomunicações aeronáuticas (ATN) e, mais especificamente, no ADS por radiodifusão 
(ADS-B), definido pela OACI como uma das aplicações da ATN.

\subsubsection{A Rede de Telecomunicações Aeronáuticas (ATN)}

Conforme ICAO (1999b), a ATN (Aeronautical Telecommunication Network) compreende entidades de aplicação e serviços de comunicação, os quais permitem elementos de Solo, ArSolo e sub-redes aviônicas de dados interoperarem por meio da adoção de protocolos e serviços de interface comuns baseados no modelo de referência de 7 camadas ISO/OSI (International Organization for Standardization (ISO) open System interconnection (OSl) reference model). A Figura 12 ilustra o modelo conceitual da ATN proposto pela Organização de Aviação Civil Internacional (OACI) em ICAO (1999b).

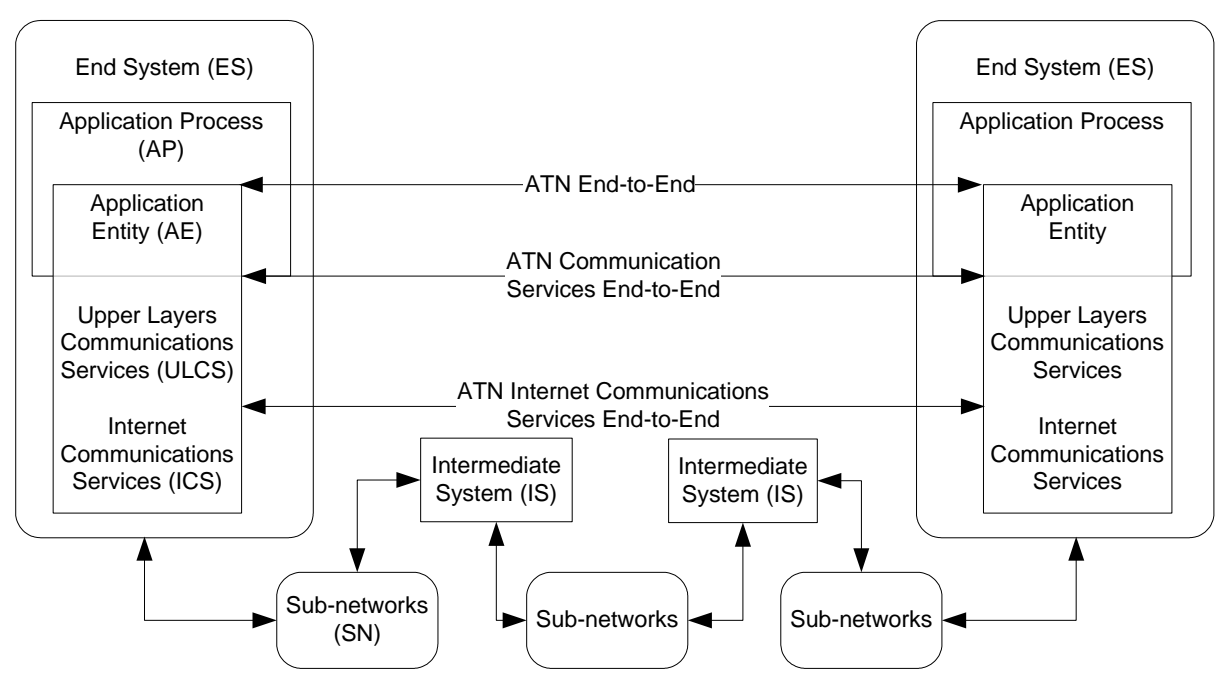

Figura 12 - Modelo conceitual da ATN (ICAO, 1999b)

Como pode ser observado por meio de seu modelo conceitual, a ATN é uma rede de comunicação entre sistemas finais (End System - ES), ou seja, entre sistemas que contenham as 7 camadas do modelo ISO/OSI e um ou mais Processos de Aplicação (Application Process - AP) para usuário final. Um AP é um conjunto de recursos, dentro de um sistema aberto real, que pode ser utilizado para desempenhar uma determinada atividade de processamento de informação.

Uma Entidade de Aplicação (Application Entity - AE) é parte de um AP e está relacionado com a comunicação dentro do ambiente de 7 camadas OSI. Os aspectos de um AP que precisam ser considerados para os propósitos do modelo OSI são representados por um ou mais AEs. Já as Camadas Superiores dos Serviços de Comunicação (Upper Layers Communication Services - ULCS) representam as camadas de Sessão (5), Apresentação (6) e 
Aplicação (7) do modelo ISO/OSI de 7 camadas.

Os Serviços de Comunicação Inter-redes (Internet Communications Service - ICS) permitem aos elementos de Solo, Ar-Solo e sub-redes aviônicas de dados interoperar adotando serviços de interface comuns baseados no modelo OSI. Os Sistemas Intermediários (Intermediate Systems - IS) tem a função de manipulação e roteamento de mensagens, correspondendo às camadas de 1 a 3 do modelo ISO/OSI (camadas física, enlace e de rede, respectivamente).

As sub-redes (Sub-networks - $\mathbf{S N}$ ) representam redes de comunicação de dados que aplicam protocolos e planos de endereçamento homogêneos e estão sob o controle de uma única autoridade. No caso do CNS/ATM, as sub-redes de comunicação Ar-Solo, alcunhadas de Data links (DL), são os meios (canais) pelos quais as aeronaves se comunicarão com os elementos de solo. Dentro das Normas e Práticas Recomendadas (SARPS) para a ATN, a OACI normalizou os seguintes tipos de Data links (DL) para uso dentro do contexto ATN (ICAO, 1999c):

- $\quad$ Serviço Aeronáutico Móvel por Satélite (AMSS): representa o uso de satélites de comunicação, tanto geoestacionários quanto não geoestacionários, possibilitando a comunicação por voz e dados em escala global.

- $\quad$ Data link em VHF (VDL): o VDL representa o uso de técnicas de comunicação de dados na faixa de VHF. Possui 4 modos distintos - Modo 1, Modo 2, Modo 3 e Modo 4, diferenciados por suas características de modulação, controle de acesso ao meio físico e, principalmente, taxas de transferência. Nominalmente, o VDL Modo 1 possui taxa de, aproximadamente, 2.400 bps. Já os modos Modos 2 e 3 possuem taxa nominal de 31.500 bps, e diferenciam-se pelo tipo de controle de acesso ao meio físico (CSMA e TDMA, respectivamente). O VDL Modo 4 possui taxas de transferência que atingem, nominalmente, os $38.400 \mathrm{bps}$.

- $\quad$ Data link em Radar Secundário (SSR) Modo S: conforme relatado anteriormente, o Radar Secundário Modo S possui a capacidade de comunicação de dados bidirecional Solo-Ar a taxas nominais de 4Mbits/s entre solo e aeronave (uplink) e 1Mbits/s entre aeronaves e solo (downlink) (ICAO, 1998b).

- $\quad$ Data link em HF (HFDL): o HFDL é a união entre as características de propagação por longas distâncias das ondas eletromagnéticas na faixa de HF com a modulação 
digital de dados, propiciando comunicação de dados em regiões remotas.

A Figura 13 ilustra um exemplo para o ambiente de comunicação planejado para o CNS/ATM, representando a relação entre Data links, ATN e os Usuários Finais (ES) do sistema de tráfego aéreo (baseado em SITA, 2005):

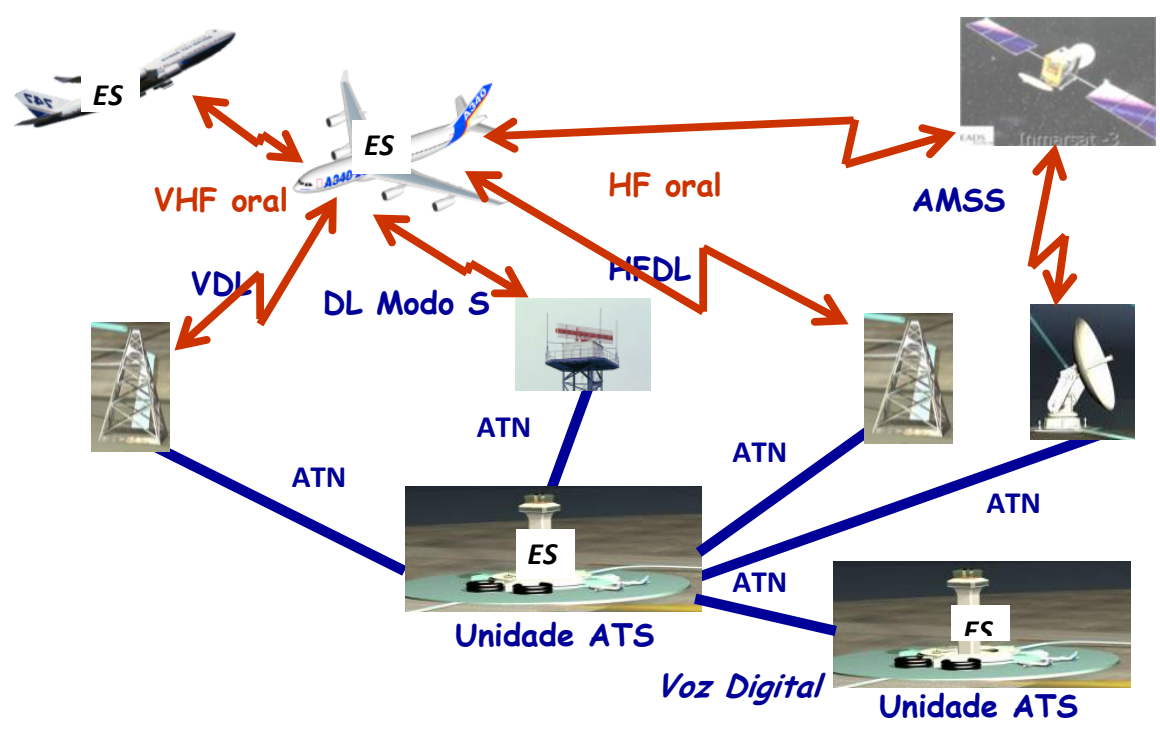

Figura 13 - Ambiente de Comunicação no CNS/ATM

Tal como definido anteriormente, a ATN é formada por "entidades de aplicação" e "serviços de comunicação". Os serviços de comunicação correspondem às Camadas Superiores dos Serviços de Comunicação (ULCS) e aos Serviços de Comunicação Inter-redes (ICS) (ICAO, 1999b). Devido este trabalho não ter o enfoque nos detalhes funcionais dos protocolos de comunicação da ATN, tais como suas primitivas de comunicação entre as camadas intermediárias, por exemplo, estes itens não serão detalhados aqui.

No ambiente da ATN, as Entidades de Aplicação (Aplication Entity - AE), definidas como as partes de um processo relacionadas com o ambiente de comunicação, são, em outras palavras, a camada de aplicação (camada 7) do Modelo de Referência ISO/OSI. Desta forma, os AEs são as funcionalidades da ATN utilizadas pelo Usuários Finais no sistema de tráfego aéreo. A OACI (ICAO, 1999b) divide as AEs em duas categorias:

- Entidades de Aplicacão Terra-Ar: são as funcionalidades da ATN providas às aplicações de comunicação entre aeronaves e sistemas finais em solo. As AEs desta categoria são o "Gerenciamento de Contexto" (Context Management - CM), que provê a capacidade de estabelecer conexão (logon) entre dois pontos; a "Vigilância 
Dependente Automática" (Automatic Dependent Surveillance - ADS), que provê aos sistemas de solo, de forma automática, a posição e outras informações pertencentes ao sistema de gerenciamento de vôo das aeronaves; a "Comunicação por Enlace de Dados entre Piloto e Controlador" (Controller-Pilot Data link Communication - CPDLC), que provê a capacidade de estabelecer comunicação, ponto-a-ponto, por meio de mensagens; e a "Informação de Serviço de Vôo" (Fligth Information Services - FIS), que permite aos pilotos requisitar e receber serviços de informação de vôo.

- $\quad$ Entidades de Aplicacão Terra-Terra: são as funcionalidades da ATN providas às aplicações de comunicação entre unidades de Solo. As AEs desta categoria são o "Serviço de Manipulação de Mensagens ATS" (ATS Message Handling Service ATSMHS), que prôve comunicação de mensagens ATS entre os usuários finais do ATM; e a "Comunicação Inter-Centros" (Inter- Center Communication - ICC), que provê comunicação entre centros ATS de mensagens de notificação, coordenação, transferência de controle, entre outras.

Mesmo que a aplicação ADS possua funcionalidades de vigilância, a mesma está estruturalmente definida no contexto de comunicação para o Sistema de Tráfego Aéreo. Desta forma, o conceito ADS possui requisitos tanto de vigilância - tais como volume de cobertura, acurácia e taxa de atualização - quanto de comunicação de dados - tais como os requisitos de qualidade de serviço (taxa de erro, tempo de atraso), formato da mensagem, manipulação das mensagens e prioridades.

Portanto, segue a descrição da Vigilância Dependente Automática (ADS), mais especificamente sua modalidade por radiodifusão (ADS-B) e sua aplicação ao sistema de controle de tráfego aéreo.

\subsubsection{A Vigilância Dependente Automática por Radiodifusão (ADS-B)}

Como relatado anteriormente, a Vigilância Dependente Automática (ADS) é uma aplicação Terra-Ar da Rede de Telecomunicações Aeronáuticas (ATN) que provê aos sistemas finais (ES), de forma automática, "mensagens ADS" (ADS reports), contendo posição e outras informações presentes no sistema de gerenciamento de vôo das aeronaves (ICAO, 1999b). 


\subsubsection{ADS-C e ADS-B}

Estão definidas 2 formas de implementação para a ADS (ICAO, 1999):

- $\quad$ ADS por Contrato (Contract) (ADS-C): nesta forma de implementação, a ADS é provida por meio de um contrato estabelecido entre a aeronave e um órgão em solo, ou seja, entre 2 endereços. Por isso, esta forma de ADS é também denominada como “endereçável” (Addressable) - ADS-A. Existem 4 tipos possíveis de contratos - por demanda, onde a entidade de solo solicita à aeronave o envio de uma única mensagem ADS; por evento, onde a entidade de solo solicita que a aeronave lhe envie mensagens ADS apenas no caso de ocorrer algum tipo de evento pré-definido (como mudança de waypoint, mudança de nível de vôo, mudança de velocidade ou de proa, por exemplo); por período, onde a entidade de solo solicita que a aeronave lhe envie mensagens ADS em intervalos de tempo pré-estabelecidos (periodicamente); e por emergência, onde a aeronave estabelece este contrato com todas as entidades de solo com as quais já possui contratos por evento ou periódicos, enviando-lhes, a cada minuto ou menos, mensagens ADS contendo tempo, posição e figura de mérito.

- $\quad$ ADS por Radiodifusão (Broadcast) (ADS-B): nesta forma de implementação, a aeronave transmite mensagens ADS, periodicamente e por meio de radiodifusão (broadcast), de forma que qualquer elemento em solo ou no ar possa recebê-las, desde que devidamente equipado e dentro da área de alcance do transmissor ADS. A aeronave não estabelece contratos com outras entidades do sistema e, desta forma, a aeronave não necessita conhecer quais elementos estão recebendo suas mensagens.

Com base nas definições anteriores, a ADS-C pode-se ser definida como uma vigilância cooperativa, pois as aeronaves cooperam com o processo de vigilância, respondendo às solicitações de estabelecimento de contrato por parte dos controladores e provendo-os com mensagens ADS, dependentes. Já a ADS-B está enquadrada na categoria de vigilância dependente, pois o monitoramento do estado das aeronaves depende das mensagens enviadas pelas mesmas, independentemente de requisição por parte do sistema de controle.

Segundo ICAO (1999b), o conteúdo básico de uma mensagem ADS-C (Basic ADS-C Reports) contém a "Posição 3-D da Aeronave" (latitude, longitude e altitude), o "Tempo da Mensagem" (no formato HHMMSS) e a "Indicação de Acurácia do Dado de Posição" (Figura de Mérito - FOM). O conteúdo opcional de uma mensagem ADS-C pode ser 
composto por "Identificação da Aeronave", "Vetor de Solo" (Trajetória, Velocidade com relação ao Solo), "Vetor de Ar" (Proa, Velocidade Indicada (IAS)), "Perfil Projetado" (próximo waypoint, nível de vôo estimado, etc), "Informações Meteorológicas" (Direção e Velocidade do Vento, Temperatura, Turbulência), entre outras informações.

O conteúdo mínimo de uma mensagem, no caso do ADS-B, deve ser composto por:

- Categoria do Emissor (emitter category): define as características da unidade originadora da mensagem. Como exemplos de categorias, existem as aeronaves leves, médias e pesadas, helicópteros, veículos aéreos não tripulados, balões, veículos terrestres, obstáculos e outros.

- Identificador do Emissor (emitter identifier): corresponde ao endereço do emissor (de 24 bits) na rede de telecomunicação aeronáutica.

- Latitude, Longitude e Nível de Vôo: correspondem à latitude e a longitude da posição da aeronave (em graus, minutos e segundo), bem como a sua altitude ou nível de vôo.

- Identificação da Aeronave: corresponde ao código alfanumérico de identificação da aeronave.

- $\quad$ Figura de Mérito (FOM): indica a acurácia das informações enviadas com base nas informações providas ao emissor.

Porém, da mesma forma que o ADS-C, o conteúdo de uma mensagem ADS-B não fica limitado ao seu mínimo, podendo ser inseridas outras informação, conforme necessidade e disponibilidade.

A ADS-B, pertencendo a camada de aplicação da rede de comunicação (ATN), possui requisitos gerais de comunicação a serem cumpridos (ICAO, 1999b):

Com relação à manipulação das mensagens (message handling), as mensagens devem ser entregues a uma taxa apropriada ao serviço (dependente da fase do vôo), além de serem geradas, transmitidas e entregues à aplicação de destino de forma ordenada no tempo. Com relação ao tempo máximo de atualização das mensagens, estabelecemse os valores de 10s para vôos em rota, 5s para áreas terminais e 1s para a superfície 
dos aeroportos, onde a probabilidade de atualização dentro destes tempos é de $98 \%$.

Com relação à prioridade das mensagens (priority), as mensagens ADS-B, utilizadas para vigilância, terão "normal priority fligth safety" sobre a ATN.

$>\quad$ Com relação à qualidade de serviço $(\mathrm{QoS})$, o data link utilizado deve corresponder a uma probabilidade de perda de mensagem de $10^{-6}$ por mensagem trafegada, latência máxima de 2s (ou, segundo Brooker, 2004, entre 0,4s e 1,2s), integridade de $10^{-7}$, confiabilidade, disponibilidade e continuidade de 99,996\%.

Com relação à base de tempo utilizada nos serviços ADS-B, deverá haver acurácia de 1 segundo comparado ao UTC (Universal Time, Coordinated), utilizada pela aviação geral.

\subsubsection{As Sub-rede ADS-B: 1090ES, UAT e VDL4}

Os requisitos apresentados para o ADS-B estão atrelados, sobretudo, aos meios físicos entre Ar e Solo (data links) utilizados por esta aplicação. Na $11^{\text {a }}$ Conferência de Navegação Aérea, foram apresentados 3 potenciais candidatos à data link para uso no ADS-B (ICAO, 2003b): o SSR Modo S Extended Squitter (1090ES), o Universal Access Transceiver (UAT) e o VHF Data Link Modo 4 (VDL4). Definiu-se que o 1090ES seria a melhor opção para vôos internacionais, deixando o UAT e VDL4 como soluções regionais (ICAO, 2003c). Desta forma, a FAA definiu (FAA, 2002), para o território norte americano, o uso do 1090ES na aviação de alto desempenho e o uso do UAT para a aviação geral. Já Europa e a região da Ásia e Pacífico adotaram o uso do 1090ES em suas operações, não definindo (até o momento) uma segunda opção para seus data links (ICAO, 2003c).

Com relação ao UAT e ao VDL4, este trabalho fará menção apenas à ICAO (2003b) para maiores informações. O SSR Modo S Extended Squitter (1090ES) aproveita as características atuais do transporder dos Sistemas de Radar Secundários Modo S, que transmite (squitter) - ominidirecionalmente, por meio do canal de resposta do Modo S (1090 MHz) e a cada segundo - uma mensagem de 56 bits contendo o endereço do transponder (ICAO, 2004). Este mecanismo é utilizado nos sistemas a bordo para prevenção contra colisão (ACAS), e permite que uma aeronave, ao receber a mensagem, interrogue o originador e obtenha informações de vigilância por meio de uma mensagem de 112 bits. No caso do ADSB, o formato "estendido" (extended) utiliza mensagens de "squitter" de 112 bits, deixando 56 
bits para o conteúdo ADS-B.

Um receptor 1090ES em solo, possuindo uma antena omnidirecional, tem capacidade de cobrir uma área superior a 200NM contendo até 120 aeronaves, considerando taxas de atualização de 5s@99,5\%. Esta cobertura pode chegar a 525 aeronaves em um raio de 200NM, fazendo uso de uma antena de 12 setores (ICAO, 2004). Desta forma, a cobertura de vigilância utilizando o ADS-B, com a opção do data link 1090ES, necessita de equipamentos relativamente simples em solo, tornando-se uma solução economicamente viável à sua adoção. Como exemplo, a Austrália tem ampliado a cobertura da ADS-B em seu território por meio da instalação de receptores 1090ES em solo. A Figura 14 ilustra o nível de cobertura ADS-B e Radar no território Australiano em Junho de 2006, além de apresentar as projeções de cobertura ADS-B para Junho de 2007 e a cobertura final para 2009 (Summer, 2007), (Dunstone, 2004).

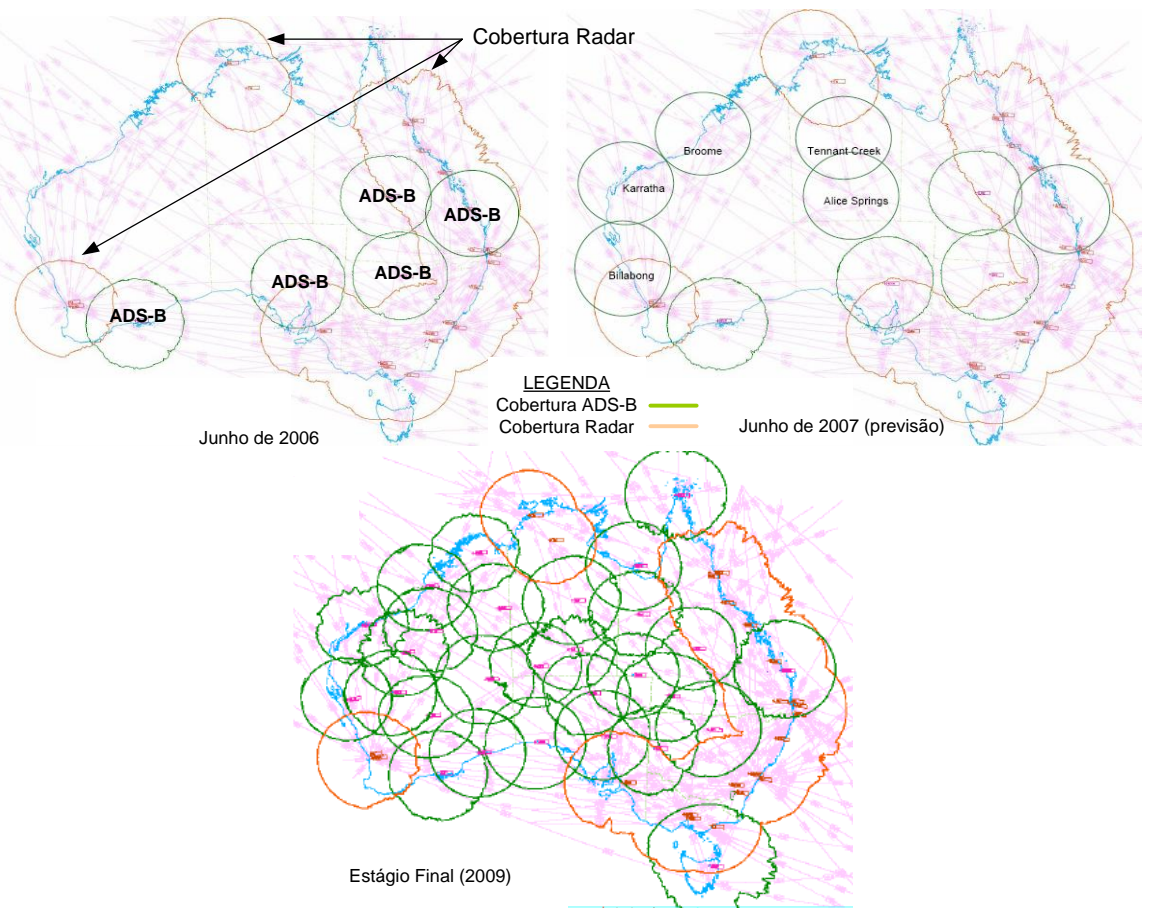

Figura 14 - Cobertura ADS-B no território Australiano

\subsubsection{ADS-B como Sistema de Vigilância no ATC}

A ADS-B, por concepção, tem a capacidade de ser utilizada em diversos níveis funcionais do Sistema de Gerenciamento de Tráfego Aéreo (ATM). Exemplos de aplicação estão na prevenção de colisão a bordo da aeronave (airborne situational awareness), na detecção e resolução de conflitos (tanto em sistemas a bordo quanto em solo) e mesmo na estimação de 
ventos e outras condições meteorológicas (ICAO, 1999b).

Porém, a aplicação primária para a ADS-B, assim como para a ADS-C, é servir como sistema de vigilância para o Controle de Tráfego Aéreo (ATC), sendo aplicada em áreas onde seria inviável, tanto técnica quanto economicamente, implementarem-se equipamentos Radar, e mesmo servindo como elemento complementar em áreas servidas por serviço Radar.

Como elemento de comunicação, a ADS-B é formada pelo elemento de transmissão (responsável pela geração e transmissão da mensagem), pelo meio de comunicação (data link) e o elemento de recepção (que recebe a mensagem, processa e apresenta à aplicação final). Desta forma, a ADS-B faz parte do processo de comunicação das informações no sistema de vigilância. As fontes de informação e a aplicação do usuário final não fazem parte do sistema ADS-B (CASA, 2007). Portanto, a "ADS-B out" (elemento de transmissão ADS-B) deve ser suprida com as informações presentes no equipamento de navegação a bordo. A Figura 15 (extraída de ICAO (2003d)) ilustra a relação funcional entre a ADS-B e o restante do sistema de vigilância.

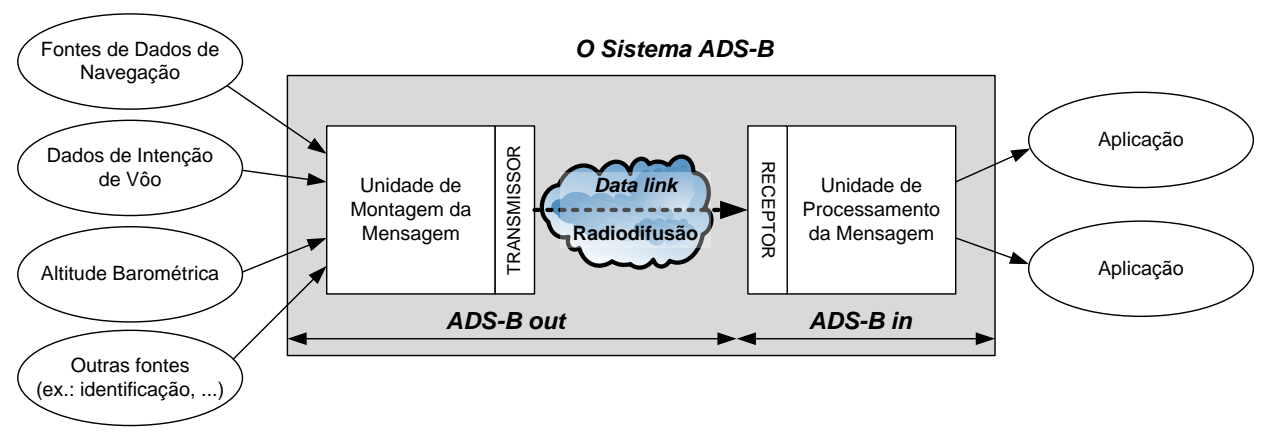

Figura 15 - Relação Funcional entre ADS-B e a aplicação de Vigilância

Conforme CASA (2007), para que o sistema de vigilância utilizando ADS-B possa ser aplicado como um sistema de vigilância Radar (ou um "Radar-like Service"), é necessário que a mensagem transmitida pelo "ADS-B out" contenha dados de Posição, Integridade da Posição, Altitude, Identificação, Número de Versão, SIL (Surveillance Integrity Level) e NACp (Navigation Acuracy Category for position).

Para que a mensagem "ADS-B out" possa conter as informações citadas, CASA (2007) especificou um conjunto mínimo de fontes de informação que deve estar disponível ao ADSB:

- para a Posição, o sistema GNSS é considerado suficiente, tanto em acurácia quanto 
em integridade, para prover este tipo de informação. O equipamento GNSS deve aderir às normas TSO-C145 $\mathrm{a}^{9}$, TSO-C146 ${ }^{10}$ ou equivalente, o que implica possuir, no mínimo, os seguintes requisitos:

$\checkmark$ o equipamento GNSS deve ser capaz de fornecer informação de posição periodicamente, com intervalo menor ou igual a 1 segundo;

$\checkmark$ o equipamento GNSS deve, continuamente, fornecer ao ADS-B informação de HPL (Horizontal Protection Limit), ou notificar o piloto caso ocorram interrupções de disponibilidade;

- para a Integridade da Posição, o equipamento GNSS deve prover, juntamente com os dados de posição, dados de integridade HPL (Horizontal Protection Level). Na ausência do HPL devido a restrições operacionais, pode-se substituí-lo pelo HFOM (Horizontal Figure of Merite).

- para a Altitude, o equipamento GNSS pode provê-la no caso de não haver disponibilidade da altitude barométrica. No caso da altitude barométrica estar disponível, a mesma deve estar de acordo com as normas estabelecidas para seu uso no Transponder.

- para a Identificação, deve ser provida pelo transponder como forma de manter-se o mesmo valor configurado no plano de vôo.

Pode-se notar que existe uma grande preocupação quanto à integridade dos dados fornecidos à ADS-B, principalmente quanto à posição. Esta preocupação é reforçada pela quantidade de padrões existentes nos equipamentos GNSS e relacionados aos parâmetros de integridade fornecidos, bem como de padrões de mensagens a serem aplicados à ADS-B, grande parte ainda em desenvolvimento (Dunstone, 2005). Porém, não é o escopo deste trabalho aprofundar-se neste tema, deixando-o aberto a futuros trabalhos de investigação.

A Figura 16 sintetiza o processo de geração, transmissão, recepção e visualização de mensagens de vigilância utilizando a ADS-B.

\footnotetext{
${ }^{9}$ TSO C-145a: "AIRBORNE NAVIGATION SENSORS USING GPS AUGMENTED BY THE WIDE AREA AUGMENTATION SYSTEM (WAAS)".

${ }^{10}$ TSO C-146a: STAND-ALONE AIRBORNE NAVIGATION EQUIPMENT USING THE GPS

AUGMENTED BY WAAS
} 


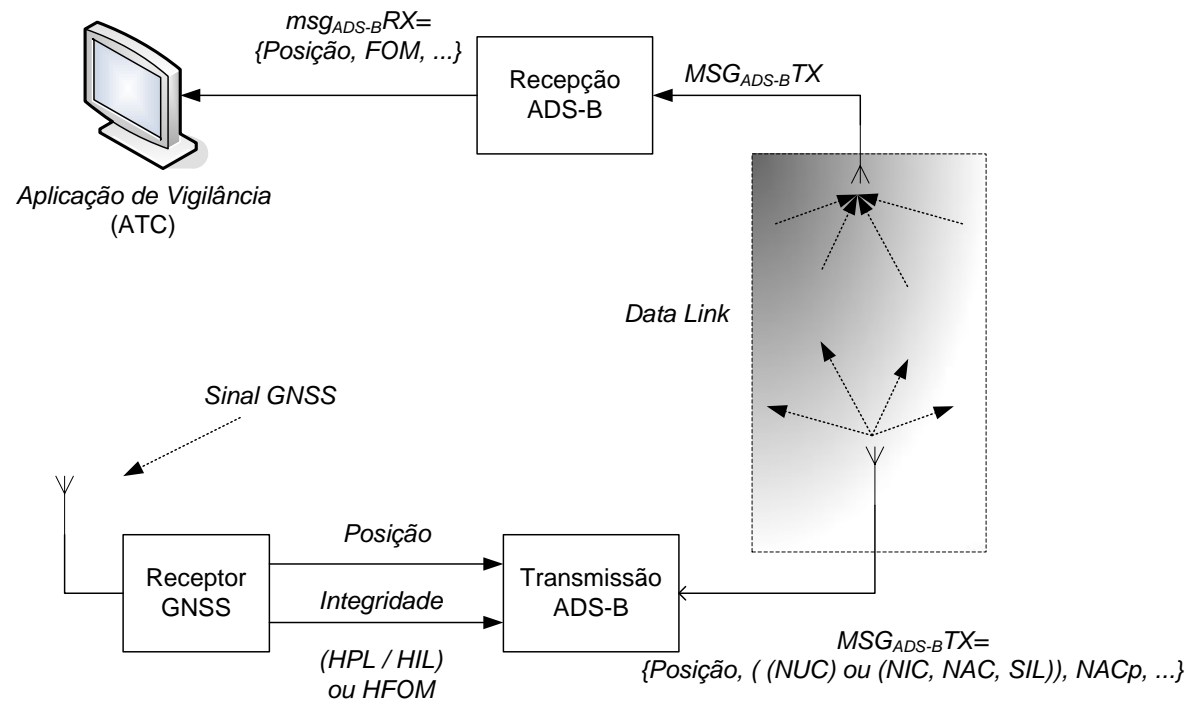

Figura 16 - Processo de Vigilância - mensagens ADS-B

Segundo estudos de Brooker, 2004, a obtenção dos seguintes valores de integridade é suficiente para prover serviço de vigilância Radar por meio da ADS-B ("Radar-like Services"):

- $\quad$ SIL $=2$, sendo que um SIL (Surveillance Integrity Level) igual a "2" corresponde à probabilidade de $\mathbf{1 0}^{-5}$ por hora de vôo do HPL (Horizontal Protection Level) ser excedido sem que haja detecção deste comportamento anormal. SIL é um valor estático, dependente da posição dos sensores utilizados.

- $\quad$ NACp $\geq 6$, sendo que a NACp (Navigation Acuracy Category for position) - um valor baseado no EPU (Estimated Position Uncertaint) - maior ou igual a 6 corresponde a um EPU menor que 0,3NM (ou seja, a posição real obtida pelo GNSS estar em um raio menor ou igual a $0,3 \mathrm{NM}$ em $95 \%$ do tempo). A EPU também é denominada como HFOM (Horizontal Figure of Merit), e equivale a uma medida de acurácia considerando que todos os satélites utilizados estão em correto funcionamento.

- $\quad$ NIC $\geq 6$, sendo que a NIC (Navigation Integrity Category) - um valor baseado no HPL - maior ou igual a 6 corresponde a um HPL menor que 0,6NM (probabilidade de $10^{-7}$ do valor real de posição estar em região fora de um raio de $0,6 \mathrm{NM}$ da posição obtida por hora de vôo).

Segundo Gleason; Moody, Russell (2002), e baseados na experiência Norte-Americana do uso 
do ADS-B como "Radar-like Service" na região do Alasca (Projeto Capstone ${ }^{11}$ ), o ADS-B necessita de um valor de $\mathbf{N U C p} \geq \mathbf{4}$ para ser utilizado em controle de tráfego aéreo aplicando separação mínima de 5NM. A NUCp (Navigation Uncertainty Category for position) é baseada no HPL, e uma NUCp $\geq 4$ implica em um HPL $<1$ NM.

Com relação às taxas de atualização e de latência para a ADS-B, Brooker, 2004 cita a Norma DO-242A (Minimum Aviation System Performance Standards), que estabelece taxas de atualização $\leq 14 \mathrm{~s} @ 95 \%$ e latência $\leq 1,2 \mathrm{~s} @ 95 \%$.

A Figura 17, adaptada de Dunstone, Owusu, Hewitt (2007), ilustra o funcionamento de um sistema de vigilância ADS-B.

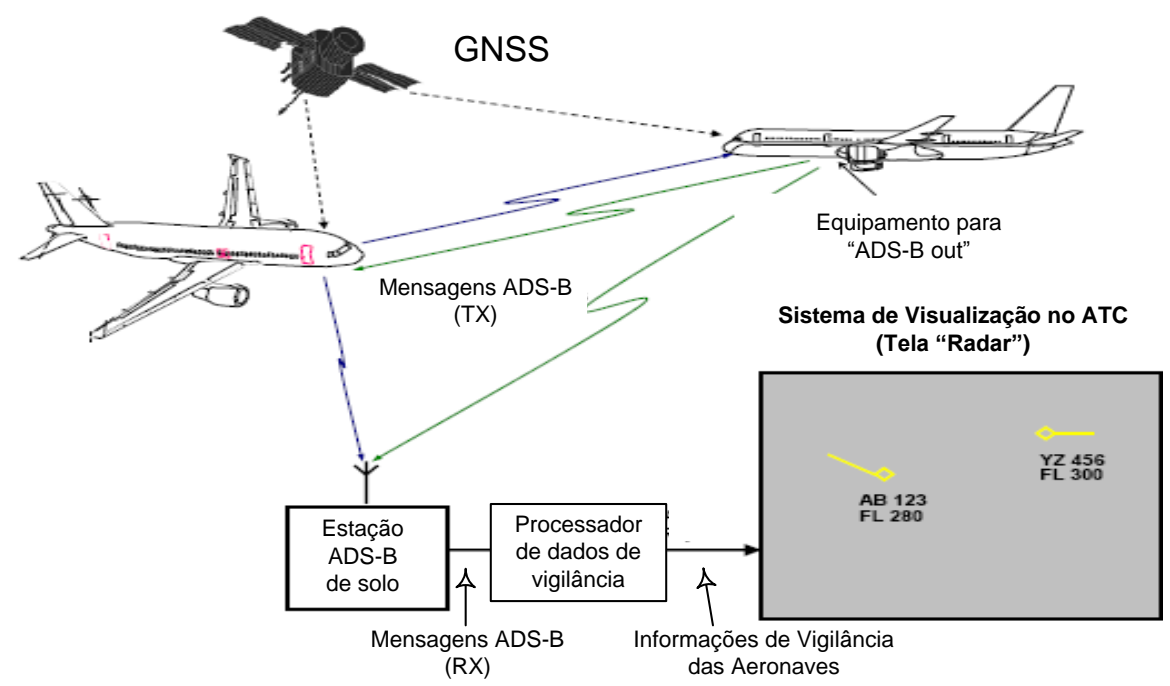

Figura 17 - Esquema Funcional de um Sistema ADS-B para ATC

Como relatado anteriormente, um sistema de vigilância deve conter Normas e Procedimentos que regrem seu uso (Dunstone; Osuwu, Hewitt, 2007). Neste sentido, existem trabalhos coordenados, porém ainda não concluídos, para estabelecer Normas e Procedimentos para aplicação do sistema de vigilância ADS-B no Controle de Tráfego Aéreo. A bibliografia aponta para o remodelamento do capítulo 8 do PANS-ATM, Doc.4444, da ICAO, substituindo a expressão "Radar" pela expressão genérica "Vigilância", de forma a englobar o conceito de Vigilância ADS-B (King, 2004).

\footnotetext{
${ }^{11}$ http://www.faa.gov/about/office org/headquarters offices/arc/programs/capstone/. Último acesso em 27/03/2007.
} 


\subsubsection{A Segurança do Tráfego Aéreo e o paradigma CNS/ATM}

Baseado nos conceitos do CNS/ATM, percebe-se que este novo paradigma tem subsídios que possibilitarão o aumento da capacidade do sistema de tráfego aéreo, pois melhorarão a qualidade das informações disponíveis a todos os elementos envolvidos no Gerenciamento de Tráfego Aéreo, permitindo um melhor controle das aeronaves nas diversas fases do vôo, "portão-a-portão" (gate-to-gate).

Porém, a segurança é um dos requisitos primários a serem respeitados pelo sistema de tráfego aéreo e, desta forma, esforços devem ser aplicados com a finalidade de poder-se garantir os níveis de segurança do CNS/ATM. No programa de transição do Sistema de Controle do Espaço Aéreo Brasileiro (SISCEAB) para os sistemas CNS/ATM (DECEA, 2003), fica explicitamente relatado a necessidade de determinar-se o “... impacto dos novos conceitos nos diversos serviços (de tráfego aéreo) prestados ...". Neste sentido, foram especificadas atividades focadas na:

$\checkmark$ “... determinação dos parâmetros associados ao modelo utilizado para determinação do risco de colisão em espaços aéreos onde se aplica a redução da separação ...",

$\checkmark$ “... determinação dos riscos de colisão associados às operações no espaço aéreo ...” e na

$\checkmark$ “... realização de comparações dos riscos obtidos com os limites de riscos aceitos ...”,

entre outros.

Percebe-se, portanto, que é fundamental compreender - além da relação direta existente entre os conceitos de capacidade, valores dos mínimos de separação e tecnologias utilizadas no sistema de tráfego aéreo, analisados ao decorrer deste capítulo - a relação existente entre $a$ segurança (safety) e os demais conceitos existentes, em especial as tecnologias / procedimentos utilizados, o que propicia determinar os “... parâmetros associados ao modelo utilizado para determinação do risco de colisão em espaços aéreos onde se aplica a redução da separação ..." (relação entre segurança, valores dos mínimos de separação e tecnologias utilizadas). Em resumo, o ponto de união entre os conceitos capacidade, segurança e tecnologias é o conceito de separação mínima entre aeronaves, conforme pode ser observado por meio da Figura 18. 


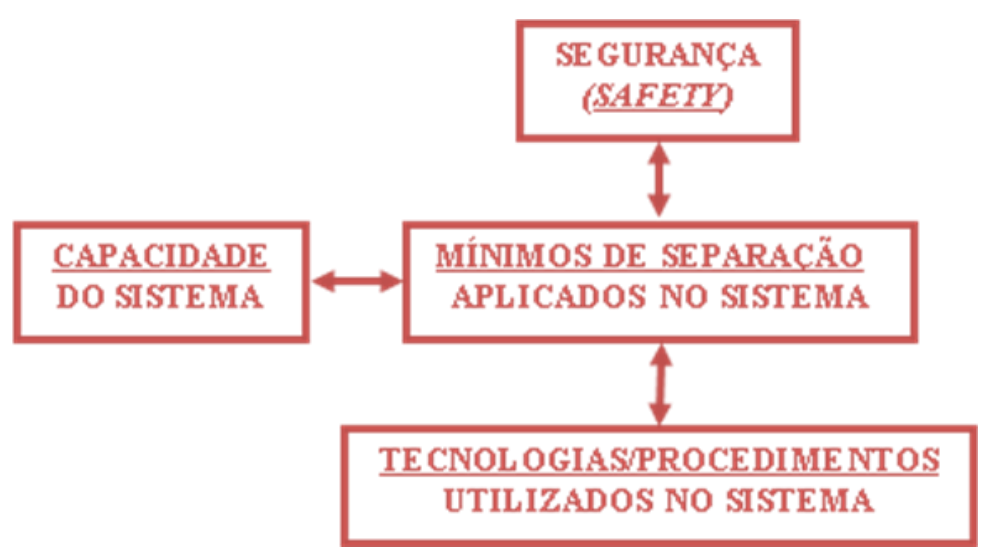

Figura 18 - Relação entre conceitos capacidade, tecnologias e segurança no ATC

Desta forma, o capítulo a seguir aborda um estudo com o objetivo de definir os conceitos relacionados à segurança no sistema de tráfego aéreo, além de determinar as formas de avaliação deste requisito considerando os demais conceitos abordados para este sistema (capacidade, tecnologias utilizadas e normas de separação mínima entre aeronaves). 


\section{A SEGURANÇA NO CONTEXTO DO TRÁFEGO AÉREO}

Este capítulo define os conceitos de sistemas críticos em segurança (safety) e de processo de análise de segurança, relacionando-os à interdependência entre os conceitos de capacidade, segurança e normas de separação mínima entre aeronaves no sistema de tráfego aéreo. Ao final deste capítulo, propõe-se uma nova abordagem, respaldada na metodologia de avaliação de segurança adotada pela Organização de Aviação Civil Internacional (OACI), para a avaliação de segurança do sistema de tráfego sob o paradigma CNS/ATM, que consiste na modelagem (utilizando em extensões da técnica das redes de Petri), simulação por eventos discretos e comparação com sistemas legados.

\subsection{Sistemas Críticos em Segurança}

Um sistema é projetado para atender determinados requisitos e, consequentemente, cumprir uma determinada missão. Quando um sistema apresenta funcionamento anormal e não atende aos requisitos previamente estabelecidos, a missão para qual foi projetado pode não ser devidamente cumprida. Em uma parcela significativa dos sistemas existentes, seu funcionamento anormal pode causar conseqüências menores, não afetando, de forma inaceitável, os envolvidos e o ambiente no qual está inserido. Porém, o funcionamento anormal de alguns sistemas pode provocar conseqüências socialmente inaceitáveis. Estes sistemas são definidos como Sistemas Críticos (Almeida Jr., 2002).

Segundo Kotonya, Sommerville (1998), existem 3 tipos principais de sistemas críticos:

- Sistemas Críticos em Negócios (Business Critical Systems): sistemas cujo funcionamento anormal pode causar danos financeiros aos negócios (exemplo: sistema de reservas de vôos).

- Sistemas Críticos em Missão (Mission Critical Systems): sistemas cujo funcionamento anormal pode causar o não cumprimento de uma missão (exemplo: sistema de controle em espaçonaves).

- Sistemas Críticos em Segurança (Safety Critical Systems): sistemas cujo funcionamento anormal pode causar danos à vida humana e ambientais significativos (exemplo: sistema de controle de máquinas de terapia utilizando radiação). 
Sistemas críticos em negócios e em missão afetam, via de regra, apenas os envolvidos com estes sistemas. Por outro lado, o funcionamento anormal de sistemas críticos em segurança pode afetar todo o ambiente no qual está inserido. Por exemplo, o funcionamento anormal dos sistemas de controle de plantas petroquímicas e nucleares pode provocar o vazamento de elementos tóxicos ou radioativos, causando mortes, ferimentos e prejuízos ambientais em uma área além de seus limites físicos. Desta forma, a segurança (safety) - propriedade na qual um sistema não causa prejuízos à vida humana e ao ambiente (Storey (1996)) - deve ser garantida nos "Sistemas Críticos em Segurança (Safety)", pois estes podem provocar, no caso de funcionamento anormal, efeitos catastróficos para pessoas e para o ambiente além dos limites funcionais no qual estão inseridos.

Quantitativamente, a segurança é a probabilidade, em um dado intervalo de tempo, de um sistema desempenhar sua função ou descontinuá-la sem causar mortes, ferimentos, prejuízos ambientais e materiais (Camargo Jr. (2002).

O funcionamento anormal de um sistema está relacionado à degradação do seu nível de desempenho à valores inferiores aos níveis mínimos especificados. Esta degradação está vinculada à presença de defeitos, os quais o impossibilitam de funcionar segundo os requisitos especificados. Conforme a necessidade, o conceito de defeito é dividido em 3 níveis: falha, erro e disfunção. Esta distinção é realizada em função do domínio no qual o defeito pertença. Segundo Johnson (1989), define-se:

- Falha: um defeito físico provocado por alguma vulnerabilidade do Hardware ou Software (defeito no universo físico do sistema). Estas vulnerabilidades podem ter origem em erros de especificação e implementação e em componentes defeituosos, tornando o sistema vulnerável a distúrbios externos e internos. Exemplos de falhas são curto-circuitos, danos aos componentes ou laços de software sem saída.

- Erro: manifestação da falha física. Especificamente, um erro é o desvio da acurácia ou corretude em alguma função do sistema (defeito no universo da informação do sistema). Um erro é, por exemplo, um bit de um barramento de dados preso em nível lógico " 1 " devido a um curto-circuito (falha).

- Disfunção: degradação do desempenho do sistema abaixo dos níveis mínimos especificados (defeito no universo externo ao sistema - usuários). A disfunção é a manifestação do erro que resulta em saídas incorretas do sistema. Uma disfunção é, por 
exemplo, a não execução do comando de fechamento de uma válvula devido ao bit que a controla ter ficado preso em nível lógico "1" (erro) por causa de um curto-circuito (falha).

Com relação à característica de segurança, disfunções podem levar um sistema a alcançar tanto estados seguros (safe) quanto estados inseguros (unsafe). Em sistemas críticos em segurança, um estado inseguro é aquele no qual o sistema não atende aos seus requisitos de segurança. Desta forma, quando um sistema está em um estado inseguro (também denominado estado perigoso), o mesmo fica exposto à ocorrência de um acidente (Camargo Jr., 2002). Um acidente pode ser definido tanto como um evento (ou seqüência de eventos) não intencional que causa mortes, ferimentos e perdas materiais e ambientais (Storey, 1996) quanto como a conseqüência do estado inseguro (ou perigoso) que promove perdas inaceitáveis de vidas, ferimentos, prejuízos ambientais e materiais (Kirner, 1997).

A Figura 19 ilustra a manifestação dos defeitos e sua relação com os estados de um sistema. Um estado inseguro (ou perigoso) contém as condições para a ocorrência de um acidente.

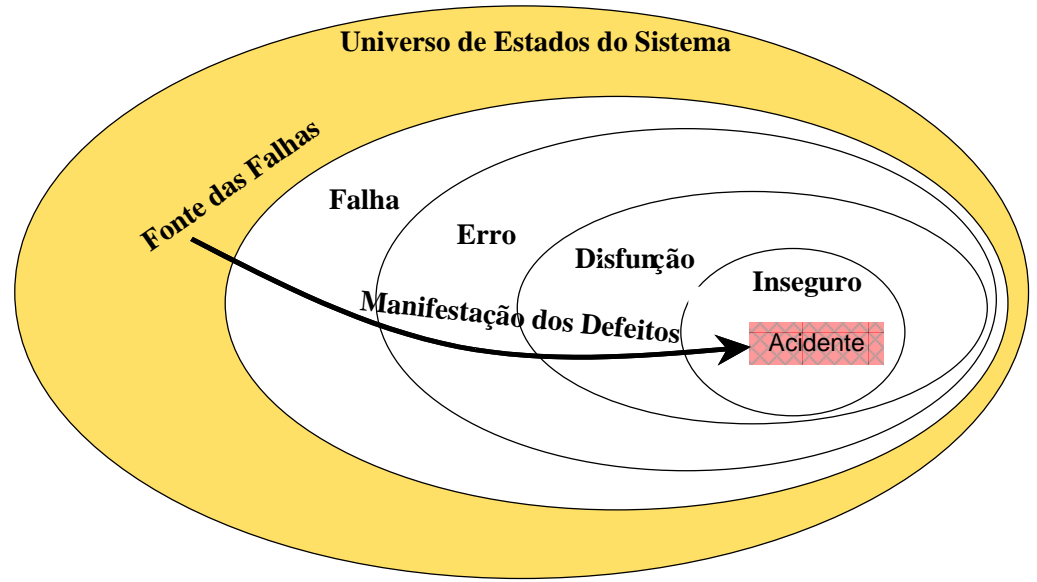

Figura 19 - Manifestação dos defeitos e relação com os estados do sistema.

Sendo um acidente o evento (ou seqüência de eventos) que viola a propriedade "segurança", o objetivo principal (de segurança) dos sistemas críticos em segurança deve ser o de minimizar, a níveis considerados aceitáveis, as condições que contribuam para a ocorrência de um acidente. 


\subsection{O processo de análise de segurança}

A seriedade e inaceitabilidade das conseqüências que podem ser causadas devido ao funcionamento anormal de sistemas críticos em segurança obrigam que seus ciclos de vida possuam um processo de análise de segurança robusto e bem estabelecido (Almeida Jr., 2002). Desta forma, o objetivo principal de um processo de Análise de Segurança é o de identificar quais estados perigosos podem ser atingidos por um sistema, avaliar seus riscos e, por fim, estabelecer medidas para minimizar os riscos e proteger o sistema contra a ocorrência de estados perigosos que possam levar a um acidente (Camargo Jr., 2002), (Leveson, 1995).

Um processo típico de análise de segurança (safety) é composto por 2 outros processos (Camargo Jr., 2002):

i. $\quad$ Processo de Gerenciamento da Segurança (safety)": normalmente realizado por um grupo responsável pela segurança do sistema em questão. Este grupo tem como objetivo formular, difundir e implantar as políticas de segurança (safety) para o sistema; rastrear e documentar perigos; adaptar e desenvolver normas; planejar, monitorar e analisar testes; investigar acidentes; entre outras atividades.

ii. Processo de Análise de Risco: tem a função de determinar quais são os perigos inerentes ao sistema e avaliar a importância e a aceitabilidade destes perigos no contexto da segurança. Uma metodologia de análise de risco possui as seguintes etapas:

a. Descrição e Especificação do Sistema.

b. Análise de Perigo (Hazard Analysis).

c. Qualificação do Risco Residual.

d. Avaliação da Severidade dos Acidentes e

e. Avaliação da Experiência Operacional.

De forma semelhante à definida anteriormente, "Perigo" é uma situação ou evento que pode, potencialmente, levar à ocorrência de um acidente (Profit, 1995). Definir as situações de acidentes potenciais, ou seja, identificar os perigos, é uma das primeiras atividades a ser realizada em uma análise de risco. Portanto, a etapa de análise de perigo (Hazard Analysis) 
tem o objetivo de identificar os perigos envolvidos no sistema, sendo composta pelos seguintes passos:

1. Análise preliminar de perigo (preliminar hazard analysis - PHA);

2. Análise de perigo do sistema (system hazard analysis - SHA);

3. Análise de perigo do subsistema (subsystem hazard analysis - SSHA);

4. Análise de perigo da operação de suporte (Operating Support System Hazard Analysis OSHA);

5. Análise final de perigo (Conclusive Hazard Analysis - CHA).

Em um processo de análise de perigo, pode-se utilizar um conjunto de técnicas e métodos, tais como: Lista de Verificação, Árvore de Falha, Árvore de Eventos, Análise de Efeitos e de Modos de Falha (Failure Modes and Effects Analysis - FMEA), Análise de Criticidade, Efeitos e Modos de Falha (Failure Modes, Effects and Criticality Analysis - FMECA), Análise de Operabilidade e Perigo (Hazard and Operability Analysis - HAZOP), Análise da Completeza das Especificações, Métodos Semi-Formais (redes de Petri, Statecharts, diagrama de transição de estado), Métodos Formais (Z, CSP, CCS, Autômatos Híbridos) (Camargo Jr., 2002).

Após a identificação dos perigos, deve-se definir a severidade das conseqüiências e a probabilidade de ocorrência para cada perigo identificado na fase anterior. Após conhecer os perigos, suas conseqüências e suas probabilidades de ocorrência, consegue-se definir os riscos relacionados ao sistema.

Portanto, o risco associado a um perigo é determinado pela combinação de dois fatores: a probabilidade (ou freqüência) da ocorrência de um acidente e a severidade da consequiência envolvida no acidente (Camargo Jr., 2002). Desta forma, o Risco é, por definição, a tripla \{Perigo, Conseqüiencia, Probabilidade\}, podendo ser expresso como (Kumamoto, Henley, 1996):

$$
\operatorname{Risco} \equiv\left\{\left(\mathbf{P}_{\mathbf{i}}, \mathbf{C}_{\mathbf{i}}\right) \mid \mathbf{i}=1,2, \ldots\right\}=\left\{\left(\mathbf{P}_{1}, \mathbf{C}_{1}\right),\left(\mathbf{P}_{2}, \mathbf{C}_{2}\right), \ldots,\left(\mathbf{P}_{\mathbf{n}}, \mathbf{C}_{\mathbf{n}}\right)\right\}
$$

Onde "i $=\mathbf{1}, \mathbf{2}$, ..." são os Perigos identificados para o sistema, "P $\mathbf{P}_{\mathbf{i}}$ " é a probabilidade (ou freqüência) da ocorrência de um acidente relacionado ao perigo "i $\mathrm{i}$ " " $\mathbf{C}_{\mathbf{i}}$ " é a consequiência 
no caso do acidente ocorrer.

Após a determinação do risco, é necessário avaliar sua aceitabilidade no contexto do sistema analisado. Diversos fatores influenciam os níveis de aceitabilidade dos riscos. A percepção de risco por parte dos usuários do sistema é um destes fatores. A aceitabilidade de um risco, e as conseqüentes medidas tomadas para minimizá-los, são baseadas em uma relação "Custos relacionados à ocorrência ou à eliminação do perigo" x "Benefício obtido na eliminação do perigo". Os esforços mitigatórios devem ser tomados em função dos níveis de aceitabilidade pertinentes aos riscos.

Os critérios de aceitabilidade em uma avaliação de segurança estão atrelados às suas métricas de segurança. A escolha de métricas e de seus respectivos níveis de aceitabilidade, que ponderem os riscos encontrados no sistema, são fatores de decisão a respeito da segurança do sistema. Por exemplo, o número de quedas de aeronaves por ano pode ser uma métrica de segurança utilizada para o sistema de tráfego aéreo. Esta métrica deve ponderar todos os riscos identificados para o acontecimento "queda de aeronave" como, por exemplo, falha de motores ou condições meteorológicas desfavoráveis, e é uma forma direta de "medir", e apresentar aos interessados, os níveis de segurança do sistema.

\subsection{Capacidade e Segurança no Sistema de Tráfego Aéreo}

No Capítulo 2 deste trabalho, justificou-se a necessidade do aumento da capacidade do sistema de tráfego aéreo como forma de suprir a demanda crescente por este modal de transporte. Demonstrou-se que a capacidade (taxa média de fluxo máximo) do sistema de tráfego aéreo, por definição, está vinculada aos tempos médios de separação aplicados entre aeronaves. A redução nos valores de separação, e conseqüiente aumento na capacidade, poderiam ser obtidos tanto pelo aumento do número de rotas em uma determinada área quanto pela redução da separação entre aeronaves que trafegam sobre uma mesma rota.

As características dos elementos atuais do sistema de controle de tráfego aéreo, tais como navegação, comunicação e vigilância (vide Figura 4), são fatores limitantes à redução da separação entre aeronaves, impactando em restrições quanto ao aumento da capacidade de tráfego. Porém, a proposta global para solucionar estas restrições vem com a adoção do paradigma CNS/ATM. Este paradigma traz melhorias significativas no desempenho dos parâmetros dos elementos do sistema de tráfego, comparado ao paradigma atual. Este fato reflete na melhoria de desempenho do processo de garantia de separação das aeronaves 
(Figura 6) e, consequentemente, possibilita a redução dos valores de separação aplicados.

Contudo, o valor da separação aplicada pelo controle de tráfego afeta, de forma inversa, as características de capacidade e segurança nos sistemas de transporte aéreo. A redução nos valores de separação entre aeronaves promove o aumento direto na capacidade do sistema de transporte aéreo. Por outro lado, esta redução nos valores de separação também promove o aumento dos riscos que contribuem para a colisão entre aeronaves, afetando diretamente a segurança do sistema. Desta forma, pode-se concluir que a capacidade e a segurança (safety) do sistema de transporte aéreo são características conflitantes. A Figura 20 ilustra a relação entre separação, capacidade e segurança no tráfego aéreo. A redução na separação, mantidos os mesmos elementos do sistema (por exemplo, os elementos atualmente utilizados), aumenta a exposição a acidentes (colisão entre aeronaves).

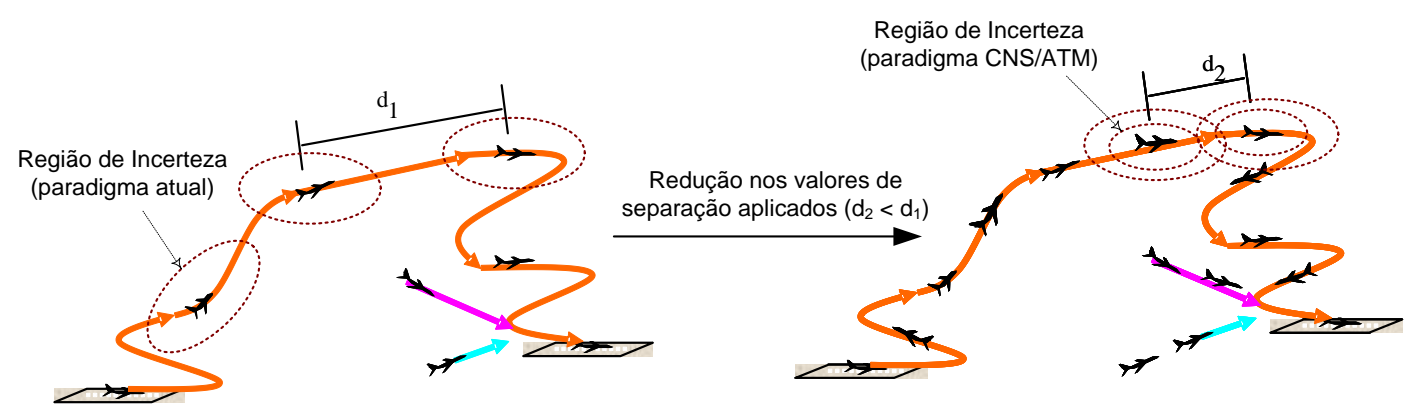

Figura 20 - Relação entre Separação, Capacidade e Risco de Colisão.

O modal aéreo de transporte é crítico em segurança e, por isso, a mesma deve ser garantida minimizando-se, a níveis considerados aceitáveis, as condições que contribuem para a ocorrência de um acidente aeronáutico. Por definição, um Acidente Aeronáutico é toda ocorrência associada com a operação de uma aeronave, e no período da intenção de vôo, onde ocorre, pelo menos, uma das situações enumeradas a seguir (Ministério da Aeronáutica, 2002b):

i. alguma pessoa morre ou sofre lesão grave;

ii. a aeronave sofre dano ou falha estrutural que afete adversamente suas características de vôo, desempenho ou resistência estrutural;

iii. a aeronave é considerada desaparecida ou encontra-se em local inacessível. 
Segundo Oliveira (2007), os riscos intrínsecos do tráfego aéreo estão relacionados tanto às ações isoladas de cada aeronave - tais como risco de incêndio, a risco de despressurização ou o choque com o solo - quanto ações provenientes da interação entre diversas aeronaves - tais como risco de colisão ou risco de desestabilização da aeronave por esteira de turbulência. Devido ao impacto social causado, a colisão entre aeronaves em vôo é o fator mais significativo à segurança aeronáutica (Profit, 1995) e, por isso, a garantia da segurança do tráfego aéreo está vinculada, em grande parte, à minimização dos riscos relacionados à interação entre diversas aeronaves, sobretudo quanto aos fatores que afetem suas separações.

Em espaço aéreo controlado, o nível mais crítico de interação entre aeronaves é de responsabilidade do Sistema de Controle de Tráfego Aéreo (ATC), pois o mesmo atua no nível tático do gerenciamento do tráfego garantindo a separação entre as mesmas. Portanto, a garantia dos níveis de segurança do tráfego aéreo é realizada, em grande parte, por meio da redução dos fatores que possam levar o ATC a estados perigosos de não garantia da separação entre aeronaves. Vale ressaltar, conforme ilustrado na Figura 20, que a ausência de uma separação mínima entre aeronaves implica em um estado com alta probabilidade de colisão (Oliveira, 2007).

A Figura 21 ilustra, segundo o trabalho de Blom (2004), alguns cenários dos 185 acidentes relacionados à perda da separação entre aeronaves e ocorridos na aviação comercial entre os anos 1980 a 1999 (em um total de 420 milhões de vôos). Estes acidentes representaram, aproximadamente, 7,9\% do total de acidentes (2.340 acidentes) e 5,0\% do total de mortes ocorridas no mesmo período (15.554 mortes). Como pode ser percebido, o cenário de colisão entre aeronaves correspondeu a, aproximadamente, 11,9\% dos acidentes relacionados com a perda de separação. Porém, estes acidentes corresponderam a uma parcela de 79,8\% das mortes provocadas, o que demonstra o alto risco (relação entre probabilidade de ocorrência e conseqüência) de colisão entre aeronaves em vôo. 


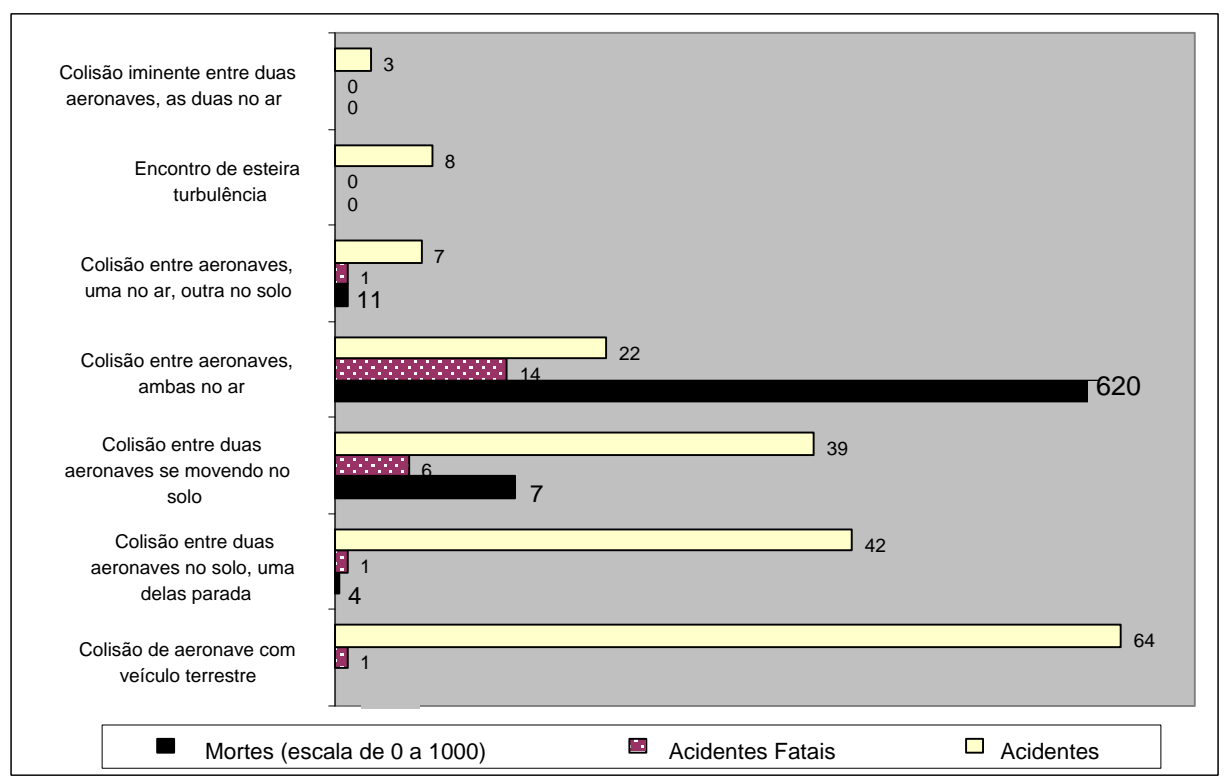

Figura 21 - Estatísticas de acidentes relacionados com perda de separação entre aeronaves e entre aeronaves e veículos terrestres (BLOM, 2004).

Desta forma, o risco de colisão entre aeronaves é fator determinante na avaliação da segurança do tráfego aéreo, sendo influenciado por diversos parâmetros do sistema. Os parâmetros que influenciam diretamente o risco de colisão podem ser compilados, segundo ICAO (1998) e Cohen (1998), como:

a) o tempo que as aeronaves ficam expostas a possíveis conflitos. Este fator está relacionado à configuração das rotas e a densidade de tráfego (e, consequentemente, aos valores de separação aplicados entre aeronaves);

b) o desempenho dos sistemas de navegação disponíveis às aeronaves;

c) o desempenho dos sistemas de vigilância e a comunicação sobre o laço de controle entre controle de tráfego aéreo (ATC) e as aeronaves.

Como visto anteriormente, após a determinação do risco de colisão, avalia-se sua aceitabilidade no contexto do tráfego aéreo. Alguns exemplos de métricas de segurança relacionadas à colisão entre aeronaves são o [número de colisões por hora de vôo] ou [número de colisões por ano]. A Organização de Aviação Civil Internacional (OACI) cita que o nível de segurança aceitável para a métrica [número de acidentes fatais por hora de vôo] está entre 1 e 6 acidentes fatais a cada 10 milhões de horas de vôo (Cohen, 1998). Neste caso, o número de colisões entre aeronaves por hora de vôo corresponde a uma parcela significativa deste 
valor.

Concluindo, o sistema de controle de tráfego aéreo, por ser crítico quanto à segurança, necessita garanti-la por meio de um processo de análise de segurança robusto e bem estabelecido (Almeida Jr., 2002). Devido à interdependência conflitante entre a "capacidade do sistema de tráfego", a "segurança" e os "valores de separação mínima aplicadas entre aeronaves", o processo de análise de segurança necessita de modelos que relacionem estas características juntamente com as características de desempenho dos elementos do ATC. Assim, podem-se produzir valores de risco a serem utilizados tanto na verificação do nível de segurança quanto para determinação de valores de separação aceitáveis para o sistema.

Portanto, segue-se com uma verificação de quais são os critérios e métodos atualmente utilizados para determinação dos valores de separação mínima entre aeronaves. O objetivo é aplicá-los sobre o conceito CNS/ATM e, desta forma, determinar se este sistema permite aumentar a oferta por transporte aéreo por meio da redução da separação sem afetar seus níveis de segurança.

\subsection{Avaliação de Segurança no contexto da Separação Mínima}

"Separação" é definida pela OACI como (ICAO, 1998b):

“... um termo genérico usado para descrever a ação (do controle de tráfego aéreo) de manter aeronaves operando em uma mesma área e a distâncias umas das outras de forma que o risco de colisão seja mantido abaixo do nível aceitável de segurança."

Desta forma, a separação mínima entre aeronaves equivale à menor distância de aproximação na qual aeronaves podem ser mantidas sem que a probabilidade de colisão exceda níveis considerados aceitáveis. Dada à natureza do movimento das aeronaves, a separação é aplicada tridimensionalmente, tanto no plano vertical quanto longitudinalmente e lateralmente (plano horizontal).

Como mencionado anteriormente, a ICAO (1998b) define duas formas pelas quais o ATC mantém a separação entre aeronaves: por separação convencional (procedural) e por separação radar. Ambas as formas estão relacionadas aos métodos de vigilância disponíveis 
aos serviços de controle de tráfego aéreo. Neste sentido, a "separação convencional" (Procedural Separation) está relacionada ao método de vigilância convencional (ou Procedural Surveillance), no qual as informações de posição são fornecidas pelos pilotos. Já a "separação radar" está relacionada ao método de "vigilância radar", na qual as informações de posição são fornecidas por meio de um equipamento Radar.

As normas de separação, que estabelecem os valores mínimos de separação aplicáveis, são distintas para cada categoria espacial de serviço de controle de tráfego (serviço de controle de área, de aproximação e de aeródromo). Tanto para o serviço de vigilância Radar quanto o serviço de vigilância convencional, as normas especificam valores de separação mínima para cada dimensão espacial. Estes valores podem ser representados em distâncias espaciais (milhas náuticas $[\mathrm{NM}]$ ou pés) ou em distâncias temporais (em minutos). Assim, o controle de tráfego aéreo (ATC) tem a incumbência de não permitir que os valores mínimos de separação sejam infringidos, simultaneamente, nas 3 dimensões.

A Organização de Aviação Civil Internacional (OACI) (ICAO, 1998), assim como a Federal Aviation Administration (FAA) e o Eurocontrol (Cohen, 1998), listam inúmeros fatores a serem considerados e que influenciam a determinação da separação, tais como a estrutura do espaço aéreo, os recursos de comunicação e vigilância, o desempenho da navegação das aeronaves, a capacidade no gerenciamento do fluxo de tráfego e as ferramentas de gerenciamento de tráfego aéreo disponíveis. Devido a estes inúmeros fatores envolvidos na determinação da separação e às características globais da navegação aérea, acordou-se que as normas de separação devem ser estabelecidas internacionalmente e publicadas por meio do documento PANS-RAC ("Procedures for Air Navigation Services: Rules of the Air Traffic Services”) da OACI (ICAO, 1998b).

Mesmo que o estabelecimento de normas adequadas de separação para o tráfego aéreo seja um dos maiores desafios na segurança dos vôos (Galati; Naldi, Pavan, 2003), a bibliografia mostra que as normas atuais de separação, sobretudo para o controle Radar, não fizeram uso de métodos formais e quantitativos que considerassem a afetação dos fatores listados sobre os valores de separação adotados. Segundo Cohen (1998), “... as primeiras normas de separação mínima (radar) não foram baseadas na acurácia Radar, mas focadas no balanceamento da ocupação das pistas (de pouso e decolagem) e na separação entre chegadas e saídas ...". Shakarian, Haraldsdottir (2001) citam que as normas de separação radar baseiam-se em critérios informais e qualitativos, que refletem as limitações do sistema de vigilância radar, 
incluindo o monitoramento humano.

Reynolds, Hansman (2001) relatam que as normas de separação mínima radar para vôos em rota foram introduzidas na década de 1950 e não mudaram até o presente. Além disto, seus critérios de definição são pouco conhecidos e documentados. Assim como Brooker (2002), eles citam que, aparentemente, as normas de separação radar foram baseadas em sua acurácia, no tamanho do alvo na tela radar, na confiança do usuário pelo equipamento e, principalmente, em consenso e julgamento de especialistas. Em face destas constatações, Reynolds, Hansman (2001) alegam que, devido à melhoria na acurácia dos sistemas de vigilância radar desde a década de 1950, sem que as normas de separação radar tenham sido alteradas, ocorreu um aumento significativo nos coeficientes de segurança do serviço de controle radar. A Figura 22 ilustra este conceito do aumento do coeficiente de segurança (relacionada com as camadas da região de proteção e incerteza no ATC, Figura 5).

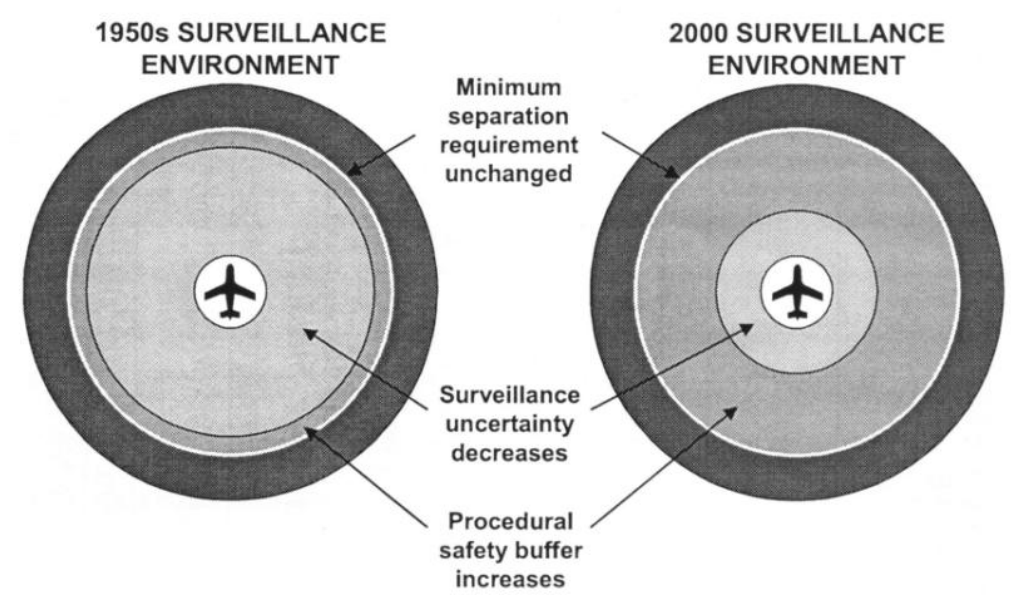

Figura 22 - Aumento conceitual nas margens de segurança do serviço de controle radar (extraído de Reynolds, Hansman (2001))

A ausência de métodos formais e quantitativos aplicados na determinação das normas de separação mínima possui, em partes, aval da própria Organização de Aviação Civil Internacional (OACI). A OACI comenta que “... modelos matemáticos apenas auxiliam na tomada de decisão quanto aos valores de separação, mas não substituem o julgamento operacional ...” (ICAO, 1998b). Porém, FAA e Eurocontrol, no sentido de justificar quantitativamente os valores de separação radar adotados, realizaram estudos com o objetivo de desenvolver um modelo que obtivesse valores de risco em função de normas de separação mínima, informações de posição, acurácia, integridade dos equipamentos e automação (Cohen, 1998). 
Diversas outras iniciativas desenvolveram metodologias que pudessem ser utilizadas na determinação das normas de separação mínima. Uma descrição destas metodologias pode ser encontrada em EUROCONTROL (2002) e Cohen (1998). Em geral, pode-se dizer que as metodologias têm como base alguma forma de processo de análise de risco, que serve para avaliar se o risco de colisão é aceitável para o sistema de tráfego aéreo em função de um determinado valor de separação. Desta forma, a modelagem de risco de colisão (ou Colision Risk Modeling - CRM) é um importante elemento na determinação das normas de separação mínima entre aeronaves.

Com base nas similaridades entre as metodologias de determinação das normas de separação mínima, e devido à adoção de seus requisitos por parte do grupo de CRM do "Action Plan 3: Air Traffic Modeling for Separation Standards" "12 (trabalho conjunto entre FAA e Eurocontrol”) para a elaboração de Análise de Risco de Colisão (Mcauley, 2004), segue a apresentação da metodologia utilizada pela Organização de Aviação Civil Internacional (OACI) para avaliação de segurança e consequentemente determinação das normas de separação mínima (ICAO, 1998).

\subsubsection{Método de Avaliação de Segurança da OACI}

Os métodos de avaliação de segurança são utilizados, sobretudo, em processos de definição dos valores de separação mínima aplicados entre aeronaves. A OACI, em seu documento "Manual on Airspace Planning Methodology for the Determination of Separation Minima" (ICAO, 1998), é um exemplo deste tipo de processo. Este documento descreve os procedimentos e os parâmetros a considerar no processo de planejamento do espaço aéreo, principalmente no que se refere à redução dos valores de separação entre aeronaves. De forma geral, os parâmetros globais a serem considerados neste processo, como relatado anteriormente, são:

i. o tempo que as aeronaves ficam expostas a possíveis conflitos. Este fator está relacionado à configuração das rotas e a densidade de tráfego (e, consequentemente, aos valores de separação aplicados entre aeronaves);

ii. o desempenho dos sistemas de navegação disponíveis às aeronaves;

\footnotetext{
${ }^{12}$ http://www.eurocontrol.int/moc-faa-euro/public/subsite homepage/homepage.html. Última visita: 10/03/2007.
} 
iii. o desempenho dos sistemas de vigilância e a comunicação sobre o laço de controle entre controle de tráfego aéreo (ATC) e as aeronaves.

O processo de determinação dos valores de separação mínima adotado em (ICAO, 1998) consiste nas etapas ilustradas pela Figura 23.

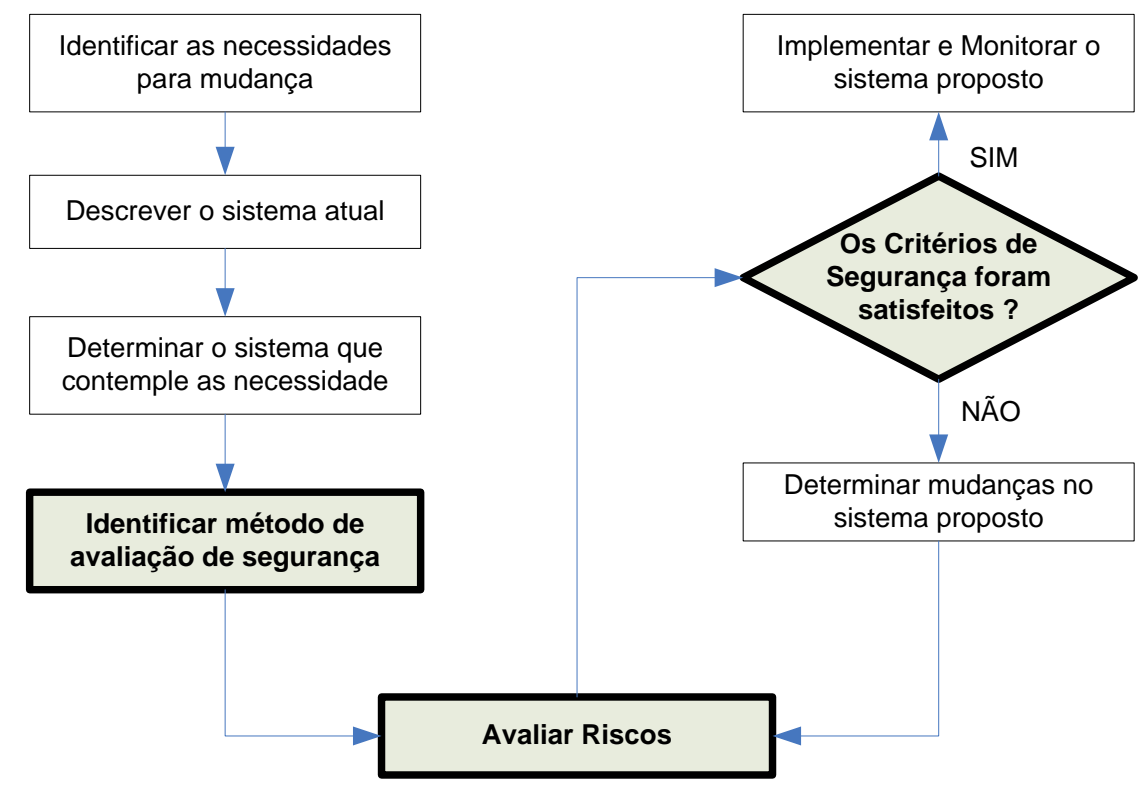

Figura 23 - Processo de determinação dos valores de separação mínima (ICAO, 1998)

Com base neste processo, e após aplicar as etapas de "identificação das necessidades", "descrição do sistema atual" e "determinação do sistema que contemple estas necessidades", deve-se avaliar se a segurança do sistema desenvolvido satisfaz os níveis considerados aceitáveis. Desta forma, a avaliação de segurança, no método OACI, está relacionada com as partes em destaque na Figura 23: "Identificar método de avaliação de segurança", “Avaliar Riscos" e decidir se os "Critérios de Segurança foram satisfeitos".

A Organização de Aviação Civil Internacional (OACI) estipula dois tipos distintos de métodos de avaliação de segurança: "Avaliação do Risco em relação a um valor de Limiar" e "Comparação com Sistema de Referência”. A OACI estabelece condições específicas para a aplicação de cada um destes métodos, que serão tratadas a seguir.

\subsubsection{Avaliação do Risco em relação a um valor de Limiar}

Neste método, realiza-se uma estimativa de risco de colisão entre aeronaves por meio da modelagem do sistema analisado. Confronta-se o valor de risco obtido por meio deste modelo com o valor de risco considerado tolerável. Neste caso, um sistema pode ser considerado 
seguro se sua estimativa de risco de colisão não for maior do que o valor de risco considerado tolerável. Ou seja, o valor de risco estimado não deve ultrapassar o limiar de segurança do sistema.

Este método é composto das seguintes etapas, ilustradas na Figura 24:

a. Definição do sistema proposto, onde se determina quais são as características importantes a serem consideradas na modelagem do sistema;

b. Definição dos critérios de avaliação, onde se definem as métricas de segurança que serão utilizadas e seus respectivos valores de aceitabilidade (ou seja, os níveis-alvo de segurança para o sistema - Target Level of Safety (TLS));

c. Identificação dos perigos que possam levar a uma colisão;

d. Estimativa da freqüiência e modelagem das conseqüências, onde se definem as frequiências com a qual os perigos ocorrem e modela-se o grau de severidade para os mesmos.

e. Estimativa dos riscos, onde se estima o risco total de colisão baseado nos valores obtidos na etapa “d.". Após obter esta estimativa, a mesma é confrontada com o valor de risco considerado aceitável para o sistema, verificando-se se o mesmo é aceitável ou não.

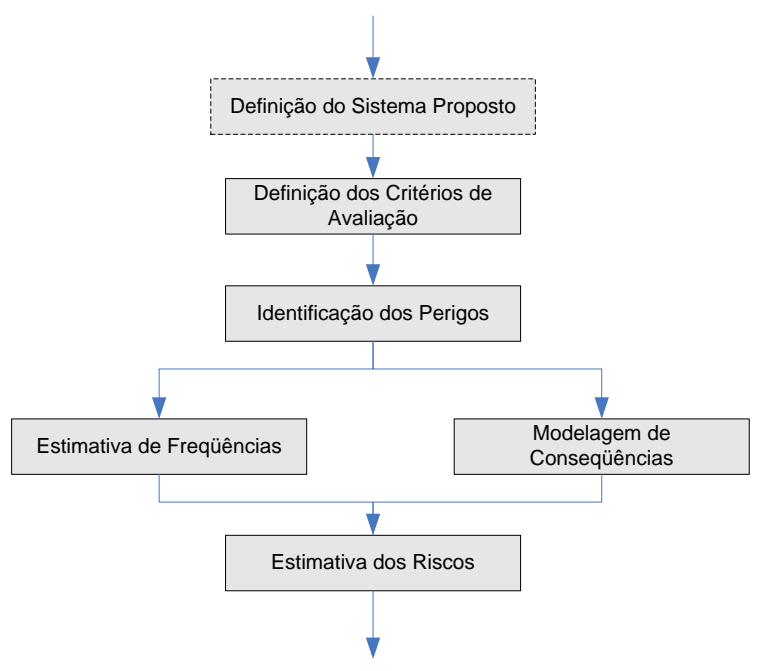

Figura 24 - Método de Avaliação do Risco em relação a um valor de Limiar (ICAO, 1998) 
A "Avaliação de Risco em relação a um valor de Limiar" é considerada um método de avaliação absoluto. Necessita, portanto, do desenvolvimento de um modelo de análise baseado nas características do próprio sistema, o qual será utilizado para detectar seus potenciais perigos. Além disto, esta avaliação de segurança é baseada em estimativas de risco de colisão, obtidas por meio de modelos matemáticos, que são alimentados por estimativas de freqüência dos eventos perigosos. Estas freqüências são estimadas, quando possível, por observações históricas dos eventos. Quando estes dados históricos não estão disponíveis (principalmente no caso de novos sistemas), estas estimativas são baseadas em julgamentos de especialistas ou obtidas indiretamente por meio dos parâmetros do sistema.

Desta forma, existem limitações quanto à utilização deste método de avaliação absoluto da segurança em novos sistemas. Primeiramente, os valores estimados para a segurança do sistema podem ser contaminados por estimativas deficientes e imprecisas de seus parâmetros de entrada, gerando valores que podem não refletir o real nível de segurança do sistema. Isto se deve ao fato de ser quase impossível obterem-se dados reais, devido a baixa taxa de ocorrência dos eventos considerados na análise (Brooker, 2002). Outro problema deste método está em definir quais são os níveis-alvo de segurança que serão considerados como aceitáveis (TLS). Este valor depende do julgamento das diversas partes interessadas no sistema (usuários, operadores, órgãos normatizadores, sociedade, etc) e, por isso, possuem variação conforme o órgão envolvido (Brooker, 2004c). Por último, pode ser citada a limitada capacidade que os modelos matemáticos utilizados na avaliação do risco de colisão, principalmente os modelos analítico-numéricos, possuem em considerar interdependências entre os parâmetros do sistema (Cohen, 1998).

Um dos modelos de risco de colisão amplamente utilizados é o Modelo de Reich (Reich, 1966). Este modelo analítico-numérico estima o risco de colisão [número de colisões por unidade de tempo] calculando, para cada dimensão do espaço aéreo, a relação (ICAO, 1998):

"Freqüência com a qual a separação é perdida na dimensão " $i$ " $\left(\mathbf{N}_{\mathbf{i}}\right)$ "

$x$

"Probabilidade de perda da separação nas outras 2 dimensões $\left(\mathbf{P}_{\mathbf{k}}\right)$ ", sendo o modelo final representado na forma: $\mathbf{C}=\mathbf{N}_{\mathbf{x}} \cdot \mathbf{P}_{\mathbf{y}} \cdot \mathbf{P}_{\mathbf{z}}+\mathbf{N}_{\mathbf{y}} \cdot \mathbf{P}_{\mathbf{x}} \cdot \mathbf{P}_{\mathbf{z}}+\mathbf{N}_{\mathbf{z}} \cdot \mathbf{P}_{\mathbf{x}} \cdot \mathbf{P}_{\mathbf{y}}$.

O Modelo de Reich, mesmo com seu amplo histórico de utilização, possui características que limitam sua aplicação na análise dos conceitos atuais do sistema de transporte aéreo. Este 
modelo parte da premissa de que os vôos ocorrem em rotas paralelas, além de não considerar o desempenho humano e a realimentação existente, por parte do controle de tráfego aéreo ou do piloto, sobre a aeronave em rota de colisão (ICAO, 1996). Outra limitação é a dificuldade de definir os parâmetros de entrada do modelo, o que pode causar estimativas de risco pouco confiáveis para o sistema em análise (Brooker, 2003).

\subsubsection{Avaliação do Risco por meio de Comparação com um Sistema de Referência}

Neste método, a avaliação de risco é realizada por meio da comparação entre parâmetros de desempenho do sistema proposto e de um sistema de referência que já tenha sido julgado como sendo seguro. O sistema proposto será considerado seguro se o seu nível de desempenho, com relação aos aspectos considerados de segurança, for igual ou superior aos níveis de desempenho encontrados no sistema de referência.

Para que seja possível aplicar este método, o sistema proposto deve atender diversos critérios de similaridade com relação ao sistema de referência. Os requisitos mínimos que devem ser considerados para garantir a mínima similaridade entre sistemas são (ICAO, 1998):

i. a separação mínima no sistema proposto não pode ser menor que a separação mínima do sistema de referência;

ii. a disponibilidade, a integridade, a acurácia e a confiabilidade da comunicação e de vigilância no sistema proposto não podem ser piores do que no sistema de referência;

iii. a frequiência e a duração da aplicação dos valores de separação mínimas entre aeronaves no sistema proposto não podem ser maiores do que no sistema de referência;

iv. o desempenho de navegação da população de aeronaves operantes no sistema proposto não pode ser pior, no sentido de promover o aumento do risco de colisão, do que a das operantes no sistema de referência.

Após definir um sistema de referência suficientemente similar ao sistema proposto, baseando-se nos critérios acima expostos, devem ser realizados os seguintes procedimentos para avaliar a segurança deste último:

1. descrever, em detalhes, as diferenças e similaridades entre os dois sistemas 


\section{(Referência e Proposto);}

2. para cada parâmetro analisado, verificar em quanto as diferenças entre os sistemas podem afetar os riscos. Esta análise pode ser realizada usando técnicas matemáticas ou julgamento operacional.

3. para cada parâmetro analisado, garantir que o sistema proposto possui, ao menos, os mesmos níveis de segurança que o sistema de referência.

O processo de Avaliação do Risco em Comparação com um Sistema de Referência, considerado um método de avaliação relativo, é ilustrado na Figura 25 (baseado em EUROCONTROL (2002)).

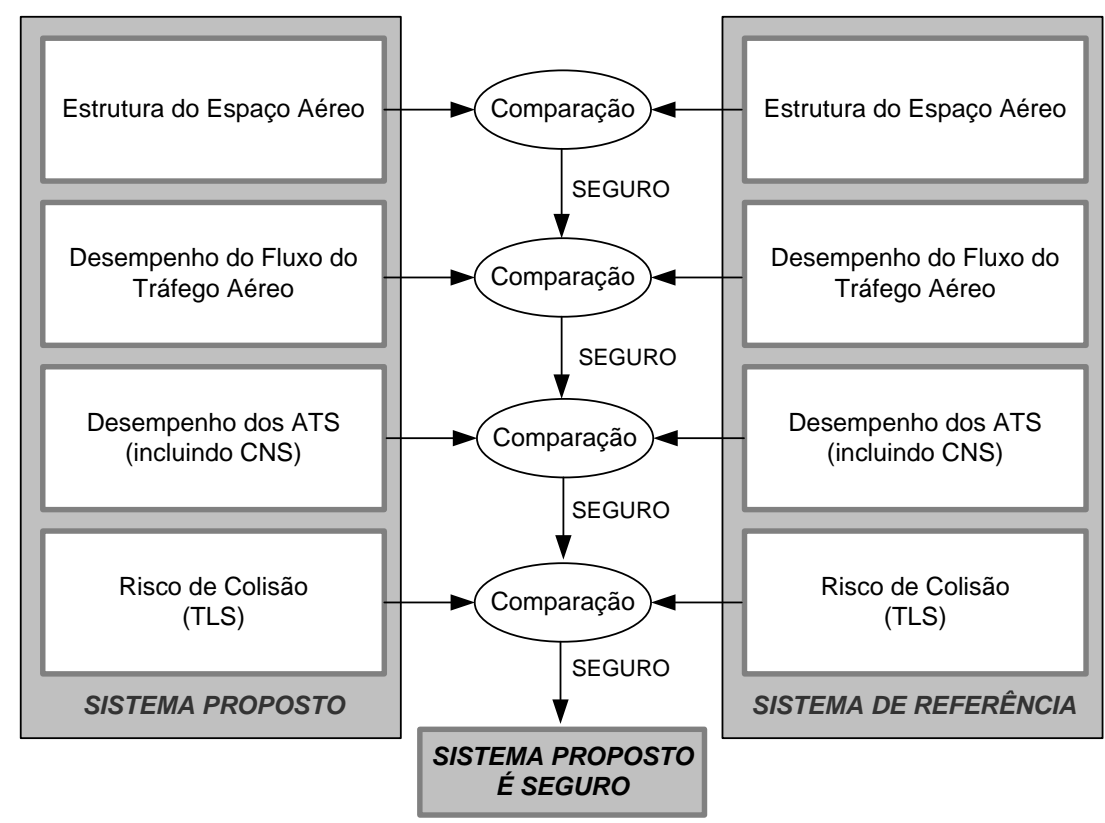

Figura 25 - Método ICAO (1998) de Avaliação do Risco por Comparação com uma Sistema de Referência (baseado em Eurocontrol (2002))

Uma das deficiências deste método está em encontrar, ao mesmo tempo, um sistema de referência que seja similar ao sistema proposto, cumprindo todos os requisitos mínimos de similaridade requeridos, e que seja considerado seguro. Mudanças radicais de filosofia no sistema, tal como ocorre no paradigma CNS/ATM, não comportam este processo de comparação "não interdependente" entre os parâmetros dos sistemas. Além disto, este método apresenta apenas resultados qualitativos, garantindo apenas que o sistema proposto é tão seguro quanto o sistema de referência. $\mathrm{O}$ método não possui um modo quantitativo para analisar em quanto um sistema estará mais seguro baseado em determinada alteração, o que é 
fundamental para a tomada de decisão no processo de mitigação de riscos.

Uma aplicação deste método relativo de avaliação é ilustrada em (Butcher et al, 2002 e 2004). Por meio da comparação entre parâmetros de desempenho do sistema de vigilância radar (sistema de referência) e do sistema de vigilância baseado em vigilância dependente automática por radiodifusão (ADS-B) (sistema proposto), aquele trabalho busca garantir que o sistema proposto (ADS-B) possua o mesmo valor de separação mínima entre aeronaves adotado para o sistema de referência (5NM). Desta forma, duas críticas podem ser feitas com relação ao mesmo:

- não é possível estabelecer o ganho em segurança que o sistema baseado em ADS-B promove ao sistema de tráfego aéreo. Apenas pode-se concluir que o mesmo é "tão seguro" quanto um sistema de vigilância baseado no radar;

- o autor limitou-se a analisar apenas uma alteração no sistema de vigilância (substituição do Radar pelo ADS-B), mantendo todos os demais parâmetros, inclusive navegação. Caso fossem realizadas alterações maiores, afetando sistemas de forma interdependente, este método de verificação de segurança tornar-se-ia não aplicável.

Em resumo, pode-se dizer que:

i. O método absoluto possui as vantagens de ser um método de avaliação que aplica modelos formais e quantitativos. Porém, este método possui desvantagens com relação à incerteza nos valores de entrada dos modelos utilizados, podendo gerar estimativas de níveis de segurança irreais para o sistema. Além disto, este método faz uso de valores pré-estabelecidos de níveis de segurança para o sistema (TLS), que podem ter sido baseados em parâmetros diferentes aos utilizados pelos analistas no modelo de estimativa da segurança. Por último, os modelos de risco de colisão (CRM) atualmente preconizados, tal como o Modelo de Reich, não consideram aspectos importantes, tais como a atuação do controlador de tráfego e do piloto na resolução de potenciais conflitos.

ii. Já o método relativo possui a vantagens de utilizar os mesmos parâmetros de comparação direta entre o sistema proposto e o de referência. Devido o sistema de referência adotado estar previamente definido como "seguro", este método não necessita definir qual TLS deve ser considerado, solucionando esta desvantagem do 
método absoluto. Porém, a própria determinação de um sistema de referência que possa ser considerado seguro e suficientemente similar ao sistema em análise é uma desvantagem, principalmente para novos sistemas. Além disto, o método relativo possui a desvantagem de ser qualitativo, podendo garantir, apenas, que o sistema em análise será tão seguro quanto o de referência, mas não informando qual foi o ganho quantitativo em segurança do sistema em relação a sua referência. Por fim, McAuley (2004) reforça que o método relativo da ICAO pode não ser apropriado, pois não se pode considerar a interação entre os diversos elementos do sistema, além de não ser possível quantificá-los.

Com base nesta apresentação, pode-se perceber que ambos os métodos de avaliação de risco apresentados possuem vantagens e desvantagens. Além disso, verifica-se que as limitações entre os métodos são complementares. Ou seja, características desvantajosas em um método são vantajosas no outro. Em face destas limitações e complementaridades, segue a proposta de um método de avaliação de segurança que combina os dois métodos adotados pela OACI. Esta fusão de métodos tem o objetivo de maximizar as qualidades em separado dos métodos e, assim, criar um método com maior poder de análise e que possa ser aplicado ao novo paradigma de tráfego aéreo.

\subsection{Proposta de Avaliação de Risco baseada em Modelagem em Redes de Petri Fluidas e Estocásticas (RPFE), Simulação e Comparação com Sistemas Legados}

O método de avaliação de risco proposto neste trabalho, e apresentado a seguir, visa minimizar as limitações encontradas nos dois métodos mencionados em ICAO (1998) e ilustrados anteriormente. Vale ressaltar que o método que será apresentado a seguir trata apenas de uma proposta inicial, cuja verificação formal de suas propriedades e característica não fará parte do escopo deste trabalho, podendo ser explorado em futuros trabalhos de investigação científica.

Portanto, propõe-se que este método faça uso da comparação entre o sistema proposto (em avaliação) e um sistema de referência. Porém, esta comparação não será feita de forma direta por meio dos parâmetros de desempenho do sistema, tal como no método relativo da OACI, mas por meio da comparação entre as métricas de segurança estimadas para cada sistema. As estimativas das métricas de segurança são obtidas por meio da modelagem e da análise de 
risco para cada sistema em separado. Porém, para garantir similaridade entre os sistemas, serão utilizados os mesmos parâmetros funcionais em ambos os modelos.

O método proposto é constituído das seguintes etapas, ilustradas na Figura 26:

A. Definição dos elementos funcionais e dos parâmetros a serem considerados em comum na modelagem e na análise de ambos os sistemas;

B. Definição dos critérios de avaliação, onde se definem quais as métricas de segurança que serão utilizadas em comum entre modelos;

C. Aplicação do processo de avaliação de risco absoluto para cada um dos sistemas (proposto e referência). Neste caso, deve-se identificar os perigos, estimar as suas freqüências, modelar as suas conseqüências e calcular os riscos para cada um dos sistemas;

D. Confronta-se o valor de risco calculado para o sistema proposto com o valor de risco calculado para o sistema de referência. O sistema proposto será considerado seguro caso seu risco estimado seja menor ou igual ao risco estimado para o sistema de referência.

Desta forma, as avaliações absoluta e relativa são combinadas neste método. A similaridade que deve existir entre sistemas é obtida em alto nível de modelagem, por meio da definição dos mesmos elementos funcionais a serem modelados em ambos os sistemas. Em ambos os modelos, devem existir os mesmo macro-elementos funcionais ao sistema de tráfego aéreo, que seriam o elemento "controlador de tráfego aéreo (ATCo)", o elemento "vigilância", o elemento "comunicação", o elemento "navegação", o elemento "aeronaves" e quaisquer outros elementos que forem julgados necessários à análise. A partir da definição dos elementos do sistema, definem-se quais os parâmetros funcionais relacionados aos mesmos, comuns a cada sistema, e considerados importantes à análise. Por exemplo, pode-se utilizar a acurácia e o tempo de atualização da vigilância, tempos de atraso e de respostas para comunicação, tempos de reação do ATC e das aeronaves, entre outros. 


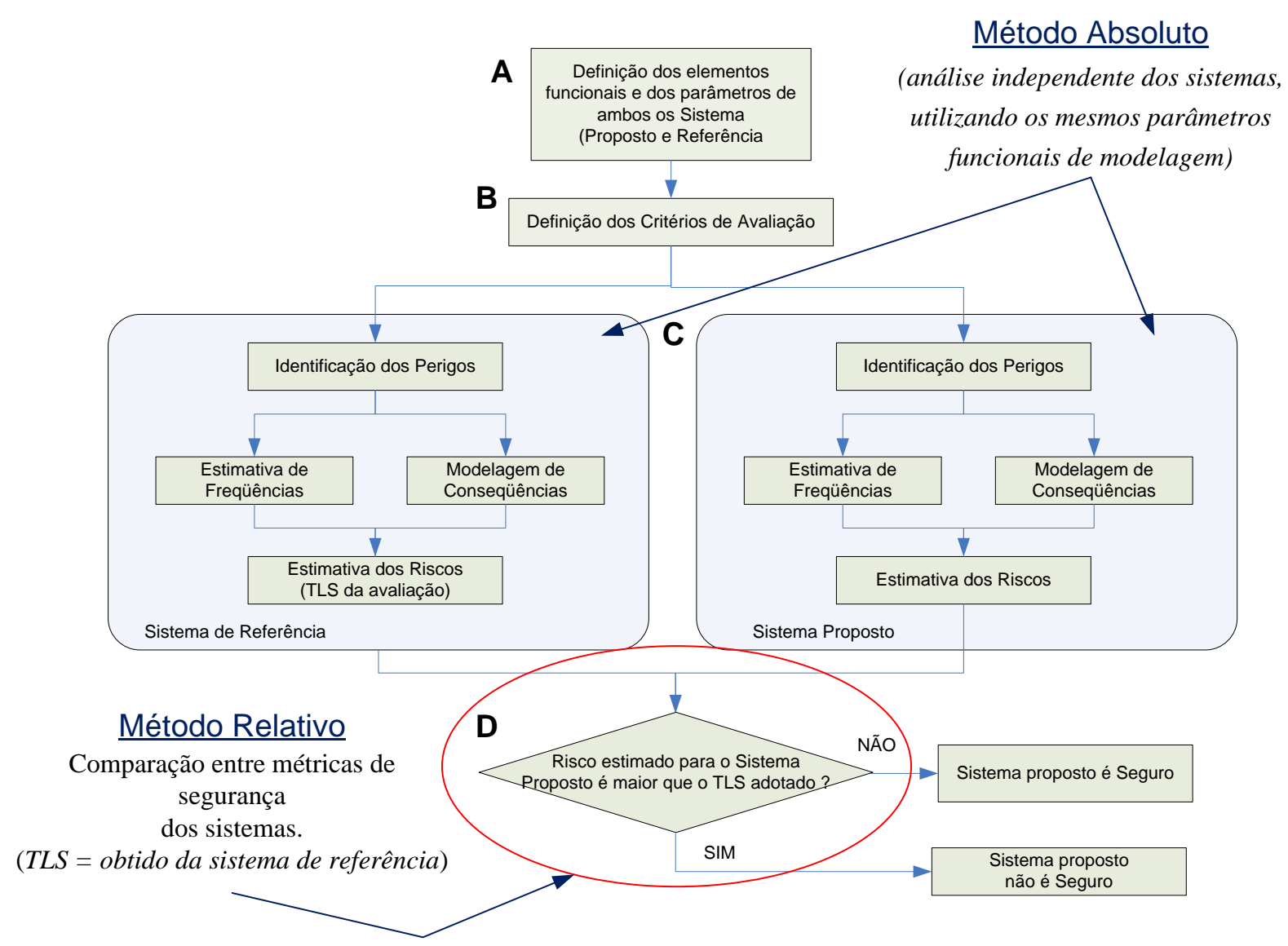

Figura 26 - Método proposto para avaliação de risco

Em posse da "arquitetura" de cada modelo de sistema, realiza-se o processo de avaliação de risco para ambos, em separado. Devido ao sistema de referência ser, normalmente, um sistema legado, onde seus níveis de segurança são conhecidos e considerados aceitáveis, o valor da estimativa de risco obtido por meio de seu modelo pode ser adotado como o nível de aceitabilidade de segurança (ou o Target Level of Safety - TLS) do sistema.

Devido à característica absoluta do processo de estimativa de risco de cada modelo, onde os parâmetros utilizados nesta estimativa são comuns a ambos os sistemas e cada análise gera as mesmas métricas de segurança, é possível realizar uma análise quantitativa com respeito ao impacto das características dos elementos do sistema proposto sobre os níveis de segurança do sistema. Esta análise de sensibilidade pode ser benéfica ao processo de mitigação dos riscos do sistema, apresentando os caminhos que devem ter prioridade na minimização dos riscos.

Em função de o método proposto possuir uma parte absoluta, o qual modela sistemas com alto grau de interdependência entre seus módulos funcionais, é necessário que se adotem técnicas formais que supram estas necessidades de modelagem nos sistemas. Além disto, é fortemente 
recomendado para sistemas complexos que a estimativa de valores de risco seja baseada em métodos heurísticos, tal como a simulação, pois a quantidade de interações existentes no sistema impossibilita uma avaliação algorítmica dos mesmos (Galati, 2003), tal como ocorre no Modelo de Reich.

Portanto, o método de avaliação de segurança proposto - fazendo uso combinado de um método absoluto, um método relativo e simulação - pode ser considerado promissor para a avaliação de segurança de sistemas baseados no paradigma CNS/ATM. Vale mencionar que os problemas com relação à incerteza nos valores de entrada dos modelos de avaliação de risco permanecem. Porém, esta desvantagem é minimizada por dois motivos:

a) o sistema de referência utilizado é, normalmente, um sistema legado, que possui valores históricos de dados para os parâmetros utilizados em seu modelo. Desta forma, a acurácia nos valores de entrada do modelo de avaliação de risco do sistema de referência é aumentada, gerando um TLS estimado com maior grau de confiança;

b) a adoção de um formalismo de modelagem e análise que permita modelar os sistemas em diversos níveis de abstração por meio do mesmo modelo torna possível estimar um parâmetro que não possui valores históricos utilizando parâmetros diretamente relacionados e que sejam de conhecimento dos analistas.

Portanto, pode-se perceber que existe a necessidade de definir por um formalismo de modelagem que possa considerar as características do paradigma CNS/ATM. No sentido de identificar qual seria o formalismo mais indicado, verificou-se, segundo a taxonomia apresentada por Almeida Jr (2003), que o Sistema de Controle de Tráfego Aéreo, incluindo o paradigma CNS/ATM, é um Sistema Crítico em Segurança (Safety Critical System), pois faz a supervisão e o controle da Aplicação Crítica em segurança “Tráfego Aéreo". Ainda segundo esta taxonomia, o funcionamento anormal de um sistema crítico em segurança (tal como o Sistema de Controle de Tráfego Aéreo) pode levar a conseqüências desastrosas (acidentes aéreos) no ambiente da aplicação crítica em segurança (o Espaço Aéreo Controlado). A Figura 27 ilustra a relação entre sistema crítico em segurança e aplicação crítica em segurança no sistema de controle de tráfego aéreo (ATC). 


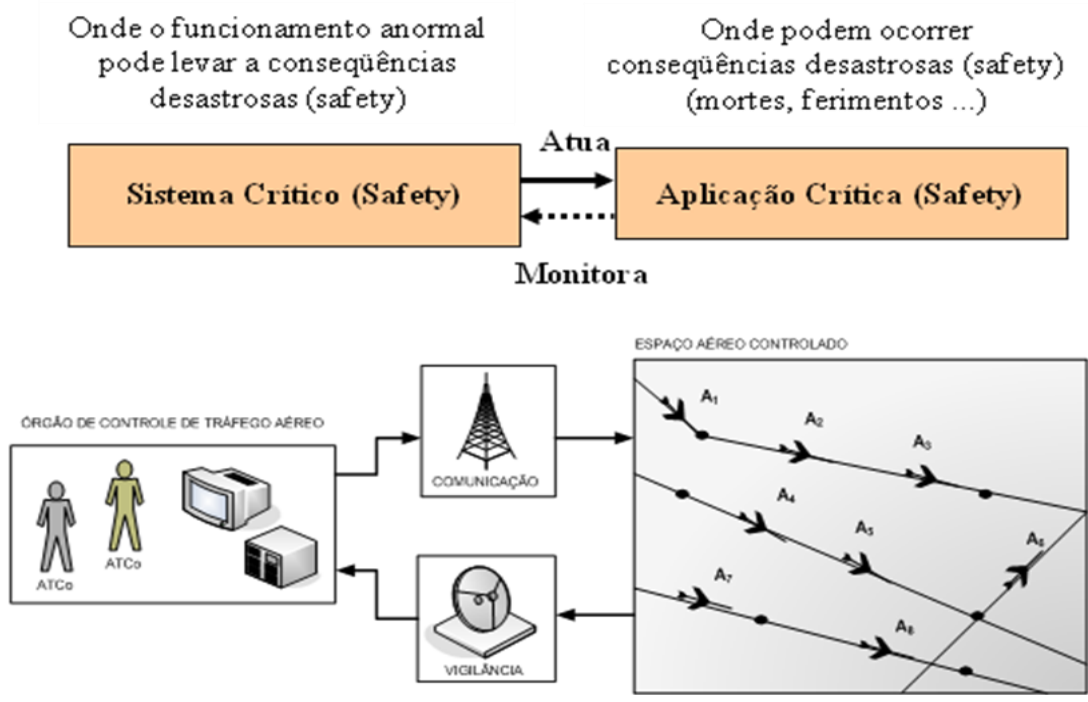

Figura 27 - Relação entre Sistema e Aplicação Crítica em Segurança no ATC

Como pôde ser observado ao decorrer deste trabalho, o sistema CNS/ATM, além de ser crítico em segurança (safety), é baseado em tecnologias digitais (tais como sistemas computacionais e redes de comunicação de dados digitais), no uso de satélites e em diversos níveis de automação. Somando estas características à propriedade intrínseca do tráfego aéreo de ser distribuído, pode-se concluir que o sistema CNS/ATM é definido pelo atual paradigma de sistemas de supervisão e controle (cujo estudo detalhado está apresentado no APÊENDICE C), baseado em arquiteturas computacionais distribuídas sobre redes de comunicação de padrão aberto. Desta forma, o CNS/ATM possui as mesmas características do atual paradigma de sistema de supervisão e controle e relacionadas aos domínios da "Segurança da Informação (security)", do "Comportamento Temporal" e do "Comportamento ContínuoDiscreto".

Com base nas características deste novo paradigma de sistemas, verificou-se na literatura que as redes de Petri Fluidas e Estocásticas (RPFE) são um formalismo para modelagem e análise de sistemas que contemplam as características identificadas (Tuffin; Chen, Trivedi, 2001), (Wolter, 2000), (Gribaudo et al, 2003). No formalismo das RPFE, os elementos primitivos de uma rede de Petri (RdP), tais como lugares, transições e arcos, podem ser tanto contínuos como discretos, modelando variáveis contínuas e variáveis discretas de um sistema híbrido, respectivamente, e o comportamento dinâmico entre estes elementos no sistema. As redes de Petri Fluidas e Estocásticas (RPFE) são utilizadas para modelar e verificar propriedades funcionais e de segurança de sistemas híbridos (Gribaudo et al, 2002). 
Ainda segundo Gribaudo et al (2003), é possível unificar a visão entre métodos formais e estocásticos com o uso das redes de Petri Fluidas e Estocásticas (RPFE) para modelagem e avaliação dos sistemas com elementos discretos e contínuos. Por ser uma evolução das redes de Petri elementares, as RPFE podem modelar e analisar propriedades funcionais dos sistemas em termos de seus estados discretos, tais como conformidade e alcançabilidade de estados, por exemplo. Já com relação à evolução das RPFE a partir das redes de Petri Estocásticas (SPN), é possível utilizar as RPFE para realizar análise estocástica de sistemas, obtendo medidas de desempenho, confiabilidade, disponibilidade e segurança (dependabilidade) com base na incerteza dos parâmetros. Por último, as RPFE possuem a capacidade de modelar espaços de estados contínuos interdependentes de processos discretos, o que a torna útil em aplicações reais.

Uma forma sistemática de definir medidas de interesse em uma rede é por meio de funções de recompensa, onde as estruturas de recompensa podem ser expressas, em alto nível, por expressões condicionais à marcação de uma rede (German, 2000). As redes de Petri Estocásticas, agregadas ao formalismo de recompensa, são definidas como "redes Estocásticas de Recompensa (ou Stochastic Reward nets - SRN)" (Muppala; Ciardo, 1994). Nestas redes, obtem-se medidas de interesse por meio de variáveis de recompensa, tais como as recompensas instantâneas, acumuladas e médias ilustradas na Figura 28.

$$
\begin{aligned}
& R_{\text {inst }}(t)=\sum_{n \in S} r r_{n} \cdot 1_{\{N(t)=n\}}, \mathrm{N}(t) \text { pertence ao espaço de estados da rede } \\
& R_{\text {acum }}(t)=\int_{0}^{t} R_{\text {inst }}(\varphi) d \varphi \\
& R_{\text {med }}(t)=\frac{1}{t} \cdot R_{\text {acum }}(t)
\end{aligned}
$$

Figura 28 - Variáveis de Recompensa Instantânea, Acumulada e Média.

A obtenção de medidas quantitativas para análise das redes de Petri Estocásticas (e suas evoluções) envolve o cálculo dos vetores de probabilidade de estado $\pi_{\mathbf{n}}(t)=\mathbf{P}(\mathbf{N}(t)=\mathbf{n})$. Podese fazer uso de 2 técnicas distintas para a resolução destas redes: Técnicas Analíticas e Simulação (COMPSciDept, 2004). Além das restrições relacionadas aos tipos de transição empregados nas SPN, a modelagem de redes complexas e não limitadas pode resultar em uma quantidade excessiva de estados, tornando infactível a resolução computacional de suas equações de estado e forçando a aplicação de aproximações numéricas às Técnicas Analíticas. Portanto, a técnica da Simulação é uma solução viável à resolução de redes de Petri não 
Markovianas, bem como à solução de redes cuja complexidade torne seu espaço de estados analiticamente inviável. Devido às redes de Petri Estocásticas (SPN) serem um método utilizado para descrever a dinâmica de sistemas de eventos discretos, cuja evolução de estados (marcações) ocorre em eventos bem definidos e discretos, sua resolução por meio de simulação por eventos discretos torna-se uma extensão do próprio método.

Fazendo uso de métodos analíticos, é possível calcular as esperanças $\mathbf{E}\left[\mathbf{R}_{\text {inst }}(t)\right], \mathbf{E}\left[\mathbf{R}_{\text {acum }}(t)\right]$ e $\mathbf{E}\left[\mathbf{R}_{\text {med }}(t)\right]$ por meio de expressões literais, que são as medidas de interesse definidas para uma rede. Porém, o uso da técnica de simulação permite apenas inferir (ou estimar) os valores destes parâmetros. Desta forma, o processo utilizado para análise quantitativa de sistemas, deve-se incorporar ao processo de análise conceitos de Inferência Estatística como meio de calcular as medidas desejadas com confiança significativa.

Concluindo, e conforme ilustrado pela Figura 29, a parte absoluta do método de avaliação de risco proposto faz uso de modelagem por meio das redes de Petri fluidas e estocásticas (RPFE); define as medidas de interesse por meio de estruturas e variáveis de recompensa; e obtém estimativas das medidas de interesse empregando simulação por eventos discretos (DES) e inferência estatística. A apresentação detalhada dos conceitos aqui apresentados está contida no APÊNDICE D.

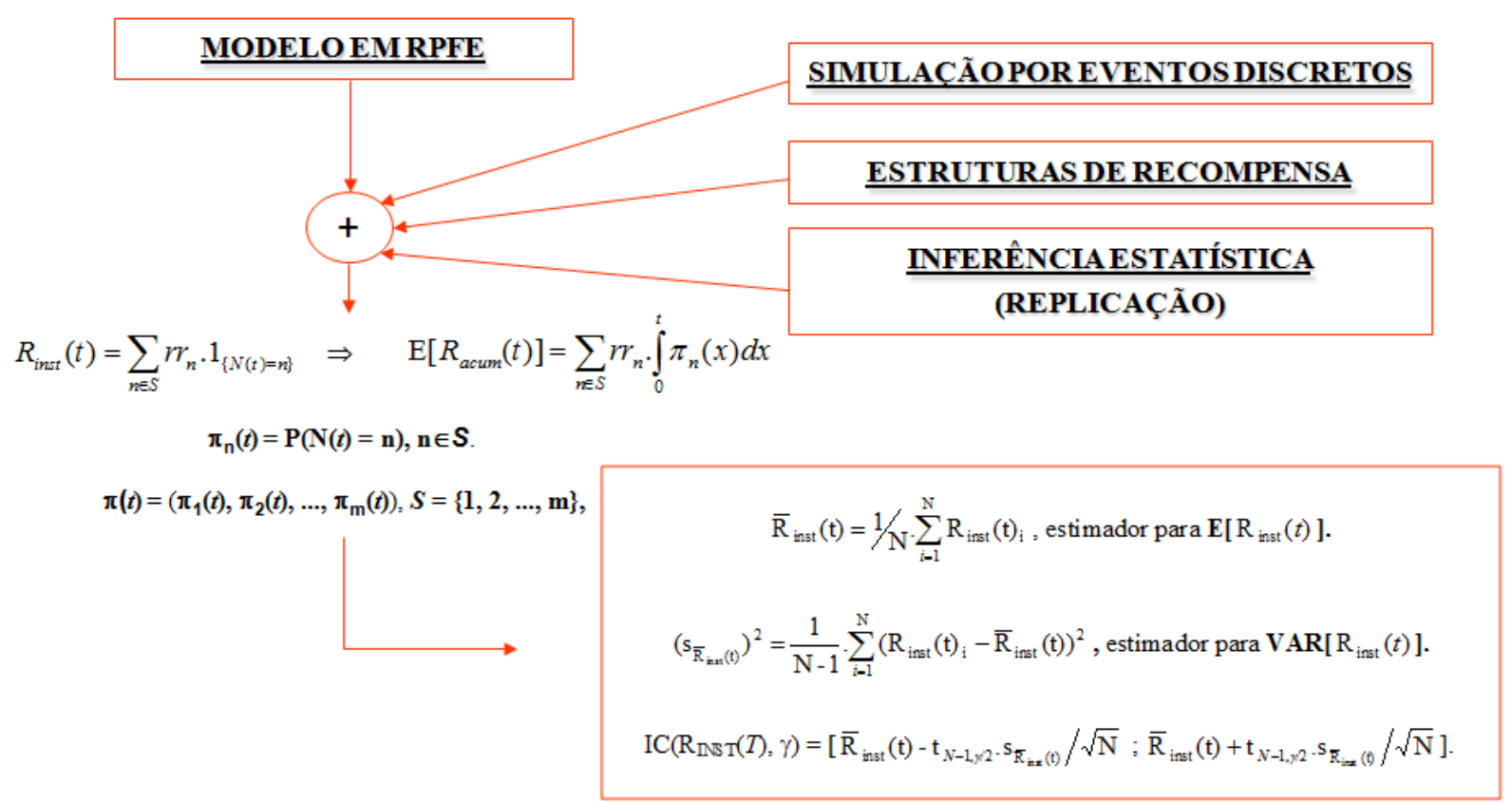

Figura 29 - Processo de obtenção de medidas de interesse no método de avaliação proposto. 


\section{AVALIAÇÃO DE SEGURANÇA DO SISTEMA DE CONTROLE DE TRÁFEGO AÉREO BASEADO EM ADS-B}

O estudo realizado no capítulo anterior resultou em uma proposta de Método de Avaliação de Risco a ser aplicado sobre os sistemas de tráfego aéreo sob o conceito CNS/ATM, apresentado no Capítulo 2. Este capítulo tem o objetivo de apresentar uma avaliação sobre o impacto que a Vigilância Dependente Automática por Radiodifusão (ADS-B) - utilizando sistemas de navegação global por satélites (GNSS) tanto no processo de vigilância quanto de navegação - exerce sobre algumas métricas de segurança do sistema de tráfego aéreo. Para isto, será aplicado o Método de Avaliação de Risco proposto no capítulo anterior, modelandose os sistemas proposto (ATC baseado em vigilância ADS-B) e de referência (ATC baseado em vigilância Radar) por meio do formalismo das redes de Petri fluidas e estocásticas (RPFE).

\subsection{O estudo de caso no contexto do CNS/ATM}

Neste capítulo, serão modelados o Sistema Proposto (Vigilância ADS-B e Navegação por Satélite) e o Sistema de Referência (Vigilância Radar e Navegação VOR), utilizando o formalismo das redes de Petri fluidas e estocásticas. Os detalhes de modelagem e os parâmetros adotados para cada sistema serão descritos a seguir. A Figura 30 ilustra, em alto nível, os dois sistemas de controle de tráfego aéreo que serão considerados.
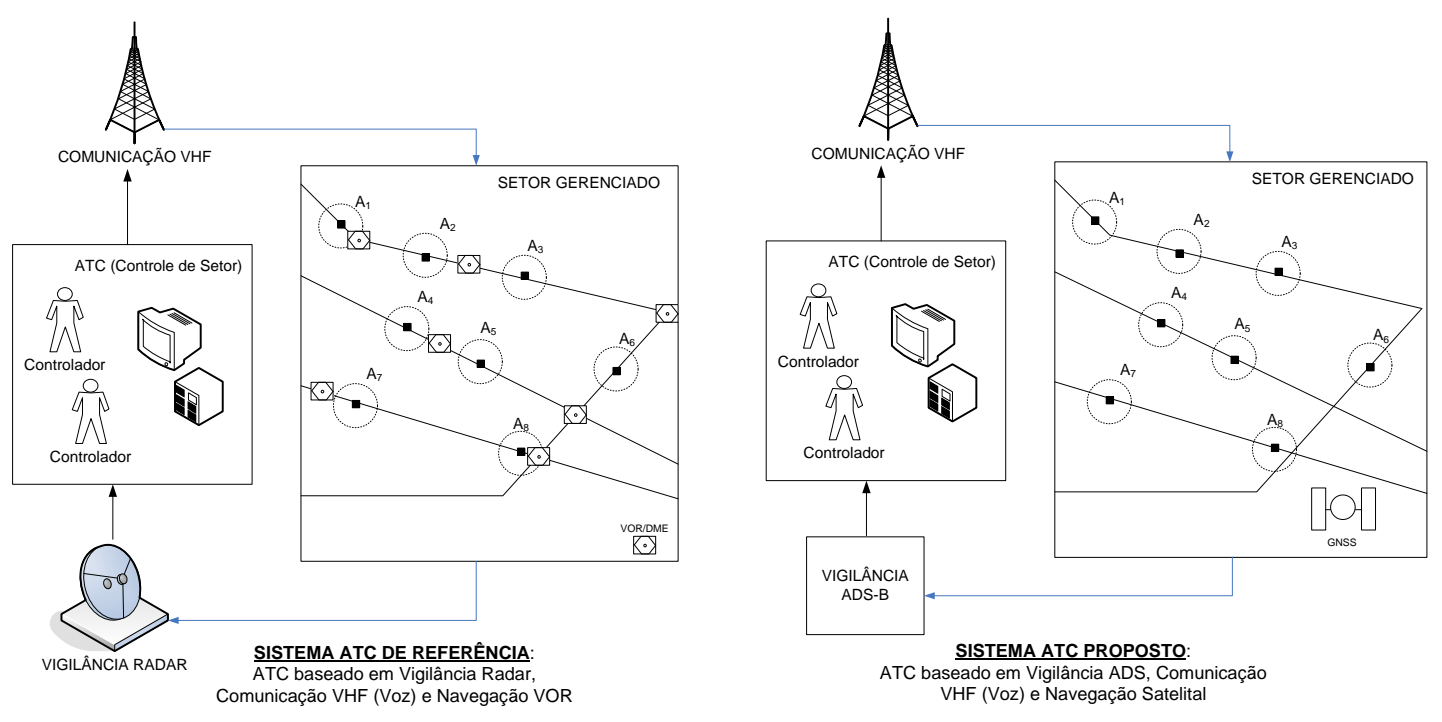

Figura 30 - Sistemas ATC de "Referência" e "Proposto"

Deseja-se avaliar qual o impacto da vigilância dependente automática por radiodifusão (ADS-

B) sobre os níveis de segurança do sistema. Com base no método de avaliação de segurança 
proposto, definiu-se que é necessário comparar o cenário do ATC (Controle de Tráfego Aéreo) atual, baseado nas normas de vigilância Radar, com um cenário onde o ADS-B recebesse a função de vigilância do sistema.

O cenário adotado será o de vôos em rota gerenciados por um controle de tráfego aéreo de área (ACC) que possua vigilância radar de área.

Serão consideradas as seguintes premissas:

1. O ambiente avaliado é o de máxima utilização da capacidade do espaço aéreo com a configuração atual (aplicação de separação mínima) e, portanto, a segurança e operacionalidade do sistema estarão dependentes das tecnologias e da automação. Neste ambiente, não se conseguiria abandonar o procedimento de vigilância radar e aplicar o procedimento de vigilância convencional, mantendo-se um nível de segurança aceitável. Este ambiente está, em curto prazo, de acordo com a proposta para o ADS-B, que preconiza o mesmo como um sistema de redundância (backup) dos sistemas de vigilância de radar secundário (Galotti, 1997), (ICAO, 2000) e, em longo prazo, como substituto dos sistemas de vigilância baseados em radar.

2. Será considerada que o tipo de sistema (automação) que dá o suporte ao ATC é transparente ao controlador. A posição de vigilância das aeronaves na tela é a informação que os controladores utilizam para basear suas decisões, independente se estas posições provêm de um radar ou do ADS-B.

3. O piloto acatará, sob qualquer hipótese, as ordens do ATC. Por isso, não será considerado neste estudo de caso elementos de auxílio anti-colisão embarcados (tal como o TCAS Traffic Colision Avoidance System). A norma brasileira (Ministério da Aeronáutica, 1999) define que o piloto, em uma operação de vetoração radar (ATCo possui a funcionalidade da navegação da aeronave), tem o papel de verificador dos comandos emitidos pelo ATC. Porém, no ambiente de céu congestionado que será considerado, o piloto não possui graus de liberdade suficientes para tomar suas próprias decisões.

Os sistemas serão modelados utilizando os mesmos módulos funcionais e considerando os mesmos parâmetros e métricas. Os módulos funcionais utilizados são: Espaço Aéreo, Aeronave, Sistema de Navegação (funcionalidade navegação, incluindo as características do Piloto), Sistema de Comunicação, Sistema de Vigilância, ATCo. 
Para ambos os sistemas, os elementos Espaço Aéreo, Aeronave, Sistema de Comunicação e ATCo serão iguais. Desta forma, como se pretende aplicar o método de avaliação proposto para verificar o impacto do uso do ADS-B sobre a segurança do sistema de tráfego aéreo controlado, as alterações existentes entre os ambientes presente (Sistema de Referência) e futuro (Sistema Proposto) ocorrerão sobre os sistemas de Vigilância e de Navegação.

No ambiente de tráfego aéreo controlado, as aeronaves navegam aderindo às rotas ATS adotadas em seus planos de vôo, as quais estão balizadas por auxílios à navegação. Em regiões cobertas por sistemas Radar, pode-se aplicar tanto o Serviço de Vigilância Radar quanto o Serviço de Vetoração Radar. Para o Serviço de Vigilância Radar, os pilotos são responsáveis por manter a aderência ao centro da rota (ICAO, 1998) e os Controladores de Tráfego Aéreo (ATCos) são responsáveis por monitorar a efetividade desta aderência. No caso da perda de aderência significativa à rota ou em situações onde se detectou um possível conflito, o ATCo intervém sobre os vôos, reorganizando o fluxo e garantindo seus níveis de segurança e eficiência. Caso o ATCo possua informações de melhor qualidade em relação ao Piloto, o ATCo pode aplicar o Serviço de Vetoração Radar, assumindo a responsabilidade por navegar a aeronave. O objetivo deste serviço é o de estabelecer separações adequadas, melhorar os padrões de segurança, corrigir desvios significativos de rota, evitar fusão de alvos, entre outros (Ministério da Aeronáutica, 1999).

O modelo considerará o Serviço de Vigilância Radar, e adotará os seguintes critérios: o modelo do sistema de Navegação considerará as suas funcionalidades de monitoramento e controle da aeronave, obtenção de dados de posição e o gerenciamento do plano de vôo. $\mathrm{O}$ sistema de Navegação (Piloto, Sistema de Gerenciamento de Vôo (FMS) e Piloto Automático) deve conhecer o rumo da rota que deve aderir e o próximo ponto de notificação a cumprir. Este sistema deve ser capaz de obter sua posição atual, sua proa e a direção para o próximo ponto de notificação através de VOR (para o Sistema de Referência) ou de GPS (Sistema Proposto), e manter a aderência à rota até este ponto de notificação. Os dados de vigilância são fornecidos ao ATCo através do Radar, no Sistema de Referência, e do ADS-B, no Sistema Proposto.

No caso do ATCo detectar conflito entre aeronaves, o mesmo aplica o Serviço de Vetoração Radar. Neste caso, o Controlador de Tráfego atua sobre a Navegação, informando ao piloto qual estado a Aeronave deve manter (Proa, Velocidade, Altitude). O estado da aeronave observado pelo Piloto deve ser obtido através de VOR (para o Ambiente de Referência) ou de 
GPS (Ambiente Proposto).

Os ambientes modelados serão simulados com o objetivo de estimar métricas de segurança. Cada ambiente considerará 2 processos: o PROCESSO REAL (estado real das aeronaves) e o PROCESSO MONITORADO (o estado observado por meio dos sistemas de supervisão e controle). As imprecisões dos valores de supervisão e controle são introduzidas sobre as variáveis de estado reais. Os eventos inseguros serão avaliados sobre o processo real (variáveis contínuas), verificando-se em quais situações estes eventos podem ocorrer devido à ineficiência do processo de monitoramento.

\subsection{Modelagem dos Sistemas Proposto e de Referência}

\subsubsection{Descrição dos Módulos Funcionais}

Os módulos funcionais que serão modelados para ambos os ambientes (aqui denominados como "Referência” e "Proposto") são: Aeronave, Espaço Aéreo, Sistema de Navegação (incluindo as características do Piloto), Sistema de Vigilância, ATCo e Sistema de Comunicação. Segue uma descrição de cada um dos módulos funcionais implementados.

\subsubsection{Aeronave (Dinâmica)}

O trabalho de Glover, Lygeros (2004) apresenta um modelo de dinâmica entre Aeronave, FMS, Plano de Vôo, ATC e Vento para representar a dinâmica de vôo sobre o ponto de vista do ATC. A Figura 31 ilustra a arquitetura adotada no trabalho de Glover, Lygeros (2004) para modelar a dinâmica do sistema de tráfego aéreo controlado.

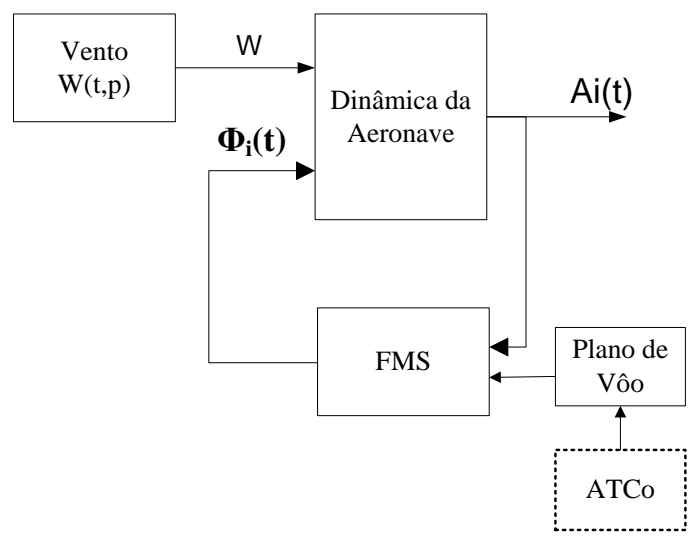

Figura 31 - Arquitetura do Sistema de Tráfego Aéreo Controlado (Glover, Lygeros (2004))

As variáveis de Estado $\left(\mathbf{A}_{\mathbf{i}}(\mathbf{t})\right)$ consideradas para a Aeronave "i” no instante "tt", são: 
Posição (baseado no referencial, em NM): $\mathbf{P}_{\mathbf{i}}(\mathbf{t})=\left(\mathbf{X}_{\mathbf{i}}(\mathbf{t}), \mathbf{Y}_{\mathbf{i}}(\mathbf{t}), \mathbf{h}_{\mathbf{i}}(\mathbf{t})\right) \in \mathbf{R}^{+\mathbf{3}} \mid \forall \mathbf{t} \in \mathbf{R}^{+}$.

Velocidade $\left(\right.$ TrueAirspeed, em kts): $\mathbf{V}_{\text {TAS,i }}(\mathbf{t})=\left(\mathbf{V}_{\text {TAS,i__ }}(\mathbf{t}), \mathbf{V}_{\text {TAS, }, \mathbf{i}_{\mathbf{y}}}(\mathbf{t})\right.$,

$\left.\mathbf{V}_{\text {TAS,i_h }}(\mathbf{t})\right) \in \mathbf{R}^{3}$.

Proa (Flight path, em graus): $\boldsymbol{\psi}_{\mathbf{i}}(\mathbf{t}) \in \mathbf{N}^{+} \mid \forall \mathbf{t} \in \mathbf{R}^{+}, \boldsymbol{\psi}_{\mathbf{i}}(\mathbf{t}) \in\left[\mathbf{0}^{\mathbf{0}} ; 359^{\circ}\right]$

Atitude (Pitch angle, em graus): $\boldsymbol{\gamma}_{\mathbf{i}}(\mathbf{t}) \in \mathbf{N}^{+} \mid \forall \mathbf{t} \in \mathbf{R}^{+}, \boldsymbol{\gamma}_{\mathbf{i}}(\mathbf{t}) \in\left[\mathbf{0}^{\mathbf{o}} ; \mathbf{3 5 9}^{\mathbf{0}}\right]$

(Roll angle, em graus): $\phi_{\mathbf{i}}(\mathbf{t}) \in \mathbf{N}^{+} \mid \forall \mathbf{t} \in \mathbf{R}^{+}, \phi_{\mathbf{i}}(\mathbf{t}) \in\left[\mathbf{0}^{\mathbf{o}} ; \mathbf{3 5 9}^{\circ}\right]$

Portanto, tem-se como estado de uma aeronave:

$$
A_{\mathbf{i}}(\mathbf{t})=\left\{\mathbf{P}_{\mathrm{i}}(\mathbf{t}), \mathbf{V}_{\mathrm{TAS}, \mathrm{i}}(\mathbf{t}), \psi_{\mathrm{i}}(\mathbf{t}), \gamma_{\mathrm{i}}(\mathbf{t}), \phi_{\mathrm{i}}(\mathbf{t})\right\}
$$

A Figura 32 representa as variáveis relacionadas ao estado da aeronave.

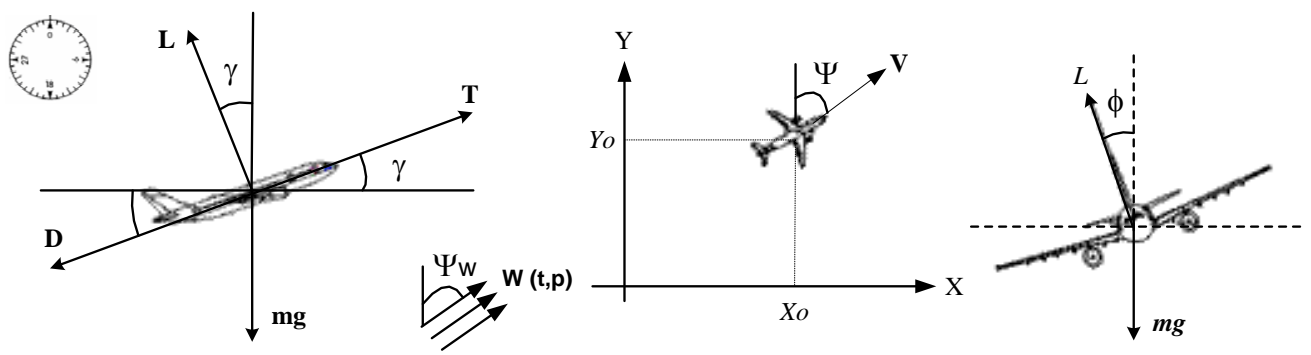

Figura 32 - Variáveis de Estado de uma Aeronave e o vetor Vento (W)

Desenvolvendo as equações das variáveis de estado anteriores, tem-se:

$\mathbf{V}_{\text {TAS }}(t)=\left(V_{\text {TAS }, \mathbf{x}}(t), \mathbf{V}_{\text {TAS }, y}(t), V_{\text {TAS }, h}(t)\right)=\left\|V_{\text {TAS }}(t)\right\| \cdot(\operatorname{sen}(\psi(t)) \cdot \cos (\gamma(t)), \cos (\psi(t)) \cdot \cos (\gamma(t))$, $\operatorname{sen}(\gamma(t)))$, onde $\left\|V_{\text {TAS }}(t)\right\|$ é o módulo da $V_{\text {TAS }}(t)$.

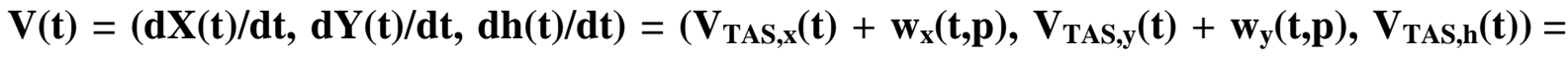
$\mathbf{V}_{\text {TAS }}(\mathbf{t})+\mathbf{W}(\mathbf{t}, \mathbf{p})$; onde $\mathrm{V}(\mathrm{t})$ é a velocidade da aeronave em relação ao solo (Groundspeed))

$\mathbf{W}(\mathbf{t}, \mathbf{p})=\left(\mathbf{w}_{\mathbf{x}}(\mathbf{t}, \mathbf{p}), \mathbf{w}_{\mathbf{y}}(\mathbf{t}, \mathbf{p})\right)=\|\mathbf{W}(\mathbf{t}, \mathbf{p})\| \cdot\left(\cos \left(\psi_{\mathrm{w}}(\mathbf{t}, \mathbf{p})\right), \operatorname{sen}\left(\psi_{\mathbf{w}}(\mathbf{t}, \mathbf{p})\right)\right.$, onde $\|\mathrm{W}(\mathrm{t}, \mathrm{p})\|$ é o módulo da $W(t, p)$.

Segundo Glover, Lygeros (2004) e Hoffman et al (2002), a dinâmica das variáveis $\mathbf{V}_{\text {TAS}}(\mathbf{t})$ e $\psi(\mathbf{t})$ são representadas das seguintes formas: 
$d V_{T A S}(t) / d t=(T(t) \cdot \cos (\alpha)-D(t)-m(t) \cdot g \cdot \sin (\gamma(t))) / m(t) ;$

$d \psi(t) / d t=(L \cdot \sin (\phi)+T \cdot \operatorname{sen}(\gamma(t)) \cdot \sin (\phi))$.

Onde T é a Força de Tração (Thrust) aplicada no sentido do movimento da aeronave, $\alpha$ é o ângulo de ataque, $\mathbf{L}$ é a sua força de sustentação (Lift) e $\mathbf{D}$ é a força de arrasto (Drag).

Para uma aeronave voando em rota, nivelada e com altitude constante, podem ser aplicadas as seguintes simplificações:

a) Movimento no Plano $(X, Y) \Rightarrow d h(t) / d t=0 \Rightarrow h(t)=h\left(t_{0}\right)$.

b) $\quad \alpha=\gamma=0 \Rightarrow d V_{\mathrm{TAS}}(\mathrm{t}) / \mathrm{dt}=(\mathrm{T}(\mathrm{t})-\mathrm{D}(\mathrm{t})) / \mathrm{m}(\mathrm{t})$.

Considerando $\mathbf{d V} \mathbf{V}_{\text {TAS }}(\mathbf{t}) / \mathbf{d t}=\mathbf{0}$ durante uma manobra horizontal $(\mathbf{d} \psi(\mathbf{t}) / \mathbf{d t} \neq \mathbf{0})$, tem-se:

$$
\mathbf{d} \psi(\mathbf{t}) / \mathbf{d t}=\mathbf{g} \cdot \tan \left(\phi_{\text {nom }}\right) /\left\|\mathbf{V}_{\text {TAS }}\right\|, \text { onde } \phi_{\text {nom }}=\mathbf{3 5}^{\mathbf{0}}(\text { Glover, Lygeros, 2004) }
$$

Nestas condições, o valor da proa depois de decorrido o período entre $\mathbf{t}_{\mathbf{0}}$ e $\mathbf{t}$ dá-se por:

$$
\psi(t)=\psi\left(t_{0}\right)+\left(t-t_{0}\right) \cdot g \cdot \tan \left(\phi_{\text {nom }}\right) /\left\|V_{\text {TAS }}\left(t_{0}\right)\right\|
$$

Considerando $\mathrm{dV}(\mathrm{t}) / \mathrm{dt}=\mathrm{d}\left(\mathrm{V}_{\mathrm{TAS}}(\mathrm{t})+\mathrm{W}(\mathrm{t}, \mathrm{p})\right) / \mathrm{dt}=\mathrm{d}\left(\mathrm{V}_{\mathrm{TAS}}(\mathrm{t})\right) / \mathrm{dt}+\mathrm{d}(\mathrm{W}(\mathrm{t}, \mathrm{p})) / \mathrm{dt}=(\mathrm{T}(\mathrm{t})-$ $\mathrm{D}(\mathrm{t})) / \mathrm{m}(\mathrm{t})+0=0 \Leftrightarrow \mathbf{T}(\mathbf{t})=\mathbf{D}(\mathbf{t})$ durante o intervalo de tempo $\left(\mathbf{t}-\mathbf{t}_{\mathbf{0}}\right)$, tem-se:

$\mathbf{P}(\mathbf{t})=\left(\mathbf{X}(\mathbf{t}), \mathbf{Y}(\mathbf{t}), \mathbf{h}\left(\mathbf{t}_{\mathbf{0}}\right)\right)=\left(\mathbf{X}\left(\mathbf{t}_{\mathbf{0}}\right)+\left(\mathbf{t}-\mathbf{t}_{\mathbf{0}}\right) \cdot\left(\left\|\mathbf{V}_{\mathrm{TAS}}\left(\mathbf{t}_{\mathbf{0}}\right)\right\| \cdot \operatorname{sen}\left(\psi\left(\mathbf{t}_{\mathbf{0}}\right)\right)+\mathbf{w}_{\mathbf{x}}\left(\mathbf{t}_{\mathbf{0}}, \mathbf{p}\right)\right), \mathbf{Y}\left(\mathbf{t}_{\mathbf{0}}\right)+\left(\mathbf{t}-\mathbf{t}_{\mathbf{0}}\right)\right.$ $\left.\cdot\left(\left\|\mathbf{V}_{\text {TAS }}\left(\mathbf{t}_{0}\right)\right\| \cdot \cos \left(\psi\left(\mathbf{t}_{0}\right)\right)+\mathbf{w}_{\mathbf{y}}\left(\mathbf{t}_{0}, \mathbf{p}\right)\right), \mathbf{h}\left(\mathbf{t}_{\mathbf{0}}\right)\right)$.

Portanto, as variáveis de estado consideradas para o modelo estão representadas na Figura 33.

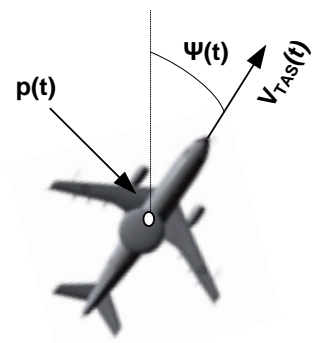

Figura 33 - Variáveis de Estado de uma Aeronave 
Resumindo, $\mathbf{A}_{\mathbf{i}}(\mathbf{t})=\left\{\mathbf{P}_{\mathbf{i}}(\mathbf{t}), \mathbf{V}_{\mathrm{TAS}, \mathbf{i}}(\mathbf{t}), \boldsymbol{\psi}_{\mathbf{i}}(\mathbf{t})\right\}$, onde:

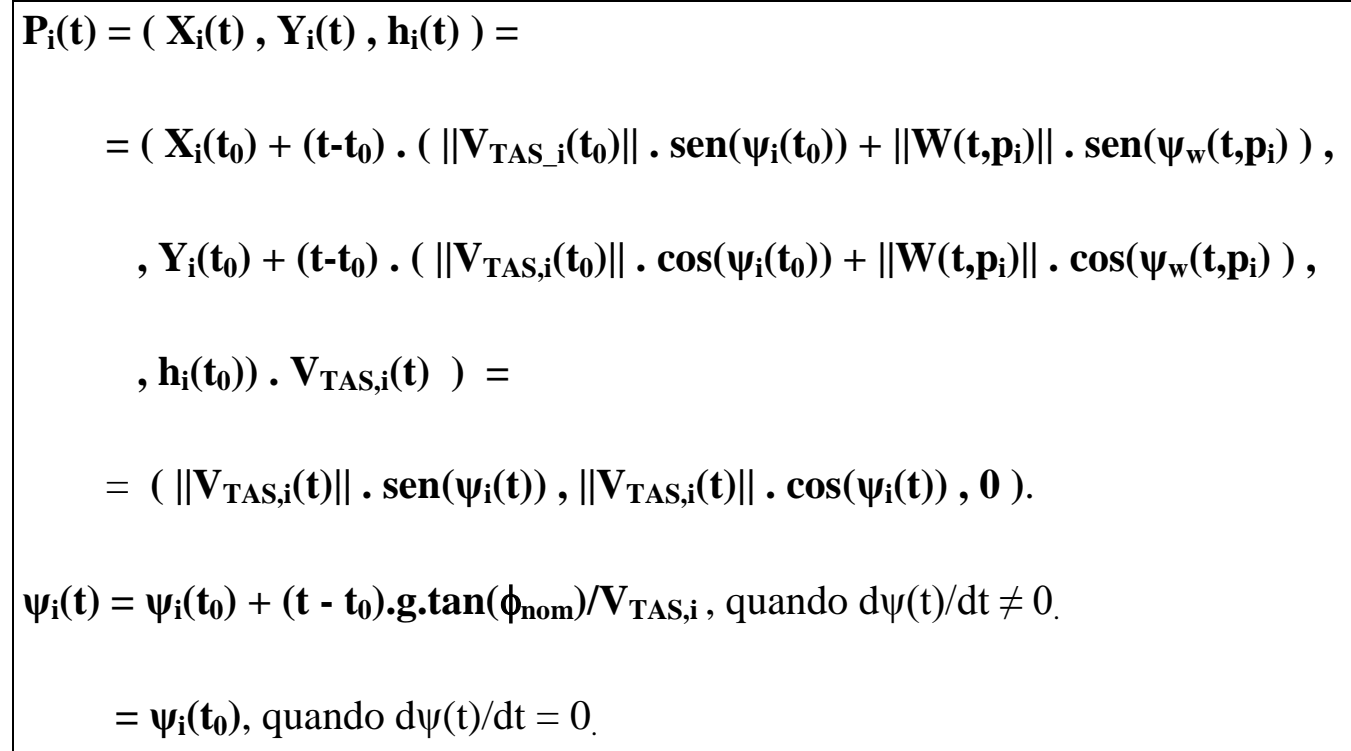

\subsubsection{Espaço Aéreo}

O elemento "Espaço Aéreo" representa o local onde as aeronaves trafegam. É caracterizado pela Estrutura de Rotas: paralelas ou não paralelas, unidirecionais ou bidirecionais; pelo valor e freqüência com que a Separação Mínima é aplicada; por sua Complexidade: demanda de tráfego (de pico e média), característica do tráfego (tráfego oposto, subindo, entre outros), números de cruzamento, características da população de aeronaves, capacidade das pistas de pouso e decolagem e dos serviços prestados, condições meteorológicas, etc; e pela Classificação designada ao mesmo (Ministério da Aeronáutica, 1998).

Neste estudo, será adotado um cenário crítico em segurança para o espaço aéreo. Em Burt (2004), demonstrou-se por meio de dados históricos que o cenário mais crítico em segurança para o espaço aéreo (neste caso, o espaço aéreo Europeu) é o de uma aeronave mudando de nível e a outra mantendo o nível, ambas em confluência com $\boldsymbol{\theta}=\mathbf{l 0}^{\circ}, \mathbf{1 8 0}^{\circ}$ [. Porém, por simplificação, serão consideradas aeronaves no mesmo nível de vôo. A Figura 34 ilustra a modelagem do espaço considerada neste estudo de caso. 


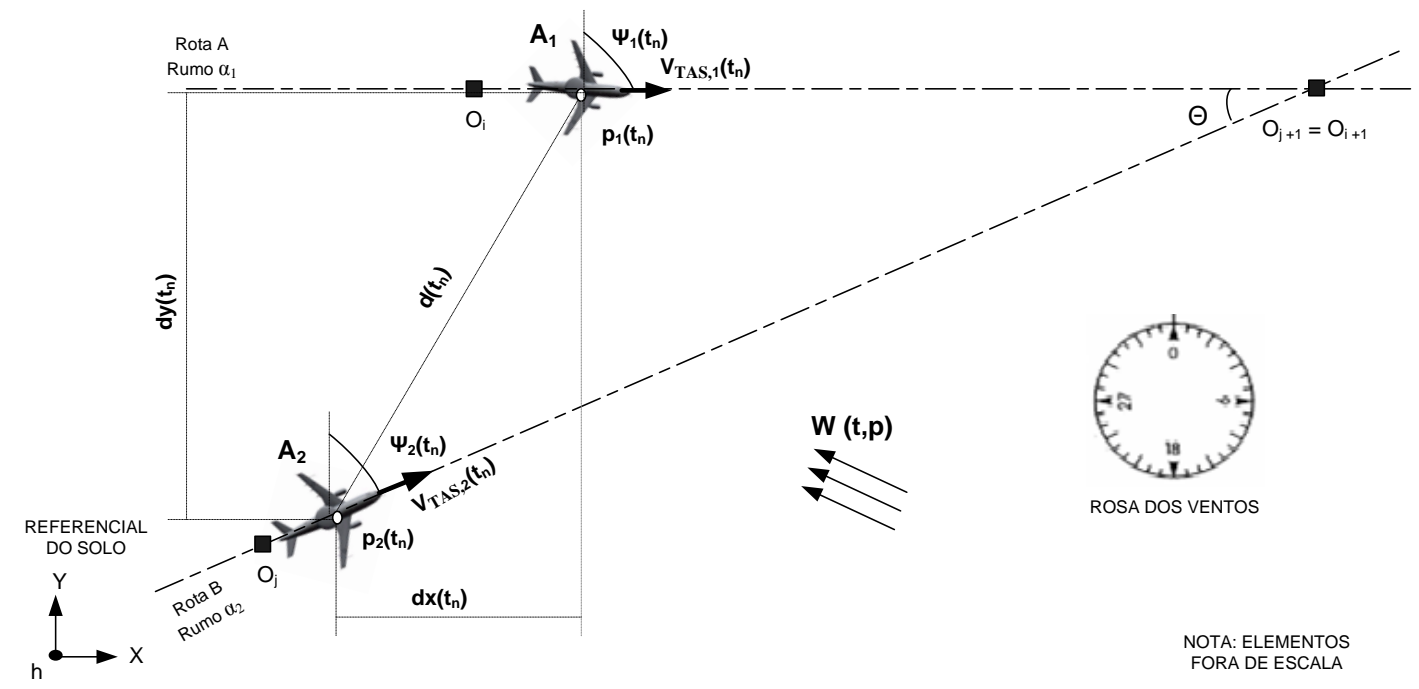

Figura 34 - Modelagem do Espaço Aéreo

Portanto, neste estudo, têm-se as seguintes características para o espaço aéreo modelado:

i. Devido às curtas distâncias percorridas pelas aeronaves no processo de simulação, considera-se que as aeronaves trafegam em um plano Cartesiano bidimensional $(\mathbf{X}$, Y) (superfície não esférica). Assume-se que $(\mathbf{X}, \mathbf{Y}) \in\left(\mathbf{R}^{+}\right)^{2}$.

ii. As aeronaves trafegam sobre as rotas A e B não paralelas, unidirecionais e com rumos $\boldsymbol{\alpha}_{1}$ e $\boldsymbol{\alpha}_{2}$, cruzando em um ponto de notificação $\mathbf{O}_{\mathbf{i + 1}}=\mathbf{O}_{\mathbf{j}+\mathbf{1}}$ com um ângulo $\boldsymbol{\theta}=\left|\boldsymbol{\alpha}_{\mathbf{1}}-\boldsymbol{\alpha}_{\mathbf{2}}\right|$. Por simplificação, será adotado $\boldsymbol{\alpha}_{1}=\mathbf{9 0}^{\circ}$ e $\boldsymbol{\alpha}_{\mathbf{2}}=\mathbf{9 0}^{\circ}$ - $\boldsymbol{\theta}$. Por definição, $\left\{\mathbf{O}_{\mathbf{n}} \in \mathbf{R}^{+\mathbf{2}}\right.$, $\forall \mathbf{n} \in \mathbf{N}\}$ e $\{\boldsymbol{\theta} \in \mathbf{N} \mid \boldsymbol{\theta}=]_{-90^{\circ}},+\mathbf{9 0}^{\circ}[\}$. Estas rotas estão contidas no espaço aéreo superior controlado (UTA).

iii. Consideram-se pares de aeronaves, $\mathbf{A}_{\mathbf{1}}$ e $\mathbf{A}_{\mathbf{2}}$, trafegando sobre os trechos $\left(\mathbf{O}_{\mathbf{i}^{-}} \mathbf{O}_{\mathbf{i}+\mathbf{1}}\right)$ e $\left(\mathbf{O}_{\mathbf{j}}-\mathbf{O}_{\mathbf{j}+1}\right)$ das rotas A e B, respectivamente. Cada ponto de notificação possui uma coordenada conhecida $\left(\mathbf{O}_{\mathbf{n}}=\left(\mathbf{X}_{\mathrm{NOT}(\mathbf{n})}, \mathbf{Y}_{\mathbf{N O T}(\mathbf{n}))}\right)\right.$. Nestes vôos em confluência, as aeronaves estão em um mesmo nível de vôo $\left(\mathbf{h}_{\mathbf{1}}=\mathbf{h}_{\mathbf{2}}\right)$;

iv. $\quad \mathrm{O}$ efeito meteorológico do vento $\left(\mathbf{W}(\mathbf{t}, \mathbf{p})=\left(\mathbf{w}_{\mathbf{x}}(\mathbf{t}, \mathbf{p}), \mathbf{w}_{\mathbf{y}}(\mathbf{t}, \mathbf{p}), \mathbf{w}_{\mathbf{h}}(\mathbf{t}, \mathbf{p})\right)\right)$ sobre as aeronaves afeta diretamente sua velocidade com relação ao solo (GroundSpeed). O vento é uma grandeza vetorial, cujo módulo, direção e sentido são função do tempo (t, $\left.\mathbf{t} \in \mathbf{R}^{+}\right)$e da posição $\left(\mathbf{p}, \mathbf{p} \in \mathbf{R}^{3}\right)$.

O vento é caracterizado da seguinte maneira: 
a. Os ventos são representados por sua intensidade e sua orientação: $\mathbf{w}(\mathbf{t}, \mathbf{p}) / \psi_{\mathrm{w}}(\mathbf{t}, \mathbf{p})$, onde $\mathbf{w}(\mathbf{t}, \mathbf{p}) \in \mathbf{R}^{+}$e $\boldsymbol{\psi}_{\mathbf{w}} \in \mathbf{N} \mid \boldsymbol{\theta}=\left[0^{\mathbf{o}}, \mathbf{3 5 9 ^ { \circ }}\right]$.

b. Por observações nas Cartas dos Ventos presentes na Rede de Informações Meteorológicas do Departamento de Controle do Espaço Aéreo Brasileiro $\left(\right.$ REDEMET $\left.^{13}\right)$, os ventos têm intensidades variando entre 30kts e 40kts no FL300 (nível de vôo de 30.000 pés) sobre o espaço aéreo brasileiro.

c. A precisão das medidas dos ventos é de $\mathbf{\pm 5 k t s} \mathbf{\$} \mathbf{\mathbf { 3 0 }} \mathbf{0}^{\mathbf{0}}$ (Ministério da Aeronáutica, 1999c).

Por simplificação, não serão consideradas suas variações $(\partial \mathbf{W}(\mathbf{t}, \mathbf{p}) / \partial \mathbf{t}=\partial \mathbf{W}(\mathbf{t}, \mathbf{p}) / \partial \mathbf{p}=$ 0) $\Rightarrow \mathbf{W}(\mathbf{t}, \mathbf{p})=\mathbf{W}, \forall \mathbf{t} \in \mathbf{R}^{+}, \forall \mathbf{p} \in \mathbf{R}^{3}$.

v. A população de aeronaves que trafega por este espaço possui características semelhantes. Isto representa, por exemplo, vôos contidos nas áreas superiores de controle (UTA), os quais estão na classe A do espaço aéreo.

vi. Utiliza-se o conceito de máxima ocupação do espaço aéreo. Desta forma, planeja-se ocupar o espaço aéreo aplicando-se a menor separação entre aeronaves com a maior frequiência possível. Ou seja, a distância $\mathbf{d}(\mathbf{t})$ entre os pares de aeronaves tende a manter-se próxima à distância mínima aceitável para o ambiente (Dmin) e, para $\forall \mathrm{t} \in \mathbf{R}^{+}, \mathbf{d}(\mathbf{t}) \in[$ Dmin $-\boldsymbol{\varepsilon} ;$ Dmin $+\boldsymbol{\varepsilon}], \operatorname{com} \boldsymbol{\varepsilon} \rightarrow \mathbf{0}$. Para o espaço aéreo em questão, servido por vigilância Radar, a Dmin é igual a 5NM (Ministério da Aeronáutica, 1999).

vii. Houve um planejamento estratégico para os vôos, de forma que as aeronaves $\mathbf{A}_{\mathbf{1}}$ e $\mathbf{A}_{\mathbf{2}}$ iniciam (teoricamente), no instante $\mathrm{t}_{0}$, sobre os pontos de notificação (waypoint) $\mathbf{O}_{\mathbf{i}} \mathrm{e}$ $\mathbf{O}_{\mathbf{j}}$, com velocidades (TAS) $\mathbf{V}_{\text {TAS, } \mathbf{1}}\left(\mathbf{t}_{\mathbf{0}}\right)$ e $\mathbf{V}_{\mathbf{T A S}, \mathbf{2}}\left(\mathbf{t}_{\mathbf{0}}\right)$, proas $\boldsymbol{\psi}_{\mathbf{1}}\left(\mathbf{t}_{\mathbf{0}}\right)$ e $\boldsymbol{\psi}_{2}\left(\mathbf{t}_{\mathbf{0}}\right)$ e altitudes $\mathbf{h}_{\mathbf{1}}\left(\mathbf{t}_{\mathbf{0}}\right)$ e $\mathbf{h}_{\mathbf{2}}\left(\mathbf{t}_{\mathbf{0}}\right)$, respectivamente.

viii. Baseado neste planejamento, e caso as aeronaves sigam seus planos de vôo, haverá sempre "separação mínima teórica" compatível com as normas de separação em vigor. Na condição planejada de menor separação entre aeronaves, a distância entre as

\footnotetext{
${ }^{13}$ http://www.redemet.aer.mil.br/, seção “Cartas de Ventos".
} 
aeronaves $\left(\mathbf{d}\left(\mathbf{t}_{\mathbf{m}}\right)\right)$ será maior ou igual à distância de separação mínima requerida (Dmin), onde $\mathbf{d}\left(\mathbf{t}_{\mathbf{m}}\right) \geq$ Dmin e $\mathbf{t}_{\mathbf{m}}$ é o instante planejado no qual a aeronave $\mathbf{A}_{\mathbf{1}}$ estará sobre $\mathbf{O}_{\mathbf{i}+\mathbf{1}}$. A Figura 35 ilustra o instante planejado onde ocorrerá a menor separação entre o par de aeronaves 1 e 2 .

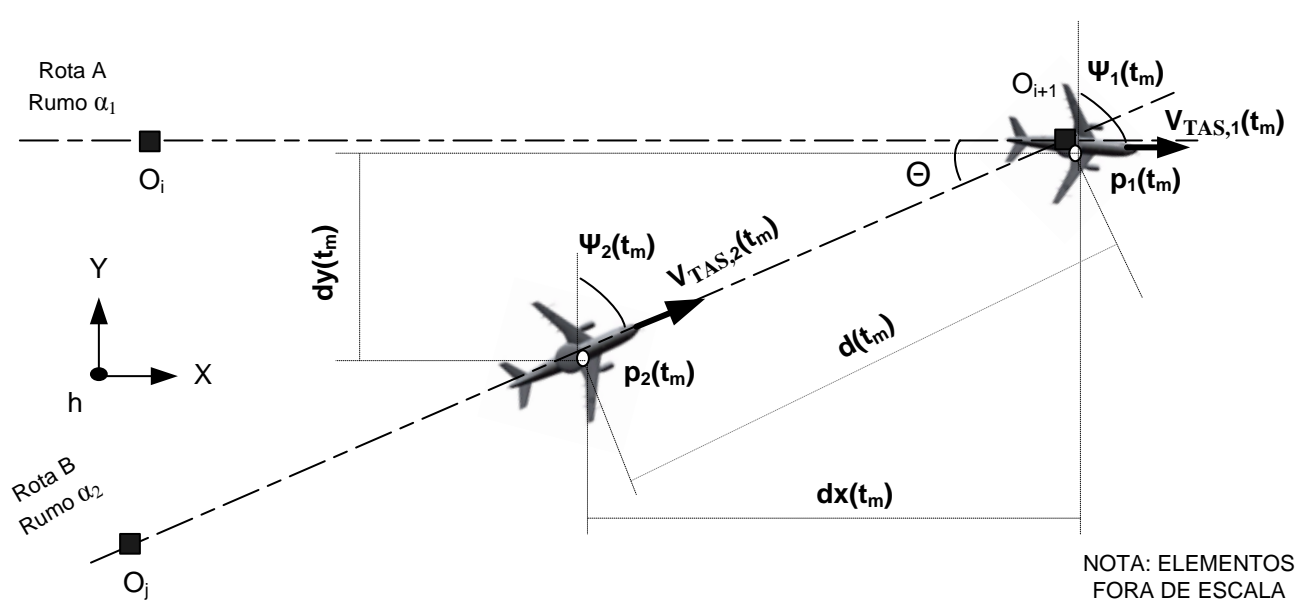

Figura 35 - Pior caso "planejado" para o Espaço Aéreo Modelado

ix. As aeronaves estão trafegando sobre um setor de tráfego aéreo provido por Serviço de Vigilância Radar constante (tanto utilizando o elemento Radar quanto o elemento ADS-B).

x. Como a modelagem considerará o processo real e o processo monitorado, devem-se inserir imprecisões sobre os valores de Estado Inicial (instante $\mathbf{t}_{\mathbf{0}}$ ) planejado. Assim, o estado de uma aeronave no Espaço Aéreo no instante $\mathbf{t}_{\mathbf{0}}$ será $\mathbf{p}\left(\mathbf{t}_{\mathbf{0}}\right) \in \mathbf{R}^{\mathbf{3}} \mid \mathbf{p}\left(\mathbf{t}_{\mathbf{0}}\right) \in\left[\mathbf{O}_{\mathbf{i}}-\boldsymbol{\varepsilon}_{\mathbf{P}}\right.$ $\left.; \mathbf{O}_{\mathbf{i}}+\boldsymbol{\varepsilon}_{\mathbf{P}}\right]$, onde a acurácia da posição é representada por $\boldsymbol{\varepsilon}_{\mathbf{P}} ; \mathbf{V}_{\mathbf{T A S}}\left(\mathbf{t}_{\mathbf{0}}\right) \in \mathbf{R}^{\mathbf{3}} \mid\left\|\mathbf{V}_{\mathbf{T A S}}\left(\mathbf{t}_{\mathbf{0}}\right)\right\|$ $\in\left[\mathbf{V}_{\mathbf{P}}-\varepsilon_{\mathbf{V}} ; \mathbf{V}_{\mathbf{P}}+\varepsilon_{\mathbf{V}}\right]=\left[\mathbf{V}_{\min }\left(\mathbf{t}_{\mathbf{0}}\right) ; \mathbf{V}_{\max }\left(\mathbf{t}_{\mathbf{0}}\right)\right]$, onde a acurácia da velocidade é representada por $\varepsilon_{\mathbf{V}} ; \psi\left(\mathbf{t}_{\mathbf{0}}\right) \in \mathbf{R} \mid \psi\left(\mathbf{t}_{\mathbf{0}}\right) \in\left[\psi_{\mathbf{P}}-\boldsymbol{\varepsilon} \psi ; \psi_{\mathbf{P}}+\varepsilon \psi\right]$, onde a acurácia da proa é representada por $\boldsymbol{\varepsilon} \psi$. Os valores $\varepsilon_{\mathbf{P}}, \boldsymbol{\varepsilon}_{\mathbf{V}}$ e $\boldsymbol{\varepsilon} \boldsymbol{\psi}$ são estocásticos, e $\mathbf{V p}$ e $\psi_{\mathbf{P}}$ são a velocidade e a proa planejadas. A Figura 36 ilustra os erros sobre as variáveis de estado consideradas para a aeronave no instante inicial $\mathbf{t}_{\mathbf{0}}$. 


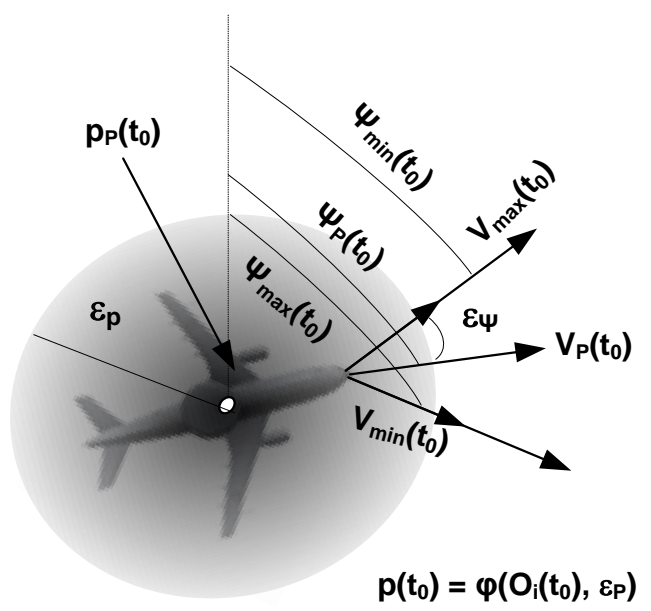

Figura 36 - Erros sobre o estado inicial da aeronave

A acurácia na posição no instante inicial $\left(\boldsymbol{\varepsilon}_{\mathbf{P}}\right)$ depende do tipo de navegação utilizado. Por simplificação, e devido às limitações no processo de modelagem, as imprecisões $\left(\boldsymbol{\varepsilon}_{\mathbf{P}}, \boldsymbol{\varepsilon}_{\mathbf{V}}, \boldsymbol{\varepsilon} \boldsymbol{\psi}\right)$ sobre os valores de estado, no instante inicial $\left(\mathbf{t}_{\mathbf{0}}\right)$, não serão consideradas.

\subsubsection{Sistema de Navegação}

O sistema de Navegação é responsável pelas funcionalidades de "obtenção de posição da aeronave", de "gerenciamento do plano de vôo" e de "monitoramento e controle da aeronave". Por princípio de funcionamento, o piloto programa o plano de vôo no Computador de Gerenciamento de Vôo (FMC), indicando as rotas que deseja trafegar (que são representadas pela seqüência de pontos de notificação que devem ser cumpridos: $\Sigma \mathbf{O}_{\mathbf{n}}$, $\mathbf{O}_{\mathbf{n}} \in \mathbf{R}^{\mathbf{2}}, \forall \mathbf{n} \in \mathbf{N}$, e $\mathbf{O}_{\mathbf{n}}=\left(\mathbf{X}_{\mathbf{N O T}(\mathbf{n})}, \mathbf{Y}_{\mathbf{N O T}(\mathbf{n})}\right.$ )), as Altitudes (ou níveis de vôo (FL)) e Velocidades de cruzeiro para cada uma das rotas a cumprir.

Durante o percurso de cada um dos segmentos $\mathbf{O}_{\mathbf{n}}-\mathbf{O}_{\mathbf{n}+\mathbf{1}}$ do vôo, o FMC gerencia o plano de vôo obtendo informações sobre sua posição através dos auxílios à navegação. No caso de utilizar-se o VOR, obtêm o valor da radial pela qual a aeronave está navegando ( $\left.\operatorname{Rad}_{\text {NAV }}\right)$. No caso de utilizar-se o GPS, obtêm-se qual a posição atual da aeronave ( $\left.\mathbf{P}_{\text {NAV }}\right)$. O FMC informa ao Piloto Automático (AP) qual estado $\left(\mathbf{V}_{\text {TAS }}, \boldsymbol{\psi}, \mathbf{h}\right)_{\text {(DESEJADO) }}$ deve ser mantido pela aeronave para que a mesma possa aderir à trajetória planejada. Em posse das informações do estado desejado, o Piloto Automático obtêm informações de estado da aeronave e atua de forma a manter $\left(\mathbf{V}_{\text {TAS }}, \psi, \mathbf{h}\right)_{(\mathbf{R E A L})}=\left(\mathbf{V}_{\text {TAS }}, \boldsymbol{\psi}, \mathbf{h}\right)_{(\text {DESEJADO })}$. Caso o FMC, por meio dos auxílios à navegação, perceba que a aeronave está fora da rota planejada, ele comanda um novo estado 
desejado ao Piloto Automático para corrigir a trajetória e fazer a aeronave aderir ao vôo planejado.

Desta forma, o Sistema de Navegação modela suas 3 funcionalidades: “obtenção de posição da aeronave" (representado no modelo de Situação Atual pelo VOR e no modelo de Situação Futura pelo GPS), de "gerenciamento do plano de vôo" (representado pelo FMC, que recebe a trajetória planejada e os valores de posição estimados para a aeronave) e de "monitoramento e controle da aeronave" (representado pelo Piloto Automático, que faz a interface com as variáveis de estado da aeronave).

O modelo gerenciamento do plano de vôo proposto implementará apenas a correção de desvios laterais à rota planejada (correção de proa), sendo este um dos motivos de se modelar apenas o VOR, e não o DME. O Piloto intervém sobre o estado da Aeronave (Proa) quando o controlador de tráfego comandar alguma ação para resolução de conflito (comando de $\left.\psi_{\text {resolucao }}\right)$, atuando diretamente sobre o Piloto Automático $\left(\right.$ fazendo $\left.\psi_{\text {desejado }}=\psi_{\text {resolucao }}\right)$.

\subsection{Modelagem do algoritmo de correção de Proa}

Como demonstrado anteriormente, a dinâmica do valor de proa $(\mathbf{d} \psi(\mathbf{t}) / \mathbf{d t})$ é dependente do valor de atitude (Roll Angle - $\phi)$ e da velocidade $\left(\left\|\mathbf{V}_{\text {TAS }}\right\|\right)$ da aeronave, no caso da mesma ser constante $\left(\mathbf{d} \mathbf{V}_{\text {TaS }}(\mathbf{t}) / \mathbf{d t}=\mathbf{0}\right)$ no período onde $\mathbf{d} \psi(\mathbf{t}) / \mathbf{d t} \neq \mathbf{0}$. Porém, por meio de observação do comportamento de aeronaves reais, percebe-se que, para variações pequenas de proa, o valor $\phi$ é menor que $35^{\circ}$.

Devido à dificuldade em se obter os algoritmos utilizados para controle de proa em aeronaves reais, e objetivando modelar, de forma mais realista, a funcionalidade do piloto automático, extraiu-se aquele algoritmo por meio do simulador de vôo Microsoft Flight Simulator $2004^{14}$, observando o comportamento, com relação à correção de proa, do Piloto Automático (AP) de um Boeing 737-400. Obtiveram-se os seguintes resultados:

1. Para qualquer ação de correção de proa, o AP aplica a intenção de fazer $\phi_{\text {desejado }}=\mathbf{3 5}^{\circ}$ no instante $\mathbf{t}_{\mathbf{0}}$ (momento no qual o AP recebe o valor de proa desejado ( $\left.\boldsymbol{\psi}_{\text {desejado }}\right)$ ), confirmando o valor relatado por Glover, Lygeros (2004). O tempo necessário para alterar o valor de $\phi$ de $\mathbf{0}^{\mathbf{0}}\left(\phi\left(\mathbf{t}_{\mathbf{0}}\right)=\mathbf{0}^{\mathbf{o}}\right)$ para $\mathbf{3 5}^{\circ}\left(\phi\left(\mathbf{t}_{\mathbf{i}}\right)=\phi_{\text {desejado }}=\mathbf{3 5}^{\circ}\right)$ é de $\mathbf{t}_{\mathbf{i}}=\mathbf{1 0}$

\footnotetext{
${ }^{14}$ http://www.microsoft.com/games/pc/flightsimulator.aspx (último acesso: 10/03/2007).
} 
segundos $\left(\mathrm{d} \phi(\mathrm{t}) / \mathrm{dt}=3,5^{\circ} / \mathrm{s}\right)$.

2. Após o instante $\mathbf{t}_{\mathbf{0}}$, quando AP faz $\phi_{\text {desejado }}=\mathbf{3 5}^{\mathbf{0}}$, o mesmo controla o valor de $\phi(\mathbf{t})$ (e, consequentemente, o valor de $\boldsymbol{\psi}(\mathbf{t})$ (proa da aeronave no instante $\mathbf{t}$ )) fazendo com que $\phi(\mathbf{t}) \approx \phi_{\text {desejado. }}$ O AP utiliza, para este fim, o seguinte algoritmo:

a. Enquanto $\left|\psi_{\text {desejado }}-\psi(\mathbf{t})\right| \geq 25^{\circ} \Rightarrow$ mantém $\phi_{\text {desejado }}=\mathbf{3 5}^{\circ}$, utilizando $\mathbf{d} \phi(\mathbf{t}) / \mathbf{d t}$ $=\mathbf{3 , 5} \%$ s enquanto $\phi(\mathbf{t}) \neq \phi_{\text {desejado }}$.

b. Caso $\left|\psi_{\text {desejado }}-\psi(\mathbf{t})\right|<25^{\circ} \Rightarrow$ faz $\phi_{\text {desejado }}=\mathbf{0}^{\circ}$, utilizando $\mathbf{d} \phi(\mathbf{t}) / \mathbf{d t}<<3,5^{\circ} / \mathrm{s}$ enquanto $\phi(t) \neq \phi_{\text {desejado }}$ e até que $\psi(t)=\psi_{\text {desejado }}$.

Como forma de manter a consistência da equação $\mathbf{d} \psi(\mathbf{t}) / \mathbf{d t}=\mathbf{g . t a n}\left(\phi_{\text {nom }}\right) /\left\|\mathbf{V}_{\text {TAS }}\right\|$, onde $\phi_{\text {nom }}$ é constante no período onde $\mathbf{d} \psi(\mathbf{t}) / \mathbf{d t} \neq \mathbf{0}$, será definida a variável $\psi_{\text {DIFERENÇA }}=\mid \psi_{\text {desejado }}-$ $\psi(\mathbf{t}) \mid$, utilizando-a para determinar os valores de $\phi_{\text {nom }}$ em função de intervalos de valor em

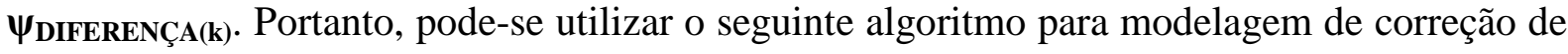
proa do AP:

$$
\begin{aligned}
& \text { Se } \psi_{\text {DIFERENÇA }} \geq 25^{\circ} \Rightarrow \phi_{\text {nom }}=\phi_{0}=35^{\circ} \text {; } \\
& \text { Se } \psi_{\text {DIFERENÇA }} \geq X_{1}^{\circ} \wedge \psi_{\text {DIFERENÇA }}<25^{\circ} \Rightarrow \phi_{\text {nom }}=\phi_{0} / \mathbf{R}_{1}, \mathbf{R}_{1}>1 \text {; } \\
& \text { Se } \psi_{\text {DIFERENÇA }} \geq \mathbf{X}_{2}^{\circ} \wedge \psi_{\text {DIFERENÇA }}<\mathbf{X}_{1}^{\circ} \Rightarrow \phi_{\text {nom }}=\phi_{0} / \mathbf{R}_{2}, \mathbf{R}_{2}>\mathbf{R}_{\mathbf{1}} \text {; } \\
& \text { Se } \psi_{\text {DIFERENÇA }}>X_{n}=0^{\circ} \wedge \psi_{\text {DIFERENÇA }}<X_{n-1}{ }^{\circ} \Rightarrow \phi_{\text {nom }}=\phi_{0} / R_{n}, R_{n}>R_{n-1} ; \\
& \text { Senão } \left.\Rightarrow \phi_{\text {nom }}=0^{\circ} \text { (equivale a } \mathbf{d} \psi(\mathbf{t}) / \mathbf{d t}=\mathbf{0}\right) \text {, onde } X_{n}<X_{n-1}<\ldots<X_{1}<25^{\circ}
\end{aligned}
$$

A Figura 37 ilustra o modelo completo para o Sistema de Navegação. 


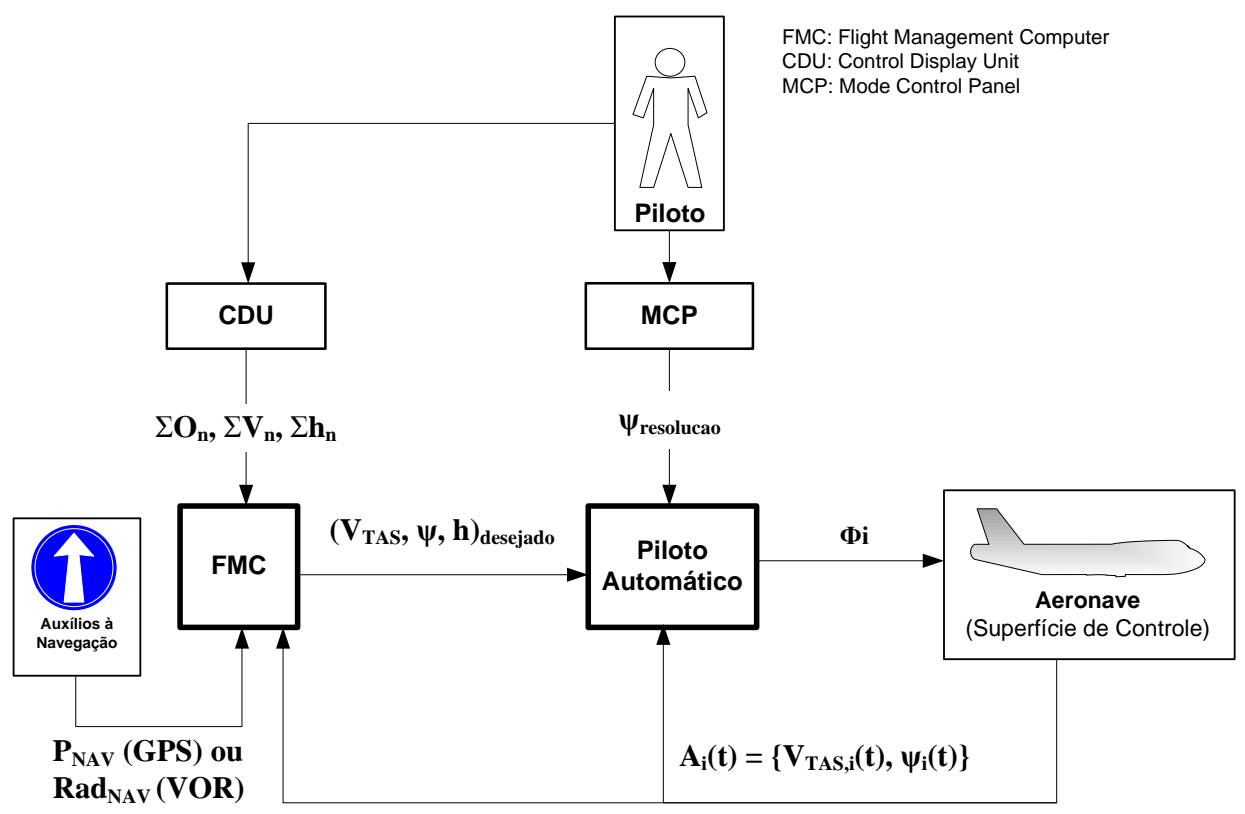

Figura 37 - Modelo para o Sistema de Navegação

Vale ressaltar que a modelagem do algoritmo de correção de Proa será a mesma em ambos os cenários analisados ("referência" e "proposto").

\subsection{Modelagem da Navegação utilizando VOR}

Um auxílio à navegação VOR emite, a partir de sua rádio-base (posicionada na coordenada $\left(\mathbf{X}_{\text {NOT(i+1) }}, \mathbf{Y}_{\text {NOT(i+1) }}\right)$, sinais de rádio que, ao serem recebidos pelas aeronaves, identificam sobre qual radial as mesmas estão sobrevoando. Portanto, a Radial ("Real” ou "Transmitida pelo $V O \boldsymbol{O}$ ”) que uma aeronave está sobrevoando no instante $\mathbf{t}_{\mathbf{n}}$ pode ser modelada através de:

$$
\operatorname{Rad}_{\text {REAL }}\left(\mathbf{t}_{\mathbf{n}}\right)=\mathbf{F}+\operatorname{arctg}\left(\mathbf{Y}_{\text {VOR }}\left(\mathbf{t}_{\mathbf{n}}\right) / \mathbf{X}_{\mathrm{VOR}}\left(\mathbf{t}_{\mathbf{n}}\right)\right), \text { onde: }
$$

$\mathbf{Y}_{\text {VOR }}\left(\mathbf{t}_{\mathbf{n}}\right)$ : distância Real, sobre o eixo cartesiano Y, entre a Aeronave e o VOR em $\mathbf{t}_{\mathbf{n}}$.

$$
\mathbf{Y}_{\text {VOR }}\left(\mathbf{t}_{\mathbf{n}}\right)=\mathbf{Y}\left(\mathbf{t}_{\mathbf{n}}\right)-\mathbf{Y}_{\text {NOT(i+1) }}
$$

$\mathbf{X}_{\text {VOR }}\left(\mathbf{t}_{\mathbf{n}}\right)$ : distância Real, sobre o eixo cartesiano X, entre a Aeronave e o VOR em $\mathbf{t}_{\mathbf{n}}$.

$$
\mathbf{X}_{\text {VOR }}\left(\mathbf{t}_{\mathbf{n}}\right)=\mathbf{X}\left(\mathbf{t}_{\mathbf{n}}\right)-\mathbf{X}_{\mathrm{NOT}(\mathbf{i}+\mathbf{1})}
$$

$\mathbf{F}=\left\{\mathbf{9 0}^{\circ}, \mathbf{2 7 0}^{\circ}\right\}$ : fator de correção de radial. Baseado no referencial de ângulo ("Rosa dos Ventos") ilustrado na Figura 38 e sabendo que VORs emitem radiais entre $0^{\circ}$ e $359^{\circ}$, deve-se aplicar as seguintes correções nos valores de radial obtidos através de $\mathbf{X}_{\mathbf{V O R}}()$ e $\mathbf{Y}_{\mathbf{V O R}}($ ): 


\section{$\operatorname{Rad}_{\text {REAL }}\left(t_{n}\right)=90^{\circ}-\operatorname{arctg}\left(Y_{\text {VOR }}\left(t_{n}\right) / X_{\text {VOR }}\left(t_{n}\right)\right)$ caso $X\left(t_{n}\right)>X_{\text {NOT(i+1) }}$. \\ $\operatorname{Rad}_{\text {REAL }}\left(t_{n}\right)=270^{\circ}+\operatorname{arctg}\left(Y_{\text {VOR }}\left(t_{n}\right) / X_{\text {VOR }}\left(t_{n}\right)\right)$ caso $X\left(t_{n}\right)<X_{\text {NOT }(i+1)}$.}

A radial observada pelo sistema de Navegação (FMS) possui imprecisões, tanto por parte do transmissor quanto dos receptores a bordo das Aeronaves. Com relação ao transmissor VOR, o desalinhamento máximo de $\mathbf{\pm 2 , 5 ^ { \circ }}$ a $\mathbf{\pm 3 , 5 ^ { \circ }}$ entre as radiais do transmissor e o azimute magnético correto (Ministério da Aeronáutica, 2002) afeta da mesma forma todas as aeronaves que estiverem recebendo seu sinal e, por isso, não será considerado. Com relação à acurácia do sinal transmitido pelo VOR, não foi encontrada nenhuma especificação, em normas nacionais, a este respeito. Os Departamentos de Defesa e de Transportes NorteAmericanos (DoD/DoT, 2001) especificam que os transmissores VOR possuem monitores em solo que os desligam no caso dos mesmos excederem $\mathbf{\pm 1 . 0 ^ { \mathbf { 0 } }}$ de acurácia. Portanto, será considerado que a acurácia do sinal de radial transmitido pelo VOR será, no máximo, de $\pm 1.0^{\circ}$.

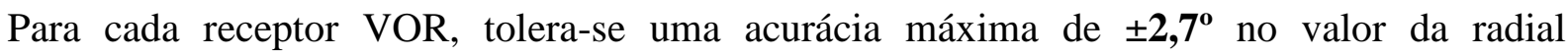
selecionada (Ministério da Aeronáutica, 2005). Já a norma ARINC 711-10 (ARINC, 2002) define que receptores VOR embarcados em aeronaves comerciais devem ter acurácia de $\mathbf{\pm 0 . 4} @ @ 95 \%$. Diferente da norma ARINC 711-10, a instrução brasileira ICA 102-9 (Ministério da Aeronáutica, 2005) não considera a acurácia como uma variável estatística, não definindo, assim, um intervalo de confiança para a mesma. Desta forma, considerar que a acurácia do VOR deverá ser menor que $\mathbf{\pm 2 , 7 ^ { \circ }}$ em $\mathbf{1 0 0 \%}$ do tempo equivale a dizer, considerando uma distribuição de probabilidade Normal, que a mesma acurácia será de 1.495\%, aproximadamente, valor este definido em DoD/DoT (2001) para a acurácia do sistema VOR (Transmissão e Recepção).

Portanto, a Radial recebida por uma Aeronave (FMC) no instante $\mathbf{t}_{\mathbf{n}}\left(\operatorname{Rad}_{\mathrm{NAV}}\left(\mathbf{t}_{\mathbf{n}}\right)\right)$ pode ser modelada como:

$$
\operatorname{Rad}_{\text {NAV }}\left(t_{n}\right)=\operatorname{Rad}_{\text {REAL }}\left(t_{n}\right)+\varepsilon_{\text {VOR }}
$$

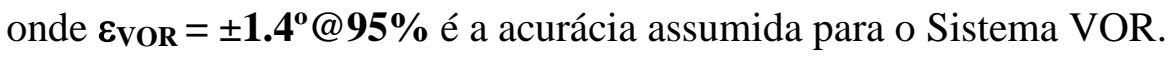




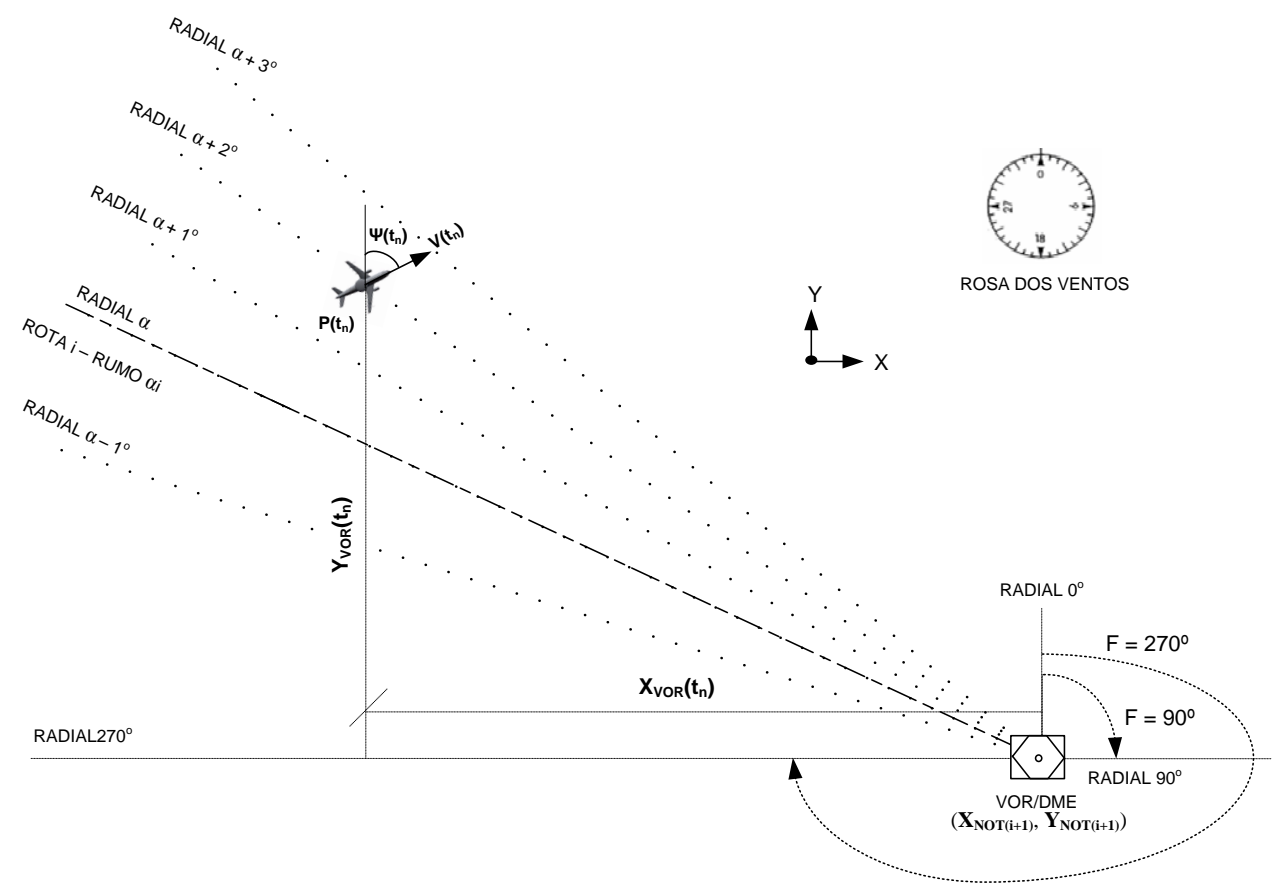

Figura 38 - Modelagem da obtenção de Radial por VOR

Com base na informação da Radial que a aeronave deve sobrevoar ( $\boldsymbol{\alpha}$, obtida do plano de vôo programado pelo Piloto e ilustrada na Figura 38) e no valor obtido de $\operatorname{Rad}_{\text {NAv }}\left(t_{n}\right)$, o Computador de Gerenciamento de Vôo (FMC) define qual o valor de proa desejada $\left(\boldsymbol{\psi}_{\text {desejado }}\right.$ ) como forma de fazer a aeronave retornar (e manter) a rota desejada. Assim, o FMC deve instruir ao Piloto Automático (AP) qual $\psi_{\text {desejado }}$ manter.

Desta forma, $\psi_{\text {desejado }}$ é definido por:

$$
\psi_{\text {desejado }}=\alpha \pm \operatorname{Tnav}\left(\operatorname{Rad}_{\mathrm{NAV}}, \alpha\right)
$$

onde $\operatorname{Tnav}\left(\operatorname{Rad}_{\mathbf{N A v}}, \boldsymbol{\alpha}\right)>1$ é um fator para convergência de proa, em função de $\left|\operatorname{Rad}_{\mathbf{N A V}}-\boldsymbol{\alpha}\right|$, ao rumo da rota desejada.

A Figura 39 ilustra o diagrama de blocos da navegação utilizando VOR.

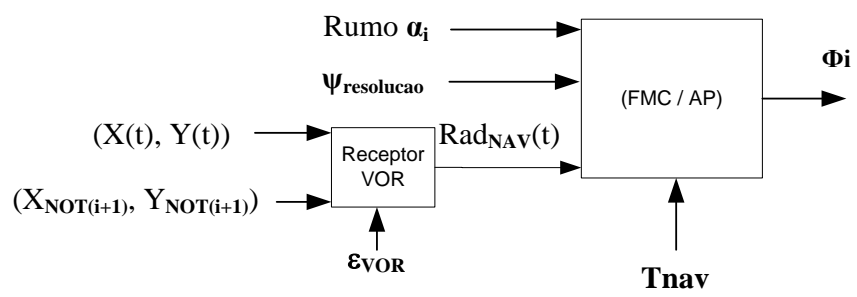

Figura 39 - Diagrama de Bloco da Navegação por VOR 


\subsection{Modelagem da Navegação utilizando GPS}

O sistema de navegação GPS fornece informações sobre a posição que a aeronave ocupa no espaço em um instante "t" de tempo $(\mathbf{P}(\mathbf{t})=(\mathbf{X}(\mathbf{t}), \mathbf{Y}(\mathbf{t}), \mathbf{h}(\mathbf{t})))$. Devido às suas características funcionais (acurácia, sobretudo), a estimativa de posição obtida pelo GPS no instante t $\left(\mathbf{P}_{\text {NAV }}(\mathbf{t})\right.$, onde $\left.\mathbf{P}_{\mathrm{NAV}}(\mathbf{t}) \in \mathbf{R}^{+2} \mid \forall \mathbf{t} \in \mathbf{R}^{+}\right)$pode ser modelada como:

$$
P_{\mathrm{NAV}}(\mathbf{t})=\left(\mathbf{X}(\mathbf{t})+\varepsilon \mathbf{X}_{\mathrm{GPS}}, \mathbf{Y}(\mathbf{t})+\varepsilon \mathbf{y}_{\mathrm{GPS}}\right)=\left(\mathbf{X}_{\mathrm{NAV}}(\mathbf{t}), \mathbf{Y}_{\mathrm{NAV}}(\mathbf{t})\right), \text { onde }:
$$

$\boldsymbol{\varepsilon}_{\mathbf{G P S}}=\left(\boldsymbol{\varepsilon} \mathbf{x}_{\mathbf{G P S}}, \boldsymbol{\varepsilon}_{\mathbf{G P S}}\right)$ é a acurácia horizontal, relativa ao GPS, introduzida sobre a posição real da aeronave $(\mathbf{X}(\mathbf{t}), \mathbf{Y}(\mathbf{t}))$.

Com base na informação da posição obtida pelo GPS $\left(\mathbf{P}_{\mathrm{NAV}}(\mathbf{t})\right)$ e conhecendo a rota que a aeronave deve sobrevoar, o Computador de Gerenciamento de Vôo (FMC) determina qual o desvio lateral da aeronave com relação à rota desejada $(\mathbf{d} \boldsymbol{\varepsilon}(\mathbf{t}))$. Desta forma, caso o desvio lateral seja maior que um máximo tolerável, o FMC instrui o Piloto Automático (AP) a atuar sobre a proa da aeronave $(\boldsymbol{\Psi}(\mathbf{t}))$ de forma a fazer a aeronave retornar à rota desejada.

Para calcular o desvio lateral de trajetória, o FMC deve conhecer a equação da rota que deve navegar. Dado que cada rota "i" possui um rumo $\boldsymbol{\alpha}_{\mathbf{i}} \in\left[\mathbf{0}^{\mathbf{0}}, \mathbf{1 8 0}^{\circ}\right]$, e a aeronave deve cumprir, como próximo ponto de notificação, o ponto $\left(\mathbf{X}_{\text {NOT(i+1) }}, \mathbf{Y}_{\text {NOT(i+1) }}\right)$ pertencente à rota “i”, temse que suas equações são dadas na forma:

$Y_{\text {ROTA(i) }}=X_{\text {ROTA(i) }} \cdot \operatorname{tg}(\theta i)+\left(Y_{\text {NOT(i+1) }} \cdot \operatorname{tg}(\theta i) \cdot X_{\text {NOT(i+1) }}\right)$, para $\alpha_{i} \in\left[0^{\circ}, 90^{\circ}\right]$, onde $\theta i=90^{\circ}-\alpha_{i} \cdot$

$Y_{\text {ROTA(i) }}=-X_{\text {ROTA(i) }} \cdot \operatorname{tg}(\theta i)+\left(Y_{\text {NOT(i+1) }}+\operatorname{tg}(\theta i) \cdot X_{\text {NOT(i+1) }}\right)$, para $\left.\left.\alpha_{i} \in\right]_{90}^{\circ}, 1_{180^{\circ}}\right]$, onde $\theta i=\alpha_{i}-$ $90^{\circ}$.

Dado um ponto $\mathbf{P}_{\mathrm{NAV}}\left(\mathbf{t}_{\mathbf{n}}\right)=\left(\mathbf{X}_{\mathrm{NAV}}\left(\mathbf{t}_{\mathbf{n}}\right), \mathbf{Y}_{\mathrm{NAV}}\left(\mathbf{t}_{\mathbf{n}}\right)\right)$ no instante $\mathbf{t}_{\mathbf{n}}$ tempo, o desvio lateral da aeronave com relação à rota desejada $\left(\mathbf{d} \boldsymbol{\varepsilon}\left(\mathbf{t}_{\mathbf{n}}\right)\right)$ é dado por:

$$
\operatorname{d} \varepsilon\left(t_{n}\right)=\left|Y_{\text {NAV }}\left(t_{n}\right)-Y^{\prime}{ }_{\text {ROTA }(i)}\right| \cdot \cos \left(\theta_{i}\right), \text { onde }
$$

$\mathbf{Y}^{\prime}{ }_{\text {Rota(i): }}$ o valor de $\mathbf{Y}_{\text {ROTA(i) }}$ quando $\mathbf{X}_{\mathbf{R O T A}(\mathbf{i})}=\mathbf{X}_{\mathrm{NAV}}\left(\mathbf{t}_{\mathbf{n}}\right)$.

A Figura 40 ilustra o equacionamento para o cálculo de desvio lateral de rota utilizando informação de posicionamento GPS. 


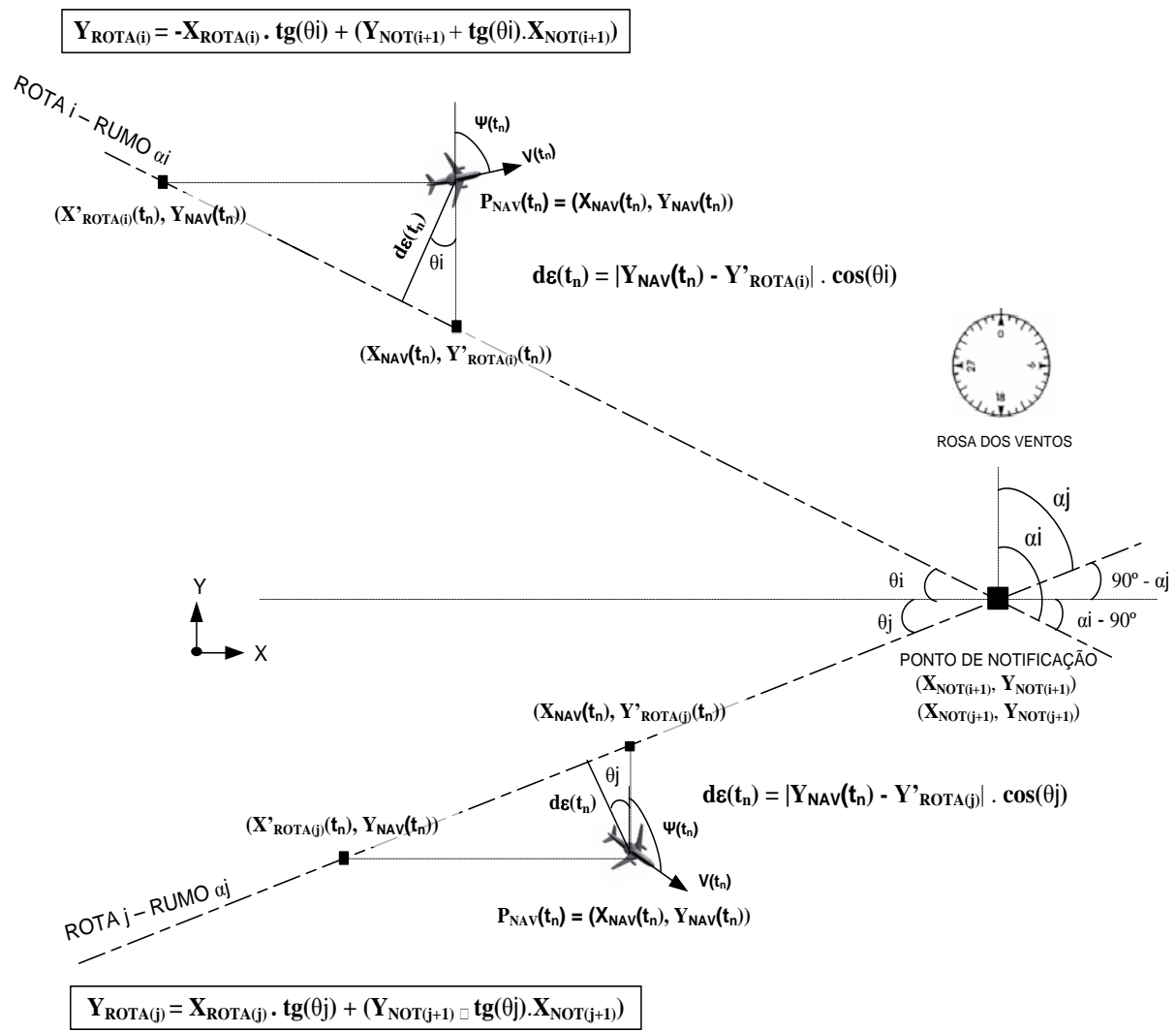

Figura 40 - Modelagem da obtenção de desvio lateral de Rota utilizando GPS

Ao detectar um valor de desvio maior ou igual ao máximo tolerável $\left(\mathbf{d} \varepsilon\left(\mathbf{t}_{\mathbf{n}}\right)>\mathbf{d}_{\mathbf{M A x}}\right)$, o percurso da aeronave deve ser corrigido para aderir novamente à rota desejada (rumo $\boldsymbol{\alpha}_{\mathbf{i}}$ ). Neste caso, o Computador de Gerenciamento de Vôo (FMC) define qual o valor de proa desejada $\left(\psi_{\text {desejado }}\right)$, instruindo-o ao Piloto Automático (AP). Desta forma, $\boldsymbol{\psi}_{\text {desejado }}$ é definido por:

$$
\psi_{\text {desejado }}=\alpha \pm \operatorname{Tnav}(d \varepsilon)
$$

onde $\operatorname{Tnav}(\mathbf{d} \boldsymbol{\varepsilon})>\mathbf{1}$ é um fator para convergência de proa, em função de $\mathbf{d} \boldsymbol{\varepsilon}$, ao rumo da rota desejada.

A Figura 41 ilustra o diagrama de blocos do sistema de navegação utilizando GPS. 


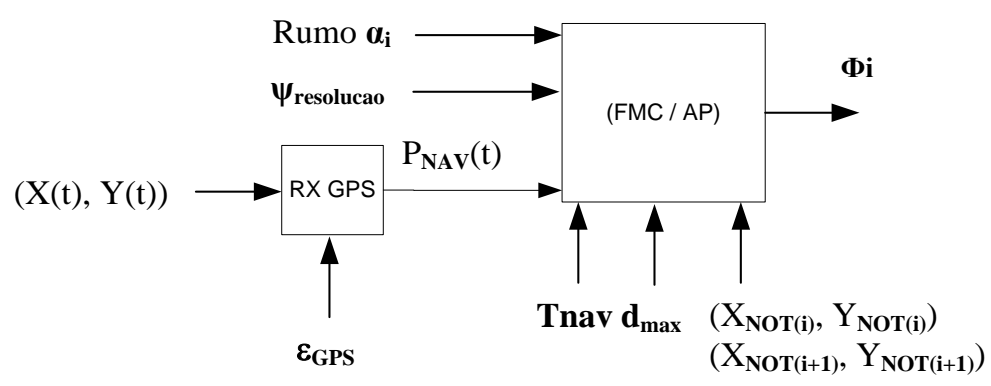

Figura 41 - Diagrama de Bloco da Navegação por GPS

\subsubsection{Sistema de Vigilância}

O sistema de vigilância tem a função de obter informações sobre a posição das aeronaves no espaço aéreo observado e apresentá-las aos ATCos. Ou seja, para cada instante "t" de tempo, o ATCo possui uma estimativa da posição da aeronave "i" no espaço aéreo:

$$
\mathbf{P}_{\text {VIG }, \mathbf{i}}(\mathbf{t})=\left(\mathbf{X}_{\text {VIG }, \mathbf{i}}(\mathbf{t}), \mathbf{Y}_{\text {VIG }, \mathbf{i}}(\mathbf{t})\right)
$$

As características que serão consideradas para o modelo do sistema de vigilância, e que afetam a estimativa de posição fornecida pelo sistema, são: Acurácia (diferença entre posição real e posição obtida no instante "t" $(\sigma \mathrm{x}, \sigma \mathrm{y})$ ), Taxa de Atualização (ou de varredura das posições das aeronaves $\left(\tau_{\text {scan}}\right)$ ) e a Latência (tempo entre a amostragem da posição e a apresentação desta informação ao $\left.\operatorname{ATCo}\left(\tau_{\text {lat }}\right)\right)$.

Serão modelados dois sistemas de Vigilância:

- $\quad$ Sistema de Referência: vigilância Radar, obtendo informações de posição $(\mathbf{X , Y})$ das aeronave por meio de Azimutes e Ranges $(\mathbf{A}(\mathbf{t}), \mathbf{R}(\mathbf{t}))$.

- $\quad$ Sistema Proposto: vigilância ADS-B, obtendo informações de posição $(\mathbf{X}, \mathbf{Y})$ das aeronaves por meio de informações GPS (navegação por satélites).

A funcionalidade Vigilância será modelada de forma semelhante para ambos os sistemas. A cada $\tau_{\text {scan }}$ unidades de tempo, o sistema de vigilância obtém a posição de uma aeronave "i" $\left(\mathbf{X}_{\mathbf{i}}\left(\mathbf{k} \cdot \tau_{\text {scan }}\right), \mathbf{Y}_{\mathbf{i}}\left(\mathbf{k} . \tau_{\text {scan }}\right)\right)$. Esta posição sofre degradação relacionada à acurácia do processo de vigilância $\left.\left(\mathbf{X}_{\mathbf{i}}\left(\mathbf{k} \cdot \tau_{\text {scan }}\right)+\sigma \mathbf{x}, \mathbf{Y}_{\mathbf{i}}\left(\mathbf{k} \cdot \tau_{\text {scan }}\right)+\sigma \mathbf{y}\right)\right)$. A posição estimada no instante $\mathbf{k} \cdot \tau_{\text {scan }}$ será apresentada ao controlador de tráfego aéreo no instante k. $\tau_{\text {scan }}+\tau_{\text {lat }}$, e permanecerá a mesma, em média, até o instante $(\mathbf{k}+\mathbf{1}) \cdot \tau_{\text {scan }}+\tau_{\text {lat }}$. Portanto, o valor estimado de posição $\left(\mathbf{X}_{\mathbf{V I G}, \mathbf{i}} \mathbf{( t )}\right.$, 
$\left.\mathbf{Y}_{\text {VIG, i }}(\mathbf{t})\right)$ sofre degradação de duas magnitudes: espacial $(\sigma \mathbf{x}, \sigma \mathbf{y})$ e temporal $\left(\tau_{\text {scan }}, \tau_{\text {lat }}\right)$, fazendo com que haja diferenças entre o valor de posicão real de uma aeronave $\left(\mathbf{X}_{\mathbf{i}}(\mathbf{t}), \mathbf{Y}_{\mathbf{i}}(\mathbf{t})\right)$ e o valor de posicão visualizada pelo controlador de tráfego aéreo, utilizado para tomada de decisão $\left(\mathbf{X}_{\text {VIG,i }}(\mathbf{t}), \mathbf{Y}_{\text {VIG,i }}(\mathbf{t})\right)$.

A Figura 42 ilustra o funcionamento do processo de vigilância e a relação entre os parâmetros $(\sigma \mathbf{x}, \sigma \mathbf{y}), \tau_{\text {scan }}, \tau_{\text {lat }}, \mathbf{X}_{\mathbf{i}}(\mathbf{t})$ e $\mathbf{X}_{\mathbf{V I G}, \mathrm{i}}(\mathbf{t})$.

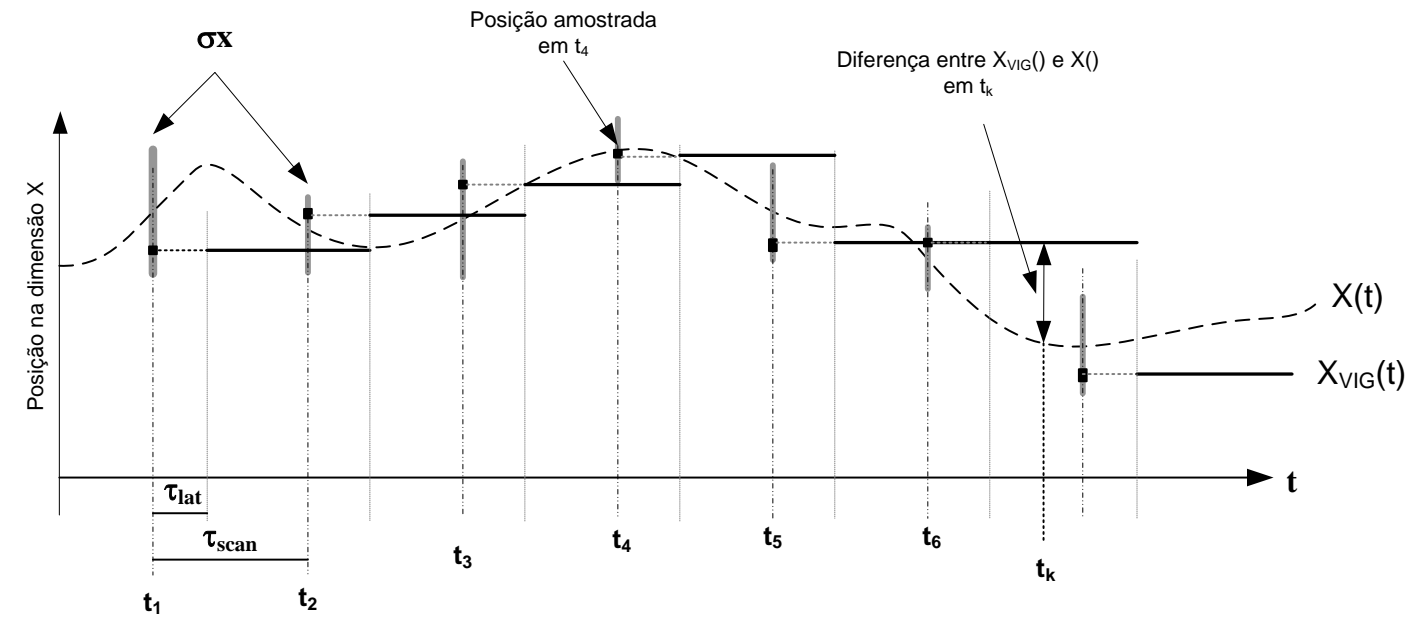

Figura 42 -Relação entre os parâmetros de Vigilância (exemplo em 1 dimensão)

Mesmo possuindo a mesma funcionalidade e os mesmos tipos de características funcionais, o sistema ADS-B e o sistema Radar possuem diferenças quanto às suas arquiteturas funcionais:

\subsection{Sistema Radar}

O Radar é um sistema de vigilância que não depende dos elementos a bordo da aeronave para obtenção de sua posição (Vigilância Independente). Para sistemas de vigilância baseados em um único Radar (sistema não mosaico), as imprecisões do equipamento Radar afetam todos os alvos da mesma maneira (Thompson, Bussolari, 2003). Além disto, pode-se considerar que sua taxa de atualização $\left(\tau_{\text {scan }}\right)$ e sua latência $\left(\tau_{\text {lat }}\right)$ são determinísticas e constantes para todos os alvos radar obtidos, pois a freqüência de rotação da antena radar é constante. Também devido ao movimento de varredura da antena radar, a diferença entre os tempos de amostragem de 2 alvos radar pode ser considerada nula desde que a diferença de azimute entre os alvos seja pequena (como exemplo, para uma taxa de atualização de 12s (radar de rota), a velocidade angular da antena é de $30 \%$ segundo). 
Em um Radar, a obtenção da posição de vigilância $\left(\mathbf{X}_{\mathbf{V I G}, \mathbf{i}}, \mathbf{Y}_{\mathbf{V I G}, \mathbf{i}}\right)$ de uma aeronave "i”" é função de suas medidas de Azimute $\left(\mathbf{A}_{\mathbf{i}}\right)$ e Range $\left(\mathbf{R}_{\mathbf{i}}\right)$. Dado $\mathbf{P}_{\mathbf{i}}=\left(\mathbf{X}_{\mathbf{i}}, \mathbf{Y}_{\mathbf{i}}\right)$ a posição da aeronave "i", $\mathbf{P}_{\text {radar }}=\left(\mathbf{X}_{\text {radar }}, \mathbf{Y}_{\text {radar }}\right)$ a posição da antena $\operatorname{Radar}$ e $\left(\boldsymbol{\sigma}_{\mathrm{A}, \mathbf{R a d a r}}, \boldsymbol{\sigma}_{\mathbf{R}, \mathbf{R a d a r}}\right)$ as imprecisões em Azimute e Range do equipamento Radar, tem-se:

$$
\begin{aligned}
& \mathbf{R}_{i}=\left(\left(\mathbf{X}_{i}-\mathbf{X}_{\text {radar }}\right)^{2}+\left(\mathbf{Y}_{\mathrm{i}}-\mathbf{Y}_{\text {radar }}\right)^{2}\right)^{1 / 2}+\sigma_{R, R a d a r} \\
& \mathbf{A}_{i}=\arctan \left(\left(\mathbf{X}_{\mathrm{i}}-\mathbf{X}_{\text {radar }}\right) /\left(\mathbf{Y}_{\mathrm{i}}-\mathbf{Y}_{\text {radar }}\right)\right)+\sigma_{\mathrm{A}, \text { Radar }} \\
& \therefore\left(\mathbf{X}_{\mathrm{VIG}, \mathrm{i}}, \mathbf{Y}_{\mathrm{VIG}, \mathrm{i}}\right)=\left(\mathbf{R}_{\mathrm{i}} \cdot \operatorname{sen}\left(\mathbf{A}_{\mathrm{i}}\right), \mathbf{R}_{\mathrm{i}} \cdot \cos \left(\mathbf{A}_{\mathrm{i}}\right)\right)
\end{aligned}
$$

Desta forma, as imprecisões espaciais e temporais (suprimida das equações acima) continuam a existir em um sistema de vigilância Radar, mas são introduzidas nas medidas de vigilância por meio indireto em $\left(\mathbf{X}_{\mathbf{V I G}, \mathbf{i}}, \mathbf{Y}_{\mathbf{V I G}, \mathbf{i}}\right)$.

A Figura 43 ilustra o esquema de funcionamento do sistema Radar.

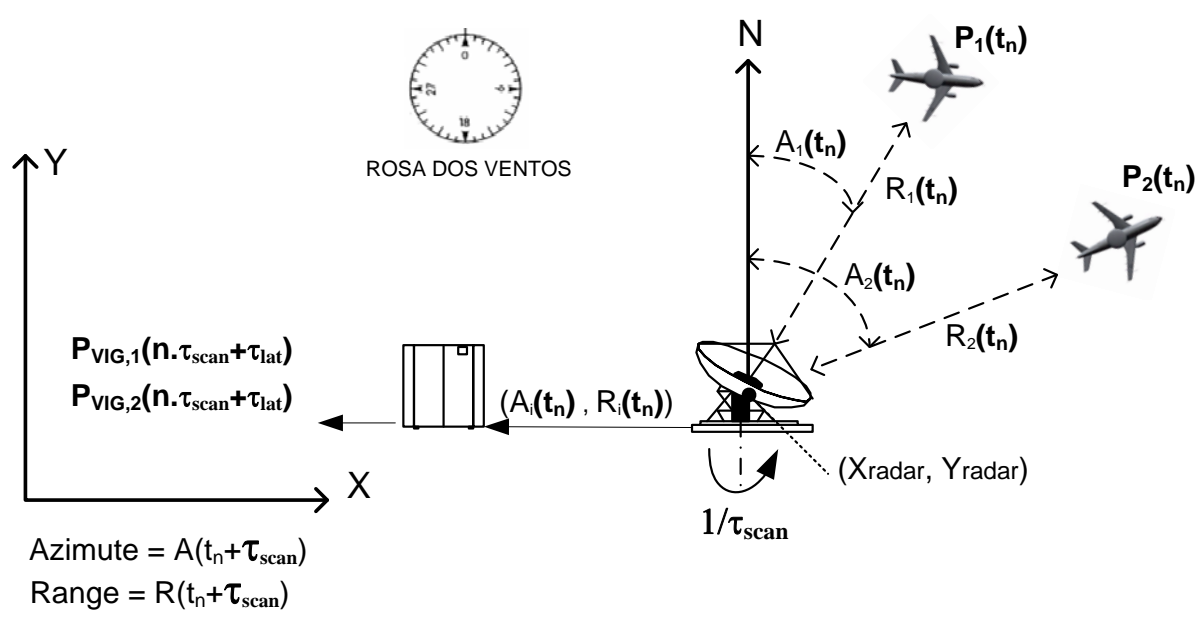

Figura 43 - Esquema de Funcionamento da Vigilância Radar

\subsection{Sistema ADS-B}

Diferentemente do Radar, o ADS-B é um tipo de vigilância que depende das informações fornecidas pelas próprias aeronaves para estimar suas posições e apresentá-las ao controlador de tráfego aéreo (Vigilância Dependente). Cada alvo obtido é afetado por características de amostragem do equipamento GPS a bordo da aeronave. Devido o ADS-B ser uma das aplicações de uma rede de comunicação digital, sua taxa de atualização $\left(\tau_{\text {scan }}\right)$ e sua latência $\left(\tau_{\text {lat }}\right)$ são não determinísticas. Também devido ao fato de que cada aeronave emite suas 
próprias informações de posição e de maneira independente umas das outras, não se pode desprezar a diferença entre os tempos de amostragem de 2 alvos.

Para o ADS-B, a obtenção da posição de vigilância $\left(\mathbf{X}_{\mathbf{V I G}, \mathbf{i}}, \mathbf{Y}_{\mathbf{V I G}, \mathbf{i}}\right)$ não necessita de conversões tais como as utilizadas no Radar. A Figura 44 ilustra o esquema funcional do sistema ADS-B.

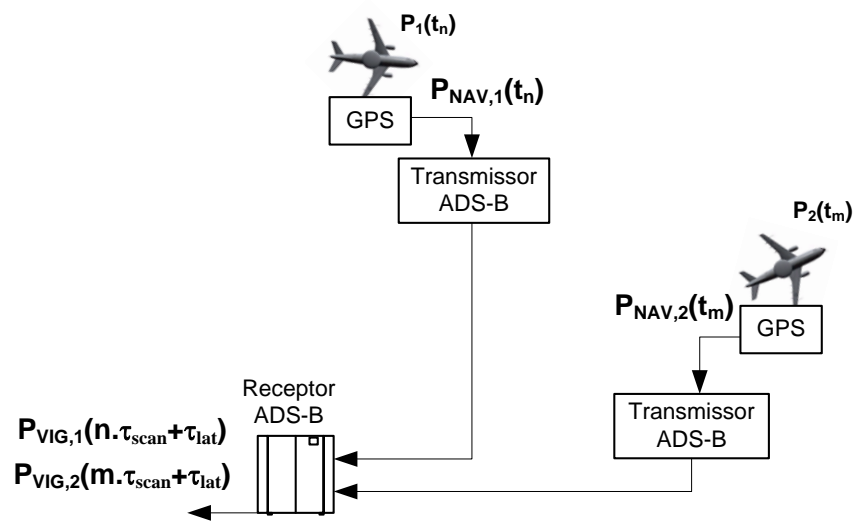

Figura 44 - Esquema de Funcionamento da Vigilância ADS-B

\subsubsection{Controlador de Tráfego Aéreo (ATCo)}

O Controlador de Tráfego Aéreo (ATCo) atua no nível de garantia da separação, monitorando a execução do tráfego, prevendo conflitos e atuando sobre a trajetória da aeronave de forma a solucionar o conflito detectado. Neste modelo de ATCo, não se considerará a característica de predição de conflitos do ATCo (predição de trajetórias e de conflitos futuros), mas apenas as características de detecção e de resolução de conflitos, tal como foi ilustrado pela Figura 6 no Capítulo 2 (descrição da funcionalidade de garantia da separação do sistema de controle de tráfego aéreo).

No modelo desenvolvido, o ATCo tem a função de monitorar o espaço aéreo através das informações de posição fornecidas pelo sistema de Vigilância (Radar ou ADS-B). O ATCo detecta um conflito e inicia o processo de resolução do mesmo quando:

a. A distância horizontal entre duas aeronaves $\left(\mathbf{A}_{\mathbf{1}} \mathbf{e} \mathbf{A}_{\mathbf{2}}\right)$, visualizada por meio do sistema de vigilância (alvos Radar), for menor do que o limite pré-estabelecido (|

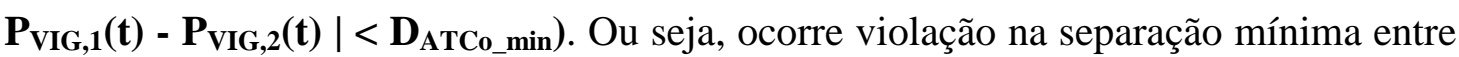
o par de aeronaves, $\mathbf{e}$ 
b. Ocorrer NConfATCo alvos sucessivos em condição de violação da separação mínima (condição “a.”) (ATCo necessita, no mínimo, de NConfATCo > 1 para realizar um julgamento a respeito das trajetórias das aeronaves (Brooker, 2004c).

Após detectar o conflito, o ATCo deve decidir qual ação deverá ser executada para que o conflito detectado seja resolvido. Esta resolução será representada pela intervenção do ATCo sobre a trajetória da aeronave. Segundo Kuchar, Yang (2000), combinações entre mudança de proa, mudança de altitude e mudança de velocidade são os tipos de intervenção praticados sobre a trajetória. Como o espaço aéreo está sendo modelado bidimensionalmente $(\mathbf{X}(\mathbf{t}), \mathbf{Y}(\mathbf{t}))$, o ATCo instrui ao piloto a mudança de proa em uma ou em ambas as aeronaves $\left(\psi_{\text {resolucao }}\left(\mathbf{t}_{\mathbf{k}}\right)\right.$ $\left.=\psi_{\mathrm{ATC}, 1} \mathrm{e} / \mathrm{ou} \psi_{\text {resolucao }}\left(\mathbf{t}_{\mathrm{k}}\right)=\psi_{\mathrm{ATC}, 2,2}\right)$, onde $\mathbf{t}_{\mathrm{k}}$ é o instante no qual a proa real da aeronave $\psi\left(\mathbf{t}_{\mathrm{k}}\right)$ está no sentido comandado pelo ATCo $\boldsymbol{\psi}_{\mathrm{ATC}}$, de forma que se inicie uma trajetória de resolução de conflito. Um exemplo de trajetórias de resolução está ilustrado na Figura 45.

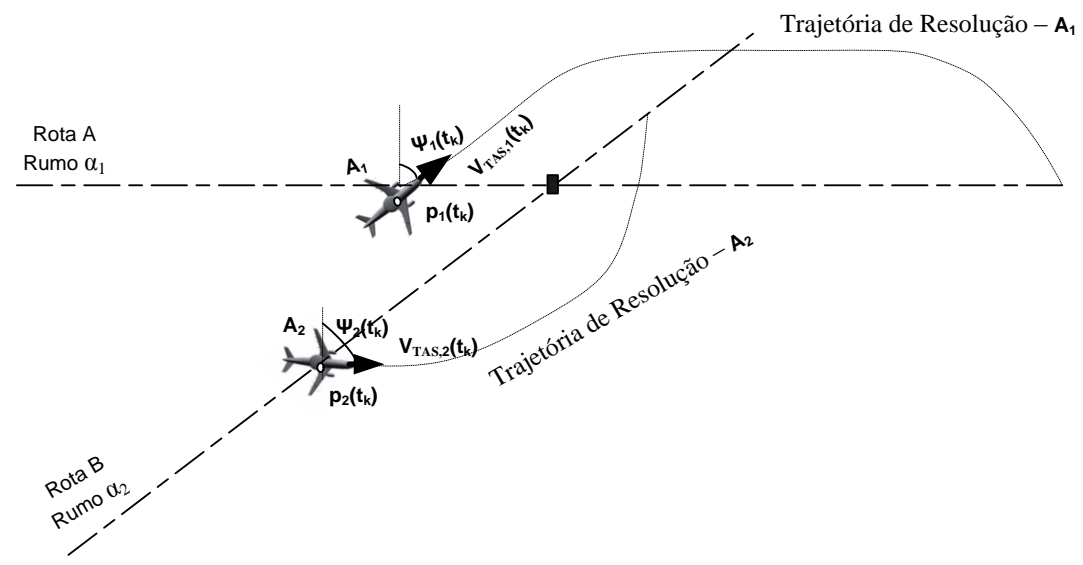

Figura 45 - Exemplo de Trajetórias para Resolução de Conflito

$\mathrm{Na}$ modelagem do Controlador de Tráfego Aéreo, serão consideradas as seguintes características: Disponibilidade do ATCo (p), Tempo de Detecção de Conflito ( $\left.\mathbf{T}_{\text {detecção }}\right)$,

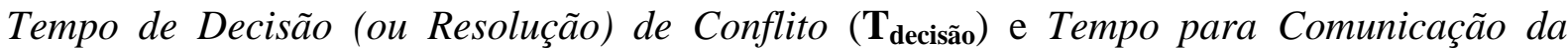

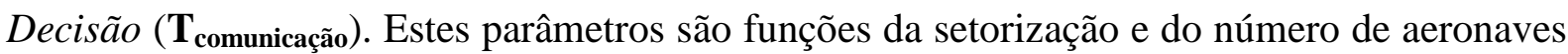
no setor (número de aeronaves comandadas pelo ATCo).

A disponibilidade do ATCo (p), segundo o Ministério da Aeronáutica (1990), é definida como o percentual do tempo em que o ATCo se dedica exclusivamente às comunicações entre aeronaves, estando excluídas as demais atividades da função (como, por exemplo, a identificação de alvos radar ou o preenchimento de strips). Desta forma, a detecção de um 
conflito ocorre na porcentagem do tempo em que o ATCo não está se comunicando com os pilotos de seu setor, ou seja, monitorando o tráfego. Segundo Manning et al (2001), a porcentagem média de tempo em que existe comunicação entre ATC e Piloto é representada por uma distribuição de probabilidade Normal com esperança 0.29 e desvio-padrão $\mathbf{0 . 0 8}(\mathbf{p}=$ $\mathbf{N}(\mathbf{0 . 2 9 , 0 . 0 8 )})$, o que representa, em média, 29\% do tempo havendo comunicação. Portanto, a disponibilidade do controlador em detectar conflitos, que afeta o tempo médio de detecção ( $\mathbf{T}_{\text {detecção)}}$ ), será balizada pela porcentagem média de tempo em que não existe comunicação entre ATCo e Pilotos $(\mathbf{q}=\mathbf{1}$ - $\mathbf{p})$.

O modelo utilizará o tempo de decisão (ou resolução) de conflito ( $\mathbf{T}_{\text {decisão }}$ ) obtido pelo trabalho de Eyferth et al (2003). Este autor definiu que o tempo decorrido para a resolução de um conflito é de, aproximadamente, 3 segundos para vôos com trajetórias em cruzamento e com tempo de conflito (tempo restante para ocorrer o evento) de 3 minutos, cenário próximo ao adotado neste estudo.

Após a decisão do conflito, o ATCo comunica a instrução que o piloto deve acatar para resolvê-lo. Segundo os estudos de Lozito et al (2003), o tempo gasto para uma transação de voz entre ATCo e Piloto (tempo gasto pelo ATCo para comunicar a instrução mais o tempo gasto pelo Piloto para confirmar o recebimento) é representado por $\mathbf{T}_{\text {comunicação }}=\mathbf{N}(\mathbf{1 2 . 8 8}$, 4.95) segundos.

Portanto, os parâmetros $\mathbf{T}_{\text {deteção, }}, \mathbf{T}_{\text {decisão }}$ e $\mathbf{T}_{\text {comunicação, relacionados aos eventos "Ocorreu }}$ Conflito", "ATCo detectou conflito", "ATCo decidiu sobre conflito" e "ATCo comunicou Piloto", estão ilustrados na Figura 46.

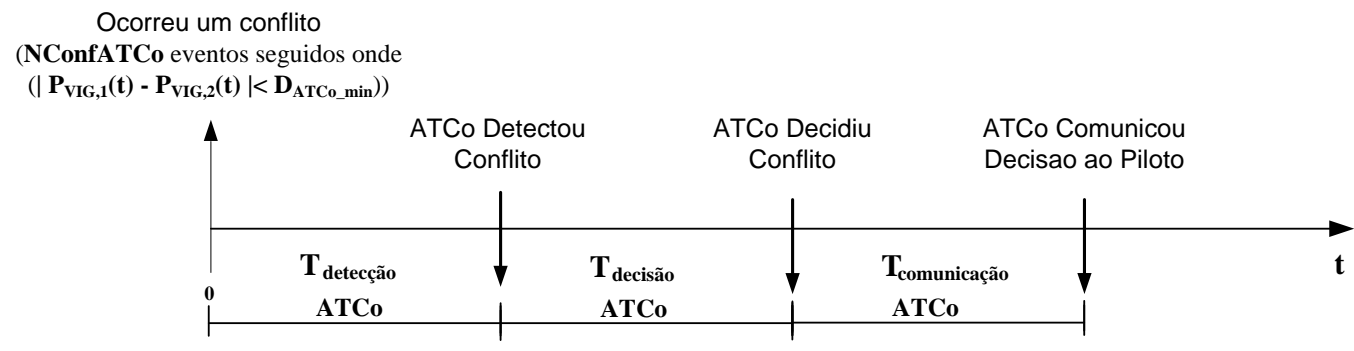

Figura 46 - Seqüência de Eventos para resolução de conflito

Como o tempo de detecção está relacionado à disponibilidade do ATCo, tem-se que:

$\mathbf{T}_{\text {detecção }} \sim \mathbf{T}_{\text {ATCo_disponivel }}$ (disponibilidade do ATCo) (Manning et al, 2001). 
Sendo $\mathbf{p}=$ porcentagem de tempo em que existe comunicação entre ATCo e Piloto:

$\mathbf{p}=\mathbf{T}_{\text {comunicação }} / \mathbf{T}_{\text {TOTAL }} \Rightarrow \mathbf{T}_{\text {TOTAL }} \cdot \mathbf{p}=\mathbf{T}_{\text {comunicação, onde }} \mathbf{p}=\mathbf{N}\left(\mathbf{0 . 2 9 , 0 . 0 8 )}\right.$ e $\mathbf{T}_{\text {comunicação }}=$ $\mathbf{N}(12.88,4.95)$.

Por simplificação, será considerado $\mathbf{T}_{\text {TOTAL }}$ constante. Aplicando a Esperança (E[]) na relação acima, tem-se:

$$
\begin{aligned}
& \mathrm{E}\left[\mathrm{T}_{\mathrm{TOTAL}} \cdot \mathrm{p}\right]=\mathrm{E}\left[\mathrm{T}_{\text {comunicação }}\right] \Rightarrow \mathrm{T}_{\mathrm{TOTAL}} \cdot \mathrm{E}[\mathrm{p}]=\mathrm{E}\left[\mathrm{T}_{\text {comunicação }}\right] \Rightarrow \\
& \Rightarrow \mathrm{T}_{\text {TOTAL }}=\mathrm{E}\left[\mathrm{T}_{\text {comunicação }}\right] / \mathrm{E}[\mathrm{p}]=12.88 / 0.29 \Rightarrow \mathrm{T}_{\mathrm{TOTAL}}=44.41 \mathrm{~s} .
\end{aligned}
$$

Dado que $\mathbf{T}_{\text {ATCo_disponivel }}=\mathbf{T}_{\text {TOTAL }}-\mathbf{T}_{\text {comunicação }}$ :

$$
\begin{aligned}
& \mathrm{E}\left[\mathrm{T}_{\mathrm{ATCo} \_ \text {disponivel }}\right]=\mathrm{E}\left[\mathrm{T}_{\mathrm{TOTAL}}\right]-\mathrm{E}\left[\mathrm{T}_{\text {comunicação }}\right] \rightarrow \mathrm{E}\left[\mathrm{T}_{\mathrm{ATCo} \_ \text {disponivel }}\right]=\mathrm{T}_{\mathrm{TOTAL}}-\mathrm{E}\left[\mathrm{T}_{\text {comunicação }}\right] \\
& =44.41-12.88=31.53 \mathrm{~s} .
\end{aligned}
$$

Para o cálculo da variância (VAR[]) de $\mathbf{T}_{\mathbf{A T C} \text { _disponivel, }}$ tem-se:

$$
\operatorname{VAR}\left[\mathrm{T}_{\mathrm{ATCo} \_ \text {disponivel }}\right]=\operatorname{VAR}\left[\mathrm{T}_{\mathrm{TOTAL}}-\mathrm{T}_{\text {comunicação }}\right]=0+\mathrm{VAR}\left[\mathrm{T}_{\text {comunicação }}\right] .
$$

Portanto: $\mathbf{T}_{\mathrm{ATC} \text { _disponivel }}=\mathbf{N}(\mathbf{3 1 . 5 3 , 4 . 9 5 )}$ segundos .

\section{$T_{\text {ATC__indisponivel }}=T_{\text {comunicaç̃a }}=\mathbf{N}(12.88,4.95)$ segundos .}

Então, os parâmetros para o ATCo são:

$\mathbf{T}_{\text {detecção }}=\mathbf{T}_{\text {ATC_disponivel }}=\mathbf{N}(31.53,4.95)$ segundos.

$\mathbf{T}_{\text {decisão }}=3$ segundos $($ Eyferth et al (2003)).

$\mathbf{T}_{\text {comunicação }}=\mathbf{T}_{\text {ATC_indisponivel }}=\mathbf{N}(\mathbf{1 2 . 8 8}, \mathbf{4 . 9 5})$ segundos $($ Lozito et al, 2003) .

\subsubsection{Sistema de Comunicação}

O elemento modelado será a comunicação VHF por voz entre Controlador de Tráfego Aéreo e ATCo. Este tipo de comunicação pode ser afetado por atrasos, por sua integridade (por erros relacionados à falta de compreensão), pela taxa de perda de transmissões (por colisão, devido à não bidirecionalidade do canal) e disponibilidade. No estudo de caso adotado, este elemento terá a função de canalizar as instruções de correção de proa transmitidas pelo ATCo ao Piloto 
e a confirmação de recebimento da instrução por parte do Piloto (comunicação entre Piloto e ATCo). Desta forma, como está sendo modelado o controle de tráfego de um único setor de um Controle de Área, onde todas as aeronaves se reportam ao mesmo controlador e viceversa, e a modelagem é comum aos dois ambientes avaliados, a afetação destas características não será considerada neste estudo.

\subsubsection{Modelagem dos Módulos Funcionais em RPFE e utilizando a SPNP}

A modelagem dos módulos funcionais, descritos no item anterior, será realizada meio do formalismo das Redes de Petri Fluidas e Estocásticas (RPFE), cujos detalhes podem ser encontrados no APÊNDICE D. Mais especificamente, serão utilizadas as RPFE, em conjunto com as potencialidades da ferramenta computacional SPNP (Stochastic Petri Net Package), para implementar características tipicamente não pertencentes à técnica, tal como acurácia espacial abordada a seguir.

A Stochastic Petri Net Package (SPNP) (Trivedi, 1999) é uma ferramenta computacional de modelagem para solução de redes de Petri Temporizadas e Estocásticas, tanto Markovianas quanto não Markovianas, e de redes de Petri Fluidas e Estocásticas (RPFE). A linguagem utilizada na descrição dos modelos é a CSPL (C-based Stochastic Petri Nets Language), baseada na linguagem de programação ANSI-C e adicionada de alguns formalismos e bibliotecas proprietárias da ferramenta (Hirel; Tuffin; Trivedi, 2000).

A SPNP utiliza como base de seu formalismo as redes de Petri Estocásticas de Recompensa (Stochastic Reward Net - SRN), uma extensão das redes de Petri estocásticas abordada anteriormente, que possibilita a análise de seus modelos utilizando tanto métodos analíticos quanto simulação por eventos discretos. Quanto à simulação por eventos discretos (Discrete Event Simulation - DES), pode-se realizar tanto análise estacionária (steady-state) quanto transitória (transient) dos formalismos das redes de Petri Fluidas e das redes não-Markovianas (Non-Markovian Nets).

O formalismo das redes de Petri Fluidas e Estocásticas, da forma como esta implementado na versão 6.01 da ferramenta SPNP (Trivedi, 1999), permite modelar sistemas com comportamento temporal estocástico e comportamento espacial determinístico, onde os valores das marcações, tanto para lugares discretos quanto contínuos, variam de forma determinística. A respeito dos lugares fluidos, este comportamento espacial determinístico é devido a sua representação por equações diferenciais de primeira ordem. Devido o Sistema de 
Controle de Tráfego Aéreo, o qual foi proposto para modelagem e análise por meio do formalismo das RPFE, possuir diversos parâmetros espaciais estocásticos relevantes, tais como erros de navegação (radiais VOR, distância DME, posição GPS) e erros de vigilância (posição Radar, posição ADS), foi necessário adaptar a ferramenta computacional para que pudesse considerar o comportamento espacial estocástico do modelo. Como a SPNP possui código-fonte proprietário, não acessível à edição, optou-se por caracterizar os parâmetros espaciais estocásticos por meio de variáveis globais de software, utilizando as potencialidades da linguagem CSPL (baseada em ANSI-C). O comportamento estocástico destas variáveis é introduzido pela chamada, a partir da dinâmica da rede envolvida, de uma função que gera a distribuição de probabilidade com as características desejadas. Estas variáveis globais são utilizadas para tomada de decisão nas funções de guarda (g), ou em quaisquer outras funções dependentes de marcação, da modelagem de uma rede de Petri Fluida e Estocástica.

Devido à extensão do tema, o APÊENDICE E apresenta os critérios empregados que levaram à escolha da ferramenta SPNP, bem como suas características, a forma de utilização, suas limitações e, principalmente, as contribuições promovidas sobre a mesma.

Segue a descrição da modelagem de cada um dos blocos funcionais e suas interações decorrentes do processo de controle de tráfego aéreo.

\subsubsection{Aeronave (Dinâmica)}

As variáveis de estado consideradas para o modelo da Aeronave "i” estão representadas por $\mathbf{A}_{\mathbf{i}}(\mathbf{t})=\left\{\mathbf{P}_{\mathbf{i}}(\mathbf{t}), \mathbf{V}_{\mathrm{TAS}, \mathrm{i}}(\mathbf{t}), \psi_{\mathrm{i}}(\mathbf{t})\right\}$, onde:

$$
\begin{aligned}
& \mathbf{P}_{\mathbf{i}}(\mathbf{t})=\left(\mathbf{X}_{\mathrm{i}}(\mathbf{t}), \mathbf{Y}_{\mathbf{i}}(\mathbf{t}), \mathbf{h}_{\mathbf{i}}(\mathbf{t})\right)=\left(\left\|\mathbf{V}_{\mathrm{TAS}, \mathrm{i}}(\mathbf{t})\right\| \cdot \operatorname{sen}\left(\psi_{\mathrm{i}}(\mathbf{t})\right),\left\|\mathbf{V}_{\mathrm{TAS}, \mathrm{i}}(\mathbf{t})\right\| \cdot \cos \left(\psi_{\mathrm{i}}(\mathbf{t})\right), \mathbf{0}\right) \\
& \mathbf{V}_{\text {TAS }, \mathbf{i}}(\mathbf{t})=\left(\left\|\mathbf{V}_{\mathrm{TAS}, \mathbf{i}}(\mathrm{t})\right\| \cdot \operatorname{sen}\left(\psi_{\mathrm{i}}(\mathrm{t})\right),\left\|\mathbf{V}_{\mathrm{TAS}, \mathrm{i}}(\mathbf{t})\right\| \cdot \cos \left(\psi_{\mathrm{i}}(\mathbf{t})\right), 0\right) . \\
& \psi_{\mathbf{i}}(\mathbf{t})=\psi_{\mathbf{i}}\left(\mathbf{t}_{\mathbf{0}}\right)+\left(\mathbf{t}-\mathbf{t}_{\mathbf{0}}\right) \cdot \mathbf{g} \cdot \tan \left(\phi_{\text {nom }}\right) / \mathbf{V}_{\mathrm{TAS}, \mathbf{i}}, \text { quando } \mathrm{d} \psi(\mathrm{t}) / \mathrm{dt} \neq 0 \\
& =\psi_{\mathbf{i}}\left(\mathbf{t}_{\mathbf{0}}\right) \text {, quando } \mathrm{d} \psi(\mathrm{t}) / \mathrm{dt}=0 \text {. }
\end{aligned}
$$

Nesta modelagem, foi considerado que a Aeronave sofre as ações do Sistema de Navegação, que controla o valor de proa desejado ( $\Psi$ correção), e também as ações dos ventos $\left(\mathbf{W}\left(\mathbf{t}, \mathbf{p}_{\mathbf{i}}\right)\right)$. Por isso, o diagrama de bloco de uma Aeronave pode ser representado conforme a Figura 47: 


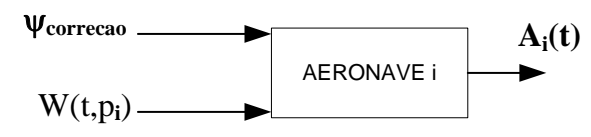

Figura 47 - Diagrama de bloco de uma Aeronave

Como apresentado no APÊNDICE E, a versão utilizada da ferramenta SPNP (Trivedi, 1999) permite a modelagem do comportamento no tempo de valores contínuos $\chi_{\mathbf{q}} \in \mathbf{R}^{+}$na forma:

$\frac{\mathrm{d} \chi_{\mathrm{q}}(\tau)}{\mathrm{d} t}=\mathrm{A}(\mu) \cdot \chi_{\mathrm{q}}(\tau)+\mathrm{B}(\mu), \mathrm{A}(\mu) \neq 0$, onde $\mathrm{A}(\mu)$ e $\mathrm{B}(\mu)$ são funções dependentes da marcação discreta da rede.

Caso $\mathbf{A}(\boldsymbol{\mu})=\mathbf{0}$, tem-se $\frac{\mathrm{d} \chi_{\mathrm{q}}(\tau)}{\mathrm{d} t}=\mathrm{B}(\mu) \Rightarrow \chi_{\mathbf{q}}(\mathbf{t})=\chi_{\mathbf{q}}\left(\mathbf{t}_{\mathbf{0}}\right)+\left(\mathbf{t}-\mathbf{t}_{\mathbf{0}}\right) . \mathbf{B}(\boldsymbol{\mu})$.

Dado que:

$$
\begin{aligned}
& \mathbf{X}_{\mathbf{i}}(\mathbf{t})=\mathbf{X}_{\mathbf{i}}\left(\mathbf{t}_{\mathbf{0}}\right)+\left(\mathbf{t}-\mathbf{t}_{\mathbf{0}}\right) \cdot\left(\left\|\mathbf{V}_{\mathrm{TAS}, \mathrm{i}}\left(\mathbf{t}_{\mathbf{0}}\right)\right\| \cdot \operatorname{sen}\left(\psi_{\mathbf{i}}\left(\mathbf{t}_{\mathbf{0}}\right)\right)+\left\|\mathbf{W}\left(\mathbf{t}_{\mathbf{0}}, \mathbf{p}_{\mathrm{i}}\right)\right\| \cdot \operatorname{sen}\left(\psi_{\mathrm{w}}\left(\mathbf{t}_{\mathbf{0}}, \mathbf{p}_{\mathrm{i}}\right)\right)\right)= \\
& =\mathbf{X}_{\mathbf{i}}\left(\mathbf{t}_{\mathbf{0}}\right)+\left(\mathbf{t}-\mathbf{t}_{\mathbf{0}}\right) \cdot \mathbf{B}_{\mathbf{X i}}(\boldsymbol{\mu}), \text { onde: } \\
& \mathbf{B}_{\mathbf{X i}}(\boldsymbol{\mu})=\left(\left\|\mathbf{V}_{\mathrm{TAS}, \mathbf{i}}\left(\mathbf{t}_{\mathbf{0}}\right)\right\| \cdot \operatorname{sen}\left(\psi_{\mathbf{i}}\left(\mathbf{t}_{\mathbf{0}}\right)\right)+\left\|\mathbf{W}\left(\mathbf{t}_{\mathbf{0}}, \mathbf{p}_{\mathbf{i}}\right)\right\| \cdot \operatorname{sen}\left(\psi_{\mathrm{w}}\left(\mathbf{t}_{0}, \mathbf{p}_{\mathbf{i}}\right)\right)\right) \\
& \mathbf{Y}_{\mathrm{i}}(\mathbf{t})=\mathbf{Y}_{\mathrm{i}}\left(\mathbf{t}_{\mathbf{0}}\right)+\left(\mathbf{t}-\mathbf{t}_{\mathbf{0}}\right) \cdot\left(\left\|\mathbf{V}_{\mathrm{TAS}, \mathrm{i}}\left(\mathbf{t}_{\mathbf{0}}\right)\right\| \cdot \cos \left(\psi_{\mathrm{i}}\left(\mathbf{t}_{\mathbf{0}}\right)\right)+\left\|\mathbf{W}\left(\mathbf{t}_{\mathbf{0}}, \mathbf{p}_{\mathrm{i}}\right)\right\| \cdot \cos \left(\psi_{\mathrm{w}}\left(\mathbf{t}_{0}, \mathbf{p}_{\mathrm{i}}\right)\right)\right)= \\
& =\mathbf{Y}_{\mathbf{i}}\left(\mathbf{t}_{\mathbf{0}}\right)+\left(\mathbf{t}-\mathbf{t}_{\mathbf{0}}\right) \cdot \mathbf{B}_{\mathbf{Y i}}(\boldsymbol{\mu}), \text { onde : } \\
& \mathbf{B}_{\mathbf{Y i}}(\boldsymbol{\mu})=\left(\left\|\mathbf{V}_{\mathrm{TAS}, \mathbf{i}}\left(\mathbf{t}_{\mathbf{0}}\right)\right\| \cdot \cos \left(\psi_{\mathbf{i}}\left(\mathbf{t}_{\mathbf{0}}\right)\right)+\left\|\mathbf{W}\left(\mathbf{t}_{0}, \mathbf{p}_{\mathbf{i}}\right)\right\| \cdot \cos \left(\psi_{\mathrm{w}}\left(\mathbf{t}_{0}, \mathbf{p}_{\mathbf{i}}\right)\right)\right)
\end{aligned}
$$

Desta forma, para o espaço de estados da Aeronave 'i', são consideradas para a rede:

- Variáveis Contínuas: $\mathbf{X}_{\mathbf{i}}(\mathbf{t}), \mathbf{Y}_{\mathbf{i}}(\mathbf{t})$.

- Variáveis Discretas: $\left\|\mathbf{V}_{\mathrm{TAS}, \mathbf{i}}(\mathbf{t})\right\|, \psi_{\mathrm{i}}(\mathbf{t}),\left\|\mathbf{W}\left(\mathbf{t}_{\mathbf{0}}, \mathbf{p}\right)\right\|, \psi_{\mathrm{w}}\left(\mathbf{t}_{\mathbf{0}}, \mathbf{p}\right)$

Como a velocidade $\mathrm{V}_{\mathrm{TAS}, \mathrm{i}}(\mathrm{t})$ não será controlada pelo Piloto Automático, considera-se $\left\|\mathbf{V}_{\text {TAS }, \mathbf{i}}(\mathbf{t})\right\|=\mathbf{V}_{\text {TAS }, \mathbf{i}} \in \mathbf{R}^{+}, \forall \mathbf{t} \in \mathbf{R}^{+}$.

O objetivo deste trabalho não é o de modelar o comportamento dinâmico dos ventos sobre o 
estado da Aeronave, principalmente por ser este estudo um método comparativo e o modelo de Aeronave ser o mesmo para ambos os sistemas. Sendo assim, as variáveis $\left\|\mathbf{W}\left(\mathbf{t}_{\mathbf{0}}, \mathbf{p}\right)\right\|=\mathbf{W}$, $\forall \mathbf{p} \in \mathbf{R}^{3}$ e $\boldsymbol{\psi}_{\mathrm{w}}\left(\mathbf{t}_{0}, \mathbf{p}\right)=\boldsymbol{\psi}_{\mathrm{w}} \in\left[\mathbf{0}^{\mathbf{o}} ; \mathbf{3 5 9}^{\circ}\right], \forall \mathbf{p} \in \mathbf{R}^{\mathbf{3}}$, são constantes e não sofrerão alterações durante a simulação.

Portanto, o modelo de Estado da Aeronave 'i' será modelo em Redes de Petri Fluidas e Estocásticas conforme ilustra a Figura 48.

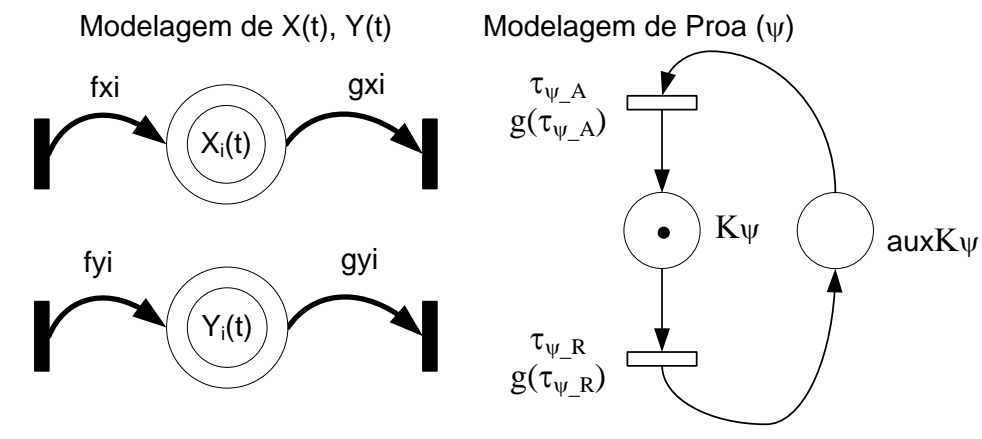

Figura 48 - Modelo de Estado da Aeronave "i" em RPFE

A proa da aeronave é modelada por uma rede discreta com lugar $\mathbf{K} \psi$ e $\mathbf{a u x K} \psi$, como forma de mantê-la conservativa. O lugar $\mathbf{K} \boldsymbol{\psi}$ representa um valor de proa na forma:

$$
\psi_{K \psi}=\alpha_{i}+(\mu(K \psi)-\mathbf{M}) . \Delta \psi, \operatorname{para} \mu(K \psi) \in \mathbf{N}^{+} \mid \mu(K \psi) \in[0,2 . M]
$$

onde $\mathbf{M}$ é o número discreto de passos de proa $(\Delta \psi)$ ao redor de $\alpha_{\mathbf{i}}$ (rumo da rota planejada), resultando em valores de proa $\psi_{i} \in \mathbf{N}^{+} \mid \psi_{i}=\left[\alpha_{i}-\mathbf{M} . \Delta \psi, \alpha_{i}+\mathbf{M} . \Delta \psi\right]$.

Como a modelagem de proa é representada por uma rede ordinária, qualquer evento de disparo da transição $\tau_{\psi_{-} \mathbf{A}}$ (aumento do valor de proa) ou $\tau_{\psi_{-} \mathbf{R}}$ (redução do valor de proa)) promove um novo valor de marcação em $\mathbf{K} \psi$ no formato $\boldsymbol{\mu}(\mathbf{K} \psi)_{(} \uparrow \tau_{\left.\psi_{-} \mathrm{A}\right)}=(\boldsymbol{\mu}(\mathbf{K} \psi)+\mathbf{1})$ ou $\boldsymbol{\mu}(\mathbf{K} \psi)_{\left(\uparrow \tau_{\psi_{-}}\right)}=(\# \mathbf{K} \psi-\mathbf{1})$, respectivamente.

Portanto, como a modelagem de proa em redes de Petri deve representar o comportamento $\psi_{\mathbf{i}}(\mathbf{t})=\psi_{\mathbf{i}}\left(\mathbf{t}_{\mathbf{0}}\right)+\left(\mathbf{t}-\mathbf{t}_{\mathbf{0}}\right) \cdot \mathbf{g} \cdot \tan \left(\phi_{\text {nom }}\right) / \mathbf{V}_{\mathbf{T A S}, \mathbf{i}}$, e o valor de proa varia em passos discretos de valor $\Delta \psi$, tem-se que:

$$
\psi_{\mathrm{i}}\left(\mathbf{t}_{\mathbf{n}+1}\right)=\psi_{\mathrm{i}}\left(\mathbf{t}_{\mathrm{n}}\right)+\tau_{\psi} \cdot \mathrm{g} \cdot \tan \left(\phi_{\mathrm{nom}}\right) /\left\|\mathbf{V}_{\mathrm{TAS}}\right\| \Leftrightarrow
$$




$$
\begin{gathered}
\psi_{\mathbf{i}}\left(\mathbf{t}_{\mathbf{n}+1}\right)-\psi_{\mathbf{i}}\left(\mathbf{t}_{\mathbf{n}}\right)=\tau_{\psi} \cdot \mathrm{g} \cdot \tan \left(\phi_{\text {nom }}\right) /\left\|\mathbf{V}_{\text {TAS }}\right\| \Leftrightarrow \\
\tau_{\psi}=\left(\Delta \psi \cdot\left\|\mathbf{V}_{\text {TAS }}\right\|\right) /\left(\text { g.tan }\left(\phi_{\text {nom }}\right)\right) .
\end{gathered}
$$

Desta forma, para cada passo de proa $\Delta \psi$, decorre-se o tempo $\tau_{\psi}=\left(\Delta \psi \cdot\left\|\mathbf{V}_{\text {TAS }}\right\|\right) /\left(\operatorname{g.tan}\left(\phi_{\text {nom }}\right)\right)$, independentemente se o valor de proa está aumentando ou reduzindo.

A variação no valor da proa da aeronave, baseada no controle do valor de $\phi_{\text {nom }}$, é realizada pelo Sistema de Navegação. Na rede, este controle é representado pelas guardas (g()) nas transições determinísticas temporizadas $\tau_{\psi_{-} \mathbf{A}}$ e $\tau_{\psi_{-} \mathbf{R}}$. Quando o sistema de navegação comanda um acréscimo no valor de proa $(\Psi(t)<\Psi$ desejado $)$, tem-se $\mathbf{g}\left(\tau_{\Psi_{-} \mathrm{A}}\right)=\mathbf{1}$ e $\mathbf{g}\left(\tau_{\Psi_{-} \mathbf{R}}\right)=\mathbf{0}$, enquanto o sistema de navegação não detectar que o valor de proa chegou ao valor desejado $(\Psi(t)=\Psi d e s e j a d o)$.

De forma semelhante, quando o sistema de navegação comanda um decréscimo no valor de proa $(\Psi(\mathbf{t})>\Psi$ desejado $)$, tem-se $\mathbf{g}\left(\tau_{\Psi_{-} \mathbf{A}}\right)=\mathbf{0}$ e $\mathbf{g}\left(\tau_{\Psi_{-} \mathbf{R}}\right)=\mathbf{1}$, enquanto o sistema de navegação não detectar que o valor de proa chegou ao valor desejado $(\Psi(\mathbf{t})=\Psi$ desejado $)$. Assim, é possível simular o incremento ou o decremento gradual do valor de proa da aeronave conforme a correção comandada, inclusive nos casos de ocorrer uma instrução por parte do ATCo (PsiRes). O valor das condições destas guardas será apresentado no item "Navegação".

As variáveis contínuas $\mathbf{X}_{\mathbf{i}}(\mathbf{t})$ e $\mathbf{Y}_{\mathbf{i}}(\mathbf{t})$ representadas na rede da Figura 48 são modeladas através dos lugares contínuos de mesmo nome, e a dinâmica de cada variável é modelada por seus arcos contínuos fxi e gxi, fyi e gyi, respectivamente. A cardinalidade para cada arco depende da rede discreta que modela a Proa da Aeronave.

Para modelar uma taxa de crescimento no valor de $\mathbf{X i}(\mathbf{t})$, deve-se fazer fxi $>\mathbf{0 . 0}$ e $\mathbf{g x i}=\mathbf{0 . 0}$. Para modelar uma taxa de redução no valor de $\mathbf{X i}(\mathbf{t})$, deve-se fazer $\mathbf{f x i}=\mathbf{0 . 0}$ e gxi $>\mathbf{0 . 0}$.

Para modelar uma taxa de crescimento no valor de $\mathbf{Y i}(\mathbf{t})$, deve-se fazer fyi $>\mathbf{0 . 0}$ e $\mathbf{g y i}=\mathbf{0 . 0}$. Para modelar uma taxa de redução no valor de $\mathbf{Y i}(\mathbf{t})$, deve-se fazer $\mathbf{f y i}=\mathbf{0 . 0}$ e gyi $>\mathbf{0 . 0}$.

Desta forma, têm-se os valores das cardinalidades fxi, gxi, fyi e gyi representadas por:

$\operatorname{Para} \mathbf{X i}(\mathbf{t})$ :

$$
B_{\mathbf{X i}}(\mu)=V_{T A S, i} \cdot \operatorname{sen}\left(\psi_{i}(\mu)\right)+W \cdot \operatorname{sen}\left(\psi_{w}\right)
$$




$$
\begin{aligned}
& \mathbf{B}_{\mathrm{Xi}}(\mu)>0.0 \rightarrow \text { fxi }=\mathbf{B}_{\mathrm{Xi}}(\mu) ; \operatorname{gxi}=0.0 ; \\
& \mathbf{B}_{\mathrm{Xi}}(\mu)<0.0 \rightarrow \text { fxi }=0.0 ; \text { gxi }=\mathbf{B}_{\mathrm{Xi}}(\mu) ;
\end{aligned}
$$

Para Yi(t):

$$
\begin{array}{r}
B_{\mathrm{Yi}}(\mu)=V_{\mathrm{TAS}, \mathrm{i}} \cdot \cos \left(\psi_{\mathrm{i}}(\mu)\right)+\mathrm{W} \cdot \cos \left(\psi_{\mathrm{w}}\right) \\
B_{\mathrm{Yi}}(\mu)>0.0 \rightarrow \text { fyi }=\mathrm{B}_{\mathrm{Yi}}(\mu) ; \mathrm{gyi}=0.0 ; \\
B_{\mathrm{Yi}}(\mu)<0.0 \rightarrow \text { fyi }=0.0 ; \text { gyi }=\mathrm{B}_{\mathrm{Yi}}(\mu) ;
\end{array}
$$

O valores de $\mathbf{B}_{\mathbf{Y i}}(\boldsymbol{\mu})$ e $\mathbf{B}_{\mathbf{X i}}(\boldsymbol{\mu})$ dependem da marcação ' $\boldsymbol{\mu}$ ' da rede que modela a Proa da aeronave. Assim, considerando $\boldsymbol{\mu}(\mathbf{K} \psi)$ o número de marcas presentes no lugar $\mathbf{K} \psi$, tem-se :

$$
\begin{aligned}
& \mathbf{B}_{\mathbf{X i}}(\mathbf{m})=V_{T A S, i} \cdot \operatorname{sen}\left(\alpha_{i}+\left(\mu\left(K \psi_{i}\right)-M_{i}\right) \cdot \Delta \psi_{i}\right)+W \cdot \operatorname{sen}\left(\psi_{w}\right) \\
& B_{Y i}(m)=V_{T A S, i} \cdot \cos \left(\alpha_{i}+\left(\mu\left(K \psi_{i}\right)-M_{i}\right) \cdot \Delta \psi_{i}\right)+W \cdot \operatorname{sen}\left(\psi_{w}\right)
\end{aligned}
$$

Portanto, as variáveis consideradas para o modelo da Aeronave 'i', i = 1, 2, são:

\section{- Variáveis de Entrada:}

$\left\{\Delta \psi_{\mathrm{i}}, \mathrm{M}_{\mathrm{i}}, \mathrm{g}, \phi_{\text {nom }}\right\}_{[\text {Aeronave }]},\left\{\alpha_{\mathrm{i}}, \mathrm{V}_{\mathrm{TAS}, \mathrm{i}}, \mathrm{W}, \psi_{\mathrm{w}}\right\}_{[\text {EspaçoAéreo }]},\{\mu($ Reduz_Proa_i $)$, $\mu($ Mantem_Proa_i $), \mu(\text { Aumenta_Proa_i) }\}_{[\text {Navegação] }}$

- Variáveis de Saída: $\mathrm{X}_{\mathrm{i}}(\mathrm{t}), \mathrm{Y}_{\mathrm{i}}(\mathrm{t}), \mu\left(\mathrm{K} \psi_{\mathrm{i}}\right)$.

Onde o Estado Inicial é dado por:

$$
\begin{aligned}
& \left(\mathbf{X}_{1}(0), \mathbf{Y}_{1}(0)\right)=\mathbf{P}_{1}\left(t_{0}\right)=\left(\mathbf{X}_{\text {NOT(A1) }}+\varepsilon_{P x}, Y_{\text {NOT(A1) }}+\varepsilon_{P y}\right) . \\
& \left(\mathbf{X}_{2}(\mathbf{0}), \mathbf{Y}_{2}(\mathbf{0})\right)=\mathbf{P}_{2}\left(\mathbf{t}_{\mathbf{0}}\right)=\left(\mathbf{X}_{\mathrm{NOT}(\mathrm{B} 1)}+\varepsilon_{\mathrm{Px}}, \mathbf{Y}_{\mathrm{NOT}(\mathbf{B} 1)}+\varepsilon_{\mathrm{Py}}\right) . \\
& \mu\left(K \psi_{1(t=0)}\right)=M_{1} \rightarrow \psi_{1}(0)=\alpha_{1} . \\
& \left.\mu\left(K \psi_{2(t=0)}\right)=M_{2} \rightarrow \psi_{2} 0\right)=\alpha_{2} .
\end{aligned}
$$

Onde $\left(\boldsymbol{\varepsilon}_{\mathbf{P x}}, \boldsymbol{\varepsilon}_{\mathbf{P y}}\right)$ estão relacionados à acurácia dos elementos de navegação, sendo:

a. Para Navegação VOR: $\left(\varepsilon_{\mathbf{P x}}, \varepsilon_{\mathbf{P y}}\right)_{\underline{i}}=\left(\varepsilon_{\text {DME }}, T_{\text {tot. }} V_{\text {TAS, } \underline{\mathbf{i}}} \cdot \operatorname{tg}\left(\varepsilon_{\text {VOR }}\right)\right)$. 
$\left(\varepsilon_{\text {DME }}, \varepsilon_{\text {VOR }}\right)$ são os erros introduzido pelo sistema DME e pelo sistema VOR, respectivamente. Mesmo que o sistema DME não esteja modelado aqui, pois não são aplicadas correções sobre a velocidade das aeronaves, $\boldsymbol{\varepsilon}_{\mathbf{D M E}}$ serve para introduzir erros espaciais sobre a posição inicial da aeronave.

b. $\quad$ Para Navegação GPS: $\left(\varepsilon_{\mathbf{P x}}, \varepsilon_{\mathbf{P y}}\right)_{\underline{i}}=\left(\varepsilon_{\mathrm{GPS}}, \boldsymbol{\varepsilon}_{\mathrm{GPS}}\right)$.

$\boldsymbol{\varepsilon}_{\mathrm{GPS}}$ é o erro introduzido pelo sistema GPS.

Por fim, vale ressaltar que o mesmo processo empregado para variar o valor de Proa $\psi$ da Aeronave pode também ser aplicado para modelar as condições $\partial \mathbf{W}(\mathbf{t}, \mathbf{p}) / \partial \mathbf{t} \neq \mathbf{0}$ e $\mathbf{d V}_{\mathbf{T A S}, \mathbf{i}}(\mathbf{t}) \mathbf{d t}$ \# 0. Ou seja, pode-se modelar uma rede discreta semelhante à ilustrada na Figura 48 para cada uma destas variáveis e utilizar suas transições para gerar a variação de seus valores. Porém, definiu-se que isto fica como proposta para trabalhos futuros.

\subsubsection{Espaço Aéreo}

Na modelagem em rede de Petri Fluida e Estocástica, o Espaço Aéreo é representado por um conjunto de valores que serão utilizados pela rede durante o processo de simulação. Sendo assim, define-se que:

- Devido às características da ferramenta SPNP, deve-se considerar que $(\mathbf{X i}(\mathbf{t}), \mathbf{Y i}(\mathbf{t})) \in \mathbf{R}^{+\mathbf{2}}$ para todo o intervalo de tempo de simulação.

- $\quad$ O efeito meteorológico do vento, $\mathbf{W}(\mathbf{t}, \mathbf{p})$, será $\partial \mathbf{W}(\mathbf{t}, \mathbf{p}) / \partial \mathbf{t}=\partial \mathbf{W}(\mathbf{t}, \mathbf{p}) / \partial \mathbf{p}=\mathbf{0}$. Como descrito anteriormente, os ventos são representados por sua intensidade e sua orientação: $w(t, p) / \psi_{w}(t, p)$, onde $w(t, p)=W \in[0$ kts; 60kts $]$ e $\psi_{w}(t, p)=\psi_{w} \in\left[0^{\circ}\right.$; $\left.359^{\circ}\right]$.

- As rotas A e B com rumos $\boldsymbol{\alpha}_{1}$ e $\boldsymbol{\alpha}_{2}$, respectivamente, cruzando em um ponto de notificação $\mathbf{O}_{\mathbf{i}+\mathbf{1}}=\mathbf{O}_{\mathbf{j}+\mathbf{1}}$ com um ângulo $\boldsymbol{\theta}=\left|\boldsymbol{\alpha}_{\mathbf{1}}-\boldsymbol{\alpha}_{\mathbf{2}}\right|$. Por simplificação, será adotado $\boldsymbol{\alpha}_{\mathbf{1}}$ $=90^{\circ}$ e $\boldsymbol{\alpha}_{2}=90^{\circ}-\boldsymbol{\theta}$, onde $\boldsymbol{\theta} \in\left[0^{\circ} ; 9^{\circ}\right]$.

- As rotas A e B são formadas pelos segmentos $\left(\mathbf{O}_{\mathrm{A1}}-\mathbf{O}_{\mathrm{A} 2}\right)$ e $\left(\mathbf{O}_{\mathbf{B} 1}-\mathbf{O}_{\mathbf{B} 2}\right)$, respectivamente, onde $\mathbf{O}_{\mathbf{A} 2}=\mathbf{O}_{\mathbf{B} 2}$. Cada ponto de notificação possui uma coordenada conhecida $\left\{\mathbf{O}_{\mathrm{A} 1}=\left(\mathbf{X}_{\mathrm{NOT}(\mathrm{A} 1)}, \mathbf{Y}_{\mathrm{NOT}(\mathrm{A} 1)}\right), \mathbf{O}_{\mathrm{B} 1}=\left(\mathbf{X}_{\mathrm{NOT}(\mathbf{B} 1)}, \mathbf{Y}_{\mathrm{NOT}(\mathbf{B} 1)}\right), \mathbf{O}_{\mathrm{A} 2}=\mathbf{O}_{\mathrm{B} 2}=\right.$ $\left(\mathbf{X}_{\text {NOT(A2) }}, \mathbf{Y}_{\text {NOT(A2) })}\right\}$. 
- $\quad$ Houve um planejamento estratégico para os vôos, de forma que as aeronaves $\mathbf{A}_{\mathbf{1}}$ e $\mathbf{A}_{2}$ iniciam no instante $\mathrm{t}_{0}$, teoricamente, sobre os pontos de notificação (waypoint) $\mathbf{O}_{\mathrm{A1}} \mathrm{e}$ $\mathbf{O}_{\mathbf{B} \mathbf{1}}$, com velocidades TAS $\mathbf{V}_{\text {TAS, }, \mathbf{1}}\left(\mathbf{t}_{\mathbf{0}}\right)$ e $\mathbf{V}_{\text {TAS, }, 2}\left(\mathbf{t}_{\mathbf{0}}\right)$, proas $\boldsymbol{\psi}_{\mathbf{1}}\left(\mathbf{t}_{\mathbf{0}}\right)=\boldsymbol{\alpha}_{\mathbf{1}}$ e $\boldsymbol{\psi}_{\mathbf{2}}\left(\mathbf{t}_{\mathbf{0}}\right)=\boldsymbol{\alpha}_{\mathbf{2}}$ e altitudes $\mathbf{h}_{\mathbf{1}}\left(\mathbf{t}_{\mathbf{0}}\right)$ e $\mathbf{h}_{\mathbf{2}}\left(\mathbf{t}_{\mathbf{0}}\right)$, respectivamente. Baseado neste planejamento, e caso as aeronaves sigam seus planos de vôo, haverá sempre "separação mínima teórica" compatível com as normas de separação em vigor. Ou seja, quando $\mathbf{P}_{\mathbf{1}}(\mathbf{T t o t})=\mathbf{O}_{\mathbf{B} 2}$, a distância entre as aeronaves d(Ttot) será maior ou igual à distância de separação mínima requerida (Dmin), onde $\mathbf{d}(\mathbf{T t o t}) \geq$ Dmin. Nestas condições, o planejamento do tráfego considera que:

$$
\begin{aligned}
& \mathbf{V}_{\mathrm{TAS}, 1}=\left|\mathrm{O}_{\mathrm{A} 2}-\mathrm{O}_{\mathrm{A} 1}\right| / \text { Ttot }=\mathrm{d}_{1} / \text { Ttot } ; \\
& \mathrm{V}_{\mathrm{TAS}, 2}=\left(\left|\mathbf{O}_{\mathrm{B} 2}-\mathrm{O}_{\mathrm{B} 1}\right|-\text { Dmin }\right) / \text { Ttot }=\left(\mathbf{d}_{2}-\text { Dmin }\right) / \text { Ttot } ;
\end{aligned}
$$

Onde Ttot é o tempo decorrido pela Aeronave $\mathbf{A}_{\mathbf{1}}$ entre os pontos de notificação $\left(\mathbf{O}_{\mathrm{A} 2}\right.$ $\left.-\mathbf{O}_{\mathrm{A} 1}\right)$.

Das equações anteriores, deriva-se $\mathbf{O}_{\mathbf{n}}=\left(\mathbf{X}_{\mathbf{N O T}(\mathbf{n})}, \mathbf{Y}_{\mathrm{NOT}(\mathbf{n})}\right), \mathrm{n}=\{\mathrm{A} 1, \mathrm{~A} 2, \mathrm{~B} 1 \mathrm{~B} 2\}$ :

$$
\begin{aligned}
& \mathbf{O}_{\mathrm{A} 2}=\mathbf{O}_{\mathrm{B} 2}=\left(\mathbf{X}_{\mathrm{NOT}(\mathrm{A} 2)}, \mathbf{Y}_{\mathrm{NOT}(\mathrm{A} 2)}\right) ; \\
& \mathbf{O}_{\mathrm{A} 1}=\left(\mathbf{X}_{\mathrm{NOT}(\mathrm{A} 2)}-\mathrm{Ttot} \cdot \mathrm{V}_{\mathrm{TAS}, 1} ; \mathbf{Y}_{\mathrm{NOT}(\mathrm{A} 2)}\right) ; \\
& \mathbf{O}_{\mathrm{B} 1}=\left(\mathbf{X}_{\mathrm{NOT}(\mathrm{A} 2)}-\left(\mathrm{Ttot} \cdot \mathrm{V}_{\mathrm{TAS}, 2}+\operatorname{Dmin}\right) \cdot \cos (\theta) ; \mathbf{Y}_{\mathrm{NOT}(\mathrm{A} 2)}-\left(\mathrm{Ttot} \cdot \mathrm{V}_{\mathrm{TAS}, 2}+\right.\right. \\
& \text { Dmin }) . \operatorname{sen}(\theta)) ;
\end{aligned}
$$

Desta forma, as variáveis consideradas para o Espaço Aéreo (EA) são:

Variáveis de Saída: $\left\{\mathrm{X}_{\mathrm{NOT}(\mathrm{A} 2)}, \mathrm{Y}_{\mathrm{NOT}(\mathrm{A} 2)}, \text { Dmin, Ttot, } \theta, \mathrm{V}_{\mathrm{TAS}, \mathrm{i}}, \mathrm{W}, \psi_{\mathrm{w}}\right\}_{[\mathrm{EA}]}$

\subsubsection{Sistema de Navegação}

O sistema de navegação modelado possui 3 estados distintos: "Manter Proa", "Aumentar Proa" e "Reduzir Proa", que correspondem às ações de correção de Proa que devem ser aplicadas à aeronave para mantê-la na rota desejada. Cada um dos estados depende de fatores relacionados ao tipo de auxílio à navegação e ao algoritmo de navegação utilizado. Estes fatores são modelados por guardas nas transições da rede, ilustrada pela Figura 49, que modelam a navegação da aeronave "i". 


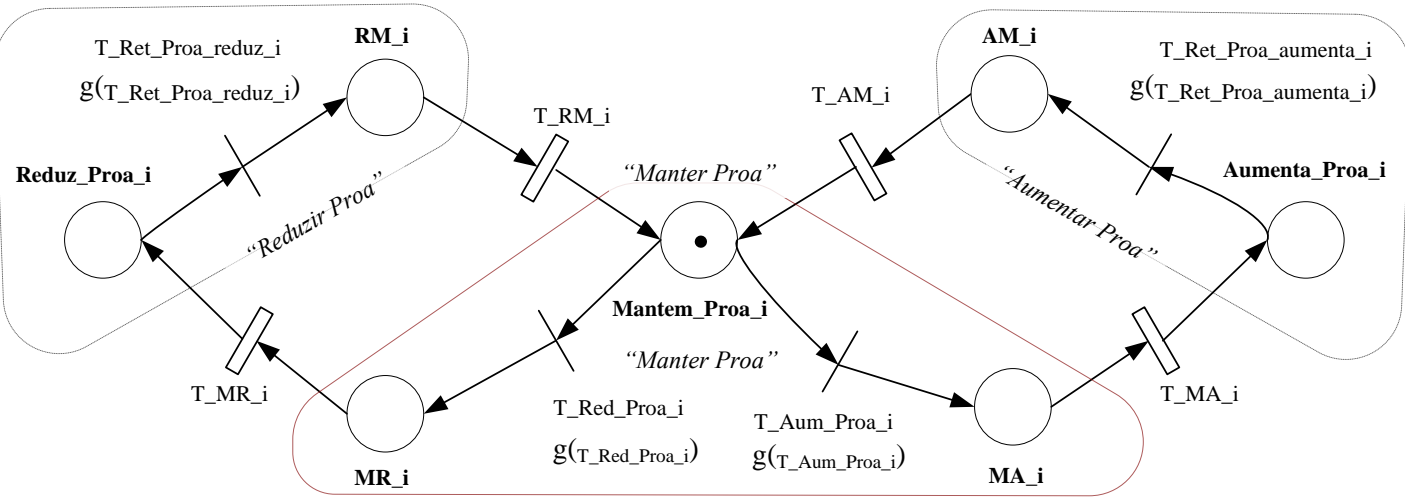

Figura 49 - Modelo de Estado da Navegação em RPFE

Considerando a funcionalidade do Computador de Gerenciamento de Vôo (FMC) e do Piloto Automático (AP), os lugares "Aumenta_Proa_i”, “AM_i”, "Mantem_Proa_i”, "MR_i”, "MA_i", "Reduz_Proa_i" e "RM_i" atuam sobre as guardas $\mathbf{g}\left(\tau_{\Psi_{-} \mathbf{A}}\right)$ e $\mathbf{g}\left(\tau_{\psi_{-} \mathbf{R}}\right)$ do modelo da Aeronave. A condição $\left(\boldsymbol{\mu}(\right.$ Aumenta_Proa_i $\left.) \vee \boldsymbol{\mu}\left(\mathbf{A M} \mathbf{M}_{-} \mathbf{i}\right)>\mathbf{0}\right)$ significa que há um $\Psi$ desejado $>\Psi(\mathrm{t})$ ou $\psi_{\text {resolucao }}=\psi_{\text {ATCo,i }}>\alpha_{i}$, fazendo com que $\mathbf{g}\left(\tau_{\psi_{-} \mathrm{A}}\right)=1$ e $\mathbf{g}\left(\tau_{\psi_{-} \mathbf{R}}\right)=\mathbf{0}$. Por

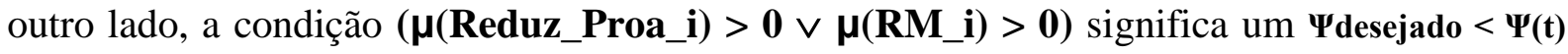
ou $\psi_{\text {resolucao }}=\psi_{\text {ATCo,i }}<\alpha_{i}$, fazendo com que $\mathbf{g}\left(\tau_{\psi_{-} \mathbf{A}}\right)=\mathbf{0}$ e $\mathbf{g}\left(\tau_{\psi_{-} \mathbf{R}}\right)=1$. Já a condição $\left(\boldsymbol{\mu}(\right.$ Mantem_Proa_i $\left.)>0 \vee \mu\left(M R \_i\right)>0 \vee \mu\left(M A \_i\right)>0\right)$ significa que não há necessidade de correção de proa e, portanto, $\mathbf{g}\left(\tau_{\Psi_{-} \mathbf{A}}\right)=\mathbf{g}\left(\tau_{\Psi_{-} \mathbf{R}}\right)=\mathbf{0}$. Neste modelo, vale ressaltar que cada aeronave possui um $\boldsymbol{\psi}_{\text {ATCo,i }}$ específico, e a existência de instrução de manobra evasiva $(\boldsymbol{\mu}($ PsiRes $)>0)$ é indicada pela rede que modela o ATCo.

“T_MA_i”, “T_MR_i”, “T_AM_ì” e “T_RM_i” são transições deterministicamente temporizadas, cujo tempo de disparo é dependente do valor de $\phi_{\text {nom. }}$ Elas são utilizadas para modelar o tempo decorrido $\left|\mathbf{t}_{\mathbf{i}}-\mathbf{t}_{\mathbf{0}}\right|$, onde $\phi\left(\mathbf{t}_{\mathbf{0}}\right)=\mathbf{0}^{\circ}$ e $\phi\left(\mathbf{t}_{\mathbf{i}}\right)=\phi_{\text {nom }}$ ou vice-versa, e onde $\mathbf{t}_{\mathbf{0}}$ é o momento em que o AP comanda alteração no valor de $\phi$.

A modelagem propriamente dita dos algoritmos de navegação, bem como dos algoritmos de modelagem VOR e GPS, são realizados por meio das guardas nas transições imediatas da rede $\left\{T_{-}\right.$Aum_Proa_i,$T_{-}$Red_Proa_i,$T_{-}$Ret_Proa_reduz_i,$T_{-}$Ret_Proa_aumenta_i $\}$.

Devido ao fato das transições $\left\{\mathbf{T}_{\_}\right.$Aum_Proa_i, $\mathbf{T}_{-}$Red_Proa_i $\}$respeitarem a condição $\mu_{\mathrm{k}}\left(\right.$ ("Mantem_Proa_i") $\geq$ (\#("Mantem_Proa_i” $\quad, \quad \mathbf{I}\left(\mathbf{T}_{-}\right.$Aum_Proa_i $\left.) \quad, \quad \mu_{\mathrm{k}}\right) \wedge$ (\#(“Mantem_Proa_i”, $\mathbf{I}\left(\mathbf{T}_{-}\right.$Red_Proa_i $\left.), \mu_{\mathrm{k}}\right)$ ), a rede calcula as guardas de ambas as transições 
para definir qual será habilitada e disparará quando $\boldsymbol{\mu}$ (“Mantem_Proa_i”) $>\mathbf{0}$. Quando a rede de navegação está nesta condição, obtém-se o valor da Radial navegada ( $\operatorname{Rad}_{\text {NAV }}$ ) (no caso de Navegação VOR) ou o valor da posição da aeronave ( $\mathbf{P}_{\text {NAV }}$ ) (no caso de Navegação GPS) e calcula-se o valor da proa desejada ( $\left.\psi_{\text {desejado}}\right)$. Nesta condição, obtém-se também o valor de $\phi_{\text {nom }}$ a ser utilizado.

O modelo da rede de Navegação utiliza as guardas das transições \{T_Ret_Proa_reduz_i , T_Ret_Proa_aumenta_i $\}$ para recalcular os valores de $\phi_{\text {nom }}$ e, desta forma, modelar o retorno gradual de $\phi(\mathbf{t})$ para $\mathbf{0}^{\mathbf{0}}$ (manter o valor de proa).

Portanto, detalhes específicos de implementação para navegação VOR e para navegação GPS estão descritos a seguir.

\subsection{Sistema de Navegação utilizando VOR}

O algoritmo utilizado para obtenção de $\operatorname{Rad}_{\mathbf{N A v}}$, e executado pelas guardas $\mathbf{g}\left(\mathbf{T}_{\text {_Aum_Proa_i }}\right)$ e g(T_Red_Proa_i), foi ilustrado em 4.2.1.3.2. "Modelagem da Navegação utilizando VOR". Os valores de $\mathbf{X}(\mathbf{t})$ e $\mathbf{Y}(\mathbf{t})$ são obtidos do modelo contínuo das aeronaves $\left(\mathbf{X}_{\mathbf{i}}(\mathbf{t}), \mathbf{Y}_{\mathbf{i}}(\mathbf{t})\right)$, por meio dos comando em CSPL fmark ("lugar contínuo"). Já o valor de $\varepsilon_{\text {Vor }}$ é obtido por meio de um gerador de números aleatórios com distribuição $\boldsymbol{\varepsilon}_{\mathbf{V O R}} \sim$ N(0, DP_ERROVOR).

A partir do valor de $\operatorname{Rad}_{\mathbf{N A v}}$, as guardas $\mathbf{g}\left(\mathbf{T}_{-}\right.$Aum_Proa_i $)$e $\mathbf{g}\left(\mathbf{T}_{-}\right.$Red_Proa_i $)$calculam o valor de proa desejada $\left(\boldsymbol{\Psi}_{\text {desejado }}\right.$ ) e, com base no valor de proa atual $\boldsymbol{\Psi}$ (obtida por meio do valor $\boldsymbol{\mu}(\mathbf{K} \psi)$ ), habilita exclusivamente uma das transições (habilita $\mathbf{T}_{\text {Aum__Proa_i }}$ no caso de $\mathbf{\Psi d e s e j a d o}$ $>\boldsymbol{\Psi}$ e $\mathbf{T}_{\text {_Red_Proa_i }}$ no caso de $\left.\boldsymbol{\Psi d e s e j a d o}<\boldsymbol{\Psi}\right)$.

Com base nos valores de $\boldsymbol{\Psi d e s e j a d o}$ e $\boldsymbol{\Psi}$, define-se o valor de $\phi_{\text {nom }}$ a ser implementado utilizando o algoritmo apresentado em 4.2.1.3.1. "Modelagem do algoritmo de correção de Proa”. Para aquele algoritmo, tem-se que:

$$
\text { Se } \psi_{\text {DIFERENÇA }} \geq 1 \mathrm{imF} \_ \text {fi_MEDIO } \Rightarrow \phi_{\text {nom }}=\phi_{\mathbf{0}}=\mathbf{3 5}^{\circ} \text {; }
$$

$$
\begin{aligned}
& \operatorname{Se}\left(\psi_{\text {DIFERENÇA }}>0^{\circ}\right) \wedge\left(\psi_{\text {DIFERENÇA }}<\text { limF_fi_MEDIO }\right) \Rightarrow \phi_{\text {nom }}=\phi_{0} / \mathbf{R}_{\mathbf{n}} \text {, onde } \\
& \mathrm{R}_{\mathrm{n}}=\mathrm{F} \_\mathrm{f} i \_\mathrm{MEDMAX} ; \\
& \text { Senão } \Rightarrow \phi_{\text {nom }}=0^{\circ} \text { e } \mathbf{g}()=0 \text {. }
\end{aligned}
$$


Comparativamente ao algoritmo proposto, o algoritmo implementado foi adaptado de forma a ponderar a taxa $\mathbf{d} \phi(\mathbf{t}) / \mathbf{d t}$ aplicada quando $\phi\left(\mathbf{t}_{\mathbf{0}}\right)=\mathbf{0}^{\mathbf{o}}$. Desta forma, os tempos de disparo “T_MA_i” ou “T_MR_i” são definidos por $\left(\phi_{\text {nom }} /\left(\mathbf{d} \phi(\mathbf{t}) / \mathbf{d t} t_{[\max ]}\right)\right)$, onde $\{\mathbf{d} \phi(\mathbf{t}) / \mathbf{d t}\}_{[\max ]}=$ $3.5 \%$.

As guardas $\mathbf{g}\left(\mathbf{T}_{-} \mathbf{R e t}_{-}\right.$Proa_reduz_$\_$) e $\mathbf{g}\left(\mathbf{T}_{-} \mathbf{R e t}_{-}\right.$Proa_aumenta_i$)$atuam no sentido de recalcular o valor de $\phi_{\text {nom }}$, permitindo que a taxa de variação de proa $(\mathbf{d} \psi(\mathbf{t}) / \mathbf{d t})$ reduza gradualmente até que $\boldsymbol{\psi}(\mathbf{t})=\psi_{\text {desejado }}$ quando, neste momento, $\mathbf{g}()=\mathbf{1}$. O algoritmo utilizado para estas guardas é:

$$
\text { Se } \psi_{\text {DIFERENÇA }} \geq \text { limF }_{-}{ } i_{-} \text {MAX } \Rightarrow \phi_{\text {nom }}=\phi_{0}=\mathbf{3 5}^{\circ} \text {; }
$$

Se $\psi_{\text {DIFERENÇA }} \geq \mathrm{limF}{ }_{-}{ }_{1} \_$MEDIO $\wedge \boldsymbol{\psi}_{\text {DIFERENÇA }}<\mathrm{limF} \_\mathrm{fi} \_\mathrm{MAX} \Rightarrow \boldsymbol{\phi}_{\text {nom }}=\boldsymbol{\phi}_{\mathbf{0}} / \mathbf{R}_{\mathbf{1}}$, onde

$$
\mathrm{R}_{1}=\mathrm{F}_{-}{ }_{\mathrm{fi}}{ }_{-} \mathrm{MEDMAX}
$$

\section{Se $\psi_{\text {DIFERENÇA }} \geq$ limF_fi_MIN $\wedge \psi_{\text {DIFERENÇA }}<$ limF_fi_MEDIO $\Rightarrow$ \\ $\phi_{\text {nom }}=\phi_{0} / \mathbf{R}_{\mathbf{2}}$, onde $\mathbf{R}_{2}=\mathrm{F}_{-}{ }_{\mathrm{fi}} \_\mathrm{MEDMIN}$;}

Se $\psi_{\text {DIFERENÇA }}>0^{\circ} \wedge \psi_{\text {DIFERENÇA }}<$ limF_fi_MIN $\Rightarrow \phi_{\text {nom }}=\phi_{0} / \mathbf{R}_{\mathbf{3}}$, onde

$$
\mathrm{R}_{3}=\mathrm{F}_{-} \mathrm{fi}{ }_{-} \mathrm{MIN} \text {; }
$$

$$
\text { Senão } \Rightarrow \phi_{\text {nom }}=0^{\circ} \wedge \mathbf{g}()=1 \text {. }
$$

Desta forma, os tempo de disparo "T_AM_i" ou “T_RM_i” são definidos por $\left(\phi_{\text {nom }} / \mathbf{d} \phi(\mathbf{t}) / \mathbf{d t}\right.$ $[\max ])$, onde $\{\mathbf{d} \phi(\mathbf{t}) / \mathbf{d t}\}_{[\max ]}=\mathbf{3 . 5} \%$.

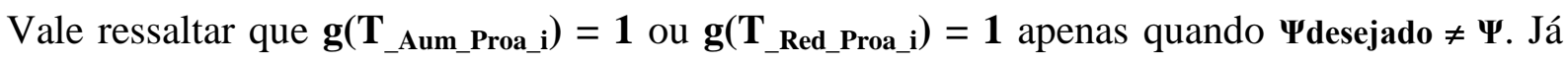

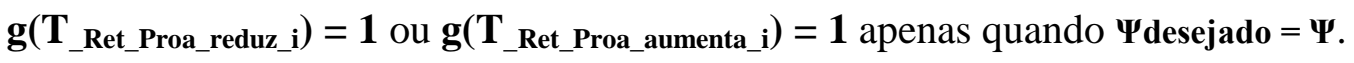

Portanto, as variáveis relacionadas ao modelo de navegação VOR são:

Variáveis de Entrada: $\left\{\text { Tnav, } \varepsilon_{\mathrm{VOR}()}\right\}_{[\text {Navegação] }},\left\{\mu\left(\psi_{\text {resolucao }}\right), \psi_{\mathrm{ATC}, \mathrm{i}}\right\}_{[\mathrm{ATCo}]}$,

$\left.\mathrm{Y}_{\mathrm{i}}, \mu\left(\mathrm{K} \psi_{\mathrm{i}}\right), \Delta \psi_{\mathrm{i}}, \mathrm{M}_{\mathrm{i}}\right\}_{[\text {Aeronave] }}$,

$\left\{\alpha_{i}, X_{\text {NOT(A2) }}, Y_{\text {NOT(A2) }}\right\}_{[\text {Espaço Aéreo] }}$.

Variáveis de Saída: $\mu($ Reduz_Proa_i), $\mu$ (Mantem_Proa_i $), \mu($ Aumenta_Proa_i).

Onde o Estado Inicial é dado por:

$\mu_{0}($ Reduz_Proa_i, Mantem_Proa_i, Aumenta_Proa_i $)=(0,1,0)$ 


\subsection{Sistema de Navegação utilizando GPS}

O algoritmo utilizado para obtenção de $\mathbf{P}_{\text {NAV }}$ e, consequentemente, para a obtenção da distância $\mathbf{d} \boldsymbol{\varepsilon}$ entre $\mathbf{P}_{\mathbf{N A V}}$ e a rota desejada, é executado pelas guardas $\mathbf{g}\left(\mathbf{T}_{-}\right.$Aum_Proa_i$)$e g(T_Red_Proa_i $)$, e foi ilustrado em 4.2.1.3.3. "Modelagem da Navegação utilizando GPS". Os valores de $\mathbf{X}(\mathbf{t})$ e $\mathbf{Y}(\mathbf{t})$ são obtidos do modelo contínuo das aeronaves $\left(\mathbf{X}_{\mathbf{i}}(\mathbf{t}), \mathbf{Y}_{\mathbf{i}}(\mathbf{t})\right)$ por meio dos comando em CSPL fmark ("lugar contínuo"). Já o valor de $\boldsymbol{\varepsilon}_{\text {GPS }}$ é obtido por meio de um gerador de números aleatórios com distribuição $\boldsymbol{\varepsilon}_{\mathbf{G P S}} \sim \mathbf{N}\left(\mathbf{0}, \mathbf{D P} \_\right.$ERROGPS).

Caso $\mathbf{d} \boldsymbol{\varepsilon}>\mathbf{d}_{\mathbf{M A X}}$, as guardas $\mathbf{g}\left(\mathbf{T}_{-}\right.$Aum_Proa_i $)$e $\mathbf{g}\left(\mathbf{T}_{-} \mathbf{R e d}_{-}\right.$Proa_i$)$calculam o valor de proa desejada $\left(\boldsymbol{\psi}_{\text {desejado }}\right)$ e, com base no valor de proa atual $\boldsymbol{\Psi}$ (obtida por meio do valor $\boldsymbol{\mu}(\mathbf{K} \psi)$ ), habilita-se exclusivamente uma das transições (habilita $\mathbf{T}_{-}$Aum_Proa_i no caso de $\boldsymbol{\Psi}$ desejado $>\boldsymbol{\Psi}$ e $\mathbf{T} \_$Red_Proa_i no caso de $\boldsymbol{\Psi d e s e j a d o}<\boldsymbol{\Psi})$.

Com base nos valores de $\Psi$ desejado e $\Psi$, define-se o valor de $\phi_{\text {nom }}$ a ser implementado, utilizando o algoritmo definido em 4.2.1.3.1. "Modelagem do algoritmo de correção de Proa". O algoritmo utilizado neste caso é o mesmo utilizado para Navegação VOR, ilustrado anteriormente.

As guardas $\mathbf{g}\left(\mathbf{T}_{-}\right.$Ret_Proa_reduz_$\left._{-}\right)$e $\mathbf{g}\left(\mathbf{T}_{\_}\right.$Ret_Proa_aumenta_i $\left._{\mathbf{i}}\right)$ atuam no sentido recalcular o valor de $\phi_{\text {nom, }}$ permitindo que a taxa de variação de proa $(\mathbf{d} \psi(\mathbf{t}) / \mathbf{d t})$ reduza gradualmente até que $\psi(\mathbf{t})$ $=\psi_{\text {desejado }}$ quando, neste momento, $\mathbf{g}()=\mathbf{1}$. $\mathrm{O}$ algoritmo utilizado neste caso é o mesmo utilizado para Navegação VOR, ilustrado anteriormente.

Portanto, as variáveis relacionadas ao modelo de navegação GPS são:

Variáveis de Entrada: $\left\{\text { Tnav, } \mathrm{d}_{\mathrm{MAX}}, \varepsilon_{\mathrm{GPS}()}\right\}_{[\text {Navegação] }},\left\{\mu\left(\psi_{\text {resolucao }}\right), \psi_{\mathrm{ATCo}, \mathrm{i}}\right\}_{[\mathrm{ATCo}]},\left\{\mathrm{X}_{\mathrm{i}}, \mathrm{Y}_{\mathrm{i}}\right.$, $\left.\mu\left(\mathrm{K} \psi_{\mathrm{i}}\right), \Delta \psi_{\mathrm{i}}, \mathrm{M}_{\mathrm{i}}\right\}_{[\text {Aeronave] }},\left\{\alpha_{\mathrm{i}}, \mathrm{X}_{\mathrm{NOT}(\mathrm{A} 2)}, \mathrm{Y}_{\mathrm{NOT}(\mathrm{A} 2)}\right\}_{[\text {Espaço Aéreo] }}$.

Variáveis de Saída: $\mu($ Reduz_Proa_i), $\mu$ (Mantem_Proa_i $), \mu($ Aumenta_Proa_i).

Onde o Estado Inicial é dado por:

$$
\mu_{0}(\text { Reduz_Proa_i, Mantem_Proa_i, Aumenta_Proa_i })=(0,1,0)
$$

\subsubsection{Sistema de Vigilância}

Tanto o sistema de Vigilância baseado em Radar quanto o sistema de Vigilância baseado em 
ADS-B possuem um modelo de referência em Redes de Petri conforme ilustrado, a seguir, na Figura 50.

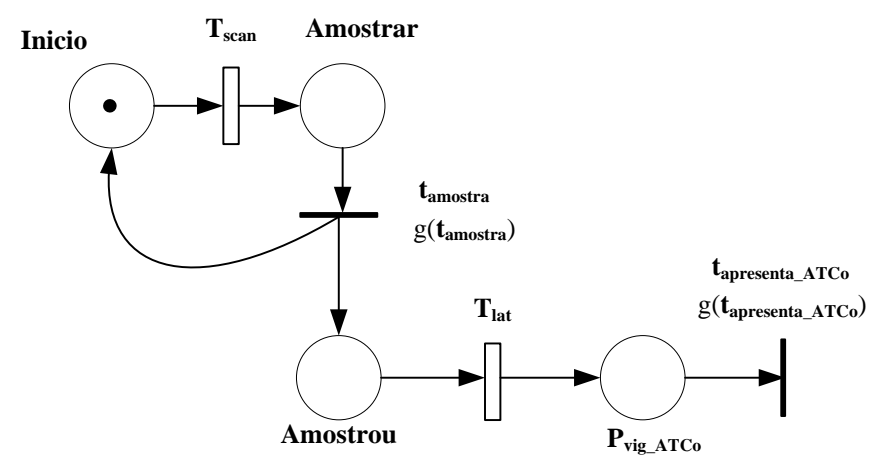

Figura 50 - Modelo-base para o Sistema de Vigilância

Neste modelo, a subrede formada pelos lugares discretos \{“Inicio", "Amostrar"\} e pelas transições \{"Tscan", "tamostra"\} representa a taxa de amostragem das posições das aeronaves pelo sistema de vigilância. A cada "Tscan" unidades de tempo, onde a transição “Tscan" pode ser tanto determinística (para o Radar) quanto estocástica (para ADS-B), promove-se uma transição em "Tscan” (个Tscan) e outra em "tamostra” (个tamostra). A guarda em "tamostra" (g(tamostra)) é utilizada para amostrar os valores contínuos de $\left(\mathbf{X}_{\mathbf{i}}(\mathbf{t})\right.$, $\left.\mathbf{Y}_{\mathbf{i}}(\mathbf{t})\right)$ e introduzir as imprecisões do processo de vigilância $(\sigma \mathbf{x}, \sigma \mathbf{y})$, gerando uma coordenada $\left(\mathbf{X}_{\mathbf{A U X} \_\mathbf{i}}, \mathbf{Y}_{\mathbf{A U X}_{-} \mathbf{i}}\right)$ ainda não apresentada ao ATCo. O algoritmo utilizado em $\mathbf{g}$ (tamostra) depende do tipo de vigilância utilizada.

O disparo de "tamostra" modela a obtenção da posição da aeronave "i" pelo sistema de

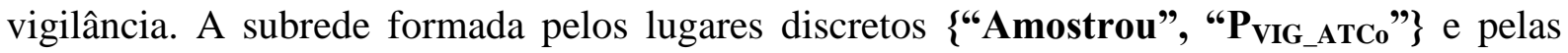
transições \{“T $\mathbf{T}_{\text {lat }}$ ", "t $\mathbf{t}_{\text {apresenta_ATCo" }}$ \} representa a latência entre a amostragem das posições das aeronaves pelo sistema de vigilância e suas apresentações para o ATCo. A transição "T $\mathbf{T}_{\mathbf{l a t}}$ " pode ser tanto determinística (para o Radar) quanto estocástica (para ADS-B). A guarda em " $\mathbf{t}_{\text {apresenta_ATCo" }}$ ( $\left.\mathbf{g}\left(\mathbf{t}_{\text {apresenta_ATCo }}\right)\right)$ é utilizada para se transferirem os valores contínuos amostrados em $\left(\mathbf{X}_{\mathbf{A U X} \mathbf{X}_{-} \mathbf{i}}, \mathbf{Y}_{\mathbf{A U X} \_\mathbf{i}}\right)$ para as variáveis $\left(\mathbf{X}_{\mathbf{V I G} \_\mathbf{i}}, \mathbf{Y}_{\mathbf{V I G} \_\mathbf{i}}\right)$, que representam os alvos apresentados aos Controladores. Desta forma, $\mathbf{g}\left(\mathbf{t}_{\text {apresenta_ATCo }}\right)$ possui o seguinte algoritmo:

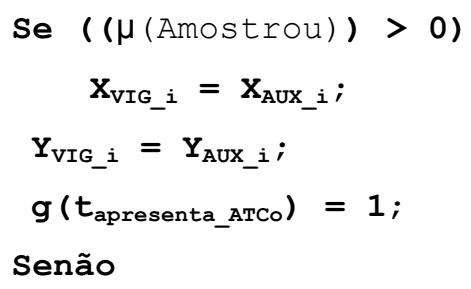




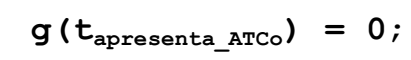

Com base no modelo-base de vigilância ilustrado na Figura 50, diferencia-se os sistemas de vigilância Radar (Sistema de Referência) e de vigilância ADS-B (Sistema Proposto) conforme se segue:

\subsection{Sistema de Vigilância de Referência (Radar)}

Para o sistema Radar, como descrito anteriormente, sua taxa de atualização $\tau_{\text {scan }}$ (representada pela transição " $T_{\text {scan }}$ ") e sua latência $\tau_{\text {lat }}$ (representada pela transição " $T_{\text {lat }}$ ") são determinísticas e constantes para todos os alvos radar obtidos. Também foi adotado que a diferença entre os tempos de amostragem de duas aeronaves será considerada nula, refletindo no uso de apenas uma subrede representada na Figura 50 para modelar a vigilância do par de aeronaves.

O algoritmo implementado para a guarda de $\mathbf{g ( t a m o s t r a ) , ~ u t i l i z a d o ~ p a r a ~ o b t e n c ̧ a ̃ o ~ d e ~ p o s i c ̧ o ̃ e s ~}$ radar por meio de Azimute e Range, é o ilustrado em 4.2.1.4.1. "Sistema Radar". Os valores de $\mathbf{X}(\mathbf{t})$ e $\mathbf{Y}(\mathbf{t})$ são obtidos do modelo contínuo das aeronaves $\left(\mathbf{X}_{\mathbf{i}}(\mathbf{t}), \mathbf{Y}_{\mathbf{i}}(\mathbf{t})\right)$, por meio dos comando em CSPL fmark ("lugar contínuo"). Já os valores ( $\left.\sigma_{\text {A,Radar }}, \sigma_{\mathbf{R}, \mathbf{R a d a r}}\right)$ são obtidos por meio de um gerador de números aleatórios com distribuições $\left(\sigma_{\mathrm{A}, \mathbf{R a d a r}}, \sigma_{\mathbf{R}, \mathbf{R a d a r}}\right) \sim$ (N(0, DP_ERRORADAR_AZIMUTE), N(0,DP_ERRORADAR_RANGE)).

Como relatado anteriormente, as transições "Tscan" e "T $\mathbf{T}_{\text {lat }}$ " são determinísticas, com tempos de disparo constantes $\tau_{\text {scan }}$ e $\tau_{\text {lat }}$, respectivamente.

Portanto, as variáveis relacionadas ao modelo de Vigilância Radar são:

Variáveis de Entrada: $\left\{\mathrm{X}_{\mathrm{i}}, \mathrm{Y}_{\mathrm{i}}\right\}_{[\text {Aeronave }]},\left\{\mathrm{X}_{\mathrm{RADAR}}, \mathrm{Y}_{\mathrm{RADAR},} \sigma_{\mathrm{Radar}}, \tau_{\text {scan }}, \tau_{\text {lat }}\right\}_{\text {[Vigilância]. }}$.

Variáveis de Saída: $\mathrm{X}_{\mathrm{VIG}, \mathrm{i}}, \mathrm{Y}_{\mathrm{VIG}, \mathrm{i}}$.

Onde o Estado Inicial é dado por:

$$
\mu(\text { Inicio })=1 ; \mu(\ldots \text { demais lugares } \ldots)=0 \text {. }
$$

\subsection{Sistema de Vigilância Proposto (ADS-B)}

Como relatado anteriormente, o ADS-B é um tipo de vigilância que depende das informações 
fornecidas individualmente pelas próprias aeronaves (obtidas pelo equipamento GPS a bordo) para estimar suas posições e apresentá-las ao controlador de tráfego aéreo. Além disso, a taxa de atualização $\tau_{\text {scan }}$ (representada pela transição " $T_{\text {scan") e a latência }} \tau_{\text {lat }}$ (representada pela transição " $\mathrm{T}_{\text {lat }}$ ) não são determinísticas.

Diferentemente da premissa adotada na modelagem Radar, a diferença entre os tempos de amostragem de 2 alvos ADS-B não pode ser considerada nula, refletindo no uso de uma subrede representada na Figura 50 para modelar o sistema de vigilância para cada uma das aeronaves. Portanto, o modelo em RPFE do sistema de vigilância proposto é o mesmo representado na Figura 50 (para cada uma das aeronaves).

O algoritmo implementado para a guarda de $\mathbf{g}$ (tamostra), utilizado para obtenção de posições ADS-B, apenas extrai o valor de $\mathbf{P}_{\mathbf{N A V}}$ utilizado no instante da amostragem, mantendo a consistência funcional da Vigilância Dependente Automática. Inclusive, as imprecisões de posição ADS-B são os valores ( $\mathbf{E x}_{\mathbf{G P S}}, \mathbf{E}_{\mathbf{G P S}}$ ) introduzidos pelo GPS.

Como relatado anteriormente, as transições "Tscan" e "T $\mathbf{T}_{\mathbf{l a t}}$ " são estocásticas, adotando-se, para ambas, a distribuição normal de probabilidade, com tempos médios de disparo $\mathrm{E}\left(\tau_{\text {scan }}\right)$ e $\mathrm{E}\left(\tau_{\text {lat }}\right)$, respectivamente.

Portanto, as variáveis relacionadas ao modelo de Vigilância ADS-B são:

Variáveis de Entrada: $\left\{\mathrm{P}_{\mathrm{NAV}, \mathrm{i}}\right\}_{[\mathrm{NAVEGAÇÃO}]},\left\{\tau_{\mathrm{scan}, 1}, \tau_{\mathrm{scan}, 2}, \tau_{\text {lat }, 1}, \tau_{\text {lat }, 2}\right\}_{\left[\mathrm{V}_{\text {igilância }]}\right.}$.

Variáveis de Saída: $\mathrm{X}_{\mathrm{VIG}, \mathrm{i}}, \mathrm{Y}_{\mathrm{VIG}, \mathrm{i}}$.

O Estado Inicial é dado por:

$\mu($ Inicio, $\mathrm{i})=1 ; \mu(\ldots$ demais lugares $\ldots)=0$.

\subsubsection{Controlador de Tráfego Aéreo (ATCo)}

O modelo em Redes de Petri do Controlador de Tráfego Aéreo (ATCo) para detecção e resolução de conflito está representado na Figura 51. 


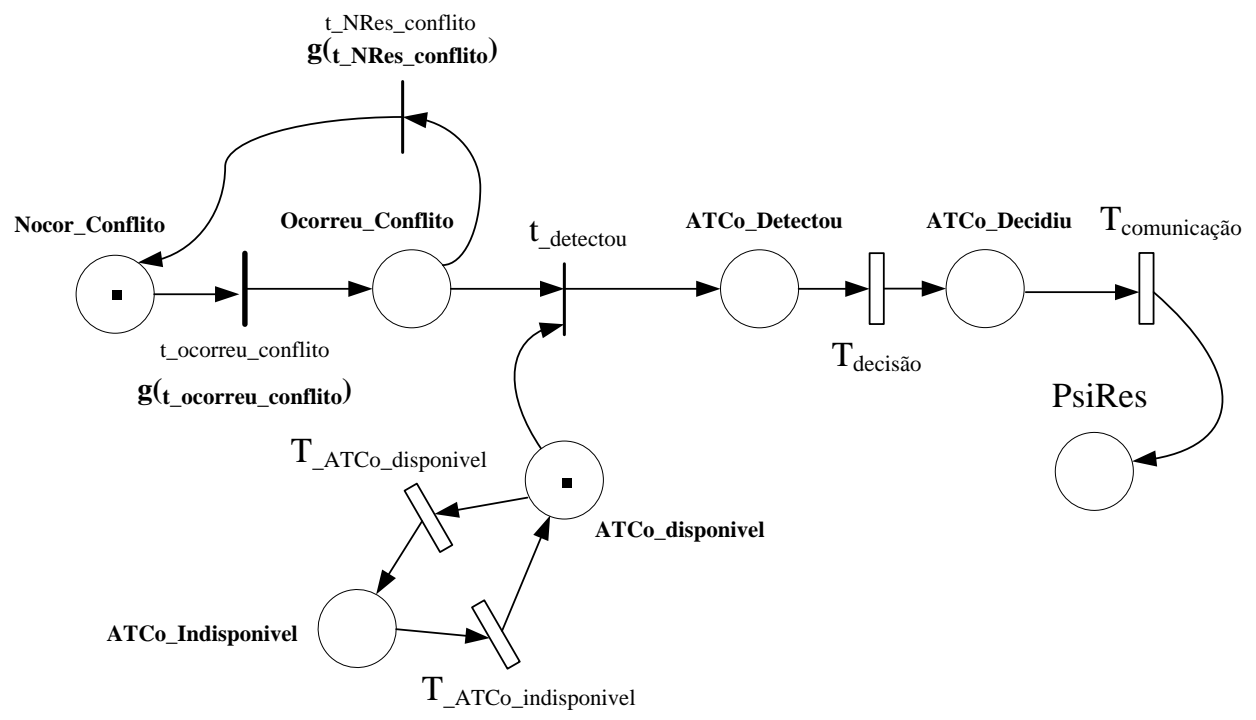

Figura 51 - Modelo do ATCo em RPFE

Este modelo representa a dinâmica de eventos ilustrada na Figura 46, onde o processo somente se inicia quando o ATCo detecta NConfATCo eventos seguidos de $\| \mathbf{P}_{\text {VIG,1 }}(\mathbf{t})$ $\mathbf{P}_{\text {VIG,2 }}(\mathbf{t}) \|<\mathbf{D}_{\text {ATCo_min. }}$ A sinalização da ocorrência de conflito (lugar "Ocorreu_Conflito")

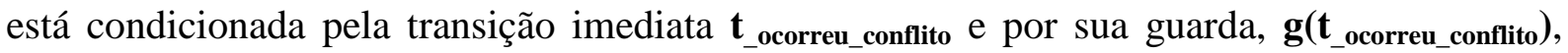
que possui o seguinte algoritmo:

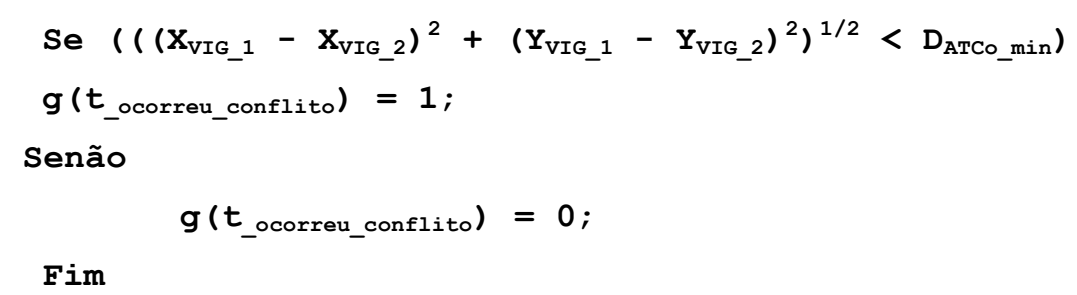

Quando o conflito ocorre $(\boldsymbol{\mu}($ Ocorreu_Conflito $)>\mathbf{0})$, a detecção por parte do ATCo ( $\uparrow \mathbf{t}_{\text {_detectou}}$ ) está condicionado à disponibilidade do ATCo, modelada pela subrede (\{ATCo_disponível, ATCo_indisponível\}, \{T_ATCo_disponível, T_ATCo_indisponível\}), e ao número seguido de conflitos ocorridos, modelado pela subrede (\{Nocor_Conflito, Ocorreu_Conflito\}, $\left.\left\{\mathbf{t} \_N R e s \_c o n f l i t o\right\}\right)$. A guarda $\mathbf{g}\left(\mathbf{t} \_\right.$NRes_conflito $)=1$ quando não há NConfATCo conflitos sucessivos, fazendo com que t_NRes_conflito dispare, pois esta tem maior prioridade de disparo do que $\mathbf{t}_{-}$detectou.

O lugar “ATCo_detectou” representa que o ATCo detectou o conflito. Em seguida, o lugar "ATCo_decidiu" e a transição T_decisão modelam o processo de decisão da resolução do conflito e o lugar "PsiRes" e a transição T_comunicação modelam o processo de comunicação, entre ATCo e 
Piloto, do valor de proa $\psi_{\text {resolucao }}$ para a resolução do conflito, onde $\psi_{\text {resolucao }}\left(\mathbf{t}_{\mathrm{k}}\right)=\boldsymbol{\psi}_{\text {ATCo,1 }}$ e/ou $\psi_{\text {resolucao }}\left(t_{k}\right)=\psi_{\text {ATCo,2, }}$, onde $t_{k}$ é o instante no qual a proa real da aeronave $\psi \boldsymbol{y}$ possui o valor $\psi_{\text {ATCo,1 }}$ e/ou $\psi_{\text {ATCo,2. }}$.

Vale salientar que $\mu($ PsiRes $)>0$ representa o Piloto ciente da manobra para $\psi_{\text {resolucao }}$, e a mesma habilita a variável $\Psi_{\text {resolucao }}$ do sistema de navegação.

Portanto, as variáveis relacionadas ao modelo do ATCo são:

Variáveis de Entrada: $\left\{\mathrm{D}_{\mathrm{ATCo} \_ \text {min }}, \mathrm{NConfATCo}_{\mathrm{ATCo} \text { disponivel }}, \mathrm{T}_{\mathrm{decisão}}, \mathrm{T}_{\text {comunicação }}\right\}_{[\mathrm{ATCo}]}$, $\left\{\mathrm{X}_{\mathrm{VIG}, \mathrm{i}}, \mathrm{Y}_{\mathrm{VIG}, \mathrm{i}}\right\}_{\text {[Vigilância]. }}$

Variáveis de Saída: $\mu$ (PsiRes), $\psi_{\mathrm{ATC}, \mathrm{i}}$.

O Estado Inicial desta rede é dado por:

$\mu($ ATCo_disponivel $)=1 ; \mu(\ldots$ demais lugares $\ldots)=0$.

\subsubsection{Sistema de Comunicação}

As premissas adotadas para o sistema de comunicação foram ilustradas no capítulo 4.2.1.6. . Desta forma, o modelo em redes de Petri para a comunicação está contido no modelo para o ATCo, mais especificamente representado pela subrede (\{ATCo_disponível, ATCo_indisponível\}, \{T_ATCo_disponível, $T_{-}$_ATCo_indisponível $\left.\}\right)$e pela subrede (\{PsiRes $\},\left\{T_{-}\right.$comunicação\}).

\subsection{Métricas e Parâmetros considerados na avaliação}

Nos itens anteriores, apresentou-se o escopo do estudo de caso e a modelagem dos sistemas proposto e de referência a serem utilizados nesta avaliação, tanto no que se refere à descrição dos seus módulos funcionais e parâmetros quanto a sua formalização por meio das redes de Petri fluidas e estocásticas. Portanto, cumpriu-se uma parte significativa do Método de Avaliação de Risco proposto, restando simular e obter as métricas de risco que, por fim, serão utilizadas na avaliação do nível de segurança do sistema proposto.

Foi citado que o risco de colisão entre aeronaves é fator determinante na avaliação da segurança do tráfego aéreo devido ao impacto social que causa (Profit, 1995). Por isto, métodos de avaliação de segurança, em geral, baseiam-se em modelos de risco de colisão e, em decorrência, utilizam métricas de segurança relacionadas ao número de "(acidentes / 
fatalidades) por horas de vôo" ou "(acidentes / fatalidades) por número de operações (de pouso, decolagem)", entre outras. Além disto, a escolha de métricas de risco de colisão é suportada pela própria Organização de Aviação Civil Internacional (OACI), que aceita a perspectiva do risco de acidente na análise de segurança dos sistemas (Blom, 1998).

Portanto, para o escopo deste trabalho, é desejável que sejam estabelecidas métricas de risco de colisão para avaliar a segurança do sistema proposto. Porém, o método de análise aqui proposto faz uso de simulação por eventos discretos e, segundo Campos, Marques (2002), é "virtualmente impossível" obter-se métricas de risco de colisão, por meio de simulação, que possuam nível de significância aceitável. Isto é explicado pela baixa frequiência esperada para a ocorrência deste tipo de evento, que é da ordem de 5 colisões por $10^{9}$ horas de vôo.

Como forma de aumentar a significância dos resultados obtidos, estes autores propõem o uso de métricas de segurança alternativas, e relacionadas ao evento "risco de colisão entre aeronaves", que possuam maior freqüência de ocorrência. Blom et al (1998) segue nesta mesma linha, propondo a modelagem de risco de colisão por meio da decomposição do problema em níveis hierárquicos factíveis de serem resolvidos.

Portanto, tal como proposto por Campos, Marques (2002), as métricas utilizadas nesta avaliação serão alternativas, porém relacionadas, ao evento "risco de colisão entre aeronaves”. Neste sentido, incidentes estão relacionados aos acidentes aeronáuticos, pois um Incidente Aeronáutico é toda ocorrência associada com a operação de uma aeronave, no período da intenção de vôo, que não se caracterize como um acidente, mas que afete ou possa afetar a segurança da operação (Ministério da Aeronáutica, 2002b). No caso do sistema de controle de tráfego aéreo, um dos tipos de incidentes considerados é o caso da proximidade entre aeronaves (conhecido como AIRPROX), cuja distância, posição relativa e velocidade das aeronaves possam comprometer a segurança do tráfego aéreo.

Desta forma, os sistemas modelados anteriormente serão simulados com o objetivo de estimar métricas de avaliação de segurança relativas aos eventos de proximidade entre aeronaves (AIRPROX) que, dependendo da norma de separação aplicada (representada pela variável Dmin_ATCo), constituem eventos de perda de separação mínima. Vale relembrar que o ambiente simulado considerará a capacidade do sistema de tráfego aéreo em manter e detectar a perda da separação entre aeronaves baseado nos sistemas que possui, principalmente, para vigilância e navegação, e que cada ambiente possui 2 processos: o 
PROCESSO REAL (estado real das aeronaves) e o PROCESSO MONITORADO (o estado observado por meio dos sistemas de supervisão e controle). Os eventos de AIRPROX serão avaliados sobre o processo real (variáveis contínuas), verificando-se em quais situações estes eventos podem ocorrer devido à ineficiência do processo de supervisão e controle.

\subsubsection{Descrição das métricas adotadas}

A obtenção das métricas de risco adotadas neste trabalho fará uso tanto do formalismo de recompensa das redes de Petri fluidas e estocásticas quanto das métricas diretas fornecidas pela ferramenta SPNP, tais como a Probabilidade de $\boldsymbol{\mu}\left(\mathbf{p}_{\mathbf{i}}\right) \neq \mathbf{0}\left(\mathbf{P}\left(\boldsymbol{\mu}\left(\mathbf{p}_{\mathbf{i}}\right) \neq \mathbf{0}\right)\right)$ (porcentagem do tempo da simulação onde o número de marcas no lugar $\mathbf{p}_{\mathbf{i}} \in \mathbf{P}$ foi maior que zero) e \#( $\left.\uparrow \mathbf{t}_{\mathbf{i}}\right)$ (número de disparos da transição $\mathbf{t}_{\mathbf{i}} \in \mathbf{T}$ durante o tempo de simulação).

No caso das funções de recompensa, vale ressaltar que as mesmas utilizam a notação “1 $\mathbf{1}_{\{\text {predicado\} }}$, que retorna o valor " 1 " caso o " $\{$ predicado\}" seja verdadeiro e " 0 " nos demais casos. Com base nestas funções de recompensa, as métricas são obtidas na forma:

$$
\text { "MétricaDesejada" }=\frac{1}{\text { IOP_SIM_RUNS }_{-}} \cdot \sum_{i=1}^{\text {(IOP_SIM_RUNS })} \int_{0}^{(\text {FOP_SIM_LENGTH) }} 1_{\{\text {predicado\} }} d t \text {, onde }
$$

IOP_SIM_RUNS e FOP_SIM_LENGTH são o "número de rodadas de simulação" e o "tempo de simulação por rodada”, respectivamente.

Portanto, segue a descrição das métricas adotadas e as respectivas expressões que as representam. Todas as métricas são relativas ao evento de cruzamento de rotas realizado pelas aeronaves (denominada como "aproximação"). Portanto, esta informação será suprimida dos textos a seguir. Vale frisar, também, que as métricas adotadas são, conforme justificado anteriormente, relativas ao evento de perda de separação (AIRPROX) entre aeronaves.

\subsubsection{Exposição à separação menor que $\operatorname{Lmin}_{[}\left[T_{L_{m i n} \_}\right]$}

Esta métrica estima o tempo médio, em [\%tempo/aproximação] $\left(\%_{\text {Lmin_i }_{-}}=\right.$ $\mathbf{T}_{\mathbf{L m i n} \_}$/ $/$Tsimulacao), a cada evento de aproximação, no qual as aeronaves permaneceram, no processo real, a distâncias menores que "Lmin + i.0,5NM", com i = 0, 1 e 2:

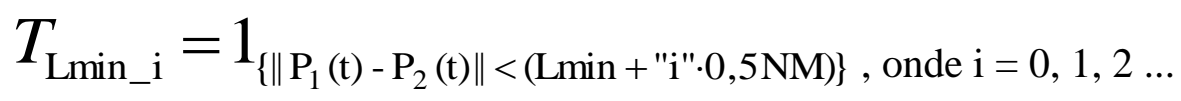


O valor adotado para Lmin foi de 2,5NM, que corresponde à metade de Dmin_ATCo.

\subsubsection{Exposição à Perda de Separação Mínima Real por intervenção [ T $_{\left.P S \_I N T\right]}$}

Esta métrica estima o tempo médio, em [segundos/aproximação], a cada evento de aproximação em que houve intervenção, no qual o par de aeronaves permanece, no processo real, a uma distância menor do que a estabelecida pela norma de separação mínima (AIRPROX). Sua função de recompensa é expressa por:

$$
\mathrm{T}_{\mathrm{PS} \_I N T}=\mathrm{T}_{\mathrm{PSR}} / \mathrm{N}_{\text {ConfDetec }}=\frac{1_{\left\{\left\|\mathrm{P}_{1}(\mathrm{t})-\mathrm{P}_{2}(\mathrm{t})\right\|<\text { Dmin_ATCo }\right\}}}{\#(\uparrow " \mathrm{t} \text { _detectou" })}
$$

$\mathrm{T}_{\mathrm{PS} \_ \text {INT }}$ é proporcional à capacidade com a qual o ATCo consegue detectar um conflito real e resolvê-lo.

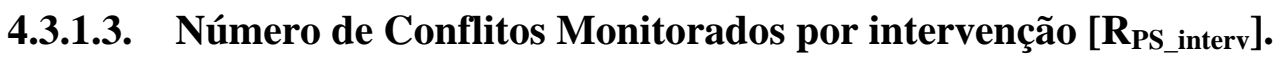

Esta métrica estima a relação entre o número médio de AIRPROXes totais apresentados ao ATCo na tela de vigilância e o número de detecções, em [nº de conflitos/aproximação], a cada evento de aproximação. Isto equivale a obter \#(†“t__ocorreu_conflito”).

$$
\mathrm{R}_{\text {PS_interv }}=\mathrm{N}_{\mathrm{PSM}} / \mathrm{N}_{\mathrm{PSM} \text { _Detec }}=\frac{\#\left(\uparrow " \mathrm{t} \_ \text {ocorreu_conflito" }\right)}{\#(\uparrow " \mathrm{t} \text { _detectou" })}
$$

Esta métrica ilustra a quantidade média de conflitos apresentados ao ATCo antes que ocorra uma detecção (intervenção).

\subsubsection{Número de Conflitos Detectados [NPSM_Detec]}

Esta métrica estima o número médio de AIRPROX apresentados ao ATCo na tela de vigilância, em [nº de conflitos/aproximação], e detectados (há intervenção por parte do ATCo), a cada evento de aproximação. Isto equivale a obter \#(个“‘t_detectou”).

Com base na modelagem dos sistemas, vale ressaltar que pode existir, no máximo, uma detecção (intervenção) do ATCo por evento de aproximação. Assim, o valor "N $\mathrm{N}_{\text {PSM_Detec } /}$ Número de Rodadas" estima a probabilidade de ocorrer uma intervenção do ATCo sobre o processo real em conflito. 


\subsubsection{Exposição à perda da separação mínima Real sem Detecção pelo ATCo}

[T PSR_NDetec $]$

Esta métrica estima o tempo médio, em [segundos/aproximação], a cada evento de aproximação, no qual um AIRPROX no processo real não é detectado pelo ATCo:

$$
\begin{aligned}
& T_{\text {PSR_NDetec }}= 1_{\left\{\left(\left\|\mathrm{P}_{1}(\mathrm{t})-\mathrm{P}_{2}(\mathrm{t})\right\|<\text { Dmin_ATCo }\right)\right.} \\
& \wedge \\
&((\mu(\text { Nocor_Corflito })=1) \vee(\mu(\text { Ocorreu_Conflito })=1))\}
\end{aligned}
$$

$\mathrm{T}_{\text {PSR_NDetec }}$ é uma métrica derivada de $\mathrm{T}_{\mathrm{PS} \_ \text {INT }}$, indicando o tempo médio no qual o espaço aéreo está exposto a um AIRPROX sem que haja detecção.

\subsubsection{Exposição à perda da separação mínima Real sem apresentação ao ATCo}

\section{[T}

Esta métrica estima o tempo médio, em [segundos/aproximação], a cada evento de aproximação, no qual o sistema de vigilância não apresentou ao ATCo a ocorrência de um AIRPROX:

$T_{\text {PSR_NVIG }}=1_{\left\{\left(\left\|\mathrm{P}_{1}(\mathrm{t})-\mathrm{P}_{2}(\mathrm{t})\right\|<\text { Dmin_ATCo }\right) \wedge\left(\left\|\mathrm{P}_{V I G, 1}(\mathrm{t})-\mathrm{P}_{V I G, 1}(\mathrm{t})\right\|>\text { Dmin_ATCo }\right)\right\}}$

A Figura 52 ilustra a relação entre as métricas adotadas e os eventos no ATCo.

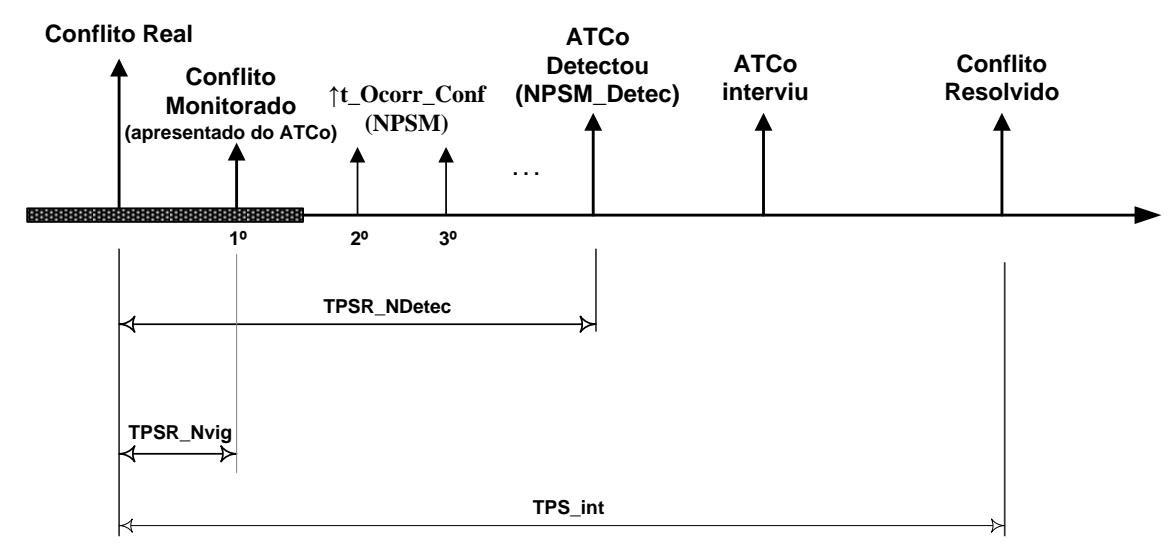

Figura 52 - Relação entre as métricas e os eventos no ATCo 


\subsubsection{Parâmetros considerados na análise}

As métricas de segurança serão obtidas em função dos parâmetros relacionados aos módulos funcionais Aeronave, Espaço Aéreo (incluindo Plano de Vôo), Sistema de Navegação (incluindo as características do Piloto), Sistema de Vigilância, ATCo e Sistema de Comunicação. Tanto a descrição funcional dos parâmetros quanto a especificação de seus valores funcionais foram descritos anteriormente.

Como o objetivo geral deste trabalho é avaliar o impacto que a vigilância dependente automática por radiodifusão (ADS-B) exerce sobre os níveis de segurança do sistema, as métricas obtidas para o Sistema de Referência em condições Normais de Funcionamento (valores dos parâmetros dentro das especificações) - a serem adotadas como os Target Levels of Safety (TLS) - serão comparadas com as métricas obtidas para o Sistema Proposto.

A avaliação deste impacto sobre a segurança será obtida para os casos de o Sistema Proposto operar:

\footnotetext{
$\checkmark \quad$ em condições Normais de Funcionamento (valores dos parâmetros dentro das especificações);

$\checkmark \quad$ em condições Degradadas de Funcionamento.
}

Os valores dos parâmetros em condiçães normais de funcionamento, tanto para o Sistema Proposto quanto para o Sistema de Referência, são:

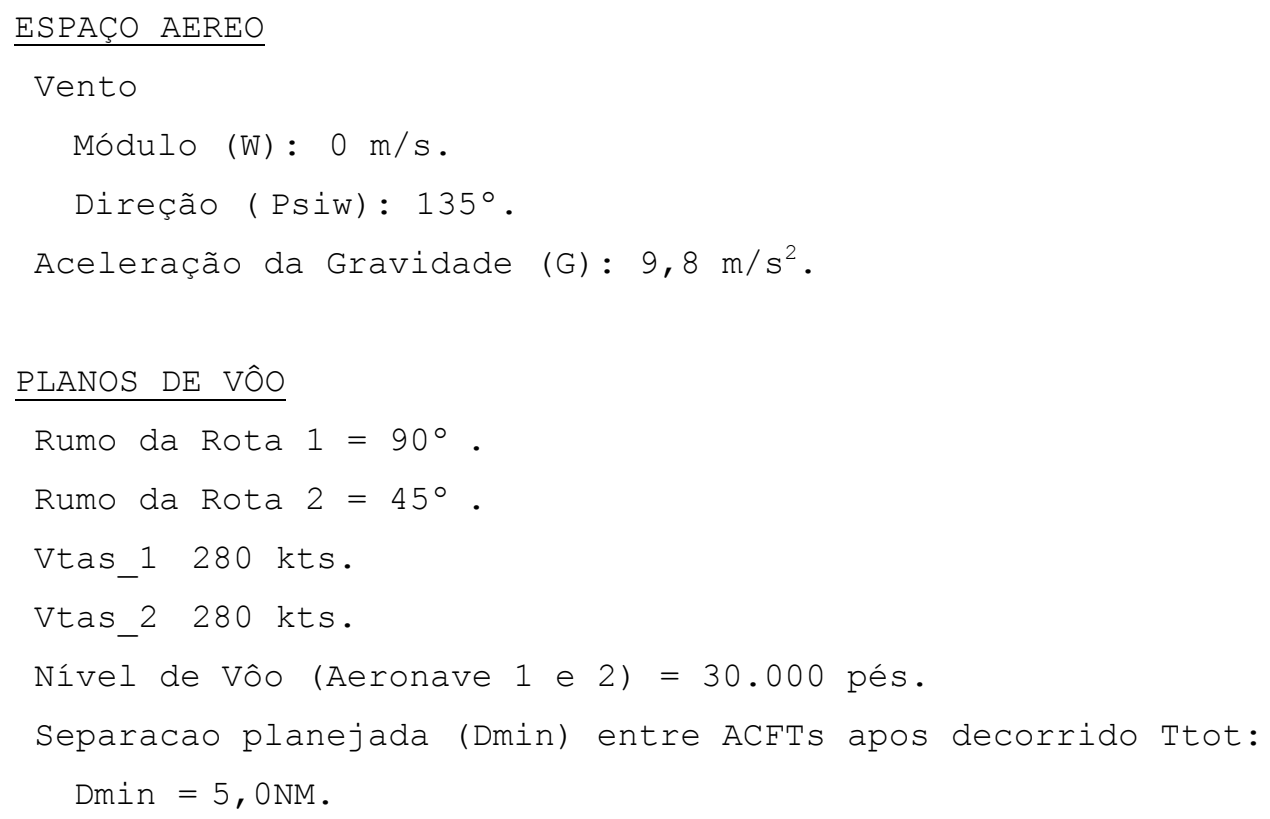




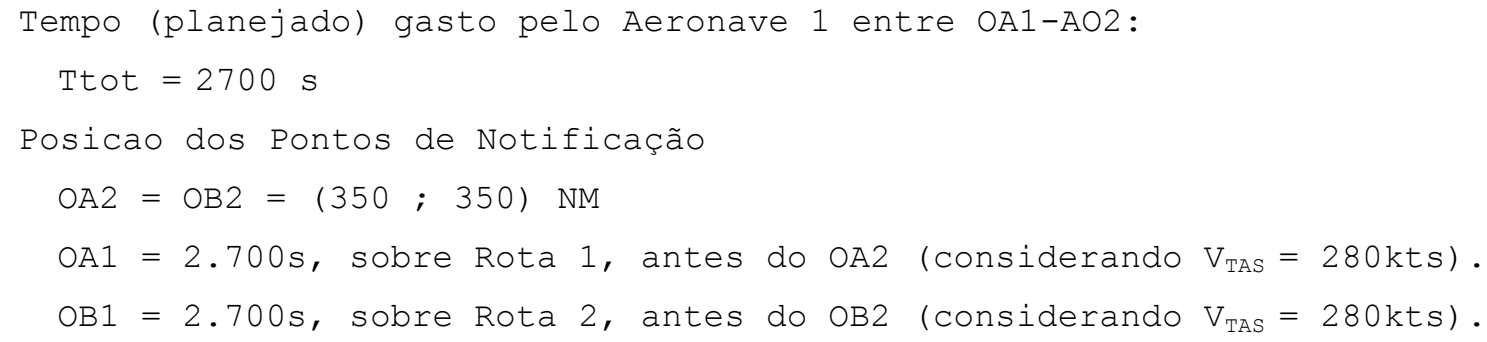

\section{VIGILÂNCIA}

SSR:

Posicao do Radar em solo: $(0,0 ; 0,0) \mathrm{NM}$.

Acurácia do Azimute $=\mathrm{N}\left(0 ; 0,15^{\circ}\right)$.

Acurácia do Range $=\mathrm{N}(0 ; 250) \mathrm{m}$.

Taxa de Varredura Radar $=12 \mathrm{~s}$

Latência $=0,5 \mathrm{~s}$

ADS-B :

Taxa de Atualização = 14,0@95\% $\mathrm{s}$. 
Latência $=1,2 @ 95 \% \mathrm{~s}$

Para obter-se a sensibilidade dos sistemas à variação do parâmetro "Norma de Separação Mínima", será realizado uma análise de sensibilidade para o parâmetro Dmin_ATCo $\in[4,4 \mathrm{NM} ; 5,8 \mathrm{NM}]$.

Os parâmetros que sofrerão degradação de seus valores são:

a. Acurácia da Posição obtida por GNSS (GPS): ERROGPS $\in[50 ; 400] \mathrm{m} \wedge$ $[800 ; 1600] \mathrm{m} \wedge[2000 ; 4000] \mathrm{m} ;$

b. Taxa de Atualização ADS-B: TSCANADS $\in[2,0 ; 34,0] \mathrm{s}$, nas condições:

i. ErroGPS=86,44m@95\% e TSCANADS@95\% (Condição Normal);

ii. ErroGPS=1,5NM@95\% e TSCANADS@95\% (Condição Degradada $)$;

Todas as simulações utilizarão IOP_SIM_RUNS $=10.000$ rodadas $\mathrm{e}$ FOP_SIM_LENGTH $=3105$ segundos $($ Ttot $=2.700$ s $)$. No caso das simulações com valores degradados, a Norma de Separação Mínima será de Dmin_ATCo=5, 0NM.

No caso da Acurácia da Posição GNSS (GPS), o valor ERROGPS equivale a sua acurácia (valor de erro acrescido ao valor de posição real da aeronave) em $95 \%$ do tempo, sendo representado por uma distribuição normal $\mathbf{N}\left(\mathbf{0}\right.$;ERROGPS/Zp) $=\mathrm{N}\left(\mathrm{E}[], \mathrm{VAR}[]^{1 / 2}\right)$, onde $\mathbf{Z} \mathbf{p}=$ 1,96 representa a frequiência de ocorrência de $95 \%$ em uma distribuição bicaudal de $\mathrm{N}(0 ; 1)$.

No caso da Taxa de Atualização ADS-B, TSCANADS equivale ao valor máximo assumido pelas mesma em $95 \%$ do tempo, sendo representado por uma distribuição normal $\mathbf{N}\left(\right.$ “Taxa”. $\frac{3.9}{3.9+Z p} ;$ “'Taxa”. $\left.\frac{1.0}{3.9+Z p}\right)=\mathrm{N}\left(\mathrm{E}[], \mathrm{VAR}[]^{1 / 2}\right)$, onde $\mathbf{Z p}=\mathbf{1 , 6 4 5}$ representa a freqüência de ocorrência de $95 \%$ em uma distribuição monocaudal de $\mathrm{N}(0 ; 1)$.

Vale notar que, dos 2 parâmetros que serão analisados por meio de análise de sensibilidade, o ERROGPS afeta tanto às características de Navegação da Aeronave quanto do Sistema de Vigilância do sistema de tráfego aéreo proposto. Já a característica TSCANADS afeta a característica de vigilância do Sistema Proposto, propiciando a comparação entre as características dos sistemas Radar e ADS-B. 
Ressalta-se aqui que a norma TSO-C129a (FAA, 2006) exige que, para o uso de GPS como elemento de navegação, deve-se utilizar um Receptor de Monitoramento de Integridade Autônomo a bordo da aeronave (RAIM). Porém, como o método de avaliação proposto baseia-se em comparação, e não foram consideradas as características de integridade tanto para o sistema proposto quanto para o de referência, esta implementação fíca como proposição para linhas futuras de investigação científica.

Portanto, tendo sido aplicado o Método de Avaliação de Risco proposto neste trabalho, com a conseqüente modelagem do sistema de referência (sistema legado) e do sistema proposto (sistema em avaliação) por meio das redes de Petri fluidas e estocásticas (RPFE), e estando definidos os parâmetros e métricas a serem considerados na análise, parte-se para o processo de estimação das métricas de interesse. As métricas foram quantificadas, para cada um dos sistemas modelados, por meio de simulação por eventos discretos. O capítulo seguinte apresenta e discute os resultados obtidos. 


\section{ANÁLISE DOS RESULTADOS}

O método de avaliação utilizado neste estudo permite comparar o Sistema de Controle de Tráfego Aéreo (ATC) legado (Sistema de Referência), considerado seguro, baseado em vigilância Radar e navegação VOR, com o Sistema de Controle de Tráfego Aéreo (ATC) proposto (Sistema Proposto), baseado em vigilância ADS-B e navegação GNSS. O foco do estudo é dado sobre o nível tático do processo de Gerenciamento de Tráfego Aéreo (ATM), relacionando o desempenho dos elementos ATC com a capacidade da manutenção dos valores de separação. A Figura 53 ilustra a relação entre as partes do processo de controle de tráfego aéreo (ATC) e os elementos do Sistema de Controle de Tráfego Aéreo.

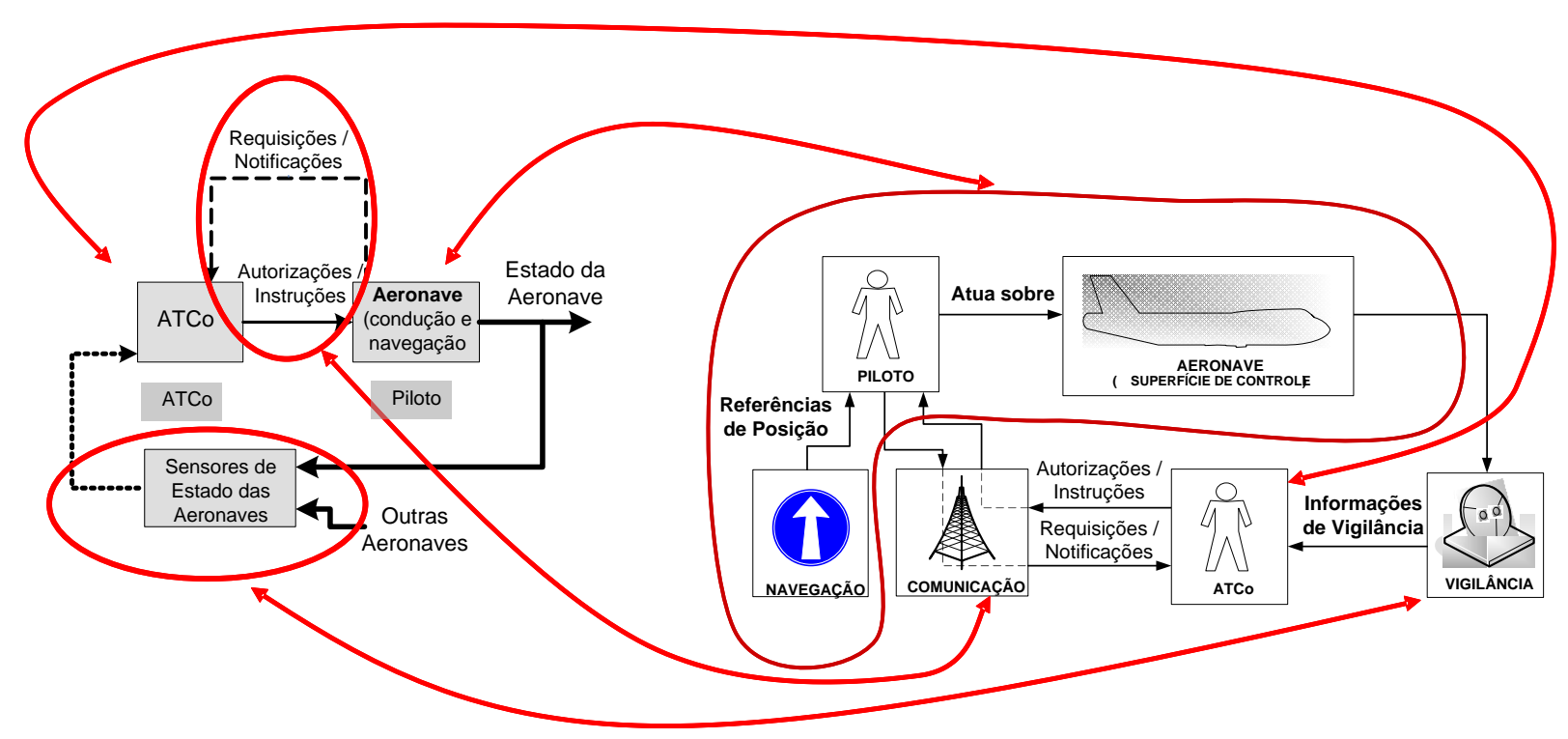

Figura 53 - Relação entre processo tático do ATM e os elementos do ATC

Os resultados obtidos serão apresentados por meio da discussão sobre suas representações gráficas, dispostas na sequiência de sua discussão. Optou-se em dividir as discussões dos resultados obtidos em 4 grupos, em função das métricas adotadas:

- "TLmin_i", que avalia a exposição das aeronaves a situações de AIRPROX, observando ocorrências de aproximação a distâncias menores que Lmin $+\mathbf{i} * 0,5 \mathrm{NM}-$ onde Lmin é igual a 2,5NM e i $=0,1,2$ - correspondendo às faixas de separação de ]0; 2,5NM[, de ]2,5NM; 3,0NM[ e de ]3,0NM; 3,5NM[.

- “TPS_INT", que avalia a exposição das aeronaves a perda de separação nos casos onde houve intervenção por parte do ATCo. 
- “TPSR_NDetec, RPS_interv e NPSM_Detec”, que avalia a exposição à perda da separação entre aeronaves antes que ocorra uma detecção (e intervenção) por parte do ATCo, além de avaliar a capacidade de detecção de conflitos por parte do ATCo e, indiretamente, sua carga de trabalho.

- “TPSR_Nvig”, que avalia a exposição à perdas reais de separação sem que haja sua apresentação ao ATCo.

Vale ressaltar que todos os valores representados nos gráficos estão acrescidos de suas barras de incertezas.

\subsection{Exposição a Perda de Separação menores que 3,5NM}

A métrica primária de segurança estipulada neste estudo está relacionada ao tempo no qual um par de aeronaves fica exposto a separações consideradas perigosas (AIRPROX). Os valores de "TLmin_i" permitem estimar situações de AIRPROX. Pode-se observar, por meio da Figura 54, que o Sistema Proposto (curvas "SP") permite que as aeronaves se exponham menos aos eventos de AIRPROX, para o caso de condições normais de funcionamento, em relação ao Sistema de Referência (curvas “SR"). No Sistema Proposto, não houve aproximações menores que 3,0NM entre aeronaves, e houve apenas uma pequena parcela de tempo (menor que $\mathbf{0 , 0 4 \%}$, o que equivale a $1,2 \mathrm{~s}$ de exposição) no qual ocorreram aproximações entre 3,0NM e 3,5NM, para regras de separação (Dmin_ATCo) entre 4,8NM e 5,4NM (considerando que a menor separação planejada foi de 5,0NM). Já no Sistema de Referência, houve uma significativa parcela de aproximações $(\mathbf{0 , 2 5 \%}$ do tempo, o que equivale a $8 \mathrm{~s}$ de exposição) para distâncias menores que 2,5NM, e aproximadamente $18,5 \mathrm{~s}$ de exposição para distâncias de separação inferiores a 3,5NM. 


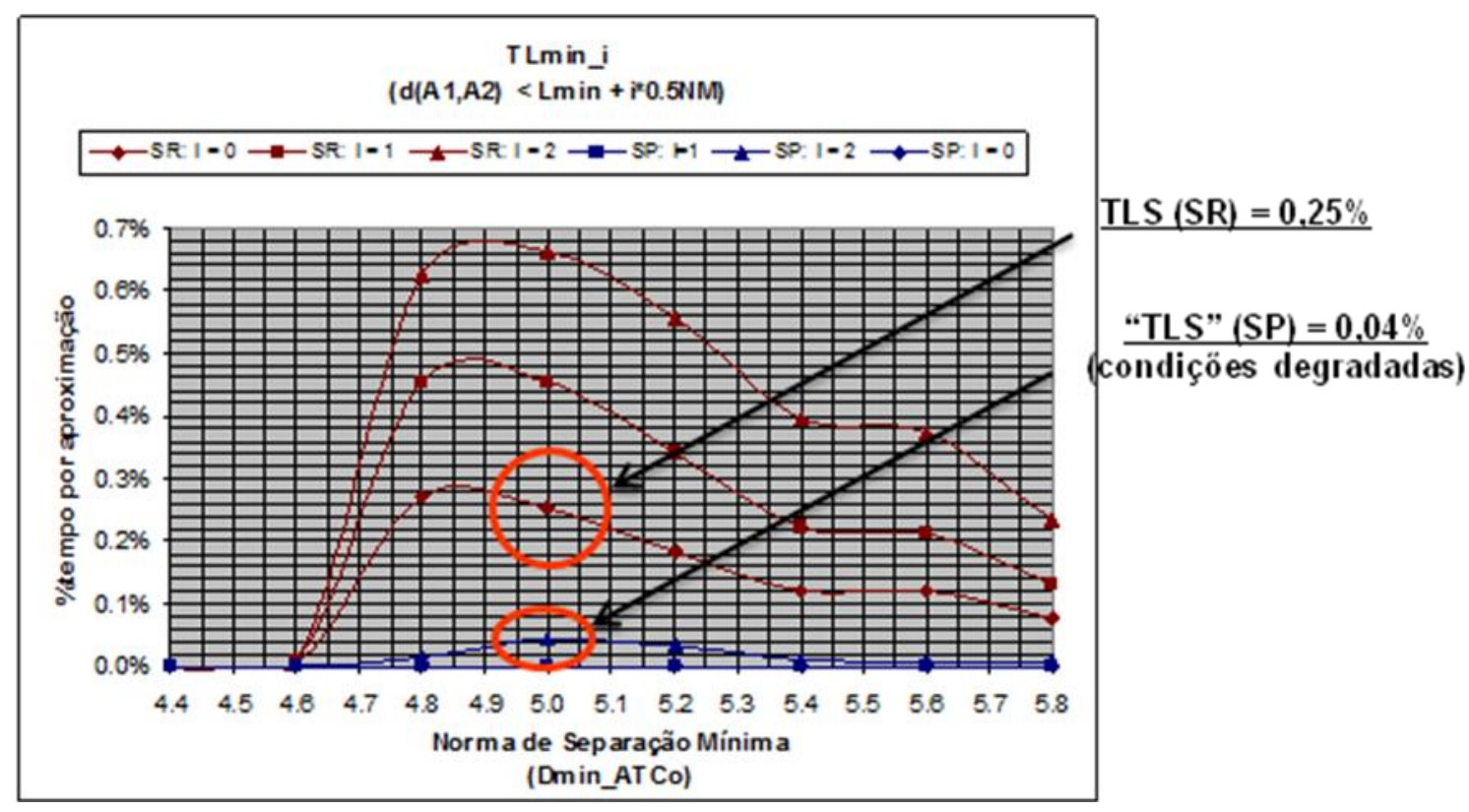

Figura 54 - Exposição à Perda de Separação (TLmin_i) para Condições Normais de Funcionamento

No caso de condições degradadas de funcionamento, tanto para degradações elevadas nos valores de Acurácia do GNSS (Figura 55) quanto para degradações nas Taxas de Atualização (Figura 56 e Figura 57), os tempos de exposição à AIRPROXes no Sistema Proposto são menores que o TLS $=\mathbf{0 , 2 5 \%}$ obtido do Sistema de Referência (indicado pelo valor métrica TLmin_0 - AIRPROXes com separação menores que 2,5NM - para Dmin_ATCo = 5NM.

Devido os resultados obtidos para o Sistema Proposto (SP) serem menores que o TLS estimado no Sistema de Referência (SL), pode-se observar que, caso se deseje obter o mesmo nível de exposição obtido no Sistema Proposto em condições normais de funcionamento (TLmin_2 = 0,04\% com Dmin_ATCo = 5NM - indicado na Figura 54 como "TLS"), devese:

- Manter a Acurácia do sistema GNSS menor que 600m a 800m (com probabilidade de 95\%), para todas as demais condições do sistema consideradas normais (Figura 55).

- Manter a Taxa de Atualização do ADS-B menor que 20s (com probabilidade de 95\%), no caso da acurácia do GNSS for considerada normal (Figura 56).

- Manter a Taxa de Atualização do ADS-B menor que 2s (com probabilidade de 95\%), no caso da acurácia do GNSS for considerada altamente degradada (Figura 57). 


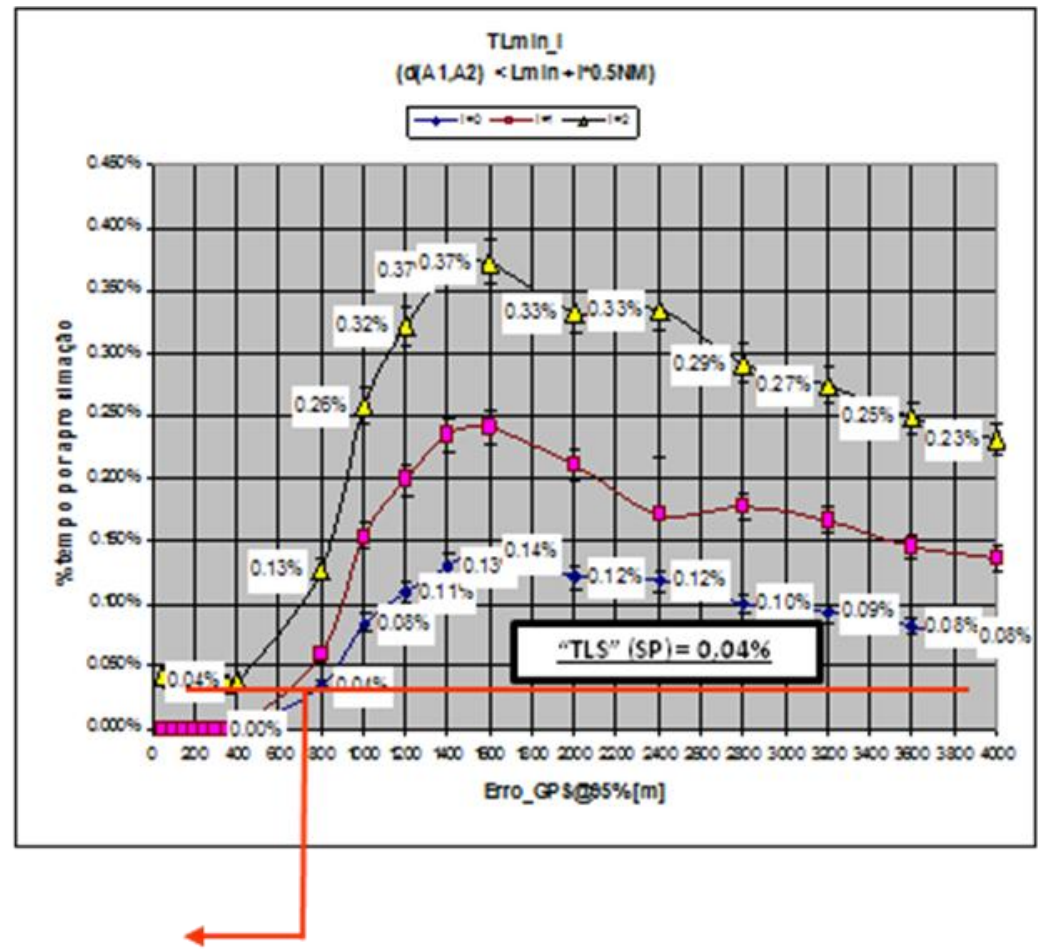

Acurácia GNSS < [600; 800]m@95\%

Dmin_ATCO $=5,0 \mathrm{NM}$

Figura 55 - Exposição à Perda de Separação (TLmin_i) para Degradação da Acurácia GNSS

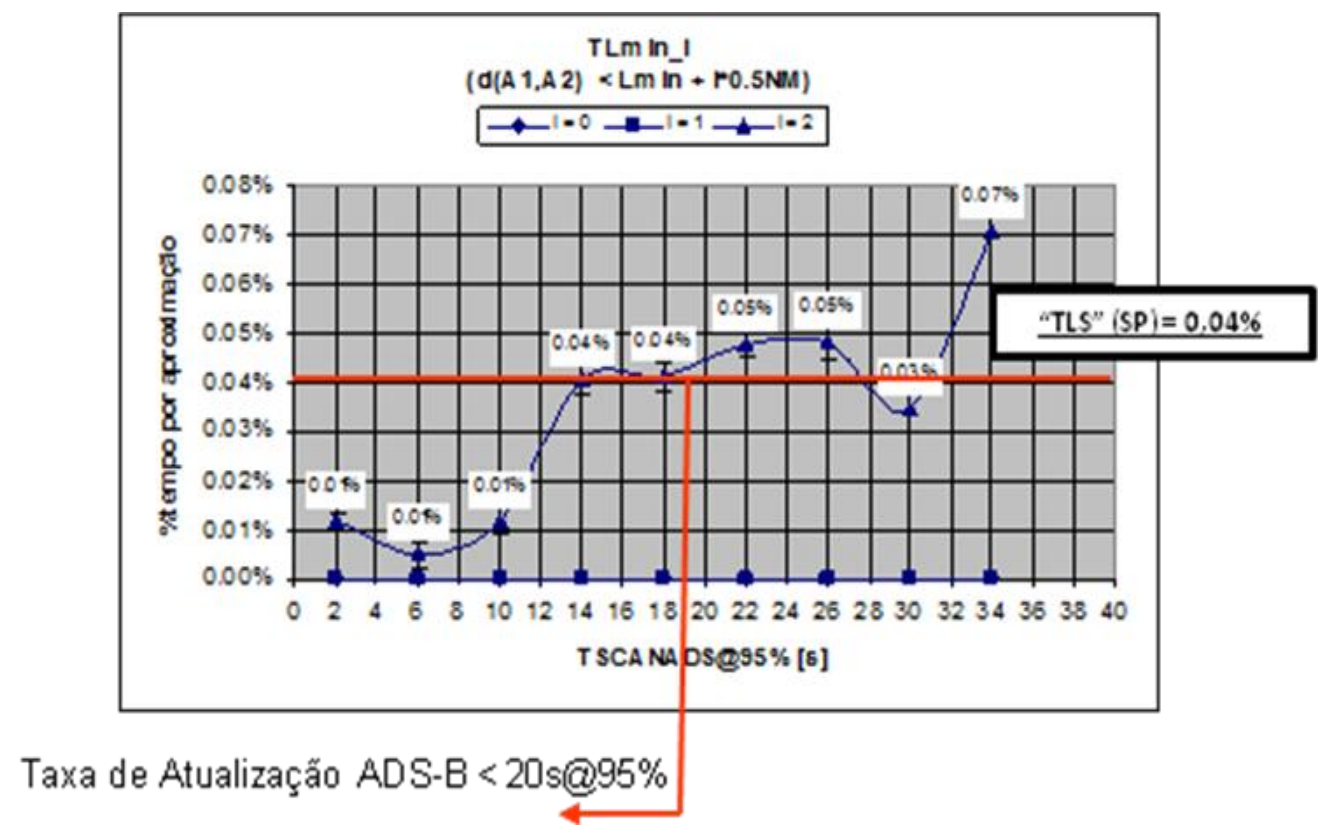

Figura 56 - TLmin_i para Degradação da Taxa de Atualização com Acurácia GNSS Normal 


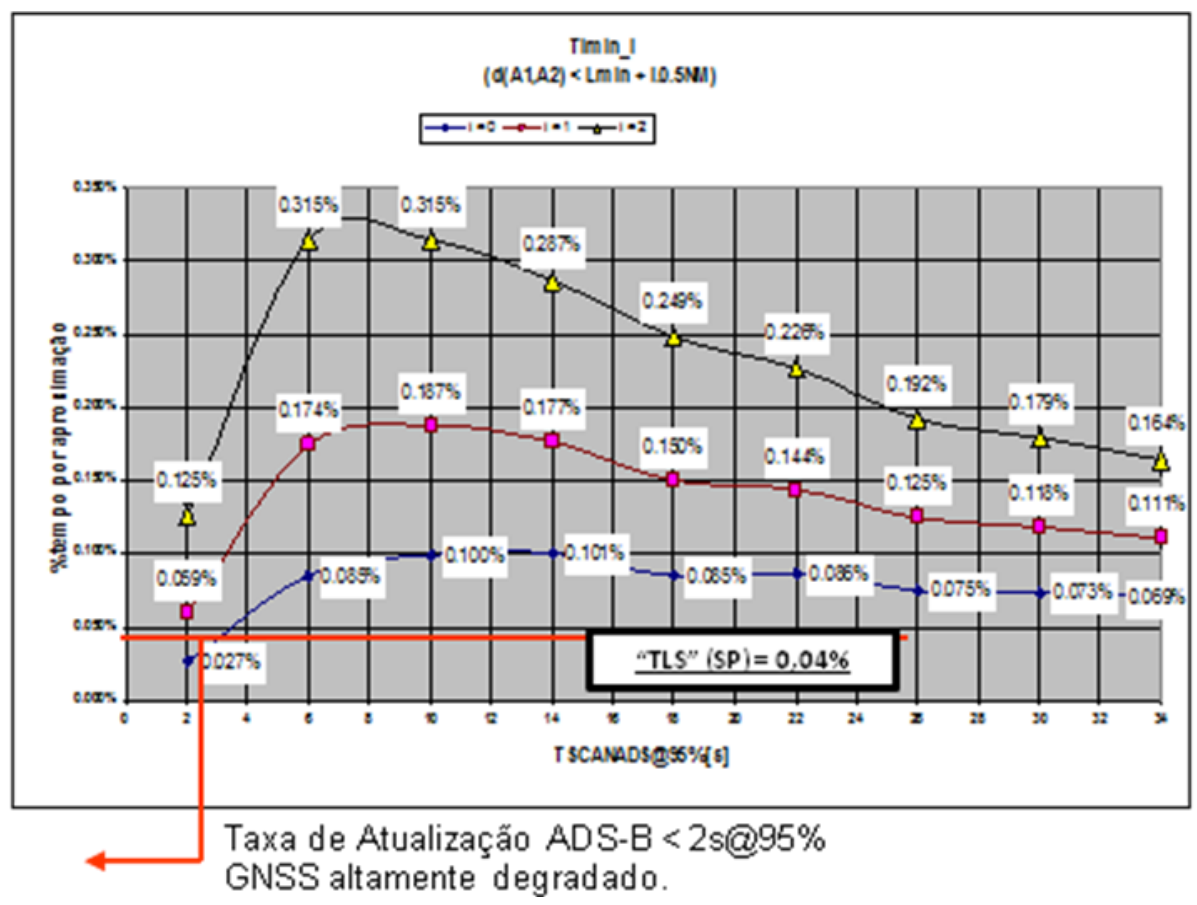

Figura 57 - TLmin_i para Degradação da Taxa de Atualização com Acurácia GNSS Degradada

Desta forma, pode-se considerar o Sistema Proposto, para as condições apresentadas, seguro, pois a taxa de atualização esperada para o ADS-B utilizando data link 1090ES é de 1s, além dos níveis de degradação esperados para a Acurácia de posição do GNSS serem menores que $600 \mathrm{~m}$.

Outra constatação importante é que o valor de acurácia mínima obtido neste estudo concorda com o valor de NACp $\geq 6$ apresentado por Brooker, 2004, que define uma “acurácia” (EPU) menor que 0,3NM (556 metros) para uso do ADS-B em serviços de vigilância ATC. Assim, reafirma-se que é necessário uma acurácia de posição GNSS menor que 0,3NM para que o ADS-B possa ser utilizado no Serviço de Controle de Tráfego Aéreo.

\subsection{Exposição à Perda de Separação mínima nos casos de Intervenção}

Esta métrica avalia o tempo de exposição das aeronaves a perda de separação nos casos onde houve intervenção por parte do ATCo. Vale ressaltar que a separação planejada para o ponto de menor aproximação entre aeronaves foi de 5,0NM. O TLS obtido para esta métrica foi de $\mathbf{1 5 4 , 8 s}$, para Dmin_ATCo de 5NM (Figura 58). 


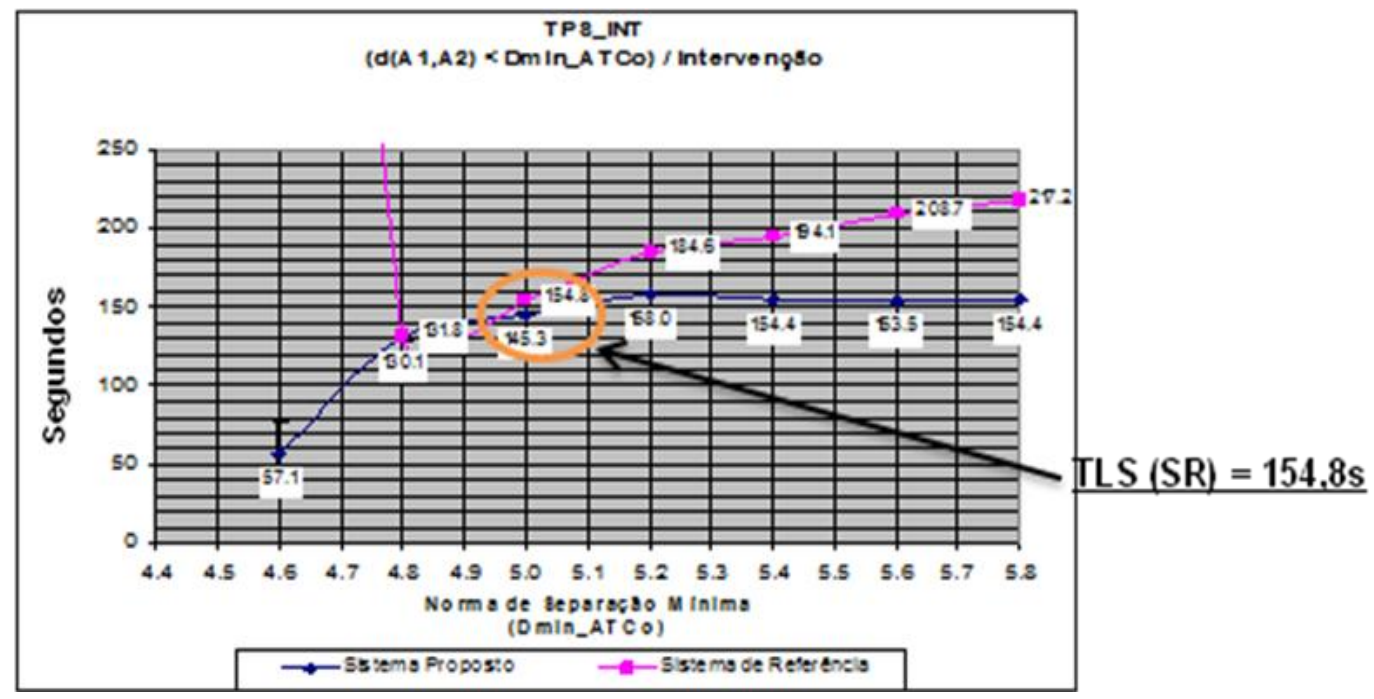

Figura 58 - TPS_INT para Condições Normais de Funcionamento

Em condições normais de funcionamento, pode-se perceber (Figura 58) que os valores de TPS_INT do Sistema Proposto são sempre menores que seu TLS (154,8 segundos). Além disto, pode-se notar, para valores de norma de separação (Dmin_ATCo) maiores que 5NM, que o tempo de exposição das aeronaves à perda de separação tende a ser constante (aproximadamente 154s) para o Sistema Proposto, diferentemente do ocorrido no sistema de referência, cujo valor de TPS_INT continua em crescimento. Supõe-se que o melhor desempenho da navegação do sistema proposto, em conjunto com a maior acurácia dos valores de vigilância, corrobore com a eficiência na detecção e resolução de conflitos. Esta tese se justifica por meio da simulação onde a regra de separação aplicada foi de 4,6NM (vide Figura 58). Neste caso, as intervenções promovidas pelo Sistema Proposto resolveram mais rapidamente o conflito comparado ao Sistema de Referência.

No caso de condições degradadas de funcionamento, o Sistema Proposto respeita o TLS estimado para degradações nos valores de Acurácia do GNSS menores que, aproximadamente, $\mathbf{5 5 0}$ metros (Figura 59). No caso do parâmetro "Taxa de Atualização", o Sistema Proposto respeita o TLS para valores menores que 19s@95\% (com acurácia GNSS em valores normais de funcionamento - Figura 60) ou menores que 5s@95\% (com acurácia em valores altamente degradados - Figura 61). 


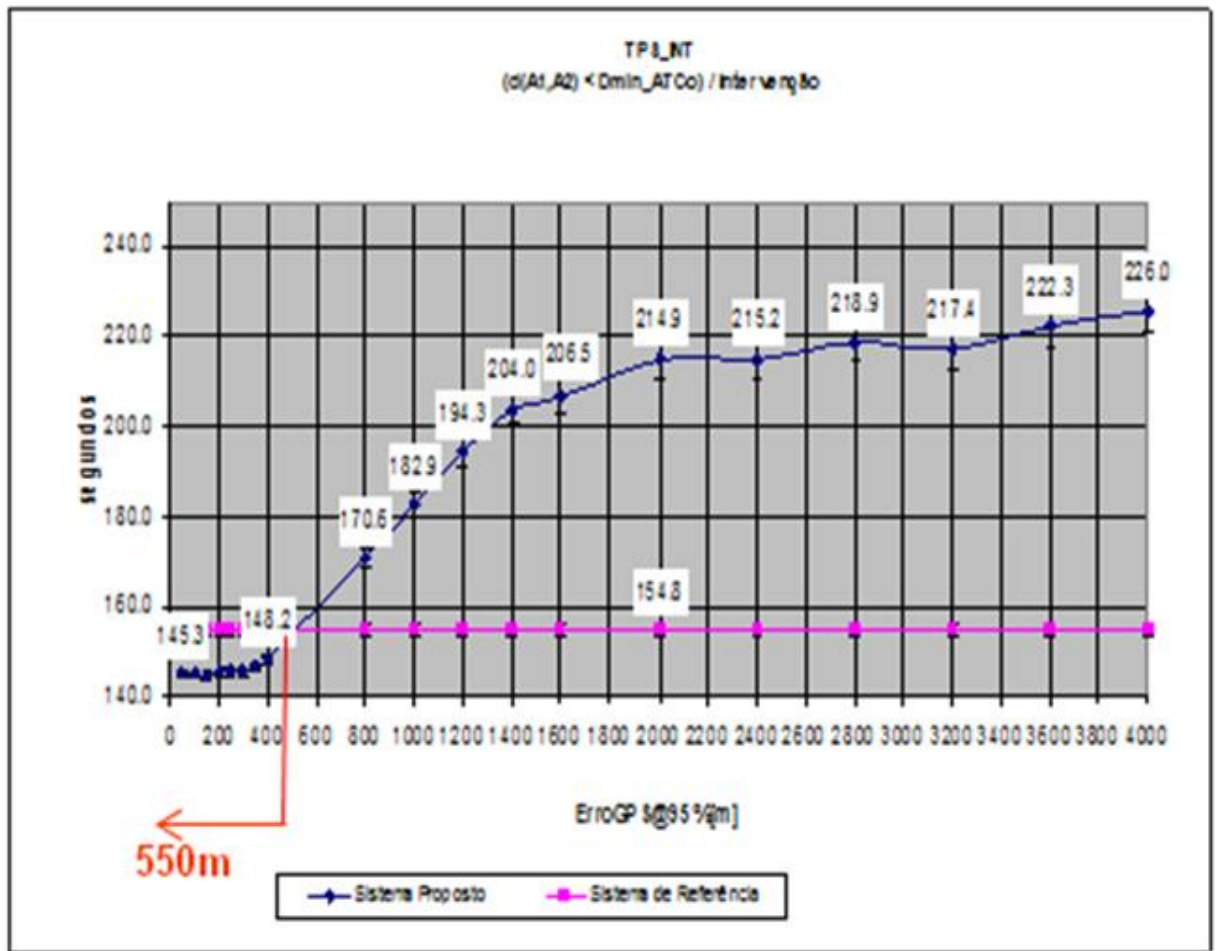

Figura 59 - TPS_INT para Degradação da Acurácia GNSS

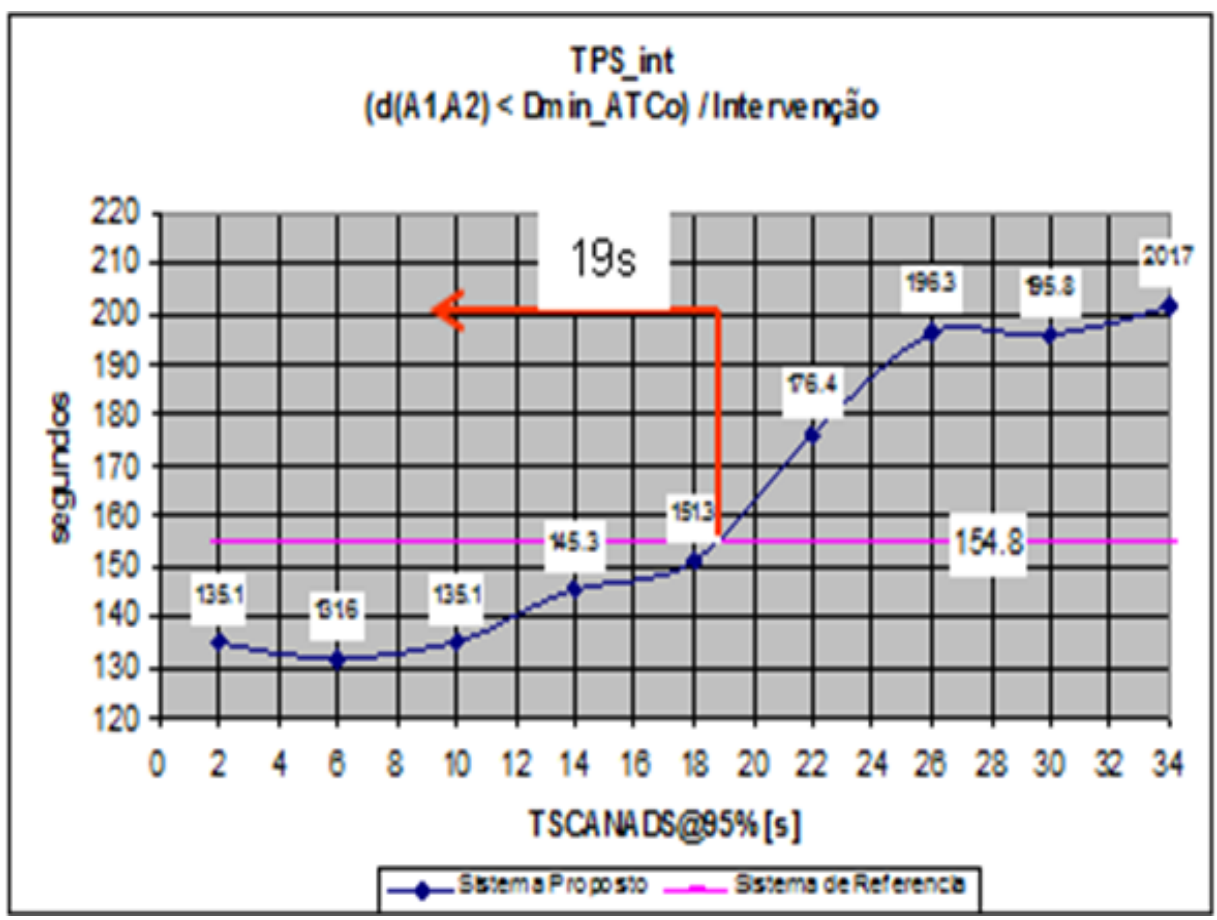

Figura 60 - TPS_INT para Degradação da Taxa de Atualização com Acurácia GNSS Normal 


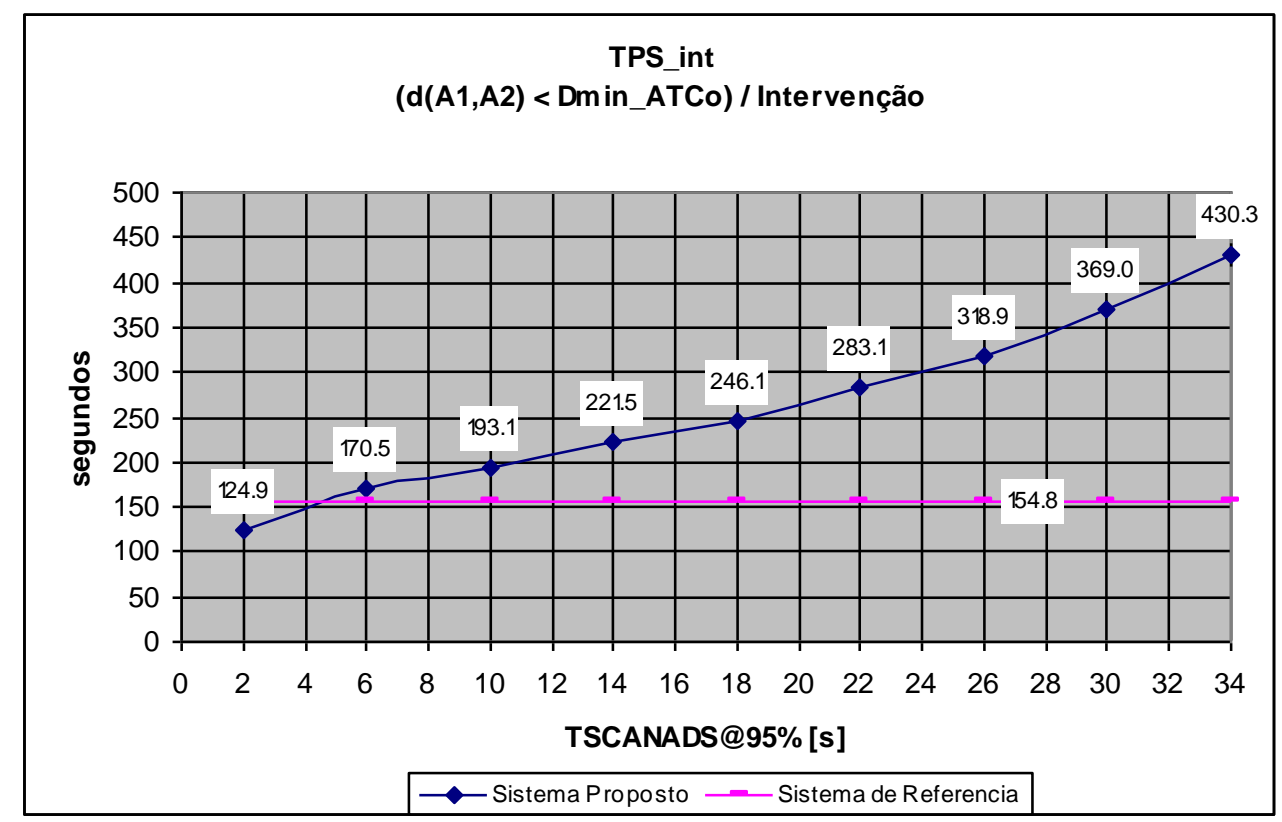

Figura 61 - TPS_int para Degradação da Taxa de Atualização com Acurácia GNSS Degradada

Desta forma, pode-se considerar o Sistema Proposto, para as condições apresentadas, seguro, pois a taxa de atualização esperada para o ADS-B utilizando data link 1090ES é de 1s, além dos níveis de degradação esperados para a Acurácia de posição do GNSS serem menores que $600 \mathrm{~m}$.

\subsection{Exposição à perda da Separação antes da Detecção pelo ATCo}

TPSR_NDetec estima o tempo de exposição à perda da separação entre aeronaves antes que ocorra uma detecção (intervenção) por parte do ATCo. RPS_interv estima a quantidade média de pares de aeronaves em conflito apresentadas ao ATCo para que ocorra uma detecção (intervenção). NPSM_Detec estima a freqüência média de detecções de conflitos por parte do ATCo (já que existe, no máximo, uma detecção por aproximação).

Devido ao assincronismo da ADS-B com relação à obtenção das posições de vigilância, o tempo necessário para o ATCo detectar um conflito é maior no Sistema Proposto do que no Sistema de Referência. Este fato pode ser percebido por meio das métricas TPSR_NDetec e RPS_interv que, no Sistema Proposto, possuem valores de $10 \%$ a $20 \%$ maiores que as métricas do Sistema de Referência (Figura 64 e Figura 62) para condições normais de funcionamento. Porém, como visto anteriormente, isto não afeta os tempos de exposição à conflito. Tampouco a carga de trabalho dos controladores, expressa indiretamente por NPSM_Detec, é afetada, permanecendo idêntica em ambos os sistemas (Figura 63). 
No caso de condições degradadas de acurácia, os valores das 3 métricas citadas, para o Sistema Proposto, são inferiores aos valores apresentados pelo Sistema de Referência, fazendo com que o tempo necessário para o ATCo detectar um conflito no Sistema Proposto seja até 23\% superior que no Sistema de Referência (Figura 67). Porém, valores degradados de acurácia da posição GNSS podem ser compensados com a elevação dos valores de Taxa de Atualização. Observando a Figura 73, verifica-se que Taxas de Atualização menores que 6s@95\%, para acurácia de posição GNSS em 1,5NM@95\% (aproximadamente 2.780m@95\%), reduzem o tempo necessário para que o ATCo detecte um conflito, no Sistema Proposto, ao nível obtido com o Sistema de Referência. Considerando valores de acurácia de posição normais, pode-se obter para o Sistema Proposto métricas melhores que as observadas no Sistema de Referência reduzindo-se a Taxa de Atualização para valores menores que 8s@95\% (Figura 68, Figura 69 e Figura 70).

Portanto, considerando que a ADS-B trabalhe com taxas menores que 2s (1s nominal), o Sistema Proposto é satisfatório, sob estes aspectos, para ser aplicado como um sistema de vigilância no ATC.

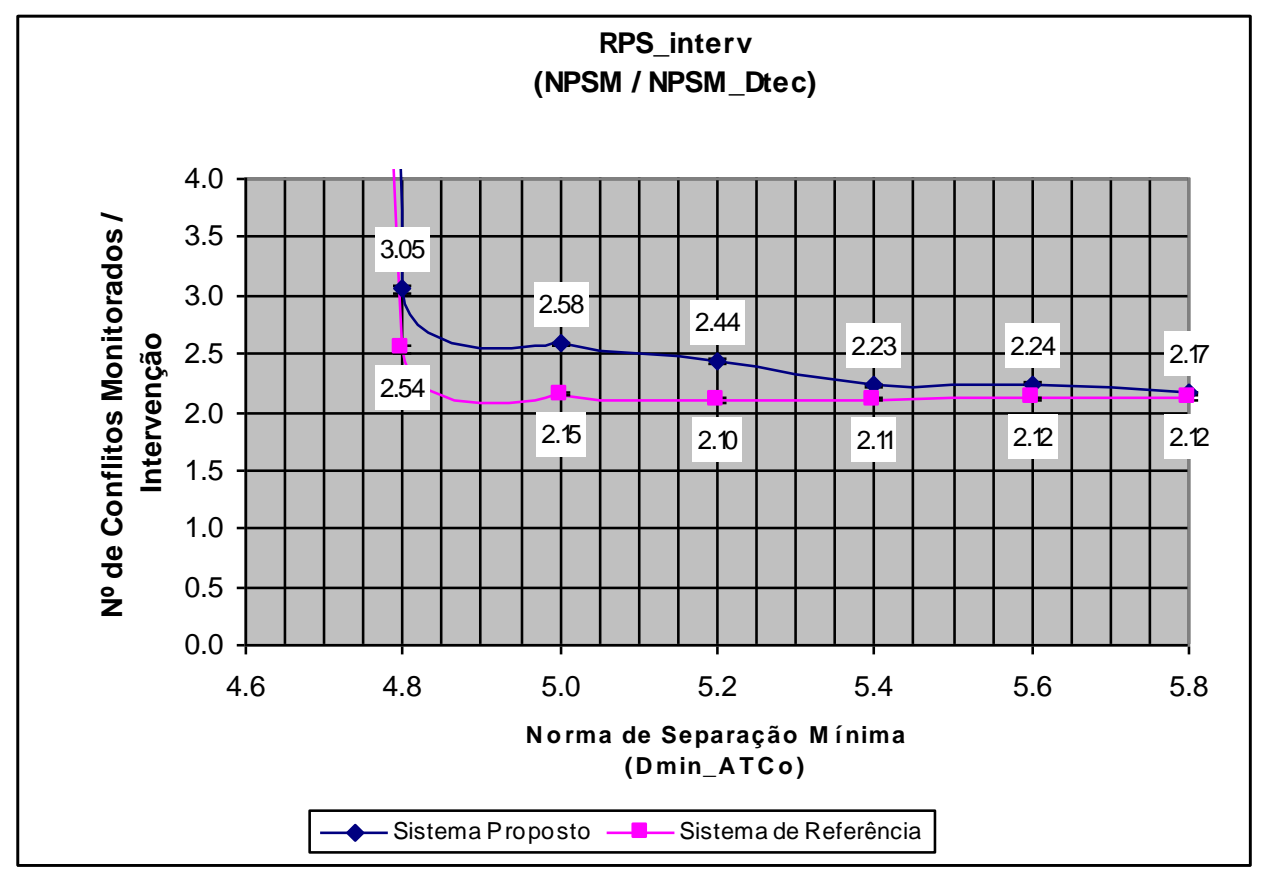

Figura 62 - RPS_interv para Condições Normais de Funcionamento 


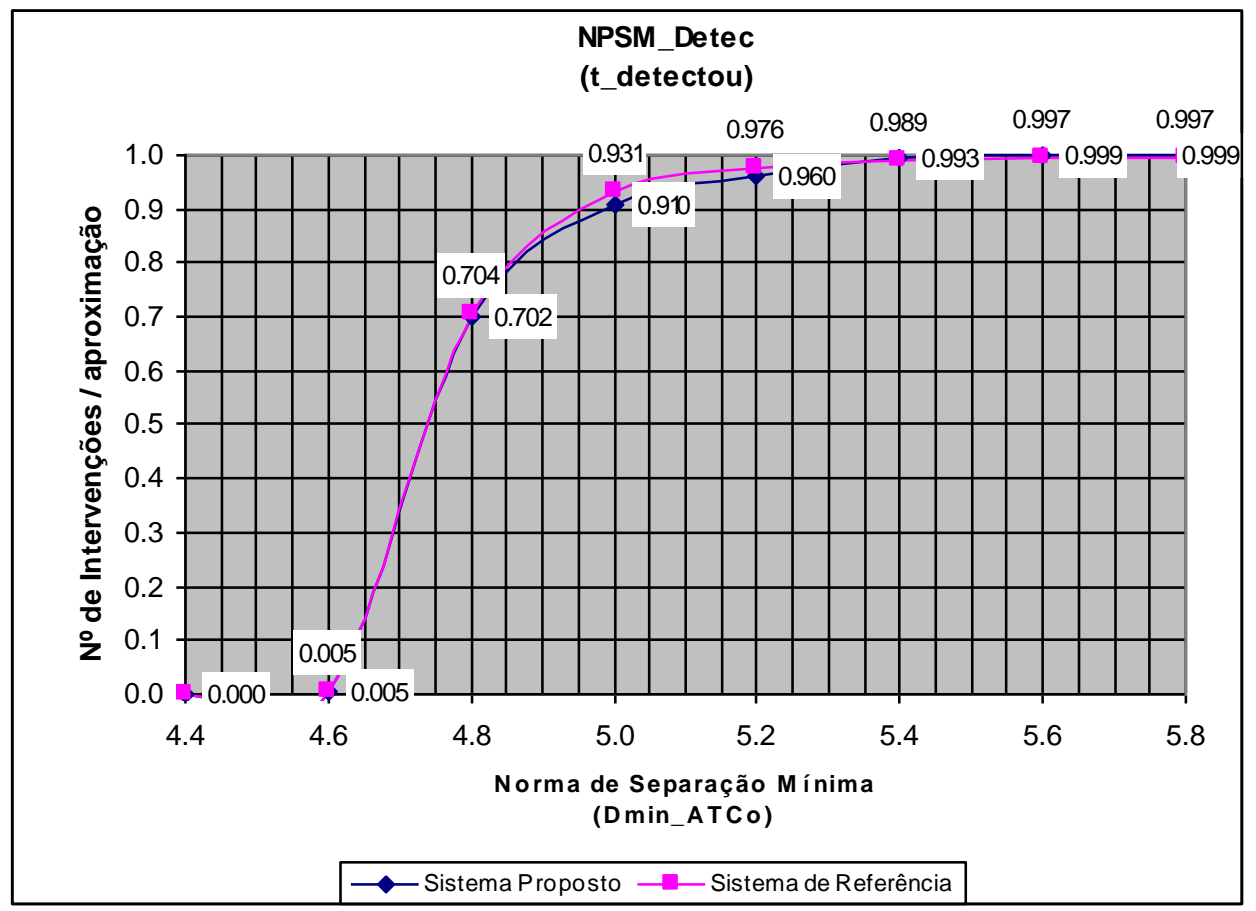

Figura 63 - NPSM_Detec para Condições Normais de Funcionamento

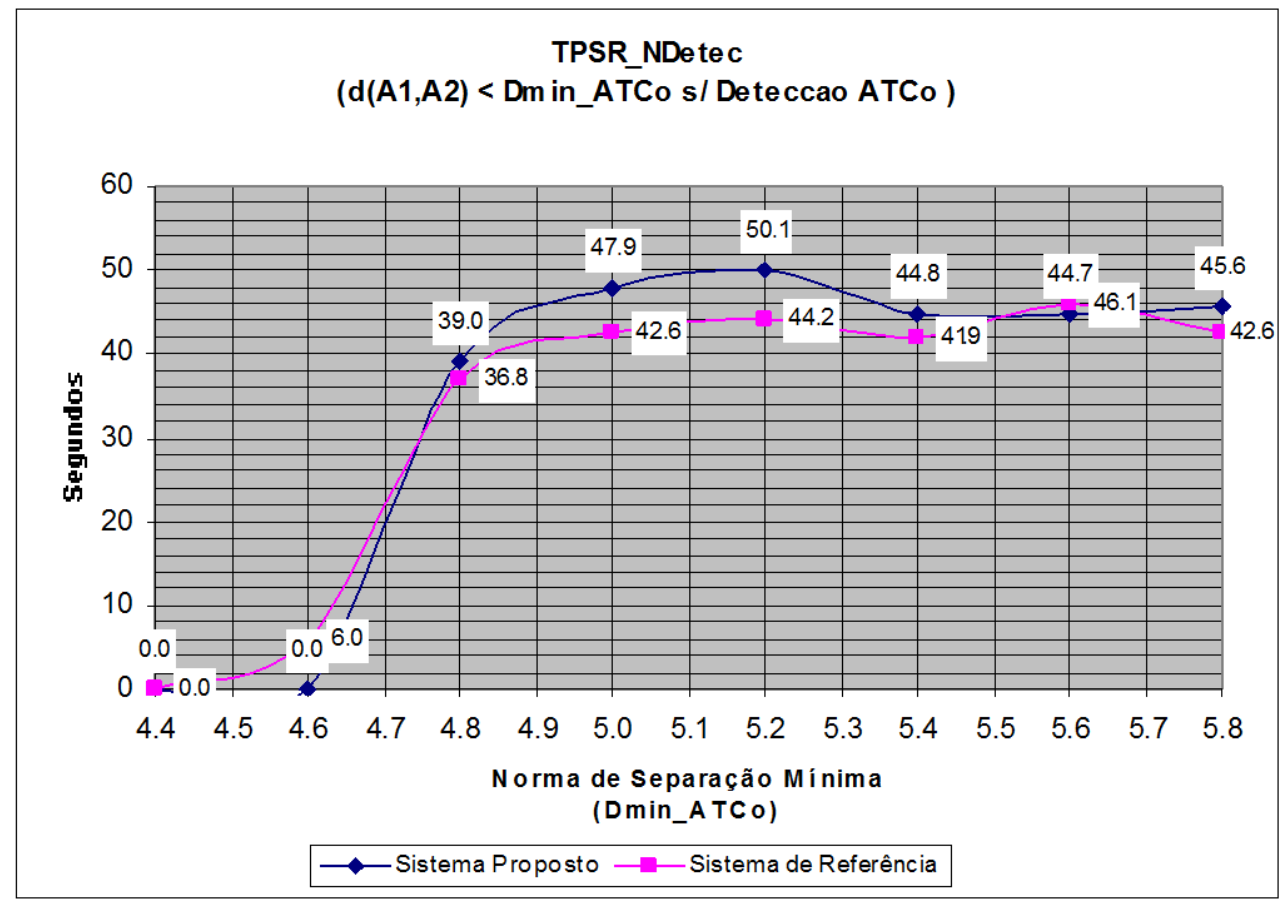

Figura 64 - TPSR_NDetec para Condições Normais de Funcionamento 
RPS_interv

(NPSM / NPSM_Dtec)

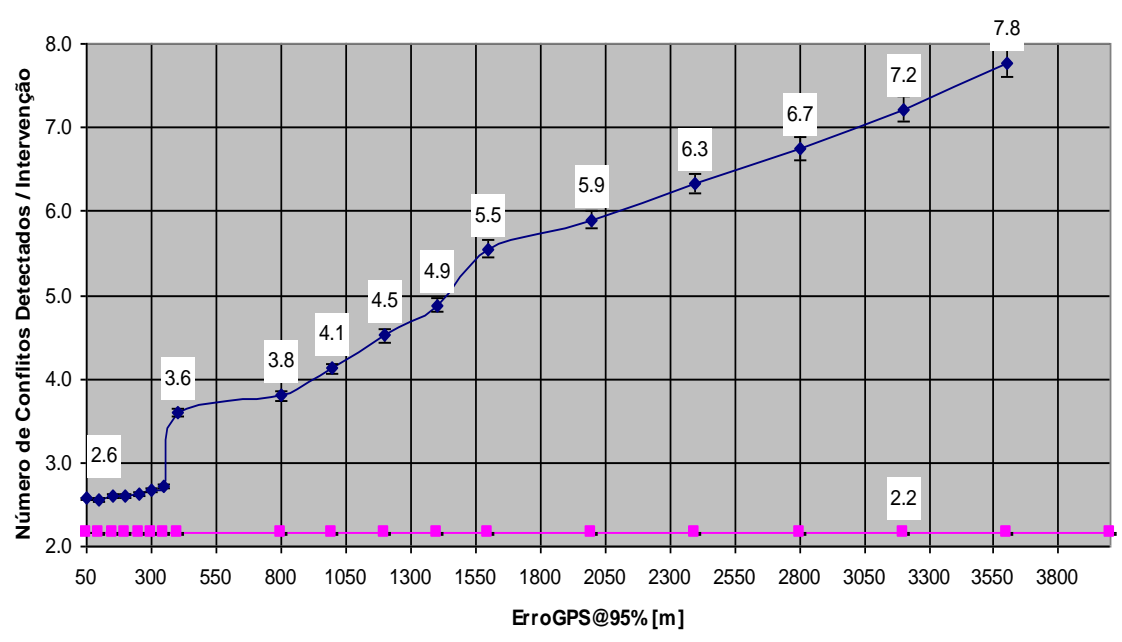

Sistema Proposto

- Sistema de Referência

Figura 65 - RPS_Interv para Acurácia GNSS Degradada

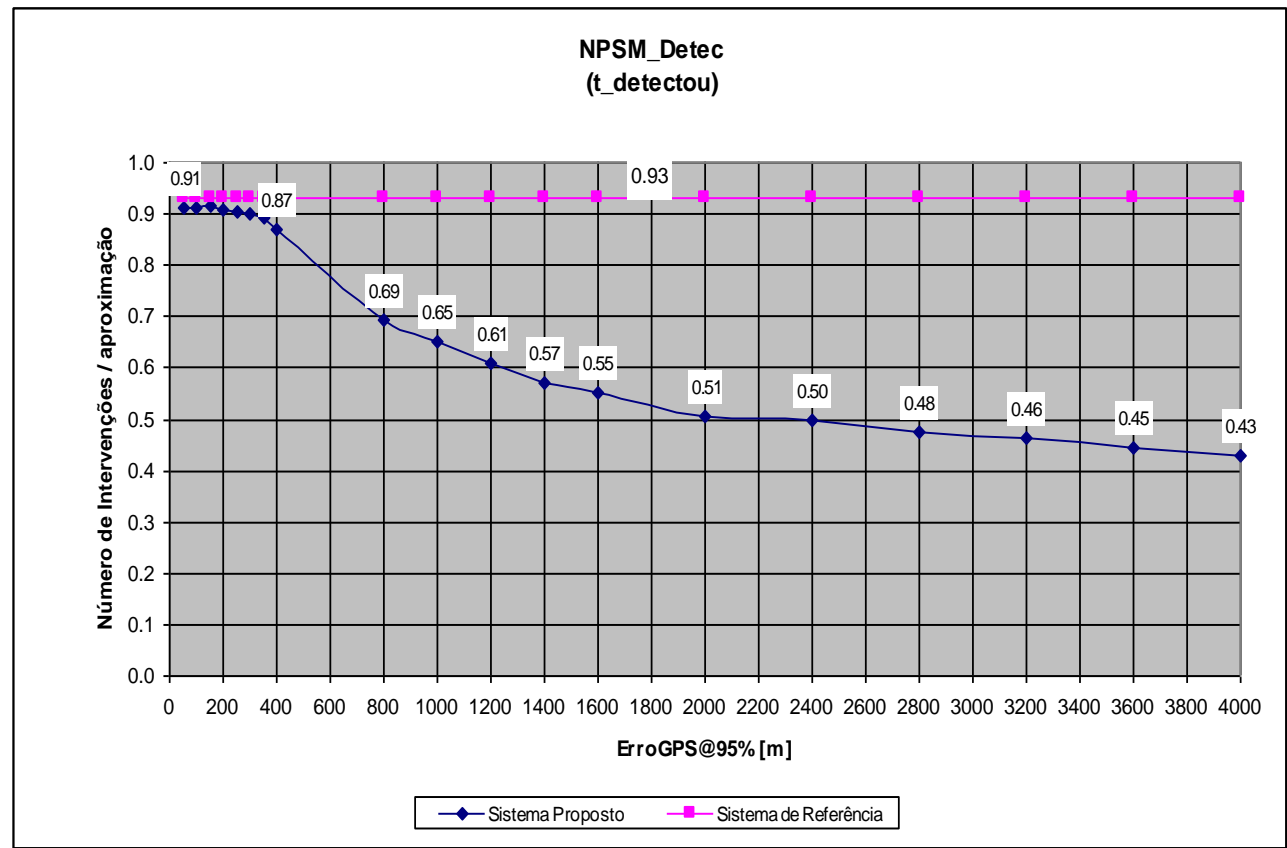

Figura 66 - NPSM_Detec para Acurácia GNSS Degradada 
TPSR NDetec

(d(A1,A2) < Dmin_ATCo sem Detecção ATCo)

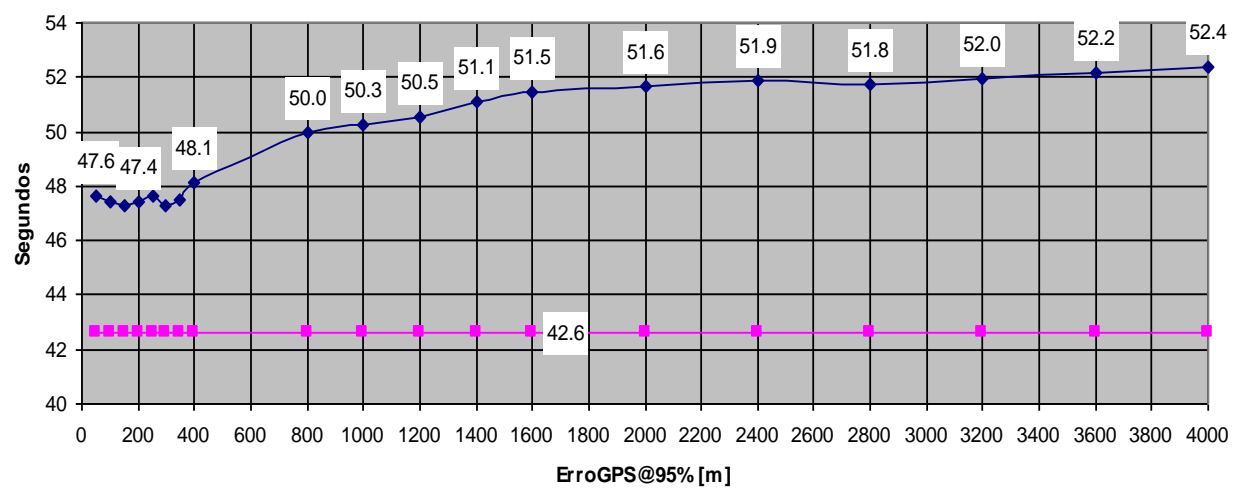

Sistema Proposto - Sistema de Referência

Figura 67 - TPSR_NDetecv para Acurácia GNSS Degradada

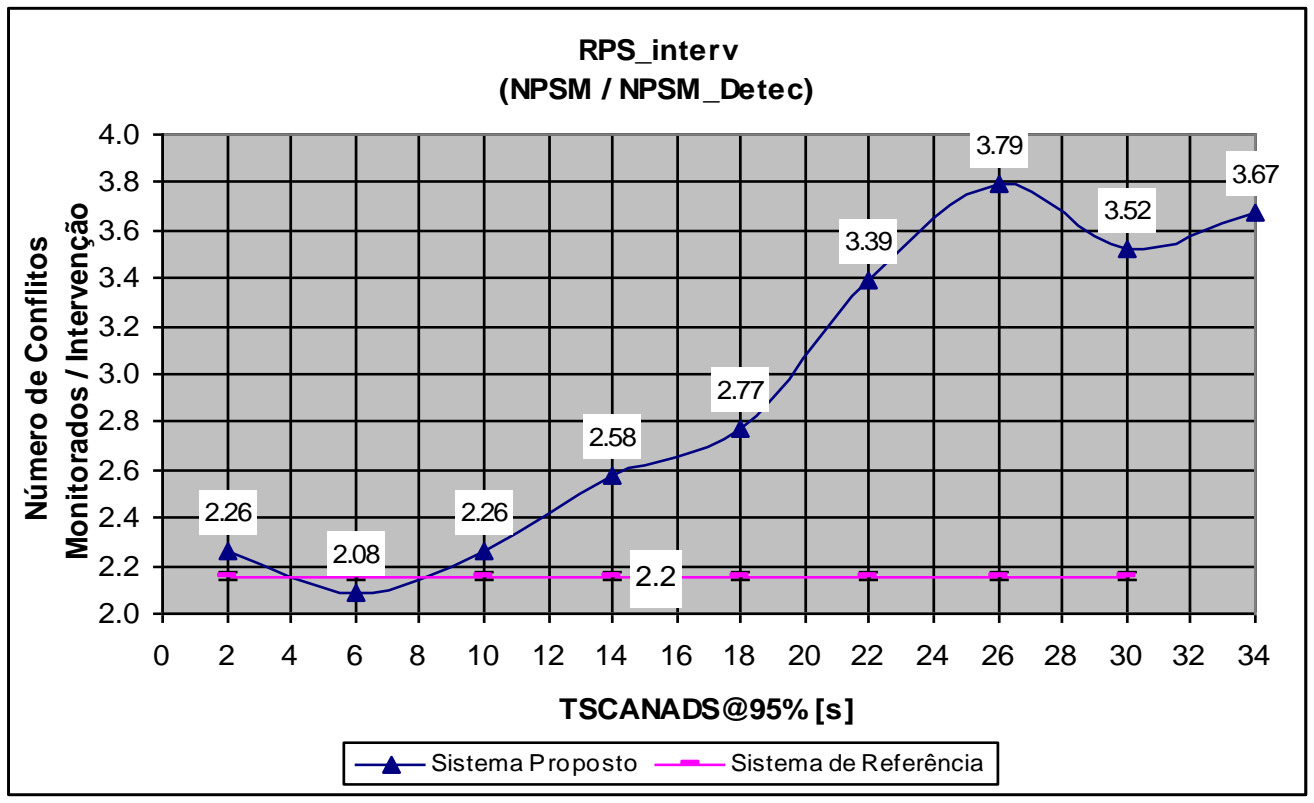

Figura 68 - RPS_interv para Degradação da Taxa de Atualização com Acurácia GNSS Normal 


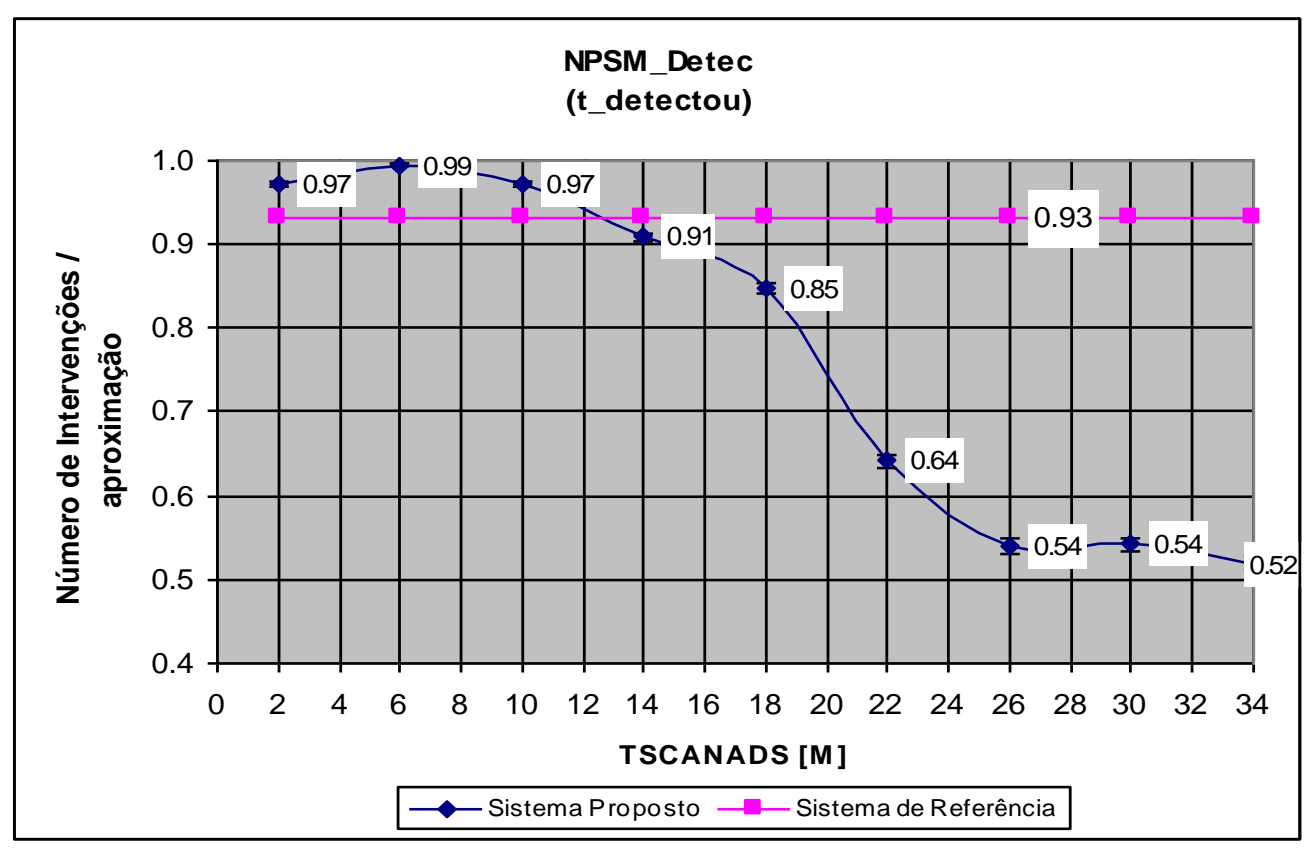

Figura 69 - NPSM_Detec para Degradação da Taxa de Atualização / Acurácia GNSS Normal

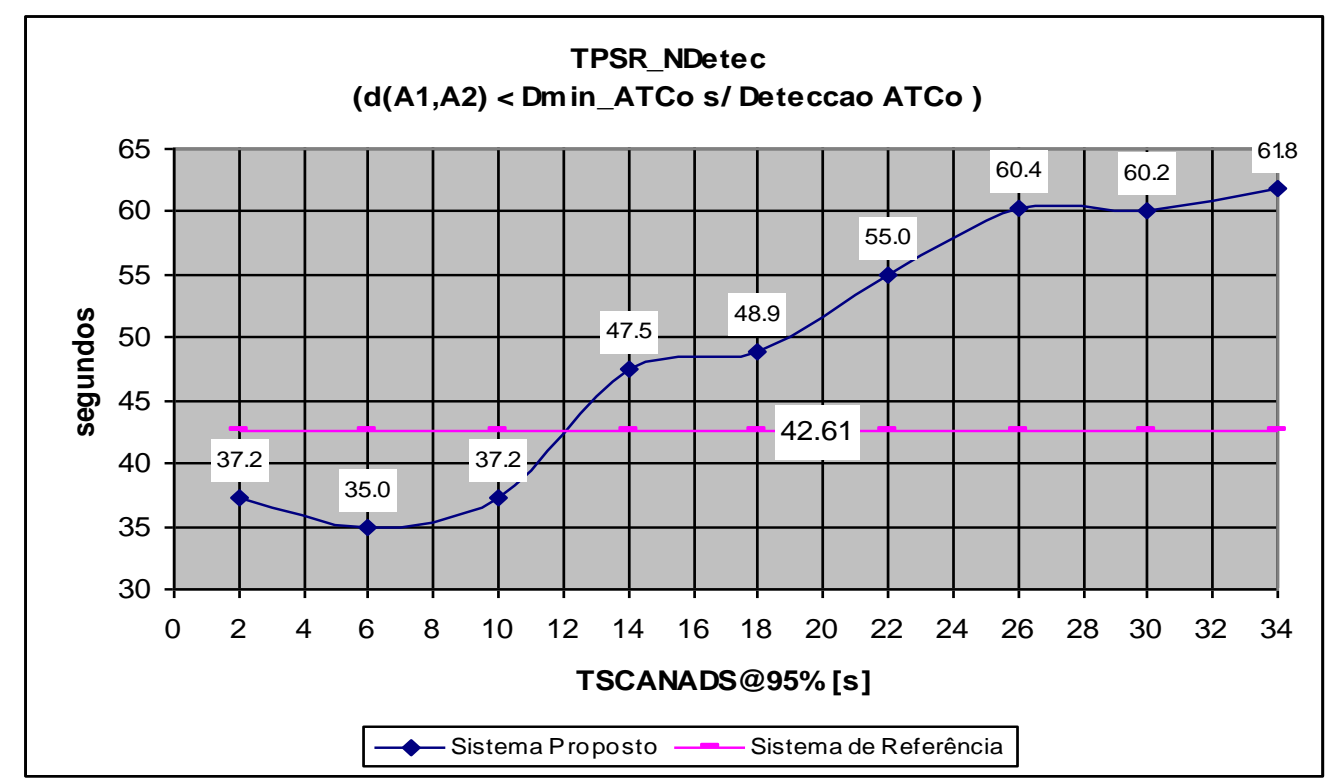

Figura 70 - TPSR_NDetec para Degradação da Taxa de Atualização / Acurácia GNSS Normal 


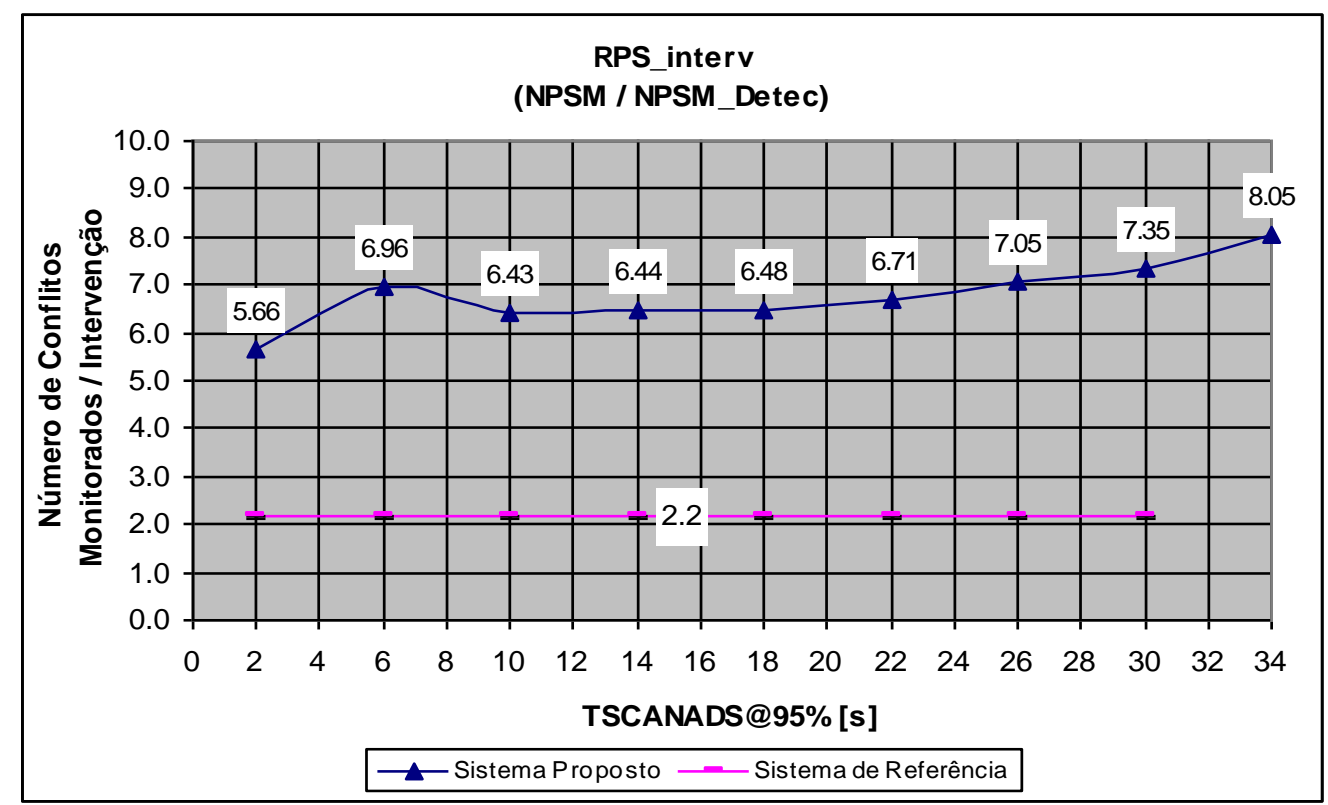

Figura 71 - RPS_interv para Degradação da Taxa de Atualização / Acurácia GNSS Degradada

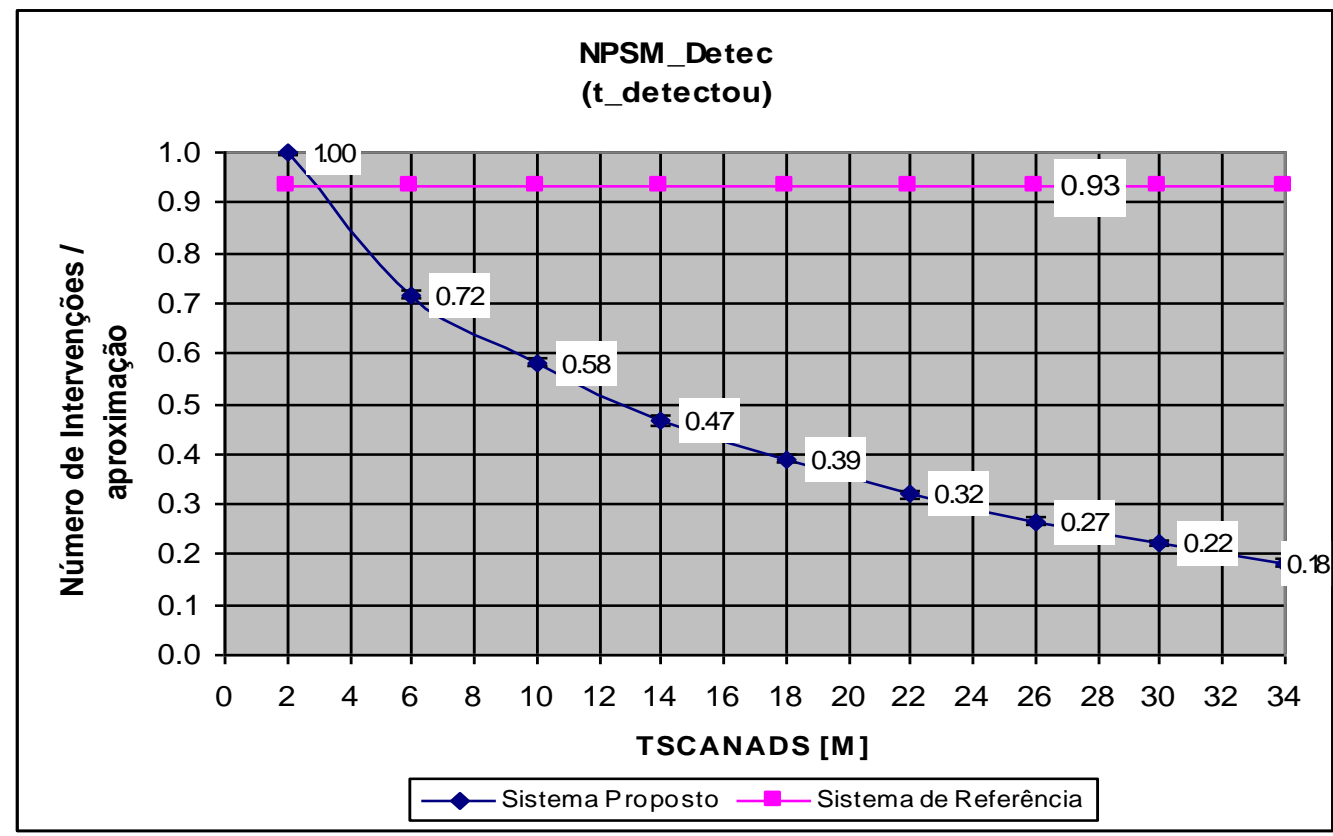

Figura 72 - NPSM_Detec para Degradação da Taxa de Atualização / Acurácia GNSS Degradada 


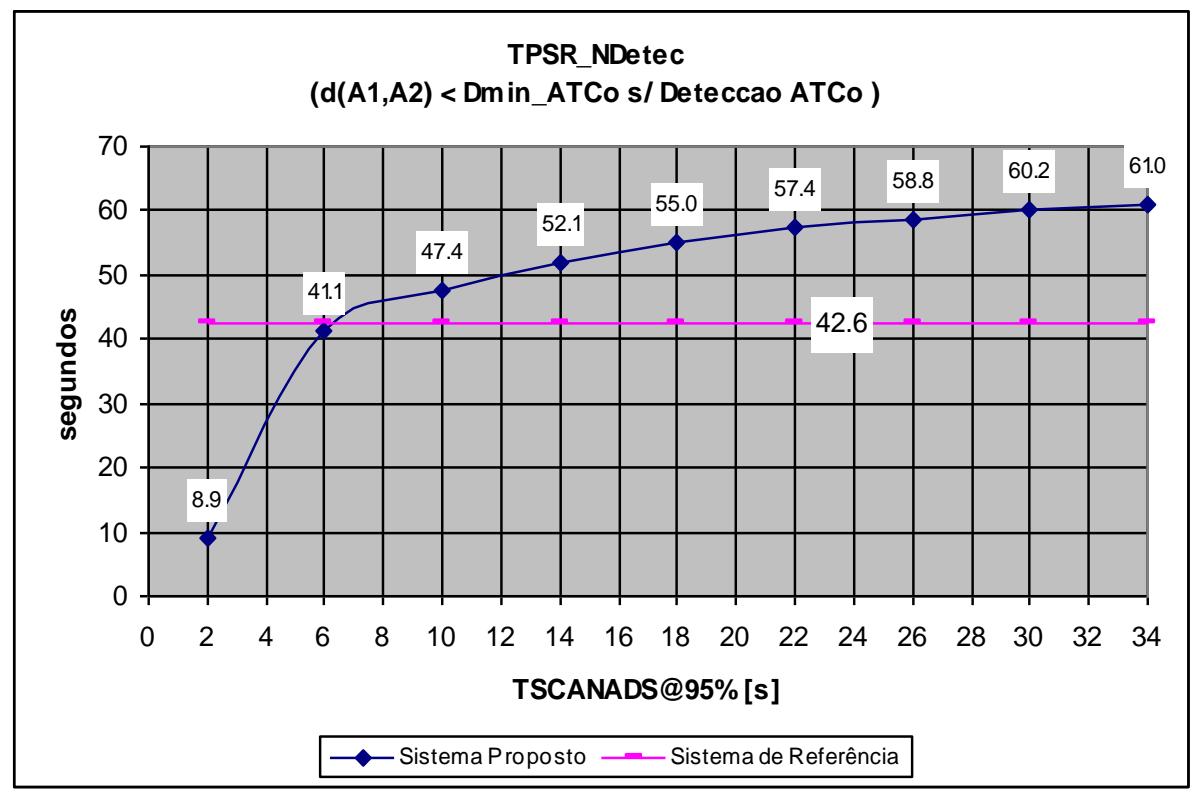

Figura 73 - TPSR_NDetec para Degradação da Taxa de Atualização / Acurácia GNSS Degradada

\subsection{Exposição à perda de Separação sem apresentação ao ATCo}

Esta métrica estima o tempo médio, por aproximação, no qual uma perda de separação real fica sem ser apresentada ao ATCo. Pode-se supor que o assincronismo da ADS-B com relação à obtenção das posições de vigilância faça com que esta métrica no Sistema Proposto seja maior que no Sistema de Referência. Este fato pode ser confirmado pela Figura 74 (condições normais de funcionamento).

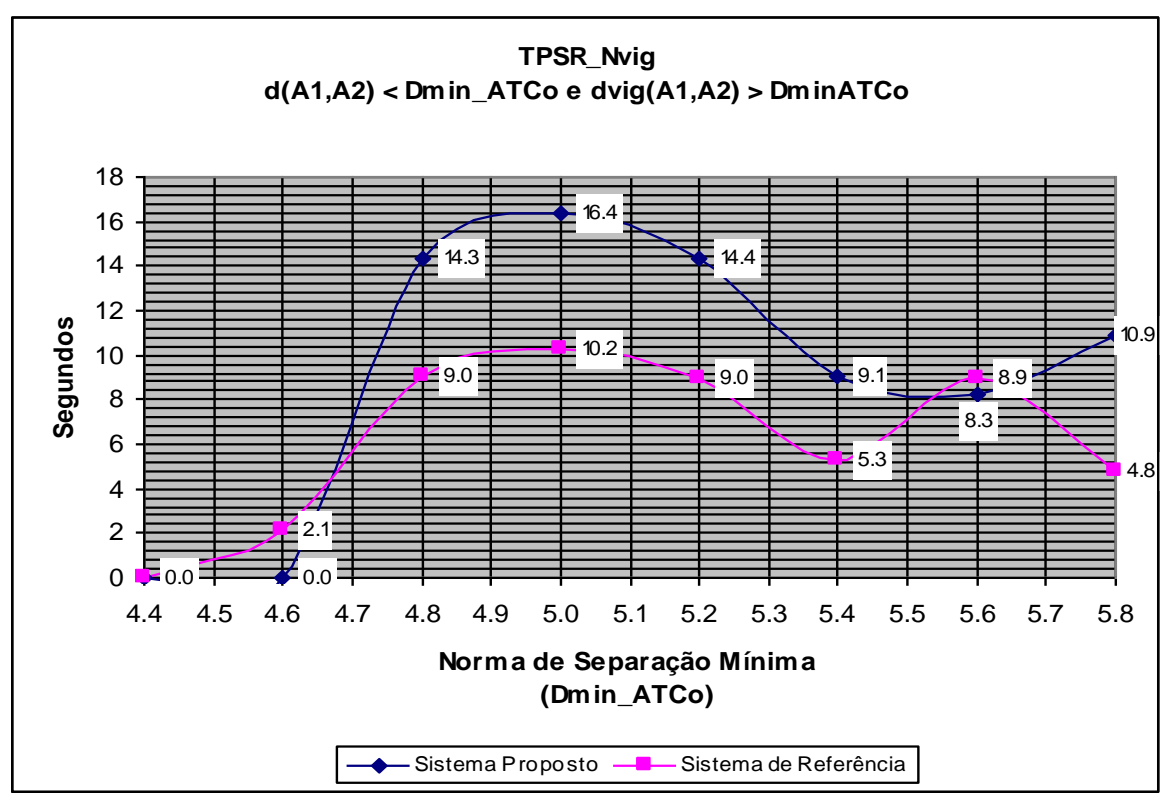

Figura 74 - TPSR_Nvig para Condições Normais de Funcionamento 
Em condições degradadas de acurácia da posição GNSS, mesmo as altas Taxas de Atualização não proporcionam ao Sistema Proposto valores de métrica compatíveis com o Sistema de Referência (Figura 75 e Figura 77). Apenas no caso de acurácia de posição normal, a taxa de atualização influencia positivamente o Sistema Proposto, fazendo-o ter um valor TPSR_Nvig menor que no Sistema de Referência para Taxas de Atualização menores que 11 segundos, com probabilidade de 95\% (11s@95\%).

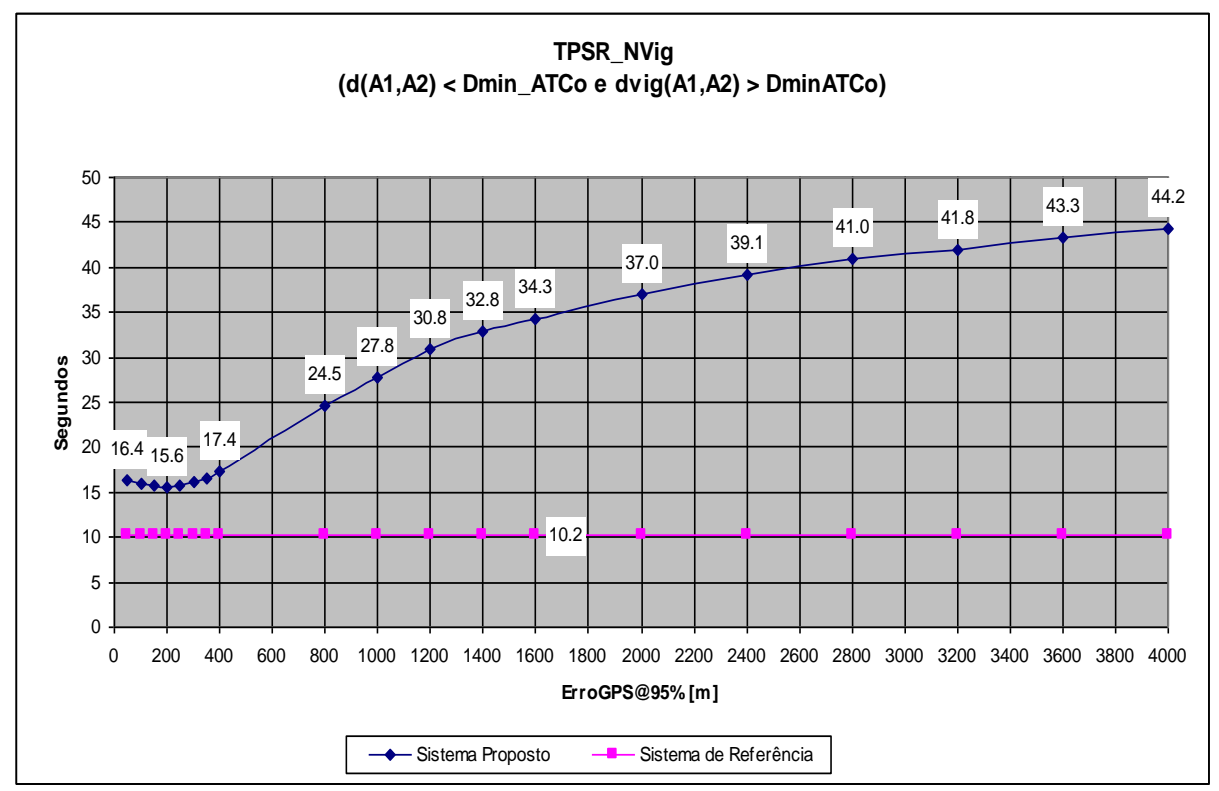

Figura 75 - TPSR_NVig para Acurácia GNSS Degradada

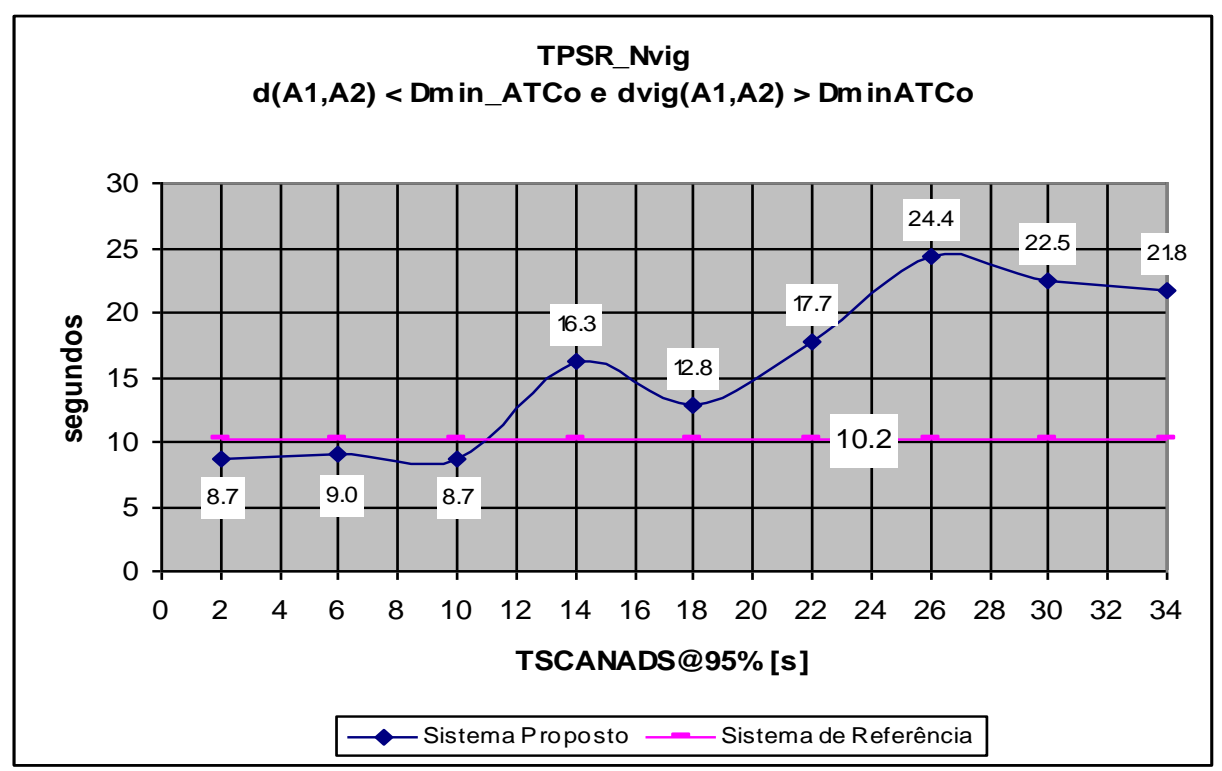

Figura 76 - TPSR_Nvig para Degradação da Taxa de Atualização / Acurácia GNSS Normal 


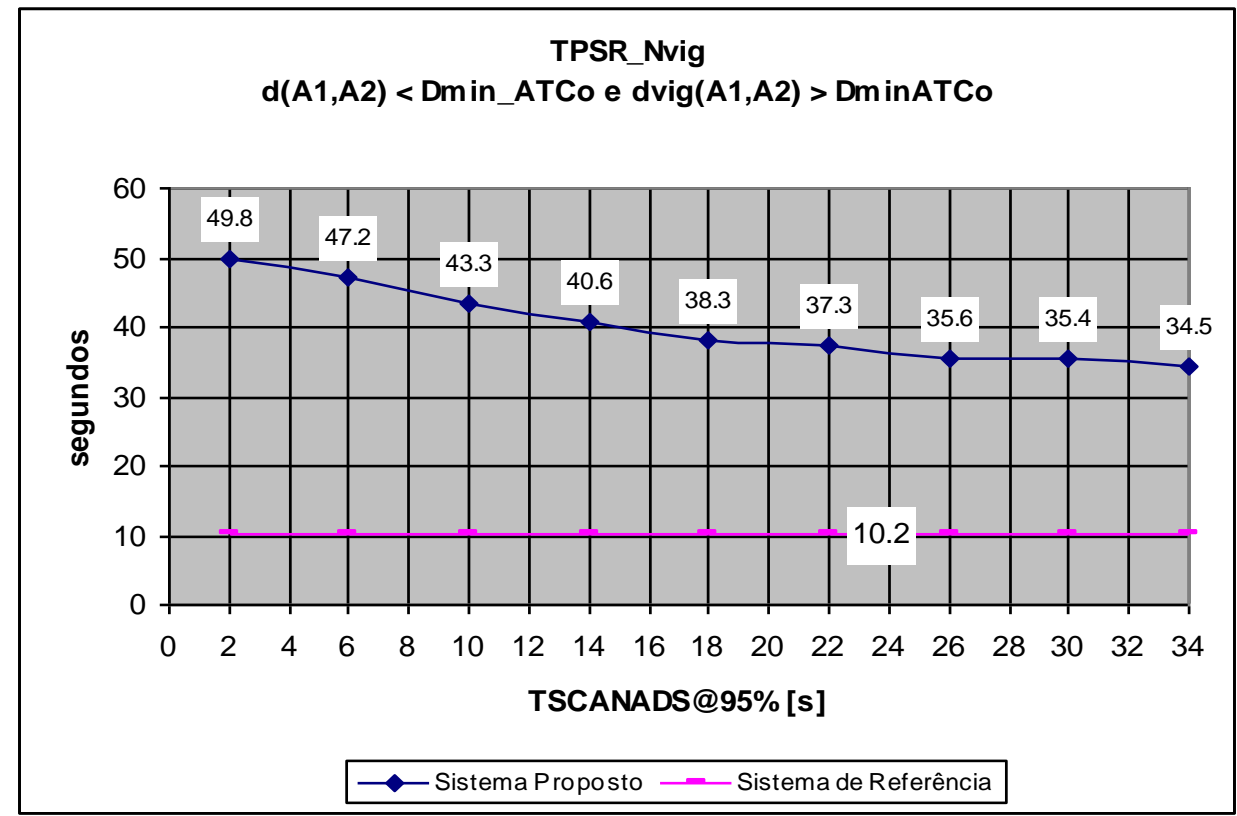

Figura 77 - TPSR_Nvig para Degradação da Taxa de Atualização / Acurácia GNSS Degradada

Portanto, considerando que a ADS-B trabalhe com taxas menores que $2 \mathrm{~s}$ ( $1 \mathrm{~s}$ nominal), o Sistema Proposto é satisfatório, sob estes aspectos, para ser aplicado como um sistema de vigilância no ATC.

Em face ao conjunto de resultados apresentados neste capítulo, o qual encerra o processo relativo à aplicação do método de avaliação de risco proposto neste trabalho, seguem, no próximo capítulo, as conclusões obtidas por meio deste trabalho. 


\section{CONSIDERAÇÕES FINAIS}

Este capítulo apresenta as Conclusões obtidas pelo autor após o término desta investigação científica, seguida de propostas de linhas de trabalhos futuros derivados dos assuntos aqui tratados.

\subsection{Conclusões}

Para alcançar os objetivos proposto para este trabalho de investigação científica foi necessário realizar um conjunto de atividades que, aplicadas em conjunto e de forma organizada, formaram seu arcabouço conceitual. Devido às diversas disciplinas abordadas aqui, faz-se necessário conclusões para cada tema trabalhado. Ao final, serão apresentadas as conclusões a respeito do objetivo principal deste trabalho, que é o de avaliar o impacto do uso da Vigilância Dependente Automática (Automatic Dependent Surveillance), mais especificamente sua forma por Radiodifusão (ADS-B), sobre os níveis de segurança do Sistema de Controle de Tráfego Aéreo.

\subsubsection{Conclusões com relação à proposta de Método de Avaliação Risco}

No Capítulo 3 deste trabalho, além dos conceitos relacionados à segurança no contexto do tráfego aéreo e seu relacionamento com o desempenho dos elementos do Sistema Controle de Tráfego Aéreo (ATC) e com a capacidade do sistema de tráfego aéreo, foram apresentados os dois métodos de avaliação de risco adotados pela Organização da Aviação Civil Internacional (OACI) no processo de planejamento do espaço aéreo (ICAO, 1998) - um método absoluto (Avaliação do Risco em relação a um valor de Limiar) e um método relativo (Avaliação do Risco por meio de Comparação com um Sistema de Referência).

Com base nestas apresentações, percebeu-se que as limitações inerentes aos Métodos de Avaliação de Risco adotados pela OACI (ICAO, 1998) são complementares. Ou seja, as características desvantajosas em um método são vantajosas no outro. Em face destas limitações e complementaridades, propôs-se um Método de Avaliação de Risco que combinasse os métodos "absoluto" e "relativo" adotados pela OACI. Esta fusão de métodos teve o objetivo de maximizar as suas qualidades em separado e, assim, criar um método com maior poder de análise e que pudesse ser aplicado ao novo paradigma de tráfego aéreo, o CNS/ATM (Comunication, Navigation, Surveillance / Air Traffic Management), apresentado no Capítulo 2. 
Como resultado de sua aplicação neste trabalho, o Método de Avaliação de Risco proposto mostrou-se promissor em avaliar a segurança de sistemas baseados no paradigma CNS/ATM. Com este método, foi possível quantificar o impacto de parâmetros do sistema em avaliação (Sistema Proposto, baseado em navegação por satélites - GNSS - e em vigilância dependente automática por radiodifusão - ADS-B), mesmo que interdependentes, sobre métricas globais de segurança. Além disto, este método de avaliação proposto permitiu determinar requisitos funcionais mínimos para o sistema proposto, avaliando quais valores de especificação de seus parâmetros tornariam suas métricas globais compatíveis com os níveisalvo de segurança (target level of safety - TLS), estimados a partir de um sistema de referência (Sistema Legado).

Com base na aplicação atual, pode-se vislumbrar que este método de avaliação proposto possa, sem dúvida, ser aplicado em outros tipos de sistemas, mesmo não críticos em segurança, para avaliação de características diversas. A aplicação ficaria condicionada aos tipos de métricas adotadas, que poderiam avaliar tanto desempenho, disponibilidade, custo, entre outras características (para avaliações funcionais, de custo-benefício, entre outros).

Portanto, pode-se concluir que o método de avaliação proposto neste trabalho atingiu seu objetivo, maximizando os benefícios (e minimizando as restrições) individuais dos métodos de avaliação propostos pela Organização da Aviação Civil Internacional (OACI).

\subsubsection{Conclusões com relação à modelagem em RPFE.}

Ao propor um Método de Avaliação de Risco que conjugasse os métodos "absoluto" e "relativo" de avaliação de risco determinados pela Organização da Aviação Civil Internacional (OACI) (Capítulo 3), verificou-se a necessidade de adotar, na parte absoluta do método proposto, um formalismo de modelagem e análise que considerasse tanto as características dos sistemas atuais de tráfego aéreo quanto as características intrínsecas aos sistemas de tráfego segundo o paradigma CNS/ATM. Desta forma, procedeu-se um estudo com o objetivo inicial de definir as características do atual paradigma de sistemas críticos em segurança (apresentado em detalhes no APÊNDICE C). Em seguida, demonstrou-se que as características levantadas para o atual paradigma de sistemas críticos em segurança são aplicáveis ao conceito CNS/ATM.

Em decorrência deste estudo, verificou-se que as redes de Petri Fluidas e Estocásticas (RPFE) são um formalismo gráfico-matemático satisfatório para modelagem e avaliação do atual 
paradigma de sistemas críticos em segurança, mais especificamente o paradigma CNS/ATM. Além de sua capacidade de representar formalmente sistemas tanto por meio de expressões quanto de forma gráfica, as RPFE propiciam a modelagem de sistemas híbridos complexos cujas partes contínuas e discretas possuam alta interdependência - e com características temporais estocásticas. Além disto, a existência de estruturas de recompensa no formalismo das RPFE permite que se avaliem sistemas híbridos e complexos com base em uma diversidade de métricas - definidas no processo de modelagem - podendo o mesmo ser utilizado em diversos domínios de aplicação. O uso de simulação por eventos discretos abre a possibilidade de modelar parâmetros com funções de distribuição estocástica diversas, não limitando o analista ao paradigma Markoviano. Um estudo detalhado das RPFE e sua aplicação à modelagem e análise de sistemas críticos pode ser encontrado no APÊEDICE D.

O problema neste formalismo, em especial quanto ao modo de resolução baseado em simulação por eventos discretos, está relacionado ao conflito entre "custo em tempo de processamento" e "intervalos de confiança satisfatórios". Como exemplo, foi utilizado, para cada rede modelada neste estudo ${ }^{15}$, aproximadamente 40 lugares discretos, 5 lugares contínuos, 80 arcos discretos, 10 arcos contínuos e 50 transições discretas. Para se obter cada um dos pontos dos gráficos apresentados no Capítulo 5, foi necessária, aproximadamente, 10.000 segundos (2,8 horas) de simulação em computadores de bom desempenho ${ }^{16}$, utilizando-se intervalos de tempo de 0,5 segundos para discretizar a análise da parte contínua das redes.

Mesmo com o alto custo de processamento, conclui-se que a utilização do formalismo das RPFE é altamente recomendável para a aplicação proposta, sobretudo quando utilizado com o método de avaliação de risco proposto neste trabalho. Além disto, o alto custo de processamento atual abre espaço para novas investigações científicas focadas na melhoria de desempenho dos métodos de simulação.

\footnotetext{
${ }^{15}$ N.E.: Segundo o método de avaliação de risco proposto neste trabalho, e seguindo suas nomenclaturas, foram modelados (por meio de redes) 2 sistemas de controle de tráfego aéreo: um Sistema Proposto (baseado em navegação por satélites e em vigilância dependente automática por radiodifusão) e um Sistema de Referência ou "Legado" (baseado em navegação VOR e em vigilância radar).

${ }^{16}$ Utilizou-se o "Cluster Alcatéia”, pertencente ao Laboratório de Computação Científica Avançada (LCCA) da Universidade de São Paulo (http://www.usp.br/lcca/).
} 


\subsubsection{Conclusões com relação à Ferramenta SPNP.}

A utilização da ferramenta computacional Stochastic Petri Nets Package (SPNP) atendeu às necessidades computacionais de modelagem e avaliação, segundo o formalismo das Redes de Petri Fluidas e Estocásticas (RPFE). A SPNP apresentou-se versátil quanto a sua capacidade de modelar, principalmente, devido à linguagem computacional utilizada ser baseada no ANSI-C. Ainda com relação a esta linguagem de modelagem, a sua versatilidade permitiu implementar características necessárias à aplicação proposta e não pertencente ao formalismo das RPFE, tais como a modelagem de características espaciais estocásticas ${ }^{17}$. Esta versatilidade também permitiu adaptar o núcleo de processamento da ferramenta de forma a realizar análise de sensibilidade sobre parâmetros de interesse. Um estudo detalhado da ferramenta computacional SPNP, e as contribuições realizadas sobre a mesma, encontram-se no APÊNDICE $\mathbf{E}$ deste trabalho.

Contudo, uma restrição ao amplo uso desta ferramenta está relacionada ao núcleo da ferramenta ser proprietário (código fechado). Esta característica não permite que se desenvolvam melhorias nos métodos de resolução das redes modeladas. Portanto, vale destacar, como linhas para trabalho futuros, a necessidade do desenvolvimento de uma ferramenta computacional com requisitos semelhantes, mas que possibilite a implementação de melhorias sobre seus mecanismos funcionais.

\footnotetext{
${ }^{17}$ N.E.: O formalismo das redes de Petri Fluidas e Estocásticas, da forma como esta implementado na versão utilizada da ferramenta computacional SPNP, permite modelar sistemas com comportamento temporal estocástico e comportamento espacial determinístico, onde os valores das marcações, tanto para lugares discretos quanto contínuos, variam de forma determinística. Devido o Sistema de Controle de Tráfego Aéreo, o qual foi proposto para modelagem e análise por meio do formalismo das RPFE, possuir diversos parâmetros espaciais estocásticos relevantes, tais como erros de navegação (radiais VOR, distância DME, posição GPS) e erros de vigilância (posição Radar, posição ADS), foi necessário adaptar a ferramenta computacional para que pudesse considerar o comportamento espacial estocástico do modelo. Como a SPNP possui código-fonte proprietário, não acessível à edição, optou-se por caracterizar os parâmetros espaciais estocásticos por meio de variáveis globais de software, utilizando as potencialidades da linguagem CSPL (baseada em ANSI-C). O comportamento estocástico destas variáveis é introduzido pela chamada, a partir da dinâmica da rede envolvida, de uma função que gera a distribuição de probabilidade com as características desejadas. Estas variáveis globais são utilizadas para tomada de decisão nas funções de guarda $(\mathbf{g})$, ou em quaisquer outras funções dependentes de marcação, da modelagem de uma rede de Petri Fluida e Estocástica.
} 


\subsubsection{Conclusões Finais sobre a segurança do ATC baseado em ADS-B}

O Capítulo 2 deste trabalho de investigação científica apresentou a relação existente entre a capacidade de tráfego e as características tecnológicas dos elementos empregados no Sistema de Controle de Tráfego Aéreo. Nele, mostra-se, por meio da bibliografia, que os gargalos promovidos pelas atuais tecnologias limitam o cumprimento da crescente demanda por transporte aéreo, e que apenas uma mudança no paradigma utilizado solucionaria este problema. A solução adotada pela comunidade mundial foi a adoção de um novo paradigma de sistema de tráfego aéreo denominado CNS/ATM (Communication, Navigation, Surveillance / Air Traffic Management).

Os conceitos introduzidos pelo paradigma CNS/ATM, tais como navegação por satélites e o uso de tecnologias digitais, possibilitam, intuitivamente, uma melhoria significativa na qualidade das informações disponíveis aos usuários do Sistema de Tráfego Aéreo, com conseqüente aumento da consciência situacional por parte dos operadores do sistema (controladores de tráfego aéreo - ATCo - e pilotos), permitindo a redução das separações aplicadas e, consequentemente, o aumento da eficiência no uso do espaço aéreo e o aumento da capacidade de tráfego como um todo. Porém, devido à segurança (safety) ser um dos requisitos primários a serem respeitados pelo sistema de tráfego aéreo, a redução nos valores de separação entre aeronaves age contra os esforços para o aumento de sua capacidade, pois, como efeito adverso, a redução nos valores de separação aplicados aumenta a exposição das aeronaves à possíveis colisões. Desta forma, esforços devem ser aplicados com a finalidade de garantir que o CNS/ATM cumpra o objetivo de aumentar a capacidade do Sistema de Tráfego Aéreo e ao mesmo tempo garanta - ou melhore - seus níveis de segurança. Neste sentido, e conforme as definições do Programa de Transição do SISCEAB para os Sistemas CNS/ATM do Departamento de Controle do Espaço Aéreo (DECEA, 2003), é necessário determinar o “... impacto dos novos conceitos nos diversos serviços (de tráfego aéreo) prestados" por meio de atividades focadas na:

\footnotetext{
$\checkmark$ “... determinação dos parâmetros associados ao modelo utilizado para determinação do risco de colisão em espaços aéreos onde se aplica a redução da separação ...", na

$\checkmark$ “... determinação dos riscos de colisão associados às operações no espaço aéreo ...” e na
}

$\checkmark$ “... realização de comparações dos riscos obtidos com os limites de riscos aceitos ...", 
entre outras atividades (DECEA, 2003).

Portanto, este trabalho de investigação científica propôs avaliar qual o impacto que o uso do conceito de Vigilância Dependente Automática, mais especificamente sua forma por Radiodifusão (ADS-B), causaria sobre os níveis de segurança do Sistema de Controle de Tráfego Aéreo. O estudo centrou-se na relação entre os paradigmas de vigilância "Atual" (baseado em Radares e com fortes características de independência, determinismo e sincronismo) e “ADS-B” ([inter]dependente, estocástico e assíncrono) e o nível de exposição das aeronaves a eventos de perda de separação ( $A I R P R O X)$.

Para cumprir os objetivos deste trabalho, desenvolveu-se um arcabouço conceitual baseado em estudos nos domínios da "Avaliação de Risco e de Segurança", das "Arquiteturas de Sistemas Críticos em Segurança", da "Modelagem e Simulação" e das "Redes de Petri", além de um amplo estudo sobre o paradigma atual do Sistema de Controle de Tráfego Aéreo e do Paradigma CNS/ATM. Calcado neste arcabouço conceitual, propôs-se um método para avaliar o risco de se aplicar o ADS-B no Sistema de Tráfego Aéreo, baseado na afetação das métricas de risco de exposição à perda de separação promovida pela variação de parâmetros-chave dos sistemas analisados.

Deve-se frisar que foram considerados para o Sistema Proposto ${ }^{18}$ modelado, como valores em condições normais de funcionamento, os piores valores especificados para a ADS-B na bibliografia, a saber:

$\Rightarrow$ Acurácia da navegação por satélites (GPS) de 86,44m com probabilidade de $95 \%$ (86,44m@95\%) por dimensão do espaço aéreo;

$\Rightarrow$ Taxa de Atualização das mensagens ADS-B de 14s@95\%; e

$\Rightarrow$ Latência na recepção das mensagens ADS-B de 1,2s@95\%.

Mesmo considerando os valores citados para o sistema ATC baseado em ADS-B, obtiveramse os seguintes resultados com a aplicação do método de avaliação de risco proposto:

\footnotetext{
${ }^{18}$ Sistema Proposto (nomenclatura adotada no Método de Avaliação de Risco utilizado): sistema de controle de tráfego aéreo (ATC) baseado em navegação por satélites e em vigilância dependente automática por radiodifusão.
} 
- o risco de exposição de pares de aeronaves a separações menores que 3,5 milhas náuticas (NM) (dado que a norma de separação aplicada foi de 5NM) foi reduzido em aproximadamente $93 \%$, comparado ao Sistema de Referência ${ }^{19}$. A melhoria na aderência aos planos de vôo e na qualidade das informações de vigilância providas ao ATCo fez com que se reduzisse, significativamente, a exposição das aeronaves a incidentes de perda de separação (AIRPROXes).

- A capacidade de detecção de um conflito por parte do ATCo, no Sistema Proposto (ATC baseado em ADS-B), é semelhante ao do Sistema de Referência (ATC atual), podendo-se considerar como "transparente" a fonte de informação de vigilância provida ao controle de tráfego aéreo;

Portanto, segundo os resultados obtidos para o cenário considerado nesta investigação, podese concluir que a Vigilância Dependente Automática por Radiodifusão (ADS-B) - mesmo tornando os elementos de Navegação e Vigilância do sistema de controle de tráfego aéreo interdependentes e influenciando a obtenção dos dados de vigilância de forma assíncrona e estocástica - é uma aplicação viável, do ponto de vista da segurança, para os sistemas de vigilância aplicados no Sistema de Controle de Tráfego Aéreo (ATC).

Além disto, devido à interdependência entre os elementos de vigilância e navegação, observou-se que é possível compensar a presença de degradação do parâmetro de acurácia de posição do GNSS causada, por exemplo, por fenômenos atmosféricos, com o aumento da taxa (frequiência) de atualização das informações de vigilância.

Concluindo, para o cenário adotado nesta investigação, pode-se dizer que objetivo proposto foi devidamente alcançado. Porém, é necessário avaliar-se outros cenários e condições do ATC, que ficam como proposta para trabalhos futuros de investigação científica.

Como comentário adicional a respeito deste trabalho, a avaliação da segurança do sistema proposto por meio de métricas alternativas, porém relacionadas ao evento "risco de colisão entre aeronaves", teve como base a limitação da capacidade computacional. Porém, a obtenção de métricas diretas de risco de colisão tornar-se-ia factível com a minimização da limitação computacional por meio da melhoria dos algoritmos de simulação. Assim, o método

\footnotetext{
${ }^{19}$ Sistema de Referência ou "Legado" (nomenclatura adotada no Método de Avaliação de Risco utilizado):
} sistema de controle de tráfego aéreo (ATC) baseado em navegação VOR e em vigilância radar. 
de avaliação de risco proposto neste trabalho pode ser empregado, sobretudo, na determinação de valores de separação mínima para os sistemas propostos, além de estar em melhor sintonia com os trabalhos de avaliação de risco de colisão verificados na bibliografia.

Como comentário geral sobre a aplicação prática da ADS-B, observou-se que diversos países, com destaque para Austrália e Estados Unidos, estão com cronogramas avançados quanto ao desenvolvimento e implantação de seus sistemas de vigilância ADS-B. Guardando características de similaridade em relação às dimensões territoriais continentais, a não homogeneidade da distribuição populacional e às faixas de latitudes em que se encontra (com influências semelhantes sobre acurácia e integridade de sinais de GNSS), seria recomendável que o Brasil seguisse o exemplo da Austrália quanto ao uso da ADS-B sobre seu território. Os baixos custos de implementação da ADS-B em comparação à implementação de Radares (AU\$6M para SSR contra AU\$ 380K para a ADS-B em rota, segundo Dunstone (2007)), associados à boa cobertura de torres de comunicação já existente em território nacional e ao estado de normalização atual dos enlaces de comunicação digitais (data link) padrão $1090 \mathrm{ES}^{20}$ permitem que Brasil possa caminhar no sentido da plena implementação do paradigma CNS/ATM.

\subsection{Trabalhos Futuros}

Com base no trabalho realizado, propõe-se algumas possíveis linhas diretas de investigação científica que poderiam ser abordadas. $O$ intuito não é o de esgotar as possibilidades existentes, mas apresentar alguns temas imediatos que surgiram como idéias durante a realização do trabalho.

- A obtenção de métricas diretas de risco de colisão depende da disponibilidade de métodos de simulação para eventos raros. Portanto, é necessário identificar, desenvolver e adaptar ao método de modelagem e simulação proposto técnicas de

\footnotetext{
${ }^{20}$ N.E.: O datalink padrão SSR Modo S Extended Squitter (1090ES) aproveita as características atuais do transporder dos Sistemas de Radar Secundários Modo S, que transmite (squitter) - ominidirecionalmente, por meio do canal de resposta do Modo S (1090 MHz) e a cada segundo - uma mensagem de 56 bits contendo o endereço do transponder (ICAO, 2004). Este mecanismo é utilizado nos sistemas a bordo para prevenção contra colisão (ACAS), e permite que uma aeronave, ao receber a mensagem, interrogue o originador e obtenha informações de vigilância por meio de uma mensagem de 112 bits. No caso do ADS-B, o formato "estendido" (extended) utiliza mensagens de "squitter" de 112 bits, deixando 56 bits para o conteúdo ADS-B. Na 11" Conferência de Navegação Aérea definiu-se que o 1090ES seria a melhor opção para vôos internacionais (ICAO, 2003c).
} 
aceleração e redução do espaço de simulação, tais como Importance Sampling, Importance Splitting, simulação Regenerativa, entre outros.

- Na mesma linha anterior, existe a necessidade de se especificar, projetar e implementar uma ferramenta de modelagem e simulação que permita a utilização do formalismo das Redes de Petri Fluidas e Estocásticas. Desta forma, ter-se-ia acesso ao código-fonte da ferramenta, permitindo melhorias em seu núcleo.

- A ADS-B é um conceito amplo, e suas mensagens podem conter diversos tipos de informação, tais como o "Perfil Projetado" (próximo waypoint, nível de vôo estimado, etc), "Informações Meteorológicas" (Direção e Velocidade do Vento, Temperatura, Turbulência), entre outras informações. Desta forma, seria interessante incorporar informações de "intenção futura" da ADS-B no modelo de detecção e resolução de conflitos do ATCo e avaliar o impacto deste conceito sobre a segurança do ATC.

- Outro tema de pesquisa, na mesma linha do anterior, seria o de avaliar a potencialidade da ADS-B na obtenção e distribuição de "Informações Meteorológicas". Sobretudo, os estudos teriam o foco na forma de se utilizar estas informações de forma a ampliar a capacidade de redução dos valores de separação entre aeronaves em nível tático.

- Ainda com relação às condições meteorológicas, propõe-se expandir o modelo de sistema apresentado e considerar características ambientais, tais como ventos, variação de pressão atmosférica, degradação ionosférica, entre outros, na avaliação do sistema de controle de tráfego aéreo.

- Para o ambiente proposto neste trabalho, aplicou-se apenas um tipo de manobra de resolução de conflito. Propõe-se a utilização do modelo aqui descrito para avaliar a segurança e a eficiência das manobras de resolução de conflito comandadas pelo ATCo ou mesmo por algoritmos de resolução embarcados.

- Propõe-se incorporar parâmetros na modelagem dos sistemas, tais como integridade, disponibilidade, continuidade, entre outros, além de considerar o conceito de RAIM.

- Poder-se-ia avaliar a eficiência do ATCo com relação aos parâmetros de Tempo de Detecção de Conflito, Tempo de Decisão de Conflito, Tempo para Comunicação da 
Decisão (e demais parâmetros de desempenho ATCo) e seus impactos sobre a segurança do tráfego aéreo.

- Propõe-se enrobustecer a modelagem por meio da utilização de distribuições de probabilidade monocaudais, tais como a distribuição Gama, que melhor representem variáveis temporais. Neste trabalho, as Taxas de Atualização e de Latência ADS-B, TSCANADS@95\% e TLATADS@95\%, assim como diversas outras variáveis temporais, foram modeladas adaptando-se distribuições de probabilidade Gaussianas ao formato "monocaudal" $\mathbf{N}\left(\right.$ (Taxa". $\frac{3.9}{3.9+Z p} ; \quad$ "Taxa". $\left.\frac{1.0}{3.9+Z p}\right)$ = $\mathrm{N}\left(\mathrm{E}[], \mathrm{VAR}[]^{1 / 2}\right)$, fazendo com que seus valores não positivos continuassem a representar os $95 \%$ de confiança dos parâmetros.

- É necessário avaliar a segurança no uso da ADS-B para outros cenários da aviação, envolvendo outras fases de vôo, outras distribuições de rotas, etc.

\subsection{Considerações Finais}

Os tomadores de decisão responsáveis por gerir os sistemas críticos em segurança, sobretudo aqueles vitais ao desenvolvimento e a soberania do país tal como o sistema de tráfego aéreo, devem ter em mente que o fator principal a ser considerado em suas decisões deverá estar baseado, tal como foi apresentado neste trabalho, no requisito básico destes sistemas: a segurança. Caso ajude, uma frase mnemônica, retirada dos conselhos quanto à "não reagir a assaltos", pode ser utilizada por esses indivíduos para que não se esqueçam: "todo dinheiro se repõe. A vida, não!’.

Assim, este trabalho espera ter contribuido com um arcabouço conceitual que possa ser utilizado pelos envolvidos com sistemas críticos em segurança para embasar suas decisões e para conscientizá-los das características importantes a serem consideradas quando se lida com sistemas que podem afetar vidas humanas. Mais especificamente, aos responsáveis pelo sistema de controle de tráfego aéreo, este trabalho espera contribuir, ainda, com um ferramental aplicável à tomada de decisão das possíveis linhas de evolução tecnológica deste sistema visando sua segurança. Espera-se que as informações aqui contidas possam fomentar e nortear novas visões estratégicas, que considerem as características brasileiras, e que possam promover o desenvolvimento sustentável e harmônico do Brasil perante as demais 
nações.

Há uma máxima que deve ser seguida: “Esperto é aquele que aprende com os próprios erros. Sábio é aquele que aprende com os erros dos outros". Que a pesquisa científico/tecnológica possa ser o caminho pelo qual possamos "aprender com os erros dos outros". 


\section{REFERÊNCIAS}

AHLSTRÖM, K.; TORIN, J; Future Architecture of Flight Control Systems. IEEE AESS Systems Magazine, p. 21-27. Dezembro 2002.

ALMEIDA JR., J.R.; Segurança em Sistemas Críticos e em Sistemas de Informação - Um Estudo Comparativo. 2003. 196p. Tese (Livre-Docência) - Escola Politécnica, Universidade de São Paulo. São Paulo.

ARINC; ARINC Characteristics 711-10 Mark 2 Airborne VOR ILS Receiver. Aeronautical Radio Incorporated (ARINC). 30 de Janeiro de 2002.

ASARIN, E.; MALER, O.: PNUELI, A.; Reachability Analysis of Dynamical Systems Having Piecewise-Constant Derivatives. Theorical Computer Science, vol.138, p.33-65, 1995.

AVIATION THEORY CENTRE; Avionics and Flight Management System for Air Transport Pilot. Austrália. 2000.

BALL, P.; Introduction to Discrete Event Simulation. In $2^{\text {nd }}$ DYCOMANS workshop on "Management and Control : Tools in Action", Algarve, Portugal. 1996, pp. 367-376.

BANKS, J.H.; Introduction to Transportation Engineering. $2^{\text {a }}$ Edição. USA: McGrawHill, 2002.

BLOOM, H.A.P et al; Accident Risk Assessment for Advanced ATM. In: : $2^{\text {th }}$ USA/EUROPE AIR TRAFFIC MANAGEMENT R\&D SEMINAR, Orlando, EUA, 1998.

BLOM, H. A. P. Hybrid stochastic dynamical modeling of accident risk in air traffic. Summer Pedagogical School in Hybrid Systems, Lecture 3. University of Patras, Greece, 2224 September, 2004.

BOBBIO, A.; System Modelling with Petri Nets. In: Proceedings of the Ispra Course 1988. Madrid, Espanha. p.103-143.

BROOKER, P.; Future Air Traffic Management: Quantitative En Route Safety Assessment. Part 1 - Review of Present Methods. The Journal of Navigation, 55, p.197-211, 2002.

BROOKER, P.; Lateral Collision Risk in Air Traffic Track Systems: a "Post-Reich" Event Model. The Journal of Navigation, 56, p.399-409, 2003.

BROOKER, P. et al; Separations Standards in an ADS-B Environment - Final Report. Helios Technology and EUROCONTROL. 105 p. Janeiro de 2004.

BROOKER, P.; Radar Inaccuracies and Mid-Air Collision Risk: Part 2. En Route Radar Separation Minima. The Journal of Navigation, 57, p.39-51, 2004c.

BURT, L.; The Eurocontrol 3-D Collision Risk Modelling Approach. FAA/EUROCONTROL AP3 TIM meeting. Agenda Item 8. Bruxelas, Bélgica. Abril 2004.

BUTCHER, R. et al. Initial comparative assessment between enroute radar services and proposal for development of enroute ADS-B services using a 5NM separation minima. In: 
SECOND MEETING OF THE WORKING GROUP OF THE WHOLE - SEPARATION AND AIRSPACE SAFETY PANEL (ICAO), Montreal, Canadá, 2002. Work Paper 30.

BUTCHER, R. et al. Development of ADS-B Separation Minima by ICAO SASP. In: AUTOMATIC DEPENDENT SURVEILLANCE - BROADCAST (ADS-B) STUDY AND IMPLEMENTATION TASK FORCE (ICAO), SECOND MEETING. Bangkok, Tailândia, 2004. Information Paper 9.

CAMARGO JR, J.B.; Metodologia de Análise de Risco em Sistemas Computacionais de Aplicação Crítica. 2002. 145p. Tese (Livre-Docência) - Escola Politécnica, Universidade de São Paulo. São Paulo.

CAMPOS, L.M.B.C.; MARQUES, J.M.G.; On Safety Metrics related to Aircraft Separation. The Journal of Navigation, 55, p.39-63, 2002.

CAMUS, P.; Required Total System Performance and Results of a Short Term Conflict Alert Simulation Study. In: AIR TRAFFIC MANAGEMENT OPERATIONAL CONCEPT PANEL (ICAO), FIRST MEETING. Montreal, Canada, 2002. Work Paper 24.

CASA; Manual of Operational Standards, Part 2.6: Operational Standards for Inertial Navigation and Reference System . Civil Aviation Safety Authority (CASA), 3a versão, 1999. Austrália. Disponível em: 〈http://www.casa.gov.au/manuals/regulate/mos/026r0206.pdf>. Último acesso em 26 Janeiro de 2006.

CASA; AIRWORTHINESS APPROVAL OF AIRBORNE AUTOMATIC DEPENDENT SURVEILLANCE BROADCAST EQUIPMENT - Advisory Circular AC 21-45(0). Civil Aviation Safety Authority (CASA), DRAFT - Março de 2007. Austrália.

CAVCAR, A.; CAVCAR, M.; Impact of Aircraft Performance Characteristics on Air Traffic Delays. Turkish Journal of Engineering \& Environmental Sciences, n.28, p.13-23, 2004.

CIARDO, G.; NICOL, D.M.; TRIVEDI, K.S.; Discrete-Event Simulation of Fluid Stochastic Petri Nets. IEEE Transactions on Software Engineering, v.25, n2, p.207-217, 1999.

CHEN, P.; SAKKA, A.E.; CLOTHIER, J.; Context Analysis of Architecture Practice within Large Organisations. DSTO C3 Research Centre, Department of Defence. Canberra/Australia. 2000. Disponível em http://www.dsto.defence.gov.au. Último acesso em 25/05/2002.

CHIAPPINI, A., ROTONDO, G.; New Components for the Exploitation of existing Networks for Safety Related Communications. In: WORLD CONGRESS ON RAILWAY RESEARCH, Firenze, Italy, 1997. p.589-595.

CHIOLA, G. et al; GreatSPN 1.7: graphical editor and analyser for timed and stochastic Petri nets. In Performance Evaluation 24. pp 47-68. 1995.

CHUJO, A.M.; WALTER, F.; Atividades do Laboratório GNSS do ITA relacionados com CNS/ATM. In: Anais do IV Simpósio de Transporte Aéreo. São José dos Campos, Brasil. 2005. pp. 219-231.

COHEN, S. (Ed); A concept paper for separation safety modelling. Federal Aviation Administration (FAA) \& EUROCONTROL, Maio de 1998.

Disponível em: 
〈http://www.faa.gov/asd/ia-or/pdf/1998-05_separation_safety_modeling.pdf $>$. Acesso em: 20 Maio. 2004.

COMPSciDept - Computer Science Department - College of Willian and Mary. On the Simulation of Stochastic Petri Nets. 36p. Disponível em: http://www.cs.wm.edu/ gli/Wpapers/PetriNet.ps. Último acesso em: 19 de Março de 2004.

COSTA, C.Q.; Análise Técnico Econômica da Implementação da Separação Vertical de 300 metros entre Aerovias (RVSM) no Espaço Aéreo da América do Sul e Caribe. In: Anais do IV Simpósio de Transporte Aéreo. São José dos Campos, Brasil. 2005.

DAC; Departamento de Aviação Civil: sítio na internet. Disponível em: <http://www.dac.gov.br>. Último acesso: em 10 Maio de 2005. 2005.

DECEA; Sistema de Posicionamento Global - GPS (AIC N17/99). Comando da Aeronáutica - Departamento de Controle do Espaço Aéreo. 1999.

DECEA; Plano Nacional de Implementação dos Sistemas CNS/ATM - PCA 63-1. Comando da Aeronáutica - Departamento de Controle do Espaço Aéreo. 2002.

DECEA; Programa de Transição do SISCEAB para os Sistemas CNS/ATM. Comando da Aeronáutica - Departamento de Controle do Espaço Aéreo. 2003.

DECEA; AIP - Publicação de Informações da Aeronáutica. Parte 1 - Generalidades. Departamento de Controle do Espaço Aéreo. 10 de Junho de 2004.

DECEA; Departamento de Controle do Espaço Aéreo: sítio na internet. Disponível em: <http://www.decea.gov.br>. Último acesso: em 10 Maio de 2005. 2005.

DECEA; Programa de Transição do SISCEAB utilizando o conceito de Sistema CNS/ATM. Comando da Aeronáutica - Departamento de Controle do Espaço Aéreo. 2006.

DoD/DoT; 2001 Federal Radionavigation Systems. Departamento de Defesa e Departamento de Transportes Norte-Americano. DOT-VNTSC-RSPA-01-3.1 / DOD-4650.5. 2001.

DUNSTONE, G; Australian ADS-B Plans. In: ADS-B TF WG MEETING (ICAO), Singapura. 2004. Information Paper 11.

DUNSTONE, G (Ed.); Required ADS-B Performance Radar-like Services. In: AUTOMATIC DEPENDENT SURVEILLANCE - BROADCAST (ADS-B) STUDY AND IMPLEMENTATION TASK FORCE (ICAO), SECOND MEETING. Bangkok, Tailândia, 2004. Work Paper 8.

DUNSTONE, G.; Can HFOM be used in certain installations? In: AirServices Australia Working Paper RFG1 version 1.2. 17 de Agosto de 2005.

DUNSTONE, G.; OWUSU, K.; HEWITT, K.; Comparison of Surveillance Technologies. In: ADS-B IMPLEMENTATION TEAM (ABIT), 10 ${ }^{\mathrm{TH}}$ MEETING. Camberra, Australia, 2007. IP8.

EL-HABBANY, A.; Introduction to GPS: the Global Positioning System. EUA: Artech House Inc, 2002. 
ELLIOT, J.; System Approach to Safety-Related System. In: "Toward System Safety Proceedings of $7^{\text {th }}$ Safety Critical System Symphosium”. UK, 1999

ENDSLEY, M.R.; Design and evaluation for situation awareness enhancement. In Proceedings of the Human Factors Society 32rd Annual Meeting. Santa Monica, EUA, 1988. p.97-101.

EYFERTH, K. et al; A model of air traffic controllers' conflict detection and conflict resolution. Aerospace Science and Technology 7. p.409-416, 2003.

EUROCONTROL. Investigation of Experience in Modelling and Determining Separartion Assurance. CARE/ASAS Activity 3. Version 2.1. Outubro, 2002. 48p.

FAA - Federal Aviation Administration; Overview of the FAA Data link Decision. June 7, 2002. Disponível em: http://www.faa.gov/asd/ads-b/06-07-02_ADS-B-Overview.pdf

FAA - Federal Aviation Administration; Airborne Supplemental Navigation Equipment using Global Positioning System (GPS). TSO-C129a. Disponível em: http://www.faa.gov/asd/international/TSO_FAR_AC/129asave.pdf. Último acesso em: $02 \mathrm{de}$ Fevereiro de 2006.

GALATI, G.; NALDI, M.; PAVAN, G.; Stochastic Simulation Techniques as Related to Innovation in Communications-Navigation-Surveillance and Air Traffic Management (CNS/ATM). Simulation Modelling Practice \& Theory, v.11, issue 3, p.197-209, 2003.

GALOTTI, V. P; The Future Air Navigation System: Communication, Navigation, Surveillance, Air Traffic Management. 1 ${ }^{a}$ Edição. England: Ashgate Publishing Company, 1997.

GERMAN, M. et al; TimeNET: a toolkit for evaluating Non-Markovian stochastic Petri nets. In Performance Evaluation 24. pp 69-97. 1995.

GERMAN, R.; Performance Analysis of Communication Systems: Modelling with NonMarkovian Stochastic Petri Nets. $1^{\text {a }}$ Edição. England: John Wiley \& Sons Ltd, 2000.

GLEASON, C.; MOODY, C.; RUSSELL, E.O.; Verifying Performance of ADS-B Position Reporting: Experience from Capstone ADS-B "Radar-like Services". In: Int. Advanced Aviation Technology Conference. Alaska, EUA. 2002. Paper 10.

GLOVER,W.; LYGEROS,J.; A Multi-Aircraft Model for Conflict Detection and Resolution Algorithm Evaluation. Projeto Hybridge. Contrato IST-2001-32460 of European Comission. Version 1.3. 18 de Fevereiro de 2004. 49p.

GORDON, G; System Simulation. USA: Wiley, 1978.

GRAHAM, R. et al; Absolute versus Relative Navigation: Theoretical Considerations from an ATM Perspective. In: $5^{\text {th }}$ EUROCONTROL / FAA ATM R\&D Seminar, Budapest, Hungary, 2003. paper 112 .

GREGORY, C.W. et al; Stability Analysis of Networked Control Systems. In IEEE Transactions on Control Systems Technology Vol10, n.3 pp 438-446. 2002. 
GRIBAUDO, M. et al; Model-Checking Based on Fluid Petri Nets for the Temperature Control System of the ICARO Co-generative Plant. In: SAFECOMP 2002, Catania, Italy, 2002. p.273-283.

GRIBAUDO, M. et al; Fluid Petri Nets and hybrid model-checking: a comparative case study . In Reliability Engineering and System Safety 81. pp 239-257. 2003.

GRITZALIS, S. et al; Security Protocols over open networks and distributed systems: formal methods for their Analysis, Design and Verification. In Computer Communications 22(8). pp 695-707. Maio de 1999.

HAMMETT, R; Flight-Critical Distributed Systems: Design Considerations. IEEE AESS Systems Magazine, p.30-36, Junho 2003.

HANSMAN,R.J. et al; Integrated Human Centered Systems Approach to the Development of Advanced Air Traffic Management Systems. In: $1^{\text {tst }}$ EUROCONTROL / FAA ATM R\&D Seminar, Sacly, France, 1997.

HARALDSDOTTIR, A. (ED); Air Traffic Management Concept Baseline Definition. NEXTOR Report \# RR-97-3. October, 1997. 198p. Disponível em:< http://www.boeing.com/commercial/caft/reference/documents/coe_report.pdf $>$. Acesso em: 13 de Agosto de 2004.

HECK, B.S et al; Software Technology for Implementing Reusable, Distributed Control Systems. IEEE Control Systems Magazine, p.21-35, Fevereiro 2003.

HIREL, C.; TUFFIN, B.; TRIVEDI, K.; SPNP: Stochastic petri nets. version 6.0. In Computer Performance Evaluation, Modelling Techniques and Tools (TOOLS 2000), Springer Verlag LNCS 1786, p.354-357, 2000.

HOFFMAN, E. et al; Analysis of Spacing Guidance for Sequences Aircraft on Merging Trajectories. In: $21^{\text {st }}$ AIAA/IEEE DIGITAL AVIONICS SYSTEM CONFERENCE, Irvine, USA, 2002.

HORTON, G. et al; Fluid Stochastic Petri Nets: Theory, applications and solution techiniques. European Jornal of Operational Research, n.105, p.184-201, 1998.

HSIEH, M.H; Adaptative Monte Carlo Methods for Rare Event Simulations. In Proc. of the 2002 Winter Simulation Conference, pp.108-115. 2002.

ICAO - International Civil Aviation Organization. "Procedures for Air Navigation Services: Rules of the Air Traffic Services - PANS-RAC". Doc 4444. 1996.

ICAO - International Civil Aviation Organization. Manual on Airspace Planning Methodology for the Determination of Separation Minima”. Doc 9689. 1998.

ICAO - International Civil Aviation Organization. Air Traffic Services Planning Manual. Doc 9426. $1998 \mathrm{~b}$.

ICAO - International Civil Aviation Organization. Manual of Air Traffic Services Data link Applications. STD 9694-AN/955. 1999. 
ICAO - International Civil Aviation Organization. Manual of Technical Provisions for the Aeronautical Telecommunication Network. Doc 9705/AN956. 1999b.

ICAO; Status of Air-Ground Data link Standardization. In: $3^{\text {rd }}$ Meeting of CAR/SAM (ICAO), Buenos Aires. 1999c. Information Paper 4.

ICAO; Global Air Navigation Plan for CNS/ATM Systems. Doc. 9750. Internacional Civil Aviation Organization (ICAO), $1^{\text {a }}$ edição, 2000.

ICAO; Annex 11 - Air Traffic Services. Internacional Civil Aviation Organization (ICAO), $13^{\mathrm{a}}$ edição, 2001.

ICAO. IATA Position on the Implementation of ADS-B. In: $11^{\text {TH }}$ AIR NAVIGATION CONFERENCE, Canadá. 2003.

ICAO. Comparative Analysis of ADS-B Data links. In: $11^{\mathrm{TH}}$ AIR NAVIGATION CONFERENCE, Canadá. 2003b. Information Paper 12.

ICAO; ADS-B Study and Implementation Task Force. In: CNS/MET - ATM, Bangkok. 2003c. WP8.

ICAO. ADS-B Concept of Use. In: $11^{\mathrm{TH}}$ AIR NAVIGATION CONFERENCE, Canadá. 2003d. WP6 (Appendix)

ICAO; Manual on the Secondary Surveillance Radar (SSR) Systems. Doc. 9684. Internacional Civil Aviation Organization (ICAO), $3^{\text {a }}$ edição, 2004.

ICAO; Outlook for the Air Transport to the Year 2015. ICAO Circular 304 AT/127. Internacional Civil Aviation Organization (ICAO), Setembro de 2004. 2004b.

ICAO. Information on Internet Protocol Suite (IPS) as a Provision for Aeronautical Internetworking. In: $3^{\text {RD }}$ MEETING ATM/CNS/SG/4 - CNS COMMITTEE (ICAO), México. 2005. Information Paper 07.

ICAO. A Regional Approach to Accelerate ADS-B Implementation. In: $5^{\mathrm{TH}}$ MEETING ALLPIRG / ADVISORY GROUP, Canadá. 2006. Information Paper 10.

IFI - Instituto de Fomento e Coordenação Industrial. Instruções para obtenção de aprovação de instalações de equipamentos de navegação usando o "Global Positioning System" (GPS). CI No 21-013B. 5 de Outubro de 2005.

IVANESCU, D.; HOFFMAN, E.; ZEGHAL, K.; Impact of ADS-B Link Characteristics on the Performance on In-Trail Following Aircraft. AIAA GUIDANCE, NAVIGATION AND CONTROL CONFERENCE, California, USA, Agosto de 2002.

JOHNSON, B.W.; Design and fault-tolerant digital systems. Charlottesville, Addison-Wesley, 1989.

KING, N. (Ed.); Progress of ADS-B Amendments to PANS-ATM. In: MEETING OF AUTOMATIC DEPENDENT SURVEILLANCE - BROADCAST (ADS-B) STUDY AND IMPLEMENTATION TASK FORCE WORKING GROUP (ICAO). Singapura, 2004. Work Paper 4. 
KIRNER, T.G.; Quality Requirements for Real-Time Safety-Critical Systems. Control Engineering Practice, v.5, n.7, p.965-973, 1997.

KNIGHT, J.C.; Safety Critical Systems: Challenges and Directions. In: INTERNATIONAL CONFERENCE ON SOFTWARE ENGINEERING WORKSHOP ON NEW SECURITY PARADIGM, 24, Orlando, USA, 2002. p.547-550.

KNIGHT, J.C.; Software Challenges in Aviation Systems. In: SAFECOMP 2002b, Catania, Italy, 2002. p.106-112.

KOTONYA, G.; SOMMERVILLE, I.; Requirements Engineering: Processes and Techniques. USA: John Wiley, 1998.

KUCHAR, J. K.; YANG, L. C.; A Review of Conflict Detection and Resolution Modeling Methods. IEEE Transactions on Intellingent Transportation Systems, v.1, n.4, p.179-189, 2000 .

KUMAmoto, H.; Henley, E. J; Probabilistic Risk Assessment and Management for Engineers and Scientists. $2^{a}$ Edição. USA: IEEE Press, 1996.

LABEAU, P.E et al. Dynamic Reliability: towards an integrated platform for probabilistic risk assessment. In Reliability Engineering and System Safety 68. pp 219-254. 2000.

LAW, A. M.; KELTON, W. D.; Simulation modeling and analysis. 3a Edição. USA: McGraw-Hill Inc, 2000.

LEVESON, N.G; STOLZY, J.L.; Analyzing Safety and Fault Tolerance using Time Petri Nets. In: JOINT CONFERENCE ON THEORY AND PRACTICE OF SOFTWARE DEVELOPMENT, Berlin, Alemanha, 1985. p.339-355.

LEVESON, N.G.; STOLZY, J.L.; Safety Analysis Using Petri Nets. IEEE Transactions on Software Engineering, v.SE-13, n.3, p.386-397. Março 1987.

LEVESON, N. G.; Safeware: System, Safety and Computers. USA: Addison-Wesley Publishing Company, 1995.

LOZITO, S. et al; The Impact of Voice, Data link, and Mixed Air Traffic Control Environments on Flight Deck Procedures. In: $5^{\text {th }}$ EUROCONTROL / FAA ATM R\&D Seminar, Budapest, Hungary, 2003. paper 57.

MACIEL, P.R.M. et al; Introdução às Redes de Petri e Aplicações. Campinas: IMECCUNICAMP, 1996.

MAGAlhães, M.N., LIMA, A.C.P.; Noções de Probabilidade e Estatística. EDUSP. 2004. 392p.

MANNING, C. et al; The Relationship between Air Traffic Control Communication Events and Measures of Controller Taskload and Workload. In: $4^{\text {th }}$ EUROCONTROL / FAA ATM R\&D Seminar, Santa Fe, EUA, 2001. paper 161.

MANONI, V.; FORTUZZI, G.; Merging Between Telecommunications and Signalling. In: WORLD CONGRESS ON RAILWAY RESEARCH, Firenze, Italy, 1997. pp 641-649. 
MCAULEY, G (Ed.); Minutes of the Meeting. FAA/EUROCONTROL TECHNICAL INTERFACE MEETING ON ACTION PLAN 3: AIR TRAFFIC MODELING FOR SEPARATION STANDARDS. Abril de 2004. 16p.

MINISTÉRIO DA AERONÁUTICA. Planejamento de Pessoal ATC e Horário de Trabalho MMA 100-30. 1990.

MINISTÉRIO DA AERONÁUTICA. Regras do Ar e Serviços de Tráfego Aéreo - IMA 10012. 1999.

MINISTÉRIO DA AERONÁUTICA. Telecomunicações Aeronáuticas - IMA 102-6. 1999b.

MINISTÉRIO DA AERONÁUTICA. Métodos de Avaliação de Previsões Meteorológicas IMA 105-8. 1999c.

MINISTÉRIO DA AERONÁUTICA. Manual do Especialista em Informação Aeronáutica MCA 53-1. 2000.

MINISTÉRIO DA AERONÁUTICA; MANINV - BRASIL - Manual Brasileiro de Inspeção de Vôo. Departamento de Eletrônica e Proteção ao Vôo. 24 de Janeiro de 2002.

MINISTÉRIO DA AERONÁUTICA. Atribuições dos Órgãos do SISCEAB após a ocorrência de Acidente Aeronáutico ou Incidente Aeronáutico Grave - ICA 63-7. 2002 b.

MINISTÉRIO DA AERONÁUTICA. Características Mínimas dos Equipamentos NAV/COM a bordo das Aeronaves que utilizam o Espaço Aéreo sob Jurisdição do Brasil - ICA 102-9. 2005 .

MONTAGUE, J.; Safey Networks Begin go Emerge. Control Engineering, p.45-50, April 2002.

MURATA, T.; Petri Nets: Properties, Analysis and Applications. Proceedings of the IEEE, v.77, n.4, p.541-579, April 1989.

MURRAY, R. M. et al; Future Directions in Control in an Information-Rich World. IEEE Control Systems Magazine, p.20-33. April 2003

NAEDELE, M. et al; Network Security for Substation Automation Systems. In: SAFECOMP 2001, Budapest, Hungary, 2001. p.25-34.

OBER, P.B. et al; Augur: RAIM for Dummies. In: IEEE Proceedings of Aerospace Conference. 1999. Volume 2. EUA. p.395-405.

OCHIENG, W.Y et al.; GPS Integrity and Potencial Impact on Aviation Safety. The Journal of Navigation, 56, p.51-65, 2003.

OGATA, P.H.; Avaliação do Perigo de Colisão entre Aeronaves em Operação de Aproximação em Pistas de Aterrissagem Paralelas. 2003. 124p. Dissertação (Mestrado) Escola Politécnica, Universidade de São Paulo. São Paulo.

OLIVEIRA, I.R.; Análise de Risco da Operação de Espaçamento Temporal Aerotransportado por meio de um Modelo em rede de Petri Estocástica e 
Dinamicamente Colorida. 2007. 265p. Tese (Doutorado) - Escola Politécnica, Universidade de São Paulo. São Paulo.

PALBUS Task 10.1. Validation of Dependable Bus Systems. Version 2.0, April 2001. Disponível em www.sp.se/pne/software\&safety/palbus/. Último acesso em 10/15/2003.

PAPACOSTAS, C.S.; PREVEDOUROS, P.D.; Transportation Engineering and Planning. $2^{a}$ Edição. USA: Prentice-Hall, 1993.

PEREIRA FILHO, A.J. et al; Demanda Global do Transporte Aéreo. Dezembro, 1998. 159p. Disponível em:<http://www.dac.gov.br/publicacoes/deglota.asp >. Acesso em: $10 \mathrm{de}$ Maio de 2005.

PETERSON, L.J.; Petri Net Theory and the Modelling of Systems. $1^{\text {a }}$ Edição. USA: Prentice-Hall, 1981.

PETRI, C.A., Kommunikation mit Automaten, Bonn: Institut für Instrumentelle Mathematik, Schriften des IIM Nr. 3, 1962. Também em inglês, "Communication with Automata”, New York: Griffiss Air Force Base, Tech. Rep.RADC-TR-65-377, vol. 1, Suppl. $1,1966$.

PHILIPPI, S.; Analysis of fault tolerance and reliability in distributed real-time system architectures. Reliability Engineering and System Safety, n.82, p.195-206, 2003.

PRESSMAN, R. S.; Software Engineering: a practitioner's approach. 5a Edição. International Edition: McGraw-Hill, 2001.

PROFIT, R.; Systematic Safety Management in the Air Traffic Services. Londres: Euromoney Publications, 1995.

RÄISÄNEN, A. V.; LEHTO, A.; Radio Engineering for Wireless Communication and Sensor Applications. EUA: Artech House Inc, 2003.

REICH, P.G.; Analysis of Long-Range Air Traffic Systems - Separation Standards (I and II). Journal of the Institute of Navigation. 1966.

REYNOLDS, T.G; HANSMAN, R.J.; Analysis of Separation Minima using a Surveillance State Vector Approach. In: : $3^{\text {th }}$ USA/EUROPE AIR TRAFFIC MANAGEMENT R\&D SEMINAR, Napoli, Italia, 2000.

REYNOLDS, T.G; HANSMAN, R.J.; Analysis of Separation Minima using a Surveillance State Vector Approach (edição revisada e ampliada). MIT. 2001.

RIPLEY, B.D.; Stochastic Simulation. USA: Wiley, 1987.

ROSS, S. M.; A course in simulation. USA: Macmillan Publishing Company, 1990.

SEIJI, T. et al; Advanced Supervisory and Control Systems for Nuclear Power Plants. Hitachi Review, v.50, n.3, pp 79-83, 2001.

SIEWERDT, E.; Tráfego Aéreo: os Limites do Crescimento. In: Revista Aeroespaço (edição especial-CNS/ATM), Ano X, no 14, p 80-82. 2000. 
SIEWERDT, E.; Vigilância Dependente Automática por Radiodifusão. In: netAtech Publicação Interna na intranet da empresa "Atech Tecnologias Críticas" (gentilmente cedido pelo próprio autor). 2004.

SILVA; P.C.M; Elementos dos Sistema de Tráfego. Apostila do curso de Engenharia de Tráfego. Universidade de Brasília , 2001.

SKELLY, J.F.; MORRIS, J.T.; Design, Evolution and Impact of the AGS/RHIC Control System. In: INTERNATIONAL CONFERENCE ON ACCELERATOR AND LARGE EXPERIMENTAL PHYSICS CONTROL SYSTEMS, Trieste, Italy, 1999. pp 42-44.

SHAKARIAN, A.; HARALDSDOTTIR, A; Required Total System Performance and Results of a Short Term Conflict Alert Simulation Study. In: $4^{\text {th }}$ US/EUROPE AIR TRAFFIC MANAGEMENT R\&D SEMINAR, Santa Fé, EUA, 2001. paper 38.

SHOOMAN, M.L.; Reliability of Computer System and Networks: Fault-Tolerance, Analysis and Design. $1^{\text {a }}$ Edição. USA: John Wiley \& Sons, 2002.

SITA. The ICAO CNS/ATM System. In: ATS Data link Semminar. São Paulo. Maio de 2005.

STOREY, N.; Safety-Critical Computer Systems. USA: Addison-Wesley Publishing Company, 1996.

SULLIVAN, K. et al; Information Survivability Control Systems. In: 21th CONFERENCE ON SOFTWARE ENGINEERING, Los Angeles, USA, 1999. pp 184-192.

SUMMER, S.; Upper Airpace Program Operacional Update. In: ADS-B IMPLEMENTATION TEAM (ABIT), $10^{\mathrm{TH}}$ MEETING. Camberra, Australia, 2007. IP4.

THOMPSON, S. D.; BUSSOLARI, S. R.; Analysis of Terminal Separation Standards and Radar Performance. In: $5^{\text {th }}$ EUROCONTROL / FAA ATM R\&D Seminar, Budapest, Hungary, 2003. paper 18.

TIPSUWAN, Y.; CHOW, M.Y.; Control Methodologies in Networked Control Systems. In Control Engineering Practice 11, p.1099-1111, 2003.

TRIVEDI, K.S., KULKARNI, V.G.; FSPN: Fluid Stochastic Petri nets. In: PROCEEDINGS OF THE 1993 PETRI NET CONFERENCE, Chicago, EUA, 1993.

TRIVEDI, K. S. (Ed); SPNP User's Manual Version 6.0. EUA: Duke University, Set. 1999.

TUFFIN, B; TRIVEDI, K.; Implementation of Importance Splitting Techniques in Stochastic Petri Net Package. In: COMPUTER PERFORMANCE EVALUATION: MODELLING TECHINIQUES AND TOOLS, Schaumburg, EUA, 2000. pp 216-229.

TUFFIN, B; CHEN, D.S.; TRIVEDI, K.; Comparison of Hybrid Systems and Fluid Stochastic Petri Nets. Discrete Event Dynamic Systems: Theory and Applications, v.11, n.1 \& 2, p.77-95, 2001.

WOLTER, K.; Modelling Hybrid Systems with Fluid Stochastic Petri Nets. In: INTERNATIONAL CONFERENCE ON AUTOMATION ON MIXED PROCESS: 
HYBRID DYNAMIC SYSTEMS, 4, Dortumund, Alemanha, 2000. p.287-294.

VARAIYA, P.; Design Simulation and Implementation of Hybrid Systems. Aplication and Theory of Petri Nets 1999. Springer Verlag. LNCS 1639, p.1-5, 1999.

VISMARI, L. F. et al; The Influences of Security Concept in Safety-Related Systems: An Approach to CNS/ATM System. WSEAS Transactions on Systems. Issue 1, v.2, p.179-184, Janeiro 2003. 


\section{GLOSSÁRIO}

Acurácia (accuracy) - diferença entre o valor obtido para uma grandeza e seu valor real.

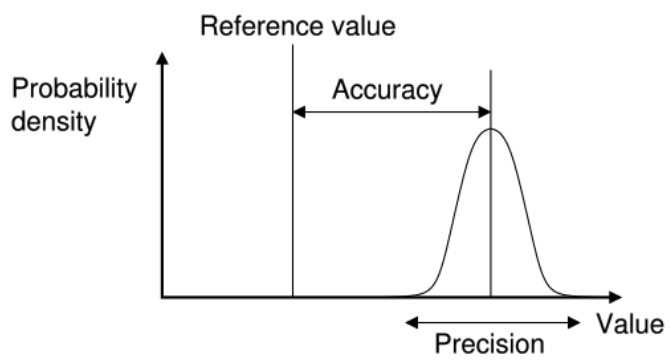

Apêndice - texto ou documento preparado pelo autor, a fim de complementar sua argumentação, sem prejuízo da unidade nuclear do trabalho.

Arquitetura - é a estrutura de componentes (de um sistema), o modo como se relacionam e os princípios e regras que governam o projeto e evolução no tempo. Uma arquitetura descreve um sistema.

Envolvidos - elementos de uma organização que possuem interesse nos sistemas como forma de realizar missões e, assim, obter os produtos e serviços que necessitam ou que possuem interesse.

FOM (Figure of Merite) - indicador de acurácia, inserido pelo emissor ADS, das informações contidas em uma mensagem ADS com base nas informações providas por suas fontes.

Missão - um objetivo ou função que os envolvidos necessitam realizar como meio de obter seus interesses, que podem ser produtos ou serviços. As missões necessitam de sistemas para serem realizadas.

Sistema - um conjunto de elementos funcionais que interagem, através de meios e de processos, com o objetivo de produzir produtos ou serviços (ou, em outras palavras, cumprir uma missão). O conceito de "sistema" está diretamente relacionado com 4 outros conceitos: Missão, Envolvidos, Ambiente e Arquitetura, e indiretamente relacionado com outros 3 conceitos: Interesses, Pontos-de-Vista e Visões. A figura a seguir ilustra o modelo relacional de entidades para os conceitos relacionados aos sistemas. 


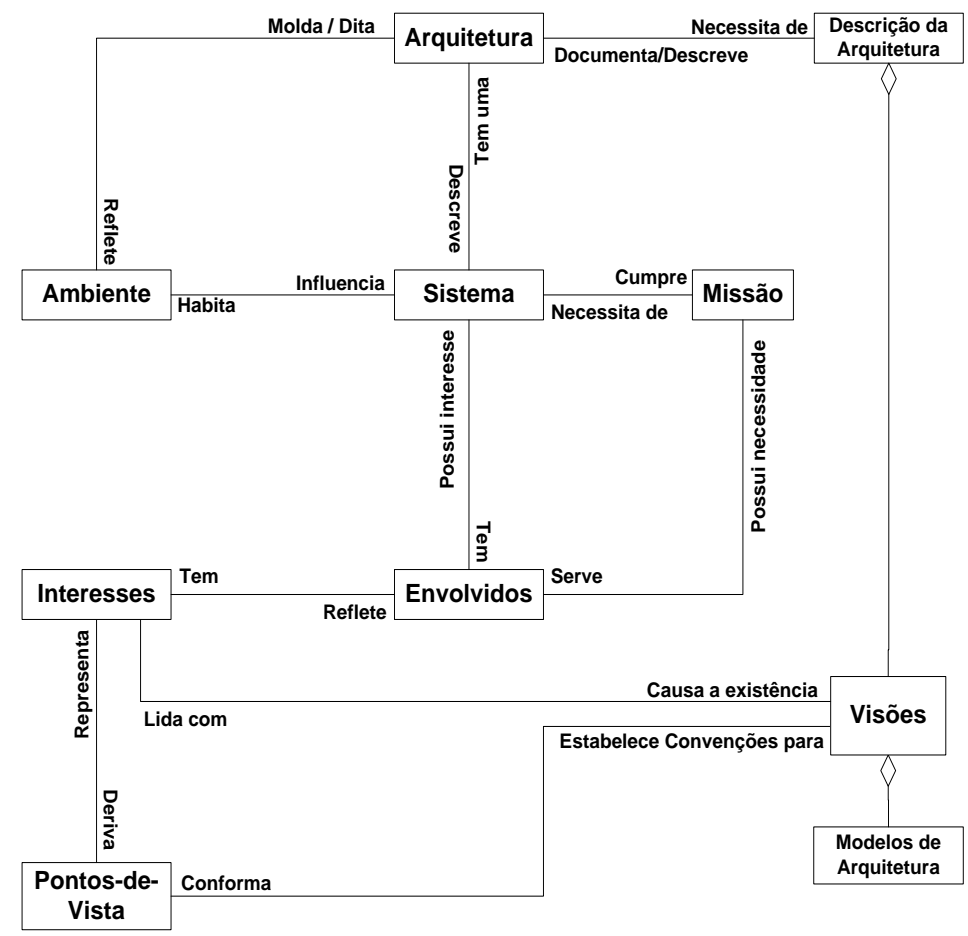

Strip de vôo - ou ficha de progressão de vôo, que contém os dados relativos a um plano de vôo em execução, e utilizada pelos controladores de tráfego aéreo no trabalho prestação de serviços de controle de tráfego aéreo. 


\section{APÊNDICE A - O Sistema de Gerenciamento do Tráfego Aéreo}

O modo aéreo de transporte possui um tipo de tráfego que possibilita ao piloto, em apenas uma quantidade limitada de situações operacionais, conduzir sua aeronave sem fazer uso de elementos funcionais que o auxilie na navegação. Em situações operacionais onde a visibilidade é prejudicada por fatores meteorológicos (noite, chuva, neve, nuvens, etc), o sistema de tráfego necessita, no mínimo, de instrumentos que auxiliem os pilotos a definir em qual posição do espaço estão suas aeronaves e, assim, aderir à trajetória desejada.

Em casos extremos, onde existam situações de alta densidade de tráfego, condições meteorológicas desfavoráveis e uma frota de aeronaves heterogênea, é necessário haver um conjunto de elementos funcionais que sejam utilizados para planejar o fluxo de tráfego aéreo antes que ele aconteça e, durante sua execução, garantir sua segurança e eficiência. $\mathrm{O}$ conjunto de elementos funcionais básicos do sistema de tráfego aéreo (aeronaves, espaço aéreo e usuários, segundo Silva (2001)), aliado aos demais elementos utilizados no planejamento e execução do tráfego, pode ser denominado como o "Sistema de Gerenciamento de Tráfego Aéreo". Este sistema tem a missão de, além de controlar o tráfego em execução, planejá-lo e acomodá-lo sobre os recursos existentes do sistema antes que o mesmo ocorra.

A seguir, são descritos os conceitos relacionados com o gerenciamento do tráfego aéreo e as suas limitações atuais, em busca do atendimento à demanda por transporte aéreo.

\section{O Tráfego Aéreo}

Trafegar é uma das missões que um sistema de transporte deve cumprir para atingir o objetivo de transferir seres ou objetos entre locais geograficamente separados. Considerando o modo de transporte aéreo, a instrução IMA 100-12, que regulamenta as regras do ar e os serviços de tráfego aéreo brasileiros, define tráfego aéreo como sendo "todas as aeronaves ${ }^{21}$ em vôo ou operando na área de manobra ${ }^{22}$ de um aeródromo ${ }^{23 "}$ (Ministério da Aeronáutica, 1999).

\footnotetext{
${ }^{21}$ Aeronave: "todo aparelho manobrável em vôo que possa sustentar-se e circular no espaço aéreo mediante reações aerodinâmicas, apto a transportar pessoas ou coisas.” (Ministério da Aeronáutica, 1999).

22 Área de Manobra: "parte do aeródromo destinada ao pouso, decolagem e táxi de aeronaves, excluindo os pátios”. (Ministério da Aeronáutica, 1999).

${ }^{23}$ Aeródromo: "área definida sobre terra ou água destinada à chegada, partida e movimentação de aeronaves." (Ministério da Aeronáutica, 1999).
} 
Desta forma, os elementos funcionais básicos que compõe o tráfego aéreo são:

- Veículos: Aeronaves.

- Vias: o espaço aéreo e as áreas de manobra dos aeródromos.

- Usuários: piloto em comando, ocupantes das aeronaves (tripulação e passageiros) e demais pessoas envolvidas, tanto direta quanto indiretamente na operação de tráfego aéreo.

No tráfego aéreo, um piloto em comando deve obedecer às regras de vôo para conduzir sua aeronave através das três dimensões do espaço aéreo. Dentro da aeronave, este piloto possui um campo de visão limitado e no sentido de seu movimento. Adicionando este fator à velocidade e à continuidade ${ }^{24} \mathrm{com}$ a qual as aeronaves se movimentam, um piloto possui intervalos relativamente curtos de tempo para detectar e atuar de forma a manter uma separação segura entre sua aeronave e os demais elementos físicos do ambiente, tanto no solo quanto no ar. Em boas condições de visibilidade, existe uma possibilidade maior de o piloto detectar um potencial conflito com relativa antecedência e, por isto, ele pode ser responsável pela condução de sua aeronave e seguir regras de vôo visual (ou VFR - Visual Flight Rules). Nestas regras de vôo, o piloto é responsável por providenciar sua própria separação em relação aos obstáculos e demais aeronaves (exceto quando o vôo for executado em espaço aéreo controlado, conforme será descrito posteriormente). Para isto, o piloto deve ser capaz de manter a referência visual com o solo ou a água, e as formações meteorológicas abaixo do seu nível de vôo não devem obstruir mais de metade da área de sua visão, além de voar a menos de 15.000 pés de altitude, e respeitar velocidades máximas estabelecidas (Ministério da Aeronáutica, 1999).

A existência de condições meteorológicas desfavoráveis para a visibilidade (noite, nuvens, chuva, etc) reduz os intervalos de tempos possíveis para a reação do piloto e, consequentemente, degrada a segurança da operação. Neste caso, o piloto deve ter acesso a elementos funcionais, tais como a comunicação com os demais elementos do ambiente, e seguir procedimentos, tais como as regras de vôo por instrumentos - ou IFR (Instrument

\footnotetext{
${ }^{24}$ Aeronaves cuja sustentação aerodinâmica não seja realizada por meio da diferença de densidade entre o veículo e o meio físico no qual está inserido, tais como dirigíveis, dependem do movimento contínuo e acima de determinados limiares de velocidade para que se mantenham suspensas no ar ("efeito asa").
} 
Flight Rules) -, como forma de ampliar seu grau de consciência situacional ${ }^{25}$. O aumento do grau de consciência sobre o ambiente no qual a sua aeronave está inserido possibilita ao piloto conhecer, com maior antecedência, as manobras que deverá realizar e, assim, poder executálas dentro de intervalos de tempo que respeitem as separações mínimas e, consequentemente, os critérios de segurança do sistema.

Além da segurança, o tráfego aéreo deve ser operado de forma eficiente. A eficiência do tráfego pode ser mensurada pela diferença entre o nível de fluxo obtido em uma operação ideal - balanceada pela relação entre capacidade, demanda e restrições existentes no sistema e o nível de fluxo de a operação realizada (Haraldsdottir, 1997). A eficiência do tráfego aéreo é fator decisivo na produtividade e, consequentemente, na eficiência do transporte aéreo. A capacidade do piloto em se localizar e cumprir o percurso desejado, sem restrições e no menor tempo possível, afeta diretamente a quantidade de serviço realizado por unidade de tempo no sistema de transporte aéreo. As características do tráfego aéreo, tais como liberdade de movimento em três dimensões e a visibilidade limitada, comprometem a capacidade em se obter a posição de uma aeronave em um determinado instante de tempo (Banks, 2002). Desta forma, o piloto deve ter acesso a elementos funcionais e seguir procedimentos que o auxiliem a navegar sobre um percurso estabelecido e aderir à trajetória desejada.

Portanto, a capacidade com a qual um piloto adere à trajetória desejada e sua consciência sobre o ambiente no qual está inserido durante a execução do vôo são fundamentais à eficiência e a segurança do tráfego. Porém, ambientes com alta densidade de tráfego, onde a ocorrência de conflitos e a competição por recursos do sistema aumentam, tornam impraticáveis que o piloto seja o único responsável pela condução da aeronave, mesmo que ele tenha acesso a elementos funcionais e procedimentos que ampliem seu grau de consciência do ambiente e o auxiliem na navegação. Nestes ambientes, e como relatado anteriormente, o piloto necessita compartilhar a responsabilidade de conduzir sua aeronave com operadores externos. Estes operadores podem assessorar ou mesmo assumir o controle na condução das aeronaves, mantendo a eficiência e a segurança do tráfego aéreo.

Mesmo que o controle das aeronaves por elementos externos promova a otimização do uso dos recursos do sistema de tráfego, estes procedimentos são realizados apenas durante a

\footnotetext{
${ }^{25}$ Consciência Situacional (Situational Awareness): "The perception of the elements in the environment within a volume of time and space, the comprehension of their meaning and the projection of their status in the near future." Endsley (1988).
} 
execução dos vôos. As velocidades elevadas que as aeronaves desenvolvem durante o vôo limitam os intervalos de tempo máximos que os elementos externos possuem para atuar. Como forma de aumentar estes tempos de atuação, o tráfego aéreo deve ser planejado antes de sua execução. Assim, é possível aumentar a eficiência do tráfego alocando-se, para cada vôo desejado, janelas de tempo sobre os recursos do sistema, reduzindo as chances de mais de uma aeronave competir, ao mesmo tempo, pelo mesmo recurso.

Concluindo, a eficiência e a segurança do tráfego aéreo dependem de um bom planejamento e de sua correta execução. Tanto as atividades de planejamento quanto de execução do tráfego dependem da existência de elementos funcionais que sejam capazes de interagir entre si e com os elementos funcionais básicos do sistema de tráfego aéreo (veículos, vias e usuários), obtendo informações, processando-as, gerando planejamentos de vôo e atuando sobre os vôos, de forma a garantir a execução destes planejamentos. A este conjunto de elementos denomina-se "Sistema de Gerenciamento de Tráfego Aéreo", e será descrito a seguir.

\section{O Sistema de Gerenciamento de Tráfego Aéreo}

A Organização de Aviação Civil Internacional (OACI) define que o objetivo principal do Gerenciamento do Tráfego Aéreo, comumente denominado pela sigla ATM (Air Traffic Management), é:

“...to enable the aircraft operators to meet their planned times of departure and arrival and adhere to their preferred flight profile with minimum constraints and without compromising agreed levels of safety." (ICAO, 1998b)

O cumprimento de uma missão depende da existência de um sistema (Chen; Sakka, Clothier, 2000). Portanto, a missão de gerenciar o tráfego aéreo, que significa habilitar os operadores das aeronaves a cumprir seus planejamentos (tanto em horários quanto em trajetórias de vôos) de forma segura, eficiente e com o mínimo de restrições é realizada pelo sistema de gerenciamento de tráfego aéreo. Desta forma, este sistema possui a função de gerenciar o fluxo das aeronaves tanto no nível de planejamento (estratégico) quanto no nível de execução (tático). A Figura 78 ilustra, em alto nível funcional, o Sistema de Gerenciamento do Tráfego Aéreo. 


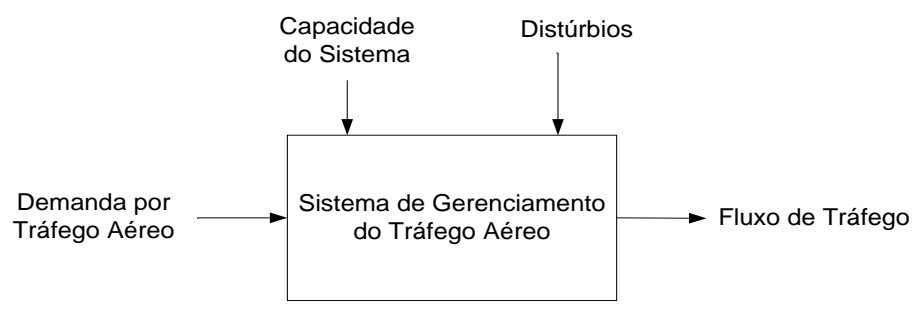

Figura 78 - O Sistema de Gerenciamento do Tráfego Aéreo

No sistema de transporte aéreo comercial, as Companhias Aéreas são os operadores das aeronaves (Organizações Operacionais, segundo Banks (2002)). Estas companhias planejam seus vôos de forma a atender o mercado consumidor, estabelecendo quais serão suas trajetórias (aeroportos de origem, de destino e os percursos que serão utilizados) e seus horários de partida e de chegada. Operacionalmente, as companhias aéreas planejam seus vôos para que tenham os menores custos (e, portanto, os maiores lucros) possíveis. Devido ao fato do consumo de combustível contribuir entre $45 \%$ e $55 \%$ dos custos diretos de um vôo e os propulsores das aeronaves possuírem desempenhos ótimos em determinados níveis de vôo (Costa, 2005), as companhias aéreas planejam realizar seus vôos utilizando as trajetórias mais diretas possíveis e nos níveis de vôo que promovam um consumo de combustível menor.

Em períodos de elevada demanda por tráfego, existe uma grande probabilidade de vários operadores competirem pelos mesmos recursos do sistema de tráfego como forma de cumprirem as trajetórias de suas preferências. Para que estes conflitos sejam minimizados, o sistema de gerenciamento do tráfego aéreo deve conter elementos que coordenem o planejamento do fluxo de tráfego aéreo. Este coordenador de planejamento, em posse dos planos dos vôos que as companhias aéreas desejam realizar, aloca janelas de tempo sobre os recursos existentes para cada um dos vôos desejados. Este planejamento é baseado nos conhecimentos do planejador sobre a capacidade do sistema (capacidade de operação dos aeroportos, dos setores de controle, disponibilidade de equipamentos, entre outros) e sobre as previsões meteorológicas (que podem restringir o acesso a determinadas áreas do espaço aéreo). Desta forma, o planejador harmoniza a relação entre a capacidade do sistema e sua demanda por tráfego aéreo, criando um planejamento global do tráfego que deve ser seguido pelas companhias aéreas.

O processo de planejamento do fluxo possui uma quantidade significativa de incertezas, influenciadas pelas características das variáveis consideradas (previsões meteorológicas, disponibilidade dos equipamentos, entre outras) e pela antecedência com o qual os 
planejamentos são realizados. Reduzir as incertezas das variáveis não é uma tarefa simples, pois envolve, por exemplo, a melhoria dos modelos de previsão meteorológicas, entre outras atividades. Uma solução é uma modificação mais dinâmica dos planejamentos, que adapta os fluxos de tráfego às restrições existentes no momento de sua execução. Desta forma, divide-se o planejamento do fluxo de tráfego aéreo em diversos níveis, flexibilizando-o. Estes níveis estão relacionados à região (nacional, regional ou setorial) e à antecedência (meses, dias, horas ou minutos) com que atuam (Haraldsdottir, 1997). Quanto menor a antecedência com a qual se planeja um fluxo de tráfego, maiores são as chances de se manter sua vazão para uma determinada região do espaço, pois menores são as incertezas sobre os estados do sistema. Porém, e em tese, quanto maior a antecedência e, sobretudo, a região de abrangência do planejamento, maior a capacidade em se obter um fluxo de tráfego eficiente.

Além de planejar os fluxos de tráfego, estabelecendo quais vôos poderão utilizar determinados recursos em intervalos de tempo específicos, o sistema de gerenciamento de tráfego aéreo é responsável também por executá-los. Desta forma, este sistema provê serviços que auxiliam os pilotos, durante o vôo, a cumprirem seus planos de vôo autorizados de modo seguro e mantendo a eficiência do fluxo de tráfego. A execução do tráfego pode ser realizada, segundo Haraldsdottir (1997), em diversos níveis funcionais: no nível da garantia da separação, no nível da condução da aeronave e da navegação e no nível da prevenção de colisão a bordo da aeronave (aircraft on-board collision avoidance). Todos estes níveis funcionais atuam durante a execução dos vôos, porém cada um atua com uma abrangência física e com horizontes de tempo diferenciados. O primeiro deles, a garantia da separação, é realizada pelo controle de solo que, conhecendo o estado de cada uma das aeronaves de um setor do espaço aéreo, atua com antecedência de forma a manter as aeronaves separadas com distâncias seguras e aderindo às trajetórias planejadas. Os níveis funcionais seguintes são realizados pela tripulação das aeronaves apenas sobre seu próprio movimento. Neste caso, a tripulação possui consciência limitada da situação ao seu redor, atuando sob orientação do controle de solo, caso seja provida com este serviço, ou de forma a executar manobras evasivas caso detecte perigo iminente de colisão.

A estrutura funcional do sistema de gerenciamento do tráfego aéreo (ATM), com seus elementos funcionais e o fluxo de informação entre os mesmos, seus domínios de atuação (planejamento ou execução), e o horizonte de tempo que cada elemento possui para atuar são ilustrados na Figura 79 (adaptado de Haraldsdottir, 1997). 


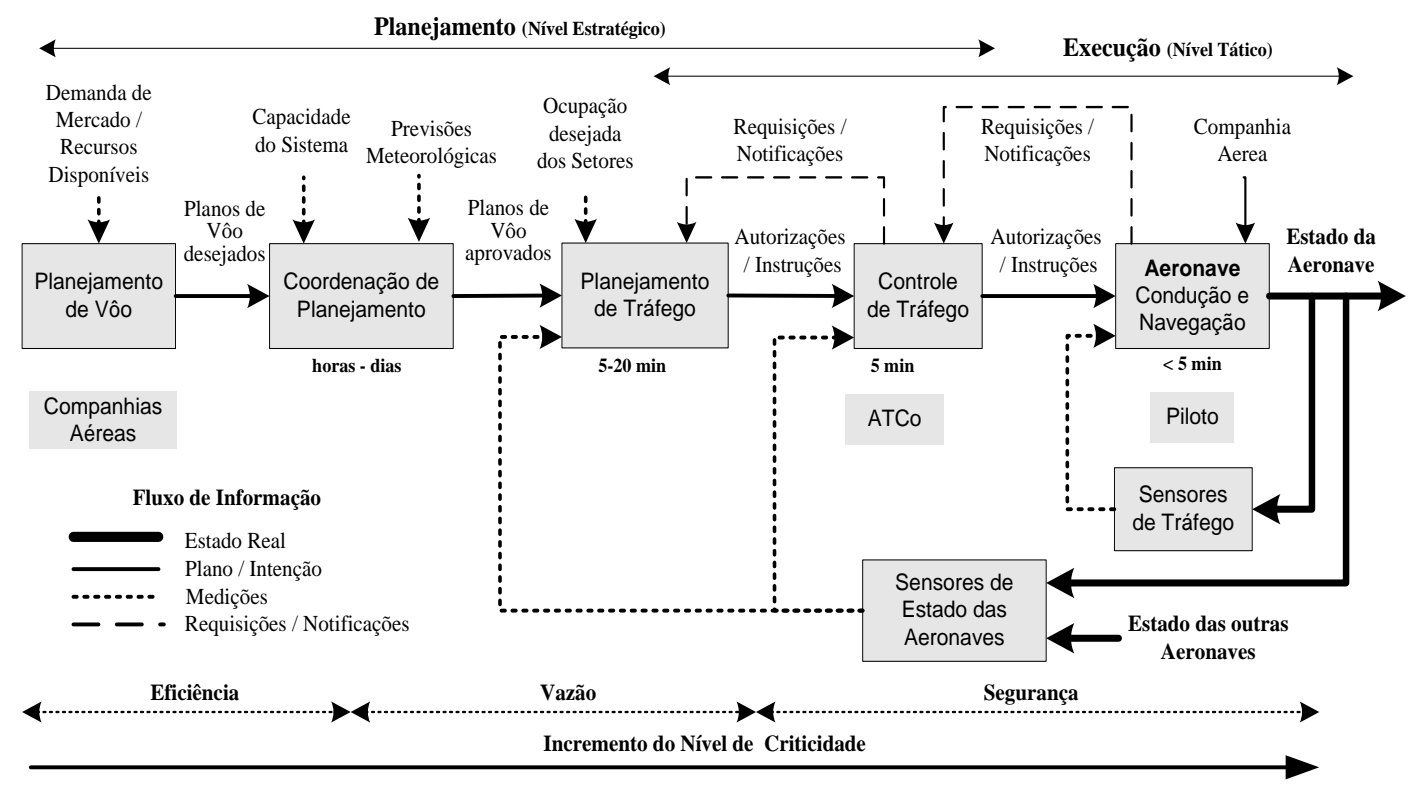

Figura 79 - Estrutura Funcional do Sistema de ATM (adaptado de Haraldsdottir, 1997)

\subsection{Os Serviços de Tráfego Aéreo (ATS)}

Tanto as atividades de planejamento quanto de execução do fluxo de tráfego aéreo fazem parte do sistema de gerenciamento do tráfego aéreo, cuja missão principal é habilitar os operadores das aeronaves a cumprirem seus percursos de forma eficiente e segura. A Organização de Aviação Civil Internacional (OACI) divide o gerenciamento do tráfego aéreo (ATM) em duas partes: Aérea e Terrestre. A parte aérea possui a capacidade funcional de interagir com a parte terrestre para cumprir os objetivos do ATM. A parte terrestre contém as funcionalidades de "Serviços de Tráfego Aéreo" (ATS), de "Gerenciamento do Espaço Aéreo" (ASM) e de "Gerenciamento do Fluxo de Tráfego" (ATFM) (ICAO, 1998b). Tanto o ASM quanto o AFTM são responsáveis pelos níveis de planejamento do tráfego, descritos anteriormente. Já o ATS, considerado pela OACI como o elemento primário do ATM, está relacionado à execução do tráfego planejado.

Os Serviços de Tráfego Aéreo (ATS) são de três tipos (ICAO, 1998b):

- $\quad$ Serviço de Alerta (ou Alerting Service - AS);

- Serviço de Informação de Vôo (ou Flight Information Service - FIS); e

- Serviço de Controle de Tráfego Aéreo (ou Air Traffic Control - ATC).

O Serviço de Alerta (AS) tem a missão de notificar os órgãos apropriados a respeito das 
aeronaves que necessitem da ajuda de busca e salvamento e para auxiliar estes órgãos no que for necessário.

O Serviço de Informação de Vôo (FIS) tem a missão de prover avisos e informações úteis à realização eficiente e segura dos vôos. Informações relativas à meteorologia, alterações nos serviços de tráfego aéreo e nos auxílios à navegação, condições de aeródromos ou qualquer outra informação que eleve o grau de consciência do piloto responsável pela condução da aeronave e que, consequentemente, reduza os riscos de colisão, são transmitidas às aeronaves que trafegam no espaço aéreo. Um exemplo de serviço de informação de vôo é o Serviço Automático de Informação Terminal (ATIS), que transmite informações gravadas, relativas a um ou mais aeródromos, pertinentes à segurança da navegabilidade (ajuste de altímetro, pista em uso, condições meteorológicas, entre outros) (Ministério da Aeronáutica, 1999).

O Serviço de Controle de Tráfego Aéreo (ATC) possui a missão de prevenir colisões, tanto entre aeronaves quanto entre aeronaves e obstáculos na área de manobras, além de acelerar e manter ordenado o fluxo do tráfego aéreo. Para atingir seus objetivos, o ATC deve conhecer o estado (posição, velocidade e direção, entre outras variáveis) de cada aeronave em sua área de controle. Através da consciência sobre o ambiente de controle, o ATC controla as aeronaves, fazendo uso de autorizações ${ }^{26}$ e de instruções ${ }^{27}$ de controle de tráfego aéreo, de forma a mantê-las separadas e o mais próximo possível das trajetórias planejadas.

Devido cada tipo de serviço de tráfego aéreo (ATS) ser mais bem utilizado em determinadas condições do espaço aéreo, a Organização de Aviação Civil Internacional (OACI) estruturou e classificou o espaço aéreo com o intuito de adequar a prestação dos serviços às necessidades específicas de cada uma de suas regiões (ICAO, 2001). Com relação a sua estrutura, o espaço aéreo possui divisões, designações e configurações. O Ministério da Aeronáutica adota as seguintes definições para o espaço aéreo (Ministério da Aeronáutica, 1999), (Ministério da Aeronáutica, 2000):

- Divisões do Espaço Aéreo:

\footnotetext{
${ }^{26}$ Autorização (ou "Autorização de Controle de Tráfego Aéreo"): “autorização para que uma aeronave proceda de acordo com as condições especificadas por um órgão de controle de tráfego aéreo.” Exemplos de autorizações são: para táxi, para pouso, para decolagem, de níveis de vôo ou altitudes. (Ministério da Aeronáutica, 1999)

27 Instruções de Controle de Tráfego Aéreo: "Diretrizes expedidas pelo controle de tráfego aéreo com a finalidade de exigir que o piloto tome determinadas medidas." (Ministério da Aeronáutica, 1999)

Exemplos de instruções são: de proa e velocidade, de ajuste de altímetro, de pista em uso, de código SSR, etc.
} 
- Espaço Aéreo Inferior: verticalmente, está contido entre a terra (solo ou água) e o nível de vôo ${ }^{28}$ de 24500 pés (FL245), inclusive. Horizontalmente, seus limites são definidos em cartas de rotas aéreas (ERC).

- Espaço Aéreo Superior: verticalmente, é constituído por toda a região acima do nível de vôo de 24500 pés (FL245). Horizontalmente, seus limites são definidos em cartas de rotas aéreas (ERC).

- Designações do Espaço Aéreo: relacionado aos tipos de serviços de tráfego aéreo prestados aos vôos.

- Regiões de Informação de Vôo (ou Fligth Information Region - FIR).

- Espaços Aéreos Controlados.

- Espaços Aéreos Condicionados.

- Configurações do Espaço Aéreo: definidos com base nas designações e nas divisões do espaço aéreo.

○ Regiões de Informação de Vôo (FIR): são constituídos, verticalmente, por todo o espaço aéreo inferior e superior (todo espaço aéreo acima do solo ou água). Horizontalmente, seus limites são definidos em cartas de rotas aéreas (ERC).

O espaço aéreo sob jurisdição do Brasil é dividido em cinco regiões de informação de vôo (FIR): Amazônica, Recife, Brasília, Curitiba e Atlântico. A Figura 80 ilustra a distribuição destas FIRs sobre o espaço aéreo brasileiro (DECEA, 2004).

\footnotetext{
${ }^{28}$ Nível de vôo: "superfície de pressão atmosférica constante, relacionada com uma determinada referência de pressão, 1013.2 hectopascais, e que está separada de outras superfícies análogas por determinados intervalos de pressão." (Ministério da Aeronáutica, 1999)
} 


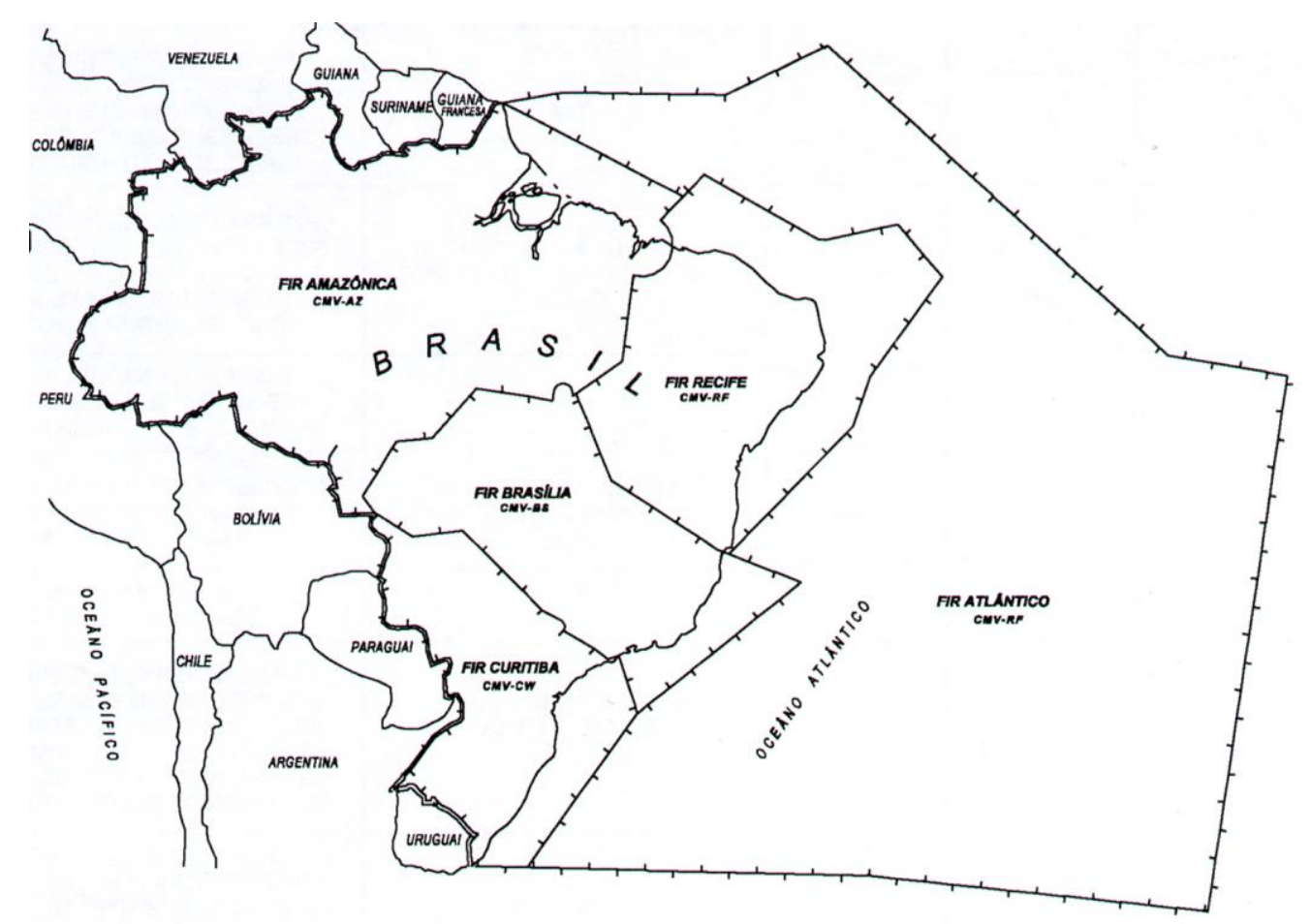

Figura 80 - FIRs do Espaço Aéreo brasileiro

○ Espaços Aéreos Controlados:

- Áreas Superiores de Controle (ou Upper Terminal Area - UTA): compreende as aerovias $^{29}$ superiores e outras partes do espaço aéreo superior (acima do FL245).

- Áreas de Controle (ou Control Area - CTA): compreende as aerovias inferiores (abaixo do FL245, inclusive) e outras partes do espaço aéreo inferior.

- Áreas de Controle Terminal (ou Terminal Area - TMA): compreende áreas ao redor de aeródromos, com configuração variável definida pelos órgãos responsáveis.

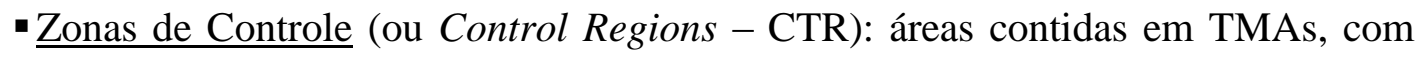
configuração variável definida pelos órgãos responsáveis.

- Zonas de Tráfego de Aeródromo (ou Aerodrome Traffic Zones - ATZ): para aeródromos controlados. Configuração variável definida pelos órgãos responsáveis.

\footnotetext{
${ }^{29}$ Aerovia: "Área de Controle, ou parte dela, disposta em forma de corredor e provida de auxílios à navegação." (Ministério da Aeronáutica, 1999).
} 
Como exemplo, a Figura 81 ilustra a relação entre os espaços aéreos do ATS ao redor de um aeródromo (Ministério da Aeronáutica, 2000).

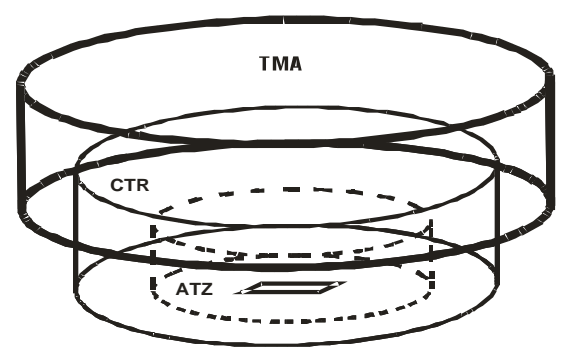

Figura 81 - Espaços Aéreos ATS

○ Espaços Aéreos Condicionados: são aqueles com configuração variável e definidos pelos órgãos responsáveis. São divididos em Áreas Proibidas (onde o vôo é proibido), Áreas Perigosas (onde há riscos potenciais para o vôo) e Áreas Restritas.

Os espaços aéreos são classificados segundo características específicas, tais como os tipos de vôo que podem receber (aeronaves seguindo regras de vôo visuais (VFR) ou regras de vôo por instrumento (IFR)); os tipos de vôo onde o Controle de Tráfego Aéreo provê serviços de separação; os tipos serviços de tráfego aéreo prestados (ATC, FIS e/ou AS); os limites de velocidade e os mínimos de visibilidade praticados (para vôos VFR); os requisitos de comunicação necessários e se os vôos estão sujeitos a autorizações por parte do controle de tráfego aéreo (ATC). Cada classe do espaço aéreo é denominada alfabeticamente por uma letra, de "A" a "G". A Tabela I ilustra as classes existentes no espaço aéreo brasileiro e os requisitos que devem ser cumpridos em cada uma delas (Ministério da Aeronáutica, 1999), (Ministério da Aeronáutica, 2000).

Tabela I - Classificação do Espaço Aéreo ATS

\begin{tabular}{|c|c|c|c|c|c|c|c|}
\hline \multirow[b]{2}{*}{ CLASSE } & \multirow[b]{2}{*}{$\begin{array}{c}\text { TIPO } \\
\text { DE } \\
\text { VÔO }\end{array}$} & \multirow[b]{2}{*}{$\begin{array}{l}\text { SEPARAÇÃO } \\
\text { PROVIDA }\end{array}$} & \multirow[b]{2}{*}{$\begin{array}{l}\text { SERVIÇO } \\
\text { PRESTADO }\end{array}$} & \multicolumn{4}{|c|}{ REQUISITOS PARA UTILIZAÇÃO } \\
\hline & & & & $\begin{array}{c}\text { MÍNIMOS DE } \\
\text { VISIBILIDADE } \\
\text { E DISTÂNCIA } \\
\text { DE NUVENS }\end{array}$ & $\begin{array}{l}\text { LIMITE DE } \\
\text { VELOCIDADE }\end{array}$ & $\begin{array}{c}\text { RÁDIO } \\
\text { COMUNICAÇÃO }\end{array}$ & $\begin{array}{l}\text { SUJEITO A UMA } \\
\text { AUTORIZAÇÃO } \\
\text { ATC }\end{array}$ \\
\hline A & IFR & $\begin{array}{l}\text { A todas as } \\
\text { aeronaves }\end{array}$ & ATC & Não aplicável & $\begin{array}{c}\text { Não } \\
\text { aplicável }\end{array}$ & $\begin{array}{l}\text { Bilateral } \\
\text { contínua }\end{array}$ & Sim \\
\hline B & IFR & $\begin{array}{l}\text { A todas as } \\
\text { aeronaves }\end{array}$ & ATC & Não aplicável & $\begin{array}{c}\text { Não } \\
\text { aplicável }\end{array}$ & $\begin{array}{l}\text { Bilateral } \\
\text { contínua }\end{array}$ & Sim \\
\hline
\end{tabular}




\begin{tabular}{|c|c|c|c|c|c|c|c|}
\hline & VFR & & & $\begin{array}{c}\text { (1) } \\
\text { Livre de } \\
\text { Nuvens }\end{array}$ & $\begin{array}{c}380 \mathrm{Kt}^{30} \\
\mathrm{IAS}^{31}\end{array}$ & & \\
\hline \multirow[b]{2}{*}{ C } & IFR & $\begin{array}{l}\text { IFR de IFR } \\
\text { IFR de VFR }\end{array}$ & ATC & Não aplicável & $\begin{array}{c}\text { Não } \\
\text { aplicável }\end{array}$ & & \\
\hline & VFR & VFR de IFR & $\begin{array}{c}\text { ATC para } \\
\text { separação de } \\
\text { IFR; } \\
\text { Informação de } \\
\text { tráfego VFR/IFR } \\
\text { e aviso para } \\
\text { evitar tráfego, } \\
\text { quando } \\
\text { solicitado. } \\
\end{array}$ & $\begin{array}{l}\quad(1) \\
\text { Distância de } \\
\text { Nuvens: } \\
\text { Horizontal: } \\
\text { 1500m } \\
\text { Vertical: } 300 \mathrm{~m}\end{array}$ & $\begin{array}{l}380 \mathrm{Kt} \mathrm{IAS} \\
\text { acima de } \\
\text { FL100 } \\
250 \mathrm{Kt} \mathrm{IAS} \\
\text { abaixo de } \\
\text { FL100 }\end{array}$ & $\begin{array}{l}\text { Bilateral } \\
\text { contínua }\end{array}$ & Sim \\
\hline \multirow{2}{*}{ D } & IFR & IFR de IFR & $\begin{array}{l}\text { ATC, incluindo } \\
\text { informação de } \\
\text { tráfego sobre } \\
\text { vôos VFR (e } \\
\text { aviso para evitar } \\
\text { tráfego, quando } \\
\text { solicitado). } \\
\end{array}$ & Não aplicável. & $\begin{array}{c}\text { Não } \\
\text { aplicável } \\
\text { acima de } \\
\text { FL100 } \\
\text { 250 Kt IAS } \\
\text { abaixo de } \\
\text { FL100 } \\
\end{array}$ & \multirow{2}{*}{$\begin{array}{l}\text { Bilateral } \\
\text { contínua }\end{array}$} & \multirow{2}{*}{ Sim } \\
\hline & VFR & Não aplicável & $\begin{array}{c}\text { Informação de } \\
\text { tráfego entre } \\
\text { vôos IFR/VFR } \\
\text { (e aviso para } \\
\text { evitar tráfego, } \\
\text { quando } \\
\text { solicitado). }\end{array}$ & $\begin{array}{l}\quad \quad(1) \\
\text { Distância de } \\
\text { Nuvens: } \\
\text { Horizontal: } \\
\text { 1500m } \\
\text { Vertical: } 300 \mathrm{~m}\end{array}$ & $\begin{array}{l}380 \mathrm{Kt} \mathrm{IAS} \\
\text { acima de } \\
\text { FL100 } \\
250 \mathrm{Kt} \mathrm{IAS} \\
\text { abaixo de } \\
\text { FL100 }\end{array}$ & & \\
\hline \multirow{2}{*}{ E } & IFR & IFR de IFR & $\begin{array}{c}\text { ATC. } \\
\text { Informações de } \\
\text { tráfego sobre } \\
\text { vôos VFR } \\
\text { sempre que } \\
\text { seja praticável. }\end{array}$ & Não aplicável & $\begin{array}{c}\text { Não } \\
\text { aplicável } \\
\text { acima de } \\
\text { FL100 } \\
\text { 250 Kt IAS } \\
\text { abaixo de } \\
\text { FL100 }\end{array}$ & $\begin{array}{l}\text { Bilateral } \\
\text { contínua }\end{array}$ & Sim \\
\hline & VFR & Não aplicável & $\begin{array}{l}\text { Informações de } \\
\text { tráfego, sempre } \\
\text { que seja } \\
\text { praticável. }\end{array}$ & $\begin{array}{l}\quad \quad(1) \\
\text { Distância de } \\
\text { nuvens: } \\
\text { Horizontal: } \\
\text { 1500m } \\
\text { Vertical: } 300 \mathrm{~m}\end{array}$ & $\begin{array}{l}380 \mathrm{Kt} \text { IAS } \\
\text { acima de } \\
\text { FL100 } \\
250 \mathrm{Kt} \mathrm{IAS} \\
\text { abaixo de } \\
\text { FL100 }\end{array}$ & Não & Não \\
\hline \multirow{2}{*}{$\mathrm{F}$} & IFR & IFR de IFR & $\begin{array}{l}\text { Serviço de } \\
\text { assessoramento } \\
\text { de tráfego } \\
\text { aéreo. } \\
\text { FIS. }\end{array}$ & Não aplicável & $\begin{array}{c}\text { Não } \\
\text { aplicável } \\
\text { acima de } \\
\text { FL100 } \\
250 \text { Kt IAS } \\
\text { abaixo de } \\
\text { FL100 }\end{array}$ & $\begin{array}{l}\text { Bilateral } \\
\text { contínua }\end{array}$ & \multirow{2}{*}{ Não } \\
\hline & VFR & Não aplicável & FIS & \begin{tabular}{l}
\multicolumn{1}{c}{$(\mathbf{1})$} \\
Distância de \\
nuvens: \\
Horizontal: \\
1500m \\
Vertical: $300 \mathrm{~m}$ \\
\multicolumn{1}{|c|}{}
\end{tabular} & $\begin{array}{l}380 \mathrm{Kt} \mathrm{IAS} \\
\text { acima de } \\
\text { FL100 } \\
250 \mathrm{Kt} \text { IAS } \\
\text { abaixo de } \\
\text { FL100 }\end{array}$ & Não & \\
\hline
\end{tabular}

${ }^{30}$ Kt (ou Knots): é uma unidade de velocidade, utilizada em aviação, que expressa a quantidade de Milhas Náuticas (NM) (onde $1 \mathrm{NM}=1.853 \mathrm{~km}$ ) percorridas em 1 hora. Ou seja: $1 \mathrm{Kt}=1 \mathrm{NM} / \mathrm{h}=1.852 \mathrm{~km} / \mathrm{h}$.

${ }^{31}$ IAS (ou Indicated AirSpeed) é a indicação de velocidade da aeronave obtida através da medição da velocidade do ar que passa pela mesma. 


\begin{tabular}{|c|c|c|c|c|c|c|c|}
\hline \multirow[b]{2}{*}{$\mathrm{G}$} & IFR & \multirow[b]{2}{*}{ Não aplicável } & \multirow[b]{2}{*}{ FIS } & Não aplicável & $\begin{array}{c}\text { Não } \\
\text { aplicável } \\
\text { acima de } \\
\text { FL100 } \\
250 \text { Kt IAS } \\
\text { abaixo de } \\
\text { FL100 }\end{array}$ & $\begin{array}{l}\text { Bilateral } \\
\text { contínua }\end{array}$ & \multirow[b]{2}{*}{ Não } \\
\hline & VFR & & & $\begin{array}{l}\quad(\mathbf{1}) \\
\text { Distância de } \\
\text { nuvens: } \\
\text { Horizontal: } \\
\text { 1500m } \\
\text { Vertical: } 300 \mathrm{~m}\end{array}$ & $\begin{array}{l}380 \mathrm{Kt} \text { IAS } \\
\text { acima de } \\
\text { FL100 } \\
250 \mathrm{Kt} \mathrm{IAS} \\
\text { abaixo de } \\
\text { FL100 }\end{array}$ & Não & \\
\hline
\end{tabular}

(1) Visibilidade Mínima: $8 \mathrm{~km}$ acima de FL100, inclusive e $5 \mathrm{~km}$ abaixo de FL100.

(2) Visibilidade Mínima: abaixo de $900 \mathrm{~m}$, inclusive, ou até $300 \mathrm{~m}$ acima do terreno, o que for maior: $5 \mathrm{~km}$, livre de nuvens e com avistamento do solo ou água.

As classes A, B C, D e E do espaço aéreo são consideradas, genericamente, como espaços aéreos controlados (onde são providos serviços de controle de tráfego aéreo - ATC). Em contrapartida, as classes F e G são espaços aéreos não controlados. Todas as áreas superiores de controle (UTA) são consideradas espaço aéreo de classe A, assim como as áreas de controle (CTA) e as áreas de controle terminais (TMA) contidas entre os níveis de vôo de 14500 e 24500 pés (FL145/FL245). Todas as aerovias abaixo do FL145, inclusive, são consideradas espaço aéreo classe D (Ministério da Aeronáutica, 2000). Devido ao teto dos vôos que seguem regras de vôo visual (VFR) ser de 14500 pés (FL145), inclusive, o espaço aéreo de classe A permite apenas vôos do tipo IFR, e todos os vôos VFR em aerovias são classe D.

No Brasil, os Serviços de Tráfego Aéreo (ATS) são prestados em todo o espaço aéreo que sobrepõe o território sob sua jurisdição, ilustrado anteriormente na Figura 80. Estes serviços são prestados segundo as regras e métodos recomendados pela Organização de Aviação Civil Internacional (Ministério da Aeronáutica, 1999). Desta forma, os serviços de informação de vôo (FIS) e de alerta (AS) são prestados em todas as Regiões de Informação de Vôo (FIR) e para todas as aeronaves cujos órgãos responsáveis por prestar o serviço tenham conhecimento de seus vôos.

O Serviço de Controle de Tráfego Aéreo (ATC) é prestado às classes A, B C, D e E do espaço aéreo brasileiro. As classes B, C e D são regiões de vôo controlado tanto para aeronaves que obedecem as regras de vôo visuais (VFR) quanto para aeronaves que obedecem as regras de vôo por instrumentos (IFR). As classes A e E são regiões de vôo controlado apenas para aeronaves que obedecem IFR. 
Desta forma, o serviço de controle de trafego aéreo é dividido em três categorias espaciais distintas: serviço de controle de área, de aproximação e de aeródromo. Cada uma destas categorias de serviço é prestada por um órgão de controle específico e sobre aeronaves em fases distintas de um vôo controlado.

As fases de um vôo que forem controladas devem possuir um plano de vôo aprovado pelo órgão ATC sob sua jurisdição, não sendo obrigatório ao vôo ser cumprido completamente de forma controlada (Ministério da Aeronáutica, 1999). Em linhas gerais, uma aeronave em vôo controlado deve taxiar e decolar do aeródromo de origem (ATZ), sair da área de jurisdição do terminal de origem (TMA), seguir por rotas aéreas (CTA ou UTA), aproximar-se do terminal de destino (TMA), aterrissar e taxiar no aeródromo de destino (ATZ). As fases de um vôo são ilustradas na Figura 82 (adaptado de Haraldsdottir (1997) e Cavcar (2004)).

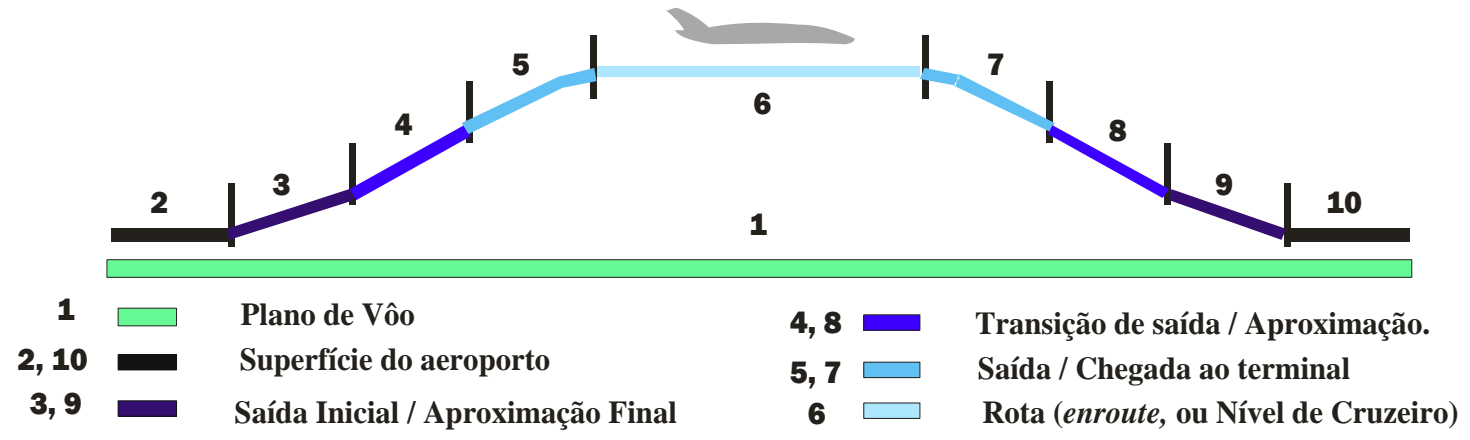

Figura 82 - Fases de um vôo (adaptado de Haraldsdottir (1997) e Cavcar (2004))

O serviço de controle de área é aplicado aos vôos controlados em $\operatorname{rota}^{32}$ (enroute) (fase 6 do vôo, Figura 82), e o órgão responsável por sua prestação são os Centros de Controle de Área (ACC). Conforme regulamentado pelo Ministério da Aeronáutica (1999), um ACC terá jurisdição dentro de uma região de informação de vôo (FIR), nas áreas de controle (CTA e

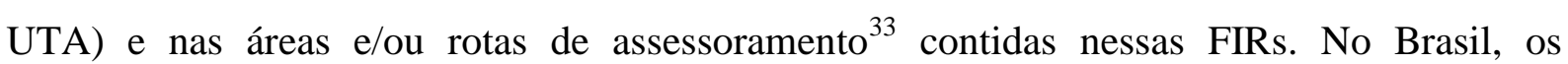
CINDACTAS (Centros Integrados de Defesa Aérea e Controle de Tráfego Aéreo) exercem as funções dos controles de área (ACC). Existem quatro CINDACTAS (DECEA, 2005): CINDACTA 1 (abrangendo o quadrilátero Rio/São Paulo/Belo Horizonte e Brasília - FIR

\footnotetext{
${ }^{32}$ A fase do vôo na qual a aeronave se mantém durante uma etapa considerável de tempo pode ser denominada como "Nível de Cruzeiro" (Ministério da Aeronáutica, 1999), vôo em rota ou enroute.

33 Área / Rota de Assessoramento: área / rota especificada em cartas aeronáutica e pertencente à classe F do espaço aéreo na qual se proporciona o serviço de assessoramento de tráfego aéreo. Este tipo de serviço possui o objetivo de manter as separações adequadas entre as aeronaves que operem segundo planos de vôo por instrumentos (IFR). Este serviço não proporciona o mesmo grau de segurança que o ATC, porém é mais efetivo que o FIS ao disponibilizar informações sobre perigo de colisão (Ministério da Aeronáutica, 1999).
} 
Brasília), CINDACTA 2 (abrangendo os Estados do Paraná, Santa Catarina e Rio Grande do Sul - FIR Curitiba), CINDACTA 3 (abrangendo do Sul da Bahia até o Maranhão, abrangendo toda a região Nordeste e, em particular, a área oceânica, que separa o Continente Sulamericano da África e Europa - FIR Recife) e CINDACTA 4 (abrangendo a região amazônica - FIR Amazônica), o qual faz uso da infra-estrutura do projeto SIVAM (SIstema de Vigilância da AMazônia) ${ }^{34}$. A Figura 83 ilustra a abrangência dos CINDACTAS sobre o território nacional, com suas respectivas áreas de cobertura dos radares de vigilância (adaptado de DECEA (2005)).

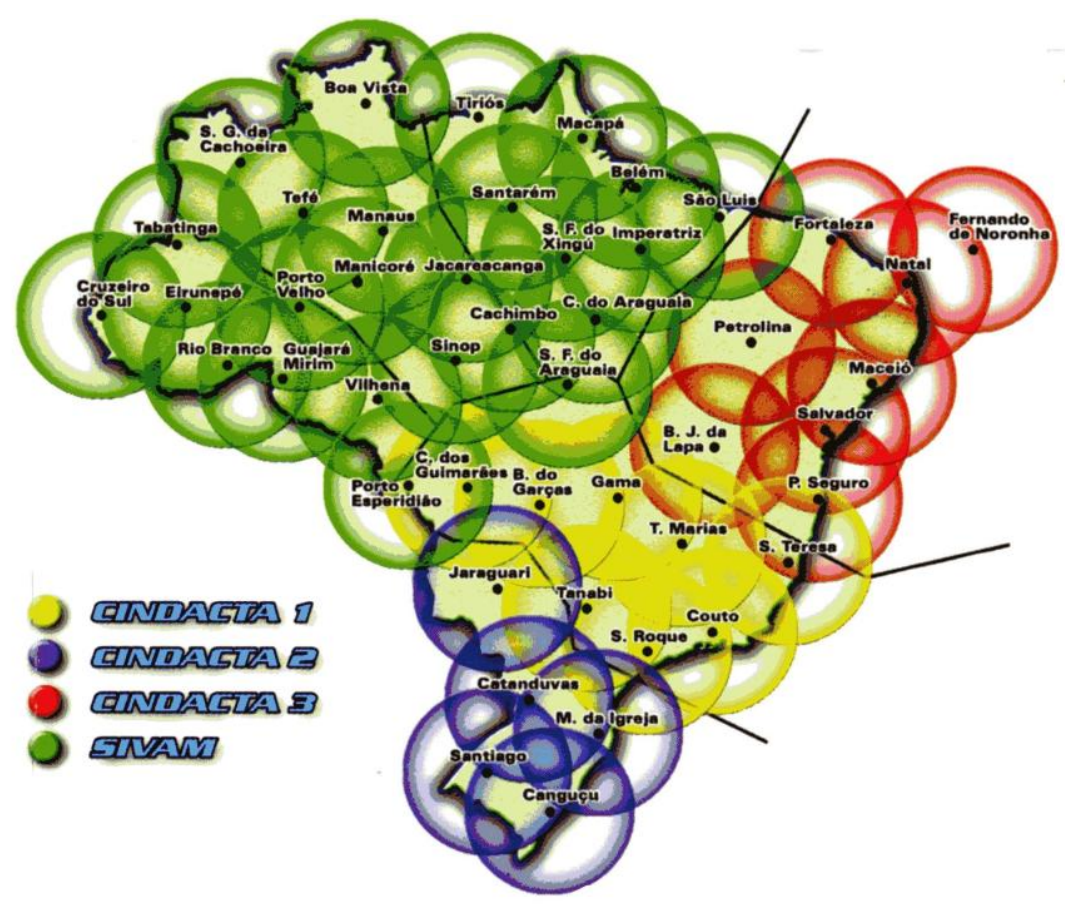

Figura 83 - Abrangência dos CINDACTAS (adaptado de DECEA (2005))

O serviço de controle de aproximação é aplicado aos vôos controlados que estão na transição de saída de um terminal, na saída de um terminal, na chegada a um terminal e na fase de aproximação (fases 4, 5, 7 e 8 do vôo, respectivamente - Figura 82). O órgão responsável por prestar o serviço de controle aproximação são os Controles de Aproximação (APP) que, conforme regulamentado pelo Ministério da Aeronáutica (1999), são subordinados aos ACCs responsáveis pelas FIRs nos quais estão contidos e terão jurisdição sobre áreas de controle terminal (TMA), sobre zonas de controle (CTR) e até sobre áreas de controle (CTAs), desde que delegadas a isto. No Brasil, o espaço aéreo possui os seguintes APPs: SP (São Paulo), RJ

\footnotetext{
${ }^{34}$ www.sivam.gov.br (último acesso: 15/03/2006).
} 
(Rio de Janeiro), BH (Belo Horizonte), CT (Curitiba), PA (Pará), BR (Brasília) e SV (Salvador) (DECEA, 2005).

O serviço de controle de aeródromo é aplicado aos vôos controlados que estão nas áreas de manobra de um aeródromo (superfície do aeroporto), na saída inicial (decolagem) e na aproximação final (pouso) (fases 2 e 10, 3 e 9 do vôo, respectivamente - Figura 82). O órgão responsável por prestar o serviço de controle aproximação são as Torres de Controle de Aeródromo (TWR), que possuem jurisdição sobre as zonas de tráfego de aeródromo (ATZs). No Brasil, nem todos os aeródromos são controlados e, consequentemente, não possuem TWR.

Em casos específicos, um órgão de controle de tráfego aéreo pode assumir a prestação de outros tipos de serviços de controle de tráfego aéreo. Por exemplo, um APP pode prestar serviço de controle de área, ou uma TWR pode prestar serviço de controle de aproximação. Porém, apenas um órgão pode ser responsável pelo controle de uma aeronave em vôo em um dado instante (Ministério da Aeronáutica, 1999), que está sujeita a autorização por parte deste órgão de controle competente, devendo se ater ao plano de vôo em vigor.

O uso do serviço de informação de vôo (FIS) e do serviço de controle de tráfego aéreo (ATC) está relacionado às características do espaço aéreo nos quais os vôos são executados. O FIS pode ser aplicado, e possui maior utilidade, nos vôos executados em ambientes de baixa complexidade de tráfego, promovendo o aumento do nível de consciência situacional dos pilotos e possibilitando que os vôos não controlados sejam executados de forma mais segura. Já o ATC é responsável pela segurança e pela eficiência dos vôos em regiões do espaço aéreo onde a complexidade do tráfego e as condições meteorológicas impeçam os pilotos de manterem, por si sós, a segurança e a eficiência dos vôos. Desta forma, pode-se notar que a parte aérea do ATM, em conjunto com os serviços de informação de vôo (FIS) e de controle de tráfego aéreo (ATC) - definidos pela OACI (ICAO, 1998b) -, compreendem os níveis funcionais de "condução da aeronave e navegação" e de "garantia da separação", definidos por Haraldsdottir (1997) e ilustrados, anteriormente, na Figura 79. Relacionando ambas as definições, verifica-se que o ATC está relacionado à funcionalidade de "garantia da separação", e o FIS está relacionado à funcionalidade de "condução da aeronave $e$ navegação", descritas anteriormente.

O ATC tem papel efetivo na execução do tráfego planejado, garantindo que as aeronaves 
mantenham distâncias seguras de separação em regiões do espaço aéreo com alta complexidade e densidade de tráfego. O controle dos vôos torna-se mais efetivo devido à elevação do grau de consciência situacional, comparado aos pilotos, o que aumenta o horizonte de tempo para atuação. Esta efetividade no controle do tráfego é proporcional ao desempenho dos elementos de vigilância (que afetam o grau de consciência do controlador sobre o estado do espaço aéreo) e de comunicação (que afetam o grau de interação entre as aeronaves controladas e os demais elementos do ambiente) do ATC, além do desempenho da navegação das aeronaves controladas. Desta forma, o desempenho dos elementos de comunicação, navegação, e vigilância, bem como de todo o serviço de tráfego aéreo (ATS), é um dos parâmetros que define a capacidade do sistema de tráfego aéreo e, consequentemente, de todo o sistema de transporte aéreo (ICAO, 1998). 


\section{APÊNDICE B - As Tecnologias atuais empregadas na Navegação Aérea}

Este APÊNDICE contém um estudo sobre as tecnologias atualmente empregadas na navegação aérea. Além de servir como base conceitual ao estudo dos Sistemas de Tráfego Aéreo, parte das informações aqui contidas será utilizada na modelagem do Sistema de Referência do Tráfego Aéreo.

\section{Sistema de Navegação Inercial}

A respeito de prover informações de posição, a obtenção da posição de uma aeronave depende, sobretudo, de referenciais. Os referenciais utilizados dependem do ambiente no qual irá trafegar a aeronave, das respectivas regras de vôo a serem seguidas (por instrumentos (IFR) ou visuais (VFR)) e da disponibilidade de recursos.

Considerando vôos IFR, uma das formas de se obter a posição de uma aeronave é por meio da Navegação Inercial. Este tipo de navegação baseia-se no princípio físico de que a distância percorrida pelo centro de massa de um corpo, sobre uma dimensão espacial “i” qualquer (considerando um espaço tridimensional) e durante o intervalo de tempo compreendido entre $t_{0}$ e $t_{1}\left(\Delta \mathrm{d}_{\mathrm{i}}\left(t_{0}, t_{1}\right)=\mathrm{p}_{\mathrm{i}}\left(t_{1}\right)-\mathrm{p}_{\mathrm{i}}\left(t_{0}\right)\right)$ pode ser obtida através da integração da velocidade instantânea deste centro de massa nesta mesma dimensão $\left(\mathrm{v}_{\mathrm{i}}(\mathrm{t})\right)$ e neste mesmo intervalo de tempo. Desta forma, $\Delta \mathrm{d}_{\mathrm{i}}\left(t_{0}, t_{1}\right)=\mathrm{p}_{\mathrm{i}}\left(t_{1}\right)-\mathrm{p}_{\mathrm{i}}\left(t_{0}\right)=\int\left(t_{0}, t_{1}\right) \mathrm{v}_{\mathrm{i}}(\varphi) \mathrm{d} \varphi$. Integrando-se a aceleração instantânea deste centro de massa nesta mesma dimensão $\left(a_{i}(\mathrm{t})\right)$ e neste mesmo intervalo de tempo, obtém-se a velocidade instantânea $\mathrm{v}_{\mathrm{i}}(t), \mathrm{t}>0$, deste centro de massa. Desta forma, $\mathrm{v}_{\mathrm{i}}(t)$ $=\mathrm{v}_{\mathrm{i}}\left(t_{0}\right)+\int\left(t_{0}, t\right) a_{\mathrm{i}}(\varphi) \mathrm{d} \varphi$.

Portanto, para estimar a posição (latitude e longitude) de uma aeronave em um instante $t$

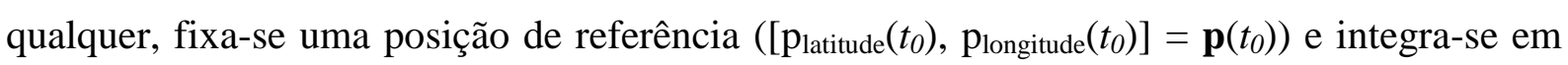
cascata, desde o instante $t_{0}$ (onde se fixou o referencial) até o instante $t$, a saída dos acelerômetros (medidores de aceleração instantânea) relativos a cada uma das dimensões consideradas. Desta forma, $\mathbf{p}(t)=\mathbf{p}\left(t_{0}\right)+\int\left(t_{0}, t\right) \mathbf{v}(\varphi) \mathrm{d} \varphi$, sendo $\mathbf{v}(t)=\left[\mathrm{v}_{\text {latitude }}(t), \mathrm{v}_{\text {longitude }}(t)\right]=$ $\mathbf{v}\left(t_{0}\right)+\int\left(t_{0}, t\right)\left[a_{\text {latitude }}(\mathrm{t}) \mathrm{dt}, a_{\text {longitude }}(\mathrm{t})\right] \mathrm{dt}$. A Figura 84 ilustra a implementação física de um navegador inercial para uma determinada dimensão "i”". 


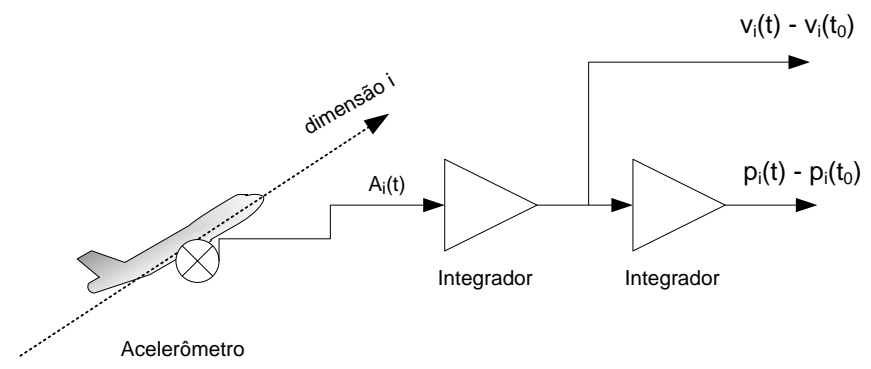

Figura 84 - Exemplo da navegação inercial em uma dimensão

A navegação inercial é denominada como "Navegação Autônoma", pois não depende de elementos externos à aeronave para determinar sua posição. Por isto, este tipo de navegação é utilizado em ambientes onde não existam outras referências disponíveis à navegação aérea, tal como em áreas oceânicas. Outra vantagem da navegação inercial é sua possibilidade em prover medidas de estado da aeronave, tais como a velocidade em relação ao solo (GroundSpeed), a distância percorrida e velocidade vertical. Devido à construção do sistema, que necessita manter os acelerômetros sempre com a mesma orientação, compensando o movimento da aeronave, é possível obter outras medidas de estado, tais como atitude e proa. Por causa desta multiplicidade de referências providas, a navegação inercial é também considerada como um Sistema de Referência Inercial (Inercial Reference System - IRS) (Aviation Theory Centre, 2000).

Em oposição às vantagens citadas, o sistema de referência inercial tem como maior desvantagem a degradação da acurácia sobre os valores de posição estimados proporcional ao intervalo de tempo de funcionamento desde sua última atualização de referencial $\left(\mathbf{p}\left(\boldsymbol{t}_{\boldsymbol{o}}\right)\right)$ (Galotti, 1997). Primeiramente, o valor de posição $\mathbf{p}(\boldsymbol{t})$ depende da correta estimação do valor $\mathbf{v}(t)$. Como $\mathbf{v}(t)$ é função de $\int\left(t_{0}, t\right) \mathbf{a}(\varphi) \mathbf{d} \varphi$, no caso dos acelerômetros não possuírem sensibilidade suficiente para mensurar pequenas variações no valor da aceleração, o valor estimado $\mathbf{v}(\boldsymbol{t})$ não contabilizará estas parcelas de aceleração ao longo do tempo de integração. Consequentemente, o valor de $\mathbf{p}(\boldsymbol{t})$ acumulará as perdas das parcelas da velocidade ao longo do tempo de integração, afetando sua acurácia. Pode-se considerar um erro na estimação da posição de até 2 milhas náuticas por hora de operação (Galotti, 1997), fazendo com que normas de operação, tal como a norma Australiana (CASA, 1999), limite em 10 horas o tempo máximo que uma aeronave pode navegar continuamente utilizando este tipo de navegação, por exemplo. 
Para solucionar a perda de acurácia ao longo do tempo, o sistema de navegação/referência inercial (INS/IRS) necessita reiniciar constantemente o processo de integração, atualizando o valor de referencial utilizado. Desta forma, o sistema de navegação aérea deve possuir outras maneiras de fornecer referenciais de posição, tanto para atualizar o valor de referencial do INS/IRS quanto como maneiras alternativas de navegação, pois além do problema de perda de acurácia em função do tempo, o INS/IRS é caro de se implementar devido ao nível de redundância e à estrutura de atualização complexa que necessita para seu funcionamento (Galotti, 1997). Assim, uma outra forma de se obter referenciais à navegação é através da Radionavegação. A radionavegação utiliza ondas eletromagnéticas na faixa da radiofrequiência para determinar posição, velocidade e outras variáveis úteis à navegação. Segundo Räisänen; Lehto (2003), os sistemas de radionavegação podem ser divididos em 2 grupos: os Sistemas Autônomos e os Sistemas de Estação-Base. O primeiro se baseia em efeitos de onda (tais como o Doppler), emitindo ondas eletromagnéticas a partir da aeronave, recebendo e processando-as como forma de estimar medidas de navegação (velocidade em relação ao solo e posição).

O segundo tipo de radionavegação, o de Estação-Base, baseia-se no princípio da Radiogoniometria, que é a técnica de medir direções e determinar posições utilizando ondas de rádios emitidas por um transmissor ou transmissores de posições conhecidas (Ministério da Aeronáutica, 2000). Por isto, os Sistemas de Estação-Base possuem estações-base (radioauxílios) que emitem ondas de rádio a partir de coordenadas conhecidas pelos navegadores. As ondas de rádio são recebidas por receptores instalados na aeronave, e sua posição é estimada ou através da obtenção da medida de distância entre um radioauxílio e aeronave, ou através da direção do radioauxílio em relação à aeronave ou através da diferença entre diversos radioauxílios e aeronave (radionavegação hiperbólica).

Atualmente, alguns radioauxílios são considerados como equipamentos básicos para navegação aérea, principalmente no espaço aéreo brasileiro (Ministério da Aeronáutica, 2005): o Radiofarol Não Direcional (Non Directional Beacon - NDB), o Radiofarol Direcional (VHF Ominidirecional Range - VOR), o Medidor de Distância ou "Equipamento Radiotelemétrico" (Distance Measure Equipment - DME), o Sistema de Pouso por Instrumentos (Instrument Landing System - ILS). 


\section{Radiofarol Não Direcional (NDB)}

O Radiofarol Não Direcional (Non Directional Beacon - NDB) consiste de radioauxílios em solo que transmitem por radiodifusão (transmissão não direcional) ondas de rádio em uma freqüência dentro das faixas: 190 a $415 \mathrm{KHz}, 510$ a $535 \mathrm{KHz}, 1705$ a $1800 \mathrm{KHz}$ e 1648 a $1708 \mathrm{KHz}$ (somente no Brasil). Um receptor a bordo da aeronave, utilizando antenas direcionais, capta a freqüência emitida pelo NDB e determina sua Marcação Relativa (MR), que é o ângulo formado entre a proa da aeronave e a direção do sinal recebido (ou seja, a direção de onde está localizado o NDB). Caso a aeronave possua um equipamento denominado ADF (Automatic Direction Finder), o mesmo utiliza os sinais do NDB para encontrar a Marcação Magnética (QDM), que é o ângulo formado entre a linha de Norte Magnético e a direção do sinal recebido (Ministério da Aeronáutica, 2000).

Utilizando um Radiofarol Não Direcional (NDB), além de ser possível encontrar a direção deste auxílio em relação à aeronave, o Norte Magnético (Nmg) e a Proa da Aeronave (Nmg MR), pode-se também estimar a própria posição da aeronave. Para isto, é necessário receber, no mínimo, o sinal de dois radioauxílios NDB. Dado os radioauxílios $\mathrm{NDB}_{1}$ e $\mathrm{NDB}_{2}$, com freqüências $f_{1}$ e $f_{2}$ e localizações $p_{1}$ e $p_{2}$ conhecidas, respectivamente, obtêm-se as Marcações Relativas $\mathrm{MR}_{1}$ e $\mathrm{MR}_{2}$. Matematicamente, em posse dos valores $\mathrm{p}_{1}, \mathrm{p}_{2}, \mathrm{MR}_{1}$ e $\mathrm{MR}_{2}$, constróise um triângulo com vértices em $\mathrm{NDB}_{1}, \mathrm{NDB}_{2}$ e na Aeronave, cujo segmento $\mathrm{NDB}_{1} \mathrm{NDB}_{2}$ tem tamanho igual a $\left|\mathrm{p}_{1}-\mathrm{p}_{2}\right|$ e cujo ângulo do vértice "Aeronave" é $\mathrm{MR}_{1}+\mathrm{MR}_{2}$. Com estas informações, pode-se estimar a distância entre a Aeronave um dos NDBs e, conhecido sua direção, encontra-se a posição da aeronave. Uma forma de estimar graficamente a posição da aeronave é, obtidas as marcações magnéticas para $\mathrm{NDB}_{1}$ e $\mathrm{NDB}_{2}\left(\mathrm{QDM}_{1}\right.$ e $\mathrm{QDM}_{2}$, respectivamente), traçar sobre as indicações dos NDBs na carta aeronáutica linhas com os ângulos $\mathrm{QDM}_{1}$ e $\mathrm{QDM}_{2}$. O ponto de encontro destas linhas será a estimativa de posição da aeronave neste determinado momento. Este método está ilustrado na Figura 85.

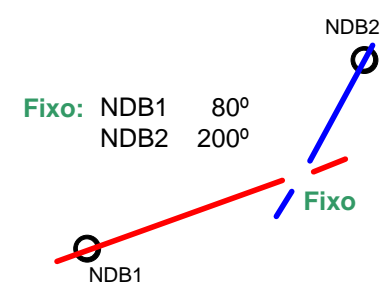

Figura 85 - Método gráfico para estimar posição de um fixo através de NDBs 
O alcance de um Radiofarol Não Direcional (NDB) é da ordem de 270 km para potências de transmissão de aproximadamente $1 \mathrm{KW}$. Mesmo possuindo uma boa área de cobertura, o sinal recebido do NBD pode não ser confiável. Devido à faixa de freqüências em que atua, a propagação do sinal emitido pelo NDB pode sofrer mudanças de direção devido a diversos fatores, tais como o efeito noturno, de linha de costa e perturbações atmosféricas (Ministério da Aeronáutica, 2000).

\section{Radiofarol Direcional (VOR)}

Em face dos problemas de propagação mencionados anteriormente, o Radiofarol Direcional (VHF Ominidirecional Range - VOR) substitui o NDB com vantagens, pois opera na faixa de freqüências muito altas (VHF) entre $108 \mathrm{MHz}$ e $117.9 \mathrm{MHz}$. Ondas eletromagnéticas na faixa do VHF têm a propriedade de se propagar em linha de visada (linha reta), não acompanhando a curvatura da Terra, além de serem mais imunes às perturbações atmosféricas.

Diferentemente do NDB, que trabalha com os conceitos de marcação relativa (MR) e marcação magnética, o VOR trabalha com o conceito de Radial, que é a direção magnética partindo de um radioauxílio VOR. De forma geral, cada valor de radial é codificado pela diferença de fase entre dois sinais produzidos pelo transmissor VOR: um sinal modulado em AM e transmitido por radiodifusão (não direcional) e outro sinal modulado em FM e transmitido por uma antena direcional rotativa, com frequiência de rotação de $30 \mathrm{~Hz}$. Quando o receptor de VOR a bordo da aeronave recebe estes sinais, o mesmo extrai esta diferença de fase e identifica qual foi a radial recebida, entre $0^{\circ}$ e $360^{\circ}$, onde a radial $0^{\circ}$ indica o norte magnético (Räisänen; Lehto (2003).

Devido o VOR irradiar em linha de visada, o alcance deste radioauxílio é menor que o alcance do NDB. Sua cobertura é função da altitude em que se encontra o receptor. Um radioauxílio VOR tem alcance de até 39 milhas náuticas para receptores 1000 pés acima de sua antena, e cobertura de até 270 milhas náuticas para receptores 10000 pés acima de sua antena (Ministério da Aeronáutica, 2000). Uma vantagem do VOR em relação ao NDB é sua maior acurácia na obtenção de informações de direção. Para o NDB, toleram-se oscilações de até $\pm 5^{\circ}$ do ponteiro do ADF (navegação por NDB) (Ministério da Aeronáutica, 2005), desde que esta oscilação não exceda 8 segundos. Já com relação ao VOR, tolera-se um desalinhamento máximo de $\mathbf{\pm 2 , 5 ^ { \circ }} \mathbf{a} \mathbf{\pm 3 , 5 ^ { \circ }}$ (dependendo da aplicação do VOR) entre as radiais do transmissor e 
o azimute magnético correto (Ministério da Aeronáutica, 2002), e uma acurácia máxima de

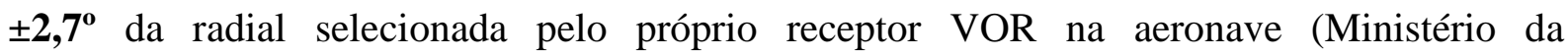
Aeronáutica, 2005).

\section{Equipamento Medidor de Distância (DME)}

Tanto NDB e VOR obtêm a direção do radioauxílio em relação à aeronave. Para estimar a posição de uma aeronave utilizando estes auxílios, é necessário receber o sinal, ao mesmo tempo, de pelo menos dois radioauxílios e calcular a posição com base em medidas angulares. Para que não seja necessário receber sinais de mais de um radioauxílio ao mesmo tempo e efetuar cálculos para estimar a posição de uma aeronave, utiliza-se em conjunto com um VOR (ou, em menor escala, com um NDB) um Equipamento Medidor de Distância (Distance Measure Equipment - DME). O DME é composto por uma estação-base, chamada Transponder, e um equipamento a bordo da aeronave chamado Interrogador. O Interrogador emite pares de pulsos, modulados por frequiências entre $960 \mathrm{MHz}$ e $1250 \mathrm{MHz}$, que são recebidos pelo Transponder e respondidos ao Interrogador através de outro par de pulsos, com frequiências diferentes das recebidas e atrasados em $50 \mu \mathrm{s}$. A distância em linha reta entre Interrogador e Transponder (conhecida como Distância Inclinada, pois ambos não estão na mesma altitude) é eletronicamente calculada verificando-se o tempo decorrido entre envio/recebimento do pulso. O princípio de operação do DME é ilustrado na Figura 86 (adaptado de Räisänen; Lehto (2003)).

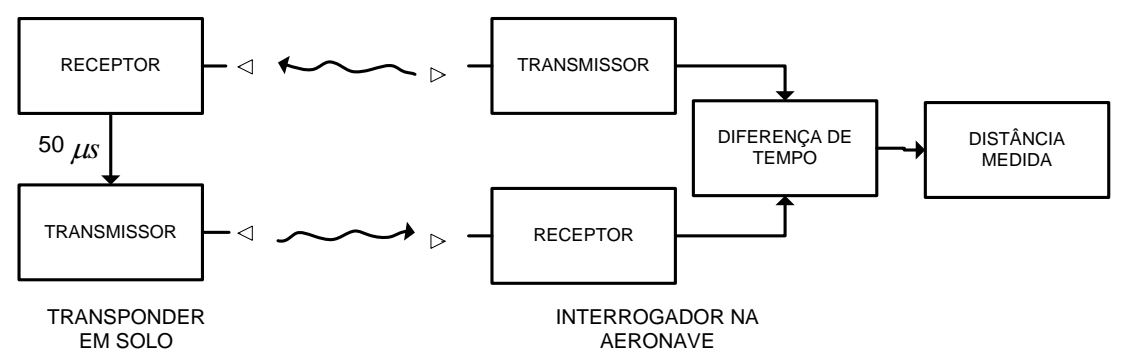

Figura 86 - Princípio de operação do DME

Desta forma, a posição de uma aeronave é obtida através das informações da direção fornecida pelo radioauxílio VOR ou NDB vinculado ao DME, da posição do radioauxílio (ilustrado nas cartas aeronáuticas) e da distância horizontal entre aeronave e DME, que é a distância inclinada calculada pelo DME corrigida para o plano. O cálculo da distância horizontal (d) pode ser feito através da fórmula $\mathrm{d}^{2}=\mathrm{D}^{2}-(\mathrm{H}-\mathrm{h})^{2}$, onde $\mathrm{D}$ é o valor de 
distância inclinada calculada pelo DME, H é a altitude da aeronave e h é a altitude da antena do radioauxílio DME (Ministério da Aeronáutica, 2000). A acurácia da distância obtida através de DME é de $\mathbf{\pm 0 , 2}$ milhas náuticas (NM), ou $\mathbf{\pm 4 \%}$ nos casos de recepção de sinais com potências próximas ao limiar do receptor. Um Interrogador DME deve ser capaz de obter uma medida confiável até 196 NM distante de um Transponder (Ministério da Aeronáutica, 2005).

O Ministério da Aeronáutica (1999b) classifica os equipamentos radiogoniométricos em 4 grupos distintos, de $\mathrm{A}$ à $\mathrm{D}$, segundo suas acurácias na obtenção de informação de marcação e de posição. Para as Marcações (em resumo, direções), os equipamentos de Classe A, B, C e D possuem, respectivamente, acurácia de $\pm 2^{\circ}, \pm 5^{\circ}, \pm 10^{\circ}$ e menor do que $\pm 10^{\circ}$. Para as Posições, os equipamentos de Classe A, B, C e D possuem, respectivamente, acurácia de 5 milhas náuticas (NM), 20NM, 50NM e menor do que 50NM.

\section{Auxílios Visuais e Pouso por Instrumentos (ILS)}

Tanto VOR quando NDB são utilizados para balizar aerovias (Rotas ATS para vôos controlados), e os VOR são normalmente vinculados aos DME, formando o radioauxílio VOR/DME (Ministério da Aeronáutica, 2000). Estes auxílios são obrigatórios em procedimentos de navegação aérea para vôos IFR nas fases de "transição de saída", "saída", "em rota", "chegada ao terminal" e "aproximação", tais como ilustradas na Figura 82. As fases de vôo "superfície de aeroporto", "saída inicial” e "aproximação final” utilizam, sobretudo, referências de navegação visuais, pois ocorrem com velocidades e em áreas de abrangência menores. Nestes casos, Auxílios Visuais tais como o VASIS (sistema indicador de trajetória de aproximação visual), o PAPI (indicador de trajetória de aproximação de precisão), o ALS (luzes de aproximação) e o SFL (sistema de flashes) são empregados com eficiência em condições meteorológicas visuais (VMC). Porém, é necessário que em determinadas condições de visibilidade seja possível fazer pousos com o auxílio de instrumentação.

O Sistema de Pouso por Instrumentos (Instrument Landing System - ILS) cumpre esta missão balizando a cabeceira de pistas de pouso em aeroportos e provendo informações de alinhamento lateral (através de seu Localizer), condução vertical (através de seu Glide Slope) e distância até a cabeceira da pista de pouso (através de seu Marker). A Figura 87 ilustra os componente do ILS em relação à pista de pouso (adaptado de Räisänen; Lehto (2003)). 


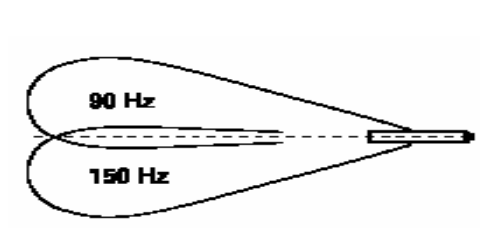

(a)

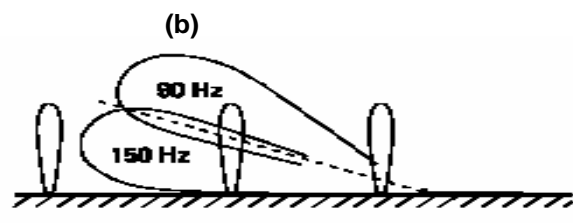

(c) (c) (c)

Figura 87 - Componentes do ILS: Localizer (a), Glide Slope (b) e Markers (c)

\section{O Sistema de Navegação Global por Satélites (GNSS)}

Da forma como são implementados e utilizados, os auxílios à navegação mencionados anteriormente possibilitam que o operador da aeronave estime sua posição, direção e distância dos pontos de passagem (waypoints) que deverão ser cumpridos. Em áreas territoriais cobertas por meio dos radioauxílios citados, é possível fazer estimativas de posição e direção com maior acurácia. Porém, devido à propagação de linha de visada, o alcance destes auxílios é pequeno, necessitando-se de uma grande quantidade de estações-base para cobrir grandes áreas. Já em áreas desprovidas destes auxílios, seja em regiões oceânicas ou em áreas de difícil acesso, a navegação inercial é uma solução, mas a acurácia das estimativas de posição degrada-se cumulativamente entre atualizações do referencial.

Uma alternativa à navegação inercial para vôos de longo alcance sobre regiões desprovidas de VOR/DME e NDB é um sistema chamado Loran-C. Este sistema se baseia nos princípios de Radiogoniometria, e é implementado por meio de estações-base distantes umas das outras em aproximadamente $1000 \mathrm{~km}$. Como os sinais emitidos se propagam até $2000 \mathrm{~km}$, é possível estimar uma posição recebendo o sinal de mais de 2 estações (navegação hiperbólica). Porém, a acurácia das estimativas é pequena e pouco confiável, pois o sinal sofre muitos distúrbios em sua propagação (Räisänen; Lehto, 2003).

Outra alternativa à navegação inercial e ao Loran-C é Navegação Global por Satélites (ou Global Navigation Satellite System - GNSS). Assim como o radiofarol direcional (VOR), o radiofarol não direcional (NDB) e o Loran-C, a navegação por satélite é também um sistema de radionavegação que se baseia no princípio da Radiogoniometria (Sistema de EstaçõesBase). Porém, diferentemente dos demais tipos de radionavegação citados, os radioauxílios da navegação por satélites são, como o próprio nome diz, satélites artificiais presentes na órbita da Terra. Desta forma, grandes áreas da superfície da Terra podem ser cobertas com o uso de poucos satélites, e uma aeronave que possua receptores para os sinais emitidos por estes satélites pode utilizá-los como referenciais de navegação e, assim, estimar sua própria 
posição, independentemente se esta aeronave está navegando ou não sobre áreas providas por outros auxílios à navegação.

Atualmente, existem em funcionamento dois sistemas de navegação por satélites: o Global Positioning System (GPS) e o Global Navigation Satellite System (GLONASS). O GPS é mantido pelo departamento de defesa Norte Americano, e o GLONASS é de propriedade Russa. Um terceiro sistema de navegação por satélites, de propriedade da Comunidade Européia e denominado "Galileo", está em processo de implementação e possui previsão para estar com sua capacidade máxima de operação em $2008^{35}$.

Dos sistemas de navegação por satélites existentes, o GPS é único que está, atualmente, em plena operacionalidade (Chujo, 2005), sendo utilizado em diversas aplicações, tais como na navegação em sistemas de transporte, na agricultura de precisão e até no levantamento topográfico em construção civil (El-Habbany, 2002). O sistema GPS é composto de 3 elementos funcionais: o Espaço, o Controle e o Usuário, conforme ilustrado na Figura 88 (adaptado de El-Habbany (2002)).

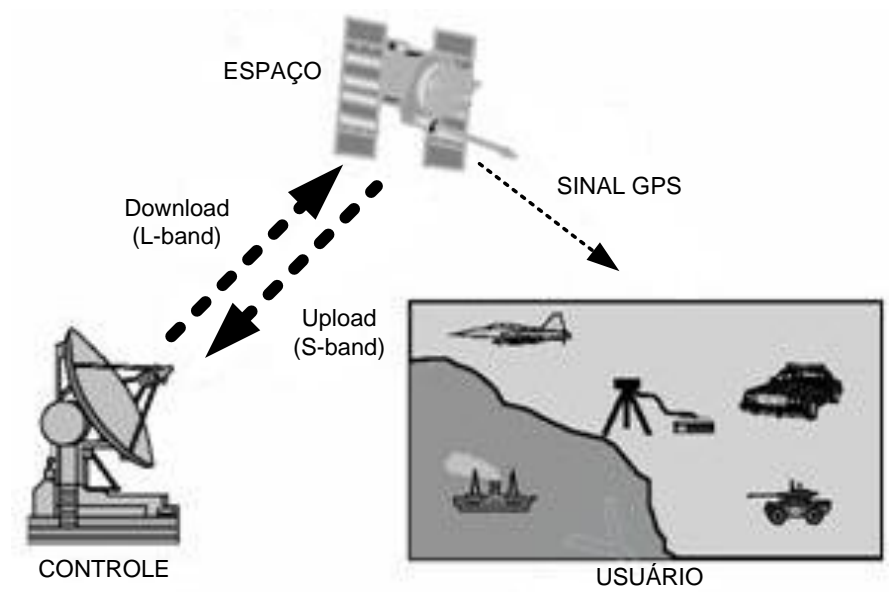

Figura 88 - Elementos do Sistema GPS

O elemento funcional "Espaço" possui uma constelação de 24 satélites, distribuídos em 6 planos orbitais circulares com 4 satélites cada e onde cada órbita está, aproximadamente, a $11.000 \mathrm{NM}$ da Terra (Figura 89a). Devido à geometria das órbitas, pelo menos 4 satélites estão em linha de visada em qualquer ponto da superfície terrestre. Cada satélite emite um sinal contendo (El-Habbany, 2002):

\footnotetext{
${ }^{35}$ European Space Agency (ESA): ESA Navigation - www.esa.int/esaNA/. Último acesso: Fevereiro de 2006.
} 
- duas portadoras (L1 e L2), com freqüências $1.575,42 \mathrm{MHz}$ e $1.227,60 \mathrm{MHz}$, respectivamente,

- dois códigos binários pseudo-aleatórios (P, de Precion, e C/A, de Coarse/Aquisition), onde $\mathrm{P}$ e C/A modulam a portadora L1 e apenas $\mathrm{P}$ modula a portadora L2, transmitidos a taxas de 10,23Mbps e 1,023Mbps, respectivamente, e

- uma mensagem de navegação de 37.500 bits, denominada Almanaque, contendo informações de suas coordenadas em função do tempo, informações de sua integridade, valores de correção do seu relógio, condições da atmosfera, etc, além de informações de navegação dos demais satélites, transmitida a uma taxa de 50bps (o que corresponde a 1 mensagem completa a cada 750 segundos).

O recebimento deste sinal e o prévio conhecimento dos códigos $\mathrm{P}$ e C/A permitem ao usuário conhecer as coordenadas dos satélites (por meio da mensagem de navegação) e a distância entre cada satélite e o receptor, podendo estimar, com acurácia significativa, a própria posição do receptor. É necessário, no mínimo, receber sinais de 3 satélites para estimar uma posição bidimensional (2D) (latitude e longitude) e 4 satélites para estimar uma posição tridimensional (3D) (latitude, longitude e altitude) (IFI, 2005). A Figura 89b ilustra o recebimento de sinais provindos de 4 satélites da constelação GPS.

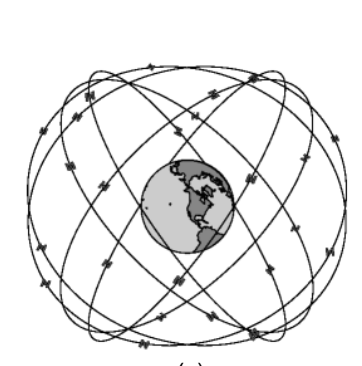

(a)

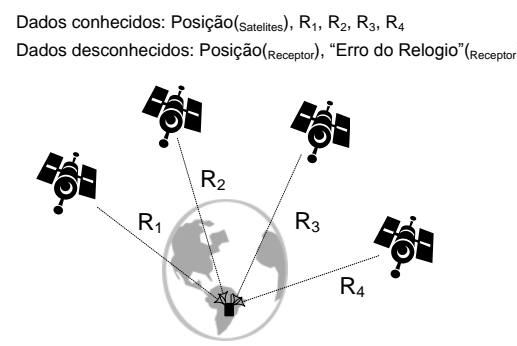

(b)

Figura 89 - Constelação GPS (a) e determinação de posição baseado na constelação GPS (b)

O elemento funcional "Controle" é constituído por uma rede de 5 estações de monitoramento espalhadas pelo planeta, coordenadas por uma Estação de Controle Mestre (Master Control Station - MCS) locada nos Estados Unidos. Cada estação possui um receptor GPS de boa acurácia e um relógio atômico (Césio). Todas as estações têm a função de rastrear a constelação GPS para determinar e predizer suas localizações, integridades, comportamento dos relógios presentes nos satélites, dados atmosféricos, entre outros. Estas informações são, 
então, retransmitidas aos satélites de forma a garantir a acurácia de suas posições e seus respectivos sincronismos.

O elemento funcional "Usuário" é qualquer indivíduo que possua um receptor GPS conectado a uma antena GPS e que, ao receber os sinais dos satélites da constelação GPS, é capaz de determinar sua posição e o tempo, além de obter estimativas de sua velocidade.

O sistema GPS oferece 2 níveis de serviço de posicionamento e temporização: o Serviço de Posicionamento de Precisão (PPS) e o Serviço de Posicionamento Padrão (SPS) (El-Habbany, 2002). O PPS utiliza ambos os códigos pseudo-aleatórios (P e C/A) para estimar posição, provendo maior nível de acurácia do que o SPS, pois este último utiliza apenas o código C/A. Como o código P é de conhecimento das forças armadas Norte-Americanas, o uso civil do sistema GPS baseia-se apenas no serviço de posicionamento padrão (SPS).

A acurácia do sistema GPS é proporcional, grosso modo, a homogeneidade da distribuição dos satélites em órbita (medida denominada como "Diluição da Precisão" (DOP)) e à acurácia com que se obtém a medida de distância entre satélites e usuário (Brooker, 2004). Estas 2 medidas são monitoradas pelo elemento de Controle do sistema GPS, seja de forma direta (tal como pela determinação da localização dos satélites da constelação GPS e a conseqüente obtenção da medida de Diluição da Precisão) ou indireta, tal como pela obtenção das condições atmosféricas, desvios na temporizarão dos relógios dos satélites e outras variáveis que influenciam a acurácia da medida de distância entre satélites e usuário. Devido o sistema GPS ser capaz de intervir sobre algumas características de seu funcionamento e, consequentemente, garantir um padrão mínimo de desempenho, seu operador (o Departamento de Defesa (DoD) dos EUA) definiu padrões de desempenho que devem ser estabelecidos.

Com relação à acurácia da posição obtida pelo sistema GPS para o nível de Serviço de Posicionamento Padrão (SPS), o DoD definiu um erro médio horizontal (latitude e longitude), no domínio global de posicionamento, menor ou igual a $13 \mathrm{~m} @ \mathbf{9 5 \%}{ }^{36}$, e um erro médio vertical (altitude), também no domínio global de posicionamento, menor ou igual a 22m@95\% (Brooker, 2004). No pior caso, o erro médio horizontal deve ser menor ou igual a 36m@95\% e um erro médio vertical deve ser menor ou igual a 77m@95\%.

\footnotetext{
${ }^{36}$ Significa que, em média, deve-se manter um erro menor ou igual a 13 metros em $95 \%$ do tempo.
} 
As precisões padronizadas para o posicionamento são obtidas por meio de medidas de monitoramento do sistema GPS, que consideram o comportamento ideal do seu sinal no espaço. Desta forma, a acurácia padronizada não representa todas as fontes principais de erros vistas pelos usuários do sistema, subestimando os erros de posicionamento. As fontes principais de erros para o posicionamento GPS estão relacionadas aos efeitos da ionosfera e à propagação do sinal GPS, tais como efeitos troposféricos e ionosféricos, ruído no receptor e multipercurso. Um estudo da Força Aérea Americana que considerou a afetação destes efeitos sobre os erros de posicionamento do sistema GPS determinou que, para o pior caso possível (máxima atividade Solar), o erro de posição horizontal segue uma distribuição de Rayleigh com parâmetro $\boldsymbol{\beta}=\mathbf{4 4 , 1}$ (Brooker, 2004), o que corresponde a um erro horizontal de 107,94m@95\% ${ }^{37}$, o que equivale a 86,44m@95\% para cada dimensão (latitude e longitude).

Devido à arquitetura do sistema GPS, onde o Elemento de Controle de Solo não pode monitorar a funcionalidade de toda a constelação de satélites simultaneamente (cada satélite é monitorado por apenas $92 \%$ do tempo (Ochieng et al, 2003)), existem limitações em alertar os usuários sobre possíveis degradações em seu funcionamento. Por exemplo, uma falha em um satélite pode ficar sem detecção (pelo elemento de solo) por mais de 2 horas (Brooker, 2004) e, durante este período, os usuários poderiam receber, sem que sejam comunicados, dados de posição com acurácia menor do que a especificada. Desta forma, o nível de confiança com o qual os usuários utilizam as informações provindas do sistema, também denominado Integridade (Galotti, 1997), deve ser garantido por meio de mecanismos de monitoramento da acurácia, alertando os usuários, em tempo hábil, no caso da acurácia do sistema ser menor do que a especificada para uma determinada fase de vôo.

Os métodos de monitoramento de integridade relevantes à navegação aérea estão baseados em confrontar medidas de posição "conhecidas" com as posições obtidas por meio do GNSS e verificar se os erros excederam limites pré-estabelecidos (Ochieng et al, 2003). O próprio monitoramento realizado pelo sistema GPS possui esta funcionalidade, identificando erros nos segmentos de controle e espaço, tais como falhas nos satélites. Porém, este monitoramento não é capaz de detectar problemas locais aos seus usuários, principalmente os problemas relacionados aos efeitos de propagação dos sinais.

\footnotetext{
${ }^{37}$ Distribuição de Probabilidade de Rayleigh acumulada: $\mathrm{P}(\mathrm{x} \leq \mathrm{X})=1-\exp \left(-\mathrm{X}^{2} / 2 . \beta^{2}\right) \leftrightarrow \mathrm{P}(\mathrm{x} \leq \mathrm{X})=0,95 \rightarrow$ $X=\left(-2 \cdot \ln (0,05) \cdot \beta^{2}\right)^{1 / 2}=\left(-2 \cdot \ln (0,05) \cdot 44,1^{2}\right)^{1 / 2}=107,94 m$
} 
Desta forma, outros métodos devem ser aplicados na garantia da integridade do sistema GNSS (GPS), tais como os métodos de monitoramento autônomo, que independem do sistema de monitoramento de integridade (de solo) do próprio GNSS. Um destes métodos se baseia no uso de um Receptor de Monitoramento de Integridade Autônomo, a bordo da aeronave, conhecido como RAIM (Receiver Autonomous Integrity Monitoring). O RAIM, fazendo uso dos sinais GPS (tais como medidas de geometria da constelação de satélites), tem a função de determinar os erros de posição obtidos, confrontá-los com os limites aceitáveis para uma determinada fase de vôo e alarmar o usuário no caso desta condição de degradação ocorrer (Ochieng et al, 2003). Devido o RAIM utilizar os sinais GPS, existem requisitos para que sua funcionalidade seja executada de forma aceitável. Portanto, para que o RAIM esteja disponível para detectar uma perda da integridade, identificando o satélite defeituoso, o receptor deve receber o sinal de, no mínimo, 5 satélites da constelação GPS (IFI, 2005). Já para detectar o satélite defeituoso e desconsiderar seu sinal na obtenção de posição GPS, o RAIM deve receber, no mínimo, sinais de 6 satélites. Outra forma de aumentar o poder de monitoramento da integridade do RAIM é fazer uso de informações de instrumentação a bordo da Aeronave, tais como altitude barométrica, transformando o RAIM em AAIM (Aircraft Autonomous Integrity Monitoring).

A integridade do sistema de navegação GNSS (GPS) é definida por 3 características: o Limite de Alerta, que é o erro máximo aceito para o valor de posição horizontal obtido pelo sistema GPS; o Tempo de Alerta, que é o tempo máximo entre o RAIM detectar uma perda de acurácia acima do aceitável e alertar o usuário; a Probabilidade Mínima de Detecção, que é o complemento da máxima probabilidade do sistema de monitoramento não detectar uma degradação existente (Brooker, 2004). A probabilidade mínima de detecção está relacionada ao conceito de Risco de Integridade, que é a probabilidade do erro de posição exceder o limite de alerta e não ser detectado, o que faz com que Probabilidade Mínima de Detecção = "1 Risco de Integridade”. Em resumo, a perda da integridade ocorre quando o erro na posição horizontal obtido pelo sistema GPS excede o Limite de Alerta e não é detectado, ou quando o mesmo é detectado e o alarme é recebido pelo usuário em tempo maior que o Tempo de Alerta, dado a fase do vôo no qual uma aeronave está operando (OCHIENG et al, 2003).

A integridade do sistema GPS é especificada em função da fase do vôo, e o documento TSOC129a, "Airbone Supplemental Navigation Equipment Using the Global Positioning System" (Brooker, 2004) define os seguintes valores de Limite de Alerta, Tempo de Alerta e Probabilidade Mínima de Detecção, respectivamente: 2,0 NM, 30 segundos e 0,999 para 
vôos em rota; 1,0 NM, 10 segundos e $\mathbf{0 , 9 9 9}$ para vôos em terminal (dentro de um raio de 30 NM da origem ou destino do vôo).

Além da Acurácia e da Integridade no posicionamento e na temporização, características mínimas de Continuidade e Disponibilidade também são padronizadas pelo operador do sistema GPS. Continuidade é a capacidade do sistema em realizar sua função, sem interrupções não programadas, durante o período planejado para uma operação (Ochieng et al, 2003) ou, segundo Ober et al (1999), continuidade é a capacidade do sistema em prover acurácia e integridade durante uma operação; Disponibilidade é a probabilidade do sistema em realizar sua função no início de uma operação (Galotti, 1997) ou, de outra forma, é a porcentagem de tempo no qual o sistema oferece serviço confiável, atendendo os requisitos de Acurácia, Integridade e Continuidade (Ochieng et al, 2003).

Segundo Ober et al (1999), o documento TSO-C129 não utiliza o conceito de continuidade, e sim o conceito de Taxa de Alarme, definido como o número máximo de alarmes aceitável, por período (hora de vôo, por exemplo), estando o equipamento RAIM em operação normal e com todos os satélites funcionais. A taxa de alarme desconsidera os momentos nos qual o RAIM não está disponível (Brooker, 2004).

Com relação à Continuidade do Serviço de Posicionamento Padrão (SPS), o mesmo deve ser maior ou igual a $\mathbf{9 9 . 7 9 \%}$ para o pior caso de operação, considerando erros menores que 30 metros e 3 falhas de serviço por ano, com 6 horas de duração cada (Brooker, 2004). Com relação à Disponibilidade do SPS, o mesmo deve ser maior ou igual a $90 \%$ para o pior caso de operação (onde a acurácia possui erro médio horizontal de 36m@95\% e erro médio vertical de 77m@95\%) (Brooker, 2004).

A navegação por satélites proporciona inúmeros benefícios, tais como a cobertura de vastas áreas com o uso de uma infra-estrutura reduzida (comparada aos outros métodos de radionavegação), a maior acurácia devido à possibilidade de frequiências mais altas e a navegação em 3 dimensões (Räisänen, Lehto, 2003). Porém, este tipo de navegação não atende, ao mesmo tempo, os requisitos de acurácia, integridade, disponibilidade e continuidade, exigidos para a aviação civil (El-Habbany, 2002). Por isto, considera-se o GPS apenas como um sistema suplementar à navegação aérea (DECEA, 1999). Um sistema suplementar de navegação aérea deve satisfazer aos requisitos de acurácia e de integridade para tal operação ou fase de vôo, não sendo necessário satisfazer aos requisitos de 
disponibilidade e de continuidade (Ministério da Aeronáutica, 2005).

Outro problema em se utilizar o GPS, principalmente no Brasil, está relacionado à diferença entre o datum $^{38}$ adotado nas cartas aeronáuticas (SAD-69, não geocêntrico) e o datum adotado pelo sistema GPS (WGS-84, geocêntrico). Como consequiência desta diferença de datuns, algumas coordenadas representadas em cartas aeronáuticas (tais como posições de aeroportos, de radioauxílios e de fixos de posição), que são definidas com base no datum SAD-69, estão deslocadas em até 74 metros (no caso do aeroporto de Guarulhos) quando localizados através do sistema GPS (Ministério da Aeronáutica, 2000). A diferença de datuns não é importante quando se navega com base em Radioauxílios, mas pode inviabilizar aproximações de precisão, por exemplo.

\section{Sistemas de Aumentação Satelital}

Sistema de Aumentação (Augmentation Systems) são utilizados em ambientes onde se necessita garantir tanto os requisitos de integridade do sistema GPS, detectando anormalidades, quanto para prover acréscimo na acurácia dos dados de posição. Os sistemas de aumentação baseiam-se no princípio do posicionamento relativo, onde 2 receptores GPS, distantes um do outro, recebem os sinais dos mesmos satélites. Um destes receptores, posicionado em coordenadas conhecidas e denominado como base, é utilizado como uma referência adicional ao outro receptor, posicionado sobre a coordenada a estimar. A base estima sua posição através do GPS, determina qual a diferença entre a posição real (conhecida) e a estimada, calcula a correção que deve ser considerada para compensar os erros existentes e informa-a ao outro receptor GPS (El-Habbany, 2002). Esta técnica de estimar uma posição GPS por meio de diferenças entre posições é também conhecida como GPS Diferencial (ou, do inglês, DGPS). Um sistema de aumentação, ou de DGPS, pode ser definido como um "Sistema de Aumentação baseado em Solo", ou GBAS (Ground-based Augmentation System) ou um "Sistema de Aumentação baseado em Satélite", ou SBAS (Satellite-based Augmentation System), cujos receptores-Base estão em solo ou em Satélite, respectivamente.

38 Datum: é um sistema de coordenadas geográficas e sua superfície matemática correspondente (elipsóide) (Ministério da Aeronáutica, 2000). Em outras palavras, é um elipsóide de revolução centrado em alguma referência (caso seja o centro de massa da Terra, é um datum geocêntrico) e que representam coordenadas na superfície da Terra (El-Habbany, 2002) 


\section{Instrumentação à Bordo e Aeronavegabilidade}

Até este ponto, ilustraram-se métodos que auxiliam os pilotos a estimar suas posições. Além disto, o operador deve ser capaz de conduzir sua aeronave mantendo tanto a proa em direção ao fixo desejado quanto o nível de vôo e a velocidade planejada e/ou comandada pelo controlador de tráfego aéreo. Atualmente, o piloto pode ser auxiliado pela automação presente na aeronave para gerenciar seu plano de vôo e para atuar e manter um perfil de vôo fixo (direção, velocidade e altitude). Com relação ao cumprimento de um plano de vôo, uma aeronave pode ser equipada com um Computador de Gerenciamento de Vôo (Fligth Management Computer - FMC). Através da Unidade Monitora de Controle (ou Control Display Unit - CDU), o piloto programa o plano de vôo desejado (trajetória) no FMC que, com base em um banco de dados local, sabe qual o posicionamento dos fixos que deverá cumprir. Através das informações de navegação disponíveis, o FMC obtém a direção para os fixos de posição e determina qual proa deverá ser tomada pela aeronave para que cumpra a trajetória planejada, retornando estas informações ao CDU (Aviation Theory Centre, 2000).

Após o FMC determinar qual proa a aeronave deverá tomar, o operador atua sobre sua superfície de controle (atuadores) de forma a levá-la ao estado desejado, e monitora seu estado de forma a manter a aeronave na proa, velocidade e nível de vôo planejado. Neste processo, o piloto tanto pode atuar diretamente sobre a superfície de controle da aeronave, utilizando os comandos manuais e orientando-se através dos indicadores de estado atual da aeronave (painel de instrumentação), quanto pode se utilizar do Piloto Automático, caso o mesmo esteja disponível na aeronave. Através do Painel de Modo de Controle (ou Mode Control Panel - MCP), o piloto configura o estado que sua aeronave deve manter (proa, velocidade e altitude) e, através do monitoramento automático do estado da aeronave, o Piloto Automático mantém o estado configurado, atuando sobre sua superfície de controle. Caso o Computador de Gerenciamento de Vôo (FMC) esteja atuante, este fornece a configuração de estado desejada ao Piloto Automático e o mesmo se encarrega de controlar e monitorar a aeronave.

A obtenção do estado para monitoramento de uma aeronave depende do nível de instrumentação embarcada na mesma. As variáveis de estado obtidas por uma instrumentação de vôo básica são sua atitude, proa, velocidade do ar (Indicated AirSpeed - IAS), altitude e velocidade vertical (Aviation Theory Centre, 2000). IAS, Velocidade Vertical e Altitude são obtidas através de medidas de pressão atmosférica e de temperatura. Para a IAS, obtém-se a 
pressão do ar na região frontal da aeronave (que se eleva com a elevação da velocidade da aeronave), e uma medida estática da pressão atmosférica ao redor da mesma. A IAS é a diferença entre ambas as medidas de pressão (em nós [kts] ou em quilômetros por hora $[\mathrm{km} / \mathrm{h}]$ ) e apresentada ao operador da aeronave. Como a pressão atmosférica se reduz em função da altitude, a indicação de velocidade do ar não é precisa em níveis de vôo elevados, pois exige uma boa sensibilidade por parte do instrumento. Além disso, necessita-se considerar a densidade e o efeito do ar sobre a estrutura da aeronave para determinar-se a velocidade real da aeronave com relação à massa de ar ao seu redor. Esta velocidade é conhecida como Velocidade do Ar Real (ou TrueAirspeed - TAS), e é baseada na IAS, na relação entre a densidade do ar na altitude em que se encontra a aeronave e a densidade do ar no nível do mar e no efeito do ar sobre a estrutura da aeronave. A velocidade da aeronave em relação ao solo (ou GroundSpeed) é a resultante entre a TAS e o vento incidente sobre a aeronave.

Com relação à obtenção de Altitude, a mesma é mensurada pela diferença entre a pressão de um referencial e a pressão barométrica obtida na posição da aeronave. Dependendo da pressão do referencial, pode-se obter a "altitude" (ajuste QNH, que é o ajuste de sub-escala do altímetro para se obter a elevação estando em terra), "altura" (ajuste QFE, que é a pressão atmosférica à elevação de um aeródromo) ou "nível de vôo" (pressão padrão de 1013.2 hectopascais - QNE) (Ministério da Aeronáutica, 1999). Porém, a pressão atmosférica em uma determinada posição do espaço varia em função da temperatura e de demais fenômenos atmosféricos. Por isso, as medidas de altitude necessitam de constantes ajustes - nem sempre precisos - que afetam a acurácia da estimativa da altitude real, em relação ao solo, de uma aeronave.

Concluindo, pode-se considerar que os auxílios à navegação, a instrumentação de vôo, o Computador de Gerenciamento de Vôo (FMC), o Piloto Automático e o Piloto formam o sistema de navegação aérea, pois permitem que a aeronave seja conduzida de modo a aderir ao vôo previamente planejado e de forma eficiente e segura. Desta forma, a interação entre os elementos de navegação, previamente apresentados pela arquitetura do Controle de Tráfego Aéreo (Figura 4), pode ser detalhada conforme ilustrado na Figura 90 (adaptada de Hansman et al (1997)). 


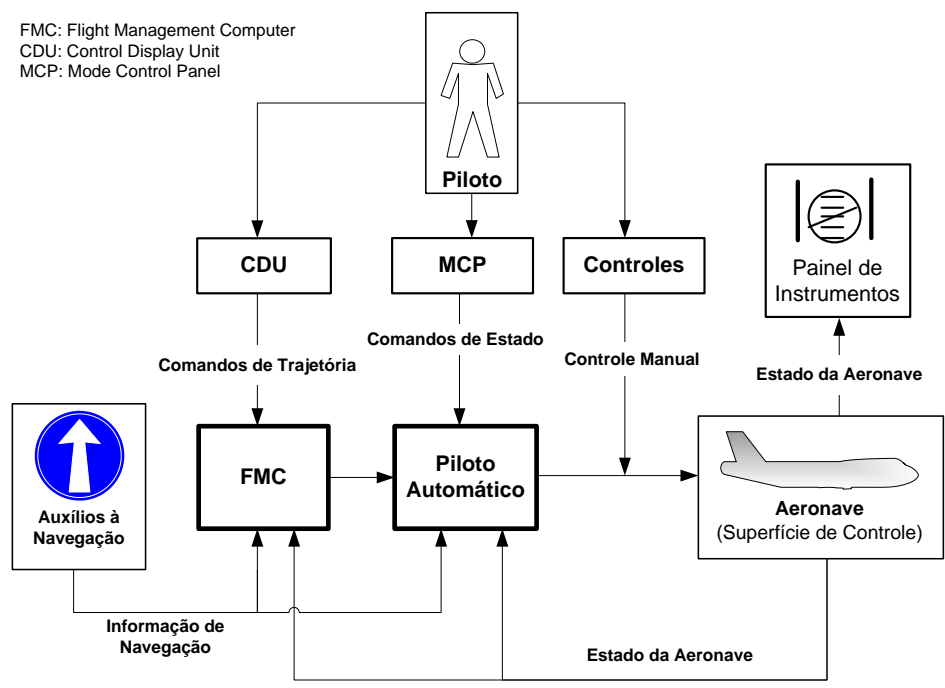

Figura 90 - Piloto, Aeronave e Navegação no Tráfego Aéreo Controlado. 


\section{APÊNDICE C - O paradigma atual dos Sistemas Críticos em Segurança}

Este APÊNDICE apresenta as características do atual paradigma de sistemas críticos em segurança (safety) e os conseqüentes novos desafios impostos aos seus ciclos de vida. Este estudo serve para demonstrar que o conceito CNS/ATM possui as mesmas características e desafios do atual paradigma de sistemas críticos em segurança, baseando a escolha do formalismo de modelagem utilizado.

Além disto, deseja-se que as informações aqui contidas possam ser utilizadas em investigações científicas relacionadas à segurança (safety) de sistemas críticos.

\section{Sistemas de controle baseados em tecnologia da informação utilizados em aplicações críticas em segurança}

Devido uma nova tecnologia alterar o paradigma do sistema legado, introduzindo consigo uma nova forma de pensar e agir a respeito de uma mesma aplicação, esta nova tecnologia traz consigo a obsolescência dos métodos, técnicas, modelos e/ou informações estatísticas anteriormente utilizadas para garantir que aquele sistema respeite determinados requisitos mínimos de funcionalidade. Desta forma, as pessoas envolvidas nas demais fases do ciclo de vida destes sistemas, tais como a engenharia de sistemas, especificação, projeto, construção, integração, verificação, validação, certificação e operação (Storey, 1996), deparam-se com novos problemas e desafios a transpor.

O problema de não garantir que um sistema funcione sob determinados requisitos é agravado em sistemas críticos, cujo funcionamento anormal pode provocar conseqüências inaceitáveis (Almeida Jr., 2002). Sistemas cujo funcionamento anormal (fora dos requisitos aceitáveis) seja catastrófico para pessoas ou para o ambiente no qual está inserido, causando mortes, ferimentos, prejuízos ambientais e materiais, são definidos como "Sistemas Críticos em Segurança (Safety)" (Storey, 1996), (Knight, 2002), (Camargo Jr., 2002).

Desde o advento dos microprocessadores e seu efetivo uso em sistemas computacionais após a década de 1960, os sistemas baseados em computadores vêm substituindo outras tecnologias (tais como as tecnologias eletromecânicas ou de eletrônica analógica) na supervisão, controle e proteção em aplicações críticas de segurança, tais como plantas nucleares, sistemas de transporte, equipamentos médicos e processos industriais. No início de sua história de utilização, o uso de computadores em aplicações críticas em segurança se tornou um novo 
paradigma para estes tipos de sistemas e, como conseqüência, tornou obsoletos os métodos, técnicas, modelos e/ou informações estatísticas anteriormente utilizadas para os sistemas legados. Assim, o uso de sistemas baseados em computadores iniciou-se de forma redundante aos sistemas legados como forma de garantir níveis de segurança mínimos aceitáveis.

Com o passar dos anos, novos métodos e técnicas foram desenvolvidos como forma de consolidar o paradigma dos sistemas críticos em segurança baseados em computadores. Atualmente, o ciclo de vida deste paradigma possui um conjunto de práticas bem estabelecidas e utilizadas para análise, projeto e implementação destes sistemas, especialmente nas áreas de hardware e de engenharia de sistemas de segurança (safety). Por outro lado, e há algum tempo (Leveson; Stolzy, 1985), não existe um conjunto de práticas e metodologias bem estabelecido aplicado na área de software em sistemas críticos em segurança (safety) (Knight, 2002), (Almeida Jr., 2002).

Recentemente, e como forma de reduzir tempo e custos de desenvolvimento, aumentar a flexibilidade no caso de expansões ou modificações, promover o reuso de componentes já avaliados e, consequentemente, reduzir os custos do ciclo de vida e aumentar o número de possíveis aplicações (Hammett, 2003), tem-se transformado sistemas tipicamente não microprocessados em sistemas baseados em computadores. Além disto, tem-se empregado o uso de tecnologia da informação e de telecomunicações (Manoni; Fortuzzi, 1997) com o objetivo de supervisionar e controlar estes sistemas.

A evolução no uso de computadores e de tecnologia da informação em sistemas de controle pode ser dividida em três fases distintas (Skelly; Morris, 1999), (Seiji et al, 2001):

i. Sistemas de controle auxiliados por computadores não centralizados (em geral, monitorando processos);

ii. Controle computadorizado centralizado, baseado em padrões fechados (padrão do fornecedor) e com implementações focadas na resolução de problemas específicos dos clientes (solução orientada ao cliente), e

iii. Controle computadorizado e distribuído em rede, baseado em padrões abertos e com uso intensivo de soluções comerciais "de prateleira" (COTS).

Desta forma, o paradigma atual de sistemas de supervisão e controle tem base em arquiteturas computacionais distribuídas sobre redes de comunicação de padrão aberto. Grande parte 
destas redes de comunicação é comercial (não dedicada), e tanto seus elementos quanto os demais componentes do sistema são de "prateleira" (commercial off the shelf - COTS), independentemente se os mesmos são hardware (elementos físicos) ou software (elementos lógicos) (Ahlström; Torin, 2002), (Knight, 2002b).

Pode-se considerar o ambiente criado pelo advento da computação pervasiva, dos sistemas de comunicação e de sensoriamento, que possibilita aos indivíduos acessar, processar e distribuir enormes quantidades de informação, como um dos maiores habilitadores para novas aplicações de sistemas de controle de larga escala e complexidade (Murray et al, 2003). Atualmente, sistemas de distribuição de energia e de água, processos de manufatura e sistemas de transportes são alguns exemplos de áreas que fazem uso de sistemas de controle baseados na integração entre computação distribuída e sistemas de comunicação, com o objetivo de otimizar seus desempenhos e aumentar a capacidade de serviço oferecida.

\section{Problemas e desafios encontrados no paradigma atual}

Se por um lado as características deste novo paradigma de sistema trazem benefícios à implementação e à utilização de diversas aplicações, por outro lado este mesmo paradigma traz consigo novos problemas e desafios a superar. Os maiores desafios ocorrem quando este paradigma é utilizado em aplicações críticas em segurança (safety), cujo funcionamento anormal pode causar mortes, ferimentos, danos materiais e ambientais (Knight, 2002).

A seguir, são apresentados alguns novos problemas e desafios encontrados no atual paradigma de sistemas críticos em segurança.

\subsection{Uso de elementos COTS}

Também denominados como elementos "de prateleira", pois são elementos produzidos em série e disponíveis comercialmente. De forma geral, não são recomendados para aplicações críticas em segurança, pois seguem o princípio de "caixa preta", não possibilitando conhecer seu completo comportamento funcional e tornando seus modos de falha imprevisíveis. $\mathrm{O}$ desafio no uso de elementos COTS em aplicações críticas em segurança está na necessidade de desenvolver meios de garantir que o funcionamento anormal destes elementos não afete a segurança do sistema (Knigth, 2002b), além de determinar quais são os novos modos de falha que os COTS promovem sobre estes sistemas. 


\subsection{Uso de redes de comunicação não dedicadas e de padrão aberto}

Estes tipos de redes de comunicação são, em sua maioria, redes comerciais de comunicação, projetadas para atender requisitos necessários à transação de informação, tais como disponibilidade, qualidade de serviço, taxa de transmissão, entre outros. Porém, estas redes não são especificadas para atender requisitos de segurança (safety) (Chiappini; Rotondo, 1997). Acrescenta-se a este fato a constatação de que muitos dos atuais sistemas de informação estão se tornando críticos em segurança, pois falhas nestes sistemas podem acarretar conseqüências inaceitáveis no domínio da segurança (safety) (Knigth, 2002). Conclui-se que o uso deste tipo de rede de comunicação pode ser um grande desafio ao ser aplicado em sistemas críticos em segurança. Além disto, o uso destas redes introduz no ciclo de vida destes sistemas novos pontos de vista a considerar, em muitos casos conflitantes, tal como o conceito de segurança da informação (security) (Vismari et al, 2003).

\subsection{Uso de arquiteturas de elevada complexidade}

A complexidade é um dos principais desafios ao se utilizar este paradigma de controle em aplicações críticas em segurança. Um sistema de alta complexidade caracteriza-se por conter uma grande quantidade de elementos funcionais fortemente interdependentes e que, no paradigma em análise, se comunicam por meio de redes de comunicação não dedicadas e de padrão aberto. Esta complexidade introduz um número desconhecido de novos modos de falha, fazendo com que o sistema tenha um comportamento imprevisível quando da ocorrência de falhas.

\subsection{Interdisciplinaridade do paradigma}

$\mathrm{O}$ atual paradigma de sistema necessita do envolvimento de equipes interdisciplinares, pois conceitos das disciplinas de controle, ciência da computação, telecomunicações e outras devem ser considerados conjuntamente. Como conseqüência, novos pontos de vista devem ser considerados durante o ciclo de vida destes sistemas. Como exemplo, características como atraso temporal, taxa de transferência de dados e comprimento de pacotes (pertencentes à disciplina de telecomunicações); estabilidade (pertencente à disciplina de controle); segurança da informação (security), computação distribuída e de tempo real (pertencentes à disciplina de computação) devem ser consideradas de modo sistêmico durante todo o ciclo de vida destes sistemas. 


\subsection{Ausência de modelos e metodologias bem estabelecidas}

O atual paradigma carece de modelos e metodologias bem estabelecidas capazes de considerar, conjuntamente, os novos pontos de vista introduzidos pelo uso da tecnologia da informação com os requisitos relacionados às aplicações críticas em segurança (safety). É necessário considerar as novas características do paradigma de sistemas de controle e a relação entre estes sistemas e o processo de aplicação controlado (balizado por requisitos de segurança (safety)). Neste caso, um dos problemas são a modelagem e a análise de sistemas híbridos, onde o comportamento de variáveis contínuas e discretas deve ser analisado conjuntamente.

\section{Características dos sistemas críticos em segurança atuais}

Sistemas de supervisão e controle baseados no paradigma atual, por serem utilizados em aplicações críticas em segurança, podem ser categorizados tanto como "sistemas de informação" quanto como "sistemas críticos". Esta aparente indistinção entre um sistema crítico em segurança (safety) e um sistema de informação que, por princípio, não contém características de segurança, pode ser observada em Sullivan et al (1999) e Knight (2002). Sullivan et al (1999) denominou como "Survivability" a característica de se proteger a infraestrutura dos sistemas de informação contra degradações (causadas por desastres naturais, acidentes, erros de projeto, manutenção ineficiente, ataques intencionais e outros) como forma de garantir a funcionalidade de suas aplicações. Knight (2002) afirma que podem ocorrer danos a um sistema como conseqüência da remoção do serviço de comunicação ou da degradação das informações, e não apenas devido a falhas nos elementos do sistema. Ou seja, têm-se, em ambos os casos, características típicas de segurança aplicadas a sistemas de informação.

Pode-se utilizar a taxonomia definida por Almeida Jr. (2003) como forma de comparar sistemas de informação "de uso geral” (não críticos em segurança (safety)) com sistemas de informação críticos em segurança (safety). Este autor faz distinções entre as expressões "sistema crítico em segurança" e "aplicação crítica em segurança", definindo que qualquer sistema que controle uma aplicação crítica em segurança pode ser definido como um "sistema crítico em segurança”. O objeto ou processo controlado pelo sistema crítico em segurança é uma "aplicação crítica em segurança". A Figura 91 ilustra a relação entre aplicações críticas em segurança e sistemas críticos em segurança. 


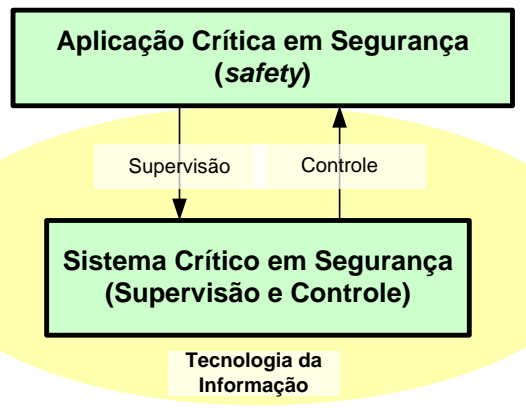

Figura 91 - Relação entre "Aplicação" e "Sistema” crítico em segurança (safety)

Devem-se ter ciência das características relacionadas ao paradigma atual dos sistemas críticos em segurança devido a importância de se considerar aspectos além do domínio da segurança (safety). Desta forma, podem-se relacionar características pertencentes a três domínios distintos de conhecimento e introduzidos aos sistemas críticos em segurança (safety) atuais: "Segurança da Informação (security)", "Comportamento Temporal" e "Comportamento Contínuo-Discreto".

\subsection{Segurança da Informação (security)}

O uso de redes de comunicação baseadas em padrões abertos faz com que os sistemas críticos em segurança (safety) atuais possuam características relacionadas à segurança da informação (security). Poucos trabalhos têm sido realizados na área de segurança da informação para redes de comunicação em sistemas de automação, sobretudo sistemas críticos em segurança (Naedele et al (2001)). Nestes sistemas, é necessário considerar os novos modos de falha e as novas ameaças introduzidas pelo domínio da segurança da informação (security), além de relacioná-las com os demais domínios de requisitos.

Atualmente, as ameaças sobre as redes de comunicação de padrão aberto estão relacionadas à inserção (Confidencialidade), modificação (Integridade) ou supressão (Disponibilidade) de mensagens (Naedele et al, 2001). A utilização de protocolos criptografados é uma das soluções adotada para minimizar estas ameaças e estabelecer uma comunicação segura sobre redes de padrão aberto (Gritzalis et al, 1999). Outra solução é a adoção de "Safety Networks" (Montague, 2002), (Chiappini; Rotondo, 1997), (Manoni; Fortuzzi, 1997), onde o protocolo utilizado nestas redes possui uma "camada de segurança" (safety layer) criada para garantir a correta transmissão/recepção das mensagens consideradas “de segurança”.

Além dos tipos de ameaças relacionadas, as mesmas podem ter origem tanto internamente 
quanto externamente ao sistema, por meio de interfaces externas (Knight, 2002b). Ameaças maliciosas e mal-intencionadas devem ser consideradas neste contexto.

\subsection{Comportamento Temporal}

O uso de arquiteturas distribuídas e controladas por meio de redes de comunicação introduz fortes restrições relacionados ao domínio do tempo sobre os sistemas que as utilizam. Um aspecto temporal importante está relacionado com a seqüência de atividades do processo, pois, em sistemas críticos em segurança, as atividades que o constituem devem ser rigorosamente e corretamente acionadas. Estes sistemas devem respeitar as restrições nos tempo de execução dos processos e nas relações de precedência do sistema (Kirner, 1997). Atualmente, protocolos acionados por tempo (time-triggered protocols) são recomendados para sistemas críticos em segurança controlados sobre redes de comunicação, pois os mesmos garantem, com níveis de confiança aceitáveis, a correta execução da sequiência de atividades do processo, apesar de possuir menor desempenho que os protocolos acionados por evento (event-triggered protocols) (Philippi, 2003), (PALBUS Task 10.1, 2001), (Heck et al, 2003).

No caso do sistema de controle fechar sua malha (haver realimentação) sobre a rede de comunicação, deve-se considerar atrasos temporais estocásticos da rede de comunicação e no processamento do controle. Atrasos promovidos pela rede de comunicação podem ser perigosos às aplicações críticas, pois podem degradar o desempenho e provocar a perda de estabilidade no sistema que as controlam (Tipsuwan; Chow, 2003), (Gregory et al, 2002). Desta forma, características de atrasos e latência das redes de comunicação devem ser consideradas sobre os sistemas críticos em segurança (safety) que as utilizam.

\subsection{Comportamento Contínuo-Discreto}

O controle de aplicações críticas utilizando computadores altera o comportamento de estado contínuo dos sistemas de controle legados. Conforme Tuffin, Chen, Trivedi (2001), um sistema híbrido é uma abstração de sistema que contém tanto partes contínuas quanto partes discretas. Os sistemas baseados em computadores, controlando aplicações críticas em segurança, desempenham atividades representadas por máquinas de estado discreto, e modeladas por estados discretos. Já as aplicações críticas em segurança têm seu comportamento modelado por meio de variáveis contínuas (e.g. velocidade, temperatura, etc). Desta forma, um formalismo híbrido é fundamental para modelar e analisar a afetação de distúrbios e falhas no sistema de controle sobre a aplicação crítica em segurança e vice-versa. 


\section{APÊNDICE D - Modelagem e Avaliação de Sistemas Críticos em Segurança utilizando Redes de Petri Fluidas e estocásticas}

Este APÊNDICE apresenta o formalismo das Redes de Petri Fluidas e Estocásticas (RPFE), adotada como o formalismo de modelagem dos sistemas avaliados segundo o método proposto neste trabalho.

São apresentados tanto os conceitos formais das RPFE quanto sua capacidade em representar sistemas híbridos. Além disto, será abordada a utilização deste formalismo para avaliar sistemas de forma quantitativa e por meio de simulação por eventos discretos.

\section{As Redes de Petri Fluidas e Estocásticas (RPFE)}

No formalismo das RPFE, os elementos primitivos de uma rede de Petri (RdP), tais como lugares, transições e arcos, podem ser tanto contínuos como discretos, modelando variáveis contínuas e variáveis discretas de um sistema híbrido, respectivamente, e o comportamento dinâmico entre estes elementos no sistema. As redes de Petri Fluidas e Estocásticas (RPFE) são utilizadas para modelar e verificar propriedades funcionais e de segurança de sistemas híbridos (Gribaudo et al, 2002).

Ainda segundo Gribaudo et al (2003), é possível unificar a visão entre métodos formais e estocásticos com o uso das redes de Petri Fluidas e Estocásticas (RPFE) para modelagem e avaliação dos sistemas com elementos discretos e contínuos. Por serem uma evolução das redes de Petri elementares, as RPFE podem modelar e analisar propriedades funcionais dos sistemas em termos de seus estados discretos, tais como conformidade e alcançabilidade de estados, por exemplo. Já com relação à evolução das RPFE a partir das redes de Petri Estocásticas (SPN), é possível utilizar as RPFE para realizar análise estocástica de sistemas, obtendo métricas de desempenho, confiabilidade, disponibilidade e segurança (dependabilidade) com base na incerteza dos parâmetros. Por último, as RPFE possuem a capacidade de modelar espaços de estados contínuos interdependentes de processos discretos, o que a torna útil em aplicações reais.

Devido as redes de Petri Fluidas e Estocásticas (RPFE) incorporarem características distintas de todo o processo de evolução das redes de Petri elementares (RdP), segue uma apresentação do formalismo e da evolução das RdP até a formalização das RPFE e sua utilização na modelagem e avaliação dos sistemas híbridos em questão. 


\subsection{Considerações iniciais a respeito das redes de Petri}

As redes de Petri (RdP) são um formalismo gráfico e matemático utilizadas na especificação, modelagem, verificação e análise das propriedades de sistemas. Elas são utilizadas, sobretudo, para modelar sistemas complexos que possuem processos concorrentes, paralelos, assíncronos, distribuídos e/ou não determinísticos (Murata, 1989), e para avaliar disponibilidade e desempenho dos sistemas modelados (COMPSciDept, 2004), (Bobbio, 1988), entre outras características. Como exemplo, as redes de Petri possuem uma vasta aplicação na modelagem de sistemas computacionais (Peterson (1989) apud Labeau (2000)), podendo considerar a relação entre Hardware, Software e Interface Homem-Máquina no contexto sistêmico (Leveson; Stolzy, 1987).

Devido as Redes de Petri (RdP) serem um formalismo matemático, observa-se na literatura que suas definições estruturais são representadas por meio de 3 formalismos matemáticos:

- Teoria Bag (Peterson, 1989), (Maciel et al, 1996), (Leveson; Stolzy, 1985);

- Álgebra Matricial (German, 2000) e

- Relações (Murata, 1989).

A Teoria Bag é uma extensão da Teoria de Conjuntos. Assim como na teoria de conjuntos, um "bag” é uma coleção de elementos sobre um determinado domínio $(\Omega)$. Porém, um bag aceita múltiplas ocorrências de um mesmo elemento (Peterson, 1989). Como exemplo, um possível bag sobre o domínio $\Omega=\{\mathrm{a}, \mathrm{b}, \mathrm{c}, \mathrm{d}\}$ seria $\mathbf{A}=\{\mathrm{c}, \mathrm{c}, \mathrm{c}, \mathrm{d}, \mathrm{d}, \mathrm{d}, \mathrm{d}, \mathrm{a}\}$. Portanto, um elemento $x$ é membro do bag $\mathbf{A}$ se o número de ocorrências de $x$ em $\mathbf{A}$ é maior do que zero $\{x \in \mathbf{A} \Leftrightarrow$ $\#(x, \mathbf{A})>0 \mid \forall x \in \Omega\}$.

A utilização de Álgebra Matricial ou de Relações não faz com que as Redes de Petri (RdP) percam suas propriedades, descritas a seguir. Estas representações são apenas modos complementares de abordar o mesmo assunto, porém necessitam de alguns detalhes para serem implementadas. Neste texto, serão apresentadas as possíveis formalizações das RdP, conforme a necessidade, as quais estarão devidamente indicadas.

\subsubsection{Estrutura elementar das Redes de Petri}

Uma Rede de Petri elementar, primordialmente introduzida por Carl Adam Petri em sua tese 
de doutorado (Petri (1962) apud Murata (1989)), é composta por 4 partes distintas e relacionadas:

- um conjunto de lugares $\mathbf{P}$, graficamente representado por círculos;

- um conjunto de transições $\mathbf{T}$, graficamente representado por barras;

- uma função de entrada I e

- uma função de saída $\mathbf{O}$, ambos representados por arcos direcionais.

As funções de entrada e de saída relacionam transições e lugares. "I" é o mapeamento entre uma transição $\mathbf{t}_{\mathbf{j}}$ e uma coleção de lugares de entrada " $\mathbf{I}\left(\mathbf{t}_{\mathbf{j}}\right)$ ". " $\mathbf{O}$ ” é o mapeamento entre uma

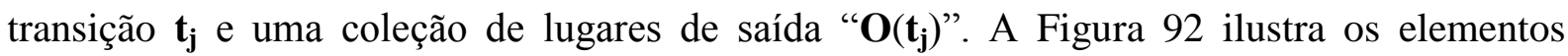
gráficos básicos de uma rede de Petri.

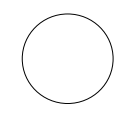

Lugar $(\mathbf{P})$

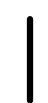

Transição (T)

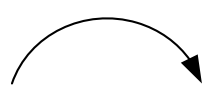

$\operatorname{Arco}(\mathbf{I}$ ou $\mathbf{O})$

Figura 92 - Elementos Gráficos básicos de uma RdP

Uma Rede de Petri, utilizando representação por Teoria Bag, é definida pela quádrupla:

$$
\mathbf{R}=(\mathbf{P}, \mathbf{T}, \mathbf{I}, \mathbf{O}), \text { onde }
$$

$\mathbf{P}=\left\{\mathbf{p}_{1}, \mathbf{p}_{2}, \ldots, \mathbf{p}_{\mathbf{n}}\right\}$ é um conjunto finito e não-vazio de lugares

$\mathbf{T}=\left\{\mathbf{t}_{1}, \mathbf{t}_{2}, \ldots, \mathbf{t}_{\mathbf{m}}\right\}$ é um conjunto finito e não-vazio de transições, onde $\mathbf{P} \cap \mathbf{T}=\varnothing$.

I : $\mathbf{T} \rightarrow \mathbf{P}^{\infty}$ é um conjunto de bags que representa o mapeamento entre transições e lugares de entrada.

$\mathbf{O}: \mathbf{T} \rightarrow \mathbf{P}^{\infty}$ é um conjunto de bags que representa o mapeamento entre transições e lugares de saída.

Um lugar $\mathbf{p}_{\mathbf{i}}$ é um lugar de entrada $\left[\right.$ saída] da transição $\mathbf{t}_{\mathbf{j}}$ se $\mathbf{p}_{\mathbf{i}} \in \mathbf{I}\left(\mathbf{t}_{\mathbf{j}}\right)\left[\boldsymbol{O}\left(\boldsymbol{t}_{\mathbf{j}}\right)\right]$.

A Multiplicidade (ou Cardinalidade) de um lugar de entrada [saída] $\mathbf{p}_{\mathbf{i}}$ para uma transição $\mathbf{t}_{\mathbf{j}}$ é $\#\left(\mathbf{p}_{\mathbf{i}}, \mathbf{I}\left(\mathbf{t}_{\mathbf{j}}\right)\right)\left[\left(\mathbf{p}_{\mathbf{i}}, \mathbf{O}\left(\mathbf{t}_{\mathbf{j}}\right)\right)\right]$. Uma definição similar para as funções $\mathbf{I}$ e $\mathbf{O}$ está em fazer: $\mathbf{I}: \mathbf{P} \rightarrow \mathbf{T}^{\infty}$ e 
$\mathbf{O}: \mathbf{P} \rightarrow \mathbf{T}^{\infty}$, onde $\#\left(\mathbf{t}_{\mathbf{j}}, \mathbf{I}\left(\mathbf{p}_{\mathbf{i}}\right)\right)=\#\left(\mathbf{p}_{\mathbf{i}}, \mathbf{I}\left(\mathbf{t}_{\mathbf{j}}\right)\right)$ e \#( $\left.\mathbf{t}_{\mathbf{j}}, \mathbf{O}\left(\mathbf{p}_{\mathbf{i}}\right)\right)=\#\left(\mathbf{p}_{\mathbf{i}}, \mathbf{O}\left(\mathbf{t}_{\mathbf{j}}\right)\right)$, respectivamente

Tal como mencionado anteriormente, pode-se encontrar a mesma definição estrutural das Redes de Petri representada através de Álgebra Matricial ou através de Relações. A representação das RdP por Álgebra Matricial é dada pela quádrupla:

$$
\mathbf{R}=(\mathbf{P}, \mathbf{T}, \mathbf{I}, \mathbf{O}), \text { onde }
$$

$\mathbf{P}=\left\{\mathbf{p}_{1}, \mathbf{p}_{2}, \ldots, \mathbf{p}_{\mathbf{n}}\right\}$ é um conjunto finito e não-vazio de lugares

$\mathbf{T}=\left\{\mathbf{t}_{1}, \mathbf{t}_{2}, \ldots, \mathbf{t}_{\mathbf{m}}\right\}$ é um conjunto finito e não-vazio de transições, onde $\mathbf{P} \cap \mathbf{T}=\varnothing$

$\mathbf{I} \subseteq \mathbf{P x T}$ é uma matriz de entrada das transições (pré-condições).

$\mathbf{O} \subseteq \mathbf{T x P}$ é uma matriz de saída das transições (pós-condições).

A título de ilustração, a representação por Relaç̃es é dada pela quádrupla:

$$
\mathbf{R}=(\mathbf{P}, \mathbf{T}, \mathbf{A}, \mathbf{V}), \text { onde }
$$

$\mathbf{P}=\left\{\mathbf{p}_{1}, \mathbf{p}_{2}, \ldots, \mathbf{p}_{\mathbf{n}}\right\}$ é um conjunto finito e não-vazio de lugares

$\mathbf{T}=\left\{\mathbf{t}_{1}, \mathbf{t}_{2}, \ldots, \mathbf{t}_{\mathbf{m}}\right\}$ é um conjunto finito e não-vazio de transições, onde $\mathbf{P} \cap \mathbf{T}=\varnothing$.

$\mathbf{A} \subseteq(\mathbf{P x T}) \cup(\mathbf{T x P})$ é a união entre os conjuntos de $\operatorname{arcos}$ orientados de entrada $\left(\mathbf{I}=\left\{\left(\mathbf{p}_{\mathbf{i}}, \mathbf{t}_{\mathbf{j}}\right)\right\}\right)$ e arcos orientados de saída $\left(\mathbf{O}=\left\{\left(\mathbf{t}_{\mathbf{j}}, \mathbf{p}_{\mathbf{i}}\right)\right\}\right)$.

$\mathbf{V}: \mathbf{A} \rightarrow \mathbf{N}$ é o conjunto de valoração dos arcos, correspondendo a sua cardinalidade.

A representação das redes de Petri por meio da álgebra matricial é útil no sentido de se aproveitar o ferramental matemático da álgebra matricial (Maciel et al, 1996), principalmente quando se deseja analisar as propriedades comportamentais e estruturais das Redes de Petri. Já a representação das redes de Petri por meio da teoria bag é útil para modelar grandes sistemas, nos quais a representação matricial não se tornaria compacta (matrizes de grandes dimensões). Por fim, a representação das redes de Petri por meio de relações é útil para realizar a demonstração de teoremas relacionados às RdP, tal como apresentado em Murata (1989). Neste texto, as representações utilizadas são escolhidas conforme a necessidade, tal como empregado por (Maciel et al, 1996). 


\subsubsection{Redes de Petri Marcadas e Espaço de Estados}

Uma marcação $(\boldsymbol{\mu})$ é uma função que mapeia todo o conjunto de lugares $\mathbf{P}$ de uma rede $\mathbf{R}$ a inteiros não-negativos $\boldsymbol{\mu}: \mathbf{P} \rightarrow \mathbf{N}$. Representando vetorialmente, uma marcação é um vetor $n$ dimensional $\mu=\left[\mu\left(\mathbf{p}_{1}\right), \mu\left(\mathbf{p}_{2}\right), \ldots, \mu\left(\mathbf{p}_{\mathbf{n}}\right)\right]$, onde $\mathbf{n}=\# \mathbf{P}$ para todo $\mathbf{p}_{\mathbf{i}} \in \mathbf{P}$ tal que $\mu\left(\mathbf{p}_{\mathbf{i}}\right)=\# \mathbf{p}_{\mathbf{i}} \in \mathbf{N}$ $=\{0,1,2, \ldots\}$. Graficamente, representa-se $\boldsymbol{\mu}\left(\mathbf{p}_{\mathbf{i}}\right)$ por meio de uma quantidade de pontos ou de um número inteiro (caso $\boldsymbol{\mu}\left(\mathbf{p}_{\mathbf{i}}\right)$ seja grande o suficiente para causar confusão gráfica) dentro do $\operatorname{lugar} \mathbf{p}_{\mathbf{i}}$

Uma marca (também denominado como "token" ou "ficha") é um conceito primitivo das Redes de Petri, e atribui informação aos lugares da rede em um determinado momento. Uma marca, em geral, é interpretada como a presença de um recurso de um determinado tipo em um determinado momento. Isto faz com que uma marcação $\mu$, em uma determinada situação, represente um estado do modelo. Portanto, o conjunto de estados de uma rede de Petri são as $\mathbf{k} \leq \mathbf{N}^{\# \mathbf{P}}$ possíveis marcações $\mu$ de uma rede, pois $\mu: \mathbf{P} \rightarrow \mathbf{N}$. Assim, tem-se que $\mu=\left[\mu_{\mathbf{k}}\left(\mathbf{p}_{1}\right)\right.$, $\left.\mu_{k}\left(\mathbf{p}_{2}\right), \ldots, \mu_{k}\left(\mathbf{p}_{n}\right)\right]$, onde $\mathbf{k} \leq \mathbf{N}^{\# \mathbf{P}}$, e $\mu_{\mathrm{k}}\left(\mathbf{p}_{\mathbf{i}}\right)=\left(\# \mathbf{p}_{\mathbf{i}}, \mu_{\mathrm{k}}\right)=\mathbf{m} \in \mathbf{N}^{+}$.

O número de marcas em $\mathbf{p}_{\mathbf{i}}$ pode mudar durante a execução de uma rede de Petri. Por exemplo, considere um estado $\mu_{\mathbf{j}} \in \boldsymbol{\mu} \rightarrow \boldsymbol{\mu}_{\mathbf{j}}\left(\mathbf{p}_{\mathbf{i}}\right)=\mathbf{m}, \mathbf{m} \in \mathbf{N}$. Após a execução, a rede migra para o estado $\mu_{(\mathbf{j}+1)} \in \boldsymbol{\mu}$, onde $\boldsymbol{\mu}_{(\mathbf{j}+\mathbf{1})}\left(\mathbf{p}_{\mathbf{i}}\right)=\mathbf{h}, \mathbf{h} \in \mathbf{N}$. Seguindo o princípio de que podem haver infinitos vetores $\mu$, o conjunto de estados de uma rede pode ser infinito e enumerável.

Uma Rede de Petri Marcada é uma dupla $\mathbf{R M}=\left(\mathbf{R}, \mu_{\mathbf{0}}\right)$, onde $\mathbf{R}$ representa uma Rede de Petri e $\mu_{0}$ representa sua marcação (ou estado) inicial. Desta forma, pode-se também representar uma Rede de Petri Marcada através da quíntupla $\mathbf{R M}=\left(\mathbf{P}, \mathbf{T}, \mathbf{I}, \mathbf{O}, \boldsymbol{\mu}_{\mathbf{0}}\right)$. Uma RM é útil quando se deseja representar e avaliar as propriedades comportamentais (dinâmicas) de um sistema modelado. As regras de execução de uma RM são descritas a seguir.

\subsubsection{Dinâmica das RdP - Regras de Execução}

A execução de uma Rede de Petri é controlada pelo número e pela distribuição das marcas (tokens) na rede. Marcas (tokens) residem nos lugares e controlam a execução das transições na rede. Desta forma, uma rede de Petri é executada através dos disparos das transições.

Uma transição somente pode ser disparada se a mesma estiver habilitada. Uma transição $\mathbf{t}_{\mathbf{j}} \in$ T em uma rede marcada RM está habilitada se e somente se: 


$$
\boldsymbol{\mu}\left(\mathbf{p}_{\mathbf{i}}\right) \geq \#\left(\mathbf{p}_{\mathbf{i}}, \mathbf{I}\left(\mathbf{t}_{\mathbf{j}}\right)\right)=\#\left(\mathbf{t}_{\mathbf{j}}, \mathbf{I}\left(\mathbf{p}_{\mathbf{i}}\right)\right), \forall \mu\left(\mathrm{p}_{\mathrm{i}}\right) \in \mu \text { e } \forall \mathrm{p}_{\mathrm{i}} \in \mathrm{P}
$$

Como a habilitação de uma transição depende da marcação da rede a que pertence, define-se $\boldsymbol{H}(\boldsymbol{\mu}) \in \mathbf{T}$ como o conjunto de transições habilitadas para a marcação $\boldsymbol{\mu}$ da rede. Estando uma $\mathbf{R M}$ em uma marcação $\boldsymbol{\mu}_{\mathbf{q}}, \mathbf{t}_{\mathbf{j}} \in \boldsymbol{H}\left(\boldsymbol{\mu}_{\mathbf{q}}\right)$ se e somente se $\boldsymbol{\mu}_{\mathbf{q}}\left(\mathbf{p}_{\mathbf{i}}\right) \geq \#\left(\mathbf{p}_{\mathbf{i}}, \mathbf{I}\left(\mathbf{t}_{\mathbf{j}}\right)\right)$ para todo $\mathbf{p}_{\mathbf{i}} \in \mathbf{P}$ e $\mathbf{t}_{\mathbf{j}} \in \mathbf{T}$.

Após o disparo de $\mathbf{t}_{\mathbf{j}}$ (cuja notação será “ $\uparrow \mathbf{t}_{\mathbf{j}}$ ”), estando a $\mathbf{R M}$ em uma marcação $\boldsymbol{\mu}_{\mathbf{q}}$, produz-se uma nova marcação $\boldsymbol{\mu}_{(\mathbf{q}+\mathbf{1})}$ obedecendo a equação:

$$
\boldsymbol{\mu}_{(\mathbf{q}+\mathbf{1})}\left(\mathbf{p}_{\mathbf{i}}\right)=\boldsymbol{\mu}_{\mathbf{q}}\left(\mathbf{p}_{\mathbf{i}}\right)-\#\left(\mathbf{p}_{\mathbf{i}}, \mathbf{I}\left(\mathbf{t}_{\mathbf{j}}\right)\right)+\#\left(\mathbf{p}_{\mathbf{i}}, \mathbf{O}\left(\mathbf{t}_{\mathbf{j}}\right)\right), \forall \mathrm{p}_{\mathrm{i}} \in \mathrm{P}
$$

Em outras palavras, quando ocorre $\uparrow_{\mathbf{t}_{\mathbf{j}}}$ em uma rede marcada $\mathbf{R M}, \mathbf{t}_{\mathbf{j}} \in \mathbf{T}$ e $\mathbf{T} \in \mathbf{R M}$, a rede remove \# $\left(\mathbf{p}_{\mathbf{i}}, \mathbf{I}\left(\mathbf{t}_{\mathbf{j}}\right)\right)$ marcas (tokens) dos lugares de entrada (o valor da cardinalidade do arco de entrada) e adiciona $\#\left(\mathbf{p}_{\mathbf{i}}, \mathbf{O}\left(\mathbf{t}_{\mathbf{j}}\right)\right.$ ) novas marcas nos locais de saída (o valor da cardinalidade do arco de saída).

Como regra, o disparo de uma transição é um processo atômico, onde não é permitido o disparo simultâneo de mais de uma transição. Como exemplo, dado $\boldsymbol{H}\left(\mu_{\mathrm{j}}\right)=\left\{\mathbf{t}_{\mathbf{g}}, \mathbf{t}_{\mathbf{m}}\right\}$ (transições $\mathbf{t}_{\mathbf{g}}$ e $\mathbf{t}_{\mathbf{m}}$ habilitadas durante a marcação $\boldsymbol{\mu}_{\mathbf{j}}$ ), apenas $\mathbf{t}_{\mathbf{g}}$ ou $\mathbf{t}_{\mathbf{m}}$ poderá ser disparada, produzindo uma nova marcação $\boldsymbol{\mu}_{(\mathbf{j}+\mathbf{1})}$. A transição não disparada durante a marcação $\mu_{\mathrm{j}}$ poderá ser disparada na nova marcação $\boldsymbol{\mu}_{(\mathbf{j}+\mathbf{1})}$ caso pertença a $\boldsymbol{H}\left(\boldsymbol{\mu}_{(\mathbf{j}+\mathbf{1})}\right)$.

\subsubsection{Função do próximo estado e "Alcançabilidade"}

Como descrito anteriormente, cada marcação pertencente a $\mu$ define um estado da rede de Petri Marcada (RM). O disparo de uma transição representa a mudança de estado de uma rede. A mudança de estado causada pelo disparo de uma transição pode ser definida por uma função $\delta$ denominada função do próximo estado. Quando a função $\delta$ é aplicada sobre uma $\mathbf{R M}=\left(\mathbf{R}, \boldsymbol{\mu}_{\mathbf{k}}\right)$ para uma transição $\mathbf{t}_{\mathbf{j}}$, a rede irá para um próximo estado $\boldsymbol{\mu}_{(\mathbf{k}+\mathbf{1})}$ se e somente se $\mathbf{t}_{\mathbf{j}}$ estiver definido para $\delta\left(\mu_{k}, \mathbf{t}_{\mathbf{j}}\right)=\boldsymbol{\mu}_{(\mathrm{k}+1)}$ ou, de forma análoga, se $\mathbf{t}_{\mathbf{j}} \in \boldsymbol{H}\left(\boldsymbol{\mu}_{\mathrm{k}}\right)$.

Por definição, a função do próximo estado $\boldsymbol{\delta}: \mathbf{N}^{\mathbf{n}} \mathbf{x} \mathbf{T} \rightarrow \mathbf{N}^{\mathbf{n}}$ para uma $\mathbf{R M}$ em uma marcação $\boldsymbol{\mu}$ e transição $\mathbf{t}_{\mathbf{j}} \in \mathbf{T}$ é definida se e somente se $\mu\left(\mathbf{p}_{\mathbf{i}}\right) \geq \#\left(\mathbf{p}_{\mathbf{i}}, \mathbf{I}\left(\mathbf{t}_{\mathbf{j}}\right)\right)$ para todo $\mathbf{p}_{\mathbf{i}} \in \mathbf{P}$. Se $\delta\left(\mu_{\mathbf{u}}, \mathbf{t}_{\mathbf{j}}\right)$ é definida, então $\delta\left(\mu_{\mathbf{u}}, \mathbf{t}_{\mathbf{j}}\right)=\mu_{(\mathbf{u}+\mathbf{1})}$, onde $\boldsymbol{\mu}_{(\mathbf{u}+\mathbf{1})}\left(\mathbf{p}_{\mathbf{i}}\right)=\mu_{(\mathbf{u})}\left(\mathbf{p}_{\mathbf{i}}\right)-\#\left(\mathbf{p}_{\mathbf{i}}, \mathbf{I}\left(\mathbf{t}_{\mathbf{j}}\right)\right)+\#\left(\mathbf{p}_{\mathbf{i}}, \mathbf{O}\left(\mathbf{t}_{\mathbf{j}}\right)\right)$, para todo $\mathbf{p}_{\mathbf{i}} \in \mathbf{P}$. 
Então, dada uma RM com marcação $\mu_{0}$ (estado inicial da rede), pode-se executá-la sucessivamente obtendo-se uma marcação $\mu_{\mathbf{n}}$. Esta seqüência de execuções, produzida por uma seqüência de transições disparáveis $\mathbf{T}_{\uparrow}=\left(\mathbf{t}_{\mathbf{0}}, \mathbf{t}_{\mathbf{1}}, \ldots, \mathbf{t}_{\mathbf{n}}\right)$, produz uma seqüência de marcações $\left(\mu_{0}, \mu_{1}, \ldots, \mu_{n}\right)$. Estas duas últimas seqüências estão relacionadas por $\delta\left(\mu_{\mathrm{k}}, \mathbf{t}_{\mathrm{k}}\right)=$ $\boldsymbol{\mu}_{(\mathbf{k}+\mathbf{1})}$, para $\mathrm{k}=0,1,2 \ldots$ Ou seja, se uma marcação $\boldsymbol{\mu}_{(\mathbf{k}+\mathbf{1})}$ é produzida a partir da marcação $\boldsymbol{\mu}_{\mathrm{k}}$, diz-se que $\boldsymbol{\mu}_{(\mathbf{k}+1)}$ é imediatamente alcançável a partir de $\mu_{\mathbf{k}}$ se existir uma transição $\mathbf{t} \in \mathbf{T}$ tal que $\delta\left(\mu_{k}, t_{k}\right)=\mu_{(k+1)}$. Se $\mu_{(k+2)}$ é imediatamente alcançável a partir de $\mu_{(k+1)}$ e se $\mu_{(k+1)}$ é imediatamente alcançável a partir de $\mu_{\mathrm{k}}$, então $\boldsymbol{\mu}_{(\mathbf{k}+2)}$ é alcançável a partir de $\mu_{\mathrm{k}}$.

O conjunto alcançabilidade $S$ para uma Rede de Petri Marcada $\left(\mathbf{R}, \mu_{0}\right)$ é todo conjunto de marcações definidos por $\boldsymbol{\mu}$ a partir de $\boldsymbol{\mu}_{0}$ sobre uma rede $\mathbf{R}$.

\subsubsection{Propriedades das redes de Petri}

Conforme relatado por German (2000), a bibliografia descreve uma enorme quantidade de tipos de propriedades das redes de Petri. Estas propriedades, tal como ilustrado por Murata (1989), são as qualidades analisadas nos sistemas modelados por meio de redes de Petri. Desta forma, os autores dividem as propriedades das redes em 2 tipos: propriedades estruturais e propriedades comportamentais.

As propriedades estruturais são independentes da marcação inicial $\mu_{\mathbf{0}}$ da rede. Portanto, estas propriedades podem ser analisadas por meio de uma inspeção da rede $\mathbf{R}$, não havendo necessidade de avaliar o conjunto alcançabilidade $S$ da mesma. De forma complementar, as propriedades comportamentais são dependentes da marcação inicial $\mu_{\mathbf{0}}$ da rede, ou seja, consideram o comportamento dinâmico (execução) da rede.

Algumas propriedades estruturais e comportamentais importantes das redes de Petri são (German, 2000), (Murata, 1989):

- Uma rede $\mathbf{R M}=\left(\mathbf{R}, \boldsymbol{\mu}_{\mathbf{0}}\right)$ é “conservativa" se $\sum_{\forall p_{i} \in P} \mu_{k}\left(p_{i}\right)=\sum_{\forall p_{i} \in P} \mu_{k+1}\left(p_{i}\right)$ para todo $\boldsymbol{\mu}_{\mathbf{k}} \in \boldsymbol{\mu}$. Ou seja, o somatório das marcas (tokens) presentes em toda a rede não se altera ao longo de sua execução.

- Uma marcação $\mu_{\mathbf{k}} \in \boldsymbol{\mu}$ é "alcançável" (reachable) a partir de $\mu_{\mathbf{0}}$ se existir uma seqüência de transições disparável $\sigma$ que leve a rede da marcação $\mu_{0}$ à marcação $\mu_{\mathrm{k}}$. 
- Uma marcação $\mu_{\mathrm{k}} \in \boldsymbol{\mu}$ é “abrangível" (coverable) se existir uma marcação $\boldsymbol{\mu}_{\mathrm{r}} \in \boldsymbol{\mu}$ tal que $\mu_{\mathbf{k}}\left(\mathbf{p}_{\mathbf{i}}\right) \leq \mu_{\mathbf{r}}\left(\mathbf{p}_{\mathbf{i}}\right)$ para todo $\mathbf{p}_{\mathbf{i}} \in \mathbf{P}$.

- Um lugar $\mathbf{p}_{\mathbf{i}} \in \mathbf{P}$ é " $k$-limitado" ( $k$-bounded) se o mesmo contém $\# \mathbf{p}_{\mathbf{i}} \leq \mathbf{k}, \mathbf{k} \in \mathbf{N}$. Uma rede $\mathbf{R M}=\left(\mathbf{R}, \mu_{\mathbf{0}}\right)$ é " $k$-limitada" se todos os lugares desta rede são " $k$-limitados". Uma rede " $k$-limitada" possui um conjunto alcançabilidade finito, com número de estados menor que $\mathbf{k}^{\# \mathbf{P}}$.

- Uma rede $\mathbf{R M}=\left(\mathbf{R}, \mu_{\mathbf{0}}\right)$ é "viva" (liveness) se, independentemente da marcação $\boldsymbol{\mu}_{\mathbf{k}} \in \boldsymbol{\mu}$ alcançada a partir de $\mu_{0}$, for possível disparar qualquer transição da rede a partir de uma seqüência de transições apropriadas. Uma rede com esta propriedade é, segundo Murata (1989), uma rede livre de impasses (“deadlocks”).

- Um lugar $\mathbf{p}_{\mathbf{i}} \in \mathbf{P}$ é "seguro" (safe) se $\mu_{\mathbf{k}}\left(\mathbf{p}_{\mathbf{i}}\right) \leq 1$ para todo $\mu_{\mathbf{k}} \in \boldsymbol{\mu}$. Uma rede $\mathbf{R}$ é "segura" se todos os lugares desta rede são "seguros". Vale frisar que o conceito de "segurança" em RdP não possui correlação direta com o conceito de segurança (safety) definido anteriormente para sistemas.

- Duas transições $\left\{\mathbf{t}_{\mathbf{k}}, \mathbf{t}_{\mathbf{j}}\right\} \in \mathbf{T}$ são "concorrentes" se existir uma marcação $\mu_{\mathbf{n}}$ alcançável na qual $\left\{\mathbf{t}_{\mathbf{k}}, \mathbf{t}_{\mathbf{j}}\right\} \in \boldsymbol{H}\left(\boldsymbol{\mu}_{\mathbf{n}}\right)$, porém o disparo de uma das transições não desabilita a outra.

- Duas transições $\left\{\mathbf{t}_{\mathbf{k}}, \mathbf{t}_{\mathbf{j}}\right\} \in \mathbf{T}$ estão em "conflito potencial" (ou "estrutural") se ambas compartilharem o mesmo lugar de entrada. As mesmas transições estão em "conflito efetivo" no caso de existir uma marcação $\mu_{\mathbf{n}}$ alcançável na qual $\left\{\mathbf{t}_{\mathbf{k}}, \mathbf{t}_{\mathbf{j}}\right\} \in \boldsymbol{H}\left(\mu_{\mathbf{n}}\right)$, porém o disparo de uma das transições desabilita a outra.

As propriedades citadas anteriormente permitem, em conjunto com a modelagem por meio das redes de Petri, avaliar características funcionais (comportamentais) e estruturais significativas dos sistemas, sobretudo sistemas complexos contendo processos concorrentes, paralelos, assíncronos e/ou distribuídos, conforme citado no início deste capítulo. Exemplos de redes elementares utilizadas em modelagem, e suas respectivas representações, estão ilustrados na Figura 93. 

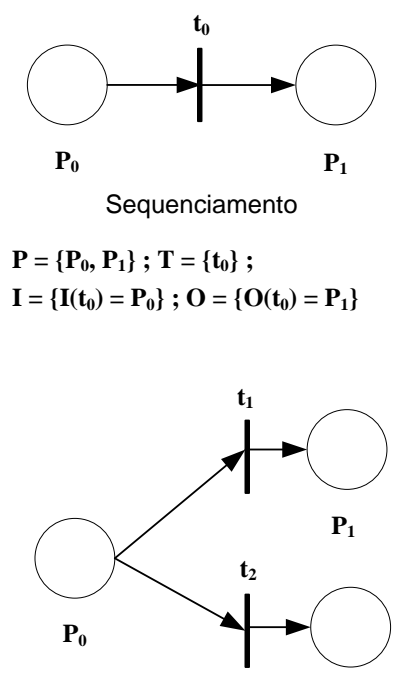

Conflito Estrutural

$$
\mathbf{P}=\left\{\mathbf{P}_{\mathbf{0}}, \mathbf{P}_{\mathbf{1}}, \mathbf{P}_{2}\right\} ; \mathbf{T}=\left\{\mathbf{t}_{\mathbf{1}}, \mathrm{t}_{\mathbf{2}}\right\} ;
$$

$\mathbf{I}=\left\{\mathbf{I}\left(\mathbf{t}_{1}\right)=\mathbf{P}_{\mathbf{0}}, \mathbf{I}\left(\mathbf{t}_{2}\right)=\mathbf{P}_{0}\right\} ;$

$O=\left\{O\left(t_{1}\right)=P_{1}, O\left(t_{2}\right)=P_{2}\right\}$

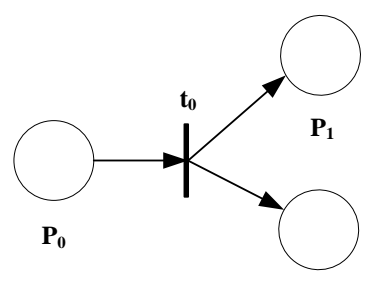

$\mathbf{P}_{2}$

$$
\text { (iniciação de Processos Paralelos) }
$$

$\mathbf{P}=\left\{\mathbf{P}_{0}, \mathbf{P}_{1}, \mathbf{P}_{2}\right\} ; \mathbf{T}=\left\{\mathrm{t}_{0}\right\} ；$

$\mathbf{I}=\left\{\mathbf{I}\left(\mathbf{t}_{\mathbf{0}}\right)=\mathbf{P}_{\mathbf{0}}\right\} ;$

$O=\left\{O\left(t_{0}\right)=P_{1}, O\left(t_{0}\right)=P_{2}\right\}$

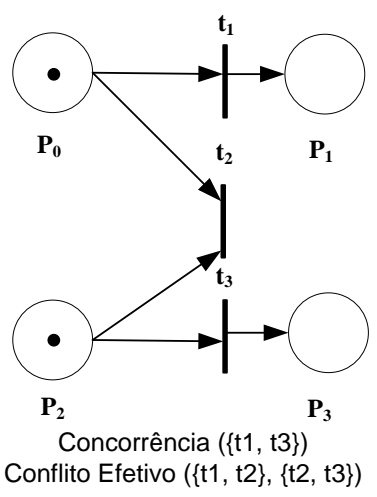

Conflito Efetivo (\{t1, t2\}, \{t2, t3\})

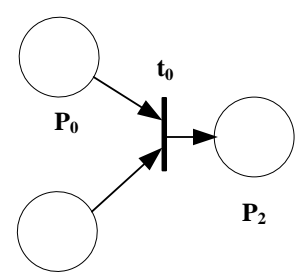

$\mathbf{P}_{1}$

Junção

(modela Sincronismo)

$\mathbf{P}=\left\{\mathbf{P}_{0}, \mathbf{P}_{1}, \mathbf{P}_{2}\right\} ; \mathbf{T}=\left\{\mathbf{t}_{\mathbf{0}}\right\} ;$

$I=\left\{I\left(t_{0}\right)=P_{0}, I\left(t_{0}\right)=P_{1}\right\} ;$

$\mathbf{O}=\left\{\mathbf{O}\left(\mathbf{t}_{0}\right)=\mathbf{P}_{2}\right\}$

$\mathbf{P}=\left\{\mathbf{P}_{0}, \mathbf{P}_{1}, \mathbf{P}_{2}, \mathbf{P}_{3}\right\} ; \mathbf{T}=\left\{\mathrm{t}_{1}, \mathrm{t}_{2}, \mathrm{t}_{3}\right\} ;$

$\mathbf{I}=\left\{\mathbf{I}\left(\mathbf{t}_{1}\right)=\mathbf{P}_{\mathbf{0}}, \mathbf{I}\left(\mathbf{t}_{2}\right)=\mathbf{P}_{\mathbf{0}}, \mathbf{I}\left(\mathbf{t}_{2}\right)=\mathbf{P}_{2}, \mathbf{I}\left(\mathbf{t}_{3}\right)=\mathbf{P}_{2}\right\} ;$

$\mathbf{O}=\left\{\mathbf{O}\left(\mathrm{t}_{1}\right)=\mathbf{P}_{1}, \mathbf{O}\left(\mathrm{t}_{3}\right)=\mathbf{P}_{3}\right\}$

$\mu_{0}=\{1,0,1,0\}$

Figura 93 - Exemplos de redes elementares e suas representações matemáticas

Para avaliação das propriedades de uma rede de Petri elementar, podem-se aplicar alguns métodos extraídos de suas próprias características, tais como: as "Árvores de Alcançabilidade" (Reachability Tree), cujo conceito é construir, a partir de uma marcação $\mu_{0}$, uma árvore contendo todos as marcações de uma RdP e as respectivas execuções que as promoveram; a "Matriz de Incidência e Equação de Estados", cujo método aproveita as características da representação por álgebra matricial e cria uma equação matricial que modela o comportamento dinâmico da rede (Murata, 1989).

\subsubsection{Extensões das redes de Petri}

A estrutura elementar de uma rede de Petri $(\mathrm{RdP})$ é restrita quanto à capacidade de modelagem de sistemas reais. Por exemplo, uma RdP elementar não permite avaliar se um lugar não possui marcas (teste de zero). Também não é possível relacionar a cardinalidade dos arcos com as marcações da rede. Outra limitação é não ser possível resolver o disparo de transições em conflito.

Como forma de aumentar o poder de modelagem, foram criadas algumas extensões no conceito elementar das RdP, tais como: 
- Guardas: permite fazer o processo de habilitação de uma transição depender, além da condição elementar $\boldsymbol{\mu}\left(\mathbf{p}_{\mathbf{i}}\right) \geq \#\left(\mathbf{p}_{\mathbf{i}}, \mathbf{I}\left(\mathbf{t}_{\mathbf{j}}\right)\right)$ para $\forall \mu\left(\mathrm{p}_{\mathrm{i}}\right) \in \mu$ e $\forall \mathrm{p}_{\mathrm{i}} \in \mathrm{P}$, de predicados sobre a marcação da rede.

- Prioridade: permite especificar a precedência de disparo de uma transição sobre outras transições em conflito.

- Multiplicidade dos Arcos: possibilita modelar arcos com cardinalidade maior que 1

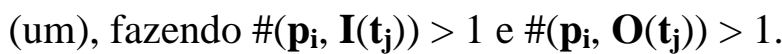

- Multiplicidade de Arcos dependentes da Marcação: mesmo conceito, mas permite definir a cardinalidade em função da marcação da rede. Por exemplo, pode-se fazer $\#\left(\mathbf{p}_{\mathbf{i}}, \mathbf{I}\left(\mathbf{t}_{\mathbf{j}}\right)\right)=\mu\left(\mathbf{p}_{\mathbf{i}}\right)$.

Uma rede de Petri Estendida (RE) possui a seguinte notação (German, 2000):

$$
\mathbf{R E}=\left(\mathbf{P}, \mathbf{T}, \mathbf{I}, \mathbf{O}, \Pi, \mathbf{g}, \mu_{\mathbf{0}}\right), \text { onde }
$$

$\mathbf{P}, \mathbf{T}$ e $\boldsymbol{\mu}_{\mathbf{0}}$ são iguais à notação de $\mathbf{R}$ utilizando álgebra matricial.

$\mathbf{I} \in\left(\mathbf{N}^{\mathbf{n}} \rightarrow \mathbf{N}\right)^{(\mathbf{n} \times \mathbf{m})}$ e $\mathbf{O} \in\left(\mathbf{N}^{\mathbf{n}} \rightarrow \mathbf{N}\right)^{(\mathbf{m} \times \mathbf{n})}$ são as matrizes de multiplicidade dependentes de marcação dos arcos de entrada e dos arcos de saída, respectivamente. Para I, a (i,j)-ésima entrada da matriz fornece a multiplicidade do arco de entrada entre $\mathbf{p}_{\mathbf{i}}$ para $\mathbf{t}_{\mathbf{j}}$. Para $\mathbf{O}$, a (i,j)ésima entrada da matriz fornece a multiplicidade do arco de saída entre $\mathbf{t}_{\mathbf{i}}$ para $\mathbf{p}_{\mathbf{j}}$. Essa multiplicidade pode ser dependente de marcação, constituindo uma função $\mathbf{N}^{\mathbf{n}} \rightarrow \mathbf{N}$.

$\Pi \in \mathbf{N}^{\mathbf{m}}$ é o vetor de prioridade de cada transição.

$\mathbf{g} \in\left(\mathbf{N}^{\mathbf{n}} \rightarrow\{\text { verdadeiro }=\mathbf{1} \text {, falso }=\mathbf{0}\}\right)^{\mathbf{m}}$ é o vetor de guarda de cada transição, e $\mathbf{N}^{\mathbf{n}} \rightarrow\{$ verdadeiro, falso $\}$ é o conjunto de predicados de uma transição relacionados às marcações da rede.

Com relação à dinâmica de execução de uma $\mathbf{R E}$, uma transição $\mathbf{t}_{\mathbf{j}} \in \mathbf{T}$ está habilitada em uma marcação $\mu_{\mathrm{k}} \in \mu$ se as seguintes condições forem respeitadas:

$$
\begin{aligned}
& \text { i. } \mu_{\mathbf{k}}\left(\mathbf{p}_{\mathbf{i}}\right) \geq \#\left(\mathbf{p}_{\mathbf{i}}, \mathbf{I}\left(\mathbf{t}_{\mathbf{j}}\right), \mu_{\mathbf{k}}\right), \forall p_{i} \in P . \\
& \text { ii.g( } \left.\mathbf{t}_{\mathbf{i}}, \mu_{\mathbf{k}}\right)=\mathbf{1}
\end{aligned}
$$


iii. $\Pi\left(\mathbf{t}_{\mathbf{j}}\right) \geq \Pi\left(\mathbf{t}_{\mathbf{i}}\right), \forall \mathbf{t}_{\mathbf{i}} \in \mathbf{T}, \mathbf{t}_{\mathbf{i}} \neq \mathbf{t}_{\mathbf{j}}$ e que, na marcação $\mu_{\mathbf{k}}$, atenda as condições "i" e "ii".

As demais regras de execução de uma RdP elementar, tais como atomicidade, são também válidas para as RE.

\subsection{Redes de Petri Temporizadas e Estocásticas}

Mesmo uma rede de Petri Estendida (RE) não considera características de tempo nas transições, impossibilitando a avaliação de aspectos importantes dos sistemas, tais como disponibilidade, confiabilidade, desempenho e segurança. Como solução para esta limitação de temporalidade nas RdP, adotou-se 2 extensões em seu conceito (Murata, 1989). A primeira extensão foi a de "redes de Petri (deterministicamente) Temporizadas", onde se associou atrasos determinísticos às transições da rede, de forma que, caso $\mathbf{t} \in \mathbf{T}$ seja temporizada com $\tau_{\mathbf{t}} \in \mathbf{R}^{+}$, e $\delta\left(\mu_{\mathrm{k}}, \mathbf{t}_{\mathrm{k}}\right)=\boldsymbol{\mu}_{(\mathrm{k}+1)}$, a mudança de estado $\mu_{\mathrm{k}} \rightarrow \boldsymbol{\mu}_{(\mathbf{k}+1)}$ consumirá um tempo determinístico $\boldsymbol{\tau}_{\mathbf{t}, \mathrm{k}}$ entre a habilitação da transição $\mathbf{t}\left(\mathbf{t} \in \boldsymbol{H}\left(\boldsymbol{\mu}_{\mathbf{k}}\right)\right)$ e seu efetivo disparo ( $\left.\uparrow \mathbf{t}\right)$. Uma transição temporizada é graficamente representada por um retângulo.

Portanto, ao se introduzir temporização nas transições de uma rede de Petri, as marcações (estados) passam agora a ser representadas por $\mathbf{S}_{\mathbf{k}}=\left(\mu_{\mathbf{k}}, \boldsymbol{\tau}_{\mathbf{t}, \mathbf{k}}\right) \in \mathbf{N}^{\# \mathbf{P}} \mathbf{x}\left(\mathbf{R}^{+}\right)^{\# \mathbf{T}}$. Desta forma, uma rede temporizada que possua uma seqüência de transições disparáveis $\mathbf{T}_{\uparrow}=\left(\mathbf{t}_{\mathbf{0}}, \mathbf{t}_{\mathbf{1}}, \ldots, \mathbf{t}_{\mathbf{n}}\right)$, $\mathbf{T} \uparrow \in \boldsymbol{\sigma}$, produz uma seqüência de marcações $\left(\mathbf{s}_{\mathbf{0}}, \mathbf{s}_{\mathbf{1}}, \ldots, \mathbf{s}_{\mathbf{n}}\right)$ associada aos instantes $\left(\mathbf{e}_{\mathbf{0}}, \mathbf{e}_{\mathbf{1}}, \ldots\right.$, $\left.\mathbf{e}_{\mathbf{n}}\right)$, onde $\left(\mathbf{e}_{\mathbf{k}+\mathbf{1}}-\mathbf{e}_{\mathbf{k}}\right)=\boldsymbol{\tau}_{\mathbf{t}, \mathbf{k}}$. Conclui-se, portanto, que o conjunto alcançabilidade $\boldsymbol{S}$ para uma rede de Petri temporizada é todo conjunto de marcações definidos por $\mathbf{s}_{\mathbf{k}} \in S$.

A segunda extensão adotada sobre as RdP foi a de "redes de Petri Estocásticas" (ou Stochastic Petri nets - SPN). Esta extensão possui o mesmo princípio de associar-se temporizações " $\boldsymbol{\tau}_{\mathbf{t}}$ " ao conjunto "T $\mathbf{T}$ " de transições. Porém, neste caso, o conjunto de temporizações " $\boldsymbol{\tau}_{\mathbf{t}}$ ” são variáveis aleatórias $\boldsymbol{\tau}_{\mathbf{t}}: \mathbf{\Omega} \rightarrow \boldsymbol{R}$ definidas no espaço de probabilidade $(\boldsymbol{\Omega}, \mathbf{P})$ com funções de distribuições de probabilidade bem definidas $\boldsymbol{F} \boldsymbol{\tau}_{\mathbf{t}}(\mathbf{x})=\mathbf{P}\left(\boldsymbol{\tau}_{\mathbf{t}}<\mathbf{x}\right)$ (Magalhães e Lima, 2004).

Devido à dinâmica de execução de uma SPN ter característica estocástica em relação ao tempo (transições estocásticas), sua dinâmica de execução pode ser representada por um processo estocástico (German, 2000). Um processo estocástico é formalmente definido como uma família de variáveis aleatórias $\{\mathbf{N}(t), t \in \Upsilon\}$, onde $\mathbf{N}(\boldsymbol{t})$ está definido sobre um espaço de 
probabilidade $\boldsymbol{S}=(\boldsymbol{\Omega}, \mathbf{P})$ e indexado pelo parâmetro $\boldsymbol{t}, \boldsymbol{t}$ variando sobre um conjunto índice $\mathbf{\Upsilon}$. Para uma SPN, tem-se que $\mathbf{N}(\boldsymbol{t}) \in S$, onde $\boldsymbol{S}$ é o espaço de estados tangível ${ }^{39}$ de uma $S P N$ e $\boldsymbol{t}$ é o parâmetro de tempo, o qual pode ser considerado tanto discreto $\left(\boldsymbol{t}=\mathbf{e}_{\mathbf{k}}=\mathbf{e}_{\mathbf{0}}+\sum_{t \in \sigma, n=[0, k]} \tau_{t, n}\right)$ quanto contínuo $\left(\boldsymbol{t} \in \mathbf{R}^{+}\right)$, descrevendo a relação entre os estados de um processo estocástico em diferentes instantes de tempo.

Existem algumas subclasses de redes de Petri Estocásticas (SPN), de acordo com os tipos de variáveis aleatórias associadas às transições (German, 2000). Como exemplos, se todas as transições possuem função de distribuição exponencial, a SPN pertence às "redes de Petri Estocásticas Generalizadas" (Generalized Stochastic Petri nets (GSPN)). No caso de todas as transições da SPN serem temporizadas (tanto com valores determinísticos quanto com valores estocásticos), a SPN pertence às "redes de Petri Determinísticas e Estocásticas" (Deterministic and Stochastic PN (DSPN)). No caso das variáveis aleatórias não possuírem distribuição exponencial, a rede de Petri Estocástica (SPN) pertence à subclasse das "redes de Petri Não-Markovianas".

No caso de uma SPN ser do tipo GSPN (todas as transições possuem função de distribuição exponencial), este tipo de SPN pode ser analisada por meio de um processo estocástico do tipo Markoviano ${ }^{40}$ e, consequentemente, o comportamento dinâmico das marcações de uma rede pode ser mapeado em uma cadeia de Markov homogênea de tempo contínuo (timecontinuos homogeneous Markov chain) com espaço de estado isomórfico ${ }^{41}$ à árvore de alcançabilidade da SPN mapeada (Bobbio, 1988). Assim, quando uma rede "não possui memória" (rede Markoviana), pode-se desconsiderar os tempos $\boldsymbol{\tau}_{\mathbf{t}}$ das transições que estavam

\footnotetext{
${ }^{39}$ Um Espaço de Estados Tangível $(\boldsymbol{S})$ possui todas as marcações $\mathbf{S}_{\mathbf{k}}=\left(\boldsymbol{\mu}_{\mathbf{k}}, \boldsymbol{\tau}_{\mathbf{t}, \mathbf{k}}\right)$ onde $\boldsymbol{\tau}_{\mathbf{t}, \mathbf{k}}>\mathbf{0}$. Em outras palavras, uma marcação tangível consome tempo, possuindo habilitadas apenas transições temporizadas $\left(\mathbf{s}_{\mathbf{k}} \in S \Leftrightarrow\left(\tau_{\mathbf{t}, \mathbf{k}}>\mathbf{0}\right.\right.$, $\left.\forall \mathbf{t} \in \boldsymbol{H}\left(\boldsymbol{\mu}_{\mathbf{k}}\right)\right)$ ). Uma marcação é considerada Imediata caso possua ao menos uma transição imediata $\left(\boldsymbol{\tau}_{\mathbf{t}, \mathbf{k}}=\mathbf{0}\right)$.

${ }^{40}$ Modelo de Markov é um modelo estocástico definido por 2 variáveis aleatórias, "o estado do sistema" (X) e o tempo de observação $(t)$, onde $\mathbf{N}\left(t \in\left(\mathbf{R}^{+} \vee \mathbf{N}\right)\right)=\mathbf{X} \in\left(\left\{\mathbf{X}_{\mathbf{0}}, \mathbf{X}_{\mathbf{1}}, \ldots, \mathbf{X}_{\mathbf{n}}\right\} \vee\left\{\mathbf{R}^{+}\right\}\right)$. Como as variáveis podem ser discretas ou contínuas, existem 4 tipos de modelos de probabilidade Markovianos, resultado da combinação 2 a 2 dos seus tipos de variáveis. Sobre o modelo, define-se um conjunto de probabilidades pi,j, que representam a passagem do estado $\mathrm{X}=\mathrm{i}$ para o estado $\mathrm{X}=\mathrm{j}$ e que forma a 'Matriz de Transição'.

A propriedade principal de um modelo de Markov é a de não conter memória, o que significa dizer que o evento futuro (próximo evento) em um sistema não depende dos eventos ocorridos no passado, ou seja: $\mathrm{P}(\mathrm{N}(\mathrm{t}+\Delta)=$ $\mathrm{x} \in \mathrm{X} \mid \mathrm{N}(\mathrm{t})=\mathrm{Xn}, \mathrm{N}(\mathrm{t}-\Delta)=\mathrm{Xn}-1, \ldots, \mathrm{N}(0)=\mathrm{Xo})=\mathrm{P}(\mathrm{N}(\mathrm{t}+\Delta)=\mathrm{x} \mid \mathrm{N}(\mathrm{t})=\mathrm{Xn})($ Shooman, 2002).

41 “Duas estruturas complexas são isomórficas quando se pode mapear uma sobre a outra de tal forma que cada parte de uma estrutura tem uma parte correspondente na outra estrutura. $\mathrm{O}$ termo correspondente, neste caso, significa que as 2 partes possuem regras similares em suas respectivas estruturas." (Douglas Hofstadter. In "Gödel, Escher, Bach: an Eternal Golden Braid", 1979. pg49)
} 
habilitadas em $\boldsymbol{\mu}_{(\mathbf{k})}$, não foram disparadas neste estado e, após um disparo qualquer, tornaramse desabilitadas em $\boldsymbol{\mu}_{(\mathbf{k}+\mathbf{1})}$.

Por outro lado, no caso de uma rede possuir transições com função de distribuição diferentes da exponencial, a SPN não pode ser representada por um processo Markoviano. Além de não se poder utilizar das propriedades de uma cadeia de Markov, a dinâmica de execução deste tipo de SPN deve estabelecer qual a política de reamostragem de tempo de $\mathbf{t}_{\mathbf{q}}$ quando $\left\{\mathbf{t}_{\mathbf{j}}, \mathbf{t}_{\mathbf{q}}\right\} \in \boldsymbol{H}\left(\mu_{\mathrm{k}}\right), \delta\left(\mu_{\mathrm{k}}, \mathbf{t}_{\mathbf{j k}}\right)=\delta\left(\mu_{\mathrm{k}}, \mathbf{t}_{\mathbf{q k}}\right)=\mu_{(\mathrm{k}+1)}$ e $\mathbf{t}_{\mathbf{q}} \notin \boldsymbol{H}\left(\mu_{(\mathrm{k}+1)}\right)$, porém $\mathbf{t}_{\mathbf{q}} \in \boldsymbol{H}\left(\mu_{(\mathrm{m}>\mathrm{k}+1)}\right)$. Definem-se, portanto, 3 políticas de reamostragem:

a) Repetição preemptiva diferente $\left(\boldsymbol{P R \boldsymbol { D } )}\right.$ : obtem-se uma nova temporização para $\mathbf{t}_{\mathbf{q}}$ quando o mesmo habilitar novamente. Isto equivale a política utilizada em um Modelo Markoviano (sem memória);

b) Repetição preemptiva idêntica (PRI): utiliza-se o mesmo valor de temporização amostrado na última habilitação de $\mathbf{t}_{\mathbf{q}}$;

c) Repetição preemptiva resumida $(\boldsymbol{P} \boldsymbol{R} \boldsymbol{R})$ : utiliza-se o valor remanescente em $\boldsymbol{\tau}_{\mathbf{t}}$ no último evento em que $\mathbf{t}_{\mathbf{q}}$ desabilitou sem disparar.

A Figura 94, adaptada de COMPSciDept (2004), ilustra exemplos de como os tipos de política de reamostragem agem sobre o valor de $\boldsymbol{\tau}_{\mathbf{t}}$ conforme a dinâmica de execução de uma SPN: habilitação (E), desabilitação antes que possa disparar (D) e disparo da transição (F).

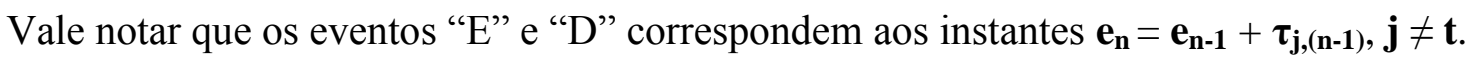

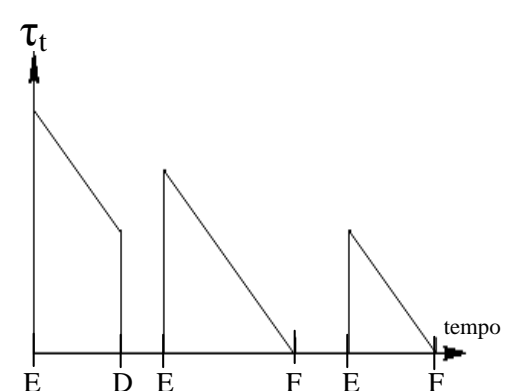

PRD

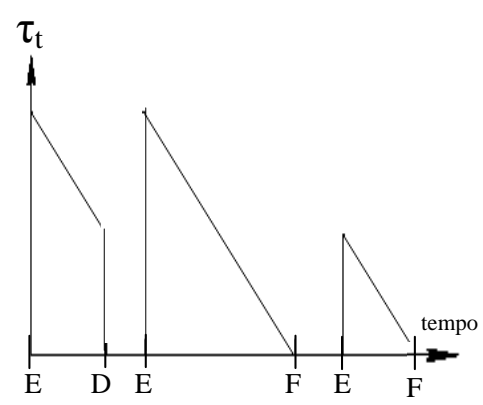

PRI

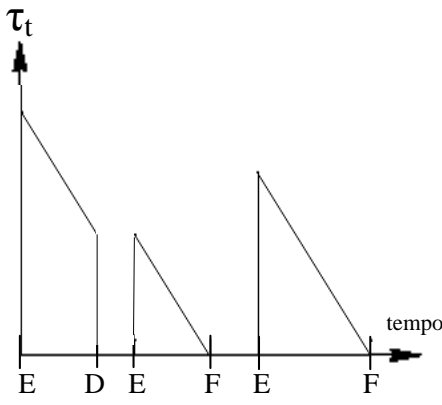

PRR

E: ponto de habilitação (enabled) ; D: ponto de desabilitação (disabled) ; F: ponto de disparo (fired)

Figura 94 - Exemplo de aplicação das políticas de reamostragem

Além das políticas de reamostragem, outra característica que deve ser considerada na execução das redes temporizadas é a existência conjunta de transições imediatas (com 
temporização igual a zero) e temporizadas $\left(\mathbf{t} \in \mathbf{T}=\mathbf{T}_{\mathbf{I}} \cup \mathbf{T}_{\mathbf{T}}\right)$. Segundo German (2000), a dinâmica de execução de uma rede temporizada segue as mesmas regras de uma RE (rede de Petri Estendida), com a adição de:

- caso exista conflito entre uma $\mathbf{t}_{\mathbf{j}} \in \mathbf{T}_{\mathbf{I}}$ e uma ou mais $\mathbf{t} \in \mathbf{T}_{\mathbf{T}},\left\{\mathbf{t}, \mathbf{t}_{\mathbf{j}}\right\} \in \boldsymbol{H}(\boldsymbol{\mu})$, dispara-se sempre a $\mathbf{t}_{\mathbf{j}} \in \mathbf{T}_{\mathbf{I}}$. Estados (marcações) que possuem $\mathbf{t} \in \mathbf{T}_{\mathbf{I}}$ e $\mathbf{t} \in \boldsymbol{H}(\boldsymbol{\mu})$ são denominados "Estados Imediatos" (vanishing).

- caso exista conflito entre mais de uma $\mathbf{t} \in \boldsymbol{H}(\mu)$, onde $\mathbf{t} \in \mathbf{T}_{\mathbf{T}}$, resolve-se o conflito através de uma "corrida" (race), onde se dispara a $\mathbf{t}_{\mathbf{k}} \in \boldsymbol{H}(\boldsymbol{\mu})$ cujo $\boldsymbol{\tau}_{(\mathbf{k})}<\boldsymbol{\tau}_{(\mathrm{t})}$ para todo $\mathbf{t}_{\mathbf{k}} \in \boldsymbol{H}(\boldsymbol{\mu})$. Estados (marcações) que possuam $\mathbf{t} \in \boldsymbol{H}(\boldsymbol{\mu})$ com todo $\mathbf{t} \in \mathbf{T}_{\mathbf{T}}$ são denominados “Estados Tangíveis" (tangible).

- caso a rede esteja em um estado imediato e exista conflito entre mais de um $\mathbf{t} \in \mathbf{T}_{\mathbf{I}}$, $\mathbf{t} \in \boldsymbol{H}(\boldsymbol{\mu})$, ou caso a rede esteja em um estado tangível e exista conflito entre mais de um $\mathbf{t} \in \mathbf{T}_{\mathbf{T}}$ mesmo após aplicar a corrida, resolve-se o conflito através de uma escolha probabilística, onde a probabilidade dos $\mathbf{t} \in \boldsymbol{H}(\boldsymbol{\mu}), w_{\mathrm{t}}(\mu)$, é $w_{t}(\mu)=\frac{\omega_{t}(\mu)}{\sum_{u \neq t, u \in H(\mu)} \omega_{u}(\mu)}$, sendo $\omega_{\mathbf{t}}(\mu)$ o peso da transição $\mathbf{t}$ na marcação $\boldsymbol{\mu}$ e onde $\boldsymbol{H}(\boldsymbol{\mu})$ é o conjunto de transições habilitadas na marcação $\mu$.

Uma rede de Petri Estocástica (SPN) possui a seguinte notação (adaptado de COMPSciDept (2004) e German (2000)):

SPN $=\left(\mathbf{P}, \mathbf{T}, \mathbf{I}, \mathbf{O}, \Pi, \mathbf{g}, \mu_{0}\right.$, Dist, $\mathbf{r}$, Afet,$\left.w\right)$, onde

$\mathbf{P}, \mathbf{T}, \mathbf{I}, \mathbf{O}, \Pi, \mathbf{g}$ e $\boldsymbol{\mu}_{\mathbf{0}}$ são iguais à notação de $\mathbf{R E}$ utilizando álgebra matricial, mas com a ressalva de que $\Pi=\mathbf{0}$ indica transição temporizada e $\Pi>\mathbf{0}$ indica transição imediata; $\mathbf{T}=\mathbf{T}_{\mathbf{T}}$ $\cup \mathbf{T}_{\mathbf{I}}$ : transições (estocástica ou deterministicamente) temporizadas $\left(\mathbf{T}_{\mathbf{T}}\right)$ e imediatas $\left(\mathbf{T}_{\mathbf{I}}\right)$. Graficamente, $\mathbf{T}_{\mathbf{T}}$ são representados por retângulos e $\mathbf{T}_{\mathbf{I}}$ continuam a ser representados por barras.

Dist $\in\left(\mathbf{N}^{\mathbf{n}} \rightarrow \boldsymbol{F}\right)^{\mathbf{m}}$ são as distribuições de tempo de disparo para as transições e dependentes da marcação (onde $\boldsymbol{F}$ é o conjunto de funções de distribuição positivas [0, $\infty[$ ). 
$\mathbf{r} \in(\{\boldsymbol{P R D}, \boldsymbol{P R S}, \boldsymbol{P R I}\})^{\mathbf{m}}$ são as políticas de reamostragem de tempo das transições.

Afet $: \mathrm{T} \rightarrow \mathbf{T}_{\mathrm{T}} \in(\{P R D, P R S, P R R\} \times\{P R D, P R S, P R R\})^{\mathbf{m}}$ é a política de reamostragem que uma transição $\mathbf{t}_{\mathbf{i}} \in \mathbf{T}_{\mathbf{T}}$ deve adotar na marcação $\boldsymbol{\mu}_{(\mathbf{k}+1)}$ quando $\left\{\mathbf{t}_{\mathbf{i}}, \mathbf{t}_{\mathbf{j}}\right\} \in \boldsymbol{H}\left(\boldsymbol{\mu}_{\mathbf{k}}\right), \mathbf{t}_{\mathbf{j}} \in \mathbf{T}, \delta\left(\mu_{\mathrm{k}}, \mathbf{t}_{\mathbf{i k}}\right)$ $=\delta\left(\mu_{\mathbf{k}}, \mathbf{t}_{\mathbf{j k}}\right)=\boldsymbol{\mu}_{(\mathbf{k}+\mathbf{1})}$ e $\mathbf{t}_{\mathbf{i}} \in \boldsymbol{H}\left(\boldsymbol{\mu}_{(\mathbf{k}+\mathbf{1})}\right)$. Esta propriedade é denominada afetação.

$\boldsymbol{w} \in\left(\mathbf{N}^{\mathbf{n}} \rightarrow \boldsymbol{R}^{+}\right)^{\mathbf{m}}$ são os pesos das transições dependentes de marcação.

As redes de Petri Estocásticas (SPN) utilizadas para modelar sistemas reais podem ser denominadas, segundo Bobbio (1988), como "redes de Condição/Evento", pois seus lugares identificam condições de partes do sistema e suas transições promovem a migração de uma condição (estado) para outra. Um evento ocorre (transição dispara) quando todas as condições são satisfeitas e dão concessão ao evento. A ocorrência de um evento modifica o estado das condições (marcação), e o tempo está associado com as atividades que induzem estas mudanças de estado.

\subsection{As RPFE e os Sistemas Híbridos (SH)}

Como visto anteriormente, as redes de Petri Estocásticas (SPN), por incorporarem características das redes de Petri elementares $(\mathrm{RdP})$ e características temporais estocásticas, podem modelar e avaliar sistemas dinâmicos com espaço de estados discretos e propriedades estocásticas. Porém, grande parcela dos sistemas reais é híbrida (Sistemas Híbridos - SH), onde processos contínuos (que contém valores reais) são controlados por processos lógicos discretos (tais como computadores). Como exemplo, o controle de aeronaves, os processos de manufatura, as redes de comunicação e sistemas inteligentes são sistemas reais híbridos de interesse (Tuffin; Chen; Trivedi, 2001).

De acordo com Varaiya (1999) apud Tuffin, Chen, Trivedi (2001), um Sistema Híbrido (SH) consiste de 2 componentes interdependentes: um componente contínuo, $\mathbf{z} \in \mathbf{R}^{\mathbf{n}}$, e um espaço de estados finito dirigido a evento $\mathbf{q} \in \mathbf{Q}$. Dado um estado $\left(\mathbf{z}_{\mathbf{k}}, \mathbf{q}_{\mathbf{k}}\right)$, apenas a parte contínua do estado evolui, segundo o conjunto de equações diferenciais $\frac{d z(t)}{d t} \in F\left(z(t), q_{0}\right) \subset R^{n}$, durante um intervalo de tempo $\left[\mathbf{t}_{\mathbf{k}}, \mathbf{t}_{\mathbf{k}+1}\right)$. No instante $\mathbf{t}_{\mathbf{k}+1}$, verifica-se $\mathbf{z}\left(\mathbf{t}_{\mathbf{k}+1}\right) \in \mathbf{G}\left(\mathbf{q}_{\mathbf{k}}, \mathbf{q}_{\mathbf{k + 1}}\right)$, onde $\mathbf{G}$ é uma "zona de habilitação" que verifica a permissão da migração do estado discreto qk para $\mathbf{q}_{\mathbf{k}+\mathbf{1}}$. Se a migração for permitida, ocorre a mudança instantânea de estado no modelo discreto $\left(\mathbf{q}_{\mathbf{k}}\right.$ para $\left.\mathbf{q}_{\mathbf{k + 1}}\right)$ e o estado contínuo é levado à $\mathbf{z}_{\mathbf{k}+1}$ segundo a relação $\left.\left(\mathbf{z}_{(} \mathbf{t}_{\mathbf{k}+1}\right), \mathbf{z}_{\mathbf{k}+1}\right) \in \mathbf{R}\left(\mathbf{q}_{\mathbf{k}}, \mathbf{q}_{\mathbf{k}+1}\right) \subset$ 
$\mathbf{R}^{\mathbf{n}} \times \mathbf{R}^{\mathbf{n}}$, onde $\mathbf{R}()$ é definido para cada par $\left(\mathbf{q}_{\mathbf{k}}, \mathbf{q}_{\mathbf{k}+1}\right)$ existente no modelo discreto. A dinâmica do modelo evolui da mesma forma para todo o tempo de avaliação.

Desta forma, a parte contínua de um sistema híbrido é modelada por meio de equações diferenciais, enquanto a parte discreta evolui em eventos temporais (COMPSciDept, 2004), e ambas se relacionam através do mecanismo explicado anteriormente. $\mathrm{O}$ formalismo das redes de Petri Fluidas e Estocásticas (RPFE) incorpora às características das redes de Petri Estocásticas (SPN) a representação de lugares e arcos contínuos, onde a evolução dos valores contínuos é representada através de funções de taxa fluida (relacionadas aos arcos fluidos), e a variação dos estados discretos segue as mesmas regras das redes de Petri Estocásticas. Primordialmente, o conceito das RPFE introduzido por Trivedi, Kulkarni (1993) tinha objetivo de resolver problemas de explosão de estados nas suas árvores de alcançabilidade, evitando o acumulo de marcas (tokens) nos lugares discretos. Portanto, uma RPFE não havia sido definida para modelar sistemas híbridos.

Ainda relacionando as diferenças entre formalismos (RPFE e SH), as RPFE, devido à herança das SPN, concentram-se na avaliação de medidas dos processos estocásticos envolvidos no sistema modelado. O formalismo dos sistemas híbridos ( $\mathrm{SH}$ ) foca na análise de alcançabilidade e de decisão (modelo de controle) do sistema. A influência das incertezas na modelagem dos SH são representadas por meio das fronteiras dos estados do modelo.

Mesmo com estas diferenças de formalismo e de aplicação, Tuffin, Chen, Trivedi (2001) demonstram que sistemas híbridos podem ser representados por meio de redes de Petri Fluidas e Estocásticas (RPFE). Portanto, segue uma descrição do formalismo das redes de Petri Fluidas e Estocásticas, utilizada neste trabalho para a modelagem e avaliação do sistema híbrido "controle de tráfego aéreo".

\subsubsection{Definição das RPFE}

A definição formal de uma rede de Petri Fluida e Estocástica (RPFE) pode ser representada pela 13-upla (adaptações de COMPSciDept (2004) e Ciardo, Nicol, Trivedi (1999)):

$$
\begin{array}{r}
\mathbf{R P F E}=\left(\mathbf{P}, \mathbf{T}, \mathbf{A}, \mathbf{f}, \Pi, \mathbf{g}, \text { Dist }, \mathbf{r}, \text { Afet }, w, \mathbf{b}, \mu_{0}, \chi_{0}\right), \text { onde } \\
\mathbf{P}=\mathbf{P}_{\mathbf{d}} \cup \mathbf{P}_{\mathbf{c}}=\left(\mathbf{p}_{1}, \mathbf{p}_{2}, \ldots, \mathbf{p}_{\# \mathbf{P d}}\right) \cup\left(\mathbf{q}_{1}, \mathbf{q}_{2}, \ldots, \mathbf{q}_{\# \mathbf{P c}}\right), \mathrm{P}_{\mathrm{d}} \cap \mathrm{P}_{\mathrm{c}}=\varnothing, \text { onde: }
\end{array}
$$

$\mathbf{P}_{\mathbf{d}} \in \mathbf{P}$ : lugares discretos da rede, graficamente representados por círculos simples, e: 
$\boldsymbol{\mu}_{(t)}\left(\mathbf{p}_{\mathbf{i}}\right) \in \mathbf{N}, \forall \mathbf{p}_{\mathbf{i}} \in \mathbf{P}_{\mathbf{d}}$ é a marcação (estado) da rede discreta no instante $\boldsymbol{t}, \boldsymbol{t} \in \mathbf{R}^{+}$, cuja representação gráfica é idêntica a uma SPN.

$\mathbf{P}_{\mathbf{c}} \in \mathbf{P}$ : lugares contínuos da rede, graficamente representados por círculos duplos concêntricos, e:

$\chi_{(t)}\left(\mathbf{q}_{\mathbf{i}}\right) \in \mathbf{R}^{+}, \forall \mathbf{q}_{\mathbf{i}} \in \mathbf{P}_{\mathbf{c}}$ é a marcação (estado) da rede contínua no instante $t, t \in \mathbf{R}^{+}$, representado graficamente por um valor $\mathbf{R}^{+}$dentro do lugar $\mathbf{P}_{\mathbf{c}}$.

$S=(\mu, \chi)_{(t)} \subseteq \hat{S}=\mathbf{N}^{\# \mathbf{P d}}\left(\mathbf{R}^{+}\right)^{\# \mathbf{P c}}{ }_{\mathbf{x}} \mathbf{R}^{+}$,onde $\hat{S}$ é o espaço de estados (marcação) potencial e $\boldsymbol{S}$ é o espaço de estados (marcação) efetivo de uma RPFE. Assim como nas SPN, as RPFE podem ser representadas por um Processo Estocástico $\left\{\mathbf{N}(t) \in \hat{S}, t \in \mathbf{R}^{+}\right\}$.

$\mathbf{T}=\mathbf{T}_{\mathbf{T}} \cup \mathbf{T}_{\mathrm{I}}=\left(\mathbf{t}_{1}, \mathbf{t}_{2}, \ldots, \mathbf{t}_{\# \mathbf{T t}}\right) \cup\left(\mathbf{u}_{1}, \mathbf{u}_{2}, \ldots, \mathbf{u}_{\# \mathbf{T i}}\right), \mathrm{T}_{\mathrm{T}} \cap \mathrm{T}_{\mathrm{I}}=\varnothing$

$\mathbf{A}=\mathbf{A}_{\mathrm{d}} \cup \mathbf{A}_{\mathbf{c}}=\left(\left(\left(\mathbf{P}_{\mathrm{d}} \boldsymbol{x} \mathbf{T}\right) \cup\left(\mathbf{T} \boldsymbol{x} \mathbf{P}_{\mathrm{d}}\right)\right) \boldsymbol{x} \hat{\boldsymbol{S}} \rightarrow \mathbf{N}\right) \cup\left(\left(\left(\mathbf{P}_{\mathrm{c}} \boldsymbol{x} \mathbf{T}_{\mathrm{I}}\right) \cup\left(\mathbf{T}_{\mathrm{I}} \boldsymbol{x} \mathbf{P}_{\mathbf{c}}\right)\right) \boldsymbol{x} \hat{\boldsymbol{S}} \rightarrow \mathbf{R}^{+}\right)$, onde:

$\mathbf{A}_{\mathbf{d}}=\mathbf{I}_{\mathbf{d}} \cup \mathbf{O}_{\mathbf{d}} \in\left(\mathbf{N}^{\# \mathbf{P d}} \rightarrow \mathbf{N}\right)^{(\# \mathbf{P d} x \# \mathbf{T})} \cup\left(\mathbf{N}^{\# \mathbf{P d}} \rightarrow \mathbf{N}\right)^{(\# \mathbf{T} x \# \mathbf{P d})}$ : cardinalidade dependente de marcação dos arcos de entrada e saída (I e $\mathbf{O})$ entre os lugares discretos $\mathbf{P}_{\mathbf{d}}$ e as transições $\mathbf{T}$.

$\mathbf{A}_{\mathbf{c}}=\mathbf{I}_{\mathbf{c}} \cup \mathbf{O}_{\mathbf{c}} \in\left(\mathbf{N}^{\# \mathbf{P c}} \rightarrow \mathbf{N}\right)^{(\# \mathbf{P c} x \# \mathbf{T i})} \cup\left(\mathbf{N}^{\# \mathbf{P c}} \rightarrow \mathbf{N}\right)^{(\# \mathbf{T i} x \# \mathbf{P c})}:$ impulso fluido dependente de marcação dos arcos de entrada e saída (I e $\mathbf{O}$ ) entre os lugares contínuos $\mathbf{P}_{\mathbf{c}}$ e as transições imediatas $\mathbf{T}_{\mathbf{I}}$.

$\mathbf{f}=\left(\left(\mathbf{P}_{\mathbf{c}} \boldsymbol{x} \mathbf{T}_{\mathbf{T}}\right) \cup\left(\mathbf{T}_{\mathbf{T}} \boldsymbol{x} \mathbf{P}_{\mathbf{c}}\right)\right) \boldsymbol{x} \hat{\boldsymbol{S}} \rightarrow \mathbf{R}^{+}$): taxa fluida (ou arco fluido) dependente de marcação dos arcos de entrada e saída (I e $\mathbf{O}$ ) entre os lugares contínuos $\mathbf{P}_{\mathbf{c}}$ e as transições temporizadas $\mathbf{T}_{\mathbf{T}}$. Graficamente, representa-se f por um arco direcional de linha cheia, com espessura maior que a dos $\operatorname{arcos} \mathbf{A}$ (representados como nas SPN).

$\Pi \in \mathbf{N}^{\# \mathbf{T i}}$ é o vetor de prioridade das transições imediatas $\mathbf{T}_{\mathbf{I}}$.

$\mathbf{g :}(\hat{\boldsymbol{S}} \rightarrow\{\text { verdadeiro }=\mathbf{1}, \text { falso }=\mathbf{0}\})^{\# \mathbf{T}}$ é o vetor de guarda das transições $\mathbf{T}$.

Dist $\in \mathbf{T}_{\mathbf{T}} \mathbf{x} \hat{\boldsymbol{S}} \rightarrow \boldsymbol{F}$ são as distribuições de tempo de disparo dependente da marcação para as transições $\mathbf{T}_{\mathbf{T}}$ (onde $\boldsymbol{F}$ é o conjunto de funções de distribuição positivas [0, $\infty[$ ).

$\mathbf{r} \in(\{\boldsymbol{P R D}, \boldsymbol{P R S}, \boldsymbol{P R R}\})^{\# \mathbf{T t}}$ são as políticas de reamostragem das transições $\mathbf{T}_{\mathbf{T}}$.

Afet $: \mathbf{T} \rightarrow \mathbf{T}_{\mathbf{T}} \in(\{P R D, P R S, P R R\} \times\{P R D, P R S, P R R\})^{\mathbf{m}}$ é a política de reamostragem 
que uma transição $\mathbf{t}_{\mathbf{i}} \in \mathbf{T}_{\mathbf{T}}$ deve adotar na marcação $\boldsymbol{\mu}_{(\mathbf{k}+\mathbf{1})}$ quando $\left\{\mathbf{t}_{\mathbf{i}}, \mathbf{t}_{\mathbf{j}} \cup \mathbf{u}_{\mathbf{j}}\right\} \in \boldsymbol{H}\left(\boldsymbol{\mu}_{\mathbf{k}}\right), \delta\left(\boldsymbol{\mu}_{\mathbf{k}}, \mathbf{t}_{\mathbf{i k}}\right)=$ $\delta\left(\mu_{\mathbf{k}}, \mathbf{t}_{\mathbf{j}} \cup \mathbf{u}_{\mathbf{j}}\right)=\boldsymbol{\mu}_{(\mathbf{k}+1)}$ e $\mathbf{t}_{\mathbf{i}} \in \boldsymbol{H}\left(\boldsymbol{\mu}_{(\mathbf{k}+1)}\right)$. Esta propriedade é denominada afetação.

$\boldsymbol{w} \in \mathbf{N}^{\# \mathbf{T}} \rightarrow \boldsymbol{R}^{+}$são os pesos, dependentes de marcação, das transições $\mathbf{T}$.

b: $\mathbf{P}_{\mathbf{c}} \mathbf{x} \mathbf{N}^{\# \mathbf{P d}} \rightarrow \mathbf{R}_{\mathbf{0}}$ são os limites fluidos para cada lugar contínuo $\mathbf{P}_{\mathbf{c}}$.

$\mu_{\mathbf{0}}=\boldsymbol{\mu}_{(\mathbf{t}=\mathbf{0})}\left(\mathbf{p}_{\mathbf{i}}\right), \forall \mathbf{p}_{\mathbf{i}} \in \mathbf{P}_{\mathbf{d}}$ : marcação da parte discreta da RPFE no instante $t=0$ (marcação inicial).

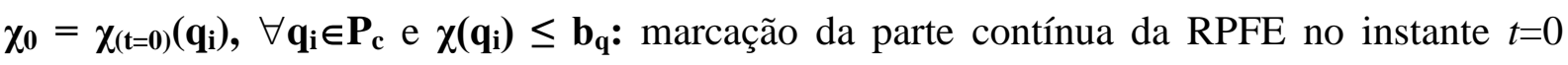
(marcação inicial).

A Figura 95 ilustra os elementos gráficos básicos de uma RPFE.

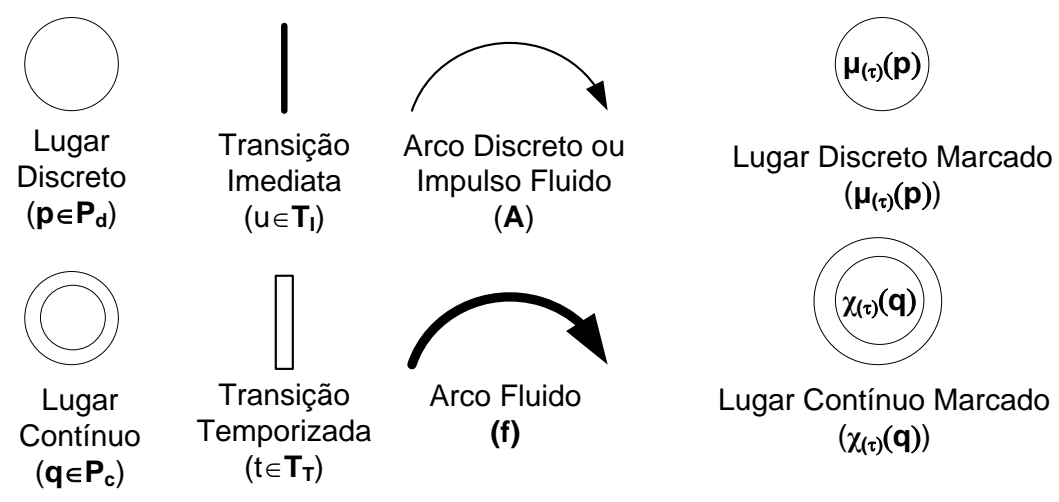

Figura 95 - Elementos Gráficos básicos de uma RRFE

\subsubsection{Dinâmica de Execução das redes de Petri Fluidas e Estocásticas}

Com relação à dinâmica de execução de uma RPFE, uma transição $\mathbf{t} \in \mathbf{T}$ está habilitada em uma marcação $(\mu, \chi)_{(t)} \in \hat{\boldsymbol{S}}$ no instante $t \in \boldsymbol{R}^{+}, \mathbf{t} \in \boldsymbol{H}\left((\mu, \chi)_{(t)}\right)$, para as mesmas condições de uma rede de Petri Estocástica, ou seja:

$$
\begin{gathered}
\mathbf{A}_{\mathbf{p i}, \mathrm{t}}\left((\mu, \chi)_{(t)}\right) \leq \mu_{(t)}\left(\mathbf{p}_{\mathbf{i}}\right) \vee \mathbf{f}_{\mathbf{q} \mathbf{i}, \mathrm{t}}\left((\mu, \chi)_{(t)}\right) \leq \chi_{(t)}\left(\mathbf{q}_{\mathbf{i}}\right), \forall \mathbf{p}_{\mathbf{i}} \in \mathbf{P}_{\mathbf{d}}, \forall \mathbf{q}_{\mathbf{i}} \in \mathbf{P}_{\mathbf{c}} \\
\mathbf{e} \\
\mathbf{g}_{\mathbf{t}}\left((\mu, \chi)_{(t)}\right)=1 .
\end{gathered}
$$


Da mesma forma, para $\mathbf{t} \in \boldsymbol{H}\left((\mu, \chi)_{(t)}\right)$, uma marcação $(\mu, \chi)_{(t)}$ é considerada imediata quando $\mathbf{t}$ $\in \mathbf{T}_{\mathbf{I}}$, e uma marcação $(\mu, \chi)_{(t)}$ é considerada tangível quando $\mathbf{t} \in \mathbf{T}_{\mathbf{T}}$.

Dado $\mathbf{t} \in \boldsymbol{H}\left((\mu, \chi)_{(t=\mathbf{k})}\right), \mathbf{t} \in \mathbf{T}$, a marcação $(\mu, \chi)_{(t=\mathbf{k})}$ é alterada para o estado $(\mu, \chi)_{(t=\mathbf{k}+\tau)}$ de 2 formas COMPSciDept (2004) (onde $\tau$ é o tempo gasto entre o evento $\mathbf{t} \in \boldsymbol{H}\left((\mu, \chi)_{(t=\mathbf{k})}\right)$ e $\uparrow \mathbf{t}$, ou seja, a temporização de $\mathbf{t}$ em $\boldsymbol{t}=\mathbf{k} \in \mathbf{R}^{+}$:

- $\underline{\mathbf{1}^{\mathbf{a}} \text { Forma: }}$ com relação aos arcos discretos $\left(\mathbf{A}_{\mathbf{d}}\right)$ e impulsos fluidos $\left(\mathbf{A}_{\mathbf{c}}\right),(\boldsymbol{\mu}, \chi)_{(t=\mathbf{k})}$ varia na forma:

$\mu_{(t=\mathrm{k}+\tau)}(\mathbf{p})=\mu_{(t=\mathbf{k})}(\mathbf{p})+\mathbf{A}_{\mathrm{t}, \mathrm{p}}\left((\mu, \chi)_{(t=\mathrm{k})}\right)-\mathbf{A}_{\mathbf{p}, \mathrm{t}}\left((\mu, \chi)_{(t=\mathbf{k})}\right), \forall \mathrm{p} \in \mathrm{P}_{\mathrm{d}}$

$\chi_{(t=\mathbf{k}+\tau)}\left(\mathbf{q}_{\mathbf{i}}\right)=\min \left(\mathbf{b}_{\mathbf{q}}\left(\mu_{(t=\mathbf{k}+\tau)}\right) ; \max \left(0 ; \chi_{(t=\mathbf{k})}(\mathbf{q})+\mathbf{A}_{\mathbf{t}, \mathbf{q}}\left((\mu, \chi)_{(t=\mathbf{k})}\right)-\mathbf{A}_{\mathbf{q}, \mathbf{t}}\left((\mu, \chi)_{(t}\right.\right.\right.$ = k))) ) ), $\forall \mathrm{q} \in \mathrm{P}_{\mathrm{c}}$.

- $\underline{\mathbf{2}^{\mathbf{a}} \text { Forma: }}$ com relação aos arcos fluidos $\mathbf{f}$, se a marcação $(\mu, \chi)_{(t=\mathbf{k})}$ é tangível, o nível fluido flui continuamente através dos $\operatorname{arcos} \mathbf{f}$ habilitados pelas transições $\mathbf{t}_{\mathbf{i}} \in \mathbf{T}_{\mathbf{T}}$ até que $\mathbf{t}_{\mathbf{i}} \notin \boldsymbol{H}\left((\mu, \chi)_{(t}={ }_{\mathbf{k}}\right)$. Considerando $\delta_{\mathbf{q}}{ }^{{ }^{\text {pot }}}\left((\mu, \chi)_{(t=\mathbf{k})}\right)=$ $\sum_{\mathrm{t} \in \Lambda}\left(\mathrm{f}_{\mathrm{t}, \mathrm{q}}(\mu, \chi)_{(t=k)}-\mathrm{f}_{\mathrm{q}, \mathrm{t}}(\mu, \chi)_{(t=k)}\right)$, onde $\quad \Lambda=\boldsymbol{H}\left((\mu, \chi)_{(t=\mathrm{k})}\right)$, como sendo a variação potencial de taxa do nível fluido no estado $(\mu, \chi)_{(t=\mathbf{k})}$. O nível fluido de $\mathrm{q} \in \mathrm{P}_{\mathrm{c}}$, durante o estado $(\mu, \chi)_{(t=\mathrm{k})}$, varia continuamente conforme:

$$
\begin{aligned}
& \frac{\mathrm{d} \chi_{\mathrm{q}}}{\mathrm{d} t}=0, \text { caso }\left(\mathbf{b}_{\mathbf{q}}\left((\mu, \chi)_{(t=\mathbf{k})}\right)=\mathbf{0}\right) \vee \\
& \left(\left(\chi_{(t=\mathbf{k})}(\mathbf{q})=\mathbf{b}_{\mathbf{q}}\left((\mu, \chi)_{(t=\mathbf{k})}\right)\right) \wedge\left(\delta_{\mathbf{q}}{ }^{\mathbf{p o t}}\left((\mu, \chi)_{(t=\mathbf{k})}\right)>\mathbf{0}\right)\right) \vee \\
& \left(\chi_{(t=\mathbf{k})}(\mathbf{q})=\mathbf{0} \wedge{\delta_{\mathbf{q}}}^{\left.{ }^{\mathbf{p o t}}\left((\mu, \chi)_{(t=\mathbf{k})}\right)<\mathbf{0}\right) .}\right. \\
& \frac{\mathrm{d} \chi_{\mathrm{q}}}{\mathrm{d} t}=\delta_{\mathbf{q}}{ }^{{ }^{p o t}}\left((\mu, \chi)_{(t=\mathbf{k})}\right), \text { para os demais casos. }
\end{aligned}
$$

A evolução estocástica das marcações de uma rede de Petri Fluida e Estocástica (RPFE) segue as mesmas regras da dinâmica de execução de uma SPN, a não ser que ocorra a desabilitação de uma transição $\mathbf{t}_{\mathbf{i}} \in \boldsymbol{H}\left((\mu, \chi)_{(t=\mathbf{k})}\right)$ devido $\chi_{(t=\mathbf{k})}\left(\mathbf{q}_{\mathbf{i}}\right)$ alcançar determinado valor antes que $\mathbf{t}_{\mathbf{i}}$ 
dispare. Além disto, a evolução das marcações discretas da rede ocorre de forma atômica, identicamente a uma SPN.

\subsection{Análise Quantitativa e as redes de Petri de Recompensa (SRN)}

As redes de Petri Estocásticas (SPN) e suas extensões (tal como as RPFE) permitem obter medidas importantes dos sistemas, tais como disponibilidade, desempenho, confiabilidade e segurança (safety), entre outras medidas baseadas em tempo.

O comportamento estocástico de uma SPN é determinado através do cálculo da probabilidade de ocorrência dos estados do sistema (Bobbio, 1988). Outras medidas são obtidas pela análise estocástica dos elementos do modelo, tal como a freqüência de disparo das transições ou o número de marcas em um lugar no instante $t$.

Uma forma sistemática de definir medidas de interesse em uma rede é por meio de funções de recompensa, onde as estruturas de recompensa podem ser expressas, em alto nível, por expressões condicionais à marcação de uma rede (German, 2000). Redes cujo formalismo permita especificar medidas de saída como funções baseadas em recompensa são definidas como "redes de Recompensa". As redes de Petri Estocásticas, agregadas ao formalismo de recompensa, são definidas como "redes Estocásticas de Recompensa (ou Stochastic Reward nets - SRN)" (Muppala; Ciardo, 1994).

Ao nível do processo estocástico, uma estrutura de recompensa é definida pelos vetores de taxa de recompensa (rr) e de recompensa impulsiva (ri), onde (German, 2000):

○ $\mathbf{r r}_{\mathbf{n}}$ é a taxa de recompensa associada com o estado $\mathbf{n} \in \boldsymbol{S}$.

○ $\quad \mathbf{r i}_{\mathbf{n}}^{\mathbf{g}}$ é a recompensa impulsiva associada com a transição $\mathbf{g} \in \mathbf{T}$ no estado $\mathbf{n} \in \boldsymbol{S}$.

São definidas 3 variáveis de recompensa para uma dada estrutura de recompensa:

$$
R_{\text {inst }}(t)=\sum_{n \in S} r r_{n} \cdot 1_{\{N(t)=n\}}+\sum_{g \in T} \sum_{n \in S} r i_{n}^{g} \cdot 1_{\{g \text { dispara em } t \text { no estado } n\}} \cdot \delta \text {, onde: }
$$

- $\mathbf{R}_{\text {inst }}(t)$ é a variável de recompensa instantânea no instante $t$.

○ $\mathbf{1}_{\{\text {predicado\} }}$ retorna “1" caso o "\{predicado\}" seja verdadeiro, e “ 0 " nos demais casos. 
○ $\mathbf{N}(t) \in S$ é o processo estocástico definido para a rede em análise.

○ $\delta$ é uma função impulsiva de $\operatorname{Dirac}^{42}$, cuja área é dada por $\mathbf{r i}_{\mathbf{n}}^{\mathbf{g}}$ no instante do disparo de $\mathbf{g}$.

$R_{\text {acum }}(t)=\int_{0}^{t} R_{\text {inst }}(\varphi) d \varphi$ é a variável de recompensa acumulada até o instante $t$.

$R_{\text {med }}(t)=\frac{1}{t} \cdot R_{\text {acum }}(t)$ é a variável de recompensa média até o instante $t$.

A variável $\mathrm{R}_{\text {inst }}(t)$ não possui comportamento estocástico devido à presença de impulsos $(\delta)$ (German, 2000). Porém, por serem aleatórias, as variáveis $\mathrm{R}_{\text {acum }}(t)$ e $\mathrm{R}_{\text {med }}(t)$ podem ser caracterizadas por meio de suas distribuições de probabilidade. Conforme Muppala, Ciardo (1994), as medidas de saída de uma SRN são expressas em termos dos valores de esperança E[] das variáveis de recompensa, definidas conforme a quantidade de interesse em análise.

Portanto, considerando $\mathbf{E}\left[\mathbf{R}_{\text {acum }}(t)\right]$ como a esperança da variável de recompensa acumulada $\mathrm{R}_{\text {acum }}(t)$, tem-se (German, 2000):

$\mathrm{E}\left[R_{\text {acum }}(t)\right]=\sum_{n \in S} r r_{n} \cdot \int_{0}^{t} \pi_{n}(x) d x+\sum_{g \in T} \sum_{n \in S} r i_{n}^{g} \cdot \int_{0}^{t} \varphi_{n}^{g}(x) d x$, onde

- $\pi_{\mathbf{n}}(t)=\mathbf{P}(\mathbf{N}(t)=\mathbf{n}), \mathbf{n} \in S:$ probabilidade de estado transitório, que representa a probabilidade da rede estar na marcação $\mathbf{n}$ no instante $t$, pois $\mathbf{E}\left[1_{\{N(t)=n\}}\right]=\pi_{\mathbf{n}}(t)$.

- $\int_{0}^{t} \varphi_{n}^{g}(x) d x=\mathbf{E}\left[\mathrm{n}^{\mathbf{o}}\right.$ de disparos de $\mathbf{g} \in \mathbf{T}$ na marcação $\mathbf{n} \in \mathbf{S}$ e durante o período [0 a $\left.\left.t\right)\right]$.

Considerando $\mathbf{E}\left[\mathbf{R}_{\text {med }}(t)\right]$ como a esperança da variável de recompensa média $\mathbf{R}_{\text {med }}(t)$, tem-se:

$$
\mathrm{E}\left[R_{\text {med }}(t)\right]=\mathrm{E}\left[\frac{1}{t} \cdot R_{\text {acum }}(t)\right]=\frac{1}{t} \cdot \mathrm{E}\left[R_{\text {acum }}(t)\right]
$$

${ }^{42}$ Função delta de Dirac: $\delta(t-\tau)=0$ para $\forall \boldsymbol{t} \neq \boldsymbol{\tau}$ e $\delta(t-\tau)=\infty$ para $t=\boldsymbol{\tau}$, onde $\int_{-\infty}^{+\infty} \delta(x) d x=1$. 
Para a variável de recompensa instantânea $\mathbf{R}_{\text {inst }}(t)$, é possível definir sua esperança no caso da mesma não conter impulsos. Portanto, obtendo-se $\mathbf{E}\left[\mathbf{R}_{\text {inst }}(t)\right]$ por meio de $\mathbf{R}_{\text {acum }}(t)$, tem-se:

$$
\mathrm{E}\left[R_{\text {inst }}(t)\right]=\frac{d}{d t} \mathrm{E}\left[R_{\text {acum }}(t)\right]=\sum_{n \in S} r r_{n} \cdot \pi_{n}(t)+\sum_{g \in T_{I}} \sum_{n \in S} r i^{g} \cdot \varphi_{n}^{g}(t)
$$

Como forma de simplificar o equacionamento, pode-se suprimir a definição dos valores de $\mathbf{r i}_{\mathbf{n}}^{\mathbf{g}}$ (recompensa impulsiva) para uma rede em análise. Desta forma, fazendo $\mathbf{r i}_{\mathbf{n}}^{\mathbf{g}}=\mathbf{0}, \forall \mathbf{g} \in \mathbf{T}$, $\forall \mathbf{n} \in S$, tem-se:

$$
R_{\text {inst }}(t)=\sum_{n \in S} r r_{n} \cdot 1_{\{N(t)=n\}} \Rightarrow \mathrm{E}\left[R_{\text {acum }}(t)\right]=\sum_{n \in S} r r_{n} \cdot \int_{0}^{t} \pi_{n}(x) d x
$$

e as demais variáveis são calculadas como conseqüência da definição acima.

A análise de uma rede por meio de suas equações de recompensa exige o cálculo das suas probabilidades de estado $\pi_{\mathbf{n}}(\boldsymbol{t})=\mathbf{P}(\mathbf{N}(\boldsymbol{t})=\mathbf{n}), \mathbf{n} \in S$. Redefinindo-o como o vetor:

$$
\pi(t)=\left(\pi_{1}(t), \pi_{2}(t), \ldots, \pi_{\mathrm{m}}(t)\right), S=\{1,2, \ldots, \mathrm{m}\}
$$

caso exista $\pi=\lim _{t \rightarrow \infty} \pi(t), \pi$ é considerado a probabilidade de estado limite. No caso desta probabilidade não existir, pode-se utilizar a definição $\pi_{\mathbf{n}}=\lim _{t \rightarrow \infty} \frac{1}{t} \int_{0}^{t} \pi_{\mathrm{n}}(x) d x$, onde $\pi_{\mathbf{n}}$ é a probabilidade de limite de tempo médio (time-averaged limit) para um estado $\mathbf{n} \in \mathbf{S}$ qualquer. Porém, no caso de $\pi$ e $\pi_{\mathbf{n}}$ existirem, ambos possuem o mesmo valor, e ambos podem ser interpretados como a fração de tempo no qual um processo permanece em um determinado estado quando o mesmo é observado por um longo período de tempo (German, 2000).

Com base na estrutura de recompensa apresentada e nos possíveis cálculos das probabilidades de estado, pode-se realizar tanto a análise transitória quanto a análise estacionária (ou em regime) de uma rede. Na análise transitória, observa-se o estado do sistema em instantes específicos de tempo. Na análise estacionária, obtém-se o comportamento do sistema quando o mesmo está em condições estáveis de funcionamento (comportamento padrão).

Seguem exemplos de algumas medidas quantitativas que podem ser obtidas para a análise de uma rede, definidos em Bobbio (1988). 


\subsubsection{Tempo gasto na condição $S$ (e Confiabilidade)}

Dado $n \in S=\{1,2, \ldots, \mathbf{m}\}$ como sendo o conjunto de marcações de interesse de uma rede, o tempo $\boldsymbol{\Psi}_{S}(\mathbf{t})$ gasto no conjunto $S$ e no intervalo $[0, t)$ é dado por:

$$
\Psi_{S}(t)=\sum_{n \in S} \int_{0}^{t} \pi_{n}(x) d x, \text { onde } \mathbf{r r}_{\mathbf{n}}=\mathbf{1} \text { e } \mathbf{r i}_{\mathbf{n}}=\mathbf{0} \text { para } \forall \mathbf{n} \in S
$$

Considerando $S=\{\mathbf{1}, \mathbf{2}, \ldots, \mathbf{m}\}$ como conjunto de estados operacionais do sistema, $\boldsymbol{\Psi}_{S}(\boldsymbol{t})$ é a confiabilidade do sistema no intervalo $[0, t)$.

Exemplo 1: considere a SPN ilustrada na Figura 97, onde:

$P=\left\{P_{1}, P_{2}\right\}, T=\left\{t_{1}\right\}, I=\left\{I\left(t_{1}\right)=P_{1}\right\}, O=\left\{I\left(t_{1}\right)=P_{2}\right\}, \operatorname{Dist}=\left\{t_{1}=\exp (-\lambda)\right\}$.

$\mu=\left\{\mu_{0}, \mu_{1}\right\}$

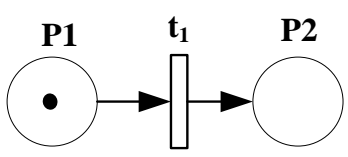

Figura 96 - Exemplo de SPN (Modelo de Funcionamento / Falha sem reparo).

O cálculo do vetor de equações de probabilidade da SPN em análise é:

$\pi(t)=\left(\pi_{0}(t), \pi_{1}(t)\right)$, onde $\pi_{0}(t)+\pi_{1}(t)=1, \pi(0)=(1,0)$ e $\pi(\infty)=(0,1)$.

$\pi(t)=\left(\pi_{0}(0) \cdot \mathrm{e}^{-\lambda . t}, \pi_{0}(0) \cdot\left(1-\mathrm{e}^{-\lambda . t}\right)\right)=\left(\mathrm{e}^{-\lambda . t},\left(1-\mathrm{e}^{-\lambda . t}\right)\right)$.

Sendo $S=\left\{\mu_{0}\right\}=\{(1,0)\}$ o conjunto de marcações de interesse, tem-se:

$$
\Psi_{S}(t)=\int_{0}^{t} \pi_{0}(x) d x=\int_{0}^{t} \mathrm{e}^{-\lambda \cdot x} d x=\frac{1}{\lambda}\left(1-\mathrm{e}^{-\lambda \cdot t}\right)
$$

Caso a marcação $\mu_{0}$ represente o estado de funcionamento (operacional) do sistema e a marcação $\mu_{1}$ represente o estado de falha (não operacional) do sistema, $\Psi_{S}(\mathbf{t})=\frac{1}{\lambda}\left(1-\mathrm{e}^{\lambda . t}\right) e^{\prime}$ a confiabilidade do sistema em análise no intervalo [0, t). 


\subsubsection{Probabilidade de ocorrência de condição $S$ (e Disponibilidade)}

Dado $\mathbf{n} \in S=\{1,2, \ldots, \mathbf{m}\}$ como sendo o conjunto de marcações de interesse de uma rede e $\pi_{\mathbf{n}}(t)=\mathbf{P}(\mathbf{N}(t)=\mathbf{n}), \mathbf{n} \in S$, a probabilidade $\mathbf{Q}_{S}(t)$ de uma rede estar nas marcações de interesse no instante $t$ é:

$$
Q_{S}(t)=\sum_{n \in S} \pi_{n}(t), \text { onde } \mathbf{r r}_{\mathbf{n}}=\mathbf{1} \text { e } \mathbf{r i}_{\mathbf{n}}=\mathbf{0} \text { para } \forall \mathbf{n} \in S
$$

Considerando $S=\{1,2, \ldots, \mathbf{m}\}$ como o conjunto de estados operacionais do sistema, $\mathbf{Q}_{S}(\boldsymbol{t})$ é a disponibilidade do sistema no instante t. Caso exista $\lim _{t \rightarrow \infty} \pi_{\mathrm{n}}(t), \mathbf{Q}_{s}(\infty)$ é a disponibilidade assintótica do sistema em análise.

Exemplo 2: considere a SPN ilustrada na Figura 97, onde:

$$
\begin{aligned}
& P=\left\{P_{1}, P_{2}\right\}, T=\left\{t_{1}, t_{2}\right\}, \\
& I=\left\{I\left(t_{1}\right)=P_{1}, I\left(t_{2}\right)=P_{2}\right\}, O=\left\{O\left(t_{1}\right)=P_{2}, O\left(t_{2}\right)=P_{1}\right\}, \\
& D i s t=\left\{t_{1}=\exp (-\lambda), t_{2}=\exp (-\mu)\right\}, \mu=\left\{\mu_{0}, \mu_{1}\right\} .
\end{aligned}
$$

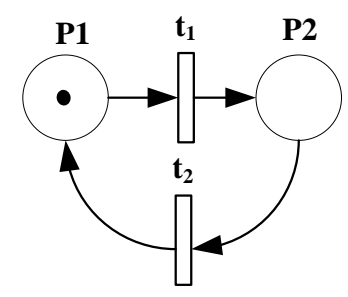

Figura 97 - Exemplo de SPN (Modelo de Funcionamento / Falha com reparo).

O cálculo do vetor de equações de probabilidade da SPN em análise é:

$\pi(t)=\left(\pi_{0}(t), \pi_{1}(t)\right) ; \pi_{0}(t)+\pi_{1}(t)=1$ e $\pi(0)=(1,0)$

Considerando $S=\left\{\mu_{0}\right\}=\{(1,0)\}$ como o conjunto de marcações de interesse, tem-se:

$$
Q_{S}(t)=\pi_{0}(t)
$$

Caso a marcação $\mu_{0}$ represente o estado de funcionamento (operacional) do sistema e a marcação $\mu_{1}$ represente o estado de falha (não operacional) do sistema, $\mathrm{Q}_{S}(\mathrm{t})=\pi_{0}(t)$ é a 
disponibilidade do sistema em análise no instante $t$, e $\mathrm{Q}_{S}(\infty)=\pi_{0}(\infty)$ é a disponibilidade assintótica para o mesmo.

A resolução de $\pi(t)$ pode ser obtida por meio da discretização de $t$, onde:

$$
\pi(t+\Delta)=\left[\begin{array}{cc}
1-\lambda & \mu \\
\lambda & 1-\mu
\end{array}\right] . \pi(t) \stackrel{\Delta<<\min (\lambda, \mu)}{\longrightarrow} \pi(\mathrm{n} . \Delta)=\left[\begin{array}{cc}
1-\lambda & \mu \\
\lambda & 1-\mu
\end{array}\right]^{n} \cdot \pi(0)
$$

\subsubsection{Tempo médio para a $1^{\mathrm{a}}$ passagem por $S(\mathrm{e} M T T F)$}

Considere $S=\{\mathbf{1}, \mathbf{2}, \ldots, \mathbf{m}\}$ o conjunto de marcações de interesse. Considerando $\mathbf{Q}_{\mathbf{S}}(\boldsymbol{t})$ definido anteriormente, o tempo médio para $1^{\text {a }}$ passagem em $\boldsymbol{S}\left(\boldsymbol{\Phi}_{S}\right)$ é definida por:

$$
\Phi_{n}=\int_{0}^{\infty}\left|1-Q_{n}(x)\right| d x \text { para } \forall \mathbf{n} \in S
$$

Considerando $\boldsymbol{S}$ como o conjunto de estados não operacionais (em falha) do sistema, $\boldsymbol{\Phi}_{S}$ é o seu Tempo Médio para Falhar (ou Mean Time to Failure - MTTF).

Exemplo 3: considere a mesma SPN ilustrada na Figura 96.

Considerando $S=\left\{\mu_{1}\right\}=\{(0,1)\}$ como o conjunto de marcações de interesse, tem-se:

$$
\Phi_{S}=\int_{0}^{\infty}\left|1-Q_{n}(x)\right| d x=\int_{0}^{\infty}\left|1-\left(1-e^{-\lambda \cdot x}\right)\right| d x=\frac{1}{\lambda}
$$

Como a marcação $\mu_{1}$ represente o estado de falha (não operacional) do sistema, $\boldsymbol{\Phi}_{S}=\frac{1}{\lambda}$ éo tempo médio para que o sistema deixe de funcionar, ou seja, seu MTTF.

\subsubsection{Distribuição de marcas (tokens) em $\mathbf{p} \in \mathbf{P}$}

Considere $\mathbb{I}_{(\mathbf{t})}(\mathbf{p i}, \mathbf{k}) \subseteq \boldsymbol{\mu}$ o conjunto de marcações, no instante $\boldsymbol{t}$, em que $\boldsymbol{\mu}_{(\mathbf{t})}\left(\mathbf{p}_{\mathbf{i}}\right)=\mathbf{k}, \forall \mathbf{p}_{\mathbf{i}} \in \mathbf{P}$. O número médio de marcas existente em $\mathbf{p}_{\mathbf{i}}$ no instante $t$ é dado por:

$$
\mathrm{E}\left[\mu_{(t)}\left(\mathrm{p}_{\mathrm{i}}\right)\right]=\sum_{k \in \mathbb{I}_{(t)}\left(\mathrm{p}_{\mathrm{i}}, t\right)} k \cdot \pi_{k}(t)
$$


Exemplo 4: considere a SPN ilustrada na Figura 98, onde:

$P=\left\{P_{1}\right\} ; T=\left\{t_{i}, t_{o}\right\} ; I=\left\{I\left(t_{o}\right)=P_{1}\right\}, O=\left\{O\left(t_{i}\right)=P_{1}\right\}$;

Dist $=\left\{F\left(t_{i}\right)=\exp \left(-\lambda_{i}\right), F\left(t_{o}\right)=\exp \left(-\lambda_{0} . \mu(P 1)\right)\right\} ; g=\{\mu(P 1) \leq K \rightarrow 1 ; 1\}$;

$\mu_{0}=(0)$.

O modelo representa um sistema de fila $M / M / 1 / K$, onde $\boldsymbol{\mu}_{(\mathrm{t})}(\mathbf{P 1})$ é o número de usuários na fila no instante $\boldsymbol{t}, \mathbf{t}_{\mathbf{i}}$ é o processo de chegada na fila, $\mathbf{t}_{\mathbf{0}}$ representa o processo de serviço e a condição $\mu(P 1) \leq K$ da guarda de $\mathbf{t}_{\mathbf{i}}$ representa a capacidade máxima da fila. O processo de serviço é dependente da marcação, sendo diretamente proporcional a $\mu(P 1)$.

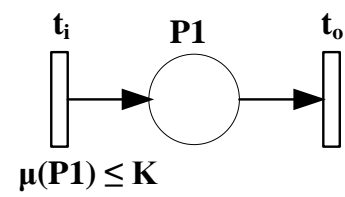

Figura 98 - Exemplo de SPN (Modelo de Fila).

O espaço de estados (marcações) desta rede é:

$\boldsymbol{\mu}=\left\{\boldsymbol{\mu}_{0}, \boldsymbol{\mu}_{1}, \boldsymbol{\mu}_{2}, \ldots, \boldsymbol{\mu}_{\boldsymbol{K}}\right\}=\{(\boldsymbol{0}),(\mathbf{1}),(2), \ldots$, , (K) $\}$, o que implica em $\mathbb{I}_{(\mathrm{t})}(\boldsymbol{P} 1,0)=\left\{\boldsymbol{\mu}_{0}\right\}$, $\mathbb{I}_{(t)}(P 1,1)=\left\{\boldsymbol{\mu}_{1}\right\}, \ldots, \mathbb{I}_{(t)}(\boldsymbol{P} 1, K)=\left\{\boldsymbol{\mu}_{K}\right\}$. Portanto, $\mathrm{E}\left[\mu_{(t)}(\mathrm{p} 1)\right]$ é calculado como:

$\mathrm{E}\left[\mu_{(t)}(\mathrm{P} 1)\right]=0 . \pi_{0}(t)+1 . \pi_{1}(t)+\ldots+K . \pi_{K}(t)$, restando o cálculo $\pi(t)$. Para este exemplo, $\mathrm{E}\left[\mu_{(t)}(\mathrm{P} 1)\right]$ representa o tamanho médio de usuário na fila no instante $t$.

\subsubsection{Número médio de disparos de $t \in T$}

Considere $\boldsymbol{S}=\{\mathbf{1}, \mathbf{2}, \ldots, \mathbf{m}\}$ o conjunto de marcações de interesse onde $\mathbf{t}_{\mathbf{i}} \in \boldsymbol{H}(\boldsymbol{S}), \mathbf{t}_{\mathbf{i}} \in \mathbf{T}$. O número médio de disparos de $\mathbf{t}_{\mathbf{i}}$ no intervalo de tempo $[0, t)$ é dado por:

$$
\eta_{\mathrm{t}_{\mathrm{i}}}(\mathrm{t})=\sum_{n \in S} \int_{0}^{t} \pi_{n}(x) \cdot \lambda_{i}(n) d x
$$

onde $\lambda \mathbf{i}(\mathbf{n})$ é a taxa de disparo de uma transição $\mathbf{t}_{\mathbf{i}} \in \mathbf{T}_{\mathbf{T}}$ na marcação $\mathbf{n} \in S$. 
Em estado estacionário, tem-se que $\eta_{\mathrm{t}_{\mathrm{i}}}(\infty)=\sum_{n \in S} \pi_{n}(\infty) \cdot \lambda_{i}(n)$.

Exemplo 5: considere a SPN ilustrada na Figura 98 onde, dado o espaço de estados (marcações) desta rede $\mu=\left\{\mu_{0}, \mu_{1}, \mu_{2}, \ldots, \mu_{K}\right\}$, deseja-se obter o número médio de disparos de $\mathbf{t}_{\mathbf{0}}$ quando a fila possui menos de L usuários, $\mathrm{L}<\mathrm{K}$. Desta forma, $\boldsymbol{S}=\left\{\boldsymbol{\mu}_{1}, \boldsymbol{\mu}_{2}, \ldots, \boldsymbol{\mu}_{L}\right\}=\{(\boldsymbol{0})$ , (1) , (2) ,..., (L) \}.

Portanto $\eta_{\text {to }}(\mathrm{t})$ é calculado como:

$$
\begin{gathered}
\eta_{\mathrm{t}_{\mathrm{o}}}(\mathrm{t})=\sum_{n \in S} \int_{0}^{t} \pi_{n}(x) \cdot\left(\lambda_{o}(n)\right) d x=\sum_{n \in S} \int_{0}^{t} \pi_{n}(x) \cdot\left(\lambda_{o} \cdot \mu_{n}\right) d x= \\
=\int_{0}^{t} \pi_{1}(x) \cdot \lambda_{o} \cdot \mu_{1} d x+\ldots+\int_{0}^{t} \pi_{L}(x) \cdot \lambda_{o} \cdot \mu_{L} d x= \\
=\lambda_{o} \cdot \int_{0}^{t} \pi_{1}(x) d x+\ldots+\lambda_{o} \cdot L \cdot \int_{0}^{t} \pi_{L}(x) d x=\lambda_{o} \cdot\left(\int_{0}^{t} \pi_{1}(x) \cdot d x+\ldots+L \cdot \int_{0}^{t} \pi_{L}(x) d x\right), \quad \text { restando }
\end{gathered}
$$

realizar o cálculo de $\pi(t)$.

Caso $t_{o}$ não fosse dependente de marcação $\left(F\left(t_{o}\right)=\exp \left(-\lambda_{i}\right)\right), \quad \eta_{\mathrm{t}_{\mathrm{o}}}(\mathrm{t})=\lambda_{o} \cdot \sum_{i=1}^{L} \int_{0}^{t} \pi_{i}(x) d x$, restando realizar o cálculo de $\pi(t)$.

\subsection{Métodos de resolução das RPFE}

No capítulo anterior, ilustraram-se algumas medidas quantitativas que podem ser obtidas para a análise de uma rede, além de exemplos práticos de aplicação. Segue, agora, uma explanação sobre possíveis formas de se obter os valores numéricos para as métricas apresentadas.

\subsubsection{Técnicas Analíticas versus Simulação por Eventos Discretos}

A obtenção de medidas quantitativas para análise das redes de Petri Estocásticas (e suas evoluções), como pôde ser notado, envolve o cálculo dos vetores de probabilidade de estado $\pi_{\mathbf{n}}(t)=\mathbf{P}(\mathbf{N}(t)=\mathbf{n})$. Pode-se fazer uso de 2 técnicas distintas para a resolução destas redes: Técnicas Analíticas e Simulação (COMPSciDept, 2004).

A utilização de Técnicas Analíticas para resolução de redes de Petri Estocásticas (SPN) presume que a rede possua características Markovianas (sistema sem memória), fato que 
restringe a modelagem ao uso de transições estocásticas com funções distribuição exponencial e/ou geométrica. Para redes cujas restrições sejam atendidas, é possível transformá-las em cadeias $^{43}$ de Markov de tempo contínuo (Continuous Time Markov Chain - CTMC) ou em cadeias de Markov de tempo discreto (Discrete Time Markov Chain - DTMC), resolvendo-as utilizando propriedades da teoria de Markov como, por exemplo, calculando as equações de probabilidade de estado, por meio de sua matriz de probabilidade de transição $\mathbf{P}$, onde $\pi(\mathbf{k})=$ $\pi(\mathbf{0}) . \mathbf{P}^{\mathbf{k}}$ (para uma DTMC) ou $\pi(\mathbf{t})=\pi(\mathbf{0}) . \mathbf{e}^{\mathbf{P t}}$ (para uma CTMC) $($ German, 2000).

Além das restrições relacionadas aos tipos de transição empregados nas SPN, a modelagem de redes complexas e não limitadas pode resultar em uma quantidade excessiva de estados, tornando infactível a resolução computacional de suas equações de estado e forçando a aplicação de aproximações numéricas às Técnicas Analíticas. Relacionado a este problema de espaço de estados está a resolução das redes de Petri Fluidas e Estocásticas (RPFE) por meio de técnicas analíticas. As técnicas propostas em Trivedi, Kulkarni (1993) e Horton et al (1998) somente são aplicáveis a determinadas condições restritas das RPFE. Devido sua alcançabilidade e a características de decisão, essas redes são calculáveis para, no máximo, duas dimensões (Asarin, Maler, Pnueli (1995) apud Ciardo, Nicol, Trivedi (1999)).

A técnica da Simulação é uma solução viável à resolução de redes de Petri não Markovianas, bem como à solução de redes cuja complexidade torne seu espaço de estados analiticamente inviável. Devido às redes de Petri Estocásticas (SPN) serem um método utilizado para descrever a dinâmica de sistemas de eventos discretos, cuja evolução de estados (marcações) ocorre em eventos bem definidos e discretos, sua resolução por meio de simulação torna-se uma extensão do próprio método.

Segundo Gordon (1978), um sistema analisado por meio de Simulação por Eventos Discretos (ou DES - Discrete Event Simulation) é modelado por um conjunto de elementos denominados descritores de estado $\left(\mathbf{D}_{\mathbf{e}}\right)$ - cujos valores representam os estados do sistema $\left(\mathbf{d}_{\mathbf{i}} \in \mathbf{N}, \forall \mathbf{i} \in \mathbf{D}_{\mathbf{e}}\right)$ - e por um elemento que representa o tempo de simulação $(\boldsymbol{t})$, tal que $\boldsymbol{t} \in \mathbf{T}_{\mathbf{S}} \mathrm{e}$ $\mathbf{T}_{\mathbf{S}} \in\left[\mathbf{0}, \mathbf{T}_{\mathbf{M A X}}\right]$ ), cuja função é representar a evolução do tempo e identificar o momento no qual é alterado o estado do sistema.

\footnotetext{
${ }^{43}$ N.E.: o conceito de cadeia pressupõe um modelo com estados discretos, e o "tipo" da cadeia é definido pela variável de tempo. Para um modelo e Markov, a variável aleatória de estado é definida por $\mathbf{X}=\left\{\mathbf{X}_{\mathbf{0}}, \mathbf{X}_{\mathbf{1}}, \ldots\right.$, $\left.\mathbf{X}_{\mathbf{n}}\right\} \in \mathbf{N}$.
} 
Os valores dos descritores de estado $\left(\mathbf{d}_{\mathbf{i}}, \forall \mathbf{i} \in \mathbf{D}_{\mathbf{e}}\right)$ são alterados em eventos discretos $\left(\boldsymbol{e}_{\mathbf{n}}\right)$, tal que $\boldsymbol{e}_{\mathbf{n}} \in \boldsymbol{E}$ e $\mathbf{n}=\{1,2, \ldots\}$, onde $\boldsymbol{E}$ corresponde ao conjunto de condições que promovem a alteração imediata em um ou mais valores dos descritores de estado $\left(\mathbf{d}_{\mathbf{i}}\right)$. A dinâmica de simulação ocorre por meio da alteração nos valores dos descritores de estado $\left(\mathbf{d}_{\mathbf{i}}\right)$ a cada evento $\left(\boldsymbol{e}_{\mathbf{n}}\right)$ executado, até que o tempo especificado para simulação seja totalmente percorrido ou até que não haja mais condições para ocorrência de eventos. Os eventos de um sistema ocorrem em ordem cronológica, gerando uma seqüência de execuções $\left(\mathbf{e}_{\mathbf{0}}, \mathbf{e}_{\mathbf{1}}, \ldots, \mathbf{e}_{\mathbf{n}}\right)$ nos instantes $\left(t=t_{0}, t_{1}, \ldots, t_{\mathrm{n}}\right)$, onde $\left(t_{0} \leq t_{1}, t_{1} \leq t_{2}, \ldots, t_{\mathrm{n}-1} \leq t_{\mathrm{n}} \leq \mathbf{T}_{\mathrm{MAX}}\right)$.

Relacionando o conceito de Simulação por Eventos Discretos (DES) com o conceito de redes de Petri Temporizadas e Estocásticas (SPN), introduzido anteriormente, segue na Tabela II a equivalência entre ambos, considerando as características de Tempo e Estado para um sistema modelado.

Tabela II - Equivalência entre modelo para DES e SPN

\begin{tabular}{|c|c|c|}
\cline { 2 - 3 } \multicolumn{1}{c|}{} & $\begin{array}{c}\text { Modelo para Simulação por } \\
\text { Eventos Discretos (DES) }\end{array}$ & $\begin{array}{c}\text { Redes de Petri Temporizadas } \\
\text { (definidas em } \mathbf{4 . 2 . 2})\end{array}$ \\
\hline \multirow{2}{*}{ Estado } & Valores dos Descritores de Estado & Valores de Marcação da rede \\
& $\left(\mathbf{d}_{\mathbf{i}} \in \mathbf{N}, \forall \mathbf{i} \in \mathbf{D}_{\mathbf{e}}\right)$ & $(\mu(\mathbf{k}) \in \mathbf{N}, \forall \mathbf{k} \in \mathbf{P})$
\end{tabular}

Como exemplo, dada uma SPN com marcação inicial $\mu_{0}$, na qual ocorra uma sequiência de disparos das transições $\left(\mathbf{t}_{\mathbf{0}}, \mathbf{t}_{\mathbf{1}}, \ldots, \mathbf{t}_{\mathbf{n}}\right) \in \sigma$, promovendo uma seqüência de marcações $\left(\boldsymbol{\mu}_{\mathbf{0}}, \boldsymbol{\mu}_{\mathbf{1}}\right.$, $\left.\ldots, \mu_{\mathbf{n}}\right) \in \boldsymbol{\mu}$ e cujos tempos de permanência em cada marcação sejam $\left(\boldsymbol{\tau}_{\mathbf{t} \mathbf{0}, \mathbf{0}}, \boldsymbol{\tau}_{\mathbf{t} \mathbf{1}, \mathbf{1}}, \ldots, \boldsymbol{\tau}_{\mathbf{t n}, \mathbf{n}}\right)$, correspondendo às notações $\left(\mathbf{s}_{0}, \mathbf{s}_{1}, \ldots, \mathbf{s}_{\mathbf{n}}\right)=\left(\left(\mu_{\mathbf{0}}, \tau_{\mathbf{t} \mathbf{0 , 0}}\right),\left(\mu_{1}, \tau_{\mathbf{t} 1,1}\right), \ldots,\left(\mu_{n}, \tau_{\mathrm{tn}, \mathbf{n}}\right)\right)$, pode-se relacionar a SPN a uma simulação por eventos discretos na forma: 


$\begin{array}{ll}\frac{\text { Dinâmica da SPN }}{\left(\mathrm{s}_{0}, \mathrm{~s}_{1}, \mathrm{~s}_{2}, \ldots, \mathrm{s}_{\mathrm{n}}\right)=} & \text { Simulacão por Eventos Discretos } \\ =\left(\left(\mu_{0}, \tau_{\mathrm{t}, 0}\right),\left(\mu_{1}, \tau_{\mathrm{t}, 1}\right), \ldots,\left(\mu_{\mathrm{n}}, \tau_{\mathrm{t}, \mathrm{n}}\right)\right)= & \cdot \\ =\left(\left(\mu_{0}, \mathrm{e}_{0}\right),\left(\mu_{1}, \mathrm{e}_{1}\right), \ldots,\left(\mu_{\mathrm{n}}, \mathrm{e}_{\mathrm{n}}\right)\right)= & \cdot \\ =\left(\left(\mu_{0}, 0\right),\left(\mu_{1}, \tau_{\mathrm{t}, 0}\right), \ldots,\left(\mu_{\mathrm{n}}, \sum_{\mathrm{i}=0}^{\mathrm{n}-1} \tau_{\mathrm{t}, \mathrm{i}}\right)\right) . \rightarrow \quad\left(\left(\mathrm{d}, \mathrm{t}_{0}=0\right),\left(\mathrm{d}, \mathrm{t}_{1}\right), \ldots,\left(\mathrm{d}, \mathrm{t}_{\mathrm{n}}\right)\right) .\end{array}$

Dado que o estado de um sistema no instante $\boldsymbol{t}$, modelado para avaliação por meio de simulação por eventos discretos (DES), é representado pelo conjunto de valores dos descritores de estado $\left(\mathbf{d}=\left(\mathbf{d}_{\mathbf{0}}, \mathbf{d}_{\mathbf{1}}, \ldots, \mathbf{d}_{\mathbf{n}}\right)\right)$ em um instante $\boldsymbol{t} \in \mathbf{T}_{\mathbf{S}}$, resultando na dupla $(\mathbf{d}, \boldsymbol{t})$, a seqüência de marcações $\mu_{\mathbf{k}}$ obtidas pela execução da SPN nos instantes de tempo $\mathbf{e}_{\mathbf{k}}$ é equivalente à evolução dos valores de $\mathbf{d}$ ocorridos nos instantes $\boldsymbol{t}_{\boldsymbol{k}}$, onde:

$$
\left(\left(\mu_{0}, 0\right),\left(\mu_{1}, \mathbf{e}_{1}=0+\tau_{t, 0}\right), \ldots,\left(\mu_{n}, e_{n}=e_{n-1}+\tau_{t}, n-1\right)\right)=\left(\left(d, t_{0}\right),\left(d, t_{1}\right), \ldots,\left(d, t_{n}\right)\right)
$$

Vale ressaltar que o conjunto de condições $(\boldsymbol{E})$ de um modelo para simulação por eventos discretos, para uma rede de Petri, é obtido por meio das regras de execução relacionadas àquela rede. Como exemplo, o processo de simulação por eventos discretos de uma DTMC (cadeia de Markov de tempo discreto) $\left\{\mathbf{N}(\mathbf{k})=\mathbf{s} \mid \mathbf{s} \in \mathbf{S}=\left\{\mathbf{s}_{\mathbf{1}}, \mathbf{s}_{2}, \ldots, \mathbf{s}_{\mathbf{n}}\right\}, \mathbf{k} \in \mathbf{N}\right\}$ com uma matriz de transição $\mathbf{P}$ pode ser executado, segundo Ripley (1987):

$\operatorname{Se} \boldsymbol{N}(\boldsymbol{n})=\boldsymbol{s}$, seleciona $\boldsymbol{N}(\boldsymbol{n}+\mathbf{1})=\mathbf{i}$ por meio da distribuição discreta $\left\{\boldsymbol{p}_{\mathrm{s}, i} \in \mathbf{P} \mid \boldsymbol{i} \in \mathbf{S}\right\}$.

No caso de uma rede de Petri Estocástica com distribuições de probabilidade qualquer, podese simulá-la por meio do processo:

1. dado $\left(\mu_{\mathrm{k}}, \mathbf{e}_{\mathrm{k}}\right)$, obtém $\mathbf{t}_{\mathbf{i}} \in \boldsymbol{H}\left(\boldsymbol{\mu}_{\mathrm{k}}\right), \forall \mathbf{t}_{\mathbf{i}} \in \mathbf{T}$.

2. amostra $\boldsymbol{\tau}_{\mathrm{ti}}$ para $\forall \mathbf{t}_{\mathbf{i}} \in \boldsymbol{H}\left(\boldsymbol{\mu}_{\mathrm{k}}\right)$ por meio de suas funções de distribuição de probabilidade.

3. respeitando as regras de execução da rede, faz $\delta\left(\mu_{\mathbf{k}}, \mathbf{t}_{\mathbf{i k}}\right)=\mu_{\mathrm{k}+\mathbf{1}} \mathrm{e}$ $\mathbf{e}_{\mathrm{k}+1}=\mathbf{e}_{\mathrm{k}}+\tau_{\mathrm{ti}}$.

4. Retorna para o passo " 1 " e repete o procedimento para o próximo estado alcançado $\left(\boldsymbol{\mu}_{\mathrm{k}+1}\right)$ e enquanto $\exists \mathbf{t}_{\mathbf{i}} \in \boldsymbol{H}\left(\boldsymbol{\mu}_{\mathrm{k}+1}\right)$, 


\section{$\forall \mathbf{t}_{\mathbf{i}} \in \mathbf{T} \vee \mathbf{e}_{\mathbf{k}+1} \leq \mathbf{T}_{\text {MAX }}$}

A representação temporal de um processo de simulação por eventos discretos (DES) (o valor do elemento tempo de simulação) pode evoluir segundo 2 métodos distintos (Gordon, 1978):

- Orientado a Evento (event-oriented): o valor do tempo de simulação avança para o instante no qual ocorrerá o próximo evento detectado. O processo é conhecido como simulação do próximo evento, pois o próximo estado e seu instante de ocorrência são simulados a partir do estado atual do modelo.

- Orientado a Intervalo (interval-oriented): o valor do tempo de simulação avança em pequenos intervalos (normalmente uniformes), nos quais se verifica a existência de condições $(\boldsymbol{E})$ para mudança de estado.

Ainda segundo Gordon (1978), a aplicação de cada um dos métodos de evolução temporal em DES é apropriada para um determinado tipo de sistema a ser simulado. O método orientado a evento é recomendado para simulação de sistemas puramente discretos, tais como os sistemas modelados por meio de redes de Petri Estocásticas, como pôde ser verificado nos exemplos de simulação por eventos discretos de uma DTMC e de uma SPN, ilustrados anteriormente. Já o método orientado a intervalo é recomendado para simulação de sistemas puramente contínuos, pois a evolução de estados em função do tempo é modelada por equações diferenciais.

Além da representação dos descritores de estado $\left(\mathbf{D}_{\mathbf{e}}\right)$ e do tempo de simulação $\left(\mathbf{T}_{\mathbf{S}}\right)$, que são utilizados para modelar o sistema em estudo, existem outros componentes importantes em um processo de simulação (Ball, 1996):

- Executor de Simulação, responsável pela dinâmica do processo, controlando o avanço do tempo de simulação $\left(\mathbf{T}_{\mathbf{S}}\right)$ e a evolução dos valores dos descritores de estado $\left(\mathbf{d}_{\mathbf{i}}\right.$, $\left.\forall \mathbf{i} \in \mathbf{D}_{\mathbf{e}}\right)$ do sistema por meio da verificação das condições do modelo $(\boldsymbol{E})$. Como este processo é executado em função do tempo, o mesmo necessita de um relógio (Base de Tempo) para o correto funcionamento;

- Gerador de Números Aleatórios (GNA), responsável pelo comportamento estocástico do processo, pois é por meio da geração de números naturais independentes, idêntica e uniformemente distribuídos que são geradas as distribuições de probabilidade dos 
tempos de transição de um modelo;

- Coleta e Apresentação de Resultados, responsável pela coleta, tratamento e apresentação dos dados gerados pela simulação.

A Figura 99, adaptada de Ball (1996), ilustra a relação entre os elementos em um processo de simulação.

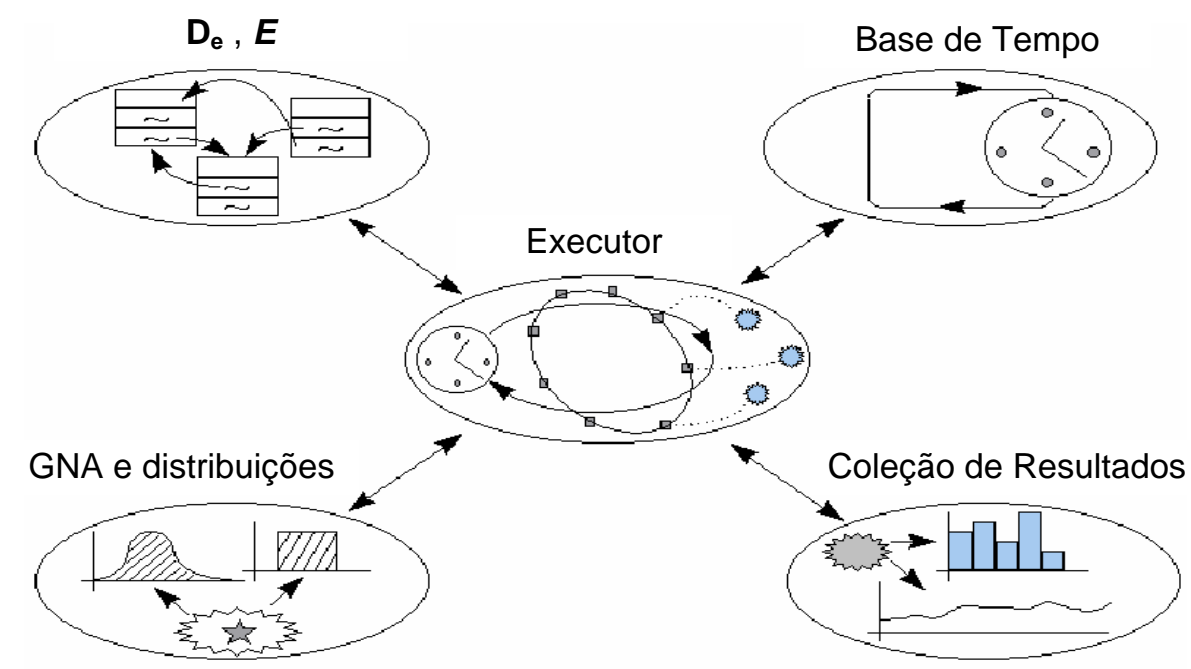

Figura 99 - Estrutura de um processo de simulação

\subsubsection{Simulação de modelos Contínuo-Discretos}

Além dos sistemas puramente discretos e dos sistemas puramente contínuos, existem tipos de sistemas cujo mecanismo de mudança de estados com relação ao tempo ocorre de forma contínuo-discreta. Nestes sistemas, os estados podem mudar de forma contínua, de forma discreta ou de forma contínua adicionando a saltos discretos (COMPSciDept, 2004). As redes de Petri Fluidas e Estocásticas (RPFE), como definido anteriormente, são um método utilizado para modelagem e avaliação de sistemas contínuo-discretos.

O processo de simulação de sistemas contínuo-discretos depende dos modos de interação entre os valores das variáveis contínuas e discretas do modelo. Segundo COMPSciDept (2004), existem 3 modos de interação possíveis entre $\boldsymbol{\mu}(\mathbf{p})$ e $\chi(\mathbf{q}), \mathbf{p} \in \mathbf{P}_{\mathbf{d}}$ e $\mathbf{q} \in \mathbf{P}_{\mathbf{c}}$ pertencentes a uma RPFE:

i. $\quad$ variações discretas sobre $\chi(\mathbf{q})$ dependentes de $\mu(\mathbf{p})$ : uma mudança discreta nos valores de estado pode ser promovida sobre as variáveis contínuas $(\chi(\mathbf{q}))$. Para as RPFE, isto 
equivale a modelar impulsos fluidos, representados pelos $\operatorname{arcos} \mathbf{A}_{\mathbf{c}}$.

ii. $\quad$ variações em $\mu(\mathbf{p})$ e/ou $\chi(\mathbf{q})$ dependentes de $\chi(\mathbf{q})$ : um evento, que altere tanto variáveis discretas $(\mu(\mathbf{p}))$ quanto contínuas $(\chi(\mathbf{q}))$, pode vir a ser executado no caso de valores das variáveis contínuas atingirem níveis pré-definidos. Para as RPFE, isto equivale a modelar guardas em transições imediatas em funções das marcações fluidas $\left(\mathbf{g :}\left(\left(\mathbf{q} \in \mathbf{P}_{\mathbf{C}}\right) \rightarrow\{\mathbf{1}, \mathbf{0}\}\right)^{\# \mathbf{T i}}\right)$

iii. taxa de variação contínua de $\chi(\mathbf{q})$ dependente de $\mu(\mathbf{p})$ : um evento discreto no tempo pode promover a alteração na descrição funcional das variáveis contínuas. Para as RPFE, isto equivale a modelar taxas fluidas dependentes da marcação $\left(\mathbf{f}=\left(\left(\mathbf{P}_{\mathbf{c}} \boldsymbol{x} \mathbf{T}_{\mathbf{T}}\right)\right.\right.$ $\left.\left.\cup\left(\mathbf{T}_{\mathrm{T}} \boldsymbol{x} \mathbf{P}_{\mathrm{c}}\right)\right) \boldsymbol{x} \hat{\boldsymbol{S}} \rightarrow \mathbf{R}^{+}\right)$

Consideram-se 2 tipos de eventos que podem promover as possíveis interações entre as mudanças de valores nas variáveis contínuas e discretas para os sistemas contínuo-discretos COMPSciDept (2004):

a. Eventos de Tempo: eventos que ocorrem em instantes específicos de tempo.

b. Evento de Estado: eventos que ocorrem quando uma determinada condição de estado é alcançada.

Como pode ser notado, o processo de simulação por eventos discretos de uma rede de Petri Fluida e Estocástica (RPFE) necessita de uma abordagem que considere tanto seus eventos de tempo quanto seus eventos de estado. Os eventos de tempo estão relacionados ao método de representação temporal orientado a eventos, e sua dinâmica de execução faz uso de filas de simulação, cujos eventos são agendados para futura execução. Já os eventos de estado estão relacionados ao método de representação temporal orientado a intervalo, os quais são monitorados durante o processo de simulação, sem serem inseridos em fila. (COMPSciDept, 2004).

Mesmo utilizando simulação por eventos discretos, a solução de casos genéricos de RPFE pode ser complexa (Ciardo; Nicol; Trivedi, 1999). Por exemplo, existem casos onde é possível modelar, por meio das RPFE, sistemas com comportamento instável, podendo produzir um número infinito de eventos discretos (como exemplificado na Figura 100 a) ou um número infinito de estados infinitesimais (como exemplificado na Figura 100 b) e Figura 
$100 \mathrm{c}))$.

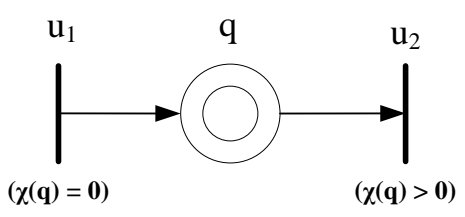

a)

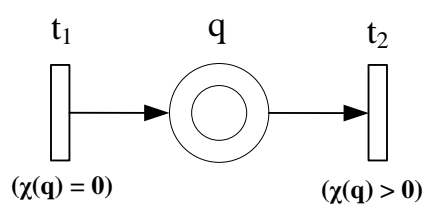

b)

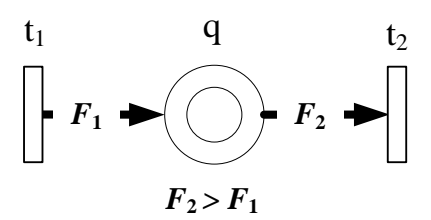

C)

Figura 100 - RPFE com comportamento instável (Ciardo, Nicol, Trivedi (1999))

Pode-se resolver, por meio de simulação por eventos discretos e respeitando suas regras de execução, uma RPFE que possua comportamento estável. Por exemplo, dado uma marcação $(\mu, \chi) \in \hat{S}$, pode-se variar o conteúdo dos lugares fluidos $\chi_{(t)}\left(\mathbf{q}_{\mathbf{i}}\right), \mathbf{q}_{\mathbf{i}} \in \mathbf{P}_{\mathbf{c}}$, enquanto existir $\mathbf{t} \in \boldsymbol{H}\left((\mu, \chi)_{(t)}\right), \mathbf{t} \in \mathbf{T}$, que possibilite esta variação. Caso $\mathbf{t} \in \mathbf{T}_{\mathbf{T}}$ e $\left(\mathbf{t}, \mathbf{q}_{\mathbf{i}}\right) \subseteq \mathbf{f}$, o valor de $\chi_{(t)}\left(\mathbf{q}_{\mathbf{i}}\right)$ varia no intervalo $[t, t+\tau)$ no qual $\mathbf{t} \in \boldsymbol{H}\left((\mu, \chi)_{(t+\tau \mathfrak{t})}\right)$ por meio do sistema de equações diferenciais apresentadas anteriormente:

$$
\forall \mathrm{q} \in \mathrm{P}_{\mathrm{C}}, \frac{\mathrm{d} \chi_{\mathrm{q}}(\tau)}{\mathrm{d} t}=\sum_{\mathrm{t} \in \Lambda}\left(\mathrm{f}_{\mathrm{t}, \mathrm{q}}(\mu, \chi)_{(t+\tau)}-\mathrm{f}_{\mathrm{q}, \mathrm{t}}(\mu, \chi)_{(t+\tau)}\right) \text {, onde } \Lambda=H\left((\mu, \chi)_{(t)}\right)
$$

A condição inicial $(\mu, \chi)_{(t)}$ no intervalo $[t, t+\tau)$ mantém-se inalterada durante este tempo, e o sistema somente perceberá que a parte contínua do estado se alterou no instante final do intervalo, onde $\mathbf{t} \notin \boldsymbol{H}((\mu, \chi)$. Devido a este fato é que os eventos de estado, principalmente os dependentes de $\chi(\mathbf{q})$, estão relacionados ao método de representação temporal orientado a intervalo. Ao evoluir-se o tempo em pequenos passos, é possível manter um taxa significativamente alta de atualização dos valores $\chi(\mathbf{q})$ (inversamente proporcional ao passo de tempo), reduzindo a latência entre a ocorrência de uma condição de mudança de estado "real" e a detecção pelo processo de monitoramento de estados da simulação ou mesmo a perda de condições desejadas.

Portanto, a resolução do sistema de equações diferenciais, durante o processo de simulação, necessita do conhecimento da evolução de $\boldsymbol{H}\left((\mu, \chi)_{(t)}\right)$ (transições habilitadas no instante $t$ ) em função do tempo. Desta forma, $\boldsymbol{H}\left((\mu, \chi)_{(t)}\right)$ pode ter as seguintes interdependências com os estados do modelo (Ciardo, Nicol, Trivedi (1999)):

i. $\quad \boldsymbol{H}\left((\mu, \chi)_{(t)}\right)$ pode ser independente dos valores de $\chi(\mathbf{q}), \mathbf{q} \in \mathbf{P}_{\mathbf{c}}$. 
ii. $\quad \boldsymbol{H}\left((\mu, \chi)_{(t)}\right)$ pode ser dependente dos valores de $\chi(\mathbf{q}), \mathbf{q} \in \mathbf{P}_{\mathbf{c}}$.

O caso mais simples de lidar é quando $\boldsymbol{H}\left((\mu, \chi)_{(t)}\right)$ é independente de $\boldsymbol{\chi ( q )}$, onde as cardinalidades dos arcos e as condições de guardas não dependem de $\boldsymbol{\chi ( q )}$. Desta forma, a parte discreta do modelo evolui pela execução dos eventos discretos, e a parte contínua pode evoluir independentemente $\mu$, atualizando os valores de $\boldsymbol{\chi ( q )}$ apenas nos instantes $\mathbf{e}_{\mathbf{n}}$ discretos e com base na diferença de tempo entre o evento atual e o evento anterior $(\tau)$. Isto equivale a utilizar apenas o método de representação temporal orientado a eventos na simulação do sistema.

O processo de simulação torna-se complexo no caso de $\boldsymbol{H}\left((\mu, \chi)_{(t)}\right)$ depender de $\chi(\mathbf{q})$, cujas

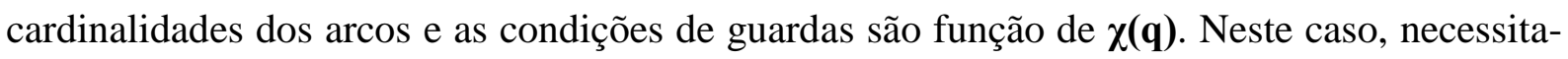
se conhecer o instante futuro $\tau$ e onde ocorrerá uma alteração em $\boldsymbol{H}\left((\mu, \chi)_{(t+\tau e)}\right)$. Em princípio, para obter $\tau \mathbf{e}$, deve-se conhecer $\chi(\mathbf{q})$ durante o período $[t, t+\Delta)$ por meio da resolução das equações diferenciais do modelo, onde $\Delta$ corresponde a um passo de tempo futuro visando obter o comportamento de $\boldsymbol{H}\left((\mu, \chi)\right.$ no período. Caso não exista alteração em $\boldsymbol{H}\left((\mu, \chi)_{(t+\Delta)}\right)$, os valores de $\chi(\mathbf{q})$ são atualizados em $\boldsymbol{t}+\Delta$, prosseguindo-se com a busca. Isto equivale a utilizar o método de representação temporal orientado a intervalo na simulação do sistema.

\subsubsection{Subclasses das RPFE e melhoria no desempenho da simulação}

Uma forma de melhorar o desempenho do processo de resolução do sistema de equações diferenciais é definir subclasses de redes de Petri Fluidas e Estocásticas, divididas conforme o comportamento da rede em função da interdependência entre sua parte contínua e discreta. Segundo Ciardo, Nicol, Trivedi (1999), pode-se definir as seguintes subclasses de RPFE:

1. Comportamento Não Acoplado: caso onde, além do processo de habilitação das transições $\left(\boldsymbol{H}\left((\boldsymbol{\mu}, \boldsymbol{\chi})_{(t)}\right)\right)$ ser independente dos valores contínuos da rede $\left(\boldsymbol{\chi}(\mathbf{q}), \mathbf{q} \in \mathbf{P}_{\mathbf{c}}\right)$, a cardinalidade dos arcos fluidos relacionados a um dado lugar contínuo $\mathbf{q}_{\mathbf{i}}, \mathbf{q}_{\mathbf{i}} \in \mathbf{P}_{\mathbf{c}}$, são independentes dos demais lugares contínuos $\mathbf{q}_{\mathbf{m}}, \forall \mathbf{q}_{\mathbf{m}} \in \mathbf{P}_{\mathbf{c}} \wedge \mathbf{q}_{\mathbf{m}} \neq \mathbf{q}_{\mathbf{i}}$. Este comportamento faz com que a variação potencial de taxa do nível fluido no estado ( $\mu$, $\chi)_{(t)}$ e no instante $\boldsymbol{t}\left(\delta_{\mathrm{qi}}{ }^{\text {pot }}\left((\mu, \chi)_{(t)}\right)\right)$ seja constante enquanto persistirem as condições de $(\mu, \chi)_{(t)}$. Neste caso, é possível representar o tempo do processo de simulação apenas utilizando a orientação a evento, pois a atualização dos valores contínuos da rede dáse apenas nos eventos discretos da mesma. 
2. Comportamento Acoplado e Pré-Definido: como forma de eliminar a necessidade de métodos numéricos de integração para resolver o conjunto de equações diferenciais do modelo, pode-se definir classes de modelagens cujas soluções numéricas das equações diferenciais sejam conhecidas (pré-definidas). Duas subclasses possíveis de comportamento são:

a. Taxa Fluida com variação Linear: dado um estado $\left.(\mu, \chi)_{(t)}\right) \in \hat{S}$, para $\forall \mathbf{q} \in \mathbf{P}_{\mathbf{c}}$, considera-se $\frac{\mathrm{d} \chi_{\mathrm{q}}(\tau)}{\mathrm{d} t}=\mathrm{A}(\mu) \cdot \chi_{\mathrm{q}}(\tau)+\mathrm{B}(\mu), \mathrm{A}(\mu) \neq 0$, onde $\mathrm{A}(\mu)$ e $\mathbf{B}(\mu)$ são funções dependentes da marcação discreta da rede. A solução desta equação é:

$$
\chi_{\mathrm{q}}(\tau)=-\frac{\mathrm{B}(\mu)}{\mathrm{A}(\mu)}+\left(\chi_{\mathrm{q}}(0)+\frac{\mathrm{B}(\mu)}{\mathrm{A}(\mu)}\right) \cdot \mathrm{e}^{\mathrm{A}(\mu) \cdot \tau} \text {, onde } \chi_{\mathrm{q}} \in\left[0, \mathrm{~b}_{\mathrm{q}}\right] \text {, durante o }
$$
intervalo $[0, \tau]$.

O tempo $\left(\tau_{\mathbf{q}}\right)$ no qual o valor contido em um lugar contínuo $\mathbf{q}, \mathbf{q} \in \mathbf{P}_{\mathbf{c}},(\boldsymbol{\chi}(\mathbf{q}))$ levará para atingir um valor $\mathbf{L q}, \mathrm{L}_{\mathrm{q}} \in\left[0, \mathrm{~b}_{\mathrm{q}}\right]$, é dado por:

$$
\tau_{q}=\frac{\ln \left(\frac{\mathrm{L}_{\mathrm{q}}+\frac{\mathrm{B}(\mu)}{\mathrm{A}(\mu)}}{\chi_{\mathrm{q}}(0)+\frac{\mathrm{B}(\mu)}{\mathrm{A}(\mu)}}\right)}{\mathrm{A}(\mu)}
$$

No caso de uma transição ser habilitada apenas quando $\chi(\mathbf{q})=\mathbf{L q}$, pode-se simplificar a obtenção do instante do próximo evento $\left(\tau_{e}\right)$ por:

$$
\tau_{e}=\min _{\mathrm{q} \in \mathrm{Pc}}\left\{\tau_{q}\right\}
$$

b. Taxa Fluida Constante: no caso anterior, quando $\mathbf{A}(\boldsymbol{\mu})=\mathbf{0}$ considera-se $\frac{\mathrm{d} \chi_{\mathrm{q}}(\tau)}{\mathrm{d} t}=\mathrm{B}(\mu), \quad$ o $\quad$ que $\quad$ implica $\quad$ em $\quad \chi_{\mathrm{q}}(\tau)=\chi_{\mathrm{q}}(0)+\mathrm{B}(\mu) . \tau, \quad$ onde $\chi_{\mathrm{q}} \in\left[0, \mathrm{~b}_{\mathrm{q}}\right]$ durante o intervalo $[0, \tau]$.

O tempo no qual $\boldsymbol{\chi ( q )}$ levará para atingir um valor Lq é dado por: 


$$
\tau_{q}=\frac{\mathrm{Lq}-\chi_{\mathrm{q}}(0)}{\mathrm{B}(\mu)}
$$

\subsection{Estimação de Medidas de Avaliação por meio de Simulação}

Como mencionado anteriormente, é possível sistematizar a obtenção de medidas de interesse em uma rede por meio de funções de recompensa, cuja formalização dá-se por meio das redes de Petri de Recompensa. Definiu-se que uma estrutura de recompensa é caracterizada pelos vetores de taxa de recompensa (rr) e de recompensa impulsiva (ri), na qual se extraem 3 variáveis de recompensa distintas, $\mathbf{R}_{\mathrm{inst}}(t), \mathbf{R}_{\text {acum }}(t)$ e $\mathbf{R}_{\text {med }}(t)$, das quais se obtém seus valores de esperança (E[]) utilizados para análise.

Fazendo uso de métodos analíticos, é possível calcular as esperanças $\mathbf{E}\left[\mathbf{R}_{\text {inst }}(t)\right], \mathbf{E}\left[\mathbf{R}_{\text {acum }}(t)\right] \mathrm{e}$ $\mathbf{E}\left[\mathbf{R}_{\text {med }}(t)\right]$ por meio de expressões literais. Porém, o uso da técnica de simulação permite apenas inferir (ou estimar) os valores destes parâmetros. Desta forma, o processo utilizado para análise quantitativa de sistemas, ilustradas anteriormente, continua válido, mas deve-se incorporar ao processo de análise conceitos de Inferência Estatística como meio de calcular as medidas desejadas com confiança significativa. As informações apresentadas a seguir foram baseadas em Magalhães e Lima (2004).

\subsubsection{Inferência Estatística aplicada ao processo de simulação}

Existem 3 definições importantes nos conceitos de Inferência Estatística:

i. $\quad$ Parâmetros: quantidades da população $(\Omega)$ que se tem interesse de estimar. Exemplos de parâmetros de uma variável aleatória "X" são esperança $(\mathbf{E}[\mathbf{X}])$ e variância (VAR[X]). No caso em análise, o parâmetro a ser analisado é a esperança $(\boldsymbol{\mu} \equiv \mathbf{E}[])$ das variáveis aleatórias $\mathbf{R}_{\text {inst }}(t), \mathbf{R}_{\text {acum }}(t)$ e $\mathbf{R}_{\text {med }}(t)$.

ii. Estimador: função que faz a combinação dos elementos da amostra com a finalidade de estimar o parâmetro. Exemplos de estimadores de uma variável aleatória "X" são a média $\operatorname{amostral}(\bar{X})$ e a variância amostral $\left(\mathrm{s}_{\mathrm{x}}^{2}\right)$.

iii. Estimativa Pontual: valor obtido por meio do estimador.

Um bom estimador para um parâmetro deve ser "não viciado" (ou "não tendencioso"), "consistente" e "eficiente". Estimadores para esperança e variância que possuem esta 
propriedade são:

$$
\overline{\mathrm{X}}=1 / \mathrm{N} \cdot \sum_{i=1}^{\mathrm{N}} \mathrm{x}_{\mathrm{i}} \quad \text { como estimador da esperança de } \mathrm{X}, \quad \mathrm{e}
$$
$\mathrm{s}_{\mathrm{X}}^{2}=\frac{1}{\mathrm{~N}-1} \cdot \sum_{i=1}^{\mathrm{N}}\left(\mathrm{x}_{\mathrm{i}}-\overline{\mathrm{X}}\right)^{2}=\frac{1}{\mathrm{~N}-1} \cdot\left(\sum_{i=1}^{\mathrm{N}} \mathrm{x}_{\mathrm{i}}{ }^{2}-\mathrm{N} \cdot \overline{\mathrm{X}}^{2}\right)$ como estimador da variância de $\mathrm{X}$, onde "N" é a quantidade de valores presentes na amostra e " $\mathbf{x}_{\mathbf{i}}$ " são os valores obtidos pela amostra.

Dado uma variável aleatória " $X$ " com distribuição de probabilidade Normal $\mathbf{X} \sim \mathbf{N}(\mathbf{E}[\mathbf{X}]$, $\left.\mathbf{V A R}[\mathbf{X}]^{1 / 2}\right)$ ), com esperança $\mathbf{E}[\mathbf{X}]$ e variância $\mathbf{V A R}[\mathbf{X}]$, a distribuição amostral da variável aleatória $\bar{X}=1 / N \cdot \sum_{i=1}^{N} x_{i}$ (combinação linear de $\left.X\right)$, onde $x_{i}$ são independentes, é dada por $\overline{\mathrm{X}} \sim \mathrm{N}(\mathrm{E}[\overline{\mathrm{X}}], \operatorname{VAR}[\overline{\mathrm{X}}])=\mathrm{N}(\mathrm{E}[\mathrm{X}], \operatorname{VAR}[\mathrm{X}] / \mathrm{N})$. Porém, essa propriedade não se aplica para o caso de X ter distribuições de probabilidade diferentes da Normal.

Com base no Teorema Central do Limite (TCL), pode-se aproximar a distribuição amostral de $\mathrm{X}(\overline{\mathrm{X}})$, cuja distribuição de probabilidade seja diferente da normal, a uma distribuição normal padronizada $(Z=\mathrm{N}(0,1))$. Matematicamente, o TCL é definido como:

$$
\lim _{n \rightarrow \infty}\left(\frac{\bar{X}-E[X]}{\sqrt{\frac{V A R[X]}{n}}}\right)=Z=N(0,1)
$$

A partir da transformação de uma variável aleatória $\bar{X} \sim \mathrm{N}(\mathrm{E}[\mathrm{X}], \mathrm{VAR}[\mathrm{X}] / \sqrt{\mathrm{N}})$ em uma variável aleatória padronizada $\mathrm{Z}=\frac{\overline{\mathrm{X}}-\mathrm{E}[\mathrm{X}]}{\sqrt{\mathrm{VAR}[\mathrm{X}] / \mathrm{N}}} \sim \mathrm{N}(0,1)$, cujos valores de $\mathrm{N}(0,1)$ são tabelados, e aplicando o TCL no caso $\overline{\mathrm{X}}$ não possuir distribuição Normal, pode-se obter a Estimacão por Intervalo para um estimador de esperança um parâmetro qualquer. Desenvolvendo $\mathrm{P}\left(|\mathrm{Z}|<\mathrm{Z}_{\gamma / 2}\right)=\gamma$, onde $0<\gamma<1$, tem-se:

$$
\begin{gathered}
\mathrm{P}\left(-\mathrm{z}_{\gamma / 2}<\mathrm{Z}<\mathrm{z}_{\gamma / 2}\right)=\mathrm{P}\left(-\mathrm{z}_{\gamma / 2}<\frac{\overline{\mathrm{X}}-\mathrm{E}[\mathrm{X}]}{\sqrt{\mathrm{VAR}[\mathrm{X}] / \mathrm{N}}}<\mathrm{z}_{\gamma / 2}\right)= \\
=\mathrm{P}\left(\overline{\mathrm{X}}-\mathrm{z}_{\gamma / 2} \cdot \sqrt{\operatorname{VAR}[\mathrm{X}] / \mathrm{N}}<\mathrm{E}[\mathrm{X}]<\overline{\mathrm{X}}+\mathrm{z}_{\gamma / 2} \cdot \sqrt{\operatorname{VAR}[\mathrm{X}] / \mathrm{N}}\right)=\gamma
\end{gathered}
$$

Este resultado pode ser interpretado como a proporção $\gamma$ de intervalos calculados 
$\left[\bar{X}-z_{\gamma / 2} \cdot \sqrt{\operatorname{VAR}[X] / N} ; \bar{X}+z_{\gamma / 2} \cdot \sqrt{\operatorname{VAR}[X] / N}\right]$ para um parâmetro E[X] que conterão o valor real do parâmetro de interesse. Portanto, a notação do Intervalo de Confiança (IC) para o parâmetro $\mathbf{E}[\mathbf{X}]$ com proporção $\gamma$ é:

$$
\mathbf{I C}(\mathbf{E}[\mathbf{X}], \gamma)=\left[\bar{X}-z_{\gamma / 2} \cdot \sqrt{\operatorname{VAR}[X] / N} ; \bar{X}+z_{\gamma / 2} \cdot \sqrt{\operatorname{VAR}[X] / N}\right]
$$

cujos valores de $\mathrm{z}_{\gamma / 2}$ são tabelados em $\mathrm{N}(0,1)\left(\mathrm{z}_{\gamma / 2}=1.645\right.$ para $\gamma=0.9 ; \mathrm{z}_{\gamma / 2}=1.96$ para $\gamma=$ 0.95 e $\mathrm{z}_{\gamma / 2}=2.575$ para $\left.\gamma=0.99\right)$.

A Estimação por Intervalo demonstrada exige que se conheça o valor de variância do parâmetro que se deseja estimar, e isto pode não ser possível. Portanto, para se estimar um parâmetro com variância desconhecida, utiliza-se da Distribuição de Student, onde:

$$
\operatorname{IC}(\mathbf{E}[\mathbf{X}], \gamma)=\left[\bar{X}-\mathrm{t}_{N-1, \gamma 2} \cdot\left(\mathrm{s}_{\mathrm{X}} / \sqrt{\mathrm{N}}\right) ; \overline{\mathrm{X}}+\mathrm{t}_{N-1, \gamma 2} \cdot\left(\mathrm{s}_{\mathrm{X}} / \sqrt{\mathrm{N}}\right)\right]
$$

cujos valores de $\mathrm{t}_{\mathrm{N}-1, \gamma / 2}$ são tabelados, e N-1 é o grau de liberdade da estatística.

Portanto, podem-se estimar as esperanças das variáveis $\mathbf{R}_{\mathrm{inst}}(t), \mathbf{R}_{\text {acum }}(t)$ e $\mathbf{R}_{\text {med }}(t)$ por meio dos estimadores $\overline{\mathrm{R}}_{\text {inst }}(t), \overline{\mathrm{R}}_{\text {acum }}(t)$ e $\overline{\mathrm{R}}_{\text {med }}(t)$, sendo:

$$
\begin{gathered}
\overline{\mathrm{R}}_{\text {inst }}(\mathrm{t})=1 / \mathrm{N} \cdot \sum_{i=1}^{\mathrm{N}} \mathrm{R}_{\text {inst }}(\mathrm{t})_{\mathrm{i}}, \text { estimador para } \mathbf{E}\left[\mathrm{R}_{\text {inst }}(t)\right] . \\
\left(\mathrm{s}_{\overline{\mathrm{R}}_{\text {inst }}(\mathrm{t})}\right)^{2}=\frac{1}{\mathrm{~N}-1} \cdot \sum_{i=1}^{\mathrm{N}}\left(\mathrm{R}_{\text {inst }}(\mathrm{t})_{\mathrm{i}}-\overline{\mathrm{R}}_{\text {inst }}(\mathrm{t})\right)^{2}, \text { estimador para } \operatorname{VAR}\left[\mathrm{R}_{\text {inst }}(t)\right] . \\
\mathbf{I C}\left(\mathbf{R}_{\text {inst }}(t), \boldsymbol{\gamma}\right)=\left[\overline{\mathrm{R}}_{\text {inst }}(\mathrm{t})-\mathrm{t}_{N-1, \gamma / 2} \cdot \mathrm{s}_{\overline{\mathrm{R}}_{\text {inst }}(\mathrm{t})} / \sqrt{\mathrm{N}} ; \overline{\mathrm{R}}_{\text {inst }}(\mathrm{t})+\mathrm{t}_{N-1, \gamma / 2} \cdot \mathrm{s}_{\overline{\mathrm{R}}_{\text {inst }}(\mathrm{t})} / \sqrt{\mathrm{N}}\right] .
\end{gathered}
$$

Os estimadores $\overline{\mathrm{R}}_{\text {acum }}(t)$ e $\overline{\mathrm{R}}_{\text {med }}(t)$ são decorrência de $\overline{\mathrm{R}}_{\text {inst }}(t)$.

$\mathrm{R}_{\text {inst }}(t)_{i}$ é a i-ésima amostra obtida da variável $\mathrm{R}_{\text {inst }}(t)$ para constituir o estimador $\overline{\mathrm{R}}_{\text {inst }}(t)$ do parâmetro $\mathbf{E}\left[\mathrm{R}_{\text {inst }}(t)\right]$. Vale ressaltar que $\mathrm{R}_{\text {inst }}(t)$ é considerada como variável aleatória quando sua parcela de recompensa impulsiva $\mathbf{r i}_{\mathbf{n}}^{\mathbf{g}}$ é nula.

Como mencionado anteriormente, estas propriedades são válidas apenas se $\overline{\mathrm{R}}_{\mathrm{inst}}(t)$ é uma variável aleatória com distribuição de normal, onde 
$\overline{\mathrm{R}}_{\text {inst }}(t) \sim \mathrm{N}\left(\mathrm{E}\left[\overline{\mathrm{R}}_{\text {inst }}(t)\right], \operatorname{VAR}\left[\overline{\mathrm{R}}_{\text {inst }}(t)\right]\right)=\mathrm{N}\left(\mathrm{E}\left[\mathrm{R}_{\text {inst }}(t)\right], \operatorname{VAR}\left[\mathrm{R}_{\text {inst }}(t)\right] / \mathrm{N}\right)$. Caso não seja, pode-se aplicar o Teorema Central do Limite (TCL) $\lim _{n \rightarrow \infty}\left(\frac{\overline{\mathrm{R}}_{\text {inst }}(\mathrm{t})-\mathrm{E}\left[\mathrm{R}_{\text {inst }}(\mathrm{t})\right]}{\sqrt{\frac{\mathrm{VAR}\left[\mathrm{R}_{\text {inst }}(\mathrm{t})\right]}{\mathrm{n}}}}\right)=\mathrm{Z}=\mathrm{N}(0,1), \mathrm{o}$ que implica em utilizar uma amostra $\mathrm{N}$ suficientemente grande.

\subsubsection{Número de Rodadas versus Comprimento da Simulação}

O processo de avaliação de um sistema por meio de simulação está relacionado ao balanço entre o Comprimento da Simulação $\left(T_{\text {length }}\right)$ e o Numero de Rodadas (Runs) a serem utilizados (COMPSciDept, 2004), pois, além do tempo total de processamento (tempo necessário à alocação de recursos computacionais) ser dado pelo produto $T_{\text {length }} \mathbf{x}$ Runs, as características $T_{\text {length }}$ e Runs influenciam os valores das estimativas obtidas.

Por exemplo, cada uma das $\mathrm{N}$ amostras “ $\mathrm{R}_{\text {inst }}(t)_{i}$ " utilizadas para estimar $\mathbf{E}\left[\mathrm{R}_{\text {inst }}(t)\right]$ por meio do estimador $\overline{\mathrm{R}}_{\text {inst }}(t)$ são obtidas realizando-se $\mathrm{N}$ rodadas (Runs), independentes entre si, de comprimento $t=T_{\text {length }}$. A este processo, onde se obtém amostras por meio da execução de $\mathrm{N}$ rodadas (Runs) independentes de comprimento $T_{\text {length }}$, dá-se o nome de Replicação. Neste caso, podem-se fazer as seguintes considerações a respeito das possíveis configurações de simulação para obter-se uma estimativa de $\overline{\mathrm{R}}_{\text {inst }}(t)$ :

- Ao utilizar um comprimento de simulação $\left(T_{\text {length }}\right)$ grande e um número de rodadas (Runs) pequeno, elimina-se a influência da condição inicial $\left((\mu, \chi)_{(0)}\right)$ sobre a estimativa, sendo útil na análise estacionária do sistema. Porém, o número pequeno de amostras (Runs = N) compromete o cálculo do intervalo de confiança (IC) da mesma, como demonstrado anteriormente.

- O IC da estimativa é melhorado, sem onerar o tempo total de simulação, aumentando o número de rodadas (Runs) e reduzindo o comprimento de simulação $\left(T_{\text {length }}\right)$. Porém, este fato faz com que a condição inicial $\left((\mu, \chi)_{(0)}\right)$ tenha forte influência sobre a estimativa, sendo útil na análise transitória do sistema.

O processo de estimação de parâmetros é útil apenas quando se pode obter uma estimativa com intervalo de confiança considerado satisfatório, o que necessita de um grande número de amostras (Runs). Porém, como pôde ser observado, um grande número de rodadas (Runs) 
eleva o tempo de processamento da simulação, pois, no caso de desejar-se realizar uma análise estacionária do sistema, necessita-se de tempos de simulação $\left(T_{\text {length }}\right)$ grandes. Portanto, ao utilizar-se do processo de simulação por replicação em análise estacionária, deve-se iniciar o modelo $\left((\mu, \chi)_{(0)}\right)$ em um estado próximo ao estado estacionário para que a condição inicial não interfira nos valores estimados COMPSciDept (2004). 


\section{APÊNDICE E - Características, Limitações e Contribuições no uso da Ferramenta SPNP}

Este APÊNDICE aborda a ferramenta computacional Stochastic Petri Nets Package (SPNP), utilizada para modelagem e simulação computacional segundo o formalismo das Redes de Petri Fluidas e Estocásticas.

\section{A ferramenta "Stochastic Petri Nets Package" (SPNP)}

Este APÊNDICE apresenta o processo utilizado pelo autor para a escolha de uma ferramenta computacional que possibilitasse o emprego do formalismo das redes de Petri fluidas e estocásticas (RPFE), definido e justificado anteriormente, na modelagem e simulação dos sistemas propostos. A ferramenta computacional escolhida foi a Stochastic Petri Nets Package (SPNP). Neste mesmo APÊNDICE estão apresentadas as adaptações e contribuições realizadas sobre esta ferramenta de forma que a mesma atendesse, por completo, os requisitos desejados.

\subsection{Avaliação das ferramentas computacionais disponíveis}

Até aqui, justificou-se a escolha do formalismo das redes de Petri fluidas e estocásticas (RPFE) para modelagem e avaliação, por meio de simulação, do novo paradigma de sistemas críticos em segurança apresentado anteriormente. Após a definição do formalismo a ser utilizado, foi necessário verificar quais seriam as ferramentas computacionais disponíveis que pudessem implementar modelos por meio daquele formalismo e que possibilitassem a análise dos mesmos utilizando simulação.

Para este fim, a fonte principal de consulta foi o sítio na Internet do Grupo de Fundamentos Teóricos da Ciência da Computação do Departamento de Informática da Universidade de Hamburgo (Alemanha). Este grupo possui uma base de dados contendo informações sobre as ferramentas computacionais disponíveis e que implementam os diversos tipos de formalismos das redes de Petri ${ }^{44}$.

\footnotetext{
${ }^{44}$ Informações disponíveis em http://www.informatik.uni-hamburg.de/TGI/PetriNets/tools/. Último acesso em 20/02/2006.
} 
Além dos requisitos básicos de "utilizar, o máximo possível, o formalismo das rede de Petri Fluidas e Estocásticas" e "realizar análise por meio de simulação", a escolha da ferramenta deveria respeitar os requisitos de "ser gratuita para uso acadêmico" e "ser suficientemente documentada". A partir destes requisitos básicos, os critérios de desempate para escolha seriam os de "ter histórico de aplicação", "uso de estruturas de recompensa" e "capacidade de implementar adaptações".

As 3 ferramentas escolhidas para avaliação cumprem os requisitos de "realizar análise por meio de simulação", "ser gratuita para uso acadêmico", "ser suficientemente documentada" e "ter histórico aceitável de aplicação":

a) Timed Net Evaluation Tool (TimeNET) (http://pdv.cs.tu-berlin.de/ timenet/),

b) GRaphical Editor and Analyser for Timed and Stochastic Petri Nets (GreatSPN) (http://www.di.unito.it/ greatspn/) e

c) Stochastic Petri Nets Package (SPNP) (http://www.ee.duke.edu/ kst/).

A ferramenta TimeNET, do Instituto de Microeletrônica e Informática da Universidade Técnica de Berlin (Alemanha), é capaz de implementar redes de Petri não markovianas (cujas distribuições de probabilidade de transição são representadas por meio de polinômios), além de permitir o uso de estruturas de recompensa aplicados à análise da simulação (German et al, 1995). Já a ferramenta GreatSPN, do Departamento de Informática da Universidade de Turim (Itália), é capaz de modelar sistemas por meio GSPN (Generalized Stochastic Petri Nets) e de redes de Petri coloridas (as quais aceitam diversos tipos de marcas em um mesmo lugar). Porém, não aceita a definição de estruturas de recompensa em sua análise (Chiola et al, 1995).

Por fim, a ferramenta SPNP, da Faculdade de Engenharia Elétrica e de Computação da Universidade de Duke (EUA), é a única das ferramentas listadas onde é possível implementar o formalismo, por completo, das redes de Petri Fluidas e Estocásticas. Este critério, somado à vasta bibliografia, ao histórico de aplicações tanto acadêmicas quanto não acadêmicas e ao tipo de linguagem utilizado na modelagem (baseada no ANSI-C) (Trivedi, 1999), foram determinantes para a escolha desta ferramenta computacional na implementação e na análise do Sistema de Controle de Tráfego Aéreo proposto neste trabalho. Segue-se uma descrição da ferramenta SPNP e de algumas adaptações desenvolvidas sobre a mesma como forma de facilitar a obtenção de resultados na análise. 


\subsection{Descrição da ferramenta SPNP}

A Stochastic Petri Net Package (SPNP) é uma ferramenta de modelagem para solução de redes de Petri Temporizadas e Estocásticas, tanto Markovianas quanto não Markovianas, e de redes de Petri Fluidas e Estocásticas. A linguagem utilizada na descrição dos modelos é a CSPL (C-based Stochastic Petri Nets Language), baseada na linguagem de programação ANSI-C e adicionada de alguns formalismos e bibliotecas proprietárias da ferramenta (Hirel; Tuffin; Trivedi, 2000). Além disto, a versão do SPNP utilizado neste trabalho (versão 6.01) é multiplataforma, sendo possível utilizá-la em Unix, Windows e Linux (Trivedi, 1999).

A SPNP utiliza como base de seu formalismo as redes de Petri Estocásticas de Recompensa (Stochastic Reward Net - SRN), uma extensão das redes de Petri estocásticas abordada anteriormente, que possibilita a análise de seus modelos utilizando tanto métodos analíticos quanto simulação por eventos discretos. Dependendo do tipo de formalismo utilizado, a SPNP dispõe de um conjunto de ferramentas de análise específico. A Figura 101, extraída de Trivedi (1999), ilustra a taxonomia do formalismo utilizado na SPNP versão 6 e apresenta os métodos de análise disponíveis para cada um deles.

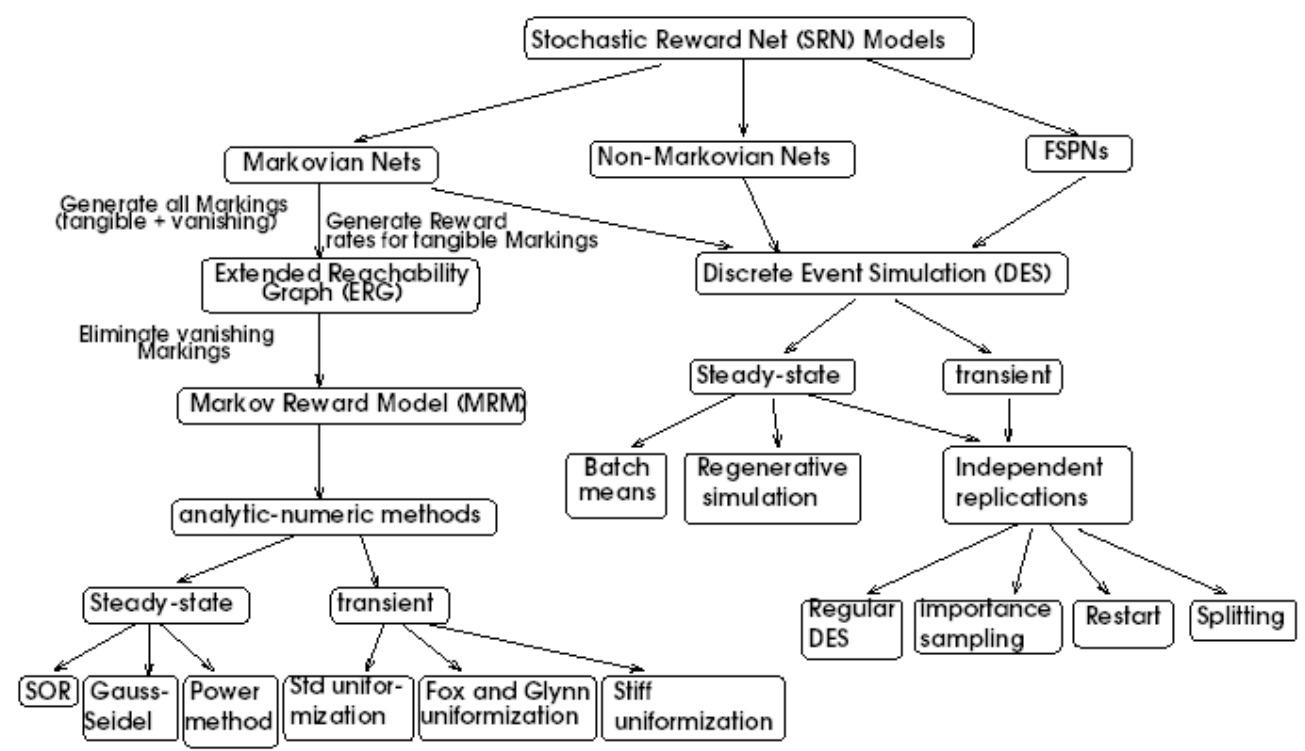

Figura 101 - Taxonomia das SRN e métodos de análise disponíveis no SPNP

Ainda com relação à figura anterior, pode-se notar que a versão 6 da SPNP disponibiliza apenas o método da simulação por eventos discretos (Discrete Event Simulation - DES) para realizar tanto análise estacionária (steady-state) quanto transitória (transient) dos formalismos das redes de Petri Fluidas e Estocásticas (Fluid Stochastic Petri nets - FSPN) e das redes não- 
Markovianas (Non-Markovian Nets). Já para as redes Markovianas (Markovian Nets), a SPNP permite tanto o uso de métodos analítico-numéricos quanto de simulação por eventos discretos.

O método de análise utilizado neste trabalho é o da simulação por eventos discretos "padrão" (denominado, na Figura, como "Regular DES"). Este método se baseia em replicações independentes, respeitando as propriedades de estimação estatística de medidas por meio de simulação descritas anteriormente. Os demais métodos, tais como o "Importance Sampling" e o "Splitting”, são utilizados para análise de sistemas com eventos raros e não foram abordados neste trabalho. Maiores informações podem ser obtidas em Trivedi (1999); Tuffin, Trivedi (2000) e Hsieh (2002).

Portanto, seguem as informações necessárias para a utilização da ferramenta computacional SPNP, tais como suas características e limitações. Segue, também, a descrição das contribuições efetuadas sobre esta ferramenta, tais como a capacidade de modelagem de comportamento espacial não determinístico e a realização de análise de sensibilidade para os parâmetros modelados.

\section{Modelagem utilizando a linguagem CSPL}

Um modelo de rede codificado em linguagem CSPL segue a mesma semântica e sintaxe de um programa escrito em linguagem de programação ANSI-C, adicionado de um conjunto de funções proprietárias para especificar e resolver as redes de Petri de Recompensa. Portanto, um modelo em CSPL aceita qualquer estrutura, tais como bibliotecas e declarações de variáveis e funções, que seriam aceitas em um programa codificado em ANSI-C (Trivedi, 1999). Porém, um modelo em CSPL deve conter, no mínimo, as seguintes funções proprietárias: options(), net(), assert(), ac_init(), ac_reach() e ac_final(), dispostas nesta ordem. O arquivo que contém o modelo possui extensão “c”.

Estas funções, obrigatórias ao modelo em CSPL, têm as seguintes finalidades:

1. void options (void) \{\}

A função options () tem a finalidade de configurar informações que são utilizadas na resolução da rede modelada, tais como o tipo de análise (método analítico ou simulação) e as características de cada tipo, bem como informações de precisão numérica (para o tempo e para os valores) e os tipos de relatórios a serem gerados (relatório padrão, 
valores cumulativos).

Informações importantes a serem definidas quando se seleciona o método da simulação (IOP_SIMULATION VAL_YES) são: Método de Simulação (IOP_SIM_RUNMETHOD), Número de Rodadas (Runs) (IOP_SIM_RUNS), Comprimento da Simulação ( $\left.T_{\text {length }}\right)$ (FOP_SIM_LENGTH), Intervalo de Confiança (IC) (FOP_SIM_CONFIDENCE) e o Valor da Semente Geradora de Números Aleatórios (seed) (IOP_SIM_SEED). As demais variáveis estão definidas no Capítulo 7 de Trivedi (1999).

2. void net(void) \{\}

A função net () tem a finalidade de descrever a rede de Petri propriamente dita. Para isto, utilizam-se funções proprietárias para definir:

- lugares discretos $\left(\forall \mathbf{p}_{\mathbf{i}} \in \mathbf{P}_{\mathbf{d}}\right)$ : void place (char " $\mathrm{p}_{\mathbf{i}}$ ") .

- lugares contínuos $\left(\forall \mathbf{q}_{\mathbf{i}} \in \mathbf{P}_{\mathbf{c}}\right)$ : void fplace (char " $\mathrm{q}_{i}$ ") .

- condição inicial para cada lugar:

i. void init ( $\operatorname{char}$ " $\mathrm{p}_{\mathbf{i}}$ ", int valor) para lugares discretos $\left(\boldsymbol{\mu}_{\mathbf{( 0 )}}\left(\mathbf{p}_{\mathbf{i}}\right)=\right.$ valor, $\left.\forall \mathbf{p}_{\mathrm{i}} \in \mathbf{P}_{\mathrm{d}}\right)$.

ii. void finit(char " $q_{i}$ ", double valor) para lugares contínuos $\left(\chi_{(0)}\left(\mathbf{q}_{\mathrm{i}}\right)=\right.$ valor, $\left.\forall \mathbf{q}_{\mathrm{i}} \in \mathbf{P}_{\mathbf{c}}\right)$.

- arcos discretos de entrada $\left(\mathbf{P}_{\mathbf{d}} \boldsymbol{x} \mathbf{T}\right)(" \uparrow "=$ "i $\mathrm{i} ")$ e de saída $\left(\mathbf{T} \boldsymbol{x} \mathbf{P}_{\mathbf{d}}\right)(" \uparrow "=$ "o"):

i. void tarc(char "transicao", char " $p_{i}$ ")) para arco de cardinalidade 1.

ii. void mtarc(char "transicao", char "pi", int mult)) para arco de multiplicidade "mult" constante.

iii. void v†arc(char "transicao", char " $\mathrm{p}_{i}$ ", int *func())) para arco de multiplicidade dependente da marcação (especificada pela função "func ()"). 
- arcos com impulso fluido de entrada $\left(\mathbf{P}_{\mathbf{c}} \boldsymbol{x} \mathbf{T}_{\mathbf{I}}\right)(" \dagger "=$ "i $")$ e de saída $\left(\mathbf{T}_{\mathbf{I}} \boldsymbol{x} \mathbf{P}_{\mathbf{c}}\right)$ $(“ \dagger ”=$ "o"):

i. void dtarc(char "transicao", char " $q_{i}$ ")) para arco com impulso fluido de cardinalidade 1 .

ii. void mtarc(char "transicao", char " $q_{i}$ ", int mult)) para arco com impulso fluido de multiplicidade "mult" constante.

iii. void vtarc(char "transicao", char " $q_{i}$ ", int *func(l))) para arco com impulso fluido de multiplicidade dependente da marcação (especificada pela função " func ()").

- arcos com taxa fluida de entrada $\left(\mathbf{P}_{\mathbf{c}} \boldsymbol{x} \mathbf{T}_{\mathbf{T}}\right)\left(“ \dagger "=\right.$ “i”) e de saída $\left(\mathbf{T}_{\mathbf{T}} \boldsymbol{x} \mathbf{P}_{\mathbf{c}}\right)$ (“†”= “o"):

i. void fltarc(char "transicao", char " $q_{i}$ ", double "f()", double " $g() "))$ para arco com taxa fluida (f) dependente da marcação, cuja derivada é definida por $\frac{d \chi_{q i}(t)}{d t}=f(\mu) \cdot \chi_{q i}(t)+g(\mu)$, onde $f()$ e $g($ ) são funções dependentes de marcação.

- guardas (g): void guard(char "transicao", int *func()), sendo "func ()" a função que estabelece $\hat{\boldsymbol{S}} \rightarrow\{$ verdadeiro $=\mathbf{1}$, falso $=\mathbf{0}\}$.

- política de reamostragem (r): void policy(char "transicao", int pol), sendo "pol" o tipo de reamostragem (PRD, PRS ou PRR).

- política de afetação (f): void affected(char " $t_{i}$ ", char " $t_{j}$ ", int pol), sendo " $t_{j}$ " a transição dispara, " $t_{i}$ " a transição afetada e "pol" $o$ novo tipo de reamostragem (PRD, PRS ou PRR) da transição afetada.

- limite fluido (b): void fbound(char " $q_{i}$ ", double b), sendo " $b$ " o valor do limite fluido do lugar " $q_{i}$ " .

- prioridade ( $\Pi)$ : void priority(char " $u_{i}$ ", int $P$ ), sendo " $P$ " a prioridade da transição " $u_{i}$ ". 
- peso das transições $(\boldsymbol{w})$ :

i. void probval (char " $t_{i}$ ", double $w$ ), sendo " $W$ " o valor do peso da transição " $t_{i}$ ".

ii. void probdep (char " $t_{i}$ ", double $w$, char " $p_{i}$ "), sendo " $w$. $\mu\left(\mathrm{p}_{\mathrm{i}}\right)$ " o valor do peso da transição " $t_{i}$ ".

iii. void probfun(char " $t_{i}$ ", double *func()), sendo "func()" a função dependente de marcação do valor do peso da transição " $t_{i} "$.

Deixou-se por último a definição das transições $\left(\mathbf{T}=\mathbf{T}_{\mathbf{T}} \cup \mathbf{T}_{\mathbf{I}}\right)$ devido a quantidade significativa de tipos que podem ser utilizados na modelagem, já que a ferramenta permite modelagem de modelos não Markovianos. Desta forma, alguns exemplos de transições são:

- transição imediata $\left(\mathbf{u}_{\mathbf{i}}\right)$ : void imm (char " $u_{i}$ ").

- transição para arco fluido $\left(\mathbf{u}_{\mathbf{i}}\right)$ : void imm ( char " $u_{i}$ ")

- transição exponencial: todas definidas na unidade [nº disparos/tempo]

i. void rateval (char "ti", double val), sendo "val" a taxa de disparo da transição " $t_{i}$ ".

ii. void ratedep(char " $t_{i}$ ", double val, char " $p_{i}$ "), sendo "val. $\mu\left(\mathrm{p}_{\mathrm{i}}\right)^{\prime \prime}$ a taxa de disparo da transição " $t_{i}$ ".

iii. void ratefun(char "t ${ }_{i}$ ", double *func()), sendo "func()" a função dependente de marcação da taxa de disparo da transição "t ${ }_{i}$ ".

- transição determinística:

i. void detval (char " $t_{i}$ ", double val), sendo "val" o tempo de disparo da transição " $t_{i}$ ". 
ii. void detdep(char " $t_{i}$ ", double val, char " $p_{i}$ "), sendo "val. $\mu\left(\mathrm{p}_{\mathrm{i}}\right)^{\prime \prime}$ o tempo de disparo da transição " $t_{i}$ ".

iii. void detfun(char " $t_{i}$ ", double *func()), sendo "func()" a função dependente de marcação do tempo de disparo da transição " $t_{i}$ ".

- transição com distribuição uniforme (U[val1,val2]):

i. void unifval (char " $t_{i}$ ", double vall, double val2), sendo "vall" e "val2" os limites inferior e superior da função de probabilidade uniformemente distribuída que calcula o tempo de disparo para a transição " $t_{i}$ ".

ii. void unifdep(char " $t_{i}$ ", double vall, double val2, char

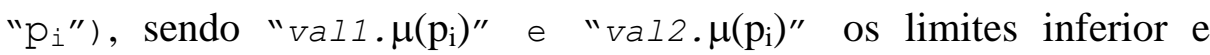
superior da função de probabilidade uniformemente distribuída que calcula o tempo de disparo para a transição " $t_{i}$ ".

iii. void uniffun(char " $t_{i}$ ", double *funcl(), double *func2()), sendo "funcl()" e "func2()" as funções dependente de marcação para os limites inferior e superior da função de probabilidade uniformemente distribuída que calcula o tempo de disparo para a transição " $t_{i}$ ".

- transição com distribuição Normal (N[val1,val2]), cujos valores são truncados em zero (não produz valores negativos):

i. void normval (char " $t_{i}$ ", double vall, double val2), sendo "vall" a esperança e "val2" a variância da função de probabilidade normalmente distribuída (não truncada) que calcula o tempo de disparo para a transição " $t_{i}$ ".

ii. void normdep(char " $t_{i}$ ", double vall, double val2, char

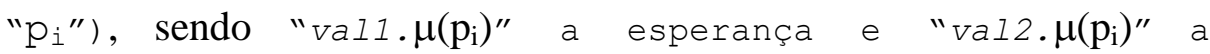
variância da função de probabilidade normalmente distribuída (não 
truncada) que calcula o tempo de disparo para a transição " $t_{i}$ ".

iii. void normfun(char " $t_{i}$ ", double *funcl(), double *func2()), sendo "funcl()" e "func2()" as funções dependente de marcação para a esperança e a variância da função de probabilidade normalmente distribuída (não truncada) que calcula o tempo de disparo para a transição " $t_{i}$ ".

A versão 6.01 ainda possibilita a modelagem de transições com funções de distribuição de probabilidade geométrica, Weibull, lognormal, Gama, Beta, Poisson, Binomial, Binomial Negativa, Hiperexponencial, Erlang, Pareto e Cauchy.

3. void ac_final (void) \{\}

A função ac_final () é o local do modelo onde se definem, por meio de funções de recompensa, quais resultados serão obtidos após um processo de análise. Os resultados de uma análise são registrados no arquivo de saída ('modelo'.out). Como este trabalho está focado na utilização do método de simulação, as seguintes funções da ferramenta SPNP são importantes neste caso:

a) void pr_std_average (void);

Chamada em ac_final ( ), esta função calculará e exibirá no arquivo de saída (*.out) algumas medidas do modelo, dependendo do valor de IOP_SIM_CUMULATIVE (VAL_YES ou VAL_NO) configurado na função net () :

i. Caso IOP_SIM_CUMULATIVE $\leftarrow$ VAL_YES :

$\checkmark$ para cada $\mathbf{p}_{\mathbf{i}} \in \mathbf{P}_{\mathbf{d}}$, calcula a proporção de tempo na qual o lugar esteve vazio $\left(\mathbf{P}\left(\boldsymbol{\mu}\left(\mathbf{p}_{\mathbf{i}}\right)=\mathbf{0}\right)\right)$ e seu número médio de marcas (tokens) (estimativa de $\mathbf{E}\left[\boldsymbol{\mu}\left(\mathbf{p}_{\mathbf{i}}\right)\right]$ ) ocorridos no período de [0, FOP_SIM_LENGTH].

$\checkmark$ para cada $\left\{\mathbf{t}_{\mathbf{i}}, \mathbf{u}_{\mathbf{i}}\right\} \in \mathbf{T}$, calcula a proporção média de tempo na qual a transição ficou habilitada $\left(\left\{\mathbf{t}_{\mathbf{i}}, \mathbf{u}_{\mathbf{i}}\right\} \in \boldsymbol{H}(\boldsymbol{S})\right)$ e seu número médio de disparos (estimativa de $\left.\eta_{\mathrm{t}_{\mathrm{i}}}(\mathrm{t})\right)$ ocorridos no período de [0, FOP_SIM_LENGTH]. 
$\checkmark$ para cada $\mathbf{p}_{\mathbf{i}} \in \mathbf{P}_{\mathbf{d}}$, calcula a probabilidade de o lugar estar vazio $\left(\mathbf{P}\left(\mu\left(\mathbf{p}_{\mathbf{i}}\right)=\mathbf{0}\right)\right)$ e seu número médio de marcas (tokens) (estimativa de $\mathbf{E}\left[\boldsymbol{\mu}\left(\mathbf{p}_{\mathbf{i}}\right)\right]$ ) no instante de tempo FOP_SIM_LENGTH.

$\checkmark$ para cada $\left\{\mathbf{t}_{\mathbf{i}}, \mathbf{u}_{\mathbf{i}}\right\} \in \mathbf{T}$, calcula a probabilidade de a transição estar habilitada ( $\left\{\mathbf{t}_{\mathbf{i}}\right.$, $\left.\mathbf{u}_{\mathrm{i}}\right\} \in \boldsymbol{H}(\boldsymbol{S})$ ) e seu número médio de disparos (estimativa de $\eta_{\mathrm{t}_{\mathrm{i}}}(\mathrm{t})$ ) ocorridos no instante de tempo FOP_SIM_LENGTH.

b) void pr_expected(char *string, double (*func) ());

Chamada em ac_final ( ), esta função calculará e exibirá no arquivo de saída (*.out) a expressão presente em "string" seguida da média instantânea resultante da função de recompensa dependente da marcação "func" no momento FOP_SIM_LENGTH. Matematicamente, pr_expected() é definida como:

$$
\begin{aligned}
& \text { pr_expected }=\frac{1}{\text { IOP_SIM_RUNS }} \cdot \sum_{i=1}^{\text {IOP_SIM_RUNS }} \mu_{\mathrm{i}}(\text { func, FOP_SIM_LENGTH) } \\
& \text { c) void pr_cum_expected (char *string, double (*func) ()); }
\end{aligned}
$$

Chamada em ac_final ( ), esta função calculará e exibirá no arquivo de saída (*.out) a expressão presente em "string" seguida da média acumulada resultante da função de recompensa dependente da marcação "func" no período [0, FOP_SIM_LENGTH]. Matematicamente, pr_cum_expected () é definida como:

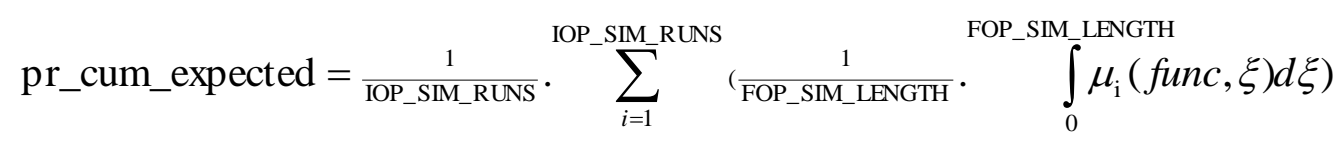

$\mathrm{Na}$ prática, a versão 6.01 da ferramenta SPNP não considera o termo $\frac{1}{\text { FOP_SIM_LENGTH }}$, devendo ser acrescido ao resultado final.

4. int assert(void), void ac_init() e void ac_reach()

Mesmo que um modelo em CSPL deva conter as funções assert (), ac_init() e ac_reach ( ), as mesmas não têm funcionalidade específica no processo de simulação. 
Devido aos modelos utilizados na ferramenta SPNP serem baseados em redes de recompensa, estão definidas na ferramenta funções proprietárias capazes de obter informações a respeito da marcação da rede em instantes específicos. As funções definidas, e que podem ser utilizadas em qualquer outra função do modelo, são:

int mark (char " $\mathbf{p}_{\mathbf{i}}$ "): ao ser chamada, obtem o valor de marcação $\mu\left(\mathbf{p}_{\mathbf{i}}\right)$ de um lugar discreto $\mathrm{p}_{\mathrm{i}}, \mathrm{p}_{\mathrm{i}} \in \mathrm{P}_{\mathrm{d}}$.

double fmark (char " $q_{i}$ "): ao ser chamada, obtem o valor de marcação $\chi\left(\mathbf{q}_{\mathbf{i}}\right)$ de um lugar contínuo $\mathrm{q}_{\mathrm{i}}, \mathrm{q}_{\mathrm{i}} \in \mathrm{P}_{\mathrm{c}}$.

int enabled (char "transicao ${ }_{i}$ "): ao ser chamada, verifica se uma "transicao ${ }_{i}$ " está habilitada (retorna 1) ou desabilitada (retorna 0 ) naquele momento.

Tal como mencionado anteriormente, os resultados de uma análise são registrados no arquivo de saída "modelo".out, onde "modelo" é o nome do arquivo com extensão ".c" utilizado para modelagem. Um exemplo de arquivo de saída "modelo.out", gerado após uma simulação, é ilustrado na Figura 102.

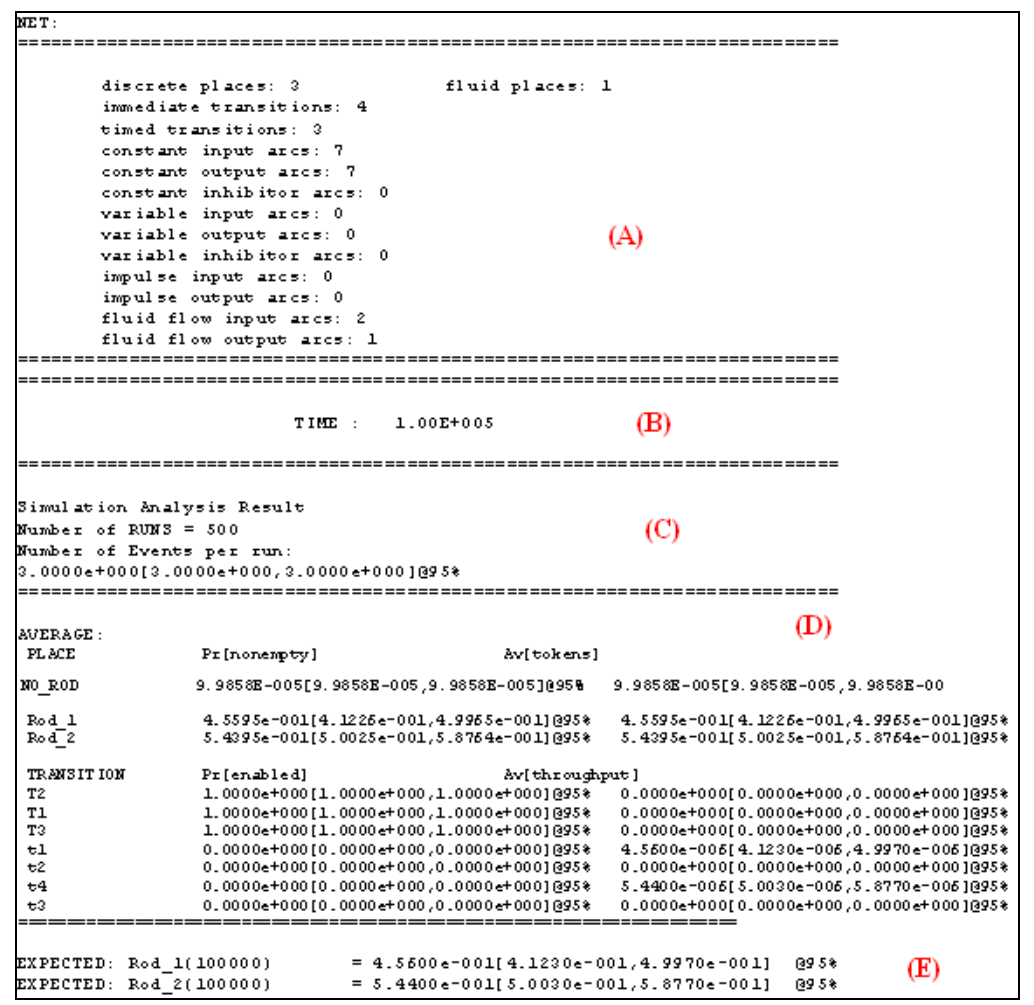

Figura 102 - Exemplo de arquivo de saída do SPNP ('modelo'.out) 
Os campos de informação presentes no arquivo de saída ('modelo'.out), ilustrado na Figura 102 são:
A) Indica os elementos presentes na rede estudada;
B) Indica o tempo definido para simulação (FOP_SIM_LENGTH).
C) Indica o valor definido para o número de rodadas (IOP_SIM_RUNS), bem como a estatística de "número médio de eventos por rodada" da simulação.
D) Resultados da simulação produzidos pela função pr_std_average ( ) .
E) Resultados de 2 funções de recompensa especificadas por meio de pr_expected ().

\section{Características aplicadas à Simulação de RPFE}

\subsection{Estrutura de Recompensa em CSPL}

Como pôde ser observado na Figura 101, o método disponível à resolução dos formalismos das redes de Petri não Markonianas e das redes de Petri Fluidas e Estocásticas é a Simulação por Eventos Discretos. Portanto, a resolução do modelo proposto neste trabalho fará uso de Simulação por Eventos Discretos utilizando Replicações Independentes. Neste caso, as amostras utilizadas na estimação de parâmetros são obtidas durante a execução de rodadas $($ Runs $=$ IOP_SIM_RUNS $)$ de comprimento $T_{\text {length }}=$ FOP_SIM_LENGTH. Além dos resultados-padrão obtidos pela utilização da função pr_std_average(), pode-se definir variáveis de recompensa utilizando as funções mark(), fmark() e enabled() e executá-las por meio das funções pr_expected() (para análise transitória) e pr_cum_expected() (para análise estacionária).

Como exemplo de utilização de uma estrutura de recompensa utilizando CSPL, considere a rede ilustrada anteriormente na Figura 98 (modelo de fila M/M/1/K), na qual o tamanho da fila, o processo de chegada e o processo de serviço são representados por $\mu(\mathrm{P} 1), \mathbf{t}_{\mathbf{i}}\left(\exp \left(-\lambda_{i}\right)\right)$ e $\mathbf{t}_{\mathbf{0}}\left(\exp \left(-\lambda_{\mathrm{o}} \cdot \mu(\mathrm{P} 1)\right)\right.$, respectivamente. Foi calculado, analiticamente, o número médio de usuários na fila no instante $t\left(\mathrm{E}\left[\mu_{(t)}(\mathrm{P} 1)\right]=0 . \pi_{0}(t)+1 . \pi_{1}(t)+\ldots+K . \pi_{K}(t)\right)$ e o número médio de disparos de $t_{o}$ quando a fila possui menos de $\mathrm{L}(\mathrm{L}<\mathrm{K})$ usuários $\left(\eta_{\mathrm{t}_{\mathrm{o}}}(\mathrm{t})=\lambda_{o} \cdot\left(\int_{0}^{t} \pi_{1}(x) \cdot d x+\ldots+L \cdot \int_{0}^{t} \pi_{L}(x) d x\right)\right)$. 
A resolução analítica não é trivial devido ao cálculo de $\pi(t)$, pois a taxa de disparo do processo de saída é dependente do número de usuários na fila. Porém, utilizando a ferramenta SPNP para o cálculo de $\pi_{n}(t)$, modela-se a variável $R_{\text {inst }}(t)=\sum_{n \in S} r r_{n} \cdot 1_{\{N(t)=n\}}$, onde $r r_{n}=$ 1 e $\mathbf{S}=\left\{\boldsymbol{\mu}_{(t)}(\mathbf{P 1})=\mathbf{n}\right\}$, por meio da linguagem CSPL na forma:

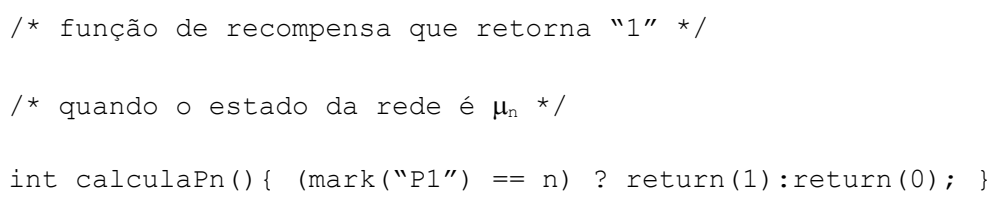

Quando esta função de recompensa é aplicada em pr_expected("”, calculaPn), a rede retorna a estimativa de $\pi_{n}(t)$ para $\mathrm{t}=$ FOP_SIM_LENGTH. Quando aplicada em pr_cum_expected("), calculaPn), retorna a proporção de tempo que a rede permanece em $\pi_{n}$ no intervalo [0, FOP_SIM_LENGTH].

Pode-se utilizar a seguinte estrutura de recompensa para o cálculo da parcela $\left(\int_{0}^{t} \pi_{1}(x) \cdot d x+\ldots+L \cdot \int_{0}^{t} \pi_{L}(x) d x\right):$

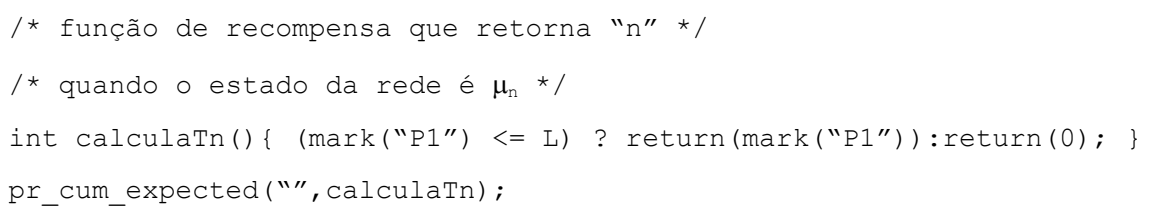

Ao multiplicar por $\lambda_{o}$ o retorno desta estrutura de recompensa, obtem-se no intervalo $\eta_{\mathrm{t}_{\mathrm{o}}}(\mathrm{t})$ para o intervalo de tempo [0, FOP_SIM_LENGTH].

Portanto, utilizando a ferramenta SPNP para resolução da fila proposta, o modelo em CSPL (apenas as funções options(), net() e ac_final() estão representadas) é:

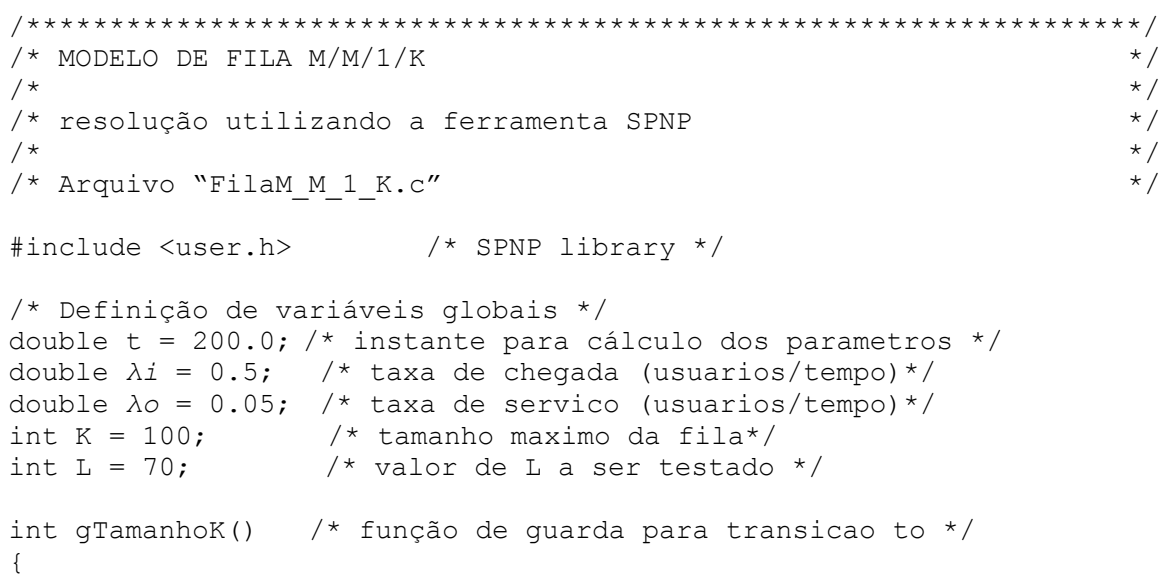




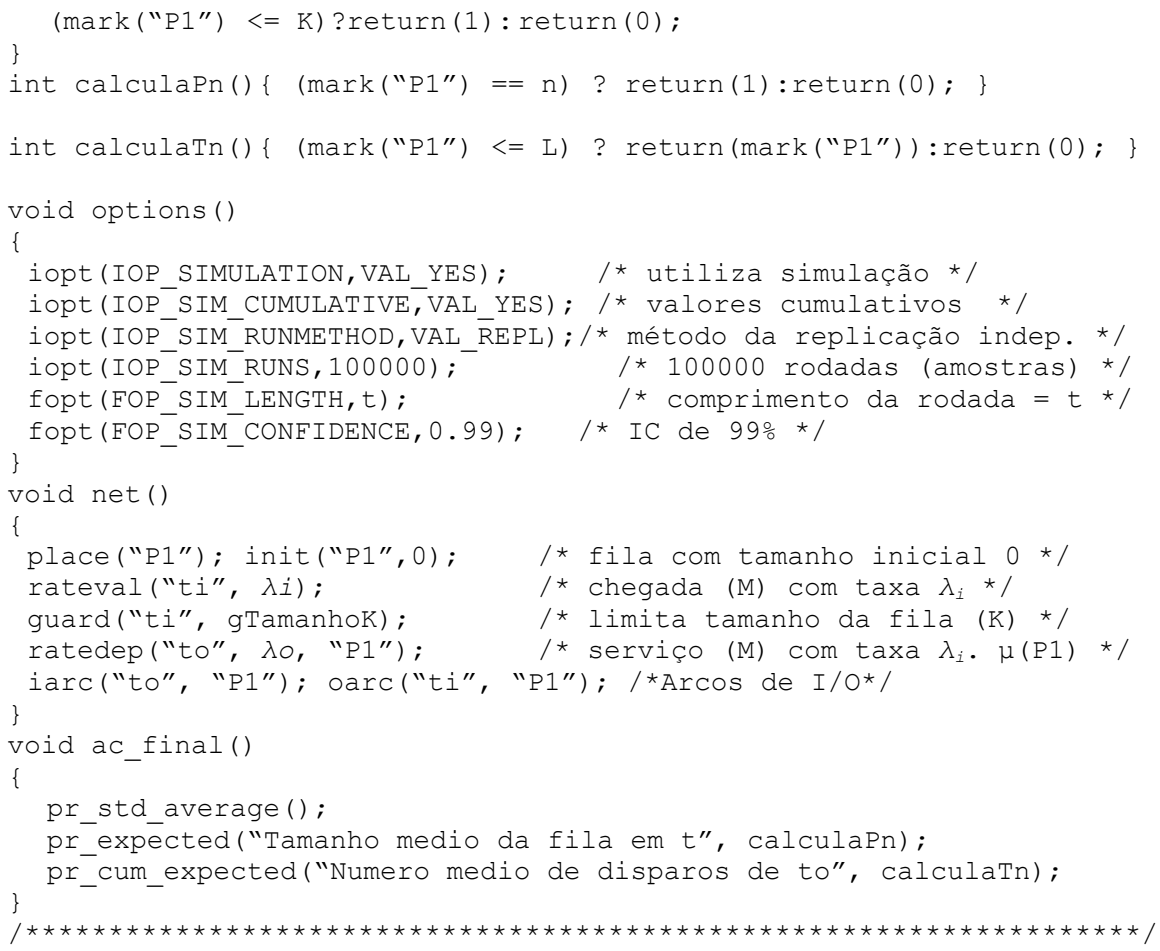

Ao ser resolvido pela ferramenta SPNP, este modelo gera o arquivo "FilaM_M_1_K. out" semelhante ao arquivo ilustrado na Figura 102, resolvendo uma fila M/M/1/100. Este arquivo possui as estimativas dos valores $\mathrm{E}\left[\mu_{(200)}(\mathrm{P} 1)\right]$ e de $\eta_{\mathrm{t}_{\mathrm{o}}}(200) / \lambda_{o}$ para $\mu(\mathrm{P} 1) \leq 70$. Além disto, a função pr_std_average () estima a proporção do tempo, de 0 a 200 , na qual a fila ficou vazia $(\mu(\mathrm{P} 1)=0)$, além de estimar seu tamanho médio no mesmo período. Também estima o número médio de disparos de $\mathbf{t}_{\mathbf{i}}, \mathbf{t}_{\mathbf{o}}$ no intervalo de [0,200], além da proporção de tempo no qual as transições $\left\{\mathbf{t}_{\mathbf{i}}, \mathbf{t}_{\mathbf{0}}\right\} \in \boldsymbol{H}(\mathbf{S})$ (onde $\mathbf{P}(\mathbf{t} \in \boldsymbol{H}(\mathbf{S})$ ) é a proporção de tempo na qual um transição fica habilitada). Neste último caso, a expressão “1 - $\mathbf{P}\left(\mathbf{t}_{\mathbf{i}} \in \boldsymbol{H}(\mathbf{S})\right)$ " calcula a proporção de tempo na qual $\mathbf{t}_{\mathbf{i}}$ estava desabilitada (fila cheia).

\subsection{Dinâmica de execução de uma rede em CSPL}

Devido a linguagem $C$ ser estruturada, sua execução é baseada na sequiência de execução das funções que a compõem. Desta forma, realizou-se um trabalho para determinar qual é a seqüência de chamada das funções que compõe um modelo em CSPL e, assim, poder modelar sistemas de forma mais consciente com relação aos instantes nos quais são acionadas suas estruturas de representação.

Um modelo em CSPL é resolvido por meio da chamada, por linha de comando do sistema operacional (Linux, Windows ou Unix), da estrutura de execução da ferramenta. Por exemplo, dado o modelo "Filam_M_1_K. ${ }^{\prime}$ ", executa-se por linha de comando: 
spnp FilaM_M_l_K

Este comando desencadeia o processo de compilar o modelo, por meio do compilador de código aberto $\mathrm{GCC}^{45}$, ligando-o às bibliotecas proprietárias da ferramenta SPNP e iniciando o processo de resolução. A seqüência de chamada das funções presentes em "FilaM_M_1_K. C" é:

1. Executa a função options(): define os parâmetros de resolução do modelo.

2. Executa a função net() 3 vezes seguidas: estrutura a rede.

3. Executa a função ac_init(): mandatória no modelo, mas sem finalidade.

4. Executa a função ac_final(): estrutura os resultados a serem gerados.

5. Executa a função assert() ao final de cada rodada de simulação, IOP_SIM_RUNS vezes.

6. Executa a função ac_final(): gera os resultados finais da análise.

Ao longo da simulação, as funções de recompensa ou quaisquer outras ligadas à estrutura do modelo (rede de Petri) são executadas tantas vezes quanto a dinâmica da simulação por eventos discretos requisitar. No caso do modelo de fila analisado anteriormente, as funções de recompensa e a função de guarda são executadas em todos os eventos da simulação, pois estão atuantes durante toda a dinâmica da simulação. Por exemplo, caso houvesse uma guarda na transição $\mathbf{t}_{\mathbf{0}}$, sua função não seria executada nos momentos onde $\boldsymbol{\mu}(\mathbf{P 1})=\mathbf{0}$, pois $\mathbf{t}_{\mathbf{o}}$ não estaria habilitada por P1.

Ao final do processo de simulação, a SPNP gera o arquivo "FilaM_M_1_K.out", contendo os resultados da simulação, conforme ilustrado na Figura 102.

\subsection{Limitações de modelagem da SPNP}

A ferramenta SPNP, versão 6.01, possui as seguintes limitações ao modelar e resolver sistemas por meio do formalismo RPFE (COMPSciDept, 2004):

- Os limites fluidos $\left(\mathbf{b}_{\mathbf{q}}\right)$ para cada lugar contínuo $\mathbf{P}_{\mathbf{c}}$ são independentes de marcação.

\footnotetext{
${ }^{45}$ Para detalhes, referir-se ao sítio http://gcc.gnu.org/ (último acesso em 05/03/2007).
} 
- $\operatorname{Arcos}(\mathbf{A}$ e f), guardas (g), pesos (w) e distribuições de tempo de disparo (Dist) não são completamente dependentes da marcação $(\mu, \chi)$. A dependência destes elementos com a parte contínua $(\chi)$ é realizada por meio de "valores de gatilho discretos". Desta forma, o comportamento da rede permanece constante até que alcance um dos valores de gatilho ou até que um disparo ocorra.

Na linguagem CSPL, a função void fbreak (char " $q_{i}$ ", double 1) define os "valores de gatilho discretos" ( 1 ) relacionados aos lugares contínuos $\mathrm{q}_{\mathrm{i}}, \mathrm{q}_{\mathrm{i}} \in \mathrm{P}_{\mathrm{c}}$.

- O comportamento fluido dos lugares contínuos $\mathbf{q} \in \mathbf{P}_{\mathbf{c}}$ é limitado a funções diferenciais na forma $\frac{\mathrm{d} \chi_{\mathrm{q}}(\tau)}{\mathrm{d} t}=\mathrm{A}(\mu) \cdot \chi_{\mathrm{q}}(\tau)+\mathrm{B}(\mu), \mathrm{A}(\mu) \neq 0$, onde $\mathrm{A}(\mu) \mathbf{e} \mathbf{B}(\mu)$ são funções dependentes da marcação discreta da rede.

Em CSPL, esta condição equivale a utilizar as funções fliarc() e floarc()).

\section{Melhorias desenvolvidas sobre a ferramenta SPNP}

\subsection{Modelagem de comportamento espacial não determinístico}

O formalismo das redes de Petri Fluidas e Estocásticas, da forma como esta implementado na versão 6.01 da ferramenta SPNP, permite modelar sistemas com comportamento temporal estocástico e comportamento espacial determinístico, onde os valores das marcações, tanto para lugares discretos quanto contínuos, variam de forma determinística. A respeito dos lugares fluidos, este comportamento espacial determinístico é devido a sua representação por equações diferenciais de primeira ordem. Caso fossem representados por equações diferenciais de segunda ordem, os valores presentes nos lugares fluidos teriam comportamento estocástico normalmente distribuído (Wolter, 2000).

Porém, a ferramenta SPNP, para lugares fluidos, modela apenas comportamento regido por equações diferenciais de $1^{\mathrm{a}}$ ordem. Desta forma, quaisquer comportamentos espaciais estocásticos devem ser introduzidos por adaptações sobre a ferramenta. Aliás, a capacidade de implementar adaptações sobre a ferramenta foi um dos requisitos utilizados em seu processo de seleção.

O Sistema de Controle de Tráfego Aéreo, o qual foi proposto para modelagem e análise por 
meio do formalismo das RPFE, possui diversos parâmetros espaciais estocásticos relevantes, tais como erros de navegação (radiais VOR, distância DME, posição GPS) e erros de vigilância (posição Radar, posição ADS). Outros parâmetros espaciais estocásticos poderiam ser introduzidos, tais como o vento (intensidade e direção).

Devido à impossibilidade de alterar o código-fonte do conjunto de bibliotecas que formam a ferramenta SPNP para introduzir o conceito de redes fluidas com equações diferenciais de $2^{\mathrm{a}}$ ordem, optou-se por caracterizar os parâmetros espaciais estocásticos por meio de variáveis globais de software. O comportamento estocástico destas variáveis é introduzido pela chamada, a partir da dinâmica da rede envolvida, de uma função que gera a distribuição de probabilidade com as características desejadas. Esta função é alimentada por um gerador de números aleatórios (GNA), independente do GNA utilizado pela SPNP, que confere a característica de aleatoriedade ao processo. Por fim, estas variáveis globais são utilizadas para tomada de decisão nas funções de guarda (g), ou em quaisquer outras funções dependentes de marcação, da modelagem de uma rede de Petri Fluida e Estocástica.

A Figura 103 exemplifica o processo de modelagem do erro espacial utilizado no Sistema de Vigilância Radar. 


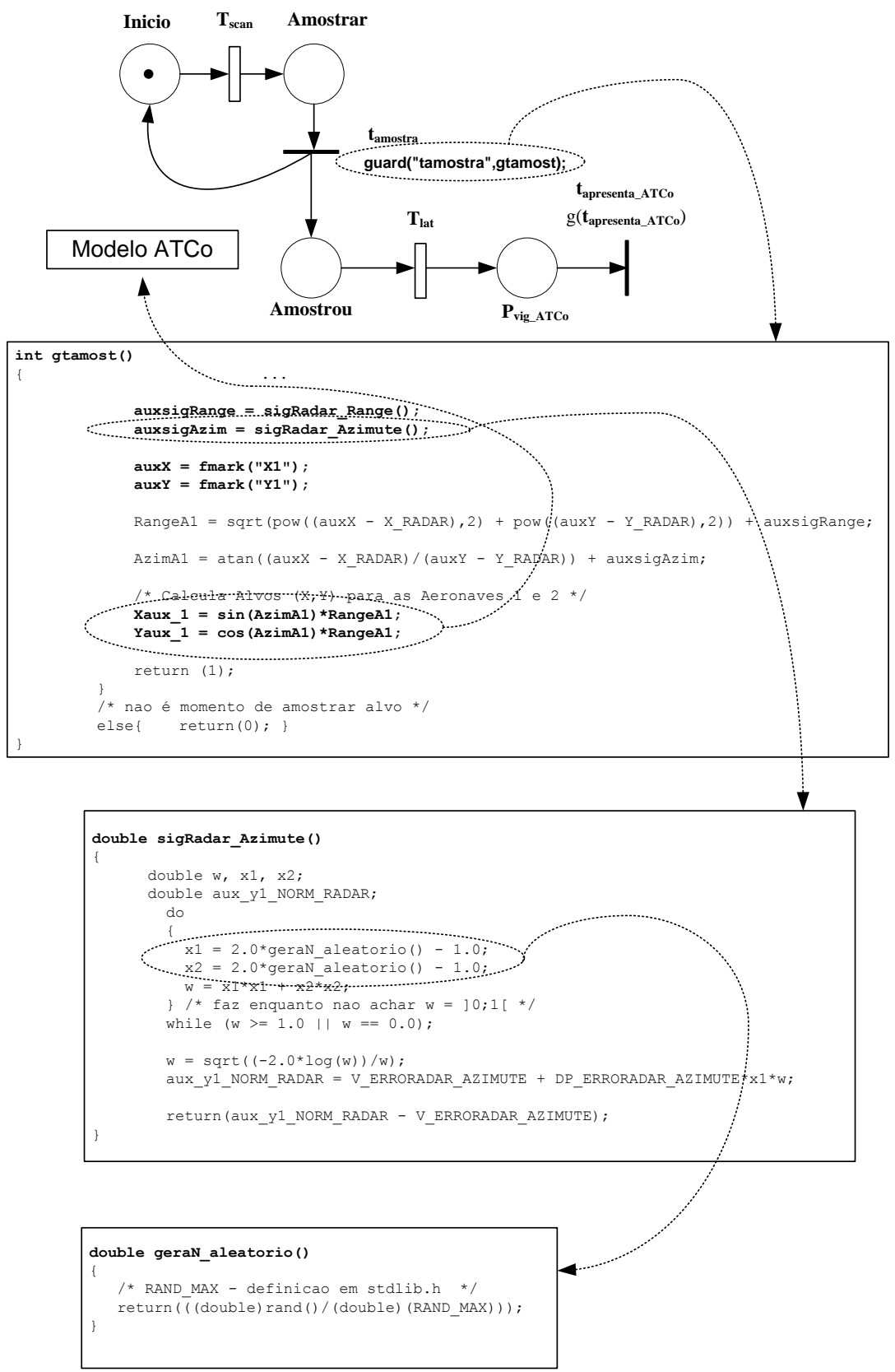

Figura 103 - Processo de modelagem do Erro Espacial para o Sistema Radar

No exemplo anterior, a obtenção das posições Radar é modelada por meio da função de guarda (g) da transição imediata "tamostra". Quando esta transição está em processo de habilitação por meio da cardinalidade de seu arco $(\boldsymbol{\mu}(\mathbf{A m o s t r a r})=1)$, a rede executa sua função de guarda "gtamost". Por sua vez, a mesma obtem a posição radar das aeronaves modeladas lendo (por meio das funções "fmark()") os valores dos lugares fluidos "X" e "Y" (posição real da aeronave) e gerando seus respectivos valores de erro para Azimute e Range. Estes erro são obtidos por meio de funções específicas (no caso, "sigRadar_Azimute()") que geram a distribuição de probabilidade desejada. Estas funções obtem números aleatórios (por 
meio da função "geraN_aleatorio()") para caracterizar suas propriedades estocásticas. No final, a função de guarda de "tamostra" obtem um valor de posição Radar com seus respectivos erros, transferindo-o ao modelo do ATCo por meio das variáveis globais "Xaux" e "Yaux", que as utiliza para tomar decisão sobre seu estado de conflito (guarda da transição "t_decisao" da rede do ATCo).

Dois conceitos importantes estão relacionados à implementação da modelagem de comportamento espacial não determinístico: o algoritmo de geração de números aleatórios e os algoritmos para a caracterização das funções de probabilidade desejadas.

\subsubsection{Gerador de Números Aleatórios}

Um número aleatório é gerado por meio de uma variável aleatória geradora. Segundo Kleijnen, Groenendaal (1992) apud Ogata (2003), uma variável que gere números aleatórios deve atender as seguintes condições:

- A variável geradora deve ser uniformemente distribuída no intervalo [0, 1].

- Os valores gerados são independentes e identicamente distribuídos (iid).

Números aleatórios gerados computacionalmente não respeitam, por completo, as condições de uma variável aleatória geradora. Uma razão deste fato é a própria característica determinística dos algoritmos, que geram números por meio de métodos de recorrência. Esta recorrência faz com que os números gerados não sejam completamente independentes. Por estas razões, números aleatórios gerados por meio de métodos computacionais são definidos como pseudo-aleatórios.

Mesmo que os números pseudo-aleatórios não sejam, em princípio, aleatórios, os mesmos podem satisfazer alguns critérios estatísticos de aleatoriedade. Os requisitos básicos que um gerador de números pseudo-aleatórios deve possuir são (Ogata, 2003):

a) Uniformidade: os números pseudo-aleatórios gerados devem aderir o máximo possível à uma distribuição de probabilidade uniforme;

b) Independência: a correlação entre os números gerados deve ser tão pequena quanto possível.

c) Período longo: o período de repetição da seqüência gerada, representado pela 
quantidade de valores gerados até que voltem a se repetir, deve ser tão longo quanto possível.

Uma seqüência pseudo-aleatória pode ser gerada por uma grande quantidade de técnicas. As mais comuns baseiam-se em recorrência, que implica em gerar um número $\mathrm{X}_{\mathrm{i}}$ com base no(s) número(s) anteriormente gerados. Um exemplo de técnica é a LCG (Linear Congruential Generator), representado por:

$$
X_{i}=\left(a \cdot X_{i-1}+c\right) \bmod m
$$

Onde a, c e m são valores constantes e mod é a operação de módulo (resto da divisão entre dois inteiros). A qualidade de um LCG, tal como sua uniformidade, independência e período, depende da escolha dos valores $\mathbf{a}, \mathbf{c}$ e $\mathbf{m}$. A escolha do valor inicial da seqüência $\left(\mathbf{X}_{\mathbf{0}}\right)$, denominada semente (seed), também é vital, pois 2 seqüências iniciadas por uma mesma semente serão idênticas, o que pode comprometer a independência das amostras geradas em uma simulação e, por decorrência, suas estimativas.

Devido a ferramenta SPNP utilizar a linguagem CSPL, baseada no ANSI-C, optou-se por utilizar o gerador de números aleatórios desta linguagem. O ANSI-C possui, em sua biblioteca <stdlib.h〉, a função "int rand(void)", que gera números inteiros e pseudo-aleatórios no intervalo [0, RAND_MAX]. Os valores de RAND_MAX podem variar em função da versão do compilador ANSI-C disponível, e influenciam no tamanho do período da seqüência gerada. A definição da semente (seed) é realizada por meio da função "void srand(unsigned int seed)".

A iniciação do valor da semente do GNA é um processo importante, pois evita que sejam geradas seqüências pseudo-aleatórias idênticas, o que invalidaria a independência de amostragem. Portanto, a solução adotada foi a de utilizar o valor truncado do relógio do sistema operacional, obtido com precisão de milésimos de segundo, para evitar a geração de seqüências idênticas. Utilizando o sistema Linux, obtem-se o valor de relógio pelo comando “date + $+\frac{\circ}{5} \% \mathbf{N}$ ", utilizando-se apenas dos 6 algarismos presentes no meio do número. Em posse desta semente, inicia-se o gerador por meio da função srand () e dentro da função options () do CSPL. Isto faz com que o gerador seja iniciado apenas na iniciação do processo de simulação.

Como forma de reduzir a correlação entre os números gerados, descartam-se os 10 primeiros 
números obtidos por meios de rand(). Empiricamente, verificou-se que uma sequiência onde se consideravam os 10 primeiros números possuía maior correlação do que em uma sequiência que descartava estes 10 primeiros números. Pode-se verificar que este descarte de números é mais efetivo para redução de correlação do que o tipo de valor de semente.

Para transformar um valor obtido por rand () em um número entre [0,1], implementou-se a função:

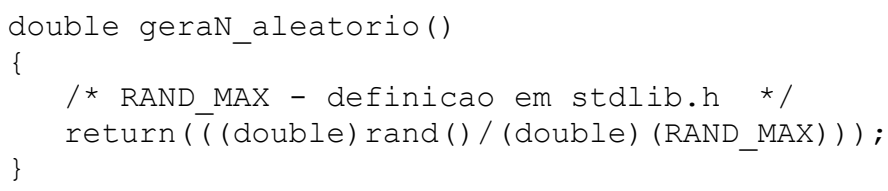

\subsubsection{Caracterização das Funções de Probabilidade}

Os números pseudo-aleatórios gerados por geraN_aleatorio () possuem distribuição de probabilidade aproximadamente uniforme e com valores entre $[0,1](\mathbf{U}[\mathbf{0 , 1}])$. Para que se obtenha um valor aleatório com probabilidade diferente da uniforme, é necessário utilizar algoritmos que façam uma transformação entre uma variável aleatória uniformemente distribuída $\mathbf{U}[\mathbf{0 , 1}]$ e uma na variável aleatória qualquer.

Para obter um número aleatório com distribuição normal $\mathbf{N}(\mathbf{E}[\mathbf{X}], \mathbf{V A R}[\mathbf{X}])$, utilizou-se a conhecida Transformação de Box-Muller, onde o algoritmo que a implementa é dado por:

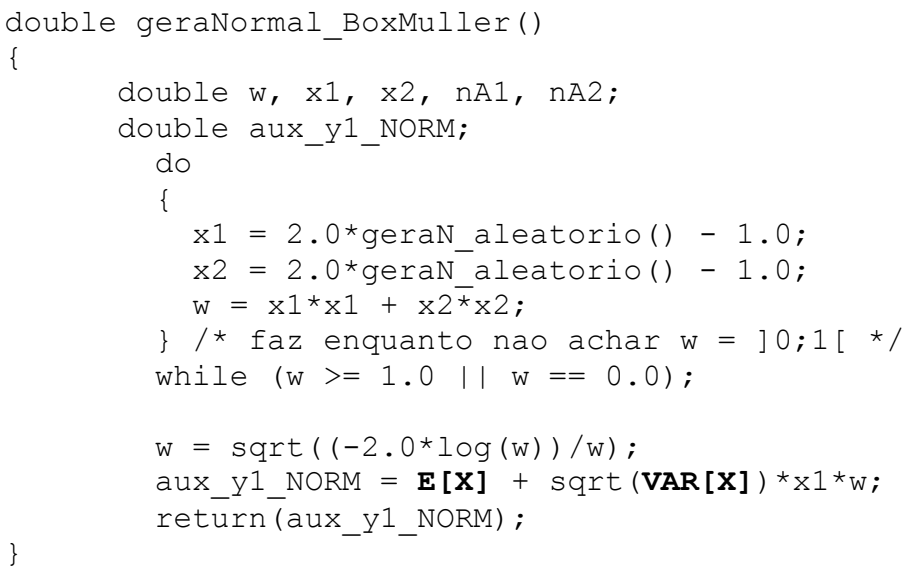

Para obter um número aleatório com distribuição uniforme $\mathbf{U}(-\mathbf{X},+\mathbf{X})$, utilizou-se a seguinte transformação:

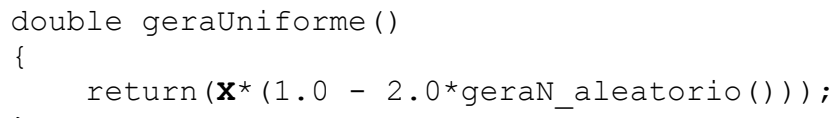




\subsection{Análise de Sensibilidade para parâmetros modelados}

É desejável que uma ferramenta de análise permita, de forma automática, obter o efeito que a mudança nos valores dos parâmetros de entrada causa sobre as medidas de saída avaliadas em um modelo. Na ferramenta SPNP utilizada, este processo de análise de sensibilidade é possível apenas para modelos Markovianos.

Desta forma, desenvolveu-se uma estrutura baseada na SPNP capaz de receber, por meio do arquivo "Analise.txt", a especificação da análise de sensibilidade que se deseja realizar, definindo qual o parâmetro de entrada a ser analisado e a faixa de valores que serão testados, desde o valor inicial até o valor final, e o tamanho de passo de variação entre cada valor considerado. A Figura 104 ilustra a estrutura de análise desenvolvida, destacando as partes relativas à estrutura básica da ferramenta SPNP.

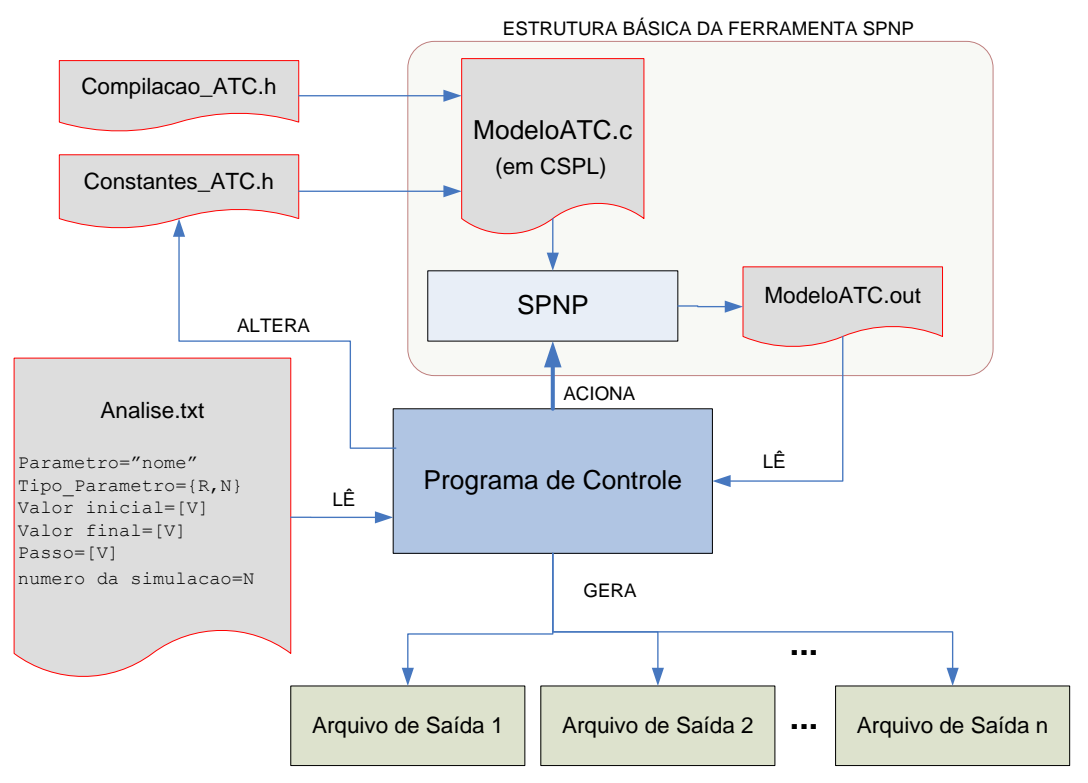

Figura 104 - Estrutura de análise desenvolvida para a ferramenta SPNP

Para cada valor de passo considerado, o "Programa de Controle" altera o parâmetro em análise no arquivo "Constantes_ATC. $h$ " e aciona a ferramenta "SPNP". A ferramenta faz a análise do modelo em CSPL "ModeloATC.c" e, ao final da análise do passo, gera o arquivo de saída "ModeloATC.txt". Então, o "Programa de Controle" lê estas informações de saída e gera um "Arquivo de Saída i", contendo um cabeçalho com a descrição da análise e os valores gerados pela SPNP. 